Proteomics of Aspergillus nidulans sexually differentiated cells

\author{
Dissertation \\ for the award of the degree \\ "Doctor rerum naturalium" \\ Division of Mathematics and Natural Sciences \\ of the Georg-August University Göttingen
}

submitted by

Benedict Dirnberger

from Vienna (Austria)

Göttingen 2018 
Es leuchtet! Seht! - Nun lässt sich wirklich hoffen, dass, wenn wir aus viel hundert Stoffen durch Mischung - denn auf Mischung kommt es an - den Menschenstoff gemächlich komponieren, in einen Kolben verlutieren und inn gehörig kohobieren, so ist das Werk im Stillen abgetan.

Faust II (Johann Wolfgang von Goethe) 


\section{Thesis Committee Members:}

Member of the Thesis Committee: Professor Dr. Gerhard H. Braus (Reviewer I) Department of Molecular Microbiology and Genetics, Institute of Microbiology and Genetics, Georg-August University Goettingen

Member of the Thesis Committee: Professor Dr. Stefanie Pöggeler (Reviewer II) Department of Genetics of Eukaryotic Microorganisms, Institute of Microbiology and Genetics, Georg-August University Goettingen

Member of the Thesis Committee: Dr. Oliver Valerius

Department of Molecular Microbiology and Genetics, Institute of Microbiology and Genetics, Georg-August University Goettingen

\section{Examination Board Members:}

Member of the Examination Board: Professor Dr. Heike Krebber

Department of Molecular Genetics, Institute of Microbiology and Genetics, GeorgAugust University Goettingen

Member of the Examination Board: Professor Dr. Kai Heimel

Department of Microbial Cell Biology, Institute of Microbiology and Genetics, GeorgAugust University Goettingen

Member of the Examination Board: Privatdozent Dr. Michael Hoppert Department of General Microbiology, Institute of Microbiology and Genetics, GeorgAugust University Goettingen

Date of oral examination: 04.07.2018 
This doctoral thesis was performed in the group of Professor Dr. Gerhard H. Braus. Department of Molecular Microbiology and Genetics, Institute of Microbiology and Genetics, Georg-August University Goettingen.

\section{Affirmation}

I declare that my doctoral thesis was written on my own having used only the listed resources and tools.

\section{Erklärung}

Die vorgelegte Arbeit wurde von mir selbständig angefertigt und nur die angegebenen Hilfsmittel wurden benutzt. Alle Stellen, die dem Wortlaut oder dem Sinne nach anderen Werken entnommen wurden, sind durch Angabe der Quelle kenntlich gemacht worden

Göttingen am 14.05.2018

Benedict Dirnberger 


\section{Table of contents}

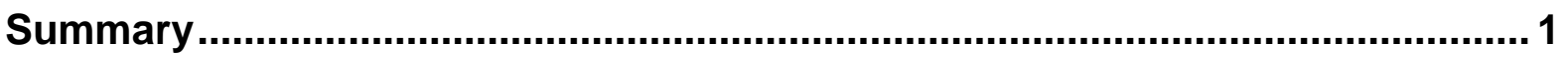

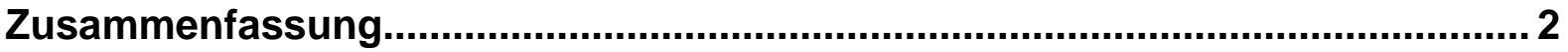

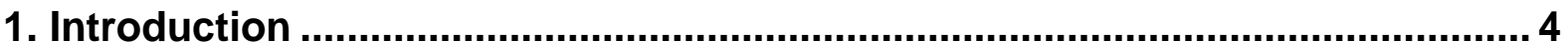

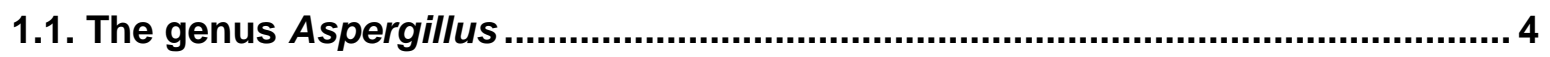

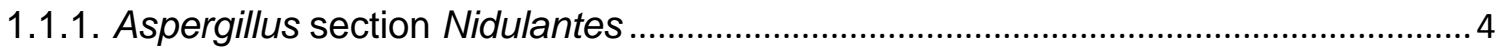

1.1.2. Aspergillus nidulans: A model organism for fungal development and secondary

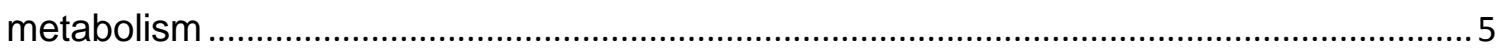

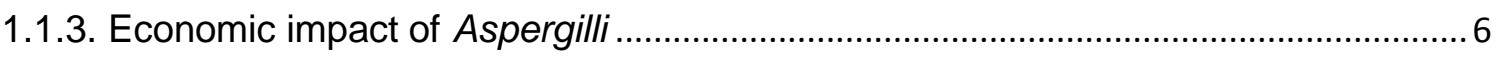

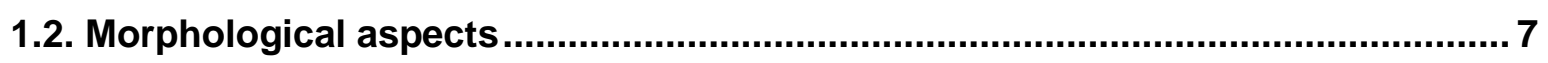

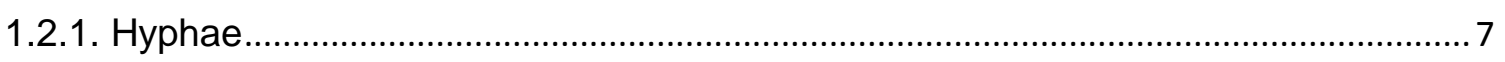

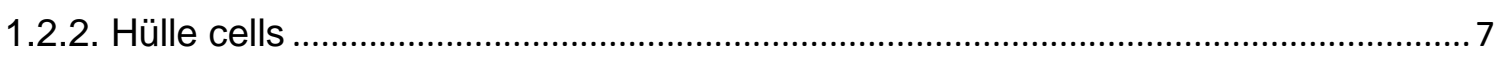

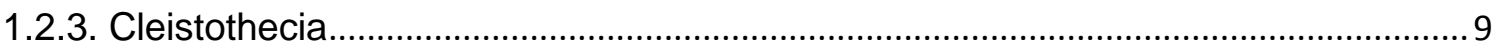

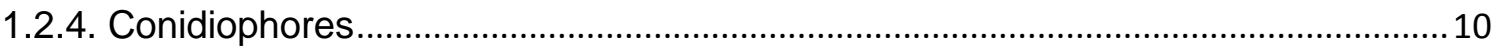

1.3. Factors influencing fungal development ................................................................ 11

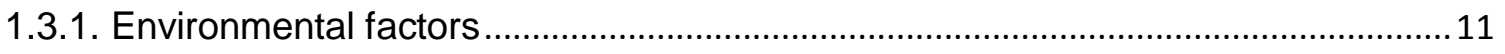

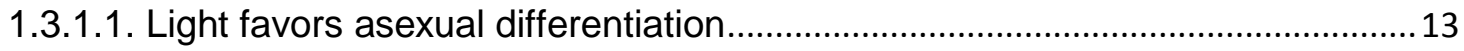

1.3.1.2. Sexual differentiation is promoted by darkness ...............................................13

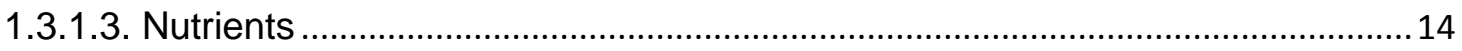

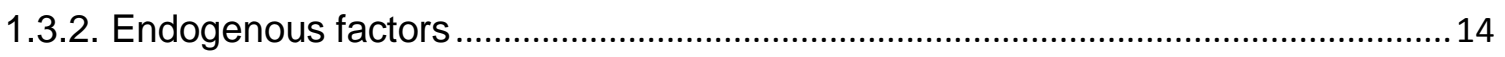

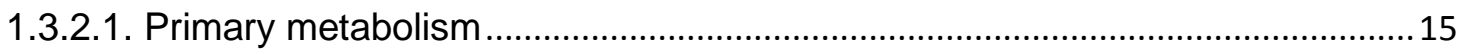

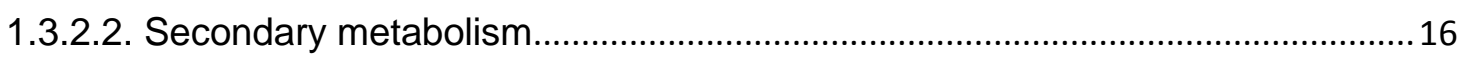

1.4. Specialized metabolism in fungal development ...............................................17

1.4.1. The monodictyphenone $(m d p)$ / xanthone $(x p t)$ secondary metabolite gene

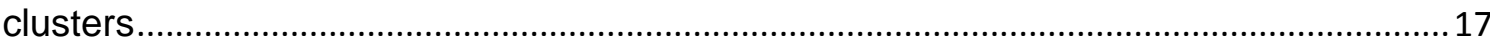

1.4.1.1. Monodictyphenone is a precursor for the synthesis of xanthones ...................18

1.4.2. LaeA as a factor that coordinates fungal development and secondary metabolism

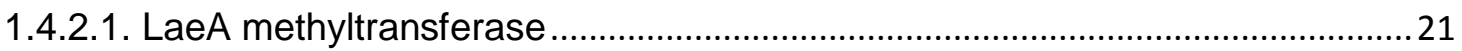

1.4.2.2. LaeA methyltransferase promotes Hülle cell formation .....................................22

1.4.2.3. LaeA regulates the monodictyphenone $(m d p)$ and other secondary metabolite

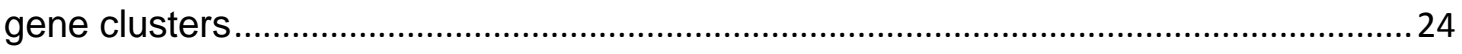

1.4.3. Relationship between fungal development and secondary metabolism..................25 
1.4.3.1. Secondary metabolites that activate sporulation

1.4.3.2. Pigments

1.4.3.3. Secondary metabolites to protect the fungus against fungivory and other environmental threats

2. Materials and methods

2.1. Materials

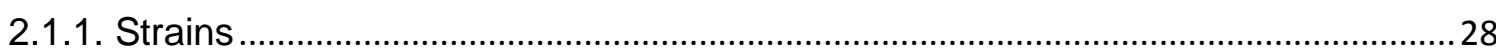

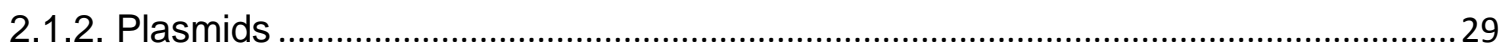

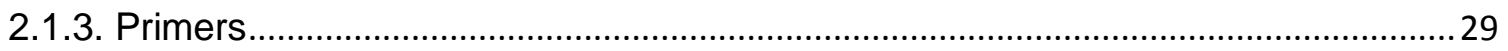

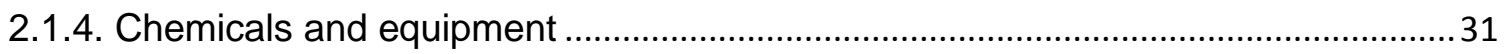

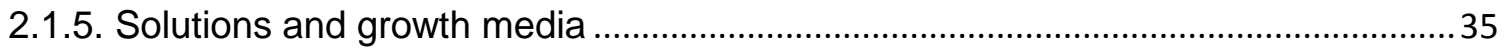

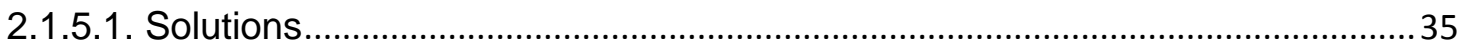

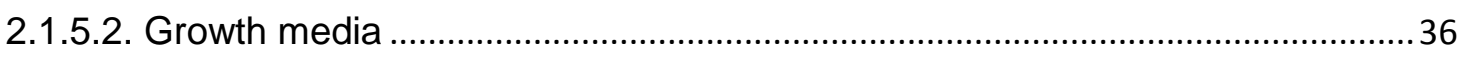

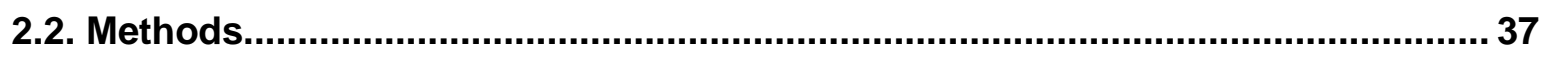

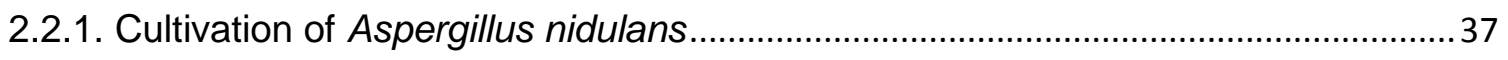

2.2.1.1. Hülle cells from solid agar plate: cleistothecia-rolling technique .......................37

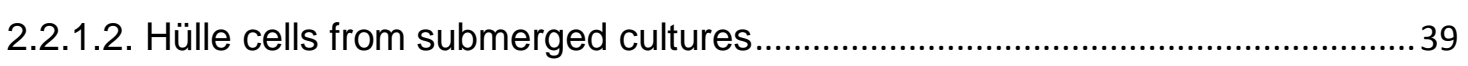

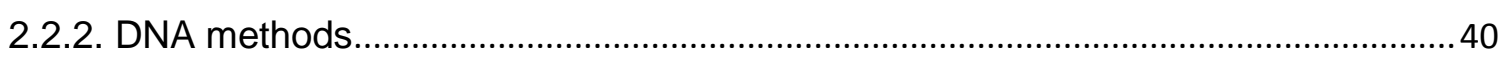

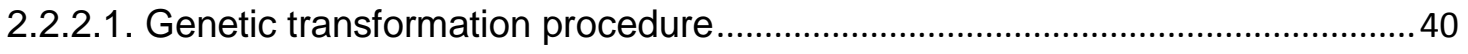

2.2.2.2. Plasmid DNA isolation from Escherichia coli.................................................... 40

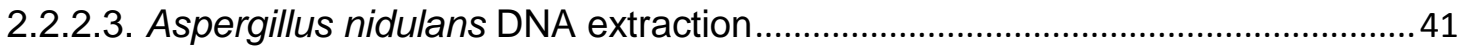

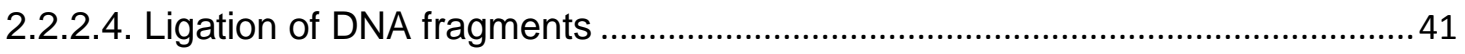

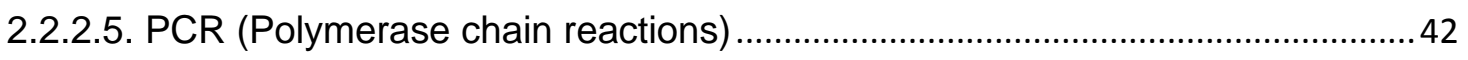

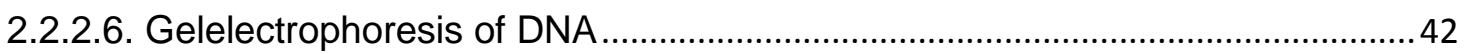

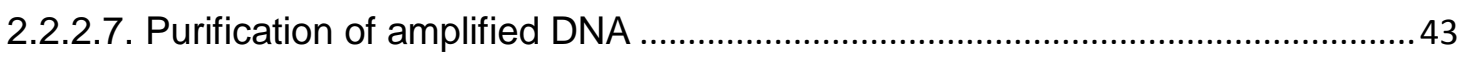

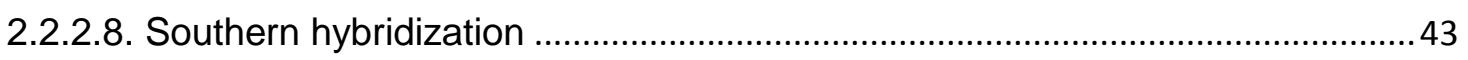

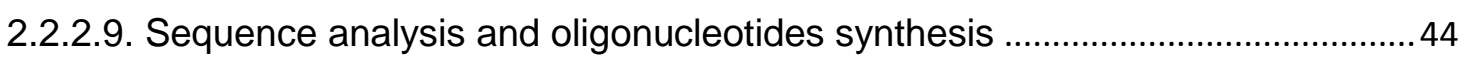

2.2.2.10. Aspergillus nidulans strain construction .......................................................... 45

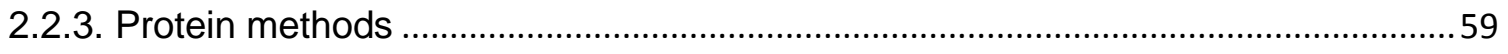

2.2.3.1. Protein extraction of Hülle cells from Aspergillus nidulans.................................59

2.2.3.2. Protein extraction of sexual mycelium from Aspergillus nidulans .....................59

2.2.3.3. Protein extraction of vegetative mycelium from Aspergillus nidulans...............60 
2.2.3.4. Protein extraction of asexual mycelium from Aspergillus nidulans .60

2.2.3.5. Protein concentration measurement .61

2.2.3.6. SDS-polyacrylamide gel electrophoresis .61

2.2.3.7. Colloidal Coomassie staining of proteins .61

2.2.3.8. In-gel protein digestion with trypsin. 61

2.2.3.9. Liquid chromatography-mass spectrometry (LC-MS) and data analysis 63

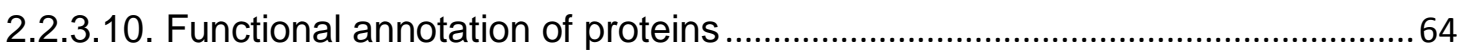

2.2.3.11. Fluorescence microscopy of fusion proteins .....................................................64

2.2.3.12. Immunoblotting. .65

3. Results 66

3.1. Enrichment of sexual tissue and specialized Hülle cells 66

3.1.1. Hülle cells can be enriched from solid agar plates for comparative proteomics ...66

3.1.2. Hülle cells can be enriched from submerged liquid cultures for comparative proteomics.

3.2. Enzymes encoded by the monodictyphenone ( $m d p)$ / xanthone (xpt) secondary metabolite gene clusters are increased during sexual differentiation: proteome comparison of Aspergillus nidulans development grown on surfaces.

3.2.1. Enrichment of surface Hülle cells enabled to perform a comparative proteome analysis .

3.2.2. Comparative proteomics revealed that the proteome of surface Hülle cells overlaps especially to that of sexual mycelium.....

3.2.3. Comparative proteomics reveal six proteins found in enriched Hülle cells from solid agar plates

3.2.4. Surface Hülle cells contain increased enzyme levels for the mobilization of complex sugar molecules

3.2.5. Enzymes encoded by the monodictyphenone $(m d p) /$ xanthone $(x p t)$ gene clusters were found in Hülle cells and sexual mycelium from solid agar plates

3.2.6. Proteins encoded by the xanthone $(x p t)$ gene cluster are enriched in the cytoplasm of Hülle cells

3.2.7. Comparative proteomics revealed that the proteome of surface Hülle cells overlaps to other fungal tissues besides of a sexual mycelium

3.2.8. Functional annotation reveals that surface Hülle cells are highly involved in carbohydrate and amino acid metabolism.

3.3. Hülle cells from surface growth and liquid media differ in their composition by $28 \%$ beside a shared core proteome: Proteomes of Aspergillus nidulans development grown on surfaces compared to liquid cultures.

3.3.1. Hülle cell formation in submerged liquid cultures for comparative proteomics....... 81 
3.3.1.1. Submerged liquid cultures revealed the proteome for comparative analysis . 85

3.3.2. Quantification of proteins in submerged liquid cultures of a laeA $\Delta$ mycelium revealed two Hülle cells proteins

3.3.2.1. Quantitative determination of proteins in laeA $\Delta$ revealed that NptA is present

in Hülle cells as well as in other fungal tissues. .88

3.3.2.2. Quantitative protein analysis revealed the kinase RfeA enriched in Hülle cells and other fungal tissues

3.3.3. The core proteome revealed a $72 \%$ overlap between the identified proteins of both types of Hülle cells

3.3.4. The proteome of surface Hülle cells compared to Hülle cells from liquid media differ in composition by $28 \%$.......

3.4. Functional analysis of genes for Hülle cell enriched proteins: A maltose permease-like protein of surface Hülle cells supports fungal growth and development

3.4.1. Comparative proteomics revealed two overlapping proteins found in Hülle cells from both approaches.

3.4.2. A similar protein to a maltose transporter is enriched in surface Hülle cells and supports growth and fungal development

3.4.2.1. The sequence of MphA a maltose permease-like protein enriched in Hülle cells contains a distinctive sugar motif.

3.4.2.2. MphA protein supports fungal growth and development ................................. 105

3.4.2.3. MphA protein is localized to the envelope of Hülle cells.

3.4.2.4. The deletion of $m p h A$ prevents mycelia differentiation at higher concentration of carbohydrates in an early developmental time point 109

4. Discussion

4.1. Hülle cells and sexual tissue grown on solid agar plates revealed the presence of proteins for the synthesis of an antimicrobial substance.

4.2. Submerged liquid cultures revealed the presence of the prenyltransferase NptA and the serine/threonine kinase RfeA in Hülle cells and in other fungal tissues ... 113 4.3. Hülle cells from surface and liquid cultures comprise shared proteins encoded by the monodictyphenone $(m d p)$ / xanthone (xpt) gene clusters

4.4. Hülle cells from surface growth and liquid media comprise an ankyrin and a tyrosinase protein

4.5. A maltose permease-like protein enriched in surface Hülle cells supports fungal

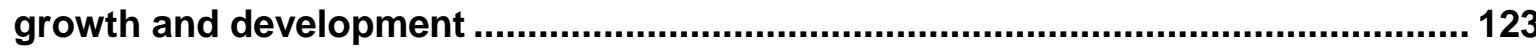

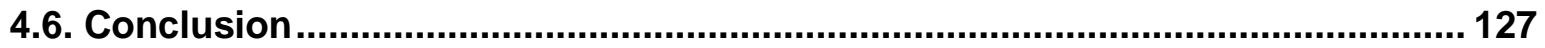


References

Abbreviations

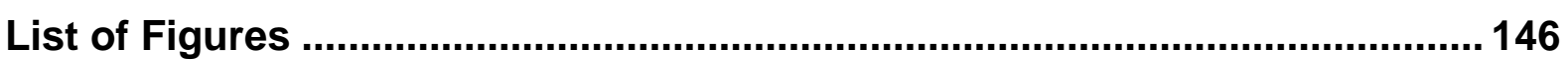

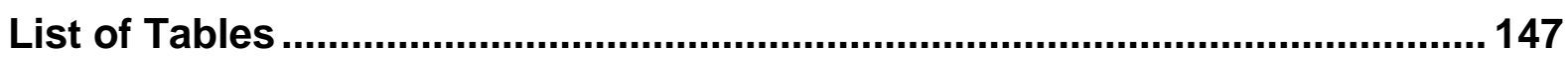

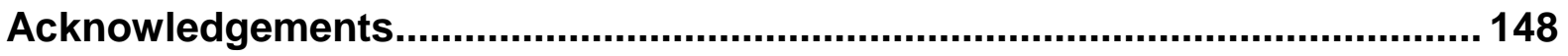

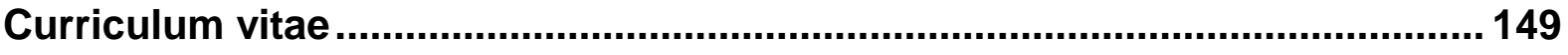

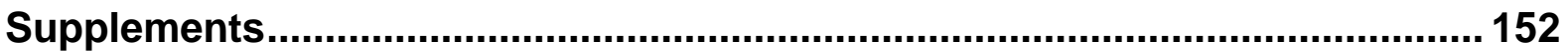




\section{Summary}

The homothallic mold Aspergillus nidulans produces as overwintering structures closed sexual fruiting bodies named cleistothecia, which contain ascospores as products of meiosis. Formation of fruiting bodies is linked to a specific secondary metabolism and includes a number of specialized cells like the globose-thick walled multinuclear Hülle cells. The LaeA methyltransferase represents an epigenetic regulator of numerous secondary metabolite clusters and is required for Hülle cell formation. Abolished Hülle cell formation correlates with a significantly reduced size of the cleistothecia, which suggested a nursing function of these cells for the growing fruiting body.

In this work, proteomes of fungal cells from different developmental programs and from enriched fractions of Hülle cells were compared to colonies grown on surfaces or in liquid medium. In a quantitative proteomics approach these results were compared to vegetative mycelia lacking the methyltransferase LaeA resulting in reduced Hülle cell formation and reduced secondary metabolism linked to the sexual program.

Comparative proteomics in combination with fluorescence microscopic investigations showed that the prenyltransferase XptB and other proteins encoded by the monodictyphenone $(m d p)$ / xanthone $(x p t)$ secondary metabolite gene clusters are found in sexual mycelium as well as in Hülle cells grown on surfaces or in submerged liquid cultures. NptA represents a second prenyltransferase, which could be identified in different fungal cell types including Hülle cells and quantitative proteomics revealed that the protein quantity of NptA is down-regulated in strains lacking LaeA.

Hülle cells grown on surfaces compared to liquid culture shared approximately $72 \%$ of the identified proteins in a core proteome. Besides the $m d p / x p t$ protein, the ankyrin domain protein (AN8434) and the tryrosine domain protein (AN8435) are part of the core proteome and showed in fluorescence microscopic investigations a cellular localization in Hülle cells.

In contrast to Hülle cells derived from liquid culture, surface cells contained increased numbers of glucanase protein levels. Another specific protein, which was only identified in surface and not liquid Hülle cells was the maltose permease-like transporter of Hülle cells MphA. Genetic studies of the corresponding deletion strain revealed that the MphA protein, which is enriched in surface Hülle cells, promotes fungal growth, asexual and sexual development. 


\section{Zusammenfassung}

Der homothallische Schimmelpilz Aspergillus nidulans produziert als Überwinterungsstrukturen geschlossene Fruchtkörper, welche man als Cleistothecien bezeichnet. Diese enthalten als Produkt der Meiose Ascosporen. Die Entwicklung der Fruchtkörper ist mit einem spezifischen sekundären Stoffwechsel verbunden, der mit der Bildung einer Reihe von spezialisierten Zellen, wie den dickwandigen globosen mehrkernigen Hülle-Zellen, gekoppelt ist. Die Methyltransferase LaeA ist als epigenetischer Regulator von zahlreichen sekundären Metabolit-Gen-Clustern für die Bildung von Hülle-Zellen erforderlich. Das Aussetzen der Bildung von Hülle-Zellen führt zu einer signifikanten Reduktion der Größe der Cleistothecien, woraus auf eine das Wachstum des Fruchtkörpers fördernde Funktion der Hülle-Zellen geschlossen werden kann.

In dieser Arbeit werden Proteome verschiedener Pilz-Zelltypen aus unterschiedlichen Entwicklungsprogrammen und aus angereicherten Fraktionen von Hülle-Zellen mit solchen verglichen, die aus Kolonien an der Oberfläche oder aus Flüssigmedien stammten. In einer quantitativen Proteom-Analyse wurden die Ergebnisse mit vegetativen Mycelien verglichen, denen die Methyltransferase LaeA fehlte. Das führte zu einer signifikanten Reduktion der Hülle-Zellen Bildung sowie des mit dem sexuellen Programm verbundenen Sekundärmetabolismus.

Vergleichende Proteomik in Verbindung mit fluoreszenzmikroskopischen Untersuchungen zeigte, dass zum Beispiel die Prenyltransferase XptB und andere Proteine, kodiert aus den Monodictyphenon ( $m d p)$ / Xanthon (xpt) sekundären Metabolit-Gen-Clustern, in Hülle-Zellen aus Fest- beziehungweise Flüssigmedium sowie aus einem sexuellen Mycel gefunden werden. NptA repräsentiert die zweite Prenyltransferase und konnte in verschiedenen Pilz-Zelltypen sowie in Hülle-Zellen identifiziert werden. Durch quantitative Proteomik-Analysen wurde festgestellt, dass bei Fehlen von LaeA die Prenyltransferase NptA eine reduzierte Proteinmenge aufwies.

Das gemeinsame überlappende (Core-) Proteom der identifizierten Proteine stimmt zu cirka $72 \%$ bei an der Oberfläche gewachsenen Hülle-Zellen und jenen, die aus Flüssigmedium stammten, überein. Neben den mdp/xpt Proteinen zeigte das gemeinsame überlappende (Core-) Proteom noch zwei weitere Proteine, das AnkyrinDomäne-Protein (AN8434) und das Tryosin-Domäne-Protein (AN8435), die eine 
zelluläre Lokalisierung in Hülle-Zellen in fluoreszenzmikroskopischen Analysen aufweisen.

Im Gegensatz zu Hülle-Zellen, welche aus Flüssigmedium stammen, zeigen HülleZellen, welche aus Oberflächen-Kulturen herrühren, eine erhöhte Protein-Anzahl an Glukanasen auf. Ein weiteres spezifisches Protein, das putative Maltose-Transport Protein MphA (Maltose Permease-artiges Protein von Hülle-Zellen) wurde ausschließlich in Hülle-Zellen aus Festmedium und nicht aus Flüssigmedium identifiziert. Genetische Studien zur Deletion von MphA zeigten, dass das MphA Protein, angereichert in Oberflächen-Hülle-Zellen, das Wachstum sowie die asexuelle und die sexuelle Entwicklung des Pilzes unterstützt. 


\section{Introduction}

Fungi produce a wide range of secondary metabolites, some of which have properties that protect the fungus against harmful environmental influences. Secondary metabolite gene clusters that encode enzymes for the production of secondary metabolites are often activated under certain environmental conditions. The activation of secondary metabolite gene clusters is often linked to developmental processes. The transition of a rather undifferentiated vegetative growth to multicellular structures such as the cleistothecia activates certain secondary metabolite gene clusters (Bayram et al., 2016). The products of meiosis, the sexual spores, are protected by the cleistothecia. Cleistothecia are embedded in nest-like structures composed mainly of Hülle cells.

In order to protect the cleistothecia against harsh environmental conditions Hülle cells might have a key role in the process of secondary metabolism.

\subsection{The genus Aspergillus}

The fungal kingdom contains about eight different phyla. Ascomycetes represent the largest fungal phylum. Phylogenetic data suggest that fungi first appeared during the late Precambrian period and that the Ascomycota diverged from the Basidiomycota approximately 1206 million years ago (Heckman et al., 2001). The Ascomycota are divided into three different subphyla: (i) Pezizomycotina, (ii) Saccharomycotina and (iii) Taphrinomycotina. Genus Aspergillus belongs to the class Eurotiomycetes within the subphylum Pezizomycotina. It is presumed that the genus Aspergillus comprises over 350 species and sexual development is known for approximately 70 species (de Vries et al., 2017, Samson et. al., 2014).

\subsubsection{Aspergillus section Nidulantes}

Aspergillus species from section Nidulantes include a variety of morphological characteristics such as biseriate conidiophores and if present, sexual fruiting bodies embedded in masses of Hülle cells (Chen et al., 2016). Aspergillus species within the section Nidulantes are common in nature and play a central role in the decomposition processes in organic material. They colonize different habitates including terrestrial, freshwater and marine environments. Aspergillus sydowii is an example that colonizes 
corals in marine habitates (Kirkwood et al., 2009, Rypien et al., 2008). Other members of the Aspergillus section Nidulantes are known to colonize humans and were reported in infectious diseases such as Aspergillus versicolor (Veraldi et al., 2010).

It was shown that different species of the section Nidulantes produce different mycotoxins (Kim et al., 2017). Secondary metabolites represent organic compounds that are important factors to protect and compete the fungus against harsh environmental conditions (Chang et al., 2017, Zhao et al., 2017, Caballero-Ortiz et al., 2013). Most of the species in the section Nidulantes produce the carcinogenic mycotoxin sterigmatocystin. Apart from the production of sterigmatocystin other mycotoxins are produced by different species in the section Nidulantes such as emestrin, fumitremorgins, asteltoxins and paxillin. Aspergillus nidulans is known to produce more than 100 different secondary metabolites including important pharmaceutically active compounds such as penicillin $\mathrm{G}$ (Chen et al., 2016).

\subsubsection{Aspergillus nidulans: A model organism for fungal development and secondary metabolism}

A. nidulans is a rapidly growing, saprophytic soil organism. The fungus is haploid and therefore, the organism is genetically better tractable. As a result, gene deletions and other mutations are possible. The fungus, therefore, can be used to answer research questions in the field of molecular biology. The presence of a sexual life cycle makes the fungus very attractive to study the molecular differences during various developmental programs.

A. nidulans was sequenced in the year 2005 (Galagan et al., 2005). The genome of A. nidulans contains 30 million base pairs, with eight haploid chromosomes and encodes 10555 proteins (Uniprot: Proteome ID UP00000056). Molecular biology, bioinformatics and comparative transcriptomics made it possible to study the expression of secondary metabolite gene clusters that are clustered within the genome and are often located near telomers (Clevenger et al., 2017). The well-studied products including important pharmaceuticals of $A$. nidulans like penicillin $\mathrm{G}$ made the fungus interesting for researchers (Itoh et al., 2017, Gerke and Braus 2014, Keller et al., 2005). Because $A$. nidulans produces different secondary metabolites in different developmental stages, it is crucial to study the life cycle of the fungus in more detail (Soukup et al., 2017). 


\subsubsection{Economic impact of Aspergilli}

Some representatives of Aspergillus spp. are of significant economic benefit such as Aspergillus niger for the production of citric acid (Yu et al., 2018). Aspergillus oryzae is used in Asian cuisines for the fermentation of soya beans for the production of soya sauces or other traditional alcoholic beverages (Nishimura et al., 2018). Other representatives of Aspergillus spp. are of negative influence for their environment. For instance, Aspergillus flavus is an opportunistic, saprophytic fungus that infects maize and other feed crops. This leads to reduced harvest and can cause a substantial economic loss. Aspergillus flavus produces carcinogenic secondary metabolites. Aspergillus flavus which produces aflatoxins and herewith contaminates maize represents a serious threat to human health (Rajasekaran et al., 2018).

There are other Aspergilli with a negative impact on the health of human beings. For instance, Aspergillus fumigatus is a widespread fungus typically found in soil and decaying organic matter and represents a serious threat for immunocompromised patients such as organ transplant recipients and people with leukemia. Conidial germination of Aspergillus fumigatus into tissue-invasive hyphae can evoke life threating infections (Shlezinger et al., 2017, Jöhnk et al., 2016). This can lead to an acute invasive and chronic pulmonary aspergillosis. Aspergillus fumigatus shows a high resistance against higher temperatures, dehydration and even desinfectants being able to survive in extremely harmful environmental conditions, even spores were isolated from the international space station (ISS); (Knox et al., 2016). 


\subsection{Morphological aspects}

The filamentous fungus $A$. nidulans develops into a multicellular organism. The transition from undifferentiated growth, such as vegetative growth, to multicellular structures requires environmental and endogenous factors. Asexual and sexual development is linked to the formation of different spore-producing structures.

\subsubsection{Hyphae}

The initial and basic unit of filamentous fungi represents undifferentiated structures named hyphae. The formation of vegetative hyphae facilitates the habitation of various ecological niches. Hyphal growth requires cell surface expansion and cell wall disposition at the hyphal tip. Different types of hypae are known and are formed during developmental processes.

Ascogenous dikaryotic hyphae are formed within cleistothecia. Through the fusion of two haploid nuclei a diploid meiotic nucleus is formed in an ascus mother cell. The ascus mother cell expands through a swelling process into an ascus (Kirk and Morris 1991).

Subtending hyphae are known to be attached to a spore from which the spore develops as a consequence of a swelling process. This is the case in Hülle cells.

\subsubsection{Hülle cells}

Eduard Eidam first described Hülle cells in 1883 where he termed Hülle cells as a "Blasenhülle" or bubble envelope (Eidam 1883). In different species, Hülle cell like structures are known such as in Candida albicans which produce at the very end of the hyphae globose blisters named chlamydospores (Navarathna et al., 2016). Eidam suggested that Hülle cells originate from the tip of "secondary hyphae" which in turn emerge from "primary hyphae" and develop as a consequence of a swelling process (Figure 1). 


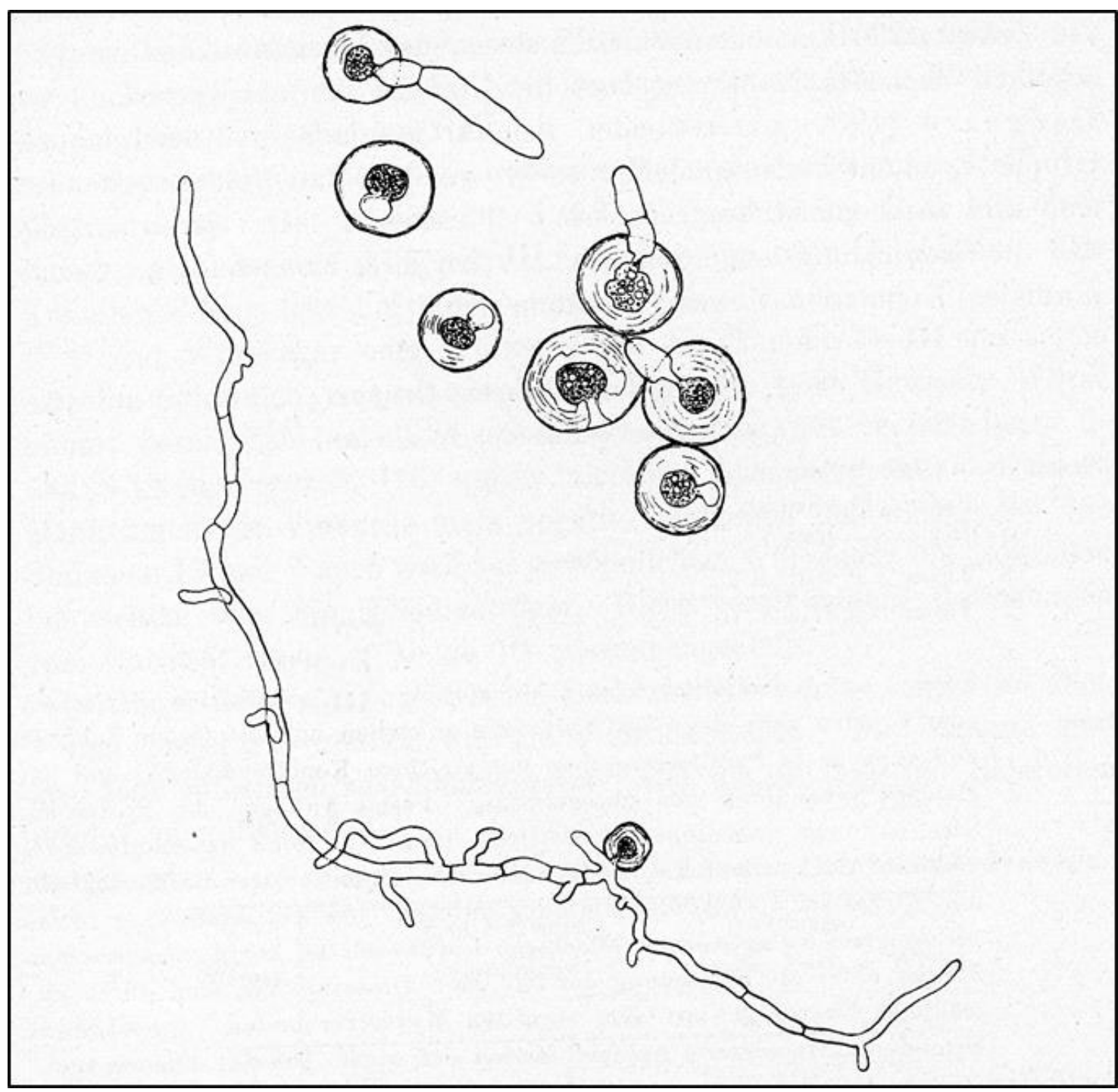

Figure 1. Adult Hülle cells and the subtending hyphae of Hülle cells.

Hülle cells are globose in shape with a thick cell wall and are often connected to subtending hyphae. These hyphae are of different size and length between very long and rather short and sometimes show a branch structure. Hyphae also contain subdividing septa. Within the globose structure of Hülle cells, a cytoplasm with metabolic activity is situated. The thick cell wall is ringshaped and open on one side. Two septa are visible in the open part of the ring (Raper and Fennel 1965).

Hülle cells and the subtending hyphae are connected via two distinct types of septa (Figure 2A). The inner one is a single perforate septum where woronin bodies can be observed and represents a typical ascomycetous septum. The second septum which separates Hülle cells from the subtending hyphae is unique and named basal septum (Figure 2B). At the basal septum vesicle fusion is observable. Consequently, to this fusion so called lomasome-like accumulations are visible. These lomasome-like structures are membrane-invaginations (Figure 2C). In Hülle cells several nuclei, mitochondria, lipid bodies and storage products can be observed (Ellis et al., 1973). 
During initial Hülle cell formation, it was shown that several nuclei fuse to form a marcronucleus (Carvalho et al., 2002). Different species of the Aspergillus genus produce Hülle cells, including A. nidulans and Aspergillus heterothallicus (Bayram and Braus 2012). Hülle cells have an average size of $12-20 \mu \mathrm{m}$, are of globose shape with an unusual thick cell wall and are mainly associated with the sexual developmental program. Hülle cells are known for all species in the section Nidulantes (Chen et al., 2016). In different species, Hülle cells vary in shape between the more elongated such as in Aspergillus ustus and the globose version like in A. nidulans. In A. nidulans and Aspergillus heterothallicus Hülle cells associate with the cleistothecia, whereas in Aspergillus protuberus and Aspergillus ustus Hülle cells are not in direct contact with the cleistothecia and are formed in masses (Muntanjola-Cvetkovic and Vukic 1972).

\subsubsection{Cleistothecia}

In A. nidulans the products of meiosis, the sexual spores, are situated and produced in the cleistothecia. The function of cleistothecia, therefore, is to protect the sexual spores against harsh environmental conditions. During sexual sporulation, certain hyphae develop to ascogenous hypae. Ascogenous hyphae contain two haploid nuclei of opposite mating type. These hyphae form a hook shaped structure, named crozier, their nuclei divide synchronously. Different septae are formed thereby forming a dikaryotic top cell. After fusion of the end cell and the basal cell of the crozier karyogamy and further ascus development take place (Braus et al., 2002, Busch and Braus 2007). Hülle cells are most probably formed through a swelling process of certain vegetative hyphae. The first morphological manifestation of a visible structure is the appearance of cleistothecial initials, 40 hours after germination (Sohn and Yoon 2002). These structures are coiled lumps of cells, which undergo further coiling and become enlarged to approximately $10 \mu \mathrm{m}$. This is the stage where Hülle cells first appear (Sohn and Yoon 2002). A. nidulans produces dark reddisch ascospores which are found in globose structures named asci (Dyer and O'Gorman 2012). These asci are protected by dark brown/violet ascomata. The ascomata are named cleistothecia in Aspergillus nidulans, due to its closed conformation (Greek: Kleistos = closed, theke = case). . Cleistothecia are surrounded by numerous hyaline to pale brown globose Hülle cells. 

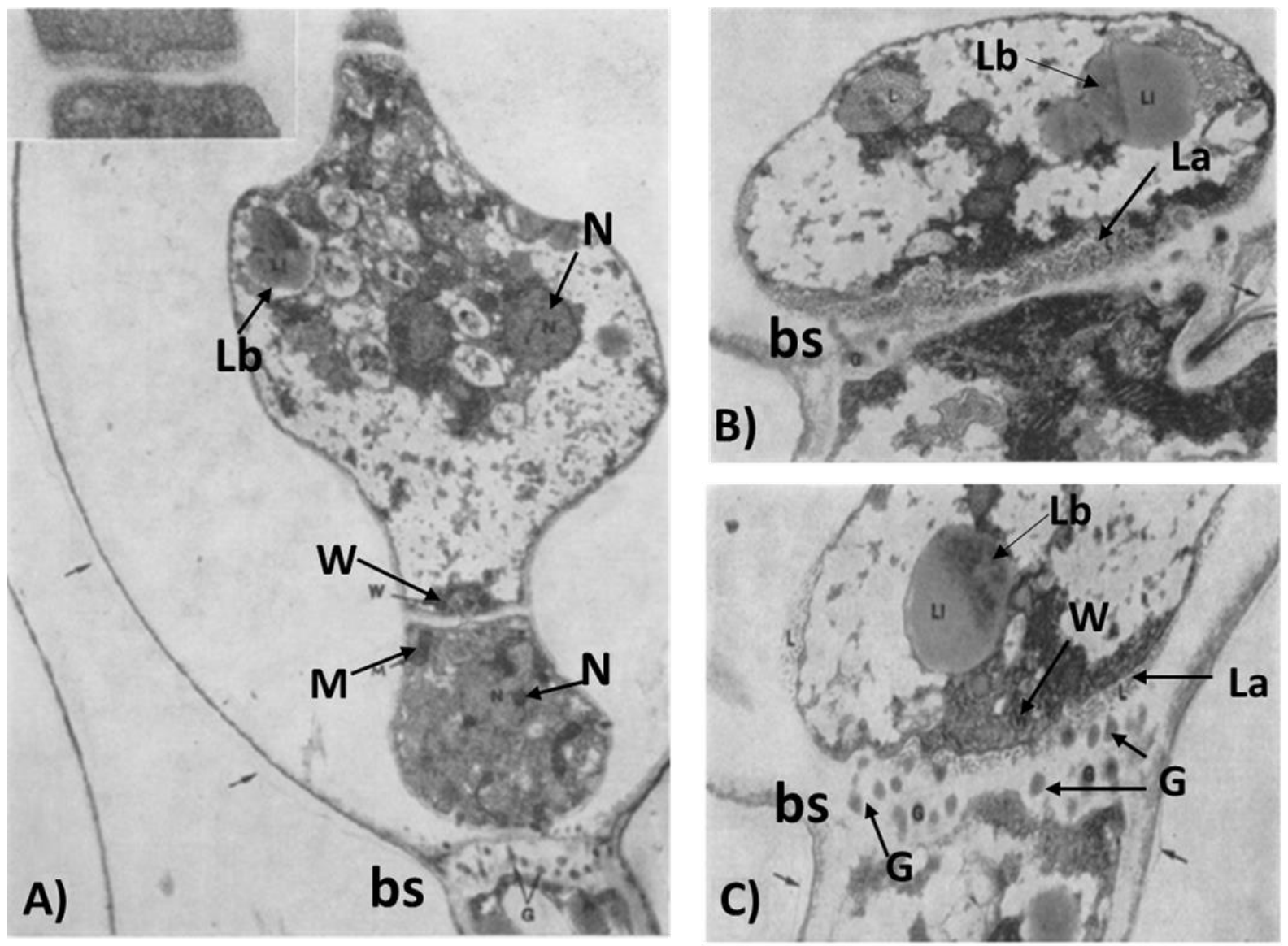

Figure 2. Electron microscope images of the content and septa found in Hülle cells of Aspergillus nidulans.

A) Overview picture of the content and the septa found in Hülle cells. The basal septum (bs) which separates Hülle cells from the subtending hyphae is unique. A second type of septum inside of Hülle cells is a typical ascomycetous septum where woronin bodies $(\mathrm{W})$ and mitochondria (M) are observed. At the Hülle cell side (cytoplasm) lipid bodies (Lb) and nuclei (N) are visible. Further septa are possible in Hülle cells. B) The unique basal septum (bs) of Hülle cells. At the periphery of this septum (at Hülle cell side) lomasome-like accumulations ( $\mathrm{La}$ ) of the membrane are present (lomasome-like structures are invaginations of the membrane). In between the two septa woronin bodies (W), lipid bodies (Lb) and nuclei $(\mathrm{N})$ are visible. Woronin bodies are close to the basal septum (bs). C) The basal septum (bs) contains globular structures (G). Image modified (Ellis et al., 1973).

\subsubsection{Conidiophores}

The Aspergillus species produces first foot cells from vegetative hyphae, which apically extend into a stalk. The very end of this cell swells to a so-called multinucleated vesicle. The vesicle produces a finger like metula as a first layer and a second layer, the phialides are formed by mitosis (Bayram and Braus 2012). These phialides undergo repeatedly asymmetric mitotically processes which lead to the production of haploid airborne conidiospores. After initial formation, conidiospores 
undergo the maturation process. The progression of condiospores is a separate process from the initial phase. The development of condiospores contains several changes in cell wall structures and chemical modifications. During the maturation process, four different cell wall layers emerge. This enables impermeability of condiospores, necessary to protect spores from harsh environmental conditions. Chemical modifications include the production of trehalose which serves as an energy source and protects against various environmental conditions such as dehydration, cold and oxidation (Elbein et al., 2003). Matured conidia are formed 15 hours after initial sporulation. The conidiophore represents the complete asexual structure which carries asexual spores called conidia.

\subsection{Factors influencing fungal development}

\subsubsection{Environmental factors}

Various environmental factors are important for $A$. nidulans to develop asexually on the surface (Figure $3 \mathrm{~A}$ ). Exposure to sunlight, in particular, represents a crucial factor (Dasgupta et al., 2016). Other environmental factors that induce the asexual developmental program are high oxygen concentrations, temperature shifts, osmotic stress and high concentrations of reactive oxygen species (ROS) (Bennett and Turgeon 2017, Noble and Andrianopoulos 2013). A. nidulans grow preferentially sexually and produce as overwintering structures, closed sexual fruiting bodies called cleistothecia in darkness under the soil (Dyer and O'Gorman 2012). Different environmental signals such as low oxygen concentrations, buffered temperature, humidity and low concentrations of ROS trigger sexual development. Asexual and sexual differentiation of $A$. nidulans is linked to significant changes in the formation of secondary metabolites and the formation of various distinct cell types of the respective developmental programs (Park et al., 2017). Asexual and sexual structures of $A$. nidulans are shown in Figure 3B. 


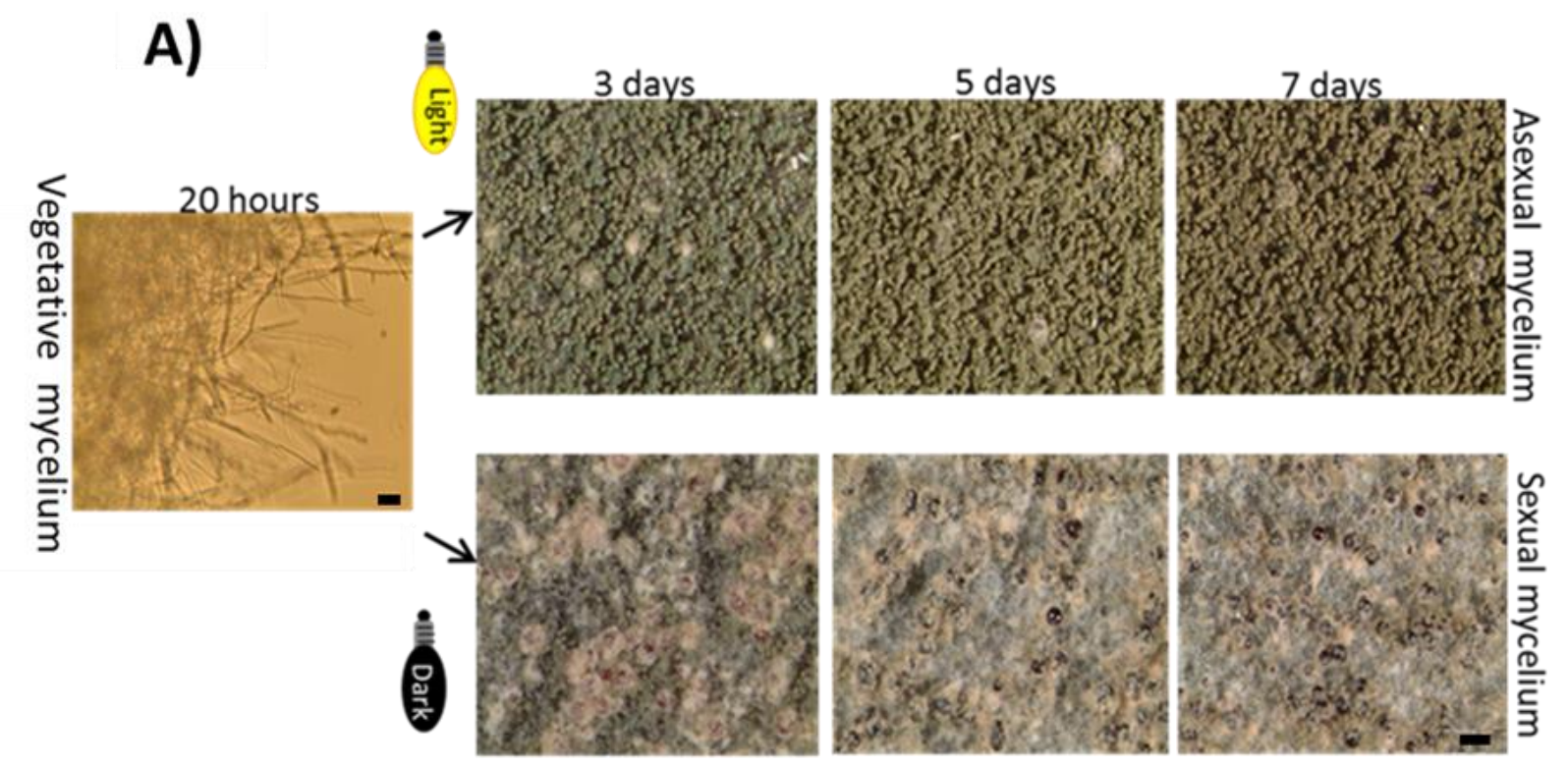

B)

Cleistothecium

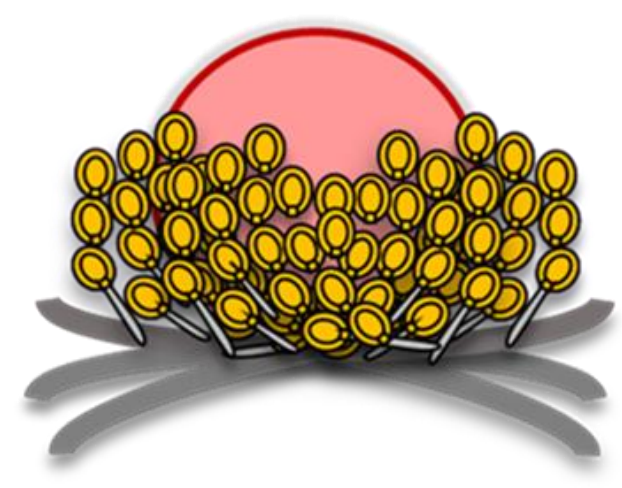

Conidiophores

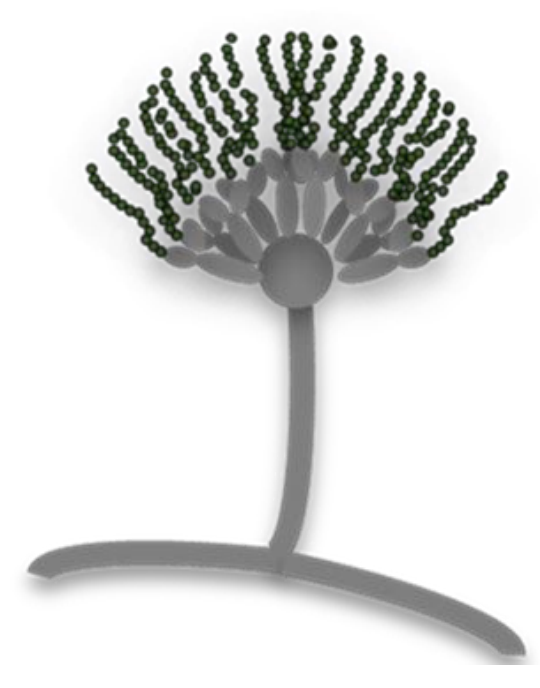

Figure 3. Asexual and sexual differentation.

A) The fungus has to develop vegetative hyphae before cellular differentiation. This type of mycelium consists of relatively undifferentiated hyphae without other cell types. After the initial growth phase the fungus reaches a competence state, which defines a barrier to enter a differentiation capability. In light vegetative mycelium develops preferentially to asexual conidiophores, whereas in darkness the sexual developmental program is favored. Vegetative, asexual and sexual mycelia are shown at different time points. B) Different spore-producing structures of Aspergillus nidulans. Sexual differentiation increases sexual cell types such as cleistothecia. Hundreds of globose Hülle cells surround each cleistothecium. The cleistothecium contains sexual spores called ascospores. The asexual cell type is named conidiophore that carries the asexual spores called conidia. Scale bar is $200 \mu \mathrm{m}$. (Bennett and Turgeon 2017, Noble and Andrianopoulos 2013, Bayram and Braus 2012). 


\subsubsection{Light favors asexual differentiation}

Light represents an important environmental factor that allows fungi to respond in different ways. Different processes are linked to light sensing in $A$. nidulans, including differentiation or changes in gene expression within primary and secondary metabolism. After the initial growth phase, the fungus reaches a competence state, that defines a barrier to enter a differentiation capability (Jiang et al., 2017, RugerHerreros et al., 2011). This allows to respond to different environmental factors. In light, $A$. nidulans preferentially develops asexually. The light-sensing function of fungi require a number of different, wave length specific receptors (Pöggeler et al., 2018). Cryptochromes (Cry) are a class of photolyase-like receptors sensitive to blue light. In $A$. nidulans the cryptochrome/photolyase CryA represses sexual differentitation beside its function in DNA-repair activities. Deletion of the corresponding gene cryA stimulated Hülle cell formation in submerged liquid cultures where usually no Hülle cells are formed. Asexual sporulation correlates with the production of few secondary metabolites. It was found that $A$. nidulans produces the antibiotic compound emericellamide (Chiang et al., 2008). The biosynthesis of the secondary metabolites emericellamide $A, C$ and $E$, is initiated by light (Bayram et al., 2016). These types of antibiotics were shown to be present after 24 hours of growth in light, whereas in darkness, growth is extremely diminished (Bayram et al., 2016).

\subsubsection{Sexual differentiation is promoted by darkness}

Illumination mainly inhibits the production of certain secondary metabolites and favors asexual sporulation. Sexual reproduction is favored in darkness and low oxygen concentration. It is accompanied with the accumulation of secondary metabolites. The heterotrimeric velvet complex VelB/VeA/LaeA coordinates light signals with fungal development together with secondary metabolism (Bayram et al., 2008b). VeA bridges VelB to the methyltransferase LaeA. During illumination VeA is mostly situated in the cytoplasm where VelB supports asexual sporulation and LaeA shows low activity. In darkness VeA is imported into the nucleus by KapA (importin).

Additionally, VeA supports the transportation of VelB into the nucleus. VelB/VeA, forms together with laeA the heterotrimeric velvet complex VelB/VeA/LaeA. This complex regulates sexual sporulation and secondary metabolism. It was shown that 
additional proteins associate with the heterotrimeric velvet complex and that specific secondary metabolite gene clusters are preferentially activated in darkness that lead to the accumulation of secondary metabolites like monodictyphenone, xanthone, asperthecin and sterigmatocystin (Sarikaya-Bayram et al., 2014, Bayram et al., 2016).

\subsubsection{Nutrients}

Sexual and asexual development in A. nidulans is strongly affected by nutrients. Han and co-workers showed that the sexual development is favored in well-nourished growth conditions, whereas carbon limitation, light exposure and high concentration of salt promotes asexual development (Han et al., 2003). This suggests that stress conditions provoke asexual development, while well-nourished growth conditions favor sexual development. Chitins, carbohydrates and other compounds of the fungal cell wall are important factors for nutrient supply during development. During initial growth phase of the fungus $\alpha-1,3$-glucans is accumulated in the fungal cell wall. Glucanases such as MutA or AngB degrade glucanes in the cell wall of storage hyphae to yield carbohydrates representing a carbon source (Zonneveld 1973, He et al., 2017, Wei et al., 2001) .

Amino acids are known to influence the growth of cleistothecia in Aspergillus nidulans. Amino acid starvation leads to impaired or stalled cleistothecia formation (Eckert et al., 1999, Serlupi et al., 1983). Storage lipids that represent carbon sources are present in lipid bodies and are found in Hülle cells (Ellis et al., 1973). It is known that fruiting body formation in various fungi is increased by addition of fatty acids (Pöggeler et al., 2006, Dyer et al., 1993; Goodrich-Tanrikulu et al., 1999).

\subsubsection{Endogenous factors}

Additional factors are required to allow the differentiation process of the fungus beside the above mentioned environmental factors. Primary as well as secondary metabolism are involved in this process. Primary and secondary metabolites are typically associated with different developmental programs. During initial growth phase primary metabolites are synthesized or obtained from the growth medium. 


\subsubsection{Primary metabolism}

Primary metabolites such as amino acids, carbohydrates and lipids are molecules essential for growth, development and reproduction. Primary metabolites are mainly accumulated during initial growth phase and are processed during different developmental stages.

The process of sexual differentiation requires massive cell proliferation and as a result, increased carbon sources are required. Zonneveld and co-workers showed that $\alpha-1,3-$ glucans are accumulated during vegetative growth in the cell wall and that these polysaccharides are degraded during sexual development (Zonneveld 1973). The $\alpha$ 1,3-glucanase MutA was shown to be localized mainly in Hülle cells (Wei et al., 2001). The mobilization of $\alpha-1,3$-glucans was affected in a mutA $\Delta$ strain although the cleistothecia were still able to grow similar to that of the wild-type (Wei et al., 2001). These results suggest that additional enzymes and carbon sources are most likely required as a nursing resource during the development of the cleistothecia (Yoshimi et al., 2017). It is assumed that Hülle cells comprise cell wall lytic enzymes that release monosaccharides (de Groot et al., 2009, Wei et al., 2001).

Furthermore, it is supposed that high affinity sugar transporters are involved to nurse the developing closed cleistothecia (Pöggeler et al., 2006). Wei and co-workers identified a putative hexose transporter, $\mathrm{HxtA}$, that is expressed in Hülle cells and in ascogenous hyphae after starvation (Wei et al., 2004). The deletion of $h x t A$ showed no effect on sexual development. The low affinity glucose transporter $\mathrm{HxtB}$ is suggested to be involved in fungal development (Dos Reis et al., 2017). Pantazopoulou and co-workers showed that the purine transporters UapA and AzgA are found in Hülle cells and on the surface of the cleistothecium (Pantazopoulou et al., 2007). The knockout of uapA and azgA showed no effect on the development of cleistothecia. This suggests that additional transporters are active during sexual development and required to supply nutrients or protective molecules to the maturating cleistothecia.

Amino acids, isopentenyl pyrophosphate and malonyl-CoA are building blocks for the synthesis of secondary metabolites. Malonyl-CoA represents in $A$. nidulans the initial unit for the synthesis of polyketides such as monodictyphenone which is a secondary metabolite (Klejnstrup et al., 2012). 


\subsubsection{Secondary metabolism}

Primary and secondary metabolism merge into each other and as a result, the border is difficult to define. The morphological border to produce secondary metabolites is mainly determined by entering distinct developmental programs and thereby forming multicellular structures such as cleistothecia (Bayram et al., 2016).

Secondary metabolites are small-molecule metabolites produced by fungi, plants and bacteria. The production of secondary metabolites allows the fungus to colonize a multitude of environmental niches and allows to compete against other bacteria, fungi and insects (Demain and Fang 2000). Additionally, secondary metabolites production is connected to developmental processes of the fungus such as asexual and sexual sporulation.

Genes that encode enzymes for the production of secondary metabolites are often clustered and the expression of these genes are under the regulation of different factors (Hou et al., 2017, Brakhage 2013). Secondary metabolite gene clusters encode typically one of several backbone enzymes: (i) a polyketide synthase (PKS); (ii) a nonribosomal peptide synthetase (NRPS); (iii) a polyketide synthase/non-ribosomal peptide synthetase hybrid (PKS-NRPS); (iv) a dimethyl-allyl-tryptophane synthase (DMATS) type aromatic prenyltransferase or (v) diterpene synthase (DTS) (FloresGallegos et al., 2016, Pan et al., 2017). The actions of the residual tailoring enzymes encoded by the residual genes from the gene cluster diversifies greatly the spectrum of the produced secondary metabolites of the gene cluster (Keller et al., 2005). The genome of $A$. nidulans encodes 29 polyketide synthases, eleven non-ribosomal peptide synthetases and seven prenyltransferases (de Vries et al., 2017, Galagan et al., 2005). Sequencing the genome of $A$. nidulans, proposes more then 40 different secondary metabolite pathways (Galagan et al., 2005).

In recent years, it was demonstrated that the expression of genes from secondary metabolite gene clusters and fungal development are coordinated through environmental factors (Cary et al., 2017, Röhrig et al., 2017). Bayram and co-workers showed that the transcripts of nine different genes from the monodictyphenone ( $m d p$ ) / xanthone $(x p t)$ gene clusters are specifically expressed during darkness in a sexual mycelium (Bayram et al., 2016). 


\subsection{Specialized metabolism in fungal development}

Secondary metabolism, also called specialized metabolism, plays an important role in fungal development. Secondary metabolites are produced under special environmental conditions, in competition with other organisms and in special developmental stages.

\subsubsection{The monodictyphenone $(m d p)$ / xanthone (xpt) secondary metabolite gene clusters}

The monodictyphenone $(m d p)$ secondary metabolite gene cluster is found to contain twelve genes that are located near the rather silent telomeric region of chromosome VIII (Figure 4). It is known that chromatin remodeling factors are needed to influence the expression of genes that are responsible for the production of secondary metabolites (Gacek and Strauss 2012).

Bok and co-workers showed that CClA, a member of the histone 3 lysine 4 methylating COMPASS (complex associated with Set1) complex regulates the expression of secondary metabolite gene clusters such as the monodictyphenone ( $m d p)$ gene cluster (Bok et al., 2009). The deletion of $c c / A$ alters the expression of genes necessary for the production of monodictyphenone. Monodictyphenone represents a precursor for the synthesis of prenyl-xanthones. The genes $x p t A, x p t B$ and $x p t C$ required for the conversion of monodicytphenone into xanthones are not embedded in the monodictyphenone gene cluster (Pockrandt et al., 2012, Sanchez et al., 2011). Instead, they are localized on two different chromosomes. The genes that encode the two prenyltransferases XptA and XptB are localized on chromosome I and II. The gene xptC that encodes an oxidoreductase that is localized on chromosome $\|$ and is separated from the gene that encodes the prenyltransferase $X p t B$ by the gene AN7998. Sanchez and co-workers showed that $m d p E$ (encodes a putative C6 zinc finger transcription factor), $m d p l$ (encodes a putative AMP-binding CoA ligase) and AN7998 (encodes a putative oxidoreductase) are not involved in the synthesis of prenyl-xanthones (Sanchez et al., 2011). 
A) Chromosome VIII

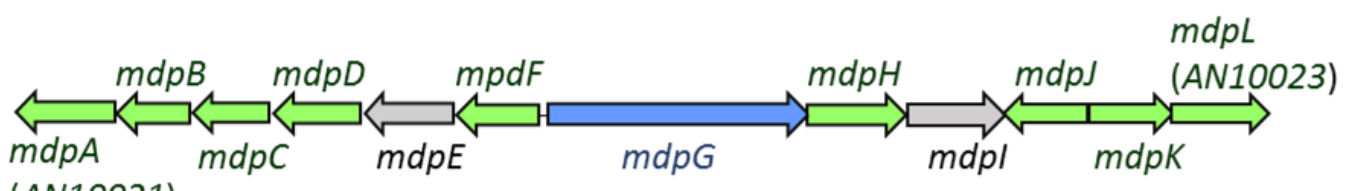

(AN10021)

B)
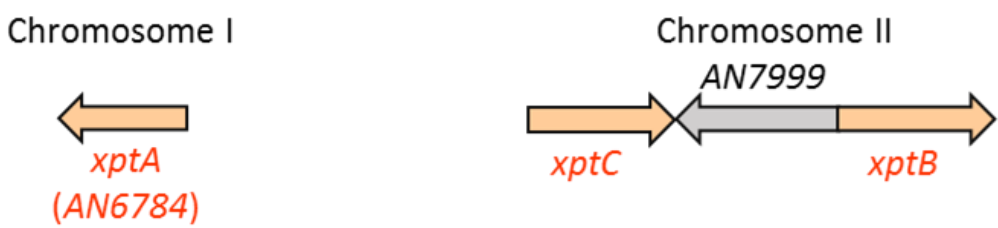

Figure 4. Secondary metabolite gene clusters which are involved in the production of monodictyphenone and xanthones.

A) The monodictyphenone $(m d p)$ gene cluster is located at the telomeric region of chromosome VIII and contains twelve genes. The gene $m d p G$ (blue) encodes a polyketide synthase that is involved in the production of the polyketide backbone core structure of monodictyphenone. The enzymes encoded by the residual genes modify the core structure resulting in the production of emodin and finally in monodictyphenone and prenyl-xanthones. The genes $m d p E$ (encodes a C6 zinc finger transcription factor) and $m d p l$ (encodes an AMP-binding CoA ligase) in grey are not essential for the production of prenyl-xanthones.

B) Monodictyphenone represents a precursor for the production of prenyl-xanthones. Two prenyltransferases $\mathrm{Xpt} A, \mathrm{XptB}$ and an oxidoreductase $\mathrm{XptC}$ are involved in the conversion of monodictyphenone into prenyl-xanthones. The genes that encode the prenyltransferases XptA and XptB are localized on chromosome I and II. The oxidoreductase XptC is localized on chromosome II and is situated next to the gene AN7999 (grey) which encodes an oxidoreductase and is not essential for the production of prenyl-xanthones (Sanchez et al., 2011, Chiang et al., 2010).

\subsubsection{Monodictyphenone is a precursor for the synthesis of xanthones}

Xanthones are organic compounds found in different species like the mangosteen tree Garcinia mangostana and are responsible for a yellow pigmentation. The chemical building block of xanthones is composed of a core structure named xanthone nucleus (9H-Xanthen-9-on) that is an aromatic oxo compound. Different modifications of the xanthone nucleus lead to a variety of different xanthones. A possible modification of the xanthone nucleus can be due to a prenylation event. Xanthones found in Garcinia mangostana are known for anticancer activities (Alam and Khan 2018).

The polyketide synthase MdpG encoded by the monodictyphenone ( $m d p)$ gene cluster is required for the synthesis of anthraquinone emodin, monodictyphenone and related compounds (Klejnstrup et al., 2012). The sequence of the polyketide synthase MdpG contains as many as 1806 amino acids with a predicted molecular mass of 196,8 kDa. 
The polyketide synthase MdpG synthesizes the main polyketide backbone core structure. MdpG polyketide synthase consists of several domains with defined functions mentioned in Figure 5. These domains of MdpG are involved in the synthesis of the polyketide backbone.

Emodin and monodictyphenone are precursors for prenyl-xanthone. Sanchez and coworkers deleted $m d p G$ and revealed that the product monodictyphenone and other compounds such as prenyl-xanthones are no longer produced (Sanchez et al., 2011). The first step in the production of emodin and monodictyphenone requires MdpG. Malonyl-CoA represents a substrate for MdpG which synthesizes the polyketide backbone. The polyketide synthase MdpG lacks a thioesterase (TE) domain which hydrolyzes the newly formed polyketide backbone off the synthase. The gene $m d p F$ that encodes a putative zinc dependent hydrolase, catalyzes most probably the release of the polyketide backbone from MdpG (Chiang et al., 2010). The gene $m d p H$ that encodes a decarboxylase, catalyzes the conversion of atrochrysone carboxylic acid into atrochrysone (Klejnstrup et al., 2012). The deletion of $m d p H$ results in an inability of the above-mentioned conversion to atrochrysone (Chiang et al., 2010). In order to convert atrochrysone to emodin two unknown dehydrating and modifying enzymes are necessary. The following enzymes finally convert emodin into monodictyphenone, a dehydratase (MdpB), a ketoreductase (MdpC), a glutathione $S$ transferase (MdpJ), an oxidoreductase (MdpK) and a Baeyer-Villiger oxidase (MdpL) (Simpson 2012, Klejnstrup et al., 2012). The monooxygenase MdpD is required for the hydroxylation of monodictyphenone (Bok et al., 2009).

As a next step the hydroxylated monodictyphenone is converted into prenylxanthones. Klejnstrup and co-workers demonstrated that the two prenyltransferases XptA and XptB are involved in the prenylation of hydroxylated monodictyphenone (Klejnstrup et al., 2012). The biosynthesis of the stereoisomers shamixanthone and epishamixanthone is finally catalyzed by the oxidoreductase XptC (Sanchez et al., 2011).

It is known that monodictyphenone and xanthones are antimicrobial agents that serve against fungivory and other environmental threats (Bok et al., 2009, Regulin and Kempken 2018). In a transcriptomic and metabolomic profiling study it was observed that after the addition of choline Hülle cell formation occurred in a vegetative mycelium and the secondary metabolite monodictyphenone was present in this liquid culture (Alves et al., 2016). 


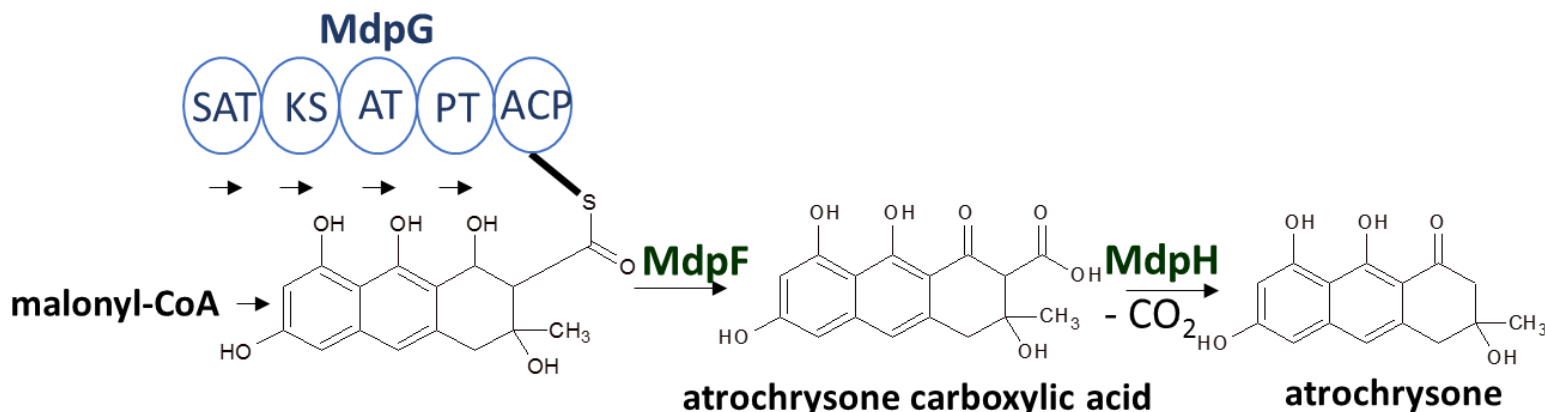

atrochrysone carboxylic acid

atrochrysone<smiles>Cc1cc(O)c2c(c1)C(=O)c1cc(O)cc(O)c1C2=O</smiles>

emodin

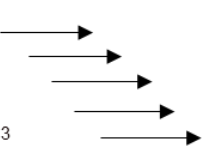

$\mathrm{MdpB}$<smiles>Cc1cc(O)c(C(=O)c2c(O)cccc2O)c(C(=O)O)c1</smiles>

monodictyphenone

MdpJ

MdpK<smiles>C=CCOc1c(C)cc2oc3cccc(O)c3c(=O)c2c1CO</smiles>

variecoxanthone $A$<smiles>CCOc1c(Cl)cc2oc3c(CC=C(C)C)ccc(O)c3c(=O)c2c1CO</smiles>

emericellin<smiles>C=C(C)[C@H]1COC2=C(c3c(c(C)cc4oc5c(CC=C(C)C)ccc(O)c5c(=O)c34)OC[C@H]2C(=C)C)[C@@H]1O</smiles>

shamixanthone

epishamixanthone

Figure 5. Biosynthesis of monodictyphenone and xanthones.

The polyketide synthase MdpG synthesizes the main polyketide backbone core structure and uses malonyl-CoA as a substrate. Several domains of MdpG are involved in the synthesis of the poyketide backbone (SAT domain an ACP-transacylase as a starter unit, KS a B-ketoacyl synthase domain and AT an acetyltransferase domain. These three domains are involved in the synthesis of a polyketide backbone intermediate. The internal product template (PT) domain is responsible for folding and cyclization of the polyketide backbone intermediate. The ACP is an acryl carrier protein domain and represents a transiently holding domain for the polyketide backbone).

The putative zinc dependent hydrolase MdpF catalyzes most probably the release of the polyketide backbone from MdpG. The decarboxylase MdpH catalyzes the conversion of atrochrysone carboxylic acid to atrochrysone. In the conversion of atrochrysone to emodin unknown enzymes are involved. Several enzymes (MdpB (dehydratase), MdpC (ketoreductase), MdpJ (glutathione S transferase), MdpK (oxidoreductase), MdpL (Baeyer-Villiger oxidase) are required for the further synthesis of emodin to monodictyphenone. The monooxygenase MdpD hydroxylates monodictyphenone. The two prenyltransferases XptB and XptA are required for the prenylation of hydroxylated monodictyphenone. Giving rise to the compounds variecoxanthone $A$ and emericellin. The oxidoreductase XptC converts emericellin into the stereoisomers shamixanthone and epishamixanthone (Simpson 2012; Klejnstrup et al., 2012). 


\subsubsection{LaeA as a factor that coordinates fungal development and secondary metabolism}

Secondary metabolism and fungal development is known to be highly coordinated by several protein complexes (Sarikaya-Bayram et al., 2014, Bok et al., 2009). The LaeA methyltransferase protein is a member of the velvet complex that regulates fungal development and secondary metabolism (Bayram et al., 2008b). In A. nidulans LaeA regulates not only secondary metabolism but also asexual and sexual sporulation. The coordination of fungal development and secondary metabolism through LaeA is known in different Aspergilli (Sarikaya-Bayram et al., 2010, Dhingra et al., 2013, Zhao et al., 2017). In Aspergillus flavus it was demonstrated that laeA is required for sclerotia formation and crucial for aflatoxin synthesis (Zhao et al., 2017). The correlation between sclerotia formation and aflatoxin production enables Aspergillus flavus to grow in harsh enviromental conditions (Chang et al., 2017). This indicates that secondary metabolism and fungal development is correlated in different species.

\subsubsection{LaeA methyltransferase}

The LaeA (loss of aflR expression of A) methyltransferase domain protein was first identified by a forward mutant screen and it was shown that lae $A \Delta$ is unable to express the AfIR transcriptional activator that controls the activation of numerous secondary metabolite gene clusters (Bok and Keller 2004). The LaeA protein of $A$. nidulans comprises 374 amino acids with a predicted molecular mass of $43.0 \mathrm{kDa}$. The protein sequence includes different domain architectures (Figure 6). At the $\mathrm{N}$-terminal region, the protein sequence contains a nuclear localization signal (NLS). LaeA is known to interact with the VeA and VelB proteins in the nucleus (Bayram et al., 2008b). In the center a putative S-adenosylmethione dependent (SAM) metyltransferase domain (MTD) is found and is typical for nuclear protein methyltransferase (Bok and Keller 2004). LaeA together with the velvet family proteins VeA and VelB represent a trimeric complex that is essential for fungal development and secondary metabolism (Bayram et al., 2008b). The deletion of laeA leads to a photoinhibition. Therefore laeA $\Delta$ strains are unable to repress sexual development in light (Sarikaya-Bayram et al., 2010). This results in a phenotype that produces more cleistothecia in light. On the other hand, a $v e A \Delta$ deletion results in total inability to enter the sexual program (Kim et al., 2009). 


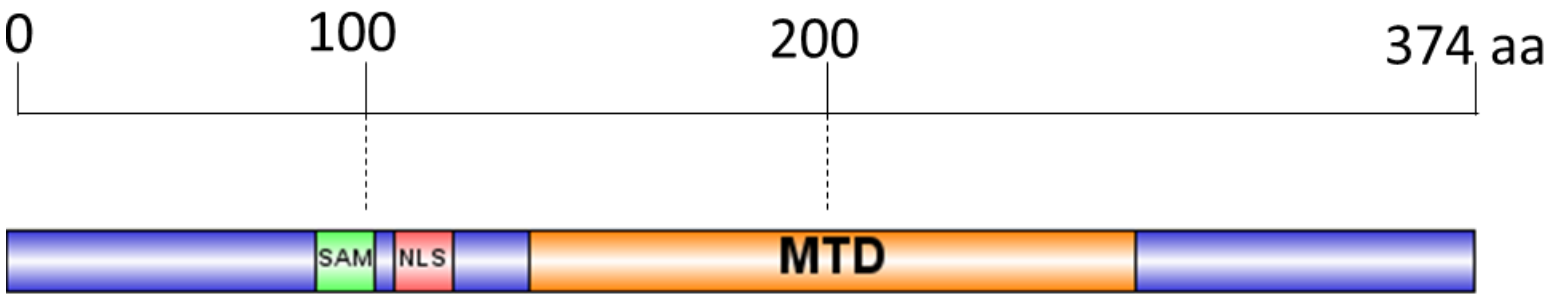

Figure 6. Domain architecture of the methyltransferase LaeA.

The sequence of the methyltransferase domain protein LaeA of $A$. nidulans comprises 374 amino acids with a molecular mass of $43.0 \mathrm{kDa}$ and contains different domain architectures (SAM: Sadenosylmethionin- binding site, NLS: nuclear localization signal, MTD: methyltransferase domain).

\subsubsection{LaeA methyltransferase promotes Hülle cell formation}

LaeA methyltransferase is required for Hülle cell formation as shown in Figure 7. Abolished Hülle cell formation correlates with a significantly reduced size of the cleistothecia from around $200 \mu \mathrm{m}$ to $40 \mu \mathrm{m}$ (Sarikaya-Bayram et al., 2010). This suggests a nursing function of Hülle cells for the growing cleistothecia. The growth of cleistothecia surrounded by Hülle cells are mainly observable under surface conditions since their growth is dependend on surface.Deleting the gene laeA led to abolished Hülle cell formation (Sarikaya-Bayram et al., 2010). Genes which are expressed in sexual mycelia and Hülle cells were monitored in a laeA $\Delta$ strain. The expression of mutA that encodes an alpha-1,3-glucanase and which is localized in Hülle cells was monitored during sexual development in a laeA $\Delta$ strain (Sarikaya-Bayram et al., 2010). The expression of mutA was reduced in a laeA $\Delta$ strain which causes significant reduction in Hülle cell formation. From other ascomycota such as Aspergillus flavus it is known that methyltransferases are crucial to coordinate fungal development and secondary metabolism (Satterlee et al., 2016).

Hülle cell formation in liquid media in A. nidulans FGSC A4 (Glasgow wild-type, ve $A^{+}$) is unobservable (Bayram et al., 2008a). Prolonging the growth of the fungus in submerged cultures has no effect on Hülle cell formation. The strain AGB552

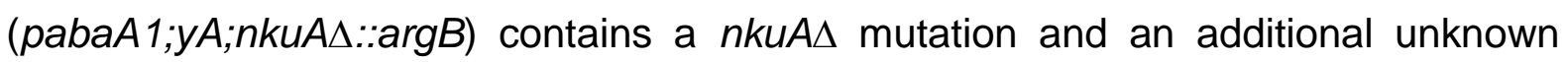
mutation which results in increased Hülle cell formation in submerged liquid cultures. The gene nkuA encodes an ATP-dependent DNA helicase II that is involved in the process of non-homologous end joining (NHEJ) and is required for the repair of double-strand breaks in DNA. For improvement of gene targeting the nkuA $\Delta$ strain is used (Nayak et al., 2006). 
A)

Wild-type FGSC A4, veA ${ }^{+}$

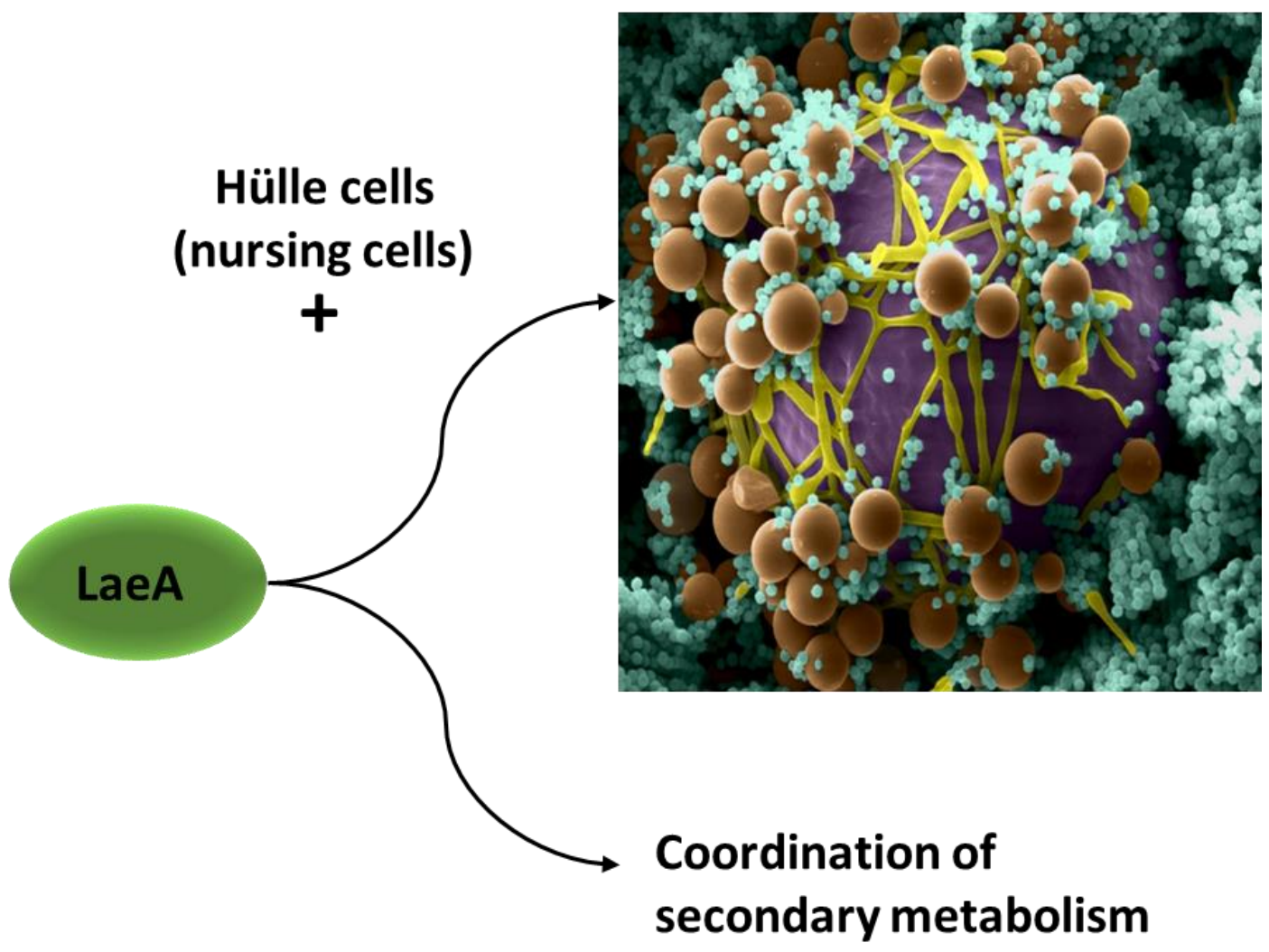

B)

laeA $\Delta$ (methyltransferase)

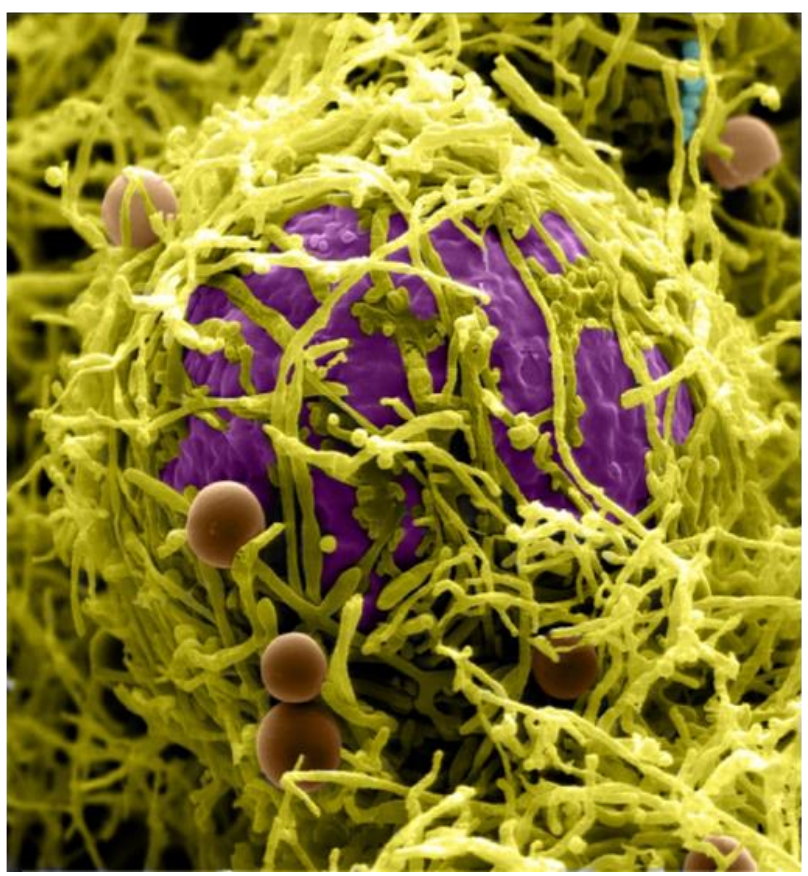

Figure 7. LaeA methyltransferase promotes Hülle cell formation.

A) LaeA methyltransferase domain protein coordinates fungal cell type specificity and secondary metabolism. Hundreds of Hülle cells (coloured beige) surround the cleistothecium. B) LaeA is required for Hülle cells formation. A Cleistothecium of a laeA $\Delta$ mycelium is shown. Abolished Hülle cells are observable and instead filamentous hyphae are covering the cleistotecium. Image modified (Sarikaya-Bayram et al., 2010). 


\subsubsection{LaeA regulates the monodictyphenone $(m d p)$ and other secondary metabolite gene clusters}

It is suggested that LaeA regulates more than $50 \%$ of all secondary metabolite gene clusters in Aspergillus nidulans, Aspergillus fumigatus and Aspergillus flavus (Sarikaya-Bayram et al., 2010, Dhingra et al., 2013, Zhao et al., 2017). Different secondary metabolite gene clusters are regulated by LaeA in $A$. nidulans including monodictyphenone $(m d p)$, terrequinone A, penicillin and sterigmatocystin (Bok et al., 2009, Bok et al., 2006, Bok and Keller 2004). Bok and co-workers indicated a role of LaeA in interaction with the CCIA (H3K4 methyltransferase) complex which regulates the expression of the monodictyphenone ( $m d p)$ gene cluster (Bok et al., 2016, Bok et al., 2009). This shows that LaeA regulates the monodictyphenone ( $m d p)$ gene cluster. The deletion of laeA gene leads to more heterochromatin formation with an increased histone $3(\mathrm{H} 3$ ) lysine (K9) trimetylation (H3K9me3) in the sterigmatocystin gene cluster (Reyes-Domingues et al., 2010). This suggests that chromatin structures are changed in laeA $\Delta$. In order to investigate methylation substrates of LaeA a biochemical study was performed. Patananan and co-workers were not able to find a specific methylation stubstrate and investgated an automethylation reaction of LaeA (Patananan et al., 2013). The methylating function of LaeA is so far unknown.

The LaeA protein regulates several secondary metabolite gene clusters that encode prenyltransferases (Bok et al., 2006, Kale et al., 2008). Seven different prenyltransferases are encoded by the genome of $A$. nidulans (Galagan et al., 2005). Prenyltransferases are involved in the prenylation of aromatic substrates and thereby modifying different secondary metabolites. LaeA regulated prenyltansferase has been characterized in A. nidulans (Bok et al., 2006). The terrequinone A biosynthetic pathway involves prenylation events (Bouhired et al., 2007). Bok and co-workers showed that the prenyltansferase $t i d B$ is not expressed in a laeA $A$ mycelium in comparison to the wild-type and is up-regulated in a laeA overexpression strain (Bok et al., 2006). 


\subsubsection{Relationship between fungal development and secondary metabolism}

Secondary metabolite production is commonly associated with the progression of sporulation and fulfills different functions during this process. First, secondary metabolites are needed in order to activate sporulation, such as hydroxylated oleic acid and linoleic acid produced by Aspergillus nidulans. Second, the process of sporulation is linked to the production of pigments. Third, mycotoxins and other toxic metabolites are crucial to protect the fungus against fungivory and other environmental threats.

\subsubsection{Secondary metabolites that activate sporulation}

A wide range of secondary metabolites are produced after the fungus has finalized its initial vegetative growth phase (Calvo et al., 2002). In A. nidulans endogenous factors such as the oxylipins, hydroxylated oleic acid and linoleic acid also called psi (precocious sexual inducer), are factors that regulate the balance between early sexual and asexual sporulation (Tsitsigiannis et al., 2004b). The oxygenase-like enzymes $\mathrm{PpoA}, \mathrm{PpoB}$ and $\mathrm{PpoC}$, are involved in the production of psi factors. Localization studies of these enzymes revealed that PpoA::GFP is localized to lipid bodies in Hülle cells and other fungal tissues (Tsitsigiannis and Keller 2004a). Deletion of ppoA gene resulted in increased asexual development. Thereby forming less cleistothecia in a sexual mycelium. The number of Hülle cells and ascospores were not affected by the deletion of ppoA (Tsitsigiannis and Keller 2004a).

\subsubsection{Pigments}

The production of the pigment melanin is known to be involved in the pigmentation process of fruiting bodies and/or ascospores (Engh et al., 2007). Aspergilli that produce no Hülle cells such as Aspergillus tonophilus and Aspergillus fisheri, also produce non-pigmented cleisthothecia (Hermann et al., 1983). In Aspergilli it is known that laccases are involved in the melanin production (Upadhyay et al., 2013). Scherer and co-workers showed that the type II laccase CpeA is highly expressed in Hülle cells (Scherer et al., 2002). The expression of $c p e A$ in Hülle cells enables the production of 
the cleistin matrix of the cleistothecia, which is possibly a polymeric product of phenolic material. Scanning and transmission electron microscopy reaveled that the cleistin matrix is an electron dense material and forms an outer layer of the cleistothecia which are pigmented (Champe and Simon 1992). Pigmentation protects most likely the cleistothecia against negative environmental influences.

\subsubsection{Secondary metabolites to protect the fungus against fungivory and other environmental threats}

A secondary metabolite-based defence mechanism provides a benefit to fungi (Döll et al., 2013, Drott et al., 2017, Caballero-Ortiz et al., 2013). In a recent study it was shown that the production of different secondary metabolites influenced the development of Drosophila melanogaster (Regulin and Kempken 2018). Analyzing effects of wild-type (FGSC A4, Glasgow wild-type, veA $A^{+}$A. nidulans compared to the deletion of the polyketide synthase $m d p G$ which is required for the biosynthesis of monodictyphenone showed a 95\% higher egg laying activity of Drosophila melanogaster on the deletion strain. The egg laying activity of Drosophila melanogaster was additionaly analyzed in a laeA $\Delta$ strain and was compared to $m d p G \Delta$ and wild-type. This resulted in an $57 \%$ egg laying activity on a laeA $\Delta$ mycelium. Döll and co-workers showed that the cleistothecia of $A$. nidulans covered with Hülle cells are more resistant against fungivory when comparing to a vegetative or asexual tissue (Döll et al., 2013). Therefore, secondary metabolites are crucial for the protection against environmental threats and provide resistance against fungivory. 


\subsection{Aim of this work}

The central aim of this thesis was to get more insight into the proteomes and their biological functions of specialized fungal cells and during sexual development with a special focus on the accessory Hülle cells. The methyltransferase LaeA is required for Hülle cell formation and normally sized closed fruiting bodies named cleistothecia. Enrichment procedures for Hülle cells were established to gain more specific access to their proteomes. Tissues without and with Hülle cells were compared and analyzed. Identified proteins from an enriched Hülle cell fraction were compared to the identified proteins from a vegetative mycelium, asexual mycelium and sexual mycelium. Two proteomic approaches were performed during this study to investigate which proteins are enriched in Hülle cells. In the first proteomic approach proteins found in surface cultures were analyzed. An enriched Hülle cell fraction was compared to a vegetative, asexual and sexual mycelium. In the second proteomic investigation proteins were analyzed and quantified from submerged liquid cultures. Therefore, a laeA $\Delta$ strain was used that causes significant reduction in Hülle cells and was compared to a $n k u A \Delta$ strain with an additional unknown mutation that cause increased numbers of Hülle cells both in submerged liquid cultures. Furthermore, proteins identified in enriched Hülle cells were analyzed and functional gene studies were performed. 


\section{Materials and methods}

\subsection{Materials}

\subsubsection{Strains}

Aspergillus nidulans strains $n k u A \Delta$ (AGB552) and lysA transformation host for deletion, complementation and GFP (green fluorescent protein) tagging. Strains used in this study are listed in Table 1.

\section{Table 1. Strains used in this study.}

Aspergillus nidulans strains are denominated AGB or FGSC, p.c. = personal communication.

\begin{tabular}{|c|c|c|}
\hline Strain & Genotype & Reference \\
\hline \multicolumn{3}{|c|}{ Escherichia coli } \\
\hline $\mathrm{DH} 5 \alpha^{\mathrm{TM}}$ & 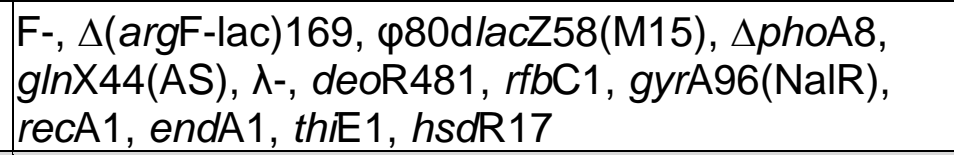 & $\begin{array}{l}\text { Invitrogen, } \\
\text { Germany }\end{array}$ \\
\hline Top10 & $\begin{array}{l}\mathrm{F}^{-} \text {mcrA } \Delta(\text { mrr-hsdRMS-mcrBC) } \Phi 80 \text { lacZ } \Delta \text { M15 } \\
\Delta / a c X 74 \text { recA1 araD139 } \Delta \text { ara-leu) } 7697 \text { gal galK } \\
\text { rpsL }\left(\mathrm{Str}^{\mathrm{R}}\right) \text { endA1 nupG } \lambda^{-}\end{array}$ & $\begin{array}{l}\text { Invitrogen, } \\
\text { Germany }\end{array}$ \\
\hline Strain & Genotype & Reference \\
\hline \multicolumn{3}{|c|}{ Aspergillus nidulans } \\
\hline A4 & Glasgow wilde type, $v e A^{+}$ & FGSC \\
\hline AGB596 & pgpdA::sgfp::phleoR;pabaA1;yA;veA $A^{+}$ & Bayram et al., 2012 \\
\hline AGB552 & pabaA1;yA;nkuAs::argB & Bayram et al., 2012 \\
\hline AGB1092 & 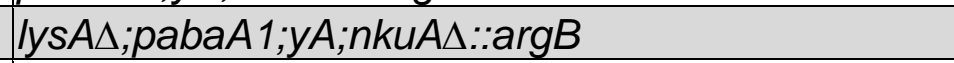 & Meister. p.c. \\
\hline AGB1073 & laeA $\Delta ; p a b a A 1 ; y A ; n k u A \Delta:: a r g B$ & This study \\
\hline AGB1074 & laeA $\Delta ; l y s A \Delta ; p a b a A 1 ; y A ; n k u A \Delta:: a r g B$ & This study \\
\hline AGB1075 & laeA $\Delta:: l a e A ; p a b a A 1 ; y A ; n k u A \Delta:: a r g B$ & This study \\
\hline AGB1076 & 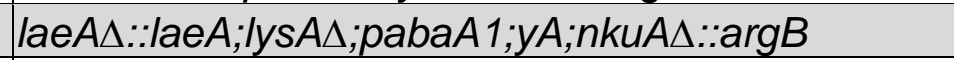 & This study \\
\hline AGB1077 & $m p h A \Delta ; p a b a A 1 ; y A ; n k u A \Delta:: a r g B$ & This study \\
\hline AGB1078 & mphA $\triangle:: m p h A:: g f p ; p a b a A 1 ; y A ; n k u A \Delta:: a r g B$ & This study \\
\hline AGB1079 & 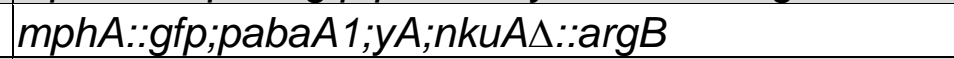 & This study \\
\hline AGB1080 & mphA $\triangle:: m p h A ; p a b a A 1 ; y A ; n k u A \Delta:: a r g B$ & This study \\
\hline ABG1081 & laeA $\Delta ; m p h A:: g f p ; p a b a 1 ; y A ; n k u A \Delta:: a r g B$ & This study \\
\hline AGB1082 & lysA $A ; n p t A:: g f p ; p a b a A 1 ; y A ; n k u A \Delta:: a r g B$ & This study \\
\hline AGB1083 & laeA ;IysA $\Delta ; n p t A:: g f p ; p a b a A 1 ; y A ; n k u A \Delta:: a r g B$ & This study \\
\hline AGB1084 & IysA $\Delta, r f e A:: g f p ; p a b a A 1 ; y A ; n k u A \Delta:: a r g B$ & This study \\
\hline AGB1085 & laeA $\Delta ; l y s A \Delta ; r f e A:: g f p ; p a b a A 1 ; y A ; n k u A \Delta:: a r g B$ & This study \\
\hline AGB1086 & lysA $\triangle ; x p t B:: g f p ; p a b a A 1 ; y A ; n k u A \Delta:: a r g B$ & This study \\
\hline AGB1088 & xptC::gfp;pabaA1;yA;nkuAA::argB & This study \\
\hline AGB1089 & AN8434::gfp;pabaA1;yA;nkuA $:: a r g B$ & This study \\
\hline AGB1090 & 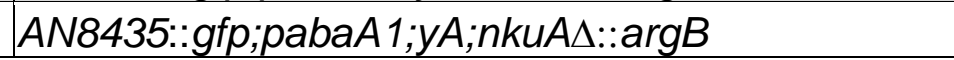 & This study \\
\hline
\end{tabular}




\subsubsection{Plasmids}

Plasmids used in this study are listed in Table 2.

Table 2. Plasmids used in this study.

$R M$ : recyclable marker, phleoRM = recyclable phleoRM resistance cassette from pME4305 or pJG292, ${ }^{\mathrm{R}}=$ resistance, ${ }^{\mathrm{P}}=$ promoter, $^{\mathrm{t}}=$ terminator, $^{\mathrm{p} . \mathrm{C}}=$ personal communication.

\begin{tabular}{|c|c|c|}
\hline Plasmid & Description & Reference \\
\hline pBluescript sk + & Cloning plasmid & Fermentas \\
\hline pME4305 & six- ${ }^{\mathrm{P}} x y I P:: B-r e c::$ trpc $^{\mathrm{t}}-$ phleo $^{\mathrm{R}}-$ six & Gerke, p.c \\
\hline pJG292 & swal:::six- ${ }^{\mathrm{P}} x y \mid P:: B-r e c::$ trpc $^{\mathrm{t}}-$ phleo ${ }^{\mathrm{R}}-$ six::Eco74l & Gerke, p.c \\
\hline pME4292 & Plasmid contains gfp & Jöhnk, p.c. \\
\hline pME4636 & AN/aeA $\Delta:$ phleoRM & This study \\
\hline pME4637 & AN/aeA::phleoRM & This study \\
\hline pME4638 & ANmphAs::phleoRM & This study \\
\hline pME4639 & PmphA::ANmphA::gfp::phleoRM & This study \\
\hline pME4640 & ANmphA::phleoRM & This study \\
\hline pME4641 & ${ }^{P} n p t A:: A N n p t A:: g f p:$ phleoRM & This study \\
\hline pME4642 & PrfeA::ANrfeA::gfp::phleoRM & This study \\
\hline pME4643 & PxptB::ANxptB::gfp::phleoRM & This study \\
\hline pME4645 & ${ }^{P} x p t C:: A N x p t C:: g f p:$ phleoRM & This study \\
\hline pME4646 & PAN8434::AN8434::gfp:::phleoRM & This study \\
\hline pME4647 & PAN8435::AN8435::gfp::phleoRM & This study \\
\hline
\end{tabular}

\subsubsection{Primers}

Oligonucleotides used in this study are listed in Table 3.

Table 3. Oligonucleotides utilized for plasmid construction.

\begin{tabular}{|c|c|c|}
\hline Designation & Sequence & Basepairs \\
\hline BD49 & $\begin{array}{l}\text { 5'-ATC GAT AAG CTT GAT GTT TAA TAA ACA ACC } \\
\text { GAG CTG GCC GTT-3، }\end{array}$ & 42 \\
\hline BD50 & $\begin{array}{l}\text { 5‘-ACC TAT AGG CCT GAG CTT GTC TCC TTT AAC } \\
\text { TTC TCT GC-3، }\end{array}$ & 38 \\
\hline BD51 & $\begin{array}{l}\text { 5'-ATA ATA TGG CCA TCT CTC ATA TCC CAA TTC } \\
\text { TCT GAT TTT-3‘ }\end{array}$ & 39 \\
\hline BD52 & $\begin{array}{l}\text { 5‘-CTG CAG GAA TTC GAT GTT TAA ACC ATC TTA } \\
\text { ACC ATC TTG GCG-3، }\end{array}$ & 42 \\
\hline BD61 & $\begin{array}{l}\text { 5'-ACG GTA TCG ATA AGC TTG ATG TTT AAA CTT } \\
\text { CTT TTG TTC CAA ACA-3، }\end{array}$ & 45 \\
\hline BD83 & $\begin{array}{l}\text { 5'-ATC GAT AAG CTT GAT GTT TAA ACA GAT TTG } \\
\text { GTA GGA GCT AAC-3' }\end{array}$ & 42 \\
\hline BD84 & $\begin{array}{l}\text { 5'-GAC CTA TAG GCC TGA GGT TGA CGA TCT CTG } \\
\text { AGA CGA-3، }\end{array}$ & 36 \\
\hline
\end{tabular}


Table 3. Continued, Oligonucleotides utilized for plasmid construction.

\begin{tabular}{|c|c|c|}
\hline BD85 & $\begin{array}{l}\text { 5'-ATA ATA TGG CCA TCT ATG AAC ATT GTC TTT GGA } \\
\text { GAG TC-3‘ }\end{array}$ & 38 \\
\hline BD86 & $\begin{array}{l}\text { 5'-CTG CAG GAA TTC GAT GTT TAA ACG TGG TGA TTA } \\
\text { TCA TCC-3" }\end{array}$ & 39 \\
\hline BD88 & 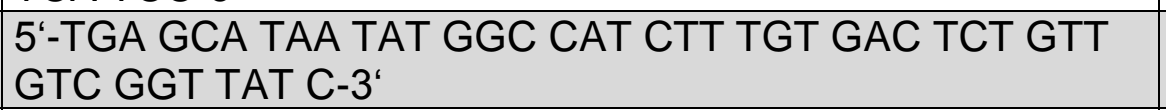 & 43 \\
\hline BD89 & $\begin{array}{l}5^{\circ}-C C G \text { GGC TGC AGG AAT TCG ATG TTT AAA CCC ATC } \\
\text { ACC CAT TCG CTT-3" }\end{array}$ & 45 \\
\hline BD63 & 5'-ATG GCC GAC GAC TAT CGC GAA GA-3‘ & 2. \\
\hline BD64 & $\begin{array}{l}\text { 5'-TAT TGA CCT ATA AGG CCT GAG CTA GAA CTT CGT } \\
\text { CTC AAG TAA CTC CT-3" }\end{array}$ & 47 \\
\hline BD70 & 5'-TGT GAG GTT ACC TCA GAT CTT GT-3‘ & 2 \\
\hline BD71 & $\begin{array}{l}\text { 5'-TAT TGA CCT ATA GGC CTG AGT TAT CTT AAT GGT } \\
\text { TTC CTA GCC TG-3` }\end{array}$ & 4 \\
\hline BD73 & $\begin{array}{l}\text { 5'-ATA AGC TTG ATG TTT AAA CGT ACG TCT TTA TTA } \\
\text { TAG TCG AG-3`}\end{array}$ & 4 \\
\hline BD76 & $\begin{array}{l}5^{\prime}-\text { ACC TAT AGG CCT GAG CGT GAA CGA ATT CGA TGT } \\
\text { G-3، }\end{array}$ & 3 \\
\hline BD87 & $\begin{array}{l}\text { 5'-ATA ATA TGG CCA TCT GGC TGT GCT TCT AGA GAG } \\
\text { ACG T-3` }\end{array}$ & 37 \\
\hline BD90 & $\begin{array}{l}\text { 5'-CTG CAG GAA TTC GAT GTT TAA ACA ATG CCA CAA } \\
\text { GGA A-3‘ }\end{array}$ & 37 \\
\hline BD93 & $\begin{array}{l}\text { 5‘-TAT TGA CCT ATA GGC CTG AGC TAC TCA TCA TCG } \\
\text { CGG ATA T-3" }\end{array}$ & 4( \\
\hline BD96 & $\begin{array}{l}\text { 5'-TTC TCC TTT ACT CAT GTT GAC GAT CTC TGA GAC } \\
\text { GAT C-3" }\end{array}$ & 3 \\
\hline BD97 & $\begin{array}{l}\text { 5'-TAC AGG CTG GTG CCA TGA GTA GCG ACA ACA CAG } \\
\text { AGA AG-3' }\end{array}$ & 3 \\
\hline BD98 & $\begin{array}{l}5^{\circ}-A C C \text { ACC GCT ACC ACC CTC ATC ATC GCG GAT ATC } \\
\text { G-3، }\end{array}$ & 3 \\
\hline BD99 & $\begin{array}{l}\text { 5'-GGT GGT AGC GGT GGT GTG AGC AAG GGC GAG } \\
\text { GAG-3، }\end{array}$ & 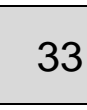 \\
\hline BD100 & $\begin{array}{l}\text { 5'-ACC TAT AGG CCT GAG CTA CTT GTA CAG TTC GTC } \\
\text { CAT GCC- } 3^{\prime}\end{array}$ & 39 \\
\hline BD104 & 5'-AAC TAC TCG ACT ATA TCA ATG GA-3" & $2 i$ \\
\hline BD105 & $\begin{array}{l}\text { 5'-CTC ACA CCA CCG CTA CCA CCT TTC TCT GGA CAA } \\
\text { GGA TGA TT-3‘ }\end{array}$ & 41 \\
\hline BD106 & 5'-GGT GGT AGC GGT GGT GTG AG-3‘ & 2 \\
\hline BD107 & $5^{6}$-CTA CTT GTA CAG TTC GTC CAT G-3" & 26 \\
\hline BD108 & 5'-TGC AGT GCC TGA TAA CTC T-3" & 15 \\
\hline BD109 & $5^{\circ}-\mathrm{AAA}$ CGA AAC CGC CGG TGC CA-3" & 2( \\
\hline BD111 & 5'-CAT ATG TGC AGG CCG CGT-3‘ & $1 \varepsilon$ \\
\hline BD112 & 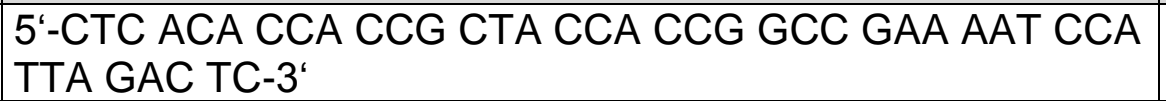 & 4 \\
\hline BD113 & 5'-TTC GTG CCG TCT TGG AGA-3‘ & $1 \varepsilon$ \\
\hline
\end{tabular}


Table 3. Continued, Oligonucleotides utilized for plasmid construction.

\begin{tabular}{|c|c|c|}
\hline BD114 & $\begin{array}{l}\text { 5'-GCT CAC ACC ACC GCT ACC ACC GTT ACC CAG CCA } \\
\text { GCC ATG-3' }\end{array}$ & 39 \\
\hline $\begin{array}{l}\text { BD113 } \\
(x p t C)\end{array}$ & 5'-AGG CTC AAC CTG ATA CTT ACC-3‘ & 21 \\
\hline $\begin{array}{l}\text { BD114 } \\
(x p t C)\end{array}$ & $\begin{array}{l}\text { 5'-GCT CAC ACC ACC GCT ACC ACC GTT ACC CAG CCA } \\
\text { GCC ATG-3" }\end{array}$ & 39 \\
\hline BD115 & 5'-ATT AGA TCT ATT AGA CCG CAG G-3‘ & 22 \\
\hline BD116 & 5'-CAC GTG ATG TGA TAC GGT AC-3‘ & 20 \\
\hline $\begin{array}{l}\text { BD119 } \\
(x p t B)\end{array}$ & 5‘-AGA TCT ATT AGA CCG CAG GC-3‘ & 20 \\
\hline $\begin{array}{l}\text { BD120 } \\
(x p t B)\end{array}$ & $\begin{array}{l}5^{`}-\text { CTC ACA CCA CCG CTA CCA CCC CAC CGA TCA TCC } \\
\text { CCC CTC C-3. }\end{array}$ & 40 \\
\hline $\begin{array}{l}\text { BD121 } \\
(x p t B)\end{array}$ & 5'-TTC CTC TCT AGA AAC TTC TCA AA-3" & 23 \\
\hline $\begin{array}{l}\text { BD122 } \\
(x p t B)\end{array}$ & 5'ACA TGT ACT CGG ACC TGG TTC-3‘ & 21 \\
\hline BD121 & 5‘-TAT TTC AAG GTA ACA GTC TGG-3‘ & 21 \\
\hline BD122 & $\begin{array}{l}5^{\circ}-C T C \text { ACA CCA CCG CTA CCA CCG TTT CTG TCC GCG } \\
\text { ATA GAC-3" }\end{array}$ & 39 \\
\hline BD123 & 5'-ACA CCA AAC ATC TGT AGA GAA CA-3" & 23 \\
\hline BD124 & 5‘-TGT AGT CAA TTG CGG GGG TA-3‘ & 20 \\
\hline BD125 & 5'-ATT GAC GAA TTT TGT CGC GA-3‘ & 20 \\
\hline BD127 & $\begin{array}{l}5^{\circ}-\text { CTC ACA CCA CCG CTA CCA CCG GTA CTA TGC ACT } \\
\text { CCC AGC-3" }\end{array}$ & 39 \\
\hline BD128 & 5'-TTT CGC TCC TAT AAC TGG ACT-3‘ & 21 \\
\hline BD129 & 5'-ACT TCT TGA TAT TTA AAG CAA TTT-3" & 24 \\
\hline
\end{tabular}

\subsubsection{Chemicals and equipment}

Different chemicals and enzymes as well as kits were used for the results of this research.

\section{Chemicals and the respective suppliers}

The following chemicals were purchased from AppliChem GmbH (Darmstadt, Germany), the order numbers are cited in brackets. Aceton (9R006076), arginine (A3709,0250), B-glycerophosphat (A2253,0100), benzamidine (A1380,0005), bromophenol blue (A3640,0005), glucose (A3617,1000), isopropanol (A0900,2500GL), I-lysine monohydrochloride (33003468), nonident ${ }^{\circledR}$ P40 (A2239,0025), potassium chloride (A3582,1000), sodium chloride $(A 3597,1000)$, 
sodium orthovanadate $(2196,0005)$, sucrose $(A 4734,1000)$, tween $20 \circledast(A 4974,0100)$, xylene cyanol (A4976,0005).

Biozym Scientific GmbH (Hessisch Oldendorf, Germany) provided agarose for agarose gels (840004).

As a subsidiary company of the American multi industry group General Electric GE Healthcare $\mathrm{GmbH}$ (Braunschweig, Germany) provided the following chemicals. Amersham $^{\mathrm{TM}}$ alkphos direct labelling reagents (11816064), amersham ${ }^{\mathrm{TM}}$ cdp-star $^{\mathrm{TM}}$ detection reagents (9766233).

Merck KGaA (Darmstadt, Germany), a leading science and technology company in the field of healthcare, life science and performance materials delivered the following chemicals. Di-sodium hydrogen phosphate (1065855000), DMSO (dimethyl sulfoxide) (1029310500), formic acid (1002641000), hydrogen peroxide $30 \% \quad\left(\mathrm{H}_{2} \mathrm{O}_{2}\right)$ (8.22287.2500), magnesium chloride hexahydrate (1.05833.1000), potassium acetate (1.04820.1000), potassium dihydrogen phosphate (1.04873.1000), sodium dihydrogen phosphate monohydrate (1.06346.1000).

\section{Chemicals and suppliers, continued}

Carl Roth GmbH \& Co. KG (Karlsruhe, Germany) is one of the leading companies in Germany for the production of fine chemicals and provided the following chemicals. In brackets the order number is again cited. Acetonitrile (T901.1), acetic acid (3738.2), acrylamide (Rotiphorese® Gel 40 37,5:1) (3029.1), agar-agar (5210.2), ammonium persulfate (APS) (9592.3), $\beta$-mercaptoethanol (4227.1), caffeine anhydrous (N815.3), calcium chloride (CN92.1), calcium chloride dihydrate (5239.1), citric acid monohydrate (3958.1), coomassie brilliant blue G-250 (9598.1), coomassie brilliant blue R-250 (3862.1), dimethylformamide (T921.1), DTT (1,4-dithiothreitol) (A1101,0025), EDTA (ethylenediamine tetraaceticacid disodium salt dihydrate) (8043.2), formaldehyde (4979.2), glycine (0079.1), glycerol (3783.1), hydrochloric acid (4625.2), imidazole (5709.3), magnesium sulfate heptahydrate (P027.2), manganese (II) chloride tetrahydrate (T881.1), manganese(II)sulfate monohydrate (4487.1), phosphoric acid (6366.1), ponceau $S$ (5938.2), potassium hydroxide (6751.1), rotiphorese Gel 40 (3030.2), SDS (sodium dodecyl sulfate) (4360.2), sodium acetate (6773.2), sorbitol (6213.1), TEMED ( $N, N^{\prime}, N^{\prime}, N^{\prime}$-tetramethylethylenediamine) (2367.3), 
trichloroacetic acid (7875.4), tris (tris-hydroxymethyl-aminomethane) (AE15.2), tris/HCl (9090.3), urea (2317.3), yeast extract (2904.1).

\section{Chemicals and the respective suppliers, continued}

SERVA Electrophoresis GmbH (Heidelberg, Germany) acts as a privately-owned company in the field of electrophoresis and also provides a wide portfolio of fine chemicals. They provided agar-agar SERVA high gel-strength, a choice quality for in vitro cultures (11396.03).

Sigma-Aldrich (Schnelldorf, Germany) is a leading life science and high technology company, being a subsidiary company of Merck KGaA (Darmstadt, Germany) and provided the following chemicals. Adenine (01830-50G), ampicillin (A9518-25G), ETDA-free protease inhibitor cocktail (48998), ethidium bromide (46065), formamide (47670), maltose monohydrate (112569), PMFS (phenylmethylsulfonylfldauoride) (P7626), triton X-114 (X114).

The global life science company Thermo Fisher Scentific (Waltham, Massachusetts, United States of America) supports scientists worldwide. Several subsidiary companies are located in Germany (Thermo Fisher Scientific GmbH, Schwerte, Germany) and provided the following chemicals and DNA as well as protein ladders. Gene ruler DNA ladder mix (Thermo Scientific, SM0331), PageRuler ${ }^{\mathrm{TM}}$ prestained $^{2}$ protein ladder (Thermo Scientific, SM26616), x-gal (5-bromo-4-chloro-3-indolyl-betaD-galacto-pyranoside) (R0404).

Ethanol (20821.321) and methanol (20864.320) were ordered from VWR International $\mathrm{GmbH}$ (Hannover, Germany).

\section{Enzymes and suppliers}

The following enzymes were purchased from different companies. Natuzym (Schliessmann, Germany, 5090), Phusion® Hot Start high-Fidelity DNA Polymerase (New England Biolabs, Frankfurt am Main, Germany, M0530S), Lysozyme (SERVA Electrophoresis GmbH, Heidelberg, Germany, 28262.03), Phospholipase C (Invitrogen life technologies, Osterode, Germany, P6466), Restriction Endonucleases (Thermo Fisher Scientific GmbH, Schwerte, Germany), RNase A (Darmstadt, Germany, 24690.0), T4 DNA ligase (Thermo Fisher Scientific GmbH, EL0011), Trypsin (SERVA Electrophoresis GmbH , 37286.01), VinoTaste® Pro (Novozymes $\mathrm{GmbH}$, Bagsvaerd, Denmark, 4518) 


\section{Kits and the respective suppliers}

The following different kits were used. Amersham ${ }^{\mathrm{TM}}$ Alkphos Direct Labelling Reagents Kit (GE Healthcare, 11816064), Gene Art ${ }^{R}$ Seamless Cloning and Assembly Kit (Invitrogen life technologies, A1328), HiSpeed Plasmid Midi Kit (QIAGEN, Hilden, Germany, 12643), NucleoSpin ${ }^{\circledR}$ Plasmid Kit (Macherey-Nagel, 740615.250), NucleoSpin ${ }^{\circledR}$ Gel and PCR Clean-up Kit (Macherey-Nagel, Düren, Germany, 740609.250), QIAprep Spin Miniprep Kit (QIAGEN, 27106), QIAquick Gel Extraction Kit (QIAGEN, 28704), QIAquick PCR Purification Kit (QIAGEN, 28104).

\section{Equipment and the respective suppliers}

Further materials were provided by different companies. Standard laboratory equipment including pipets, petri dishes and other plastic consumables were purchased from Gilson, Inc., (Limburg-Offheim, Germany), Sarstedt AG \& Co (Nümbrecht, Germany). In order to centrifuge samples abiofuge fresco and biofuge pico (Heraeus Instruments $\mathrm{GmbH}$ ) were used. To grind mycelia a retsch mill MM400 (Retsch $\mathrm{GmbH}$, Haan, Germany 56789.1) was applied. Measuring the concentration of DNA and proteins a nanodrop ND-1000 photospectrometer (peqlab biotechnologie $\mathrm{GmbH}$, Erlangen, Germany) was used. In order to image gel pictures a gel IX20 imager (Intas Science Imaging Instruments $\mathrm{GmbH}$, Göttingen, Germany) was used. Southern hybridization experiments were performed with x-ray films (Protec $\mathrm{GmbH}$, Oberstenfeld, Germany) and amersham TM hyperfilm TM ECL (GE Healthcare, 28906837). For protein work the following instruments were used. Mini-protean ${ }^{\circledR}$ tetra cell (Bio-Rad Laboratories GmbH, Munich, Germany 1658005EDU), mini transblot ${ }^{\circledR}$ electrophoretic cell (Bio Rad, 1703930), mini-sub ${ }^{\circledR}$ cell GT (Bio Rad, 1704487EDU), powerpac ${ }^{\text {TM }} 200$ (Bio Rad, 1645050). For western hybridization experiments a nitrocellulose transfer membrane (protran $^{\circledR}$ BA (Sigma-Aldrich, 10401196)) was used. Besides savant speedvac concentrator (Thermo Scientific) and sterile filters 0.45/0.2 $\mu \mathrm{m}$ (Sarstedt, 83.1826/83.1826.001) were used. A liquid chromatography (LC) coupled to an Orbitrap Velos Pro ${ }^{\text {TM }}$ Hybrid Ion Trap-Orbitrap mass spectrometer (MS) (Thermo Fisher Scientific, Bremen, Germany) was used for the two different proteomics investigations. 


\subsubsection{Solutions and growth media}

\subsubsection{Solutions}

\section{Solutions regarding Aspergillus nidulans}

The trace-element stock solution consisted of $18 \mu \mathrm{M} \mathrm{FeSO}_{4,174} \mu \mathrm{M}$ ETDA, $76 \mu \mathrm{M}$ $\mathrm{ZnSO}_{4}, 178 \mu \mathrm{M} \mathrm{H}_{3} \mathrm{BO}_{3}, 25 \mu \mathrm{M} \mathrm{MnCl}_{2}, 7.1 \mu \mathrm{M}, \mathrm{CoCl}_{2}, 6.4 \mu \mathrm{M} \mathrm{CuSO}_{4}, 6.2 \mu \mathrm{M} \mathrm{Na}_{2} \mathrm{MoO}_{4}$. The resulting solution was sterilized with a sterile filter.

In order to extract DNA from Aspergillus nidulans the following extraction buffer was used and consisted of $1 \mathrm{M}$ Tris (pH 7.2), 0.5 M ETDA (Ethylenediaminetetraacetic acid), $3 \mathrm{~g}$ SDS and $1 \mathrm{ml}$ mercaptoethanol.

In order to perform transformations in Aspergillus nidulans the following solutions were used.

As a citrate buffer consisting of $150 \mathrm{mM} \mathrm{KCl}, 580 \mathrm{mM} \mathrm{NaCl}, 50 \mathrm{mM}$ sodium citrate, $\mathrm{pH}$ 5.5 was used.

Protoplast solution consisted of $20 \mathrm{mg} / \mathrm{ml}$ VinoTaste $\circledast$ Pro (Novozymes $\mathrm{GmbH}, 4518$ ) and $15 \mathrm{mg} / \mathrm{ml} \mathrm{lysozyme} \mathrm{(Serva} \mathrm{GmbH}, 28262.03$ ).

\section{Solutions regarding Southern hybridizations:}

Alkphos direct hybridization buffer (GE Healthcare, RPN 36888) was used as a prehybridization buffer. Additionally, $0.5 \mathrm{mM} \mathrm{NaCl}, 4 \%$ blocking solution was added.

Gels were washed in three different washing buffers: Buffer 1: $0.25 \mathrm{M} \mathrm{HCl}$, Buffer 2: $0.5 \mathrm{M} \mathrm{NaOH}$, Buffer 3: 0.5 M Tris, $1.5 \mathrm{M} \mathrm{NaOH}$.

Southern hybridization membranes were washed in two different washing buffers.

Washing buffer 1: $2 \mathrm{M}$ urea, $0.1 \% \mathrm{SDS}, 50 \mathrm{mM} \mathrm{NaH} 2 \mathrm{PO} 4 \times \mathrm{H}_{2} \mathrm{O} \mathrm{pH}$ 7, $150 \mathrm{mM} \mathrm{NaCl}$, $1 \mathrm{mM} \mathrm{MgCl} 2,0.2 \%$ blocking reagent.

Washing buffer 2: $1 \mathrm{M}$ Tris $\mathrm{pH}$ 10, $2 \mathrm{M} \mathrm{NaCl}, 1 \mathrm{mM} \mathrm{MgCl}$. 


\section{Solutions regarding polyacrylamide gel electrophoresis:}

A 10X SDS running-buffer was used consisting of $0.25 \mathrm{M}$ Tris/base, $1.92 \mathrm{M}$ glycine and $10 \mathrm{~g}$ SDS.

A 10X transfer-buffer was used consisting of $0.25 \mathrm{M}$ Tris/base, $1.92 \mathrm{M}$ glycine and $0.2 \%$ SDS.

A 10X TBST (Tris buffered saline with tween 20) solution was used consisting of 100 $\mathrm{mM}$ Tris/HCl pH 8, 1.5 M NaCl and 0.5\% tween 20.

Protease inhibitor solution was used and consisted of $100 \mathrm{mM}$ PMFS (phenylmethylsulfonylfluoride), $0.5 \mathrm{mM}$ benzamidine, $1 \mathrm{M}$ DTT (1,4-dithiothreitol) and $1 \mathrm{M}$ imidazole.

A 100X phosphatase inhibitor solution was used consisting of $100 \mathrm{mM}$ sodium fluoride, $50 \mathrm{mM}$ sodium vanadate and $800 \mathrm{mM}$ ß-glycerophosphat.

$\mathrm{A} \mathrm{B}^{+} 300$ buffer for protein extraction was used and consisted of $100 \mathrm{mM}$ Tris $\mathrm{pH} 7.5$, $300 \mathrm{mM} \mathrm{NaCl}, 10 \%$ glycerol, 1 mM EDTA, 0.1\% NP-40, 1 mM DTT (1,4-dithiothreitol), $0.5 \mathrm{M}$ benzamidin, $100 \mathrm{mM}$ PMFS (phenylmethylsulfonylfluoride) and additionally a protease inhibitor and phosphatase inhibitor were added.

Coomassie staining solution was used and consisted of $0.1 \%(\mathrm{w} / \mathrm{v})$ coomassie brilliant blue G250, 2\% (w/v) ortho-phosphoric acid and 10\% (w/v) ammonium sulfate.

Ponceau S staining solution was used and consisted of $0.2 \%$ ponceau $S$ and $3 \%$ trichloroacetic acid.

A destaining solution was used and consisted of $40 \%(\mathrm{v} / \mathrm{v})$ ethanol and $10 \%(\mathrm{v} / \mathrm{v})$ acetic acid.

\subsubsection{Growth media}

\section{Growth medium regarding Aspergillus nidulans:}

Minimal medium (MM) was used as a growth medium for Aspergillus nidulans and consisted of 1\% (w/v) glucose, 1\% (w/v) AspA, $2 \mathrm{mM} \mathrm{MgSO}_{4}, 2 \%(\mathrm{w} / \mathrm{v})$ Agar and trace elements (added after autoclaving), $\mathrm{pH} 6.5$ and $2 \mathrm{mM} \mathrm{MgSO}_{4}$. 


\section{Growth media regarding Escherichia coli:}

Escherichia coli cultures were cultivated in LB medium and consisted of $1 \%(\mathrm{w} / \mathrm{v})$ tryptone/peptone, $0.5 \%(\mathrm{w} / \mathrm{v}) \mathrm{NaCl}, \mathrm{pH} 7.2 ; 0.5 \%(\mathrm{w} / \mathrm{v})$ yeast extract, $1.5 \%(\mathrm{w} / \mathrm{v})$ agaragar for solid medium and ampicillin $(100 \mu \mathrm{g} / \mathrm{ml})$ selection.

Escherichia coli cultures were cultivated in SOB medium and consisted of $0.5 \%(\mathrm{w} / \mathrm{v})$ yeast extract, $2 \%(\mathrm{w} / \mathrm{v})$ tryptone/peptone, $10 \mathrm{mM} \mathrm{NaCl}, 2.5 \mathrm{KCl}, 10 \mathrm{mM} \mathrm{MgCl} 2$ and 10 $\mathrm{mM} \mathrm{MgSO}_{4}$.

\subsection{Methods}

\subsubsection{Cultivation of Aspergillus nidulans}

Spores of $A$. nidulans wild-type FGSC A4, ve $A^{+}$were inoculated on solid minimal medium (1\% glucose, 1\% AspA, $2 \mathrm{mM} \mathrm{MgSO}_{4}, 2 \%$ Agar and trace elements (added after autoclaving), $\mathrm{pH} 6.5 ; 2 \mathrm{mM} \mathrm{MgSO}_{4}$ ). Fungus was then cultivated under sexual (incubation in complete darkness and reduced oxygen conditions, therefore the petri dish was sealed with a parafilm) or under asexual conditions (incubation in light). The plates were incubated at $37^{\circ} \mathrm{C}$. The percentage of conidiophores in asexual mycelium were determined as described (Christmann et al., 2013). The diameter of cleistothecia were measured using an Olympus binocular SZX12-ILLB2-200 (Olympus GmbH, Hamburg, Germany). In order to determine the diameter of cleistothecia three biological replicates were considered. For each biological replicate the diameter of five cleistothecia were determined. In order to measure the diameter of cleistothecia Hülle cells were removed from cleistothecia using the cleistothecia-rolling technique.

\subsubsection{Hülle cells from solid agar plate: cleistothecia-rolling technique}

Hülle cells are globose multicellular cells associated with sexual tissue of Aspergillus nidulans. In order to perform the cleistothecia-rolling technique, fungus was cultivated on solid agar plates under sexual conditions (incubation in complete darkness and reduced oxygen conditions, therefore the petri dish was sealed with a parafilm). Three, five and seven days after inoculation Hülle cells were enriched and the sexual 
mycelium was harvested. In order to enrich Hülle cells, cleistothecium was transferred (with a fine tipped syringe) from sexual mycelium to a fresh petri dish containing $2 \%$ agar (Figure 8). This step was performed under a stereo microscope. Cleistothecium was then rolled back and forth on the solid agar plate with the fine tipped syringe and the Hülle cells adhered to the surface of the solid agar plate. In order to collect Hülle cells, they were picked with a fine tipped syringe. Hülle cells were collected into a collection tube containing $40 \mu \mathrm{l}$ of $\mathrm{dH}_{2} \mathrm{O}$. Hülle cells were transferred from the solid agar petri dish to the collection tube with the fine tipped syringe. Hülle cells in the collection tube were centrifuged by $13.000 \mathrm{rpm}$ for one minute and $35 \mu \mathrm{l} \mathrm{of} \mathrm{dH}_{2} \mathrm{O}$ was removed. In order to observe enriched Hülle cells, they were visualized under a light

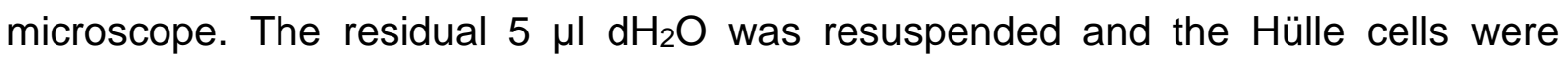
transferred on a microscope slide.
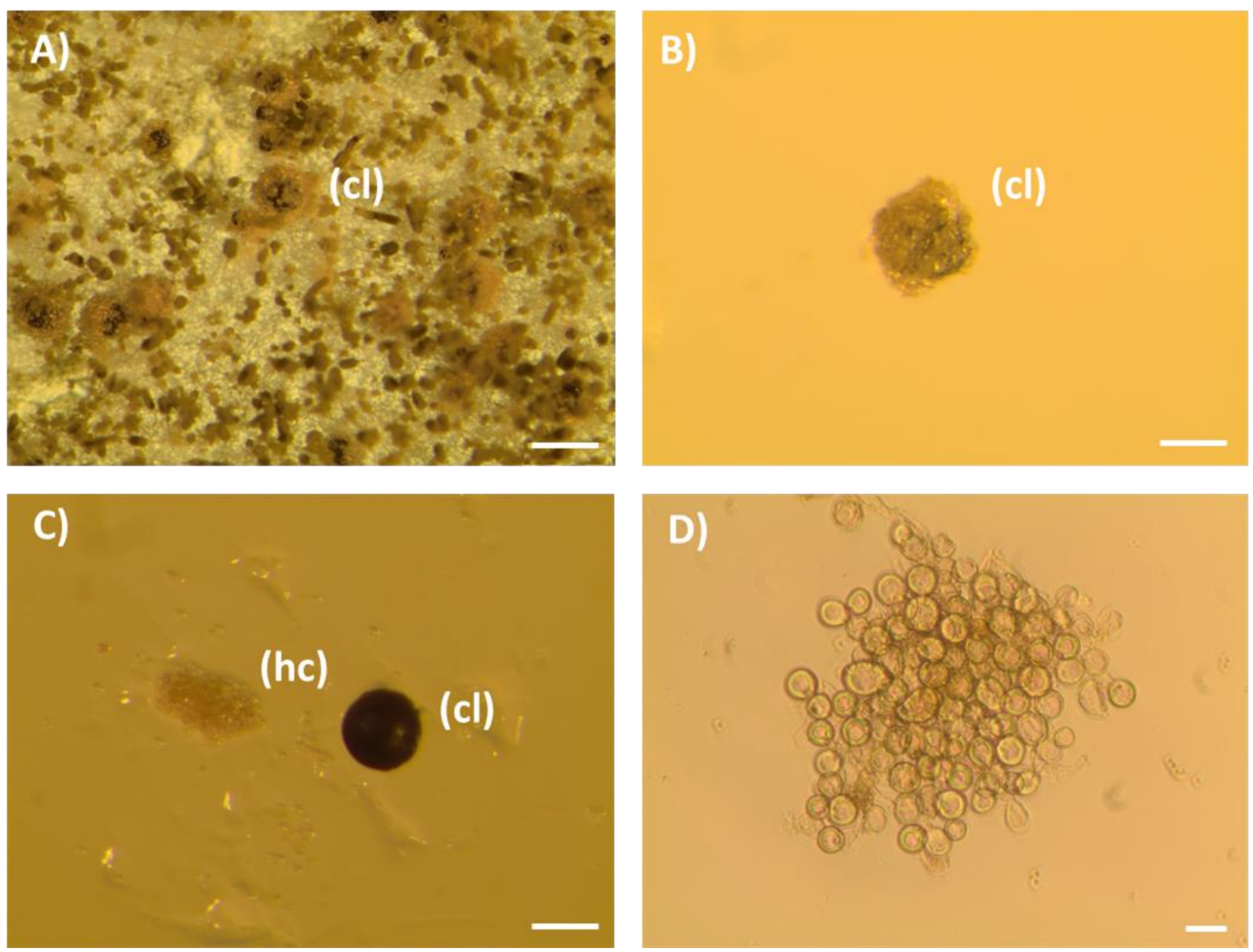

Figure 8. Illustration of enrichment of Hülle cells from solid agar plates: the cleistothecia-rolling technique.

A) Sexual mycelium of $A$. nidulans (FGSC A4 Glasgow wild-type, ve $A^{+}$) grown on solid minimal medium. Scale bar is $200 \mu \mathrm{m}$. B) The cleistothecium was transferred with a fine tipped syringe to a new petri dish containing $2 \%$ agar. Scale bar is $200 \mu \mathrm{m}$. C) The cleistothecium was rolled with the help of the syringe on solid agar plate and Hülle cells adhered to the surface of the solid agar plate. Hülle cells were collected into a collection tube. Scale bar is $200 \mu \mathrm{m}$. D) Enriched Hülle cells seen under a light microscope (cl, cleistothecium, hc Hülle cells). Scale bar is $20 \mu \mathrm{m}$. 


\subsubsection{Hülle cells from submerged cultures}

In order to cultivate vegetative mycelium spores were inoculated in $50 \mathrm{ml}(250 \mathrm{ml}$ shake flask) minimal medium (1\% glucose; 1\% AspA; $2 \mathrm{mM} \mathrm{MgSO} 4$; and trace elements; $\mathrm{pH} 6.5 ; 5.937 \times 10^{5} \mathrm{sp} / \mathrm{ml}$ ) for 20 hours at $37^{\circ} \mathrm{C}$ and with constant shaking. Hülle cells were observed under a light microscope. After 20 hours at $37^{\circ} \mathrm{C}$ no Hülle cells were observed in wild-type FGSC A4, ve $A^{+}$. The minimal medium was filtered off and vegetative mycelium was washed with $0.96 \% \mathrm{NaCl}$. After 72 hours, vegetative mycelium was harvested and Hülle cells were observed in the hyphal ball of vegetative mycelium of the lysine prototroph $n k u A \Delta$ (AGB552) strain with an additional unknown mutation and lysine auxotroph lysA $\Delta$ (AGB1092) strains under a light microscope. The percentage of observable Hülle cells in the hyphal ball was determined within an area of $5 \mathrm{~mm}^{2}$. Hülle cells were counted and their number was put into relation to the parental and the complementation strain with three biological replicates. Additionally, the dry weight of the submerged cultures was measured. Vegetative mycelia were first filtered to remove the liquid media, then they were dried for 12 hours in a drying cabinet $\left(75^{\circ} \mathrm{C}\right)$.

In order to perform a triple SILAC experiment the three lysine auxotroph strains were labeled with different stable isotope lysine and the labels were added from the point on where the strains were inoculated. lysA $\Delta$; nkuA $\Delta$ (AGB1092) was labeled light (Llysine final concentration: $0.75 \mathrm{mM}$ ) lys $A \Delta$; laeA $\Delta$; $n k u A \Delta$ (AGB1074) was labeled heavy (L-lysine ${ }^{13} \mathrm{C}_{6}{ }^{15} \mathrm{~N}_{2} \mathrm{HCl}$ final concentration $0.75 \mathrm{mM}$ ) and $l y s A \Delta$; laeA $\Delta:: / a e A$; $n k u A \Delta$ (AGB1076) was labeled medium (L-lysine D4 labeled $2 \mathrm{HCl}$ final concentration $0.75 \mathrm{mM}$ ). For a label swap experiment strains were labeled lys $A \Delta ; n k u A \Delta$ was labeled heavy, lys $A \Delta$; laeA $\Delta$; $n k u A \Delta$ was labeled light and lys $A \Delta$; laeA $\Delta: . l a e A ; n k u A \Delta$ was labeled medium. $300 \mathrm{mg}$ of each mycelium was merged and grinded with a retsch ${ }^{\mathrm{TM}_{-}}$ mill for 2 min by 30 frequency $\mathrm{l} / \mathrm{s}$. 


\subsubsection{DNA methods}

\subsubsection{Genetic transformation procedure}

Transformations of Escherichia coli and A. nidulans cells were performed as described (Hanahan et al., 1991, Punt and van den Hondel 1992).

\section{Escherichia coli:}

For transformation $200 \mu \mathrm{l}$ of chemo-competent cells were mixed with plasmid DNA and incubated on ice for 20 minutes, followed by an incubation for 1 minute at $42{ }^{\circ} \mathrm{C}$. Next LB - liquid media were added to the cells and the samples were incubated for 30 minutes at $37{ }^{\circ} \mathrm{C}$ with $200 \mathrm{rpm}$. Cells were then inoculated on a solid agar plate containing LB-media with respective antibiotics.

\section{Aspergillus nidulans:}

For transformation protoplasts were used and prepared. Vegetative mycelium was used. Vegetative mycelium was harvested and washed with citrate buffer. Mycelium was transferred into a $300 \mathrm{ml}$ flask and $25 \mathrm{ml}$ of an enzyme mix was added (VinoTaste® Pro (Novozymes $\mathrm{GmbH}, 4518$ )/lysozyme (Serva $\mathrm{GmbH}, 28262.03$ )). The flask was incubated for 90 minutes at $30{ }^{\circ} \mathrm{C}$ by $70 \mathrm{rpm}$ and protoplasts were filtered. After a washing step with $100 \mathrm{ml}$ STC 1700 protoplasts were mixed with DNA cassettes. Successively $1.5 \mathrm{ml}$ PEG 4000 was carefully added. Protoplasts were incubated for 30 minutes over ice to avoid crystral formation. Protoplasts were then washed with $50 \mathrm{ml}$ STC 1700 buffer and inoculated on sorbitol-solid agar plates at 37 ${ }^{\circ} \mathrm{C}$.

\subsubsection{Plasmid DNA isolation from Escherichia coli}

For the isolation of plasmids from Escherichia coli the following kits were used, HiSpeed Plasmid Midi Kit (QIAGEN, 12643), NucleoSpin ${ }^{\circledR}$ Plasmid Kit (MachereyNagel, 740615.250), QIAprep Spin Miniprep Kit (QIAGEN, 27106). Plasmid DNA isolation was performed according to the manufacturer's instructions. Therefore, Escherichia coli was inoculated in LB media with the respective antibiotic. Cultures were centrifuged at $13.000 \mathrm{rpm}$ in a $2 \mathrm{ml}$ reaction tube. The pellet was resuspended 
in $250 \mu \mathrm{l}$ buffer P1. As a next step $250 \mu \mathrm{l}$ P2 was added and the reaction tube was inverted several times for 5 minutes. Next $350 \mu$ of buffer N3 was added and the reaction tube was centrifuged for 10 minutes at $13.000 \mathrm{rpm}$. The supernatant was added into a DNA spin column. The DNA spin column was centrifuged for one minute at $13.000 \mathrm{rpm}$. The column was washed with a washing buffer. The DNA spin column was centrifuged at $13.000 \mathrm{rpm}$ to remove the washing buffer. As a final step the plasmid DNA was eluted in $30 \mu \mathrm{l}$ of $\mathrm{dH}_{2} \mathrm{O}$. The plasmid concentration was measured with a NanoDrop ND-1000 photospectrometer (peqlab biotechnologie, Erlangen, Germany).

\subsubsection{Aspergillus nidulans DNA extraction}

Vegetative mycelium of $A$. nidulans was used to extract genomic DNA (Lee and Taylor 1990). The mycelium was ground and $500 \mu$ l of lysis buffer ( $1 \mathrm{M}$ Tris ( $\mathrm{pH} 7.2), 0.5 \mathrm{M}$ ETDA, $3 \mathrm{~g}$ SDS, $1 \mathrm{ml}$ mercaptoethanol) was added and heated at $65^{\circ} \mathrm{C}$ for $20 \mathrm{~min}$. $100 \mu \mathrm{l}$ of $8 \mathrm{M}$ potassium acetate was added and tubes were inverted for 8-10 times. The samples were centrifuged for $15 \mathrm{~min}$ at $13000 \mathrm{rpm}$. This step was repeated. The supernatant was transferred into a new tube and $300 \mu \mathrm{l}$ isopropanol was added. The samples were centrifuged for $15 \mathrm{~min}$ and the pellet was washed with $1000 \mu$ l of ethanol and dissolved in $120 \mu \mathrm{l}$ of water/RNase $\mathrm{A}$ and stored at $4{ }^{\circ} \mathrm{C}$.

\subsubsection{Ligation of DNA fragments}

Fragments were ligated into the respective vectors using the Gene Art $^{R}$ Seamless Cloning and Assembly Kit (Invitrogen life technologies, A1328) or the T4 ligase (T4 DNA ligase (Thermo Scientific, EL0011)). Seamless cloning and assembly procedure was performed according to the manufacturer's instructions. The ligation procedure using the T4 ligase was performed as described by (Lehman 1974). The T4 ligase reaction was performed as following: 2-4 $\mu$ l hydrolyzed vectors, 10-15 $\mu$ l of the respective amplified DNA fragments and $2 \mu \mathrm{l}$ T4 ligase buffer were mixed together. The ligation reaction was performed for 3 hours at room temperature. In order to perform the ligation, the hydrolyzed vectors were first dephosphorylated with calf intestine alkaline phosphatase (CIAP, Thermo Scientific). The dephosphorylation was performed as following: $17 \mu \mathrm{l}$ hydrolyzed vectors, $2 \mu \mathrm{l}$ calf intestine alkaline 
phosphatase buffer, $1 \mu \mathrm{ICIAP}$, were mixed together. The samples were incubated for 10 minutes at $37{ }^{\circ} \mathrm{C}$. The enzyme reaction was then inactivated at $75{ }^{\circ} \mathrm{C}$ for 10 minutes. The amplified DNA fragments were phosphorylated as following: $15 \mu \mathrm{LNA}$, $1 \mu \mathrm{l} \mathrm{T4}$ Polynucleotide kinase (T4PNK, Thermo Scientific), $2 \mu$ kinase buffer, $2 \mu \mathrm{l} 10$ $\mathrm{mM}$ adenosine triphosphate, were mixed together. The samples were incubated for 20 minutes at $37^{\circ} \mathrm{C}$. In order to inactivate the enzyme reaction, the samples were then incubated for 10 minutes at $75^{\circ} \mathrm{C}$.

\subsubsection{PCR (Polymerase chain reactions)}

Polymerase chain reactions PCR (Saiki et al., 1988) were performed using either a platinum ${ }^{\circledR}$ Taq polymerase (Fermentas $\mathrm{GmbH}$, St. Leon Rot, Germany) or a highfidelity DNA polymerase Phusion ${ }^{\circledR}$ (Thermo Fisher Scientific GmbH, Schwerte, Germany, 89846). The PCR program which was used in this study is illustrated in Table 4.

Table 4. PCR program used in this study.

\begin{tabular}{|r|r|r||r|}
\hline Step & Temperature $\left[{ }^{\circ} \mathrm{C}\right]$ & Duration [min] & loops \\
\hline \hline 1 & 98 & $00: 30$ & \\
\hline 2 & 98 & $00: 10$ & \\
\hline 3 & 60 & $00: 30$ & \\
\hline 5 & 72 & $02: 00$ & repeated 36 times \\
\hline 5 & 72 & $05: 00$ & \\
\hline 6 & 4 & pause & $\infty$ \\
\hline
\end{tabular}

\subsubsection{Gelelectrophoresis of DNA}

DNA was separated on a $1 \%$ agarose gel described by (Aaij and Borst 1972). DNA fragments were mixed with $1 \mathrm{X}$ loading dye and gelelectrophoresis was performed with $90 \mathrm{~V}$ using a horizontal gel chamber. The agarose gel contained ethidium bromide and DNA fragments were visualized in a DNA documentation system, Gel IX20 imager (Intas science instruments, Göttingen, Germany). 


\subsubsection{Purification of amplified DNA}

For the purification of amplified DNA the following kit was used. QIAquick Gel Extraction Kit (QIAGEN, 28704) or QIAquick PCR Purification Kit (QIAGEN, 28104). This procedure was performed according to the manufacturer's instructions. Excised DNA of agarose gels were transferred into a $2 \mathrm{ml}$ reaction tube. $400 \mu \mathrm{lQC}$ buffer was added and the reaction tube was put into a $65^{\circ} \mathrm{C}$ thermobloc for 10 minutes until the excised agarose gel piece melted. As a next step the melted solution was transferred into a DNA spin column. The DNA spin column was centrifuged by $13.000 \mathrm{rpm}$ for one minute. The procedure was repeated for a second time. $650 \mu$ l of washing buffer was added and the DNA spinning column was centrifuged for $13.000 \mathrm{rpm}$ for one minute. This procedure was repeated for a second time and the DNA spin column was centrifuged for $13.000 \mathrm{rpm}$ to remove the washing buffer. As a final step the amplified DNA was eluted in $30 \mu \mathrm{l}$ with $\mathrm{dH}_{2} \mathrm{O}$. The concentration of the amplified DNA was measured with a NanoDrop ND-1000 photospectrometer (peqlab biotechnologie, Erlangen, Germany).

\subsubsection{Southern hybridization}

Southern hybridization was performed with a non-radioactive probe (Amersham Bioscience, Buckinghamshire, United Kingdom) as described by (Southern 1975). Primers used for amplification of Southern probes are listed in Table 5. In order to confirm the successful integration of the mutagenesis cassette genomic DNA of the fungal mutant strains was digested with restriction enzymes for 12 hours. The DNA fragments were separated according to size by agarose gel electrophoresis. The agarose gels were washed with three different washing buffers, buffer $1(0.25 \mathrm{M} \mathrm{HCl}$, 10 minutes), buffer $2(0.5 \mathrm{M} \mathrm{NaOH}, 25$ minutes), buffer $3(0.5 \mathrm{M}$ Tris, $1.5 \mathrm{M} \mathrm{NaCl}, \mathrm{pH}$ $7.4,30 \mathrm{~min})$. All steps were performed at room temperature. DNA was transferred onto an Amersham ${ }^{\mathrm{TM}}$ Hybond- $\mathrm{N}^{\mathrm{TM}}$ Nylon membrane (GE Healthcare, 676409), by dry blotting for 150 minutes at room temperature. Membranes were dried $(7$ minutes, $75^{\circ} \mathrm{C}$ ) and the transferred DNA was cross linked to the membranes using UV light ( $\lambda=$ $254 \mathrm{~nm}, 3$ minutes per each side). Membranes were transferred into a prehybridization glass tube and $10 \mathrm{ml}$ preheated prehybridization buffer was added. The membranes were incubated in a hybridization oven (60 minutes, $55^{\circ} \mathrm{C}$, rotated). After 30 minutes 
$40 \mu \mathrm{l}$ DNA southern probes were added. DNA probes were made according to the Amersham ${ }^{\mathrm{TM}}$ Alkphos Direct Labelling Reagents Kit (GE Healthcare, 11816064). Labelling of DNA probes were performed according to the manufacturer's instructions. The membrane was incubated with the DNA Southern probes for 12 hours at $55^{\circ} \mathrm{C}$ and rotated in the hybridization oven. The membrane was washed in $25 \mathrm{ml}$ washing buffer 1 for 10 minutes. This step was performed twice at $55^{\circ} \mathrm{C}$ and the membrane was rotated in the hybridization oven. $30 \mathrm{ml}$ washing buffer 2 was added. The washing step was performed at room temperature for 5 minutes, shaking. For detection of DNA the Amersham ${ }^{\mathrm{TM}}$ Cdp-star ${ }^{\mathrm{TM}}$ Detection reagents (GE Healthcare, 9766233) were applied to the membrane. Finally, the labeled DNA on the membrane was detected with an Amersham TM Hyperfilm TM ECL (GE Healthcare, 28906837).

Table 5. Primers used for amplification of Southern probes.

\begin{tabular}{|l|l|}
\hline Probe & Primer \\
\hline laeA 5' UTR & BD45/BD46 \\
\hline laeA 3' UTR & BD47/BD48 \\
\hline mphA 3' UTR & BD85/BD86 \\
\hline nptA 3' UTR & BD108/BD109 \\
\hline rfeA 3' UTR & BD113/BD114 \\
\hline
\end{tabular}

\subsubsection{Sequence analysis and oligonucleotides synthesis}

In order to analyze DNA sequences the software tool lasergene DNASTAR, Inc., Madison, Wisconsin, United States of America (Durfee and Schwei 2008) was used. Oligonucleotides were ordered from Eurofins MWG GmbH, Ebersberg, Germany. DNA was sequenced at SEQLAB-Sequencing Laboratories $\mathrm{GmbH}$, Göttingen, Germany. 


\subsubsection{Aspergillus nidulans strain construction}

\subsection{Construction of laeA $\Delta$, laeA complementation and other strains in laeA $\Delta$}

DNA sequence informations were obtained from AspGD (Cerqueira et al., 2014). Strains used in this study contain a recyclable marker module (Krappmann et al., 2005). In order to generate the laeA deletion construct the 5 ' UTR region was amplified from wild-type FGSC A4, ve $A^{+}$genomic DNA with primers BD45/BD46 and the 3' UTR was amplified with the primers BD47/BD48. The two amplicons were fused with the recyclable phleo cassette (the phleo cassette contains a bleomycin $(\mathrm{Bm})$ resistanceencoding gene ble) using a seamless cloning reaction (Gene Art@ seamless cloning and assembly kit, Invitrogen life technologies, A13288). The deletion cassette was integrated into a pBluescript $S K(+)$ vector. The linear deletion cassette was excised from the vector using a Pmel restriction cutting site and transformed into a $n k u A \Delta$ (AGBB52) and in a lysA $\Delta$; $n k u A \Delta$ (AGB1092) parental strain. For complementation of lae $A \Delta$ the laeA genomic locus was amplified from wild-type FGSC $\mathrm{A} 4, v e A^{+}$genomic DNA (primers BD45/BD76) fused together with a recyclable phelo marker and with the 3 ' UTR using a seamless cloning reaction.

In order to construct the nptA::gfp cassette a two-step cloning strategy was used (Mounts et al., 1989). The 5' UTR plus the sequence coding region of nptA was amplified with BD104/BD105 and the 3' UTR was amplified with the primers BD108/BD109. The gfp (green fluorescent protein) sequence was amplified using BD99 and BD100. The gfp sequence was fused with the coding sequence of $n p t A$ by fusion PCR. The fragment was integrated in the plasmid pJG229 containing a recyclable phleo cassette using a Swal restriction cutting site. In the second step, the 3' UTR was integrated into the plasmid using an Eco74l restriction cutting site. In order to construct the rfeA::gfp cassette the 5' UTR plus the gene $r f e A$ was amplified with the primers BD111/BD112. The 3' UTR was amplified with the primers BD113/BD114. The amplicons were fused using the two-step cloning strategy explained above. Linear cassettes of nptA::gfp and rfeA::gfp were transformed into a lysA $\Delta$; nkuA (AGB1092) and a laeA $\Delta$; lys $A \Delta ; n k u A \Delta$ (AGB1074) strain. All strains were confirmed by Southern hybridization (Figure 9-13). 


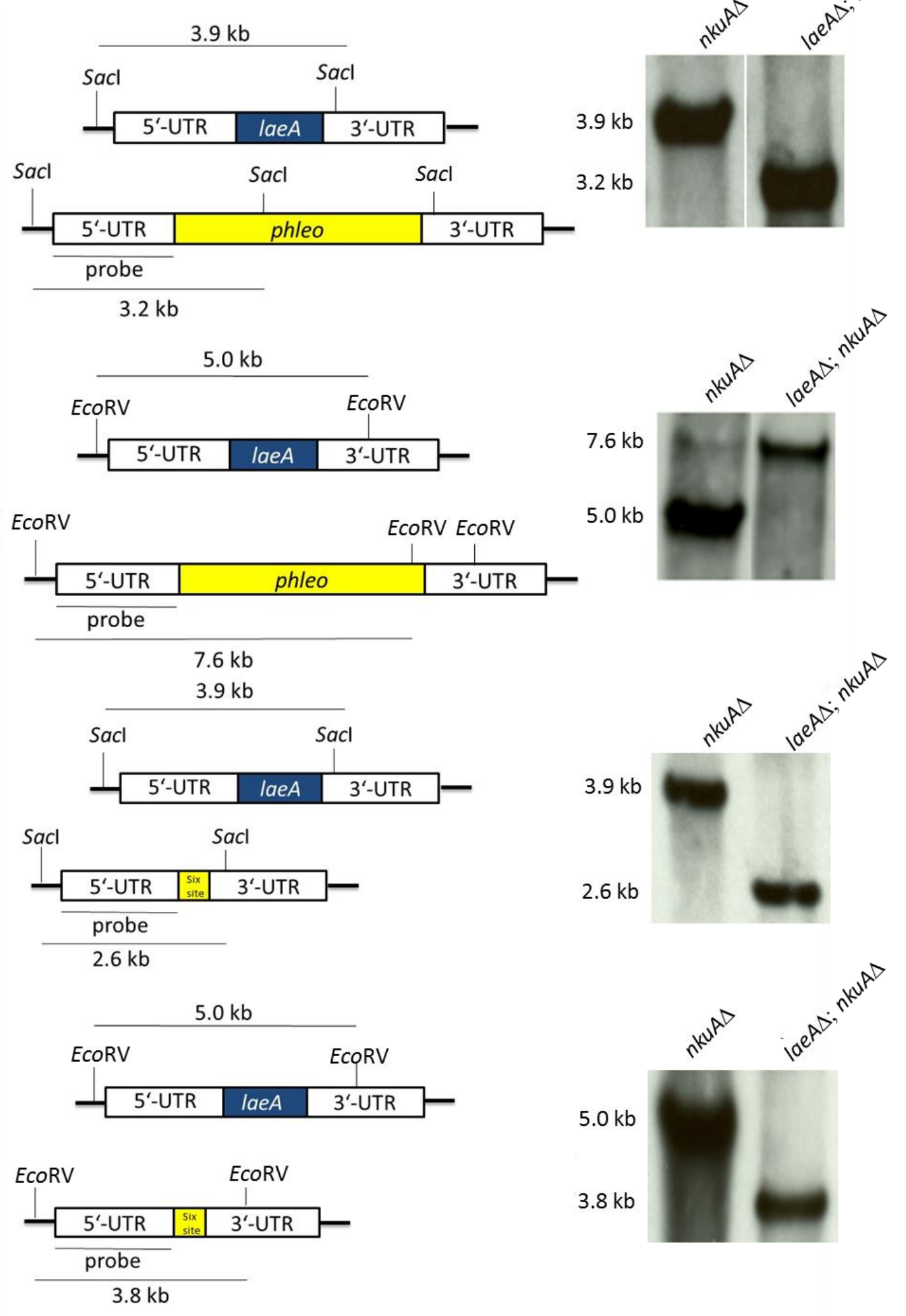

Figure 9. Restriction map and Southern hybridization before and after the marker was recycled for the deletion strain laeA $\Delta$; nkuA (AGB1073).

The following restriction enzymes were used: Sacl and EcoRV. 


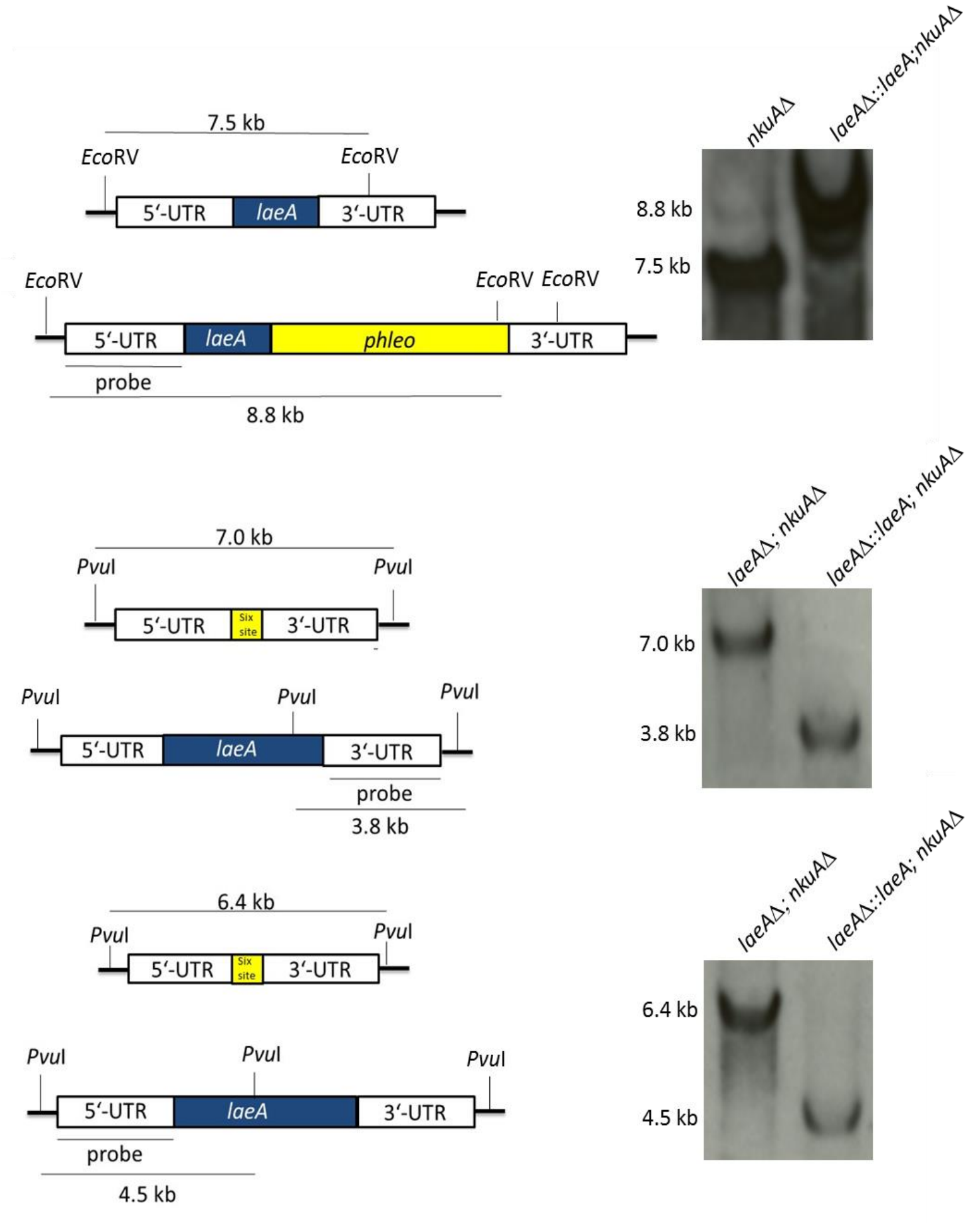

Figure 10. Restriction map and Southern hybridization before and after the marker was

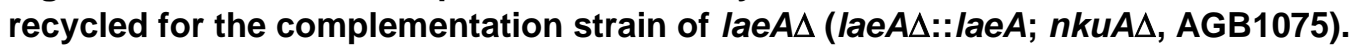
The following restriction enzymes were used: EcoRV and Pvul. 


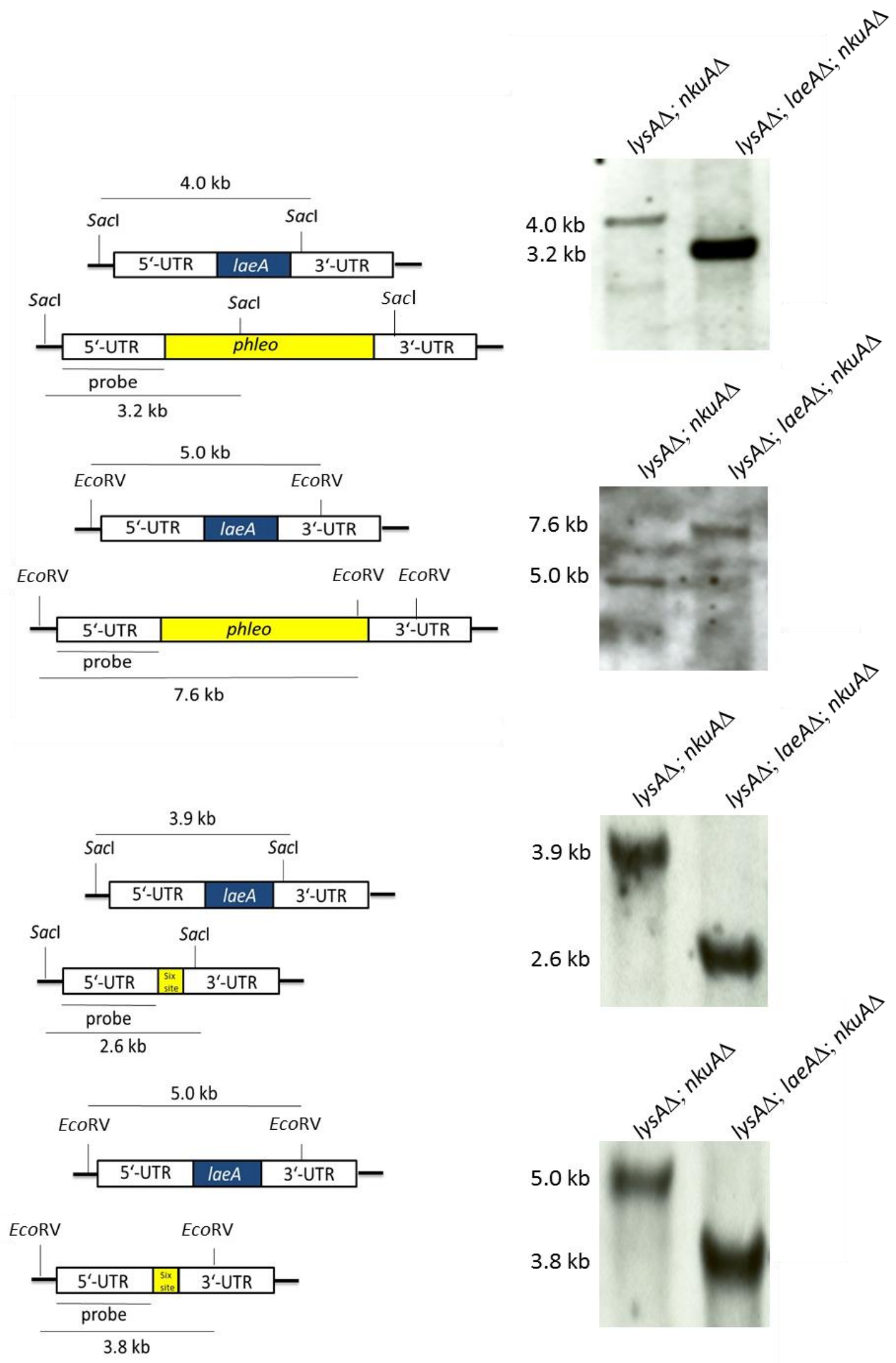

Figure 11. Restriction map and Southern hybridization before and after the marker was recycled for lysine auxotrophic laeA $\Delta$ strain (lysA $\Delta$; laeA $\Delta$; nkuA $\Delta$, AGB1074). The following restriction enzymes were used: Sacl and EcoRV. 


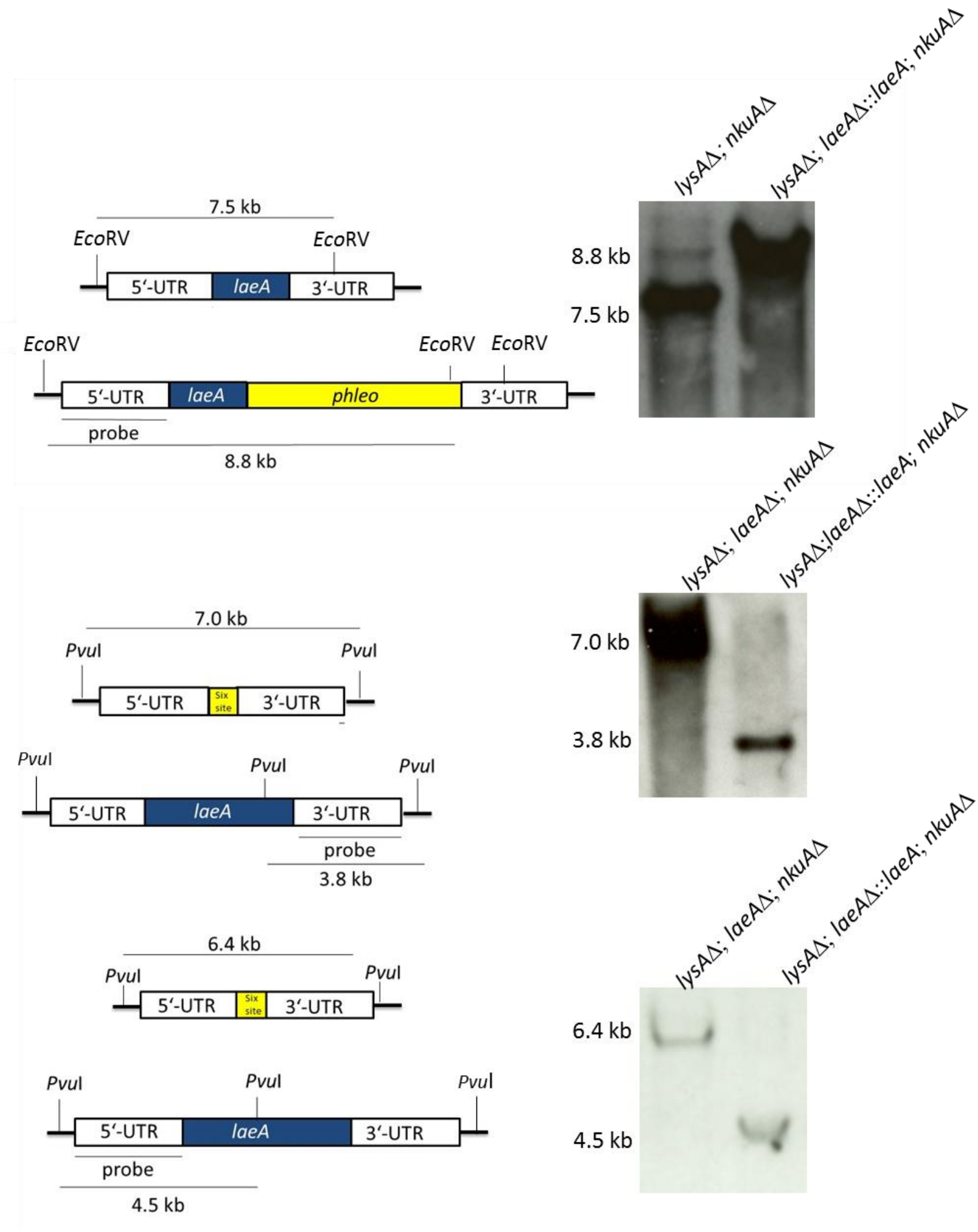

Figure 12. Restriction map and Southern hybridization before and after the marker was recycled for the complementation strain lysA $\Delta$; laeA $\Delta$ (lysA $\Delta ; / a e A \Delta:$ laeA;nkuA $\Delta$, AGB1076). The following restriction enzymes were used: EcoRV and Pvul. 


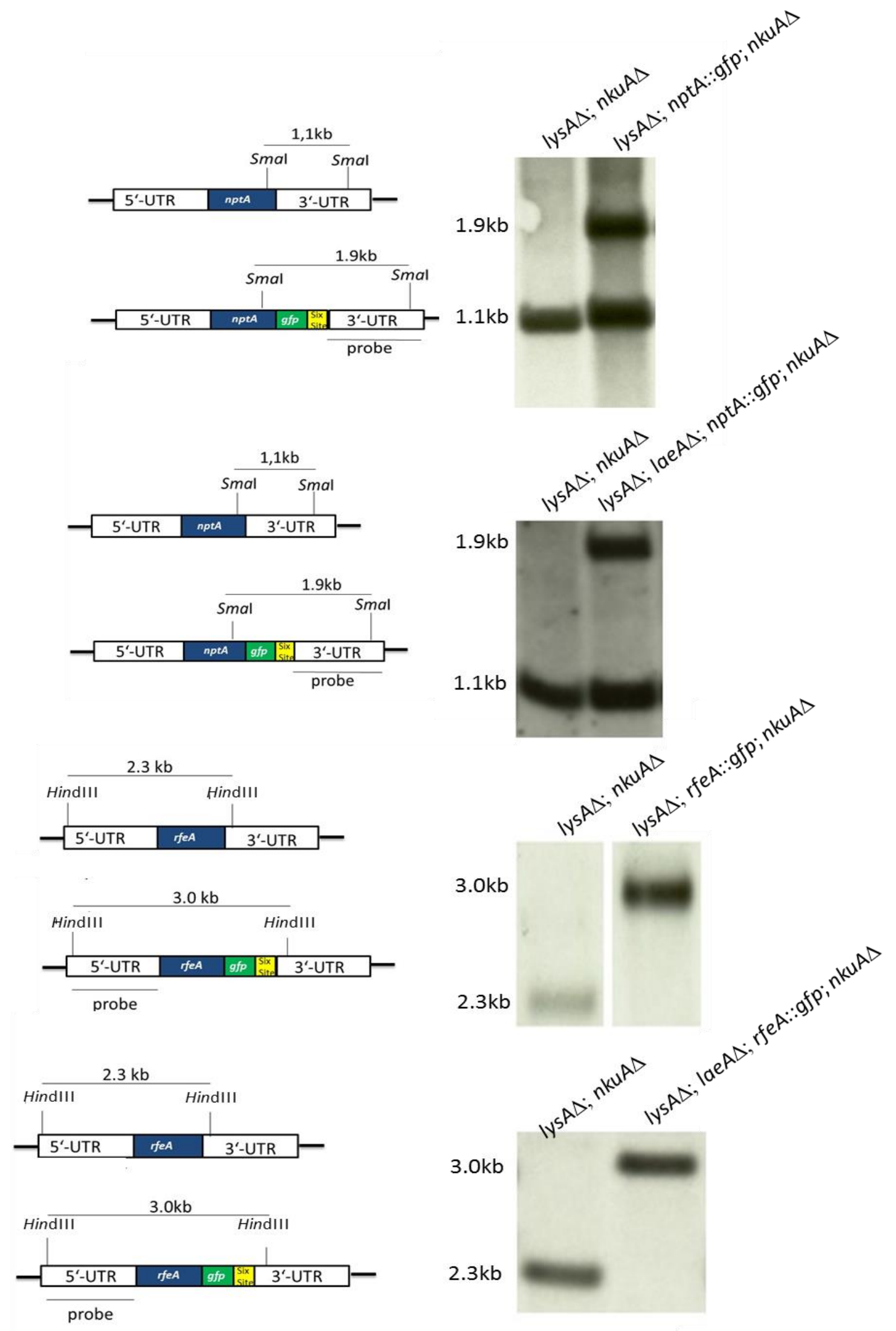

Figure 13. Restricition map and Southern hybridization to confirm nptA::gfp and rfeA::gfp strains Strains: lysA $\Delta ; n p t A:: g f p ; n k u A \Delta$ (AGB1082), lysA $\Delta ; l a e A \Delta ; n p t A:: g f p ; n k u A \Delta$ (AGB1083). Strains: lysA $\Delta ;$;feA::gfp;nkuA $\Delta$ (AGB1084), lysA 4 ;aeA $\Delta ; n p t A:: g f p ; n k u A \Delta$ (AGB1085). The following restriction enzymes were used: Smal and Hindlll. The strains contained a recyclable phleo cassette and were already recycled 


\subsection{Construction of xptB::gfp strain}

The $x p t B$ (xanthone prenyltransferase) gene was fused with $g f p$. The $x p t B:: g f p$ cassette was constructed using a two-step cloning strategy (Mounts et al., 1989). In order to construct the xptB::gfp cassette the 5' UTR plus the coding sequence of the gene $x p t B$ was amplified with the primers BD119/BD120(xptB) (Figure 14). The 5' UTR plus the coding sequence of the gene $x p t B$ were fused with the sequence of $g f p$. This fusion fragment was integrated into the plasmid pJG229 containing a recyclable phleo cassette using a Swal restriction cutting site. The 3' UTR was amplified with the primers BD121(xptB)/BD122(xptB). Next the 3' UTR was integrated into the plasmid pJG299 using an Eco74l restriction cutting site.

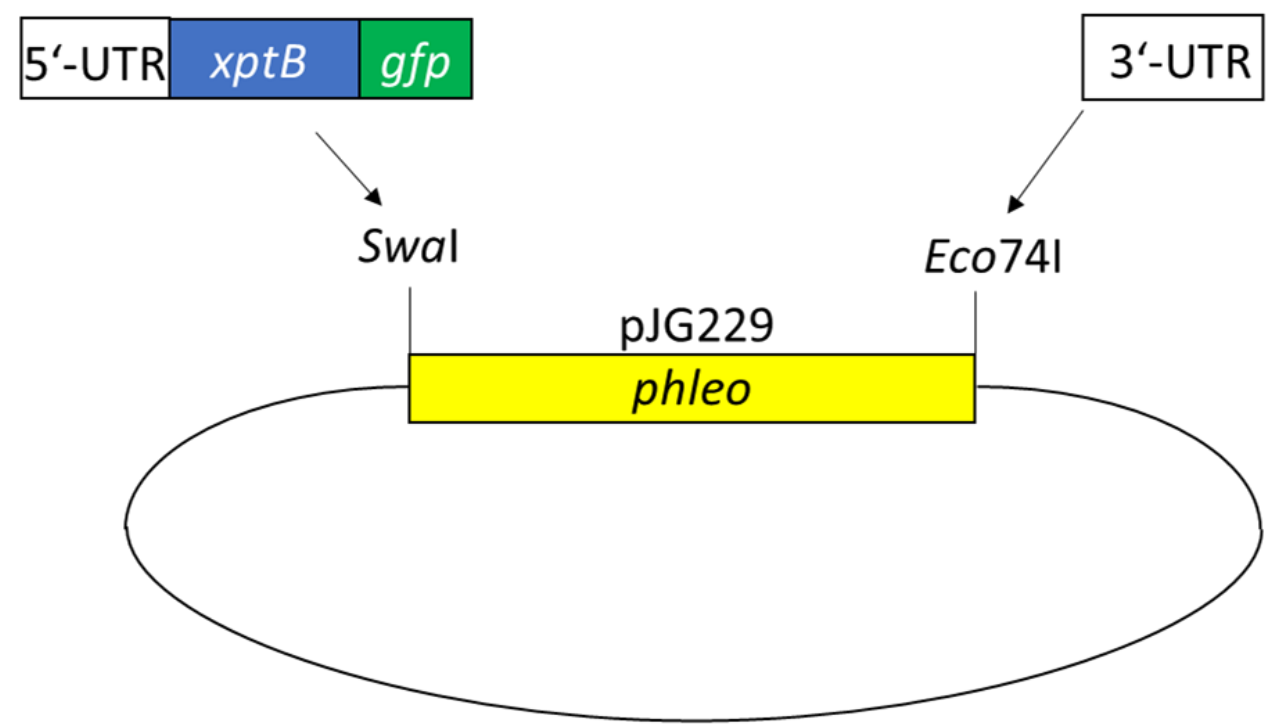

Figure 14. Schematic illustration of the two-step cloning strategy.

The sequence of the 5' UTR fused with the coding sequence of the $x p t B$ and with gfp was first integrated into the plasmid pJG229 containing a recyclable phleo cassette using a Swal cutting site. Next the 3' UTR was integrated into the plasmid pJG229 using an Eco74I restriction cutting site.

The xptB::gfp cassette was transformed into a lysAL; nkuA (AGB1092) parental strain and integration of the $x p t B:: g f p$ cassette was confirmed by diagnostic PCR (Figure 15). In order to perform the diagnostic PCR to confirm the integration of the cassette the 5' UTR plus the coding sequence and the sequence of $g f p$ was amplified using genomic DNA with the primers xptB::gfp BD119/BD107. Additionally, the gfp sequence was amplified with the primers BD106/BD107. 


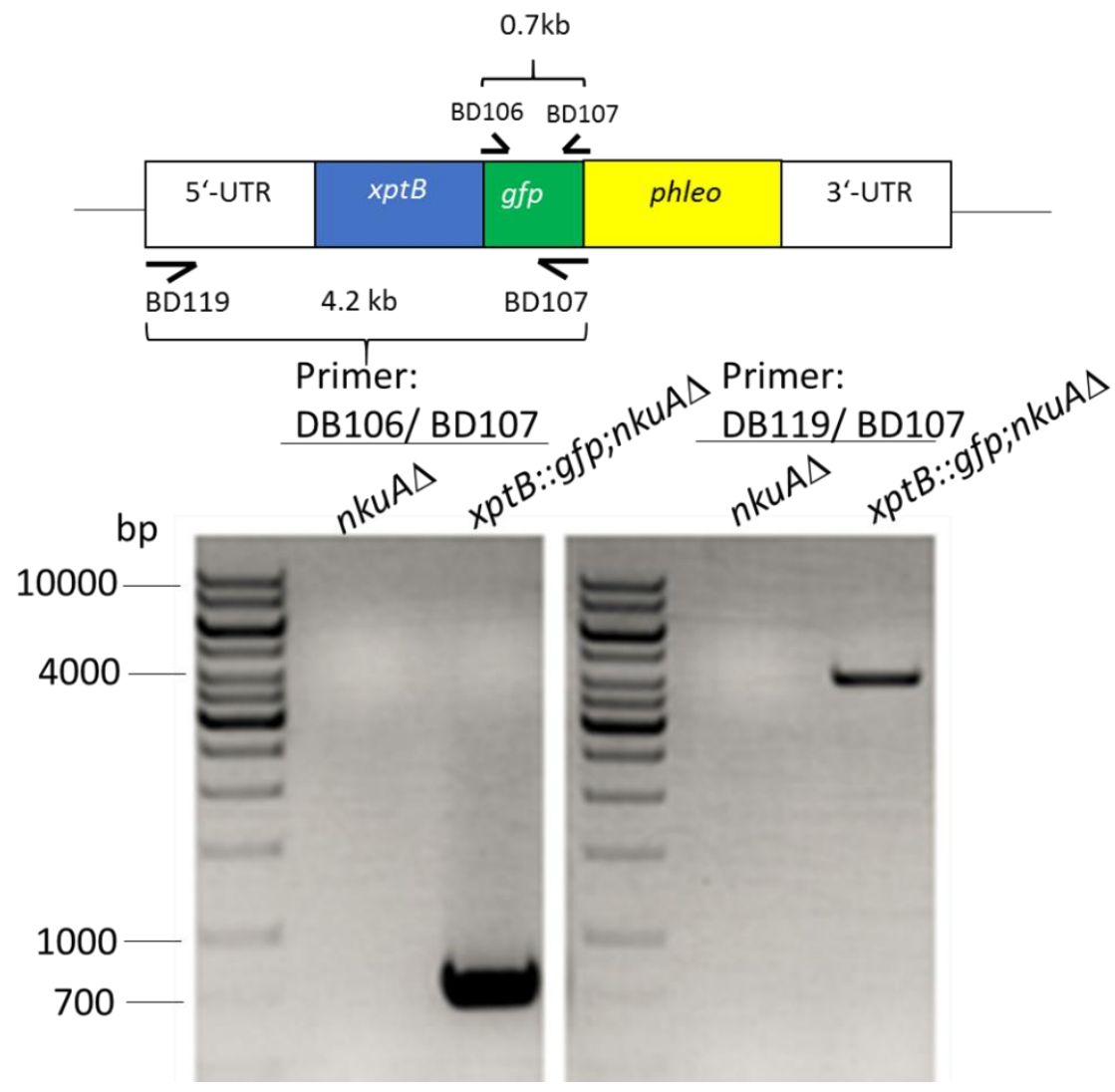

Figure 15. Diagnostic PCR to confirm the integration of the xptB::gfp cassette.

The 5' UTR plus the coding sequence of $x p t B$ and the sequence of gfp was amplified using genomic DNA (xptB::gfp; nkuA $\Delta$; lysA $\Delta$, AGB1086) with the primers BD119/BD107. The amplified product has a size of $4.2 \mathrm{~kb}$. As negative control genomic DNA of $n k u A \Delta ;$; lys $A \Delta$ was used. In order to amplify the gfp sequence the primers BD106 and BD107 were used. The amplified product has a size of $0.7 \mathrm{~kb}$.

\subsection{Construction of xptC::gfp strain}

The $x p t C$ (oxidoreductase) gene was fused with $g f p$. In order to construct the $x p t C:: g f p$ cassette the 5' UTR plus the coding sequence of the gene $x p t C$ was amplified with the primers BD113(xptC)/BD114(xptC). The sequence of $x p t C$ was fused with gfp. The 3' UTR was amplified with the primers BD115/BD116. The amplicons were fused using the two-step cloning strategy mentioned above. The fragments were integrated into the plasmid pJG229 using a Swal and an Eco74l restriction cutting site. The xptC::gfp cassette was transformed into a $n k u A \Delta$ (AGB552) parental strain and integration of the xptC::gfp cassette was confirmed by diagnostic PCR (Figure 16). In order to perform the diagnostic PCR to confirm the integration of the cassette the 5' UTR plus the coding sequence and the sequence of gfp was amplified using genomic DNA with the primers BD114/BD107. Additionally, the gfp sequence was amplified with the primers BD106/BD107. 


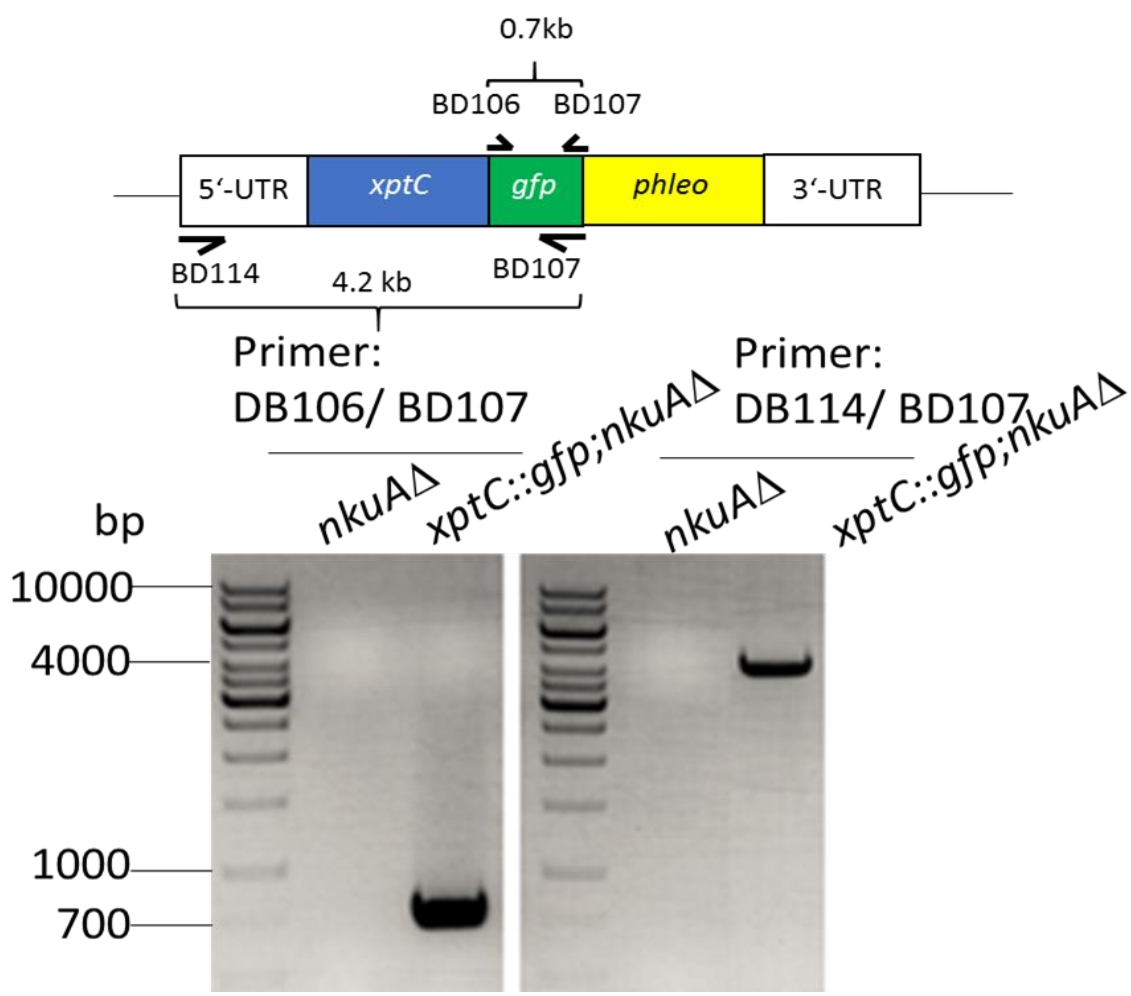

Figure 16. Diagnostic PCR to confirm the integration of xptC::gfp cassette.

The 5' UTR plus the coding sequence of $x p t C$ and the sequence of $g f p$ was amplified using genomic DNA (xptC::gfp;nkuAL, AGB1088) with the primers BD114/BD107. The amplified product has a size of $4.2 \mathrm{~kb}$. In order to amplify the gfp sequence the primers BD106 and BD107 were used. The amplified product has a size of $0.7 \mathrm{~kb}$. As negative control genomic DNA of $n k u A \Delta$ (AGB552) was used and no amplified products were observable.

\subsection{Construction of AN8434::gfp strain}

In order to construct the AN8434::gfp cassette the 5' UTR plus the gene AN8434 was amplified with the primers: BD121/BD122. The 3' UTR was amplified with the primers BD123/BD124. The amplicons were fused using the two-step cloning strategy mentioned above. First the 5' UTR and the coding sequence of AN8434 was fused with the sequence of $g f p$. The fragment was integrated into the plasmid pJG229 containing a recyclable phleo cassette using a Swal restriction cutting site. The 3' UTR was integrated into the plasmid pJG229 using an Eco74l restriction cutting site. The AN8434::gfp cassette was transformed into a nkuA $\triangle$ (AGB552) parental strain. Integration of the AN8434::gfp was confirmed by diagnostic PCR (Figure 17). In order to perform the diagnostic PCR to confirm the integration of the cassette the 5' UTR plus the coding sequence and the sequence of $g f p$ was amplified using genomic DNA with the primers AN8434::gfp (BD121/BD107). Additionally, the gfp sequence was amplified with the primers BD106/BD107. As negative control genomic DNA of the parental strain $n k u A \Delta$ was used. 


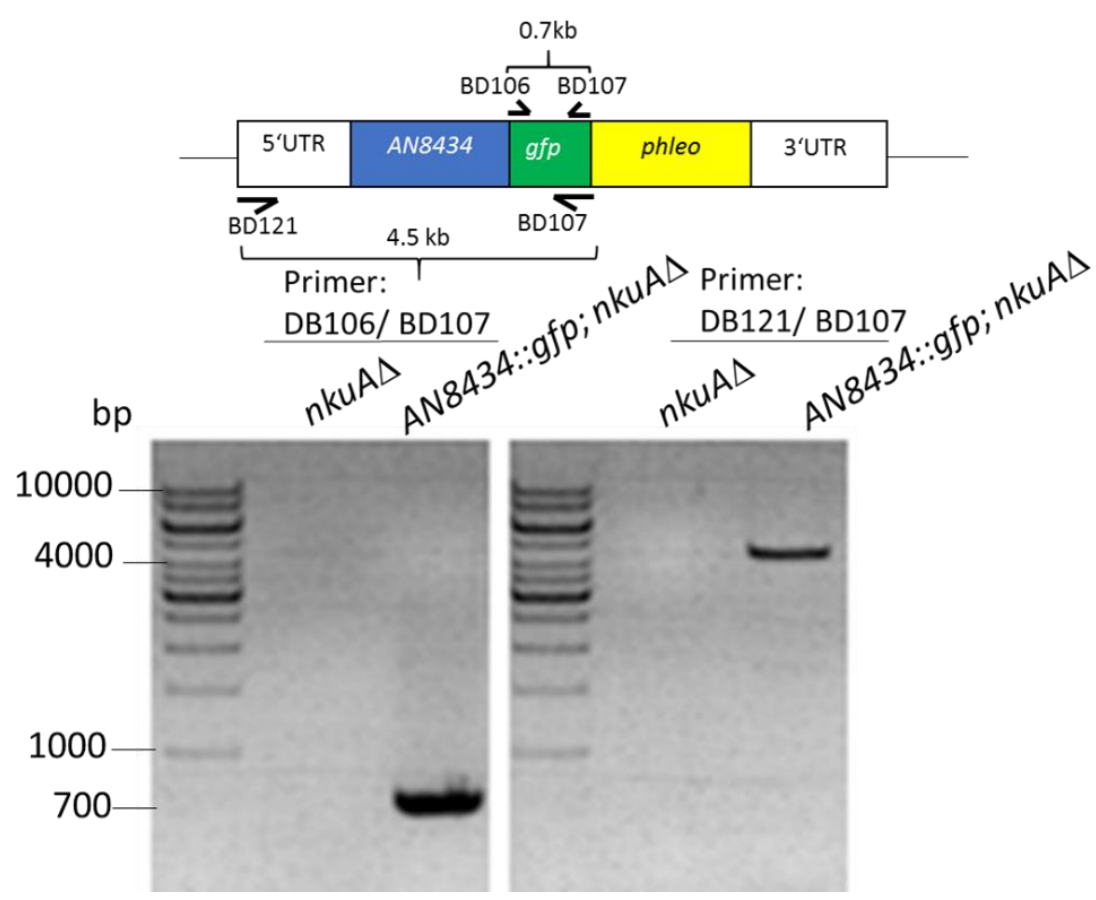

Figure 17. Diagnostic PCR to confirm the integration of the AN8434::gfp cassette.

The 5' UTR plus the coding sequence AN8434 and the sequence of $g f p$ was amplified using genomic DNA (AN8434::gfp;nkuAL, AGB1089) with the primers BD121/BD107. The amplified product has a size of $4.5 \mathrm{~kb}$. The sequence of gfp was amplified using the primers BD106/BD107. The amplified product has a size of $0.7 \mathrm{~kb}$. As negative control genomic DNA of $n k u A \Delta$ (AGB552) was used and no amplified products were observable.

\subsection{Construction of AN8435::gfp strain}

In order to construct the AN8435:: gfp strain cassette the 5' UTR plus the gene AN8435 was amplified with the primers BD125/BD127. This sequence AN8435 was fused with the sequence of gfp. The 3' UTR was amplified with the primers BD128/BD129. The amplicons were fused using the two-step cloning strategy. The fragments were integrated into the plasmid pJG229 using a Swal and an Eco74I restriction cutting site. The AN8435:: gfp cassette was transformed into a nkuA $\triangle$ (AGB552) parental strain and integration of $A N 8435::$ gfp was confirmed by diagnostic PCR (Figure 18). In order to perform the diagnostic PCR to confirm the integration of the cassettes the 5' UTR plus the coding sequence and the sequence of $g f p$ was amplified using genomic DNA with the primers AN8435::gfp (BD125/BD107). Additionally, the gfp sequence was amplified with the primers BD106/BD107. As negative control genomic DNA of the parental strain $n k u A \Delta$ was used. 


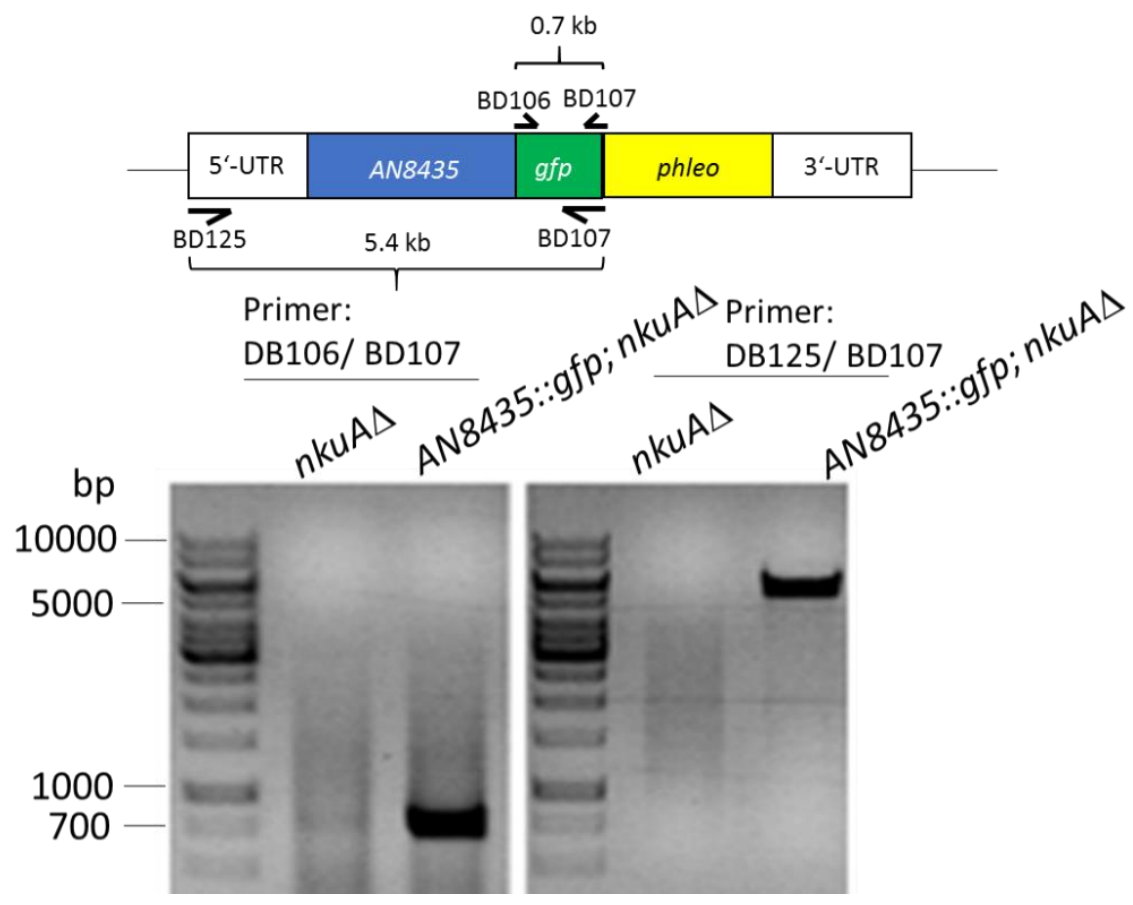

Figure 18. Diagnostic PCR to confirm the integration of the AN8435::gfp cassette.

The 5' UTR plus the coding sequence of $A N 8435$ and the sequence of $g f p$ was amplified using genomic DNA (AN8435::gfp;nkuA $\Delta$, AGB1090) with the primers BD125/BD107. The amplified product has a size of $5.4 \mathrm{~kb}$. The sequence of $g f p$ was amplified using the primers BD106/BD107. The amplified product has a size of $0.7 \mathrm{~kb}$. As negative control genomic DNA of $n k u A \Delta$ (AGB552) was used and no amplified products were observable.

\subsection{Construction of $m p h A \Delta, m p h A$ complementation and other strains in $m p h A \Delta$}

The mphA (maltose permease-like protein of Hülle cells) knockout plasmid and knockout strain was constructed as mentioned above using the seamless cloning and assembly strategy. The 5' UTR and the 3' UTR region was amplified from the wildtype FGSC A4, veA+ genomic DNA using the primers BD83/BD84 and BD85/BD86. The linear deletion cassette was excised from the vector using a Pmel restriction cutting site and transformed into a nkuA (AGBB52) parental strain. In order to construct the gfp fusion plasmids the $\mathrm{C}$ - terminus of $m p h A$ was tagged. Therefore, the 5' UTR plus the coding sequence of $m p h A$ was amplified with the primers BD83/BD98. The gfp sequence was amplified using the primers BD99/BD100. As mentioned above 3' UTR was amplified using the primers BD85/BD86. The complementation of $m p h A \Delta$; $n k u A \Delta$ was performed with and without $g f p$. The $m p h A:: g f p$ cassette was transformed into a laeA $\Delta ; n k u A \Delta$ (AGB1073) strain. All strains were confirmed by Southern hybridization (Figure 19-21). 


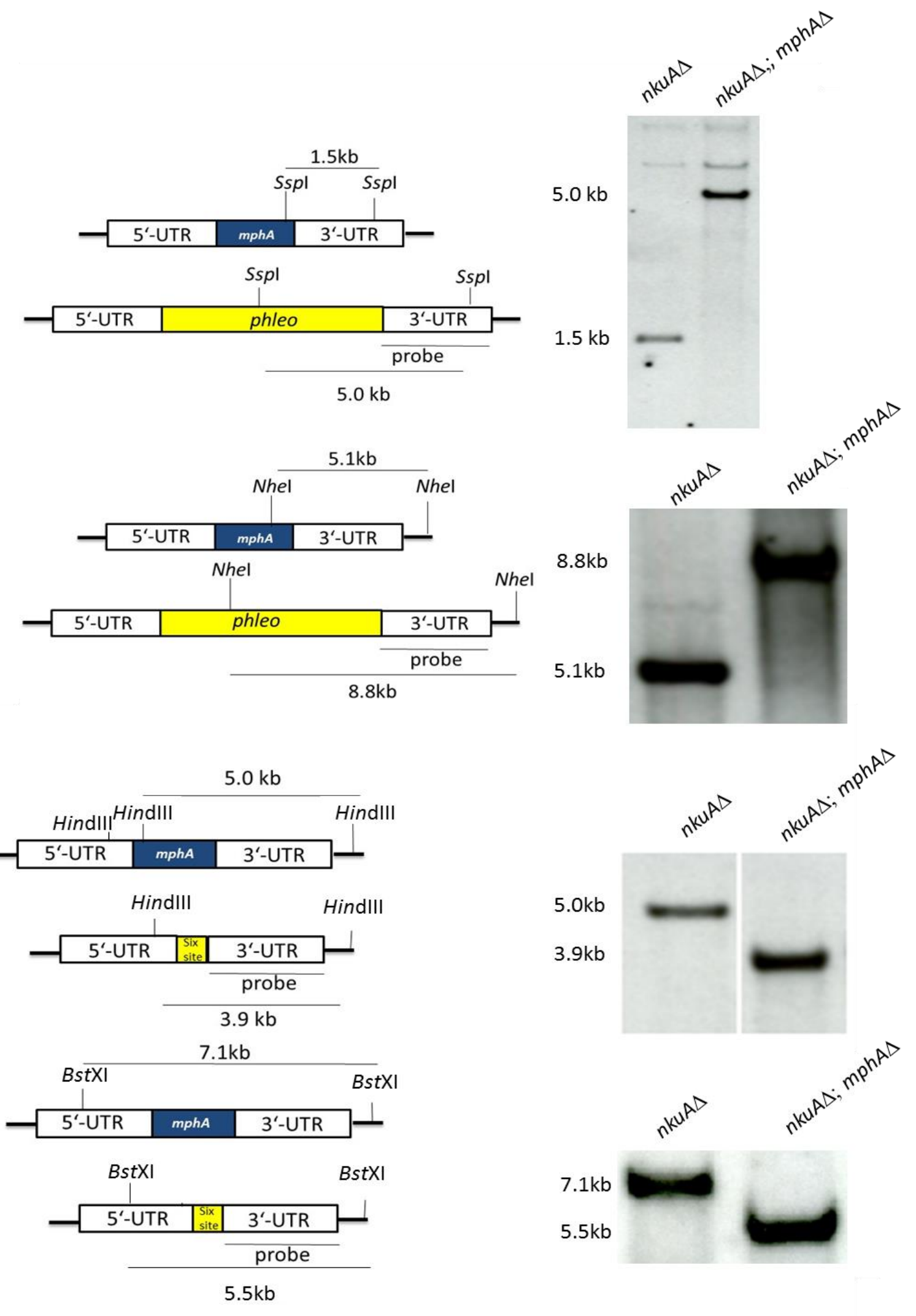

Figure 19. Restriction map and Southern hybridization before and after the marker was recycled for the $n k u A \Delta ; m p h A \Delta$ (AGB1077) strain.

The following restriction enzymes were used: Sspl, Nhel, HindlII and BstXI. 


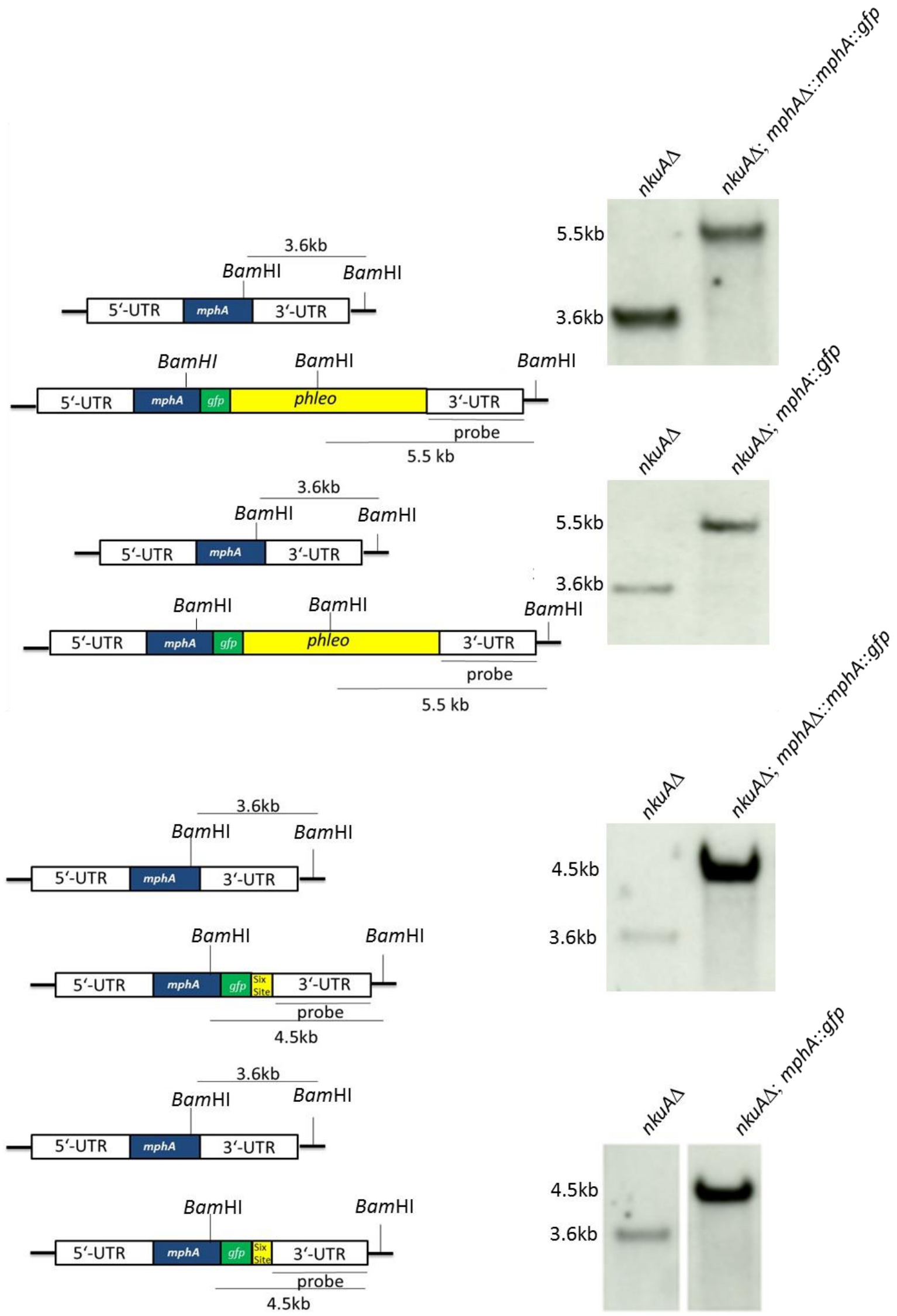

Figure 20. Restriction map and Southern hybridization before and after the marker was recycled for the complementation strain (nkuA $\Delta ; m p h A \Delta:: m p h A:: g f p, A G B 1078)$ plus the mphA::gfp;nkuA $\Delta$ (AGB1079) strain.

$B a m \mathrm{HI}$ was used as a restriction enzyme. 


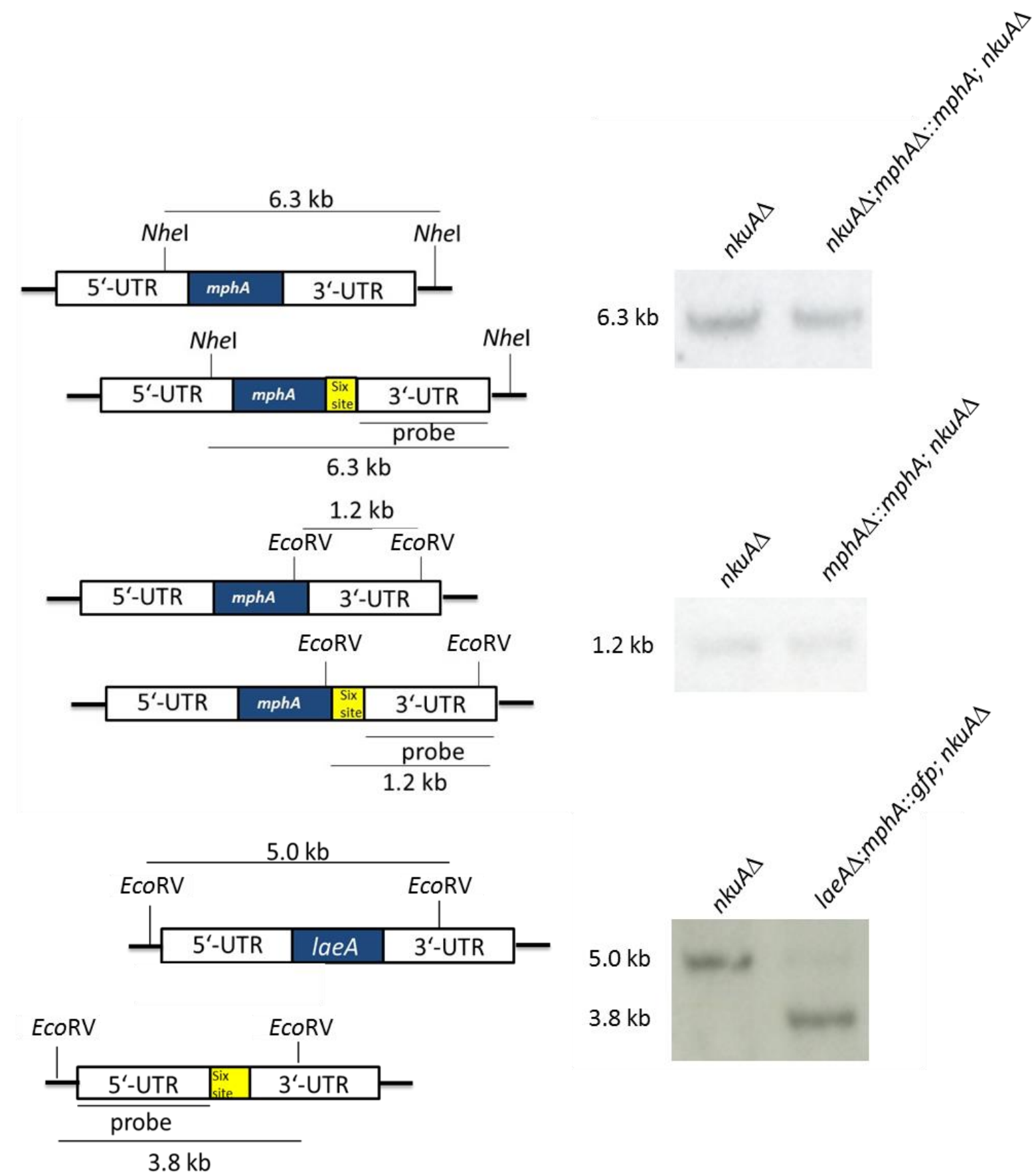

Figure 21. Restricition map and Southern hybridization to confirm the complementation strain (mphA $\Delta:: m p h A, n k u A \Delta, A G B 1080)$ and the laeA $\Delta ; m p h A:: g f p ; n k u A \Delta$ (AGB1081) strain. Nhel and EcoRV were used as restriction enzymes. The strains contained a recyclable phleo cassette and the recyclable phleo cassette was already recycled. 


\subsubsection{Protein methods}

\subsubsection{Protein extraction of Hülle cells from Aspergillus nidulans}

In order to extract proteins from enriched Hülle cells the cleistothecia-rolling technique was used as mentioned above. Sexual mycelium of $A$. nidulans wild-type (FGSC A4 Glasgow, $v e A^{+}$) was grown on solid agar plate cultures. Therefore, spores were inoculated on a solid agar plate and the petri dish was sealed with a parafilm to lower the oxygen condition and was covered with an aluminium foil. After three, five and seven days the cleistothecia were transferred to a new petri dish with the help of a syringe. In order to separate Hülle cells from the cleistothecium they were rolled on the solid agar plate and Hülle cells adhered to the surface. Hülle cells were then transferred with the help of the syringe from the solid agar plate to a $1.5 \mathrm{ml}$ collection tube containing $40 \mu$ lextraction buffer $B+300(100 \mathrm{mM}$ Tris pH 7.5, $300 \mathrm{mM} \mathrm{NaCl}$, 10\% glycerol, $1 \mathrm{mM}$ EDTA, 0.1\% NP-40, $1 \mathrm{mM}$ DTT, protease inhibitor mix (Roche Pharma AG, Grenzach-Wyhlen, Germany), 0.5 M benzamidine, 100 mM PMSF) with phosphatase inhibitor (100 mM NaF, $50 \mathrm{mM}$ sodium orthovanadate, $50 \mathrm{mM} \beta$ glycerolphosphate; sterile filtered). All further steps were performed on ice. $270-300$ cleistothecia were rolled on the solid agar plate and the resulting Hülle cells were used for further protein extractions. Hülle cells were sonicated (60 seconds, $60 \%$ of sonoporation power, in between centrifugation steps for 30 seconds at $4{ }^{\circ} \mathrm{C}$, procedure repeated 6 times). The tube was centrifuged for $10 \mathrm{~min}$ by $13.000 \mathrm{rpm}$ at $4^{\circ} \mathrm{C}$ and the supernatant was transferred into a new $1.5 \mathrm{ml}$ tube. The cell disruption was verified by observation of cellular debris. Protein extract was then loaded onto $12 \%$ SDS-PAGE.

\subsubsection{Protein extraction of sexual mycelium from Aspergillus nidulans}

Sexual mycelium of $A$. nidulans wild-type FGSC A4, ve $A^{+}$was harvested from the same plate as Hülle cells were collected to be enriched. Sexual mycelium was scraped off the solid agar plate with a spatula and transferred into a $1.5 \mathrm{ml}$ tube. Sexual mycelium was frozen in liquid nitrogen and grinded in a retsch ${ }^{\mathrm{TM}}$-mill. $300 \mu \mathrm{l}$ of 
extraction buffer $\mathrm{B}^{+} 300$ (100 mM Tris pH 7.5, $300 \mathrm{mM} \mathrm{NaCl,} 10 \%$ glycerol, $1 \mathrm{mM}$ EDTA, 0.1\% NP-40, 1 mM DTT, protease inhibitor mix (Roche Pharma AG, GrenzachWyhlen, Germany), 0.5 M benzamidine, $100 \mathrm{mM}$ PMSF) with phosphatase inhibitor (100 mM NaF, 50 mM sodium orthovanadate, $50 \mathrm{mM} \beta$-glycerolphosphate; sterile filtered) was added and a sonication step as described before followed by centrifugation (10 $\mathrm{min}, 13.000 \mathrm{rpm}, 4^{\circ} \mathrm{C}$ ) was performed. Protein extraction was performed as described (Bayram et al., 2012). $80 \mu \mathrm{g}$ of protein were loaded onto a $12 \%$ SDS-PAGE. All other steps were performed as mentioned above.

\subsubsection{Protein extraction of vegetative mycelium from Aspergillus nidulans}

In order to cultivate the vegetative mycelium spores were inoculated in $50 \mathrm{ml}(250 \mathrm{ml}$ shake flask) minimal medium (1\% glucose; 1\% AspA; $2 \mathrm{mM} \mathrm{MgSO} 4$; and trace elements; pH 6.5; $5.937 \times 10^{5} \mathrm{sp} / \mathrm{ml}$ ) for 20 hours (for Hülle cell formation 72 hours) at $37^{\circ} \mathrm{C}$ with constant shaking. The vegetative mycelium was filtered to remove the media and washed twice with $0.96 \% \mathrm{NaCl} 300 \mathrm{mg}$ of vegetative mycelium was transferred into a $2 \mathrm{ml}$ reaction tube. The vegetative mycelium was grinded with a retsch $^{\mathrm{TM}}$-mill for $2 \mathrm{~min}$ by 30 frequency $\mathrm{I} / \mathrm{s}$. Proteins were extracted as described (Bayram et al., 2012). $80 \mu \mathrm{g}$ of total protein extract was loaded onto a $12 \%$ SDSPAGE.

\subsubsection{Protein extraction of asexual mycelium from Aspergillus nidulans}

Protein extraction of an asexual mycelium was performed at the same time points as a sexual mycelium. Harvesting and protein extraction was performed as mentioned above. Asexual mycelium was grown on solid agar plate cultures. Therefore, spore solution was directly inoculated on the solid agar plate. Asexual mycelium was grown in light conditions at $37^{\circ} \mathrm{C}$. The asexual mycelium was scratched off the solid agar plate and proteins were extracted as mentioned above and as described (Bayram et al., 2012). 


\subsubsection{Protein concentration measurement}

In order to determine the concentration of proteins a Bradford assay was used (Bradford 1976). Additionally, the concentration of proteins was measured with an NanoDrop ND-1000 photospectrometer (peqlab biotechnologie $\mathrm{GmbH}$, Erlangen, Germany).

\subsubsection{SDS-polyacrylamide gel electrophoresis}

Protein samples were mixed with $4 \mathrm{X}$ loading dye (50 mM Tris pH 6.8, $2 \%$ SDS, $10 \%$ glycerol, $1 \% \beta$-mercaptoethanol, $12.5 \mathrm{mM}$ EDTA, 0.02\% bromophenol blue). The samples were heated for 5 minutes at $95{ }^{\circ} \mathrm{C}$. The protein samples were loaded onto a $12 \%$ SDS page according to (Laemmli 1970). SDS-gels were prepared manually and consisted of a lower running gel ( $1 \mathrm{M}$ Tris $\mathrm{pH} 8.8,0.1 \%$ SDS, $12 \%$ acrylamide (Rotiphorese ${ }^{\circledR}$ Gel 40 37,5:1) (Roth $\mathrm{GmbH}, 3029.1$ ), 10\% ammonium persulfate (APS), $20 \mu \mathrm{l}$ TEMED) and an upper stacking gel (1 M Tris pH 6.8, 0.1\% SDS, 12\% acrylamide, $5 \%$ ammonium persulfate (APS), $10 \mu$ TEMED). Proteins were separated electrophoretically for 60 minutes at 180-200 V. The PageRuler ${ }^{\mathrm{TM}}$ prestained protein ladder (Thermo Scientific, SM26616) was used as size marker.

\subsubsection{Colloidal Coomassie staining of proteins}

Protein staining was performed according (Neuhoff et al., 1988). Gels were fixed in $40 \%(\mathrm{v} / \mathrm{v})$ ethanol, $10 \%(\mathrm{v} / \mathrm{v})$ acetic acid for $60 \mathrm{~min}$, washed two times in water for 10 minutes and stained for 12 hours in coomassie solution $(0.1 \%(\mathrm{w} / \mathrm{v})$ coomassie brilliant blue G250, 5\% (w/v) aluminum sulfate-(14-18)-hydrate, 10\% (v/v) methanol, 2\% (v/v) ortho-phosphoric acid). The lanes were excised from the polyacrylamide gels. The gel pieces were divided into equal lots into six $1.5 \mathrm{ml}$ peptide low binding reaction tubes, destained in $\mathrm{v}$ (methanol):v (water) (40:60).

\subsubsection{In-gel protein digestion with trypsin}

The protein lane was excised from the gel and separated into six peptide low binding reaction tubes and tryptic digestion with trypsin was performed as described (Shevchenko et al., 1996). The gel pieces were covered with acetonitrile and shaken 
for 10 minutes at room temperature. Acetonitrile was removed and the gel pieces were dried in a speedvac (savant speedvac concentrator, Thermo Scientific). $150 \mu 10 \mathrm{mM}$ DTT (in $100 \mathrm{mM} \mathrm{NH}_{4} \mathrm{HCO}_{3}$ ) was added to the gel pieces. The samples were incubated at $56{ }^{\circ} \mathrm{C}$ for 60 minutes. DTT solution was removed and $150 \mu \mathrm{l} 55 \mathrm{mM}$ iodoacetamide (in $100 \mathrm{mM} \mathrm{NH}_{4} \mathrm{HCO}_{3}$ ) was added and the samples were incubated for 45 minutes at room temperature in dark. lodoacetamide solution was removed and the gel pieces were washed in $150 \mu \mathrm{NH}_{4} \mathrm{HCO}_{3}$, shaken for 10 minutes at room temperature. The solution was removed and $150 \mu \mathrm{l}$ acetonitrile was added. The samples were shaken for 10 minutes at room temperature. The washing steps were repeated once. The gel pieces were dried in a speedvac at $50{ }^{\circ} \mathrm{C}$ and covered subsequently with trypsin (SERVA GmbH, Heidelberg, Germany, 37286.01). The trypsin buffer was prepared according to the manufacturer's instructions. The samples were incubated for $45 \mathrm{~min}$ on ice and the remaining digestion buffer was removed. Next $30 \mu \mathrm{l} 25 \mathrm{mM} \mathrm{NH}_{4} \mathrm{HCO}_{3}$ $\mathrm{pH} 8.0$ was added and the samples were incubated for 12 hours at $37^{\circ} \mathrm{C}$.

The samples were centrifuged ( 1 minute by $13.000 \mathrm{rpm}$ ) and the supernatant was collected in a $1.5 \mathrm{ml}$ peptide low binding reaction tube. The gel pieces were covered with $20 \mathrm{mM} \mathrm{NH}_{4} \mathrm{HCO}_{3}$ and shaken for 10 minutes at room temperature. The samples were centrifuged ( 1 minute by $13.000 \mathrm{rpm}$ ) and the supernatant was collected into the collection tube. Next the gel pieces were covered with $50 \%$ acetonitrile / $5 \%$ formic acid. After an incubation step of 20 minutes, shaken and at room temperature the samples were centrifuged ( 1 minute by $13.000 \mathrm{rpm}$ ) and the supernatant was collected. This step was repeated twice. The final volume of the combined supernatant was completely dried in a speedvac at $50^{\circ} \mathrm{C}$. The peptides were resupended in $20 \mu \mathrm{l}$ sample buffer ( $2 \%$ acetonitrile, $0.1 \%$ formic acid).

After tryptic digestion peptides were desalted with the use of C18-StageTips as described (Rappsilber et al., 2007). Therefore, three C18 disks were punced out from a solid phase extraction disk (3M, Neuss, Germany, 2215) and placed into a $200 \mu \mathrm{l}$ tip. The $\mathrm{C} 18$ material was equilibrated. The C18-StageTips were placed into a $2 \mathrm{ml}$ reaction tube using an adaptor. For equilibration of the C18-StageTips $100 \mu \mathrm{l}$ methanol $0.1 \%$ formic acid was added to the $\mathrm{C} 18$ material. After a centrifugation step ( 2 minutes, $13.000 \mathrm{rpm}) 100 \mu \mathrm{l} 70 \%$ acetonitrile $0.1 \%$ formic acid was added. Then the C18StageTips were centrifuged and $100 \mu \mathrm{l} 0.1 \%$ formic acid was added. This step was repeated. The peptide solution was added onto the C18 material and the C18StageTips were centrifuged for 5 minutes by $4.000 \mathrm{rpm}$. This step was repeated. The 
C18-StageTips were washed twice with $100 \mu \mathrm{l} 0.1 \%$ formic acid. The peptides were eluted from the C18 material with $70 \%$ acetonitrile $0.1 \%$ formic acid. The C18StageTips were centrifuged for 5 minutes at $4.000 \mathrm{rpm}$. The peptide samples were dried in a speedvac. For LC-MS analysis the peptide samples were resuspended in $20 \mu \mathrm{L}$ LC-MS sample buffer.

\subsubsection{Liquid chromatography-mass spectrometry (LC-MS) and data analysis}

Peptides were analyzed on a Liquid chromatography (LC) coupled to an Orbitrap Velos Pro ${ }^{\mathrm{TM}}$ Hybrid Ion Trap-Orbitrap mass spectrometer (MS) (Thermo Fisher Scientific, Bremen, Germany). Peptides were dissolved in 2\% ( $/ / \mathrm{v})$ acetonitril, $0.1 \%$ $(\mathrm{v} / \mathrm{v})$ formic acid and raw data were searched with SEQUEST and Mascot algorithms present in Proteome Discoverer 1.4 (Eng et al., 1994, Koenig et al., 2008). The search parameter for SEQUEST and Mascot algorithm were: (i) precursor ion mass tolerance $10 \mathrm{ppm}$, (ii) fragment ion mass tolerance $0.6 \mathrm{Da}$, (iii) maximum of two missed cleavage sites were set, (iv) fixed cysteine static modification by carboxyamidomethylation, (v) variable modification by methionine oxidation. The MS/MS spectra were matched against the $A$. nidulans genome database (UBMG0112_Anidulans_20120325.fasta). Results filter settings of Proteome Discoverer 1.4 were set to: (a) high peptide confidence and (b) minimal number of two peptides per protein. The MS/MS data were furthermore analyzed with the Andromeda search engine operating in MaxQuant 1.5.1.0 software with the program's default parameters using the same genome database as mentioned above (Tyanova et al., 2016).

Identified proteins of enriched Hülle cells from solid agar plate cultures were analyzed within three different time points. For each time point three biological replicates were considered. The proteome of sexual mycelium was analyzed from the same solid agar plates from where Hülle cells were enriched. The proteome of sexual mycelium was also analyzed within three different time points. The same conditions were applied to analyze the proteome of asexual mycelium. For each time point three biological replicates were considered. Only proteins identified in two or more biological replicates and with two or more peptides per protein were considered for the analysis. For visualization of the analysis the accession numbers of the proteins were inserted into 
a Venn diagram (Oliveros 2016). The proteome of a vegetative mycelium in submerged liquid cultures was analyzed by three biological replicates. Only proteins identified in two or more biological replicates and with two or more peptides per protein were considered for the analysis. For peptide quantification Lys 4 was defined as medium peptide labels and Lys8 as heavy peptide labels. The peptide median ratio distribution was determined using Proteome Discoverer 1.4. In order to correct experimental bias, the protein median was normalized. Only peptide ratios that were determined similar in two or more biological replicates were considered for the analysis. Additionally, normalized ratios were analyzed and processed using the Perseus 1.5.0.15 software. A t-test ( $p$ value 0.05 ) was performed to statistically compare the $\log _{2}$ SILAC ratios across three biological replicates. The $\log _{2}$ SILAC ratio was determined for the strains laeA $\triangle$ (AGB1074) in comparison to laeA (AGB1092). The following threshholds were set. In the range of a $\log _{2}$ SILAC ratio between - 5.0 and -0.5 the protein quantity of identified proteins was down-regulated. In the range of a $\log _{2}$ SILAC ratio between +0.5 and +5.0 the protein quantity of identified proteins was up-regulated. In the range between a -0.5 and $+0.5 \log _{2}$ SILAC ratio the protein quantity of identified proteins was unchanged. Workflows to process the proteomic data are illustrated in supplementary table 1 and 2.

\subsubsection{Functional annotation of proteins}

Functional annotations of identified proteins were performed using the basic local alignment search tool Blast2GO (http://www.Blast2GO.com/b2ghome). BlastP was used to blast against the NCBInr database (NCBI: National Center for Biotechnology Information) with a blast expect value of $1 \times 10^{-3}$. The number of blast hits were set to 20 and the cutoff value for the GO terms was set to 20 (Conesa et al., 2005).

\subsubsection{Fluorescence microscopy of fusion proteins}

In order to visualize the localization of fusion proteins (fused to GFP) fluorescence microscopy was used. Hülle cells were enriched in $40 \mu \mathrm{l}$ of $\mathrm{dH}_{2} \mathrm{O}$ using the cleistothecia-rolling technique. After centrifugation (2 minutes at $13.000 \mathrm{rpm}$ ) the supernatant was removed. The cellular pellet was resuspended in $5 \mu \mathrm{d}_{2} \mathrm{O}$ and transferred to an object slide. The cells were observed under a reflected-light 
microscope (Zeiss Axiolab - Zeiss AG, Jena, Germany) and an Olympus SZX12ILLB2-200 binocular (Olympus GmbH, Hamburg, Germany). Fluorescence photograph pictures were taken with a confocal light microscope (Zeiss Axiolab - Zeiss AG, Jena, Germany) equipped with a QUAN-TEM: S12SC (Photometrics, Tucson, Arizona, United States of America) digital camera and the SlideBook 6 (Intelligent Imaging Innovations GmbH, Göttingen, Germany) software package. For GFP fusion protein visualization, the following parameters were used; DIC filter 200 ms; GFP filter $300 \mathrm{~ms}$.

\subsubsection{Immunoblotting}

Proteins were extracted from different types of mycelia as described above. For immunoblotting experiments, proteins were first separated using a polyarcrylamide gel electrophoresis and transferred onto a nitrocellulose membrane as previously described (Jöhnk et al., 2016, Schinke et al., 2016). Protein concentrations were determined as described above and as reference for equally loaded proteins amount 0.2\% Ponceau S (Sigma- Aldrich, Copenhagen, Denmark), 3\% TCA was used. Blocking was performed in 5\% milk powder (skimmed milk powder (Sucofin, 562570765347)). Membranes were incubated for 12 hours with $\alpha$-GFP antibody (dilution: 1:1000, sc-9996, Santa Cruz Biotechnology Inc., Dallas, Texas, United States of America and Heidelberg, Germany). The nitrocellulose membranes were washed three times in $150 \mathrm{ml} 1 \mathrm{X}$ TBST (Tris buffered saline with tween 20) for 10 minutes at room temperature. Membranes were incubated for 60 minutes using an $\alpha$ mouse secondary antibody (dilution 1:2000, G21234, Invitrogen AG, Carlsbad, California, United States of America). The nitrocellulose membranes were washed three times in $150 \mathrm{ml} \mathrm{1X} \mathrm{TBST} \mathrm{(Tris} \mathrm{buffered} \mathrm{saline} \mathrm{with} \mathrm{tween} \mathrm{20).} \mathrm{For} \mathrm{peroxidase}$ reaction $100 \mu \mathrm{l} 2.5 \mathrm{mM}$ luminol, $44 \mu \mathrm{l} 400 \mu \mathrm{M}$ paracoumarat, $100 \mathrm{mM}$ Tris $\mathrm{pH} 8.5$

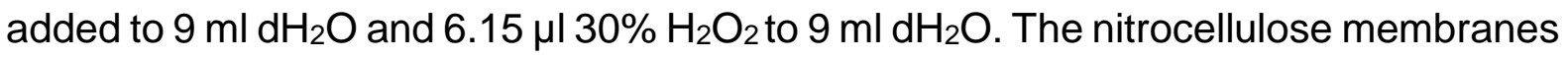
were incubated with both solutions for 2 minutes, shaken and in darkness. Detection was performed on a Fusion-SL7 (Vilber Lourmat, Eberhardzell, Germany) system. Western hybridization experiments were performed with three biological replicates and samples were loaded twice on the $12 \%$ SDS-PAGE. 


\section{Results}

\subsection{Enrichment of sexual tissue and specialized Hülle cells}

\subsubsection{Hülle cells can be enriched from solid agar plates for comparative proteomics}

Aspergillus nidulans develops closed sexual fruiting bodies during its sexual life cycle. So-called cleistothecia contain thousands of asci and are surrounded by several layers of thick-walled Hülle cells. It is assumed that Hülle cells have a protective capacity and therefore they could function e.g. in secondary metabolite formation (Alves et al., 2016, Sarikaya-Bayram et al., 2010). In order to identify and compare proteins from enriched Hülle cells from solid agar plates as well as from submerged liquid cultures, a proteome study was performed. To separate Hülle cells from cleistothecia grown on surface cultures, the cleistothecia-rolling technique was performed (Figure 22).

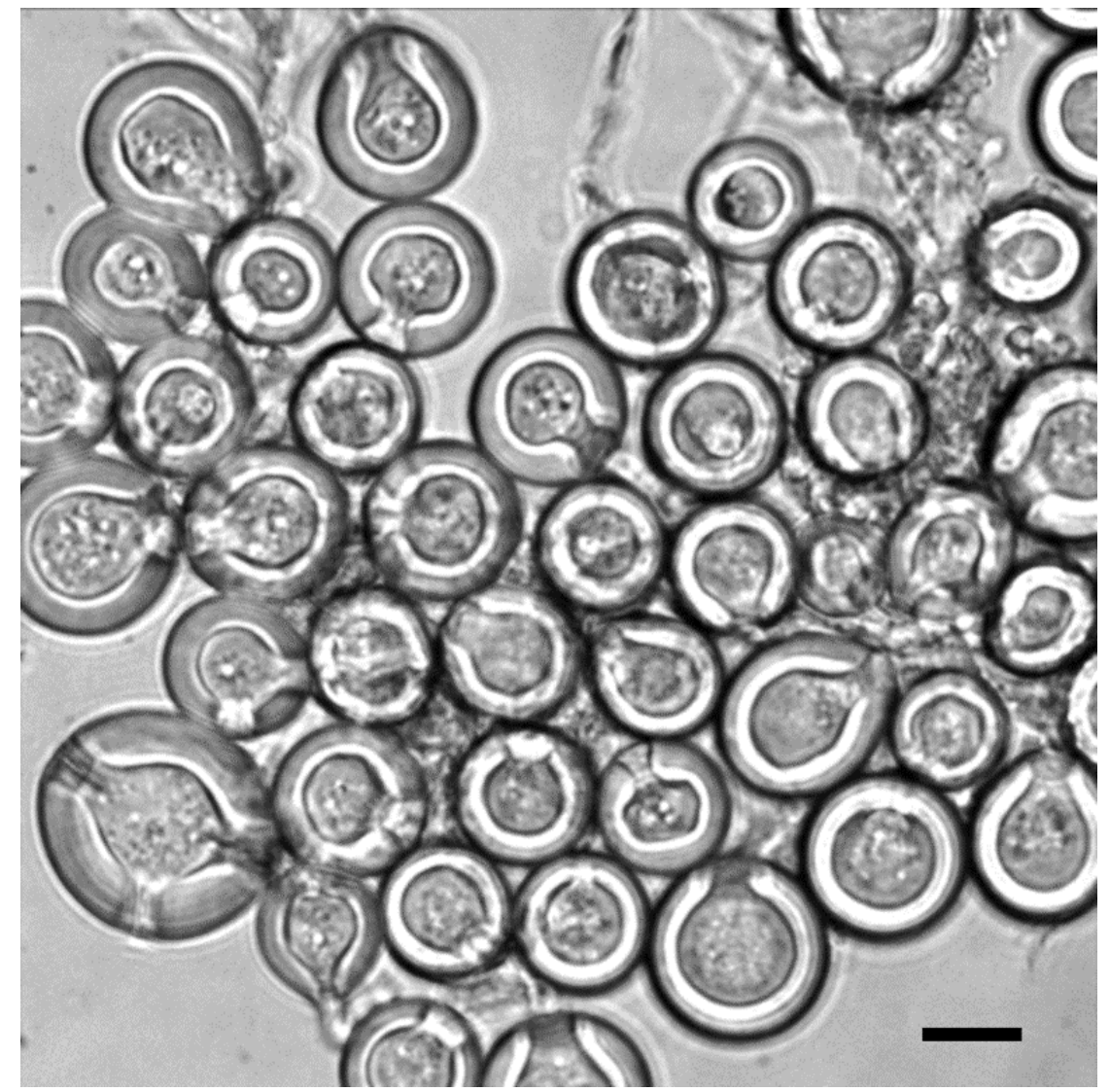

Figure 22. Enrichment of Hülle cells of cultures from solid agar plates The cleistothecia-rolling technique was used for enrichment of Hülle cells from a single cleistothecium. Enriched surface Hülle cells from sexual mycelium using the cleistothecia-rolling technique are shown. Scale bar is $10 \mu \mathrm{m}$. 
Hülle cells from sexual mycelium grown on solid agar plates were separated and harvested. Cleistothecia of sexual mycelium were transferred with a fine tipped syringe to a fresh solid agar plate. The cleistothecium was then rolled on the solid agar plate with a fine tipped syringe and the Hülle cells adhered to the surface of the solid agar plate. Hülle cells were collected with a fine tipped syringe and transferred into a collection tube.

\subsubsection{Hülle cells can be enriched from submerged liquid cultures for comparative proteomics}

In order to compare the proteome of enriched surface Hülle cells to Hülle cells grown in liquid cultures a second proteomic approach was performed. The proteomic approach from Hülle cells grown in liquid media will be discussed within the next chapter.

Hülle cells have been observed in submerged liquid cultures in different strains (Alkahyyat et al., 2015, Bayram et al., 2009, Bayram et al., 2008a, Vienken et al., 2005, Kim et al., 2002, Han et al., 2001). Vegetative mycelia under submerged liquid conditions usually form no cleistothecia and Hülle cells are, therefore, more randomly distributed throughout the mycelia ball (Bayram et al., 2009, Bayram et al., 2008a). In order to perform a quantitative proteome experiment a lysine auxotroph $l y s A \Delta$; $n k u A \Delta$ (AGB1092) strain was compared to a lysine auxotroph laeA $\Delta ; \operatorname{lys} A \Delta$; $n k u A \Delta$ (AGB1074) strain that causes significant reduction in formation of Hülle cells (Sarikaya-Bayram et al., 2010). Hülle cells were observed in the lysine auxotroph and in the lysine prototroph parental $n k u A \Delta$ (AGB552) strain after 72 hours in submerged liquid cultures. The strain AGB552 (pabaA1;yA;nkuA $\Delta:: a r g B$ ) contains a $n k u A \Delta$ mutation with an additional unknown mutation which results in Hülle cell formation in submerged liquid cultures. Deletion of gene $n k u A$ in $A$. nidulans leads to an improvement in gene targeting (Nayak et al., 2006). These cultures represent a version of enriched Hülle cells from submerged liquid conditions and were compared to Hülle cells enriched from solid agar plates. In the first two chapters, the results of both proteomic approaches are shown. First of all, the proteome of surface Hülle cells are compared to different mycelia types grown on surface agar plates. The proteome of surface Hülle cells is then compared to the proteome of Hülle cells grown in liquid 
media. This finding emphasizes that Hülle cells can be enriched in a vegetative mycelium grown for 72 hours in submerged liquid media.

\subsection{Enzymes encoded by the monodictyphenone ( $m d p)$ / xanthone (xpt) secondary metabolite gene clusters are increased during sexual differentiation: proteome comparison of Aspergillus nidulans development grown on surfaces}

\subsubsection{Enrichment of surface Hülle cells enabled to perform a comparative proteome analysis}

In the first analysis (proteome experiment 1), proteome of $A$. nidulans wild-type FGSC A4, ve $A^{+}$was analyzed to determine differentially expressed proteins in Hülle cells compared to other developmental stages. Vegetative mycelium without Hülle cells was compared to a sexual mycelium with Hülle cells and an asexual mycelium. Proteomes of Hülle cells, sexual and asexual mycelium were analyzed at three different time points, namely three, five and seven days after germination. At each developmental stage three biological replicates were considered. In order to analyze the proteome of surface Hülle cells, they were first enriched from sexual mycelium grown on solid agar plates using the cleistothecia-rolling technique. Therefore, a spore solution was directly inoculated on solid agar plates and the fungus was grown in darkness and reduced oxygen conditions to induce sexual development. Proteins from enriched Hülle cells were extracted, digested with trypsin and peptides were analyzed with a Liquid chromatography (LC) coupled to an Orbitrap Velos Pro ${ }^{\mathrm{TM}}$ Hybrid Ion TrapOrbitrap mass spectrometer (MS) (Thermo Fisher Scientific). Different mycelia types were used as controls, namely undifferentiated vegetative mycelium without Hülle cells, sexual mycelium with a high amount of Hülle cells and an asexual mycelium with a low amount of Hülle cells. The total proteome of vegetative mycelium from at least three biological replicates grown under submerged conditions for 20 hours was analyzed. Shaking cultures with submerged mycelia represent undifferentiated filaments without Hülle cells at this time point. In order to harvest vegetative mycelia a spore solution was directly inoculated in liquid media. The amount of vegetative mycelium grown for 20 hours in submerged liquid conditions is significantly higher than that of a vegetative mycelium grown on solid agar plates. Therefore, the vegetative 
mycelium of submerged liquid cultures was used for the analysis. Additionally, the proteome of sexual mycelium from where the Hülle cells were enriched was analyzed. The proteome of asexually grown mycelium was also analyzed as outlined in Figure 23.

Hülle cells from solid agar plate cultures

$$
20 \text { hours (no Hülle cells) }
$$

Vegetative mycelium

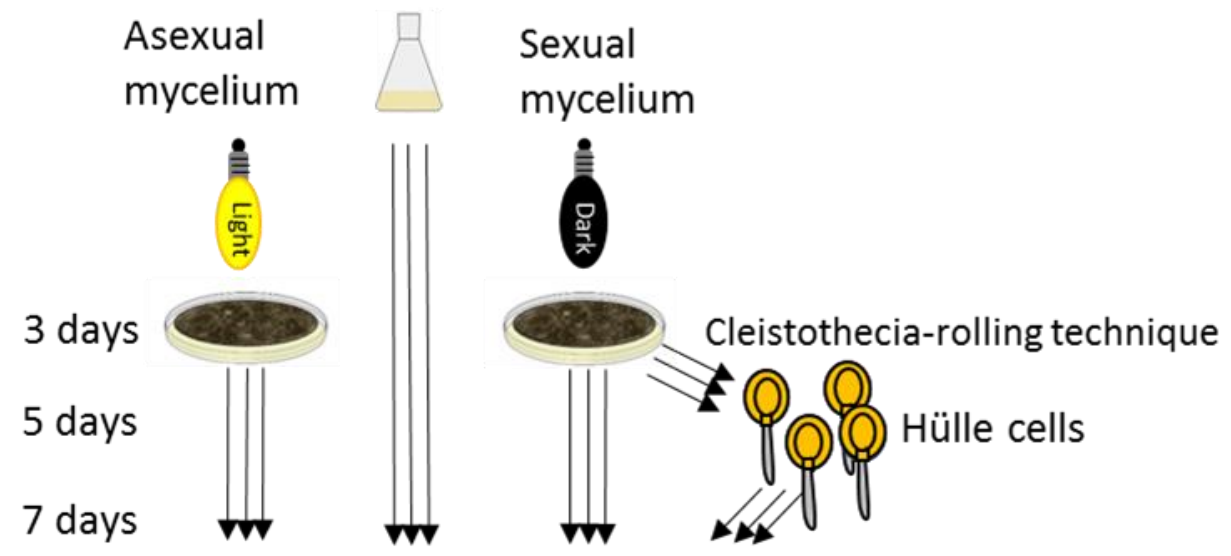

Protein extraction, trypsin digestion \& MS

Figure 23. Proteomics workflow for analyzing enriched surface Hülle cells grown on solid agar plates and different types of mycelia.

For the first proteome analysis (Proteome experiment 1) A. nidulans wild-type (FGSC A4, ve $A^{+}$) was used. Hülle cells were enriched from sexual mycelium using the cleistothecia-rolling technique and from the same solid agar plates sexual mycelium was harvested (all steps were performed on day 3, 5 and 7 after germination). Sexual mycelium contained high amounts of Hülle cells. Vegetative mycelium was cultivated under submerged conditions and was harvested 20 hours after germination. At this time point no Hülle cells were observable in vegetative mycelium. Asexual mycelium was harvested from solid agar plates on day 3, 5 and 7 after germination. For each time point three biological replicates of Hülle cells as well as the other fungal tissues mentioned above were considered and are highlighted with three arrows.

\subsubsection{Comparative proteomics revealed that the proteome of surface Hülle cells overlaps especially to that of sexual mycelium}

Analysis of different mycelia types and Hülle cells at all three time points revealed a total number of 1.525 identified proteins (Figure 24). Detailed evaluation of all LC-MS data by using the MaxQuant, Perseus and Proteome discoverer is described in Materials and Methods. Only proteins identified in two or more biological replicates and with two or more peptides per protein were considered for analysis. In this study 401 proteins were identified from surface Hülle cells enriched from solid agar plates and they are highlighted in the red rectangle (Figure 24); (Supplementary Table 3). 
Additionally, the list of identified proteins in sexual, asexual and vegetative mycelium is listed in Supplementary Table 4.

In this study, six proteins were identified in enriched Hülle cells that were unidentified in other fungal tissues (Table 6). Proteins that were common in Hülle cells and different mycelia types were validated. 253 proteins were common in all different cell types. 24 proteins were present in sexual mycelium with high amounts of Hülle cells and overlapped to an enriched Hülle cell fraction from sexual mycelium. The list of proteins identified in surface Hülle cells and sexual mycelium is shown in Table 7. Proteins which are found in sexual mycelium and Hülle cells are potentially crucial during sexual development. The localization of several proteins found in Hülle cells and sexual mycelium, therefore, were studied in detail and functional gene studies were performed. Findings imply that identified proteins of Hülle cells overlap to other fungal tissues, especially to that of sexual mycelium.

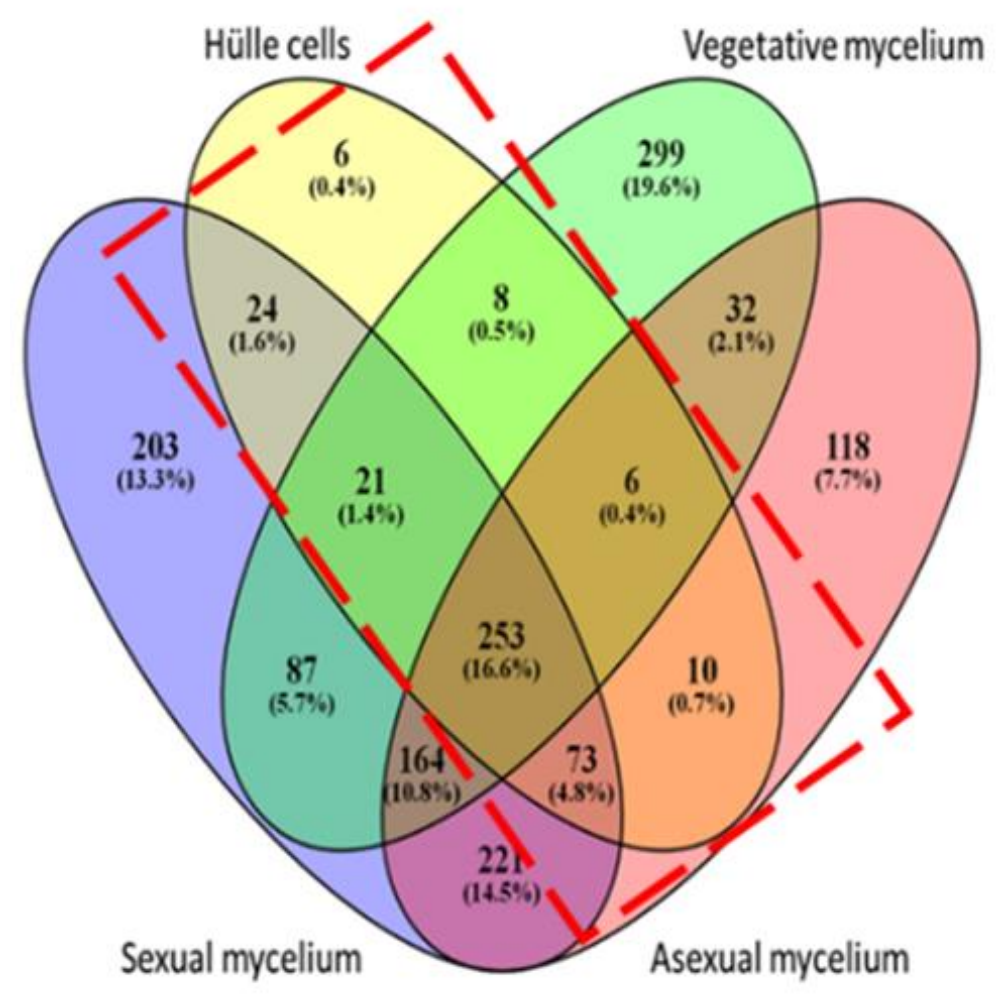

Figure 24. Comparative analysis of identified proteins from surface cultures.

A. nidulans wild-type (FGSC A4, ve $A^{+}$) was used for the analysis. The figure shows a Venn diagram of identified proteins of enriched surface Hülle cells, sexual mycelium, asexual mycelium and vegetative mycelium. Vegetative mycelium was grown in submerged liquid cultures and enabled to obtain the sufficient amount of mycelia for the analysis. The Venn diagram contains the 1525 proteins that were identified within the different mycelia types and surface Hülle cells from the first proteomic approach. Proteins that could be identified in two or more biological replicates and with two or more peptides per proteins were used for the analysis. The red rectangle represents the 401 proteins found in surface Hülle cells after 3, 5 and 7 days of inoculation. 


\subsubsection{Comparative proteomics reveal six proteins found in enriched Hülle cells from solid agar plates}

Comparing the proteome of surface Hülle cells enriched from solid agar plates to the proteome of different mycelia types mentioned above revealed in this study six proteins which were identified only in surface Hülle cells enriched from solid agar plates. The specific proteins and their putative function are listed in Table 6. Two transmembrane proteins (AN2601 and AN9392) predicted to belong to the major facilitator superfamily (MSF) were identified in surface Hülle cells three, five and seven days after inoculation. A putative peptidase (AN3407) with a predicted serine-type peptidase activity was also found after five and seven days in Hülle cells. The HexA (AN4695) putative woronin body protein was also identified at the same time points. Hülle cells and the subtending hyphae are connected via two distinct types of septa. The inner one is a single perforate septum where woronin bodies often can be observed (Ellis et al.,1973). Woronin bodies were also found to be associated with septal pores of vegetative hyphae (Beck and Ebel 2013). The HexA protein was identified in one biological replicate from a vegetative mycelium and sexual mycelium. Only proteins identified in two or more biological replicates were considered for the analysis. Therefore, the HexA protein was filtered out from vegetative and sexual mycelium. In this study, a protein with an ankyrin repeat containing domain protein (AN8434) and a putative tyrosinase protein (AN8435) was observed in surface Hülle cells after five and seven days.

The biological function of the transporter protein (AN2601) was only identified in Hülle cells from solid agar plate cultures. It was studied in more detail because transporters are considered to be crucial to transport nutrition and other molecules across Hülle cells and thereby, most probably, supporting the cleistothecia (Wei et al., 2004, Pantazopoulou et al., 2007). Additionally, the cellular localization of the ankyrin repeat containing domain protein (AN8434) and the putative tyrosinase protein (AN8435) identified in Hülle cells from surface and liquid media were studied in detail as these two proteins were uniquely found in Hülle cells. This finding shows that surface Hülle cells comprise only few proteins that were not overlapping to other fungal tissues. 
Table 6. Comparative proteomics revealed six proteins that were identified in the enriched Hülle cells.

Only proteins identified in two or more biological replicates and with two or more peptides per protein were considered for the analysis. Numbers in brackets represent the average of spectral counts from three biological replicates. The yellow colour represents the six proteins found in the Venn diagram (Figure 24). The entire list of proteins identified from solid agar plate cultures is presented in Supplementary table 3.

\begin{tabular}{|c|c|c|c|c|c|c|}
\hline Gene ID & Description & $\begin{array}{l}\text { Found in } 3 \\
\text { days Hülle } \\
\text { cells }\end{array}$ & $\begin{array}{l}\text { Found in } 5 \\
\text { days Hülle } \\
\text { cells }\end{array}$ & $\begin{array}{l}\text { Found in } 7 \\
\text { days Hülle } \\
\text { cells }\end{array}$ & Orthologs & $\begin{array}{l}\text { Phenotypes and localization in Hülle } \\
\text { cells. Literature is cited. }\end{array}$ \\
\hline \multicolumn{7}{|c|}{ Transporter } \\
\hline $\begin{array}{l}\text { AN2601 } \\
\text { (MphA) }\end{array}$ & Major facilitator superfamily & & $\mathrm{X}(8)$ & $\mathrm{X}(8)$ & $\begin{array}{l}\text { Saccharomyces cerevisiae } \\
\text { MaL31 maltose permease } \\
\text { Aspergillus fumigatus putative } \\
\text { MFS maltose transporter } \\
\text { Afu4g00150 }\end{array}$ & $\begin{array}{l}\text { Knockout effects cleistothecia } \\
\text { maturation, growth and development in } \\
\text { Aspergillus nidulans. Phenotypes in } \\
\text { other fungal species are unknown }\end{array}$ \\
\hline AN9392 & Major facilitator superfamily & $\mathrm{X}(7)$ & $\mathrm{X}(4)$ & & $\begin{array}{l}\text { Saccharomyces cerevisiae TnA1 } \\
\text { nicotinic acid permease }\end{array}$ & No literature available \\
\hline \multicolumn{7}{|c|}{ Cellular process } \\
\hline AN3407 & $\begin{array}{l}\text { Protein with a predicted } \\
\text { serine-type peptidase } \\
\text { domain }\end{array}$ & & $\mathrm{X}(25)$ & $X(29)$ & $\begin{array}{l}\text { Neurospora crassa NCU05016 } \\
\text { predicted serine-type } \\
\text { endopeptidase acitivity }\end{array}$ & No literature available \\
\hline $\begin{array}{l}\text { AN4695* } \\
\text { (HexA) }\end{array}$ & Woronin body protein & & $\mathrm{X}(8)$ & $\mathrm{X}(7)$ & $\begin{array}{l}\text { Aspergillus fumigatus woronin } \\
\text { body major protein }\end{array}$ & $\begin{array}{l}\text { Ellis et al., 1973. In Hülle cells one can } \\
\text { find woronin bodies }\end{array}$ \\
\hline $\begin{array}{l}\text { AN8434 } \\
\text { (AnkG) }\end{array}$ & $\begin{array}{l}\text { Ankyrin repeat domain } \\
\text { protein }\end{array}$ & & $X(4)$ & $X(4)$ & $\begin{array}{l}\text { Neurospora crassa NCU5316 } \\
\text { ankyrin-like protein }\end{array}$ & $\begin{array}{l}\text { Ankyrin repeat domain protein (AN8434) } \\
\text { is localized to the subtending hyphae of } \\
\text { Hülle cells }\end{array}$ \\
\hline AN8435 & Tyrosinase domain protein & & $X(2)$ & $\mathrm{X}(3)$ & $\begin{array}{l}\text { Aspergillus oryzae MelB } \\
\text { tyrosinase associated with } \\
\text { melanization }\end{array}$ & $\begin{array}{l}\text { AN8435 is localized in Hülle cells and } \\
\text { most probably in an unstable form }\end{array}$ \\
\hline
\end{tabular}

*The HexA protein was identified in one biological replicate from a vegetative mycelium and sexual mycelium. 


\subsubsection{Surface Hülle cells contain increased enzyme levels for the mobilization of complex sugar molecules}

Whithin the next two sections 24 proteins common between Hülle cells and sexual mycelium are discussed. Six of these proteins are enzymes involved in carbohydrate metabolism (Table 7). Glucanase MutA (AN7349) was found in Hülle cells and sexual mycelium at all three time points. This protein is known to be strongly expressed in Hülle cells (Wei et al., 2001). Additionally, another glucanase AgnB (AN3790) was identified. It is thought that additional enzymes for the mobilization of different carbon sources are available during sexual development and are found in Hülle cells (Wei et al., 2001). Putative glucoamylase GlaA (AN11143) and the glucosidase AgdC (AN0941) with a predicted role in the starch and maltose metabolism were identified. This result shows that Hülle cells contain various glucanases that are involved in the mobilization of carbohydrates. Hülle cells are most probably involved in the mobilization of carbohydrates and therefore, enzymes are needed in this process.

\subsubsection{Enzymes encoded by the monodictyphenone ( $m d p)$ / xanthone (xpt) gene clusters were found in Hülle cells and sexual mycelium from solid agar plates}

Six enzymes out of the 24 proteins shown in Table 7 found in sexual mycelium and enriched Hülle cells are encoded by the monodictyphenone ( $m d p)$ as well as the xanthone (xpt) gene cluster (MdpL (AN10023), AN7999 (a putative oxidoreductase), XptC (AN7998), XptB (AN12402), MdpH (AN10022), MdpG (AN0150)). In a previous work it could be demonstrated that the transcripts of 10 genes within the $m d p$ and $x p t$ gene clusters are specifically expressed during sexual development (Bayram et al., 2016). Five enzymes encoded by the $m d p$ and the xpt gene clusters were found again in the second approach in vegetative mycelium from submerged liquid conditions where Hülle cell formation occurred (MdpL (AN10023), XptB (AN12402), MdpG (AN0150), XptC (AN7998) and AN7999 (a putative oxidoreductase). The results of the identified proteins in submerged liquid cultures will be presented in the next chapter. This finding shows that enzymes encoded by the $m d p / x p t$ gene clusters are present in Hülle cells grown on surface and liquid cultures as well as in sexual mycelium. 
Table 7. 24 proteins that were common between sexual mycelia and Hülle cells and were identified from solid agar plate cultures.

Only proteins identified in two or more biological replicates and with two or more peptides per protein were considered for the analysis. Numbers in brackets represent the average of spectral counts from three biological replicates. The grey colour represents the 24 proteins found in the Venn diagram (Figure 24). The entire list of proteins identified from solid agar plate cultures is presented in Supplementary table 3.

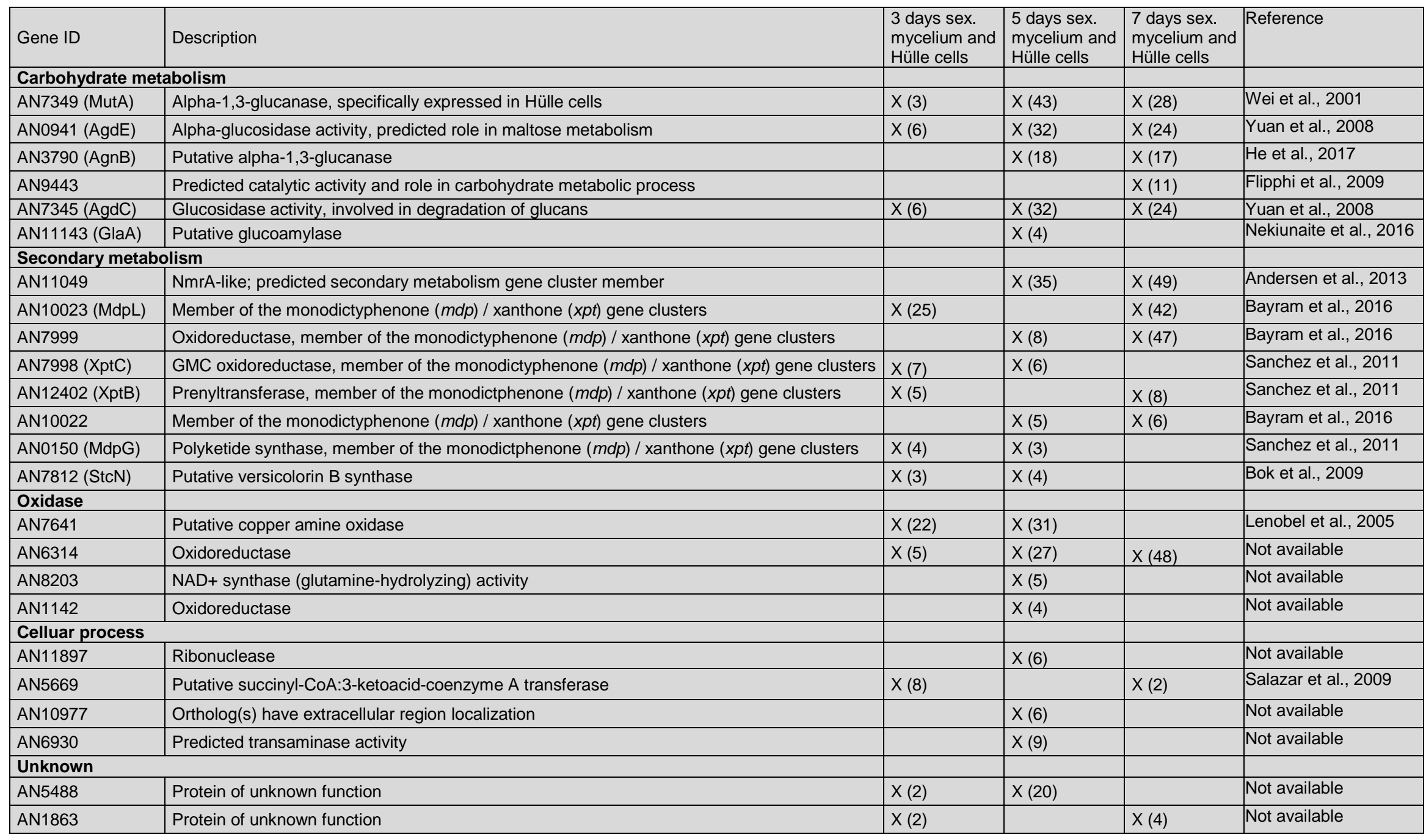




\subsubsection{Proteins encoded by the xanthone (xpt) gene cluster are enriched in the cytoplasm of Hülle cells}

Hülle cells might produce specific secondary metabolites to protect the cleistothecia from fungivors. It is known that xanthones are secondary metabolites with antimicrobial activities (Chen et al., 2017, Noordin et al., 2016). To gain more insight into the production of an antimicrobial agent in Hülle cells the localization of enzymes encoded by the xanthone (xpt) secondary metabolite gene cluster was further investigated. Monodictyphenone represents a precursor for the production of xanthones. As an example of the 24 proteins that were common between Hülle cells and sexual mycelia the prenyltransferase XptB and the oxidoreductase XptC were found and their localization was investigated (Figure 25). The second prenyltransferase XptA was only found in a sexual mycelium and is listed in Supplementary table 4 . The criteria concerning the localization investigation were the presence of the protein in both sexual mycelium and Hülle cells in the proteomics approach. Therefore, the localization of XptA is not shown.

The prenyltransferase XptB and the oxidoreductase XptC are involved in the conversion of monodictyphenone into xanthones, which are antimicrobial agents. Localization of the prenytransferase XptB and the oxidoreductase XptC involved in the conversion of monodictyphenone into xanthones in Hülle cells was investigated and their presence could be confirmed (Figure 25). Hülle cells were enriched from sexual mycelium using the cleistothecia-rolling technique and the localization of XptB::GFP, XptC::GFP was observable in the cytoplasm of Hülle cells. The fusion proteins were mainly observed in the center of Hülle cells. XptB::GFP and XptC::GFP seem to be mainly equally distributed in the cytoplasm of Hülle cells. XptB::GFP and XptC::GFP was not clearly observable in the membrane. This suggests that proteins identified by the applied enrichment of Hülle cells correlate between the proteomic approach and the microscopic data in their fungal localization. 


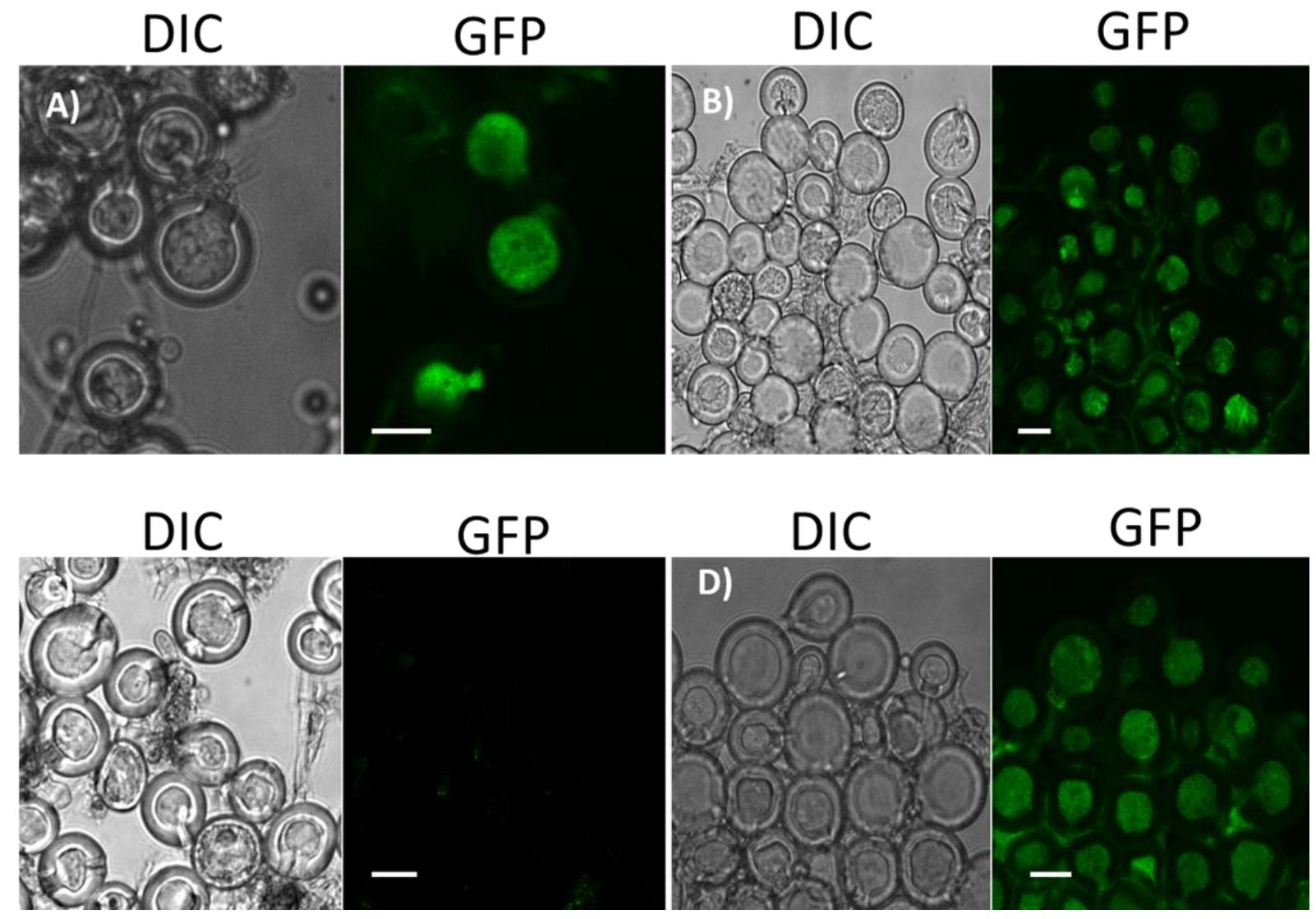

Figure 25. Enzymes encoded by the xanthone (xpt) gene cluster are localized in Hülle cells.

$X \mathrm{ptB}:$ :GFP and XptC::GFP are observable in the cytoplasm of Hülle cells. Fluorescence microscopy of Hülle cells: A) xptB::gfp;lysA $\Delta ; n k u A \Delta$ (AGB1086) B) xptC::gfp; nkuA $($ AGB1088) C) $n k u A \Delta$ (AGB552) parental strain D) A strain expressing GFP constitutively (AGB596). Scale bar is $10 \mu \mathrm{m}$.

Additionally, the localization of $\mathrm{XptB}$ and $\mathrm{XptC}$ was apparent during initial vegetative growth. Therefore, vegetative hyphae in submerged liquid cultures were used to visualize the presence of the fusion proteins. The localization of the fusion proteins XptB::GFP and XptC::GFP could be confirmed mainly in the cytoplasm of vegetative hyphae(Figure 26). This suggests that proteins encoded by the xanthone (xpt) gene cluster are found not only in Hülle cells but also in vegetative hyphae suggesting that these proteins are found during initial vegetative growth. 

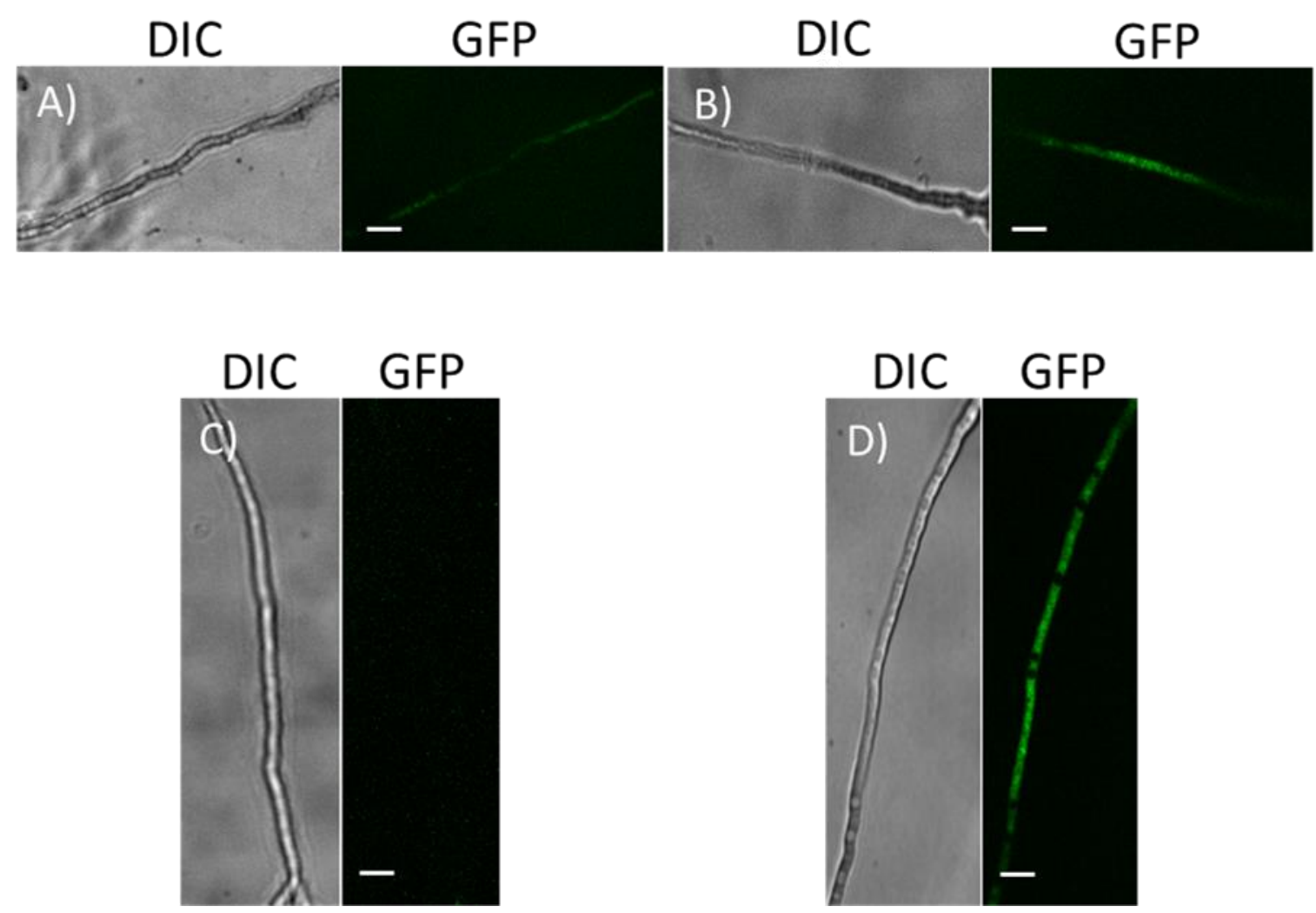

Figure 26. Enzymes encoded by the xanthone (xpt) gene cluster are localized in vegetative mycelium.

XptB::GFP and XptC::GFP are localized in the cytoplasm of vegetative hyphae. Fluorescence

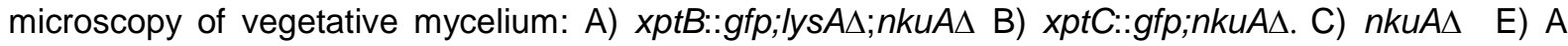
strain expressing GFP constitutively (AGB596). Scale bare is $20 \mu \mathrm{m}$

The protein sequence of green fluorescent protein (GFP) consists of 239 amino acids with a predicted molecular mass of $26.9 \mathrm{kDa}$. The XptB protein consists of 463 amino acids with a predicted molecular mass of $52.4 \mathrm{kDa}$. The XptC protein consists of 622 amino acids with a predicted molecular mass of $67.8 \mathrm{kDa}$.

Western hybridization experiments showed that XptB::GFP is detectable as expected around $79 \mathrm{kDa}$ and that XptC::GFP is detectable as expected around $95 \mathrm{kDa}$ in three and five day old sexual mycelium with high amounts of Hülle cells plus a three day old vegetative mycelium (Figure 27). A strain expressing GFP constitutively (AGB596) served as a positive control where GFP was detectable around $27 \mathrm{kDa}$. The parental $n k u A \Delta$ (ABG552) strain served as negative control where GFP was not observable. A proteolytic cleavage product of XptB::GFP was detectable around $27 \mathrm{kDa}$. This is most likely a degradation product of the full-length XptB::GFP fusion protein and represents the degraded GFP product. This result implies that the prenytransferase XptB and the oxidoreductase XptC is found in the cytoplasm of Hülle cells and that these proteins are present in vegetative and sexual mycelia. 


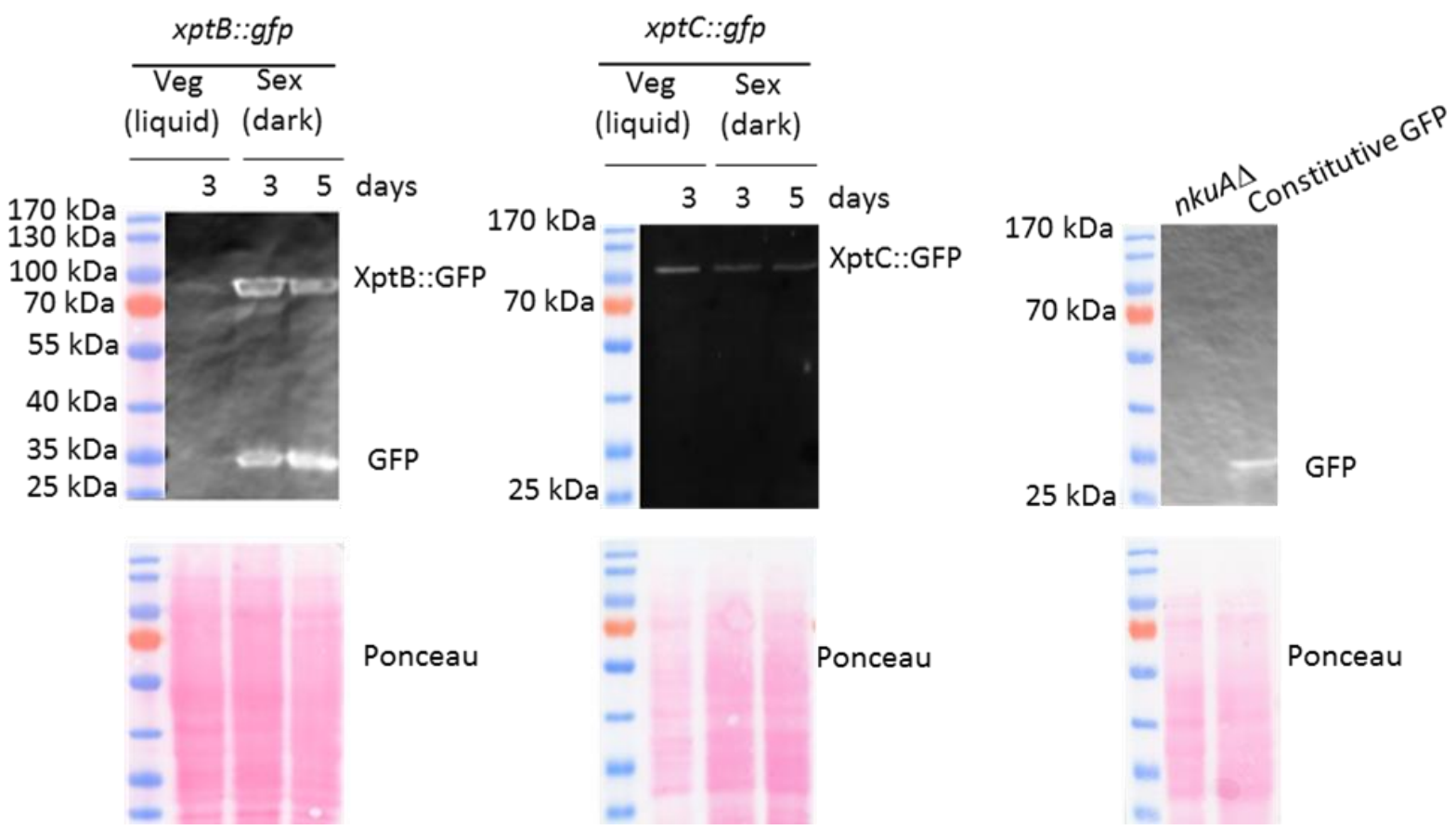

Figure 27. The fusion proteins XptB::GFP and XptC::GFP are found in sexual mycelium with high amounts of Hülle cells and a vegetative mycelium.

Western hybridization of vegetative and sexual mycelium of xptB::gfp; lysA $\Delta ; n k u A \Delta$ (AGB1086) and $x p t C:: g f p ; n k u A \Delta$ (AGB1088). Vegetative mycelium was harvested after 3 days. Sexual mycelium with high amounts of Hülle cells was harvested 3 and 5 days after inoculation. The XptB protein consists of 463 amino acids with a predicted molecular mass of $52.4 \mathrm{kDa}$. The XptC protein contains 622 amino acids with a predicted molecular mass of $67.8 \mathrm{kDa}$. In order to detect XptB::GFP (xptB::gfp; lysA $\Delta$; $n k u A \Delta, A G B 1086$ ) and XptC::GFP (xptC::gfp; nkuA $\Delta$, AGB1088) a primary $\alpha$-GFP antibody (sc-9996; Santa Cruz) was used followed with an incubation of an $\alpha$-mouse secondary antibody (G21234, Invitrogen). The fusion protein XptB::GFP was detected as expected around $79 \mathrm{kDa}$ and XptC::GFP was detected as expected around $95 \mathrm{kDa}$. A strain expressing GFP constitutively served as a control where GFP was detectable around $27 \mathrm{kDa}$. Proteolytic cleavage product of XptB::GFP was detectable around $27 \mathrm{kDa}$. This is most likely a degradation product of the full-length XptB::GFP fusion protein. The parental strain $n k u A \Delta$ served as a negative control where GFP and the fusion proteins were not detectable.

\subsubsection{Comparative proteomics revealed that the proteome of surface Hülle cells overlaps to other fungal tissues besides of a sexual mycelium}

As shown in the Venn diagram (Figure 24) the proteome of surface Hülle cells overlapped to other fungal tissues such as asexual and vegetative mycelium besides sexual mycelium. Ten proteins were identified in Hülle cells and asexual mycelium (Table 8). These proteins were unidentified in Hülle cells grown in liquid media. This suggests that these proteins are only present during surface growth. Since these proteins were unidentified in Hülle cells grown in liquid media in the second proteomic 
approach the focus was not laid on these proteins. Proteins that were common in Hülle cells and vegetative mycelium are listed in Table 8 . These proteins were identified in Hülle cells grown in liquid media and are discussed in the context of core proteome of both types of Hülle cells within the next chapter. Data reveal that the proteome of surface Hülle cells overlaps to that of other fungal tissues besides sexual mycelium.

Table 8. Overlapping proteins of Hülle cells (HC), asexual (Asex.) and vegetative mycelium (Veg.). The listed proteins are found in the red rectangle of the Venn diagram of Figure 16. Only proteins identified in two or more biological replicates and with two or more peptides per protein were considered for the analysis. Six proteins are listed and represent the proteins with the highest spectral counts. Numbers in brackets represent the average of spectral counts from three biological replicates. Six proteins out of ten are listed with the highest spectral counts, that were common in Hülle cells and asexual mycelium. The orange colour represents proteins found in Hülle cells and asexual mycelium. Six proteins out of eight are listed with the highest spectral counts, that are common in Hülle cells and vegetative mycelium. The green colour represents the proteins that were found in Hülle cells and vegetative mycelium.

\begin{tabular}{|c|c|c|c|c|c|}
\hline \multicolumn{6}{|c|}{ Hülle cells \& asexual mycelium } \\
\hline Gene ID & Function & 3 days HC \& Asex. & 5 days HC \& Asex. & 7 days HC \& Asex. & Reference \\
\hline AN5324 (DlpA) & Dehydrin-like protein & $\mathrm{X}(9)$ & $\mathrm{X}(9)$ & $X(6)$ & Wartenberg et al., 2012 \\
\hline AN5004 & Induced in light & $\mathrm{X}(2)$ & $\mathrm{X}(30)$ & $\mathrm{X}(7)$ & Ruger-Herreros et al., 2011 \\
\hline AN6856 & Up-regulated in atm $\Delta$ & $\mathrm{X}(5)$ & $X(6)$ & & Malavazi et al., 2007 \\
\hline AN5015 (ConJ) & Induced in light & $\mathrm{X}(2)$ & $X(8)$ & $X(2)$ & Ruger-Herreros et al., 2011 \\
\hline AN5971 & Induced in light & $\mathrm{X}(7)$ & $X(4)$ & & Ruger-Herreros et al., 2011 \\
\hline AN1362 & Cue5 ortholog & & $X(4)$ & & Not available \\
\hline \multicolumn{6}{|c|}{ Hülle cells \& vegetative mycelium } \\
\hline Gene ID & Function & 3 days HC \& Veg. & 5 days HC \& Veg. & 7 days HC \& Veg. & Reference \\
\hline AN1182 (BenA) & Beta-tubulin & $\mathrm{X}(5)$ & $X(4)$ & $X(23)$ & Oakley et al., 2004 \\
\hline AN4236 & $\begin{array}{l}\text { Proteasome } \\
\text { regulatory particle }\end{array}$ & $\mathrm{X}(3)$ & & $X(5)$ & Not available \\
\hline AN6688 (AspB) & Putative Septin B & $\mathrm{X}(7)$ & & $\mathrm{X}(2)$ & $\begin{array}{l}\text { Hernández-Rodríguez et } \\
\text { al.,2012 }\end{array}$ \\
\hline AN2918 (Cct4) & $\begin{array}{l}\text { Chaperonin complex } \\
\text { component }\end{array}$ & $\mathrm{X}(3)$ & & $\mathrm{X}(3)$ & Malavazi et al., 2007 \\
\hline AN4159 (GlnA) & $\begin{array}{l}\text { Glutamate-ammonia } \\
\text { ligase }\end{array}$ & $x(4)$ & & & Margelis et al., 2001 \\
\hline AN2149 (Cct1) & Chaperonin & $X(2)$ & & $X(2)$ & Malavazi et al. 2006 \\
\hline
\end{tabular}




\subsubsection{Functional annotation reveals that surface Hülle cells are highly involved in carbohydrate and amino acid metabolism}

In order to perform a gene ontology (GO) annotation based on a multiple NCBI blast search for biological functions of all 401 proteins found in surface Hülle cells the highquality functional annotation tool Blast2GO was used (Conesa et al., 2005). The largest subsegment of the pie chart with the GO term carbohydrate metabolic process revealed that Hülle cells are highly involved in the carbohydrate metabolism (Figure 28). The presence of enzymes to degrade certain carbohydrates, such as $\alpha-1,3-$ glucanase and other glucanases in Hülle cells most probably represents an additional energy source to support the energy-consuming process of the development of cleistothecia. The second largest subsegment with the GO term amino acid metabolism process together with the GO terms translation plus generation of precursor metabolites and energy highlights that Hülle cells are necessary to promote growth and development. In Hülle cells one can find the laccase type II enzyme CpeA. It is presumed that laccase acts on phenolic compounds in Hülle cells, leading to the generation of reactive oxygen species (ROS), (Scherer et al., 2002). The subsegment with the GO term response to stress reveals that Hülle cells have to deal with reactive oxygen species. The subsegment with the GO term secondary metabolite process shows that Hülle cells are involved in this process. Enzymes encoded by the monodictyphenone $(m d p)$ / xanthone $(x p t)$ gene clusters were found in the enriched Hülle cell fraction and sexual mycelium. This points out that the proteome of surface Hülle cells comprise high amounts of proteins involved in carbohydrate and amino acid metabolism.

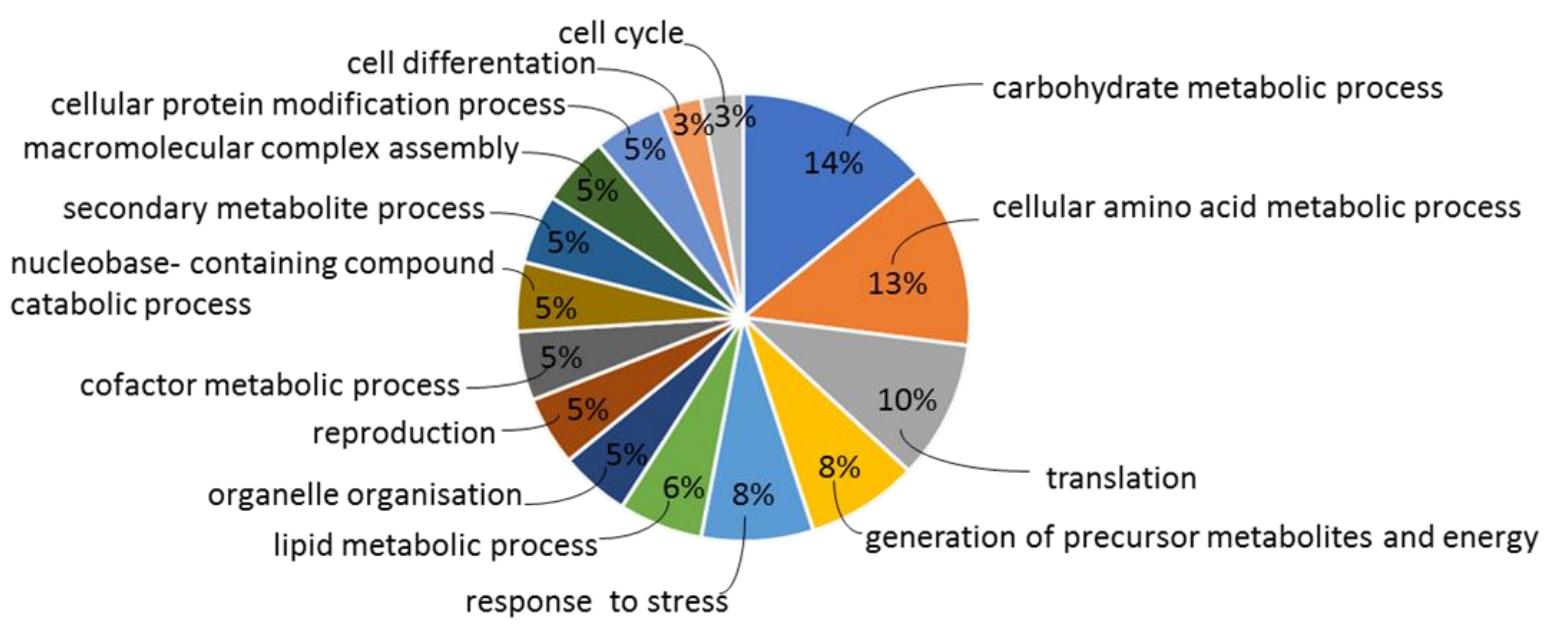

Figure 28. Functional annotation of identified proteins found in surface Hülle cells.

Blast2GO was used to perform the functional annotation of all 401 proteins that were found in surface Hülle cells. The gene ontology (GO) annotations for biological functions and the percentages of all GO terms are shown. 


\subsection{Hülle cells from surface growth and liquid media differ in their composition by $28 \%$ beside a shared core proteome: Proteomes of Aspergillus nidulans development grown on surfaces compared to liquid cultures}

\subsubsection{Hülle cell formation in submerged liquid cultures for comparative proteomics}

A second proteomic approach (proteome experiment 2) from submerged cultures was performed to compare proteomes of Hülle cells from liquid cultures versus solid plates (Figure 29). Stable isotope labeling by amino acids in cell culture (SILAC) is a technique for the relative quantification of changes in protein abundances within complex mixtures (Schmitt et al., 2017). It was shown that the LaeA protein promotes Hülle cell formation and therefore the deletion of laeA leads to a significant reduction of Hülle cells (Sarikaya-Bayram et al., 2010).

In order to gain insight into the regulation of proteins involved in secondary metabolism and Hülle cell formation the second proteome approach was performed with a laeA $\Delta$ strain. In order to identify and quantify proteins in a laeA $\triangle$ mycelium with high and low amounts of Hülle cells from submerged cultures the gene lae $A$ was deleted in a lysine auxotroph strain. The deletion of the gene $I y s A$ that encodes a putative saccharopine dehydrogenase enabled the efficient incorporation of isotopically labeled lysines into proteins and with that a SILAC study could be performed.

In order to observe Hülle cells in submerged cultures the strains were cultivated for three days in liquid medium and labeled with isotopic lysine variants from the point on where the strains were inoculated. The parental strain lysA $\Delta$; nkuA $\Delta$ (AGB1092) was labeled with light lysine. The knockout strain lysA $\Delta$; laeA $\Delta$; nkuA $\triangle$ (AGB1074) was labeled with heavy lysine and the complementation strain lys $A \Delta$; laeA $A::$ laeA; nkuA $\Delta$ (AGB1076) was labeled with medium lysine. For a label swap experiment, the light and the heavy labels were exchanged. This serves as a control that allows to confirm that the isotopically labeled lysines do not influence the analysis. 
Hülle cells from submerged liquid cultures

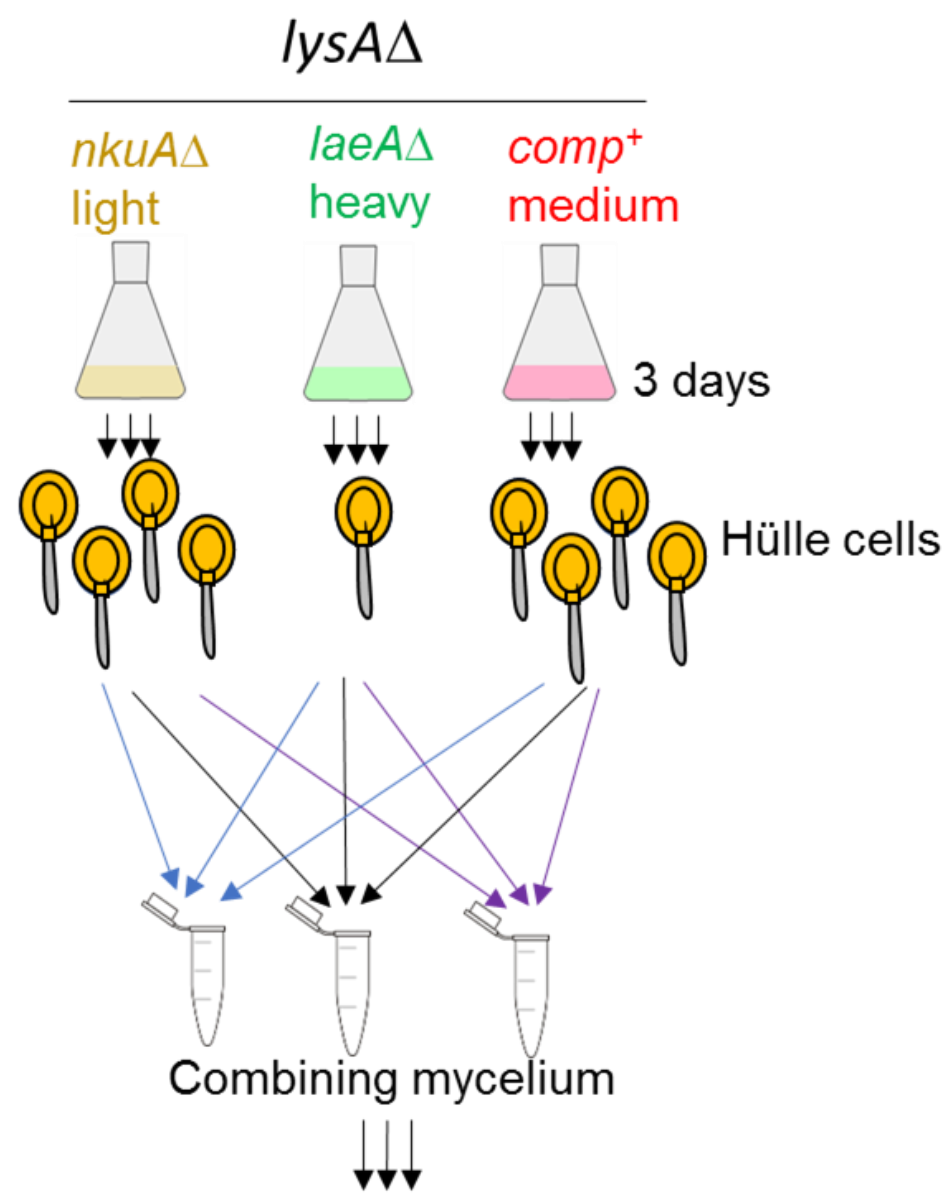

Protein extraction, trypsin digestion \& MS

Figure 29. Proteomics workflow for analyzing enriched Hülle cells from submerged cultures. For the second proteomic approach (Proteome experiment 2) three lysine auxotrophic strains were

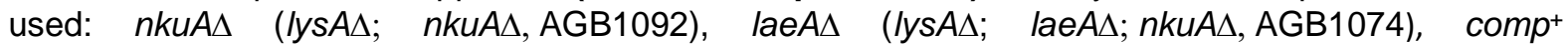

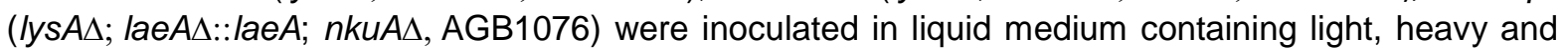
medium labeled lysine. The strains were grown for three days and Hülle cells were observed in the hyphal balls of vegetative mycelium. The amount of $300 \mathrm{mg}$ of each mycelium was pooled together and proteins were extracted and digested into peptides. The experiment was performed with three biological replicates and is highlighted with three arrows in this figure.

After growing the three strains in submerged conditions for three days $300 \mathrm{mg}$ mycelia of each individual labeled strain were pooled together and proteins were extracted and digested as described (Shevchenko et al., 1996). Peptide analytics were done with a liquid chromatography (LC) coupled to an Orbitrap Velos Pro ${ }^{\mathrm{TM}}$ Hybrid Ion TrapOrbitrap mass spectrometer (MS). The labeled peptides of the samples allowed accurate quantification of peptide ratios relative to each other. The percentage of observable Hülle cells was determined in the hyphal balls of vegetative mycelium and almost no Hülle cells could be observed in the laeA $\Delta$ strains in contrast to the parental and the complementation strains (Figure 30). 

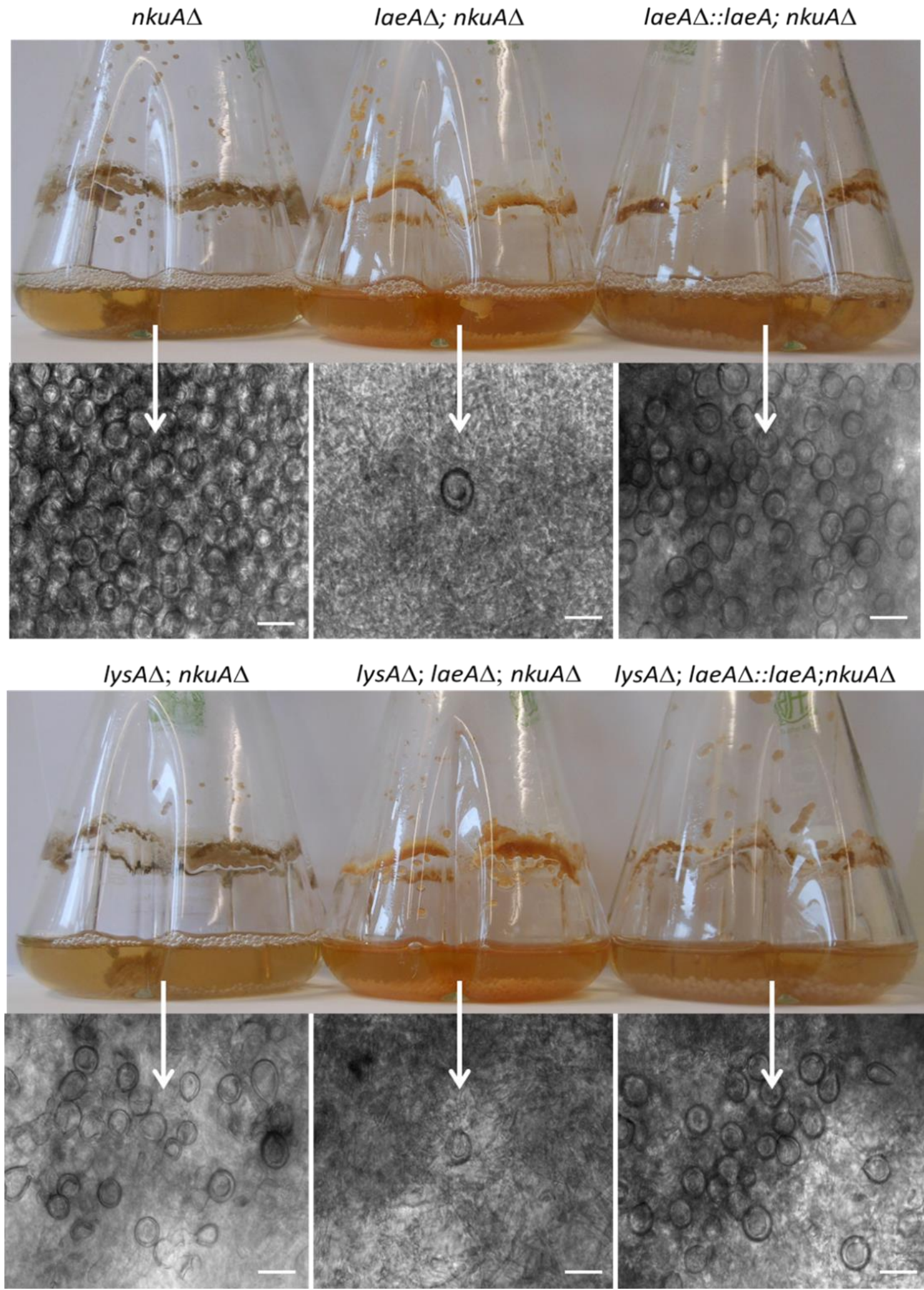

Figure 30. Lysine prototroph and auxotroph laeA $\Delta$ strains for the quantitative analysis of Hülle cells under submerged liquid conditions.

Hülle cells were observed in submerged cultures on day 3 after inoculation. High amounts of Hülle cells were observed in the lysine prototrophic nkuA $\triangle$ (AGB552) strain with an additional unknown mutation; as well as in the lysine auxotrophic lysA $\Delta$; nkuA $(A G B 1092)$ strain. The deletion of the gene laeA (AGB1073, AGB1074) in $n k u A \Delta$ as well as in lysA $\Delta$; nkuA $\Delta$ strain resulted in a significant reduction in the amount of Hülle cells. The phenotype could be restored in the complementation strains laeA $\Delta:: / a e A ; n k u A \Delta$ (AGB1075) and lysA $\Delta ; / a e A \Delta:: / a e A$; $n k u A \Delta$ (AGB1076) where high amounts of Hülle cells were present. Scale bar is $20 \mu \mathrm{m}$. 
The number of observable Hülle cells, determined within an area of $5 \mathrm{~mm}^{2}$ in the hyphal ball were counted and their number was put in relation to the parental and the complementation strain with three biological replicates (Figure 31A). Additionally, the dry weight of the submerged cultures was measured (Figure 31B). Vegetative mycelia were first filtered to remove the liquid media, then dried for 12 hours in a drying cabinet $\left(75^{\circ} \mathrm{C}\right)$. The dry weight was weighed and determined for three biological replicates. A prolongation of the drying time had no significant effect on the dry weight. The dry weight did not change in the laeA $\Delta$ lysine prototroph and auxotroph strain in comparison to the parental and the complementation strain.

A)

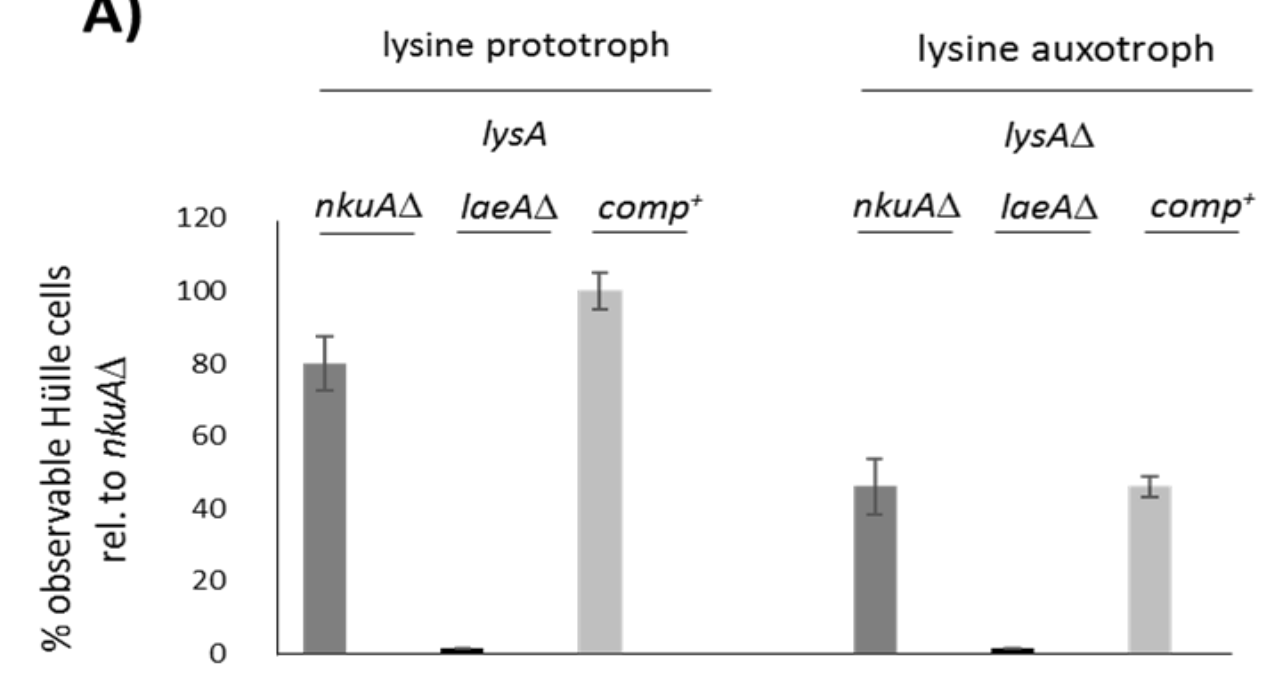

B)
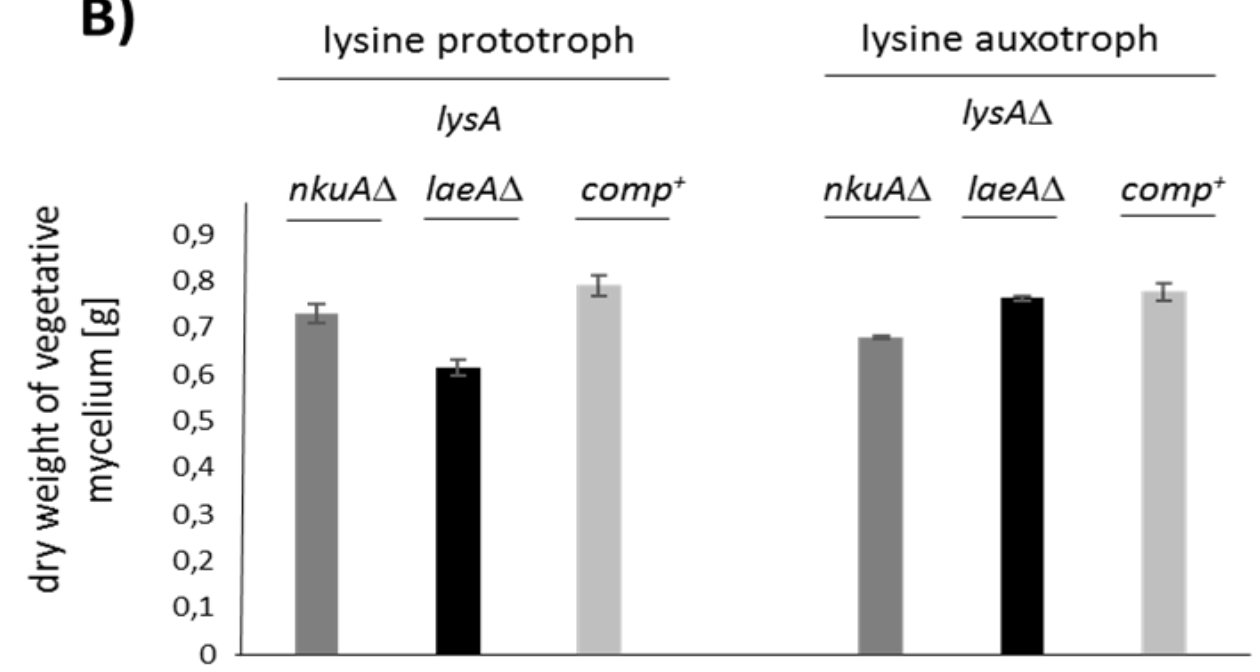

Figure 31. Determination of the number of Hülle cells in vegetative mycelia and determination of the dry weight of the vegetative mycelia.

A) The percentage of Hülle cells in the hyphal balls of vegetative mycelium of all strains were determined. The number of observable Hülle cells, determined within an area of $5 \mathrm{~mm}^{2}$ in the hyphal ball were counted and their number was put in relation to the parental and the complementation strain with three biological replicates. B) The dry weight of all strains was measured. Vegetative mycelia were dried for 12 hours in a drying cabinet $\left(75^{\circ} \mathrm{C}\right)$. The dry weight was weighed and determined. Three biological replicates were considered. 


\subsubsection{Submerged liquid cultures revealed the proteome for comparative analysis}

The proteome analysis of Hülle cells grown in submerged liquid cultures revealed a total number of 974 identified proteins (Supplementary Table 5). Three biological replicates were considered for the analysis. Only proteins identified in two or more biological replicates and with two or more peptides per protein were considered for the analysis. Comparing the proteomes of Hülle cells from solid agar plates versus submerged liquid cultures revealed a common core proteome consisting of 286 proteins that represents $72 \%$ of overlapping identified proteins. Therefore, the proteome of Hülle cells from surface growth and liquid media differ in their composition by $28 \%$ that corresponds to 115 identified proteins. Two proteins identified in the proteome of a vegetative mycelium in submerged conditions were chosen for further investigation regarding their localization. Prenyltransferase NptA (AN11080) and the serine/threonine kinase RfeA (AN2943) could be identified and quantified in the SILAC approach. These two proteins involved in the process of secondary metabolism showed a significant reduction in quantity in a laeA $\Delta$ strain compared to the parental strain. A substantial reduction of Hülle cells in a laeA $\Delta$ strain could correlate with the absence of these two proteins. NptA and RfeA, therefore, were investigated regarding the localization of these two proteins to gain more insight into the secondary metabolism in Hülle cells. $72 \%$ as a result shows a high overlapping of proteins in the core proteome of Hülle cells grown in solid agar plates and liquid media.

\subsubsection{Quantification of proteins in submerged liquid cultures of a lae $A \Delta$ mycelium revealed two Hülle cells proteins}

Protein quantities of the prenyltransferase NptA (AN11080) and the serine/threonine kinase RfeA (AN2943) were reduced in laeAs (AGB1074) mycelium. These two proteins are involved in the process of secondary metabolism (De Souza et al., 2013, Oakley et al., 2017). It is known that LaeA is a key regulator of secondary metabolism and Hülle cell formation in A. nidulans (Bok and Keller 2004, Sarikaya-Bayram et al., 2010). 
SILAC, stands for stable isotope labeling of amino acids in cell cultures and was applied as a technique for the relative quantification of changes in protein abundance within complex mixtures. The $\log _{2}$ SILAC ratio was determined for the strains laeA $\Delta$ (AGB1074) in comparison to laeA (AGB1092). The following threshholds were set. In the range of a $\log _{2}$ SILAC ratio between -5.0 and -0.5 identified proteins are down-regulated. In the range of a $\log _{2}$ SILAC ratio between +0.5 and +5.0 identified proteins are up-regulated. In the range between a -0.5 and $+0.5 \log _{2}$ SILAC ratio identified proteins were unchanged.

The protein quantity of identified proteins that is significantly down-regulated in a laeA $\Delta$ vegetative mycelium in submerged liquid cultures is shown in Table 9. Proteins that are down-regulated in laeA $\Delta$ vegetative mycelium are involved in secondary metabolism (2 proteins, NptA and RfeA), amino acid metabolism (6 proteins). In addition, the quantity of tRNA charging enzymes (16 enymes), proteins that are required for protein folding (4), nuclear import protein (1), proteins that are involved in the carbohydrate metabolism (4) and proteins which are involved in metabolic processes (8) are reduced. The prenyltransferase NptA (AN11080) showed the most significant reduction in quantity in a laeA $\Delta$ mycelium (Table 9). Bok and co-workers showed that the prenyltransferase $t i d B$ is not expressed in a laeA $\Delta$ mycelium in comparison to the wild-type (Bok et al., 2006). The serine/threonine kinase RfeA (AN2943) is predicted to be involved in the regulation of secondary metabolism (De Souza et al., 2013). This kinase was significantly reduced in a laeA $\Delta$ mycelium (Table 9). A substantial reduction of Hülle cells in a laeA $\Delta$ strain could correlate with the reduction of the two proteins $\mathrm{NptA}$ and $\mathrm{RfeA}$. These two proteins were further analyzed in more detail to gain insight into the process of secondary metabolism in Hülle cells.

Table 9. Proteins that are down-regulated in a laeA $\Delta$ mycelium

SILAC is applied as a technique for the relative quantification of changes in protein abundance within complex mixtures. The protein quantity of the following proteins is reduced in a laeA $\Delta$ vegetative mycelium. These proteins are down-regulated in laeA $\Delta$ mycelium. The $\log _{2}$ SILAC ratio was determined for the strains laeA $\triangle$ (AGB1074) in comparison to laeA (AGB1092). The following threshholds were set. In the range of a $\log _{2}$ SILAC ratio between -5.0 and -0.5 identified proteins are down-regulated. In the range between a -0.5 and $+0.5 \log _{2}$ SILAC ratio identified proteins are unchanged. The $\log _{2}$ SILAC ratio for the complementation strain (laeAcomp ${ }^{+}$, AGB1076) in comparison to the parental laeA strain (AGB1092) is between -0.5 and +0.5 . The color scales represent $\log _{2}$ SILAC ratios. $\varnothing=$ median of $\log _{2}$ SILAC ratio, $\mathrm{SD}=$ standard deviation, $\mathrm{NaN}=$ not a number. Biological replicates are numbered 1-3. 
\begin{tabular}{lllllllllllllllll|ll}
-5 & -3.25 & -1.5 & -1.3 & -1 & -0.75 & -0.5 & -0.25 & 0 & 0.25 & 0.5 & 0.75 & 1 & 1.25 & 1.5 & 3.25 & 5
\end{tabular}

\begin{tabular}{|c|c|c|c|c|c|c|c|c|c|c|c|c|c|c|}
\hline \multirow[t]{2}{*}{ Gene ID } & \multirow[t]{2}{*}{ Description } & \multicolumn{3}{|c|}{ Spectral counts } & \multicolumn{3}{|c|}{ IaeAL/laeA } & \multirow[t]{2}{*}{$\varnothing$} & \multirow[t]{2}{*}{ SD } & \multicolumn{3}{|c|}{ laeAcomp+/laeA } & \multirow[t]{2}{*}{$\varnothing$} & \multirow[t]{2}{*}{ SD } \\
\hline & & 1 & 2 & 3 & 1 & 2 & 3 & & & 1 & 2 & 3 & & \\
\hline \multicolumn{15}{|c|}{ Secondary metabolimsm } \\
\hline AN11080 (NptA) & Prenyltransferase & 122 & 79 & 47 & -4.9 & -3.9 & -4.2 & -4.2 & 0.5 & -0.2 & -0.5 & 0.4 & -0.2 & 0.5 \\
\hline AN2943 (RfeA) & Kinase & 19 & 33 & 63 & -2.0 & -1.3 & -0.6 & -1.3 & 0.7 & -0.5 & -0.2 & -0.5 & -0.5 & 0.2 \\
\hline \multicolumn{15}{|c|}{ Amino acid metabolism } \\
\hline AN5591 & Aminotransferase & 21 & 63 & $\mathrm{NaN}$ & -3.6 & -3.9 & $\mathrm{NaN}$ & -3.8 & 0.2 & 0.5 & -0.1 & $\mathrm{NaN}$ & 0.2 & 0.3 \\
\hline AN2901 (AgaA) & Arginase & 28 & 99 & 173 & -3.0 & -1.9 & -2.3 & -2.5 & 0.6 & -0.5 & 0.2 & -0.6 & -0.5 & 0.4 \\
\hline AN4159 (GInA) & Glutamate-ammonia ligase & 367 & 384 & 481 & -3.1 & -1.0 & -0.5 & -2.1 & 1.4 & -0.4 & -0.2 & 0.5 & -0.2 & 0.5 \\
\hline AN5886 (LuA) & Isomerase & 46 & 60 & 218 & -1.9 & -1.0 & -1.7 & -1.5 & 0.5 & 0.0 & 0.0 & $\mathrm{NaN}$ & 0.0 & 0.0 \\
\hline AN0797 & Role in histidine metabolism & 20 & 41 & 71 & -1.7 & -1.1 & -0.7 & -1.4 & 0.5 & 0.0 & -0.4 & -0.1 & -0.1 & 0.2 \\
\hline AN4218 & Translation elongation factor & 384 & 845 & 1035 & -1.4 & -0.6 & -1.5 & -1.0 & 0.5 & 0.2 & 0.1 & -0.1 & 0.1 & 0.1 \\
\hline \multicolumn{15}{|c|}{ tRNA charging enzyme } \\
\hline AN0046 & Histidyl-tRNA ligase & 46 & 66 & 100 & -3.6 & -1.8 & -0.8 & -1.8 & 1.4 & -0.4 & -0.4 & 0.0 & -0.4 & 0.3 \\
\hline AN0705 & Isoleucine-tRNA ligase & 57 & 113 & $\mathrm{NaN}$ & -2.2 & -1.2 & $\mathrm{NaN}$ & -1.7 & 0.7 & -0.5 & -0.1 & $\mathrm{NaN}$ & -0.3 & 0.3 \\
\hline AN11125 & Glycine-tRNA ligase & 117 & 159 & $\mathrm{NaN}$ & -2.1 & -0.9 & $\mathrm{NaN}$ & -1.5 & 0.8 & -0.5 & -0.3 & $\mathrm{NaN}$ & -0.4 & 0.3 \\
\hline AN0057 & Tyrosine-tRNA ligase & 33 & 68 & 33 & -1.9 & -0.9 & -1.3 & -1.3 & 0.5 & -0.5 & -0.3 & $\mathrm{NaN}$ & -0.4 & 0.3 \\
\hline AN10475 & Tryptophan-tRNA ligase & 36 & 40 & $\mathrm{NaN}$ & -2.0 & -0.7 & $\mathrm{NaN}$ & -1.3 & 0.9 & -0.4 & -0.1 & $\mathrm{NaN}$ & -0.3 & 0.2 \\
\hline AN10474 & Tryptophan-tRNA ligase & 97 & 113 & 178 & -1.9 & -0.7 & -1.3 & -1.3 & 0.6 & -0.4 & -0.3 & 0.4 & -0.3 & 0.4 \\
\hline AN6368 & tRNA charging enzyme & 52 & 117 & 125 & -2.0 & -1.1 & -0.7 & -1.1 & 0.6 & -0.4 & -0.1 & 0.0 & -0.1 & 0.2 \\
\hline AN8224 & Glutamate-tRNA ligase & 60 & 101 & 171 & -2.0 & -1.0 & -1.0 & -1.0 & 0.6 & -0.5 & -0.3 & 0.3 & -0.3 & 0.4 \\
\hline AN3824 & Phenylalanine-tRNA ligase & 30 & 52 & 103 & -2.0 & -1.0 & -0.9 & -1.0 & 0.6 & -0.4 & -0.4 & 0.3 & -0.4 & 0.4 \\
\hline AN8867 & Serine-tRNA ligase & 83 & 104 & 147 & -1.2 & -1.0 & -1.0 & -1.0 & 0.1 & 0.5 & 0.1 & 0.0 & 0.1 & 0.3 \\
\hline AN3702 & Leucine-tRNA ligase & 73 & 115 & 213 & -2.3 & -0.8 & -0.9 & -0.9 & 0.8 & -0.4 & -0.2 & 0.2 & -0.2 & 0.3 \\
\hline AN4086 & Phenylalanine-tRNA ligase & 40 & 67 & 93 & -2.0 & -0.7 & -0.9 & -0.9 & 0.7 & -0.4 & -0.2 & 0.3 & -0.2 & 0.4 \\
\hline AN9419 & Alanine-tRNA ligase & 149 & 200 & 374 & -2.0 & -0.8 & -0.9 & -0.9 & 0.7 & -0.3 & 0.1 & 0.0 & 0.0 & 0.2 \\
\hline AN2150 & Proline-tRNA ligase & 149 & 225 & 329 & -1.8 & -0.7 & -0.9 & -0.9 & 0.6 & -0.4 & -0.1 & 0.3 & -0.1 & 0.3 \\
\hline AN1380 & Methionine-tRNA ligase & 60 & 114 & 148 & -1.8 & -0.8 & -0.7 & -0.8 & 0.6 & -0.3 & -0.3 & 0.2 & -0.3 & 0.3 \\
\hline AN10195 & Valine-tRNA ligase & 119 & 109 & 280 & -1.9 & -0.7 & -0.6 & -0.7 & 0.7 & -0.5 & -0.1 & 0.5 & -0.1 & 0.5 \\
\hline \multicolumn{15}{|c|}{ Protein folding } \\
\hline AN10202 (HscA) & Heat shock protein & 89 & 285 & $\mathrm{NaN}$ & -1.8 & -0.7 & -1.8 & -1.8 & 0.7 & -0.3 & 0.0 & $\mathrm{NaN}$ & -0.2 & 0.2 \\
\hline AN1047 & Heat shock protein & 136 & 186 & $\mathrm{NaN}$ & -1.7 & -0.7 & -2.1 & -1.7 & 0.7 & -0.2 & -0.3 & $\mathrm{NaN}$ & -0.2 & 0.1 \\
\hline AN2918 (Cct4) & Chaperonin complex & 46 & 48 & 102 & -1.6 & -0.7 & -1.7 & -1.6 & 0.6 & -0.1 & -0.2 & -0.5 & -0.2 & 0.2 \\
\hline AN2062 (BipA) & Chaperonin complex & 177 & 142 & 287 & -1.9 & -1.0 & -1.4 & -1.4 & 0.5 & 0.0 & 0.0 & -0.2 & 0.0 & 0.1 \\
\hline \multicolumn{15}{|c|}{ Nuclear import } \\
\hline AN5482 (Ran) & RAS-related nuclear protein & 54 & 38 & $\mathrm{NaN}$ & -1.6 & -0.7 & $\mathrm{NaN}$ & -1.1 & 0.7 & -0.2 & -0.1 & 0.3 & -0.1 & 0.3 \\
\hline \multicolumn{15}{|c|}{ Carbohydrate metabolism } \\
\hline AN6655 (GudC) & Glucose 1-dehydrogenase & 15 & 16 & 7 & -1.5 & -1.3 & -0.5 & -1.3 & 0.5 & 0.4 & -0.2 & 0.3 & 0.3 & 0.3 \\
\hline AN3223 (pfkA) & 6-phosphofructokinase & 184 & $\mathrm{NaN}$ & 431 & -1.9 & -0.7 & $\mathrm{NaN}$ & -1.3 & 0.9 & -0.1 & -0.2 & $\mathrm{NaN}$ & -0.1 & 0.1 \\
\hline AN7459 (HxkA) & Hexokinase & 53 & 121 & 146 & -2.3 & -1.2 & -0.7 & -1.2 & 0.8 & -0.3 & -0.5 & -0.2 & -0.3 & 0.2 \\
\hline AN0285 & 6-phosphogluconolactonase & 91 & 100 & 119 & -1.8 & -0.7 & -1 & -1.1 & 0.6 & -0.4 & -0.4 & -0.4 & -0.4 & 0.0 \\
\hline \multicolumn{15}{|c|}{ Metabolic process } \\
\hline AN4923 & HMG-CoA synthase & 7 & 49 & 212 & -5.0 & -2.6 & -2.3 & -2.6 & 1.5 & -0.5 & -0.4 & 0.5 & -0.4 & 0.6 \\
\hline AN0565 & Multifunctional enzyme & 61 & 91 & 458 & -2.0 & -0.9 & -2.2 & -2.0 & 0.7 & -0.5 & -0.4 & 0.3 & -0.4 & 0.4 \\
\hline AN3581 (TrxR) & Thioredoxin reductase & 100 & 105 & 184 & -2.1 & -1.1 & -1.7 & -1.7 & 0.5 & -0.5 & -0.3 & -0.4 & -0.4 & 0.1 \\
\hline AN9180 & Transketolase & $\mathrm{NaN}$ & 113 & 133 & $\mathrm{NaN}$ & -1.3 & -1.5 & -1.4 & 0.8 & $\mathrm{NaN}$ & -0.2 & 0.5 & 0.2 & 0.4 \\
\hline AN10220 (Ccp1) & Cytochrome c peroxidase & 25 & 29 & 57 & -2.4 & -1.2 & -0.7 & -1.2 & 0.9 & -0.5 & -0.5 & -0.4 & -0.5 & 0.1 \\
\hline AN0641 & TCTP family protein & 76 & 17 & $\mathrm{NaN}$ & -1.4 & -0.8 & $\mathrm{NaN}$ & -1.1 & 0.7 & 0.5 & 0.3 & $\mathrm{NaN}$ & 0.4 & 0.2 \\
\hline AN0232 (UreD) & Nickel-binding protein & 24 & 45 & 43 & -2.2 & -1.0 & -0.7 & -1.0 & 0.8 & 0.0 & -0.3 & 0.5 & 0.0 & 0.4 \\
\hline AN7710 & Haloacid dehalogenase & 153 & 336 & 273 & -1.4 & -0.7 & -0.9 & -0.9 & 0.4 & 0.5 & 0.1 & -0.3 & 0.1 & 0.4 \\
\hline
\end{tabular}


The proteins that are up-regulated in a lae $A \Delta$ vegetative mycelium are shown in Table 10. The following four proteins are up-regulated in a laeA $\Delta$ mycelium e.g. alcohol oxidase, two alcohol dehydrogenases (AlcA and AlcB) and a choline oxidase. These proteins are most likely not found in Hülle cells since laeA $\Delta$ causes significant reduction in formation of Hülle cells.

Table 10. Proteins that are up-regulated in a laeA $\Delta$ mycelium

The protein quantity of the following proteins is increased in a laeA $\Delta$ vegetative mycelium. These proteins are up-regulated in laeA $\triangle$ mycelium. The $\log _{2}$ SILAC ratio was determined for the strains laeA $\Delta$ (AGB1074) in comparison to laeA (AGB1092). The following threshholds were set. In the range of a $\log _{2}$ SILAC ratio between +5.0 and +0.5 identified proteins are up-regulated. In the range between a 0.5 and $+0.5 \log _{2}$ SILAC ratio identified proteins are unchanged. The $\log _{2}$ SILAC ratio for the complementation strain (laeAcomp ${ }^{+}$, AGB1076) in comparison to the parental laeA strain (AGB1092) is between -0.5 and +0.5 . The color scales represent $\log _{2}$ SILAC ratios. $\varnothing=$ median of $\log _{2}$ SILAC ratios, $\mathrm{SD}=$ standard deviation, $\mathrm{NaN}=$ not a number. Biological replicates are numbered 1-3. Spectral counts (PSM) for three biological replicates are shown.

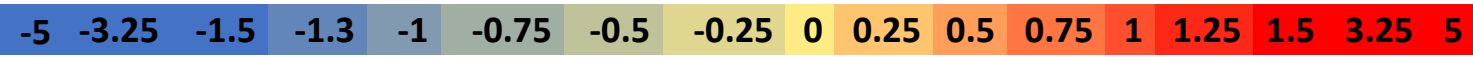

\begin{tabular}{|c|c|c|c|c|c|c|c|c|c|c|c|c|c|c|}
\hline Gene ID & Description & Spe & tral cou & ints & & $A \Delta / / a$ & & $\varnothing$ & SD & laeAc & $m p+1$ & IaeA & $\varnothing$ & SD \\
\hline & & 1 & 2 & 3 & 1 & 2 & 3 & & & 1 & 2 & 3 & & \\
\hline AN0567 & Alcohol oxidase & 149 & 315 & $\mathrm{NaN}$ & 4.2 & 4.4 & $\mathrm{NaN}$ & 4.3 & 0.1 & -0.5 & -0.3 & $\mathrm{NaN}$ & -0.4 & 0.3 \\
\hline AN3741 (AlcB) & Alcohol dehydrogenase II & 32 & 44 & 55 & 4.0 & 4.5 & $\mathrm{NaN}$ & 4.2 & 0.4 & 0.3 & 0.4 & $\mathrm{NaN}$ & 0.4 & 0.2 \\
\hline AN8979 (AlcA) & Alcohol dehydrogenase & 307 & $\mathrm{NaN}$ & 82 & 2.5 & $\mathrm{NaN}$ & 3.0 & 2.5 & 0.3 & 0.5 & $\mathrm{NaN}$ & -0.4 & 0.5 & 0.6 \\
\hline AN1429 (CodA) & Choline oxidase & 14 & 27 & 93 & 1.8 & 0.8 & 0.2 & 1.3 & 0.8 & 0.3 & -0.4 & 0.2 & -0.1 & 0.4 \\
\hline
\end{tabular}

\subsubsection{Quantitative determination of proteins in laeA $\Delta$ revealed that NptA is present in Hülle cells as well as in other fungal tissues}

NptA (nidulanin A prenyltransferase A, AN11080) is involved in the prenylation of the secondary metabolite nidulanin A (Oakley et al., 2017). In order to verify the localization of the prenyltransferase NptA in Hülle cells, a nptA::gfp; lysA $\Delta$; nkuA $\Delta$ (AGB1082) strain was used. Hülle cells were enriched from sexual mycelium using the cleistothecia-rolling technique and the localization of NptA::GFP was observable in the cytoplasm of Hülle cells (Figure 32). The parental strain lysA $\Delta ; n k u A \Delta$ (AGB1092) was used as a negative control. The strain laeA $\Delta ; n p t A:: g f p ; l y s A \Delta ; n k u A \Delta$ (AGB1083) was used to verify the reduced protein abundance of NptA in a laeA $\Delta$ mycelium. Fluorescence microscopy revealed that almost no NptA::GFP was observable in the remaining Hülle cells except for a weak autofluorescence. A strain expressing GFP constitutively served as a control where GFP was mainly observable in the cytoplasm of Hülle cells. 
A)
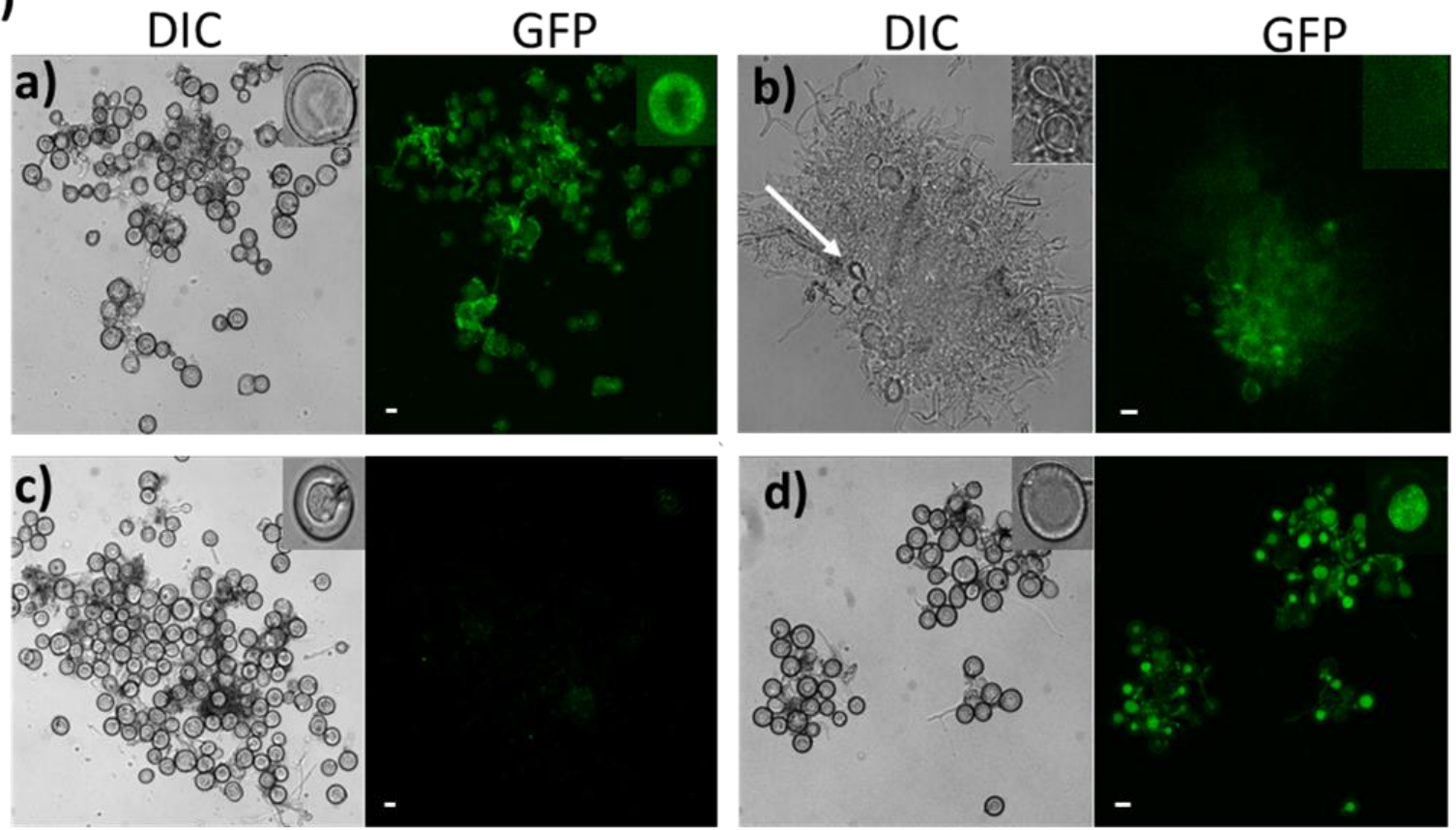

B)

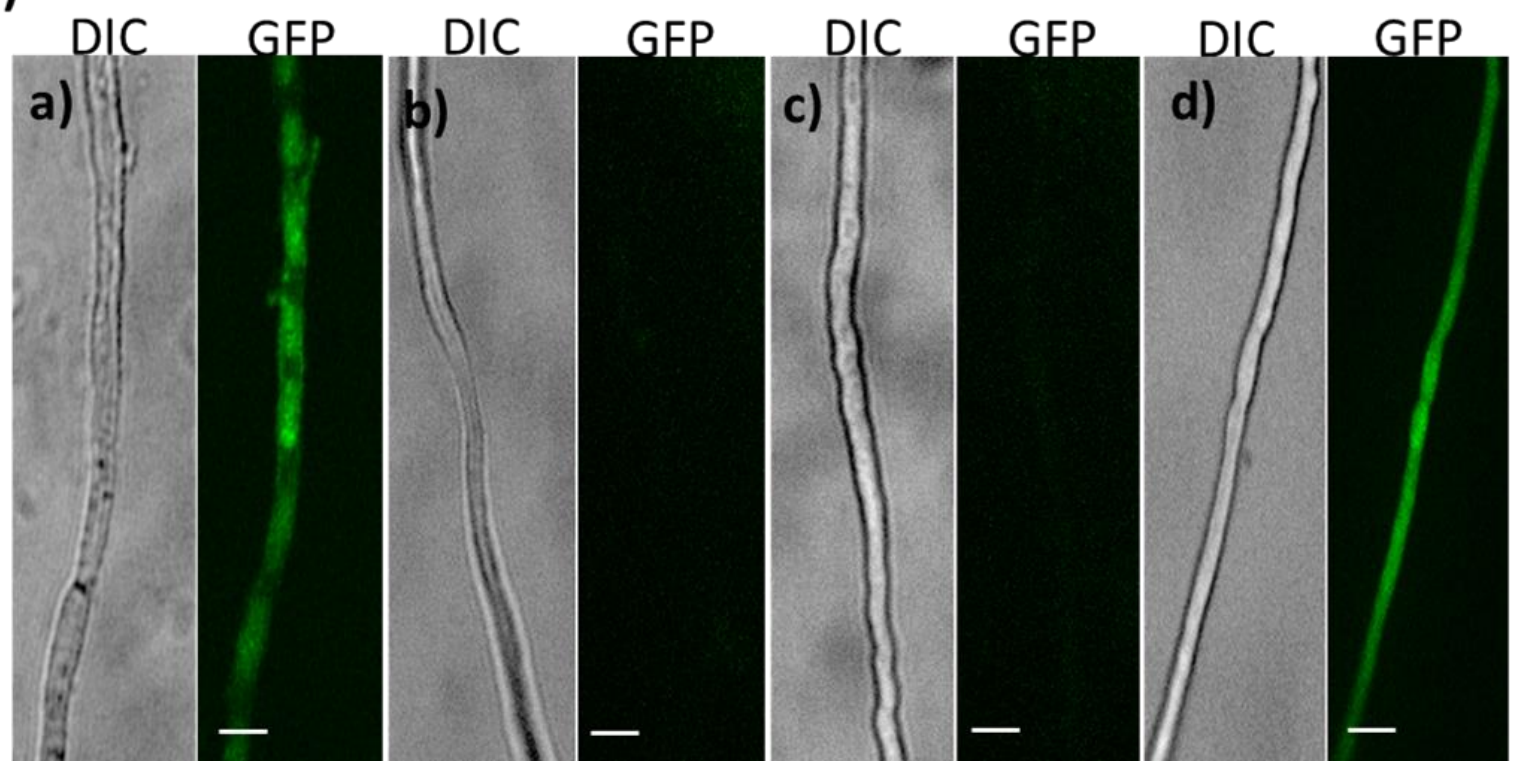

Figure 32. The prenyltransferase NptA is localized in the cytoplasm of Hülle cells.

A) Fluorescence microscopy pictures of Hülle cells: a) The picture shows the strain nptA::gfp; lysA ; $n k u A \Delta$ (AGB1082). NptA::GFP is localized to the cytoplasm of Hülle cells. b) The picture shows the strain laeA $\Delta$; nptA::gfp; lysA $\Delta$; $n k u A \Delta$ (AGB1083). Reduced NptA::GFP was observed in the remaining Hülle cells (white arrow) and in hyphae caused by laeA $\Delta$. c) The picture shows the strain

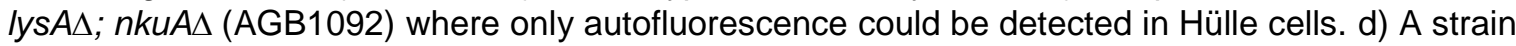
expressing GFP constitutively (AGB596) where GFP was mainly observable in the cytoplasm of Hülle cells. Scale bar is $10 \mu \mathrm{m}$. B) Fluorescence microscopy pictures of a vegetative hypha: a) $n p t A:: g f p ;$ lysA $\Delta ; n k u A \Delta$ where NptA::GFP was detectable b) laeA $\Delta ; n p t A:: g f p ; l y s A \Delta ; n k u A \Delta$ where NptA::GFP was significantly reduced. c) lys $A \Delta$; nkuA $\Delta$ where only autofluorescence could be detected. d) A strain expressing GFP constitutively where GFP was observable in the cytoplasm of the vegetative hypha. Scale bar is $20 \mu \mathrm{m}$. 
The protein quantity of NptA was significantly reduced in a laeA $\Delta$; lys $A \Delta ; n k u A \Delta$ strain. Western hybridization experiments revealed that the quantity of NptA::GFP protein is reduced in a laeA $\Delta ; n p t A:: g f p ;$ lys $A \Delta ; n k u A \Delta$ strain in a vegetative, sexual and asexual mycelium (Figure 33). The NptA protein consists of 434 amino acids with a predicted molecular mass of $48.9 \mathrm{kDa}$. NptA::GFP was detected as expected around $75 \mathrm{kDa}$. Additionally, degradation products of the NptA::GFP fusion protein were observable. A strain expressing GFP constitutively served as a positive control where GFP was detectable around $27 \mathrm{kDa}$. The parental $n k u A \Delta$ (ABG552) strain served as a negative control where GFP and the fusion protein was not observable. This finding shows that prenyltransferase NptA is reduced in a lae $A \Delta$ mycelium and that this prenyltransferase is localized in Hülle cells and other types of mycelia.

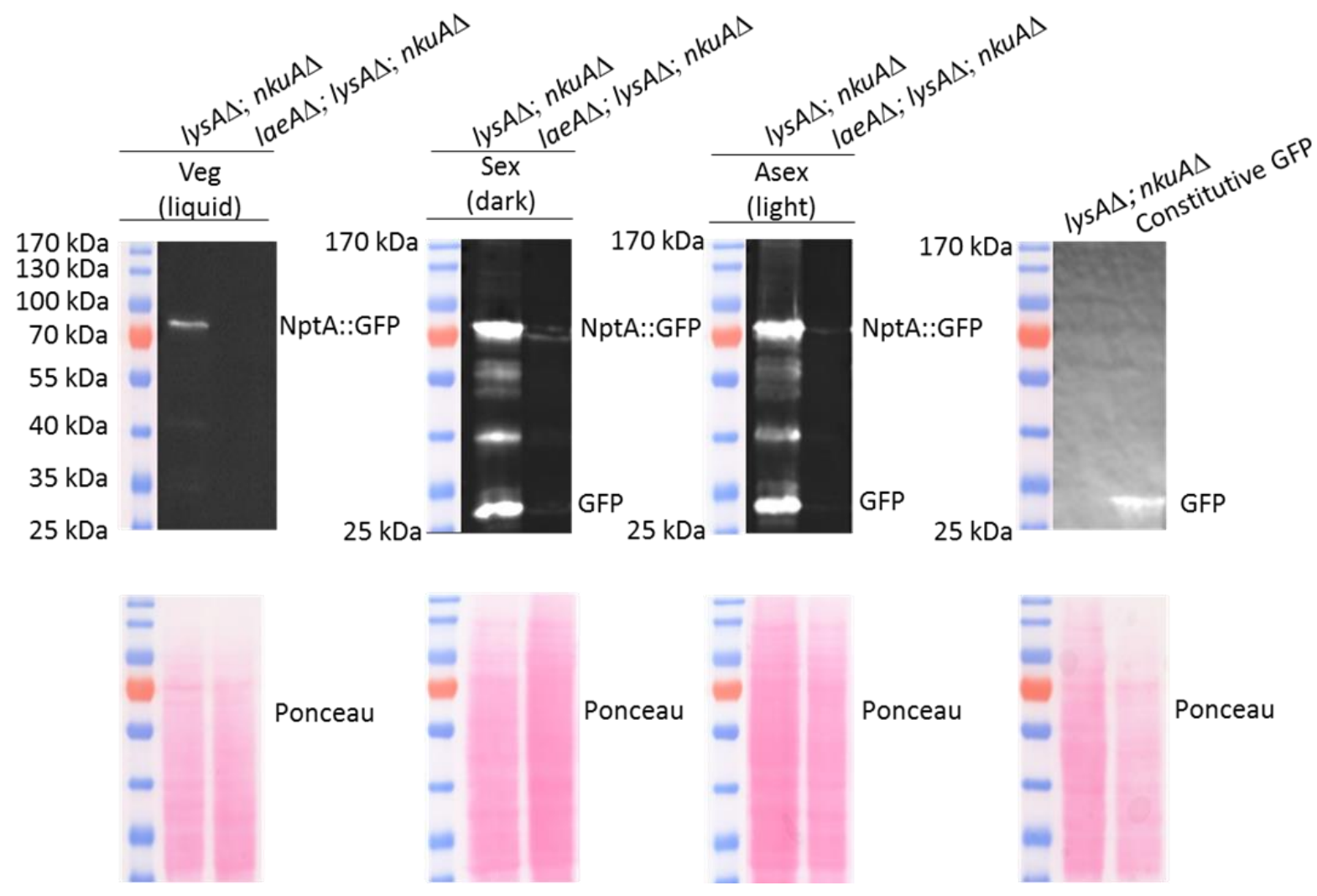

Figure 33. Reduced protein abundance of the prenyltransferase NptA in a laeA $\Delta$ mycelium. Western hybridization to detect NptA::GFP in a laeA $\Delta$ (AGB1083) strain. NptA::GFP was detected weakly in laeA $\Delta$; $n p t A:: g f p ;$ lysA $\Delta ; n k u A \Delta$ (AGB1083) strain. In order to detect NptA::GFP a primary $\alpha-$ GFP antibody (sc-9996; Santa Cruz) was used followed with an incubation of an $\alpha$-mouse secondary antibody (G21234, Invitrogen). The NptA protein consists of 434 amino acids with a predicted molecular mass of $48.9 \mathrm{kDa}$. NptA::GFP was detected as expected around $75 \mathrm{kDa}$. Additionally, degradation products of the NptA::GFP fusion protein were observable. A strain expressing GFP constitutively served as a positive control where GFP was detectable around $27 \mathrm{kDa}$. Parental $n k u A \Delta$ (AGB552) strain served a a negative control where GFP and the fusion protein were not detectable. 


\subsubsection{Quantitative protein analysis revealed the kinase RfeA enriched in Hülle cells and other fungal tissues}

Besides NptA, a serine/threonine kinase RfeA (AN2943) showed a siginifcant reduction in quantity in a lae $A \Delta$ strain. To gain more insight into secondary metabolism in Hülle cells RfeA was further investigated. RfeA was identified and quantified in submerged liquid cultures and the localization of RfeA was further analyzed. The localization of RfeA::GFP was mainly observable in the cytoplasm of Hülle cells and vegetative hyphae (Figure 34). RfeA::GFP is possibly also located in other cellular compartments. In order to observe the localization of RfeA::GFP Hülle cells were

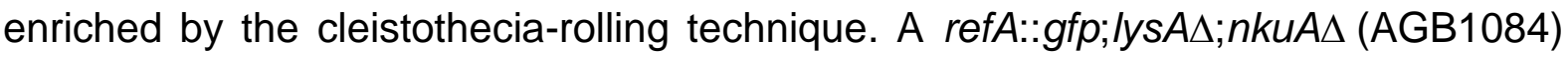
strain was used to observe RfeA::GFP in Hülle cells. In a laeA $\Delta ; r f e A:: g f p ;$ lysA $\Delta$; nkuA $\Delta$ (AGB1085) strain Hülle cells were observed in a reduced number. In the remaining Hülle cells, RfeA::GFP was used to verify the reduced quantity of RfeA::GFP protein in a laeA $\Delta$ mycelium.

Additionally, RfeA::GFP was observed in vegetative hyphae grown in submerged liquid cultures. In a laeA $\Delta ;$ rfe $A:: g f p ; l y s A \Delta ; n k u A \Delta$ strain, significantly reduced RfeA::GFP was observed in vegetative hyphae. The parental strain $l y s A \Delta$; $n k u A \Delta$ (AGB1092) was used as a negative control. Only autofluorescence could be detected in the lysA $\Delta$; $n k u A \Delta$ strain. A strain expressing GFP constitutively served as a control where GFP was mainly observable in the cytoplasm of Hülle cells. The quantity of RfeA::GFP protein is reduced in a laeAL (AGB1085) strain.

Western hybridization experiments confirmed that without LaeA the amount of RfeA protein is reduced in vegetative, sexual and asexual mycelium (Figure 35). The RfeA protein consists of 448 amino acids with a predicted molecular mass of $50.5 \mathrm{kDa}$. The RfeA::GFP fusion protein was detected as expected around $76 \mathrm{kDa}$. A strain expressing GFP constitutively served as a positive control where GFP was detectable around $27 \mathrm{kDa}$. Parental $n k u A \Delta$ (ABG552) strain served as a negative control where GFP and the fusion protein were not detectable. The abundance of RfeA::GFP protein was reduced in a laeA $\Delta ; n p t A:: g f p ; l y s A \Delta ; n k u A \Delta$ strain in a vegetative, sexual and asexual mycelium. Additionally, degradation products of the RfeA::GFP fusion protein were observable. This suggests that RfeA is unstable in different fungal tissues. 
A)
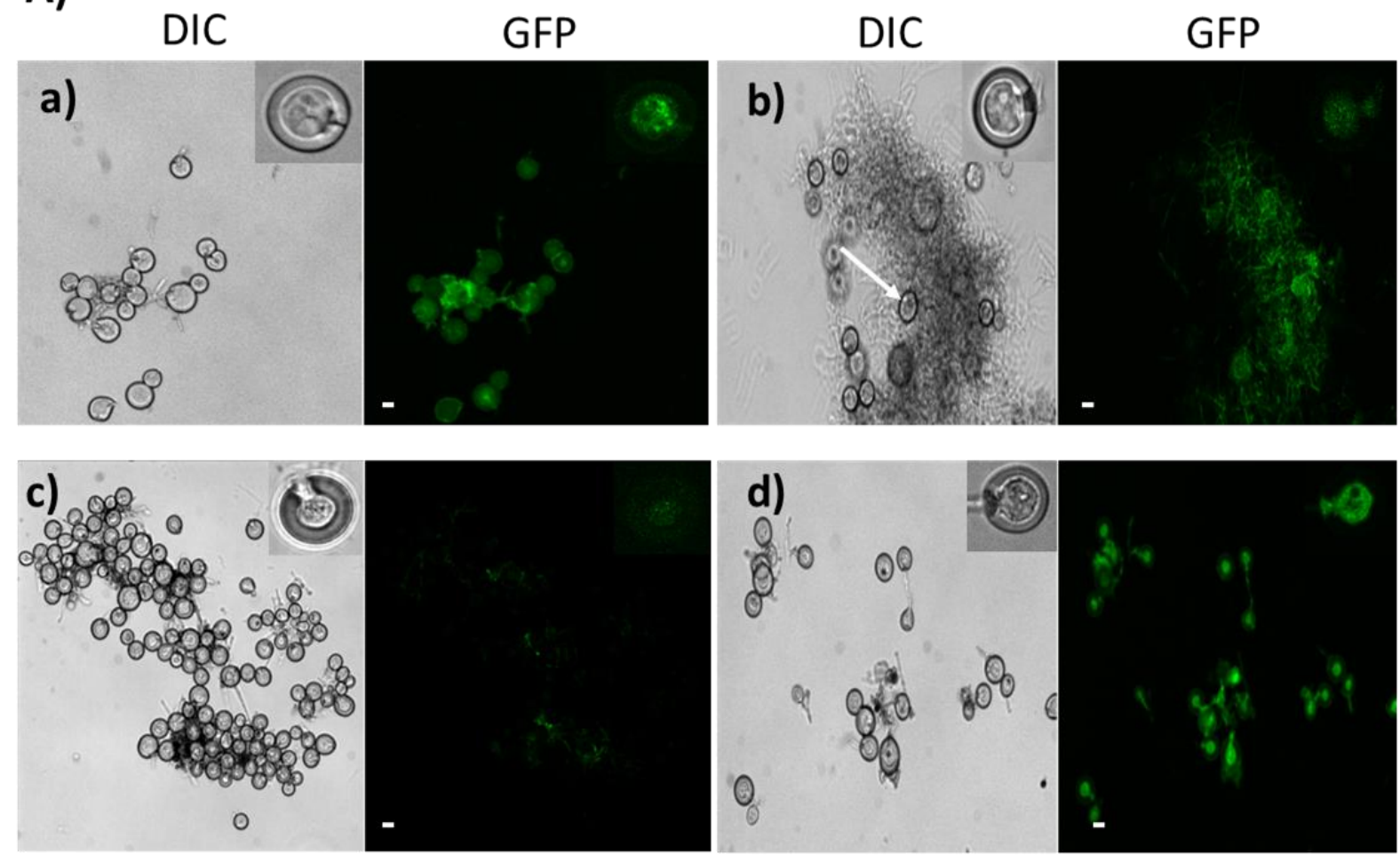

B)
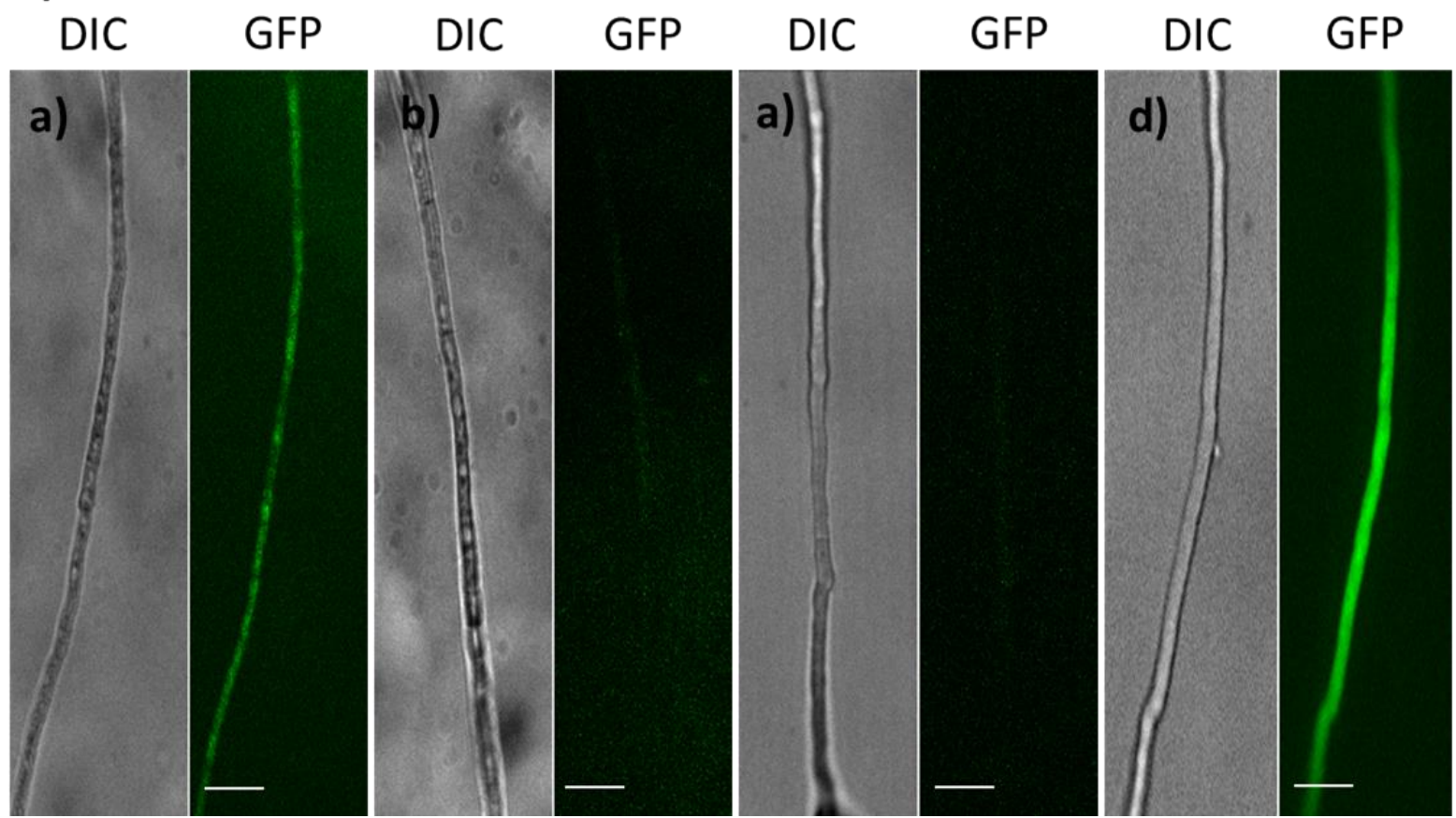

Figure 34. The serine/threonine kinase RfeA is localized in Hülle cells and is reduced in a laeA $\Delta$ mycelium.

A) Fluorescence microscopy pictures of Hülle cells and a vegetative hypha: a) $\operatorname{rfe} A:: g f p$; lys $A \Delta$; $n k u A \Delta$ (AGB1084) b) laeA $\Delta$; rfeA::gfp; lysA $\Delta$; nkuA $\Delta$ (AGB1085) (white arrow points to one Hülle cell) c) lysA $\Delta$; $n k u A \Delta$ (AGB1092) d) A strain expressing GFP constitutively (AGB596). Scale bar is $10 \mu \mathrm{m}$. B) Fluorescence microscopy pictures of a vegetative hypha: a) rfeA::gfp; lys $A \Delta$; $n k u A \Delta$ (AGB1084) b) laeA $A$; rfeA::gfp; lysA $\Delta$; nkuA $\Delta$ (AGB1085) c) lysA $\Delta$; nkuA $\Delta$ (AGB1092) d) A strain expressing GFP constitutively (AGB596). RfeA::GFP is localized in Hülle cells and vegetative hyphae and might be in different cellular compartments. RfeA::GFP is reduced in a laeA $\triangle$ mycelium. Scale bar is $20 \mu \mathrm{m}$. 
This result indicates that the amount of RfeA is reduced in a laeA $\Delta$ mycelium and that this kinase is found in Hülle cells and other types of mycelia and that RfeA::GFP is most probably unstable in different fungal cell types including Hülle cells.

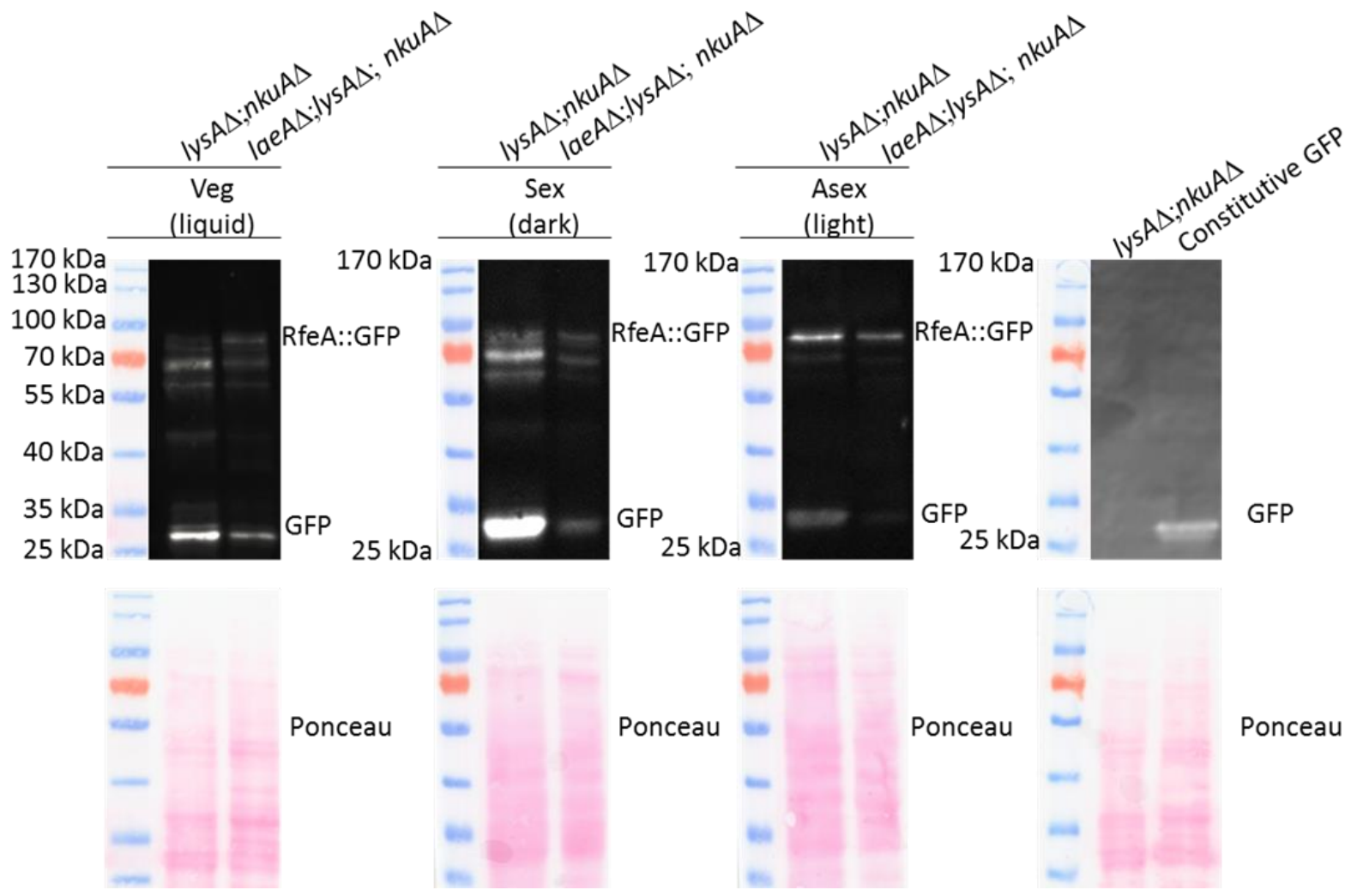

Figure 35. The serine/threonine kinase RfeA is localized in Hülle cells and the protein quantity is reduced in a laeA $\Delta$ mycelium.

Western hybridization of rfeA::gfp; lysA ; nkuA (AGB1084) and laeA $\Delta ; \operatorname{rfe} A:: g f p ; \quad l y s A \Delta$; $n k u A \Delta$ (AGB1085). In order to detect RfeA::GFP a primary $\alpha$-GFP antibody (sc-9996; Santa Cruz) was used followed with an incubation of an $\alpha$-mouse secondary antibody (G21234, Invitrogen). The RfeA protein consists of 448 amino acids with a predicted molecular mass of $50.5 \mathrm{kDa}$. RfeA::GFP was detected as expected around $76 \mathrm{kDa}$. Additionally, degradation products of the RfeA::GFP fusion protein were observable. It seems that RfeA::GFP is unstable in different fungal tissues. A strain expressing GFP constitutively served as a positive control where GFP was detectable around $27 \mathrm{kDa}$. Parental $n k u A \Delta$ strain (AGB552) served as negative control where GFP and the fusion proteins were not detectable. 


\subsubsection{The core proteome revealed a $72 \%$ overlap between the identified proteins of both types of Hülle cells}

Proteomic approaches from solid agar plates and submerged cultures were compared to identify overlapping proteins found in enriched Hülle cells from solid agar plates versus submerged conditions. As such, the 401 proteins identified in Hülle cells from solid agar plates were overlaid with the proteins in submerged liquid cultures where Hülle cell formation occurred. This comparison revealed a $72 \%$ overlap between identified proteins from Hülle cells originated from solid agar plates compared to ones that were found in vegetative mycelium in submerged liquid cultures (Figure 36). The core proteome that represents the overlapping identified proteins from Hülle cells grown on solid agar plates and in liquid media consists of 286 proteins which are shortlisted in Table 11. The criterium to select proteins for the shortlist is that these proteins were identified with the highest spectral counts in Hülle cells from surface and liquid media.

The localization of the two proteins (AN8434, AN8435) uniquely found in Hülle cells from solid agar plates, were identified again in vegetative mycelium where Hülle cell formation occur, are discussed within the next chapter. The core proteome of both types of Hülle cells contain five enzymes that are encoded by the monodictyphenone (mdp) / xanthone (xpt) gene clusters (MdpG (AN0150), MdpL (AN10023), XptC (AN7998), XptB (AN12402) and AN7999 (a putative oxidoreductase). This means that five out of the six enzymes found in Hülle cells from solid agar plates were identified again in Hülle cells from submerged liquid cultures. Alves and co-workers demonstrated in a recent study that after the addition of choline Hülle cell formation occurred in a vegetative mycelium and the secondary metabolite monodictyphenone was present in these cultures (Alves et al., 2016).

These findings imply that Hülle cells from surface and liquid cultures comprise shared proteins encoded by monodictyphenone $(m d p)$ / xanthone $(x p t)$ gene clusters and that these enzymes are also found in a sexual mycelium with high amounts of Hülle cells. 
Table 11. List of overlapping proteins identfied in Hülle cells from solid agar plates and submerged liquid cultures (Hülle cells core proteome).

Only proteins identified in two or more biological replicates and with two or more peptides per protein were considered for the analysis. 1.2.3: spectral counts of three biological replicates. ${ }^{*}$ Identified proteins in two replicates and not in all three biological replicates.

\begin{tabular}{|c|c|c|c|c|c|}
\hline Gene ID & Function & 1 & 2 & 3 & Reference \\
\hline \multicolumn{6}{|c|}{$\begin{array}{l}\text { Uniquely found in both Hülle } \\
\text { cell types }\end{array}$} \\
\hline AN8435 & Tyrosinase domain protein & 58 & 110 & 73 & $\begin{array}{l}\text { This study \& Bayram et } \\
\text { al., } 2016\end{array}$ \\
\hline AN8434 & Ankyrin repeat domain protein & 36 & 102 & 62 & $\begin{array}{l}\text { This study \& Bayram et } \\
\text { al., } 2016\end{array}$ \\
\hline \multicolumn{6}{|c|}{$\begin{array}{l}\text { Identified in both Hülle cell } \\
\text { types \& sex. mycelium }\end{array}$} \\
\hline AN10023 (MdpL) & Member of the $m d p / x p t$ gene clusters & 14 & 19 & 18 & Bayram et al., 2016 \\
\hline AN12402 (XptB) & Prenyltransferase, member of the mdp/xpt gene clusters & 9 & 10 & 17 & Sanchez et al., 2011 \\
\hline AN0150 (MdpG) & Polyketide synthase, member of the $m d p / x p t$ gene clusters & 4 & 17 & 5 & Sanchez et al., 2011 \\
\hline AN7998* (XptC) & GMC oxidoreductase, member of the $m d p / x p t$ gene clusters & 3 & 7 & & Sanchez et al., 2011 \\
\hline AN7999 & Oxidoreductase, member of the mdp/xpt gene clusters & 63 & 64 & 84 & Bayram et al., 2016 \\
\hline AN8203 & Hydolase & 10 & 16 & 35 & Not available \\
\hline AN6314* & Oxidoreductase & & 15 & 10 & Not available \\
\hline \multicolumn{6}{|c|}{$\begin{array}{l}\text { Identified in both Hülle cell } \\
\text { types \& asex. mycelium }\end{array}$} \\
\hline \multicolumn{6}{|c|}{$\begin{array}{l}\text { No overlapping proteins were } \\
\text { identified }\end{array}$} \\
\hline \multicolumn{6}{|c|}{$\begin{array}{l}\text { In both Hülle cells types \& } \\
\text { vegetative mycelium ( } 7 \\
\text { proteins were identical, } 6 \text { are } \\
\text { listed) }\end{array}$} \\
\hline AN1182 (BenA) & Beta-tubulin & 327 & 352 & 648 & Oakley et al., 2004 \\
\hline AN6688 (AspB) & Putative septin B & 180 & 124 & 8 & Hernández et al., 2012 \\
\hline AN4159 (GlnA) & Glutamate-ammonia ligase & 384 & 367 & 481 & Margelis et al., 2001 \\
\hline AN2918 (Cct4) & Chaperonin complex component & 48 & 46 & 102 & Malavazi et al., 2007 \\
\hline AN2149 (Cct1) & Putative chaperonin complex component & 27 & 12 & 86 & Malavazi et al., 2006 \\
\hline AN4236 (RPT5) & Proteasome regulatory particle & 25 & 32 & 55 & Not available \\
\hline \multicolumn{6}{|c|}{$\begin{array}{l}\text { In both Hülle cells types, } \\
\text { sexual \& vegetative mycelium } \\
\text { (18 proteins were identical, } 6 \\
\text { are listed) }\end{array}$} \\
\hline AN7570 (TubB) & Alpha-tubulin & 236 & 192 & 363 & Kirk et al., 1991 \\
\hline AN8182 (AspC) & Septin & 160 & 139 & 252 & Hernández et al.,2012 \\
\hline AN4997 (AspA) & Phosphatidylinositol transporter & 44 & 85 & 110 & Hernández et al.,2012 \\
\hline AN2142 (KapA) & Karyopherin (importin) alpha & 66 & 43 & 111 & Etxebeste et al., 2013 \\
\hline AN5895 (GdiA) & Rab GDP-dissociation inhibitor & 142 & 112 & 251 & Goody et al., 2017 \\
\hline AN4775 & Cullin deneddylation & 47 & 45 & 101 & Dambacher et al., 2016 \\
\hline \multicolumn{6}{|c|}{$\begin{array}{l}\text { In both Hülle cells types, } \\
\text { sexual } \& \text { asexual mycelium } \\
\text { ( } 35 \text { proteins were identical, } 6 \\
\text { are listed) }\end{array}$} \\
\hline AN11080 (NptA) & Prenyltransferase & 79 & 122 & 47 & Oakley et al., 2017 \\
\hline AN7912* (OrsC) & Tyrosinase & 14 & 24 & & Guerriero et al., 2017 \\
\hline AN7914 & Alcohol dehydrogenase & 203 & 159 & 75 & Sanchez et al., 2010 \\
\hline AN4871 (ChiB) & Chitinase & 44 & 66 & 43 & $\begin{array}{l}\text { Shin et al., 2009, } \\
\text { Yamazaki et al., } 2007\end{array}$ \\
\hline AN1502* $(\mathrm{NagA})$ & Chitin hydrolysis & 8 & 8 & & $\begin{array}{l}\text { Pusztahelyi et al., 2006, } \\
\text { Kim et al., } 2002\end{array}$ \\
\hline AN2017* (AgdA) & Alpha-glucosidase & 6 & & 8 & Nakamura et al., 2006 \\
\hline \multicolumn{6}{|c|}{$\begin{array}{l}\text { Identified in all cell types ( } 213 \\
\text { proteins were identical, } 6 \text { are } \\
\text { listed) }\end{array}$} \\
\hline AN8041 (GpdA) & Glyceraldehyde-3-phosphate dehydrogenase & 971 & 1104 & 1794 & Punt et al., 1988 \\
\hline AN7388 (CpeA) & Laccase & 319 & 450 & 63 & Scherer et al., 2002 \\
\hline AN9339 (CatB) & Catalase & 637 & 669 & 575 & Calera et al., 2000 \\
\hline AN0359 (SgdA) & Translation initiation factor 3 (elF3) & 4 & 13 & 217 & Obayashi et al., 2017 \\
\hline AN7105 & Translation initiation factor 3 (elF3) & 7 & 22 & 237 & Obayashi et al., 2017 \\
\hline AN6542 (ActA) & Actin A & 335 & 425 & 563 & Upadhyay et al., 2008 \\
\hline
\end{tabular}




\subsubsection{The proteome of surface Hülle cells compared to Hülle cells from liquid media differ in composition by $28 \%$}

Identified proteins of the proteome from surface Hülle cells differ in $28 \%$ composition compared to identified proteins found in vegetative mycelium grown in submerged liquid cultures (Figure 36A). The difference between the proteomes of both types of Hülle cells revealed that surface Hülle cells contain increased numbers of glucanases as shown in Figure 36B. In a recent study it was shown that the transcripts of the $\alpha$ 1,3-glucanase mutA and agnB are expressed during sexual development on surface agar plates (He et al., 2017).

The MphA (AN2601) maltose permease-like protein was identified from surface Hülle cells within different developmental time points mentioned above. These results show that sexual differentiation increases $\alpha-1,3$-glucanase levels and a maltose permeaselike protein found in surface Hülle cells preferentially surrounding the cleistothecia. Proteins such as the $\alpha-1,3-$ glucanase MutA, reduced in a laeA $\Delta$ mycelium, are potentially found in Hülle cells (Sarikaya-Bayram et al., 2010). Hülle cell growth in submerged liquid cultures revealed several proteins that were reduced in a laeA $\Delta$; lysA $\Delta$; nkuA $\Delta$ (AGB1074) mycelium. Among these proteins, several tRNA ligases were identified in this type of mycelium shown in Figure 36B. The reduction of tRNA ligases in laeA $\Delta$ vegetative mycelium suggests most probably that protein synthesis is reduced in this type of mycelium. This finding suggests that tRNA ligases are found in a submerged liquid mycelium where Hülle cell formation occurred and that these ligases are reduced in a lae $A \Delta$ mycelium. 
A)

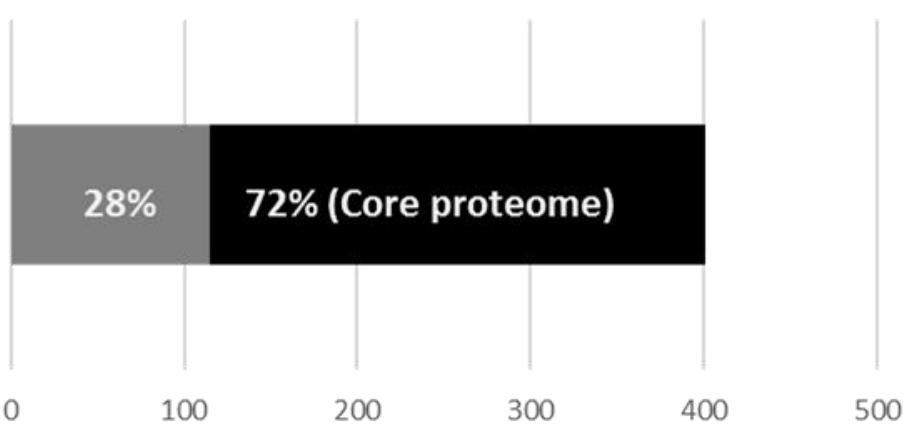

Number of identified proteins from surface Hülle cells

B)

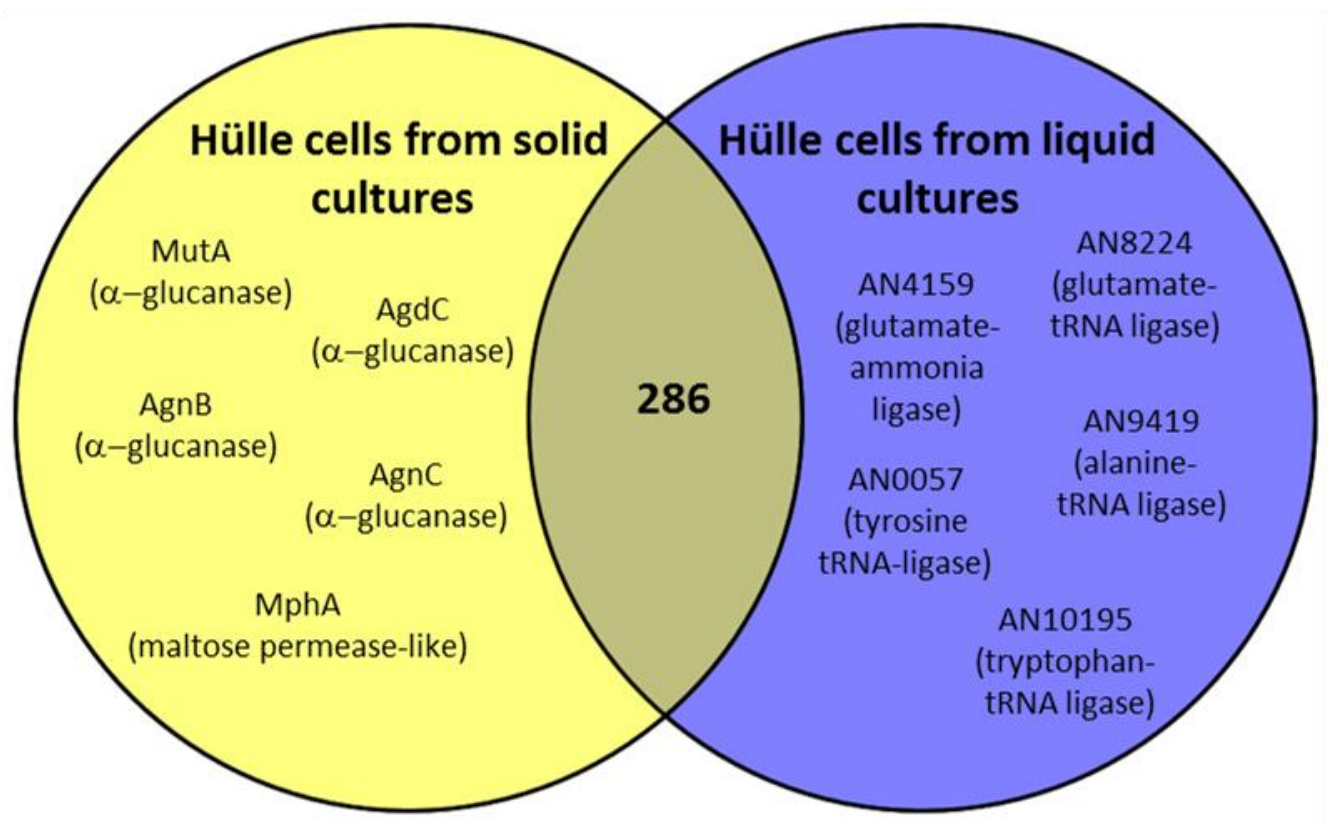

Figure 36. Hülle cells from surface growth compared to Hülle cells from liquid media differ in composition by $28 \%$ beside a shared core proteome.

A) 401 proteins shown in the graph were identified from surface Hülle cells and were overlaid with the proteins that were identified in Hülle cells grown in submerged liquid cultures. The percentages of overlapping and non-overlapping proteins are shown. The black box represents the overlapping proteins identified from Hülle cells grown on solid agar plates versus Hülle cells grown in liquid media. The grey box represents the non-overlapping proteins identified from Hülle cells grown on solid agar plates versus Hülle cells grown in liquid media. B) Comparison between proteins that were identified either from solid agar plates or from liquid cultures. The core proteome of Hülle cells that represents the identified overlapping proteins from Hülle cells grown on solid agar plates and liquid media contains 286 proteins and are shortlisted in Table 11 (page 95). 


\subsection{Functional analysis of genes for Hülle cell enriched proteins: A maltose permease-like protein of surface Hülle cells supports fungal growth and development}

\subsubsection{Comparative proteomics revealed two overlapping proteins found in Hülle cells from both approaches}

Comparative proteomics revealed that two proteins were uniquely found in both types of Hülle cells and these are listed in Table 11. These two proteins encoded by the neighboring genes, $A N 8434$ and AN8435, are predicted to contain an ankyrin repeat and a tyrosinase domain. Bayram and co-workers showed that the transcripts of AN8434 and AN8435 are expressed in an asexual and sexual mycelium (Bayram et al., 2016).

In order to verify the localization of the ankyrin repeat domain protein (AN8434) and the putative tyrosinase domain protein (AN8435) in Hülle cells, an AN8434::gfp (AGB1089) and an AN8435::gfp (AGB1090) strain were used. Proteins with an ankyrin repeat domain are adaptor proteins bound to the membrane and are known to interact with multiple protein interaction partners for instance with the mammalian transcription factor NF-кB (König et al., 2017). NF-кB comprises structural similarities to the velvet domain protein VosA (Ahmed et al., 2013). It was shown that the laeA ortholog of Trichoderma reesei (lae1) regulates genes encoding ankyrin-proteins (KarimiAghcheh et al., 2013). The amino acid shared between AN8434 and their Homo sapiens homologs is $36.2 \%$ to Ank3 (Cerqueira et al., 2014). The AN8434 protein was named AnkG and stands for ankyrin repeat domain protein $G$.

In order to study the localization of AnkG::GFP Hülle cells were enriched from sexual mycelium using the cleistothecia-rolling technique and AnkG::GFP was detectable at the membrane of the subtending hyphae of Hülle cells as shown in Figure 37. Additionally, AnkG::GFP was observed in vegetative hyphae grown in submerged liquid cultures and was underrepresented in the membrane of vegetative hyphae and is most likely localized primarily in the endoplasmic reticulum (ER) and in the cytoplasm. The $n k u A \Delta$ (ABG552) parental strain was used as negative control. Only autofluorescence could be detected in the $n k u A \Delta$ strain. A strain expressing GFP constitutively revealed that GFP is mainly visible in the cytoplasm of vegetative hyphae. 

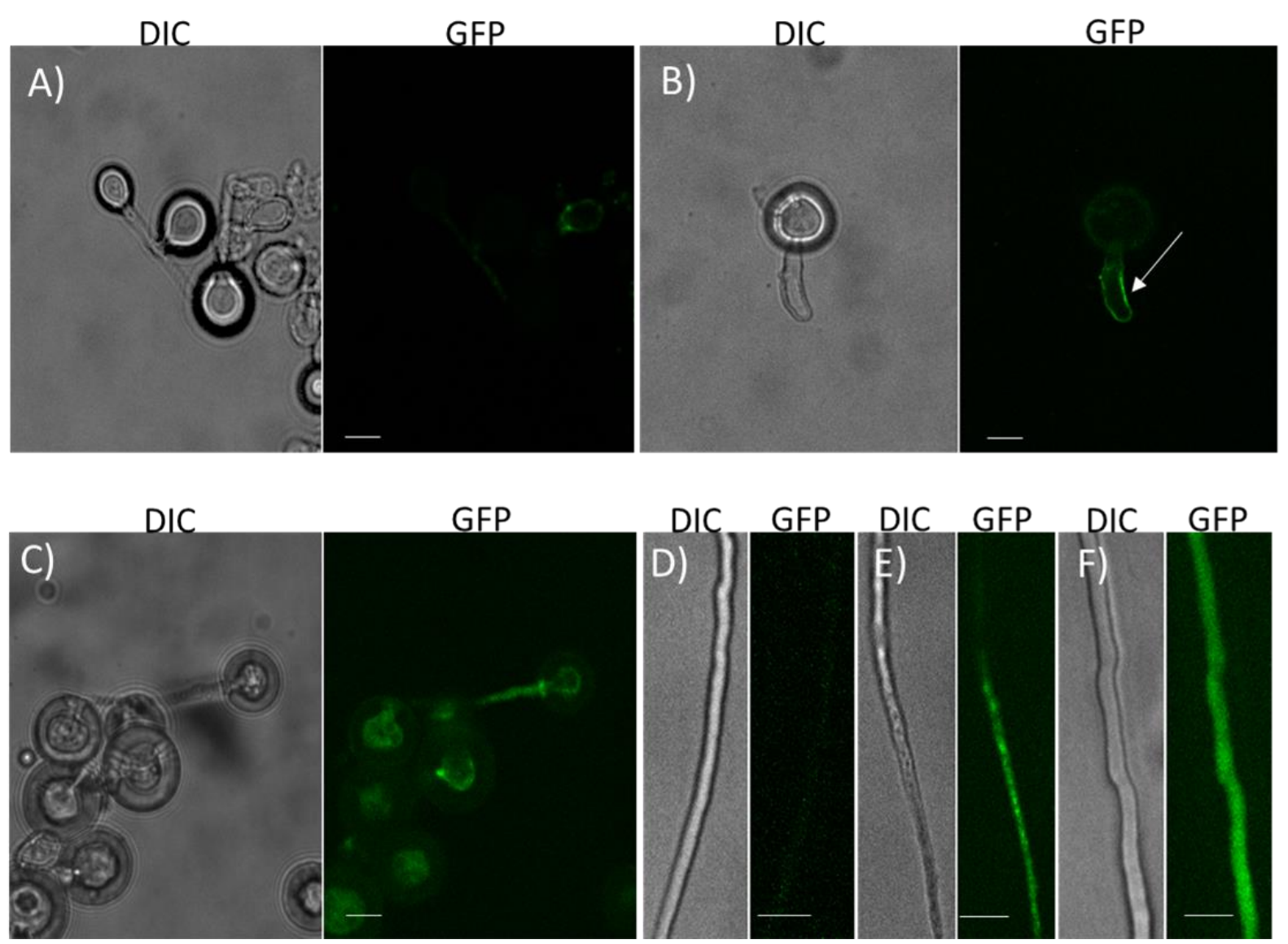

Figure 37. The AnkG (AN8434) ankyrin repeat domain protein is localized at the membrane of the subtending hyphae of Hülle cells.

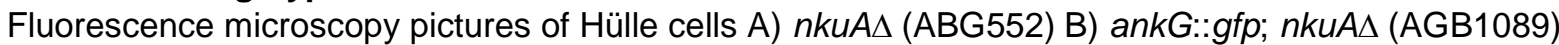
C) A strain expressing GFP constitutively (AGB596). AnkG::GFP is detectable at the membrane of the subtending hyphae of Hülle cells (white arrow points to one subtending hypha of Hülle cell). Scale bar is $10 \mu \mathrm{m}$. Fluorcence microscopy picture of a vegetative hypha D) $n k u A \Delta \mathrm{E})$ ankG::gfp; nkuA $\mathrm{F}$ ) A strain expressing GFP constitutively. AnkG::GFP is detectable mainly in the cytoplasm as well as in the endoplasmic reticulum (ER) of a vegetative hypha. Scale bar is $20 \mu \mathrm{m}$.

The AnkG protein consists of 477 amino acids with a predicted molecular mass of 52.0 $\mathrm{kDa}$. Western hybridization experiments revealed that AnkG::GFP is detectable as expected around $79 \mathrm{kDa}$ in a three and five day old sexual mycelium with high amounts of Hülle cells plus a three day old vegetative mycelium (Figure 38). Proteolytic cleavage product of AnkG::GFP fusion protein was detectable around $27 \mathrm{kDa}$. This is most likely the degradation product of the full-length AnkG::GFP fusion protein and represents the degraded GFP product. A strain expressing GFP constitutively served as a positive control where GFP was detectable around $27 \mathrm{kDa}$. Parental $n k u A \Delta$ (ABG552) strain served as a negative control where GFP and the fusion protein was not observable. 


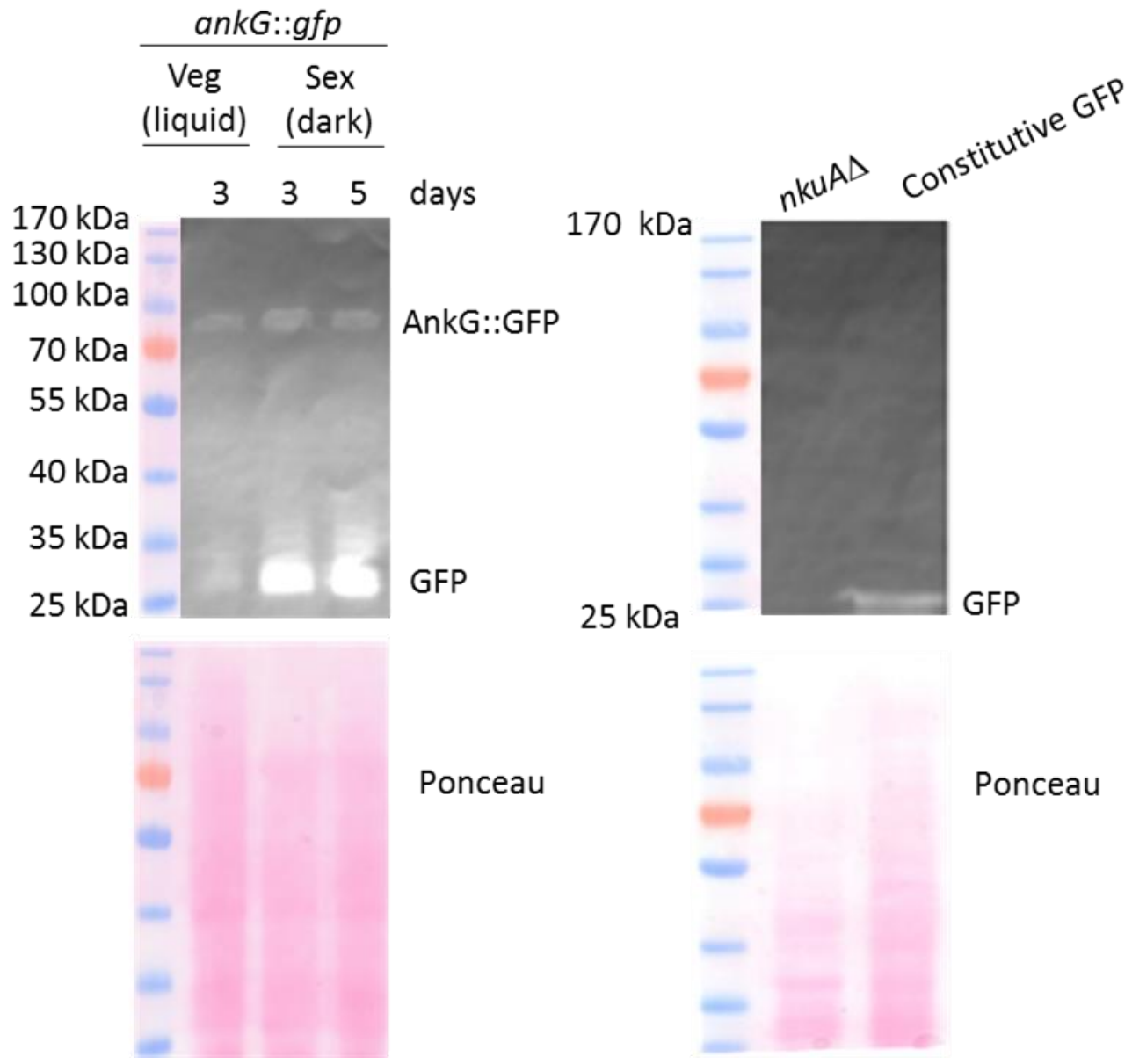

Figure 38. The AnkG::GFP fusion protein is found in sexual mycelium with high amounts of Hülle cells and a vegetative mycelium.

Western hybridization of ankG::gfp; nkuA $\Delta$ (AGB1089) of a vegetative and a sexual mycelium. To detect AnkG::GFP (ankG::gfp;nkuAL, AGB1089) a primary $\alpha$-GFP antibody (sc-9996; Santa Cruz) was used followed with an incubation of an $\alpha$-mouse secondary antibody (G21234, Invitrogen). The AnkG protein consists of 477 amino acids with a predicted molecular mass of $52.0 \mathrm{kDa}$. AnkG::GFP was detected as expected at around $79 \mathrm{kDa}$. A proteolytic cleavage product of AnkG::GFP fusion protein was detectable around $27 \mathrm{kDa}$ and represents most probably the degraded GFP. A strain expressing GFP constitutively served as a positive control where GFP was detectable around $27 \mathrm{kDa}$. Parental nkuA $\Delta$ (AGB552) strain served as negative control where GFP and the fusion proteins were not detectable.

In order to study the localization of the putative tyrosinase domain protein (AN8435) Hülle cells were enriched from sexual mycelium using the cleistothecia-rolling technique and AN8435::GFP fusion protein was observable (Figure 39). It is possible that AN8435::GFP is situated in different cellular compartments within Hülle cells such as the cytoplasm. AN8435::GFP was also observable at the thick cell wall ringshaped structure of Hülle cells. AN8435::GFP was observable in vegetative hyphae in submerged liquid cultures. It seems that AN8435::GFP is not stable in different fungal cell types. 

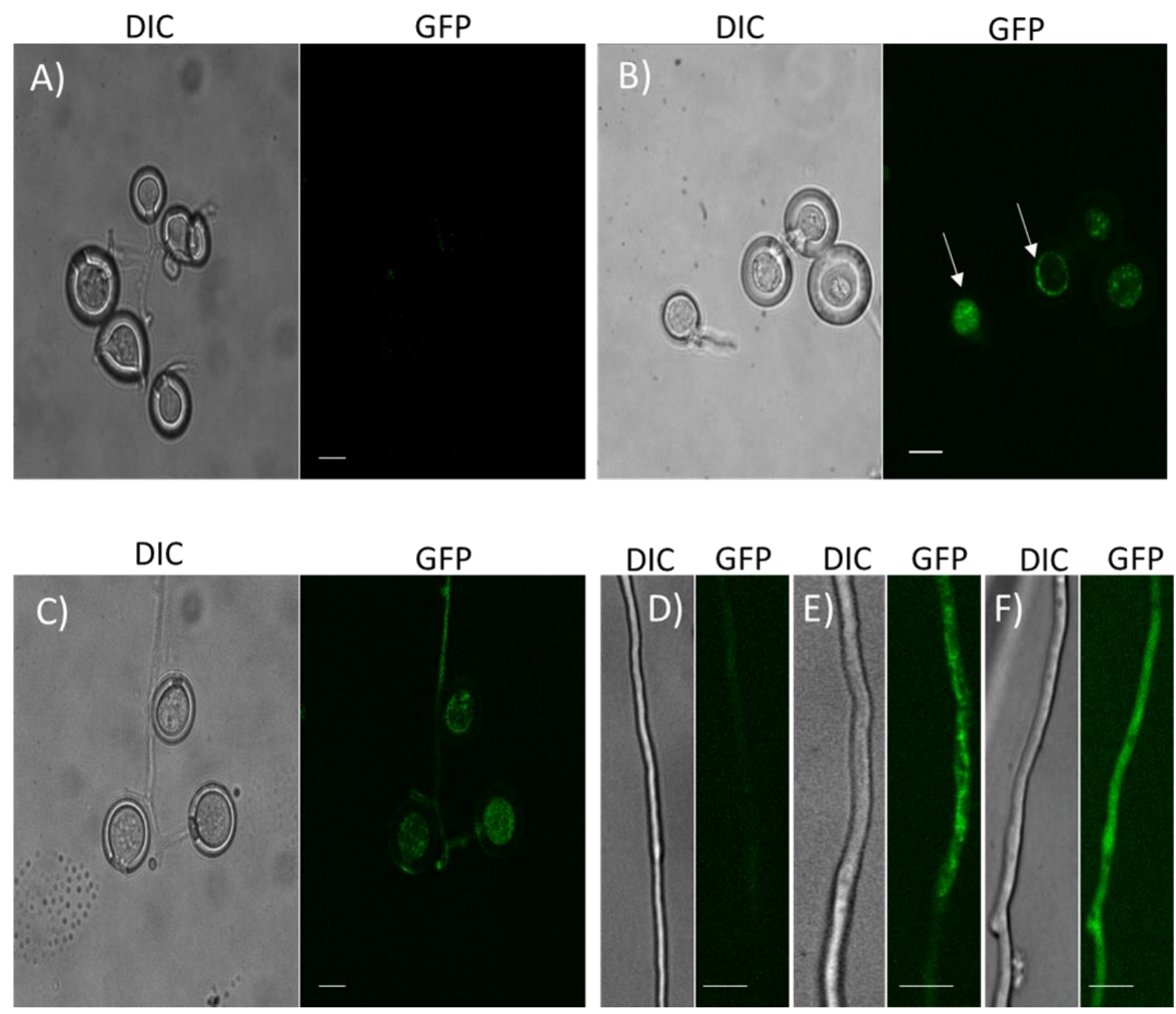

Figure 39. The localization of the tyrosinase domain protein (AN8435).

Fluorescence microscopy pictures of Hülle cells A) nkuA $\Delta$ (AGB552) B) AN8435::gfp; $n k u A \Delta$ (AGB1090) C) A strain expressing GFP constitutively (AGB596). AN8435::GFP was observed in different regions in Hülle cells (white arrows point to cytoplasm and ringshaped structures of Hülle cells). Scale bar is $10 \mu \mathrm{m}$. Fluorcence microscopy picture of a vegetative hypha $D$ ) nkuA $E$ ) AN8435::gfp; $n k u A \Delta$ F) A strain expressing GFP constitutively. AN8435::GFP is detectable mainly in the cytoplasm of a vegetative hypha. Scale bar is $20 \mu \mathrm{m}$

The AN8435 protein consists of 846 amino acids with a predicted molecular mass of $95.7 \mathrm{kDa}$. Western hybridization experiments revealed that AN8435::GFP is probably detectable at the expected size of $123 \mathrm{kDa}$ in a sexual mycelium with high amounts of Hülle cells and vegetative mycelium (Figure 40). Additionally, products with a higher size were observable, suggesting that the tyrosinase domain protein (AN8435) could have been modified. Degradation products of the AN8435::GFP fusion protein were also observable. 
A strain expressing GFP constitutively served as a positive control where GFP was detectable around $27 \mathrm{kDa}$. Parental $n k u A \Delta$ (ABG552) strain served as a negative control where GFP and the fusion protein were not detectable. It seems that the fusion protein AN8435::GFP is not stable.

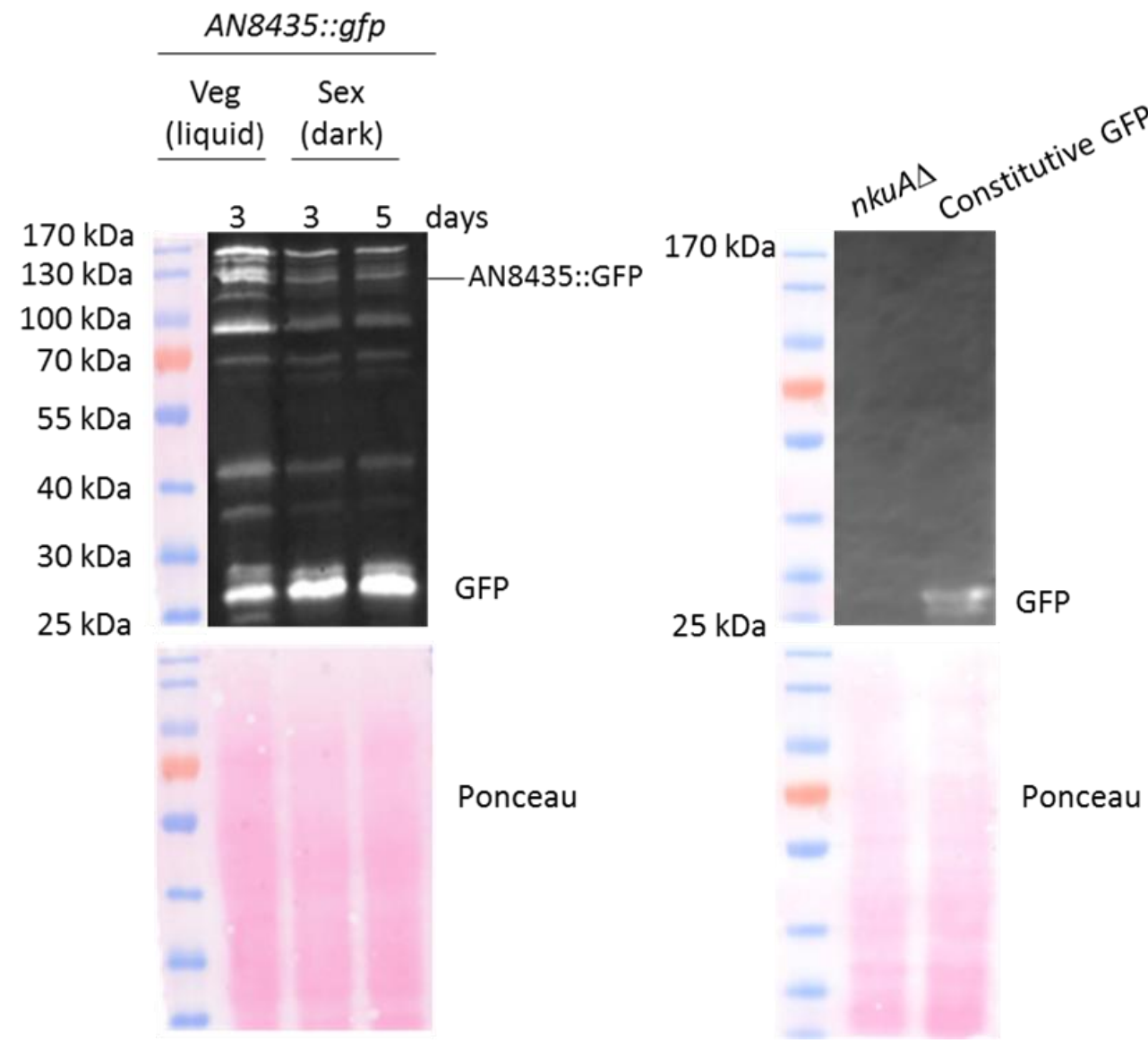

Figure 40. Western hybridization of AN8435::GFP of a vegetative and a sexual mycelium.

In order to detect AN8435::GFP (AN8435::gfp; nkuA 4 , AGB1090) a primary $\alpha$-GFP antibody (sc-9996; Santa Cruz) was used followed with an incubation of an $\alpha$-mouse secondary antibody (G21234, Invitrogen). The sequence of AN8435 consists of 846 amino acids with a predicted molecular mass of $95.7 \mathrm{kDa}$. AN8435::GFP was most probably detected at the expected size of $123 \mathrm{kDa}$. Additionally, products with a higher size were observable. Degradation products of the AN8435::GFP fusion protein were also observable. A strain expressing GFP constitutively served as a positive control where GFP was detectable around $27 \mathrm{kDa}$. Parental nkuA $(\mathrm{ABG} 552)$ strain served as a negative control where GFP and the fusion protein were not detectable.

These findings reveal that the AnkG (AN8434) ankyrin domain protein is localized to the membrane of the subtending hyphae of Hülle cells. It seems that AnkG is localized in the cytoplasm as well as in endoplasmic reticulum (ER) during vegetative growth. The localization of AN8435::GFP fusion protein was investigated. Probably AN8435 is located in different fungal tissues such as Hülle cells and vegetative mycelium. The fusion protein seems not to be stable. 


\subsubsection{A similar protein to a maltose transporter is enriched in surface Hülle cells and supports growth and fungal development}

\subsubsection{The sequence of MphA a maltose permease-like protein enriched in Hülle cells contains a distinctive sugar motif}

The putative transmembrane transporter AN2601 was found in enriched Hülle cells of solid agar plates mentioned above. Transporters are thought to be crucial to transport nutritions and other molecules across Hülle cell membranes thereby supporting the cleistothecia (Wei et al., 2004, Pantazopoulou et al., 2007). The biological function of this putative transmembrane transporter was studied in detail. The AN2601 protein was named MphA and stands for maltose permease-like protein of Hülle cells. The best hit for an orthologous gene in an Aspergillus species for MphA is the putative MFS maltose transporter (Afu4g00150) of Aspergillus fumigatus and has a sequence identity of $88.3 \%$. This is shown with other sequences of maltose transporters in the multiple sequence alignment in Figure 41.

The sequence of MphA contains 540 amino acids with a predicted molecular mass of $60.3 \mathrm{kDa}$. The secondary structure of $\mathrm{MphA}$ is predicted to contain twelve transmembrane helices which, in turn, consist of two 6-helix bundles connected by a cytoplasmic loop. The $\mathrm{N}$-terminal tail of the sequence with a predicted length of 64 residues is longer than the $\mathrm{C}$-terminal end with 34 residues. The sequence of MphA contains one conserved distinctive sugar motif (Horák 1997). All four sequences of the multisequence alignment (Figure 41) contain a conserved sequence region after the sixth putative transmembrane region. This region contains a sequence motif (PESP(W)L) which is specific to all sugar transporters (Horák 1997). This points out that the MphA sequence contains similarities with other sugar transporters such as the Mal31 of Saccharomyces cerevisiae. 

A. nidulans
A. fumigatus
A. niger
S. cerevisiae
A. nidulans
A. fumigatus
A. niger
S. cerevisiae
A. nidulans
A. fumigatus
A. niger
S. cerevisiae
A. nidulans
A. fumigatus
A. niger
S. cerevisiae
A. nidulans
A. fumigatus
A. niger
S. cerevisiae
A. nidulans
A. fumigatus
A. niger
S. cerevisiae
A. nidulans
A. fumigatus
A. niger
S. cerevisiae
A. nidulans
A. fumigatus
A. niger
S. cerevisiae
A. nidulans
A. fumigatus
A. niger
S. cerevisiae

A. nidulans

A. fumigatus

A. niger

S. cerevisiae

A. nidulans

A. fumigatus

A. niger
------------------MS SDNTEKQT SALEVEAQPT----------SKGE PVYD -MDNVTEKQT SALELEEQPV---------SKGGPVYD MAAESV-----AEQRDEKPQ----------SEKVDIHQ MKGLSSL INRKKDRNDSHLDEIENGVNA TE FNS IEMEEQGKKSDFDLSHLEYGPGSL I PN $:::$ : : : SDEK-VD----YDRTGAINAERVEFDMTVLEAVKAYPAASWWA FVMSCTI IMESYCVFLM VNEK-VG----LDRAGAINAEDVEHKMTVVEAVKAYPAA SWWA FVMSCTI IMESYCVFLM SEVLDNP----DLMHEAFDGENYEHQMGVWEAAKQYPWACFWAFLMCFT IVMESFDMFLN DNNEEV PDLLDEAMQDAKEADESERGMPLMTALKTYPKAAAWSLLVSTTLIQEGYDTAIL

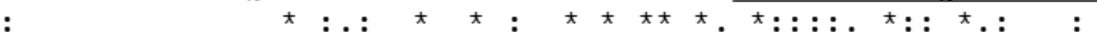
GQFIATQKFADDFGVYSERDQAY I IEASWQSAFQC SGPI GAFIGVFLAGPIT SWIGYRWA GQFIAT KRFARDYGVWSDVKQDF I IEASWQ SAFQC SGPVGAFIGVFIAGPIT SWIGYRWA TNFVALDHFS KVFGVETS-PGVYAIPT KWQSALFQ SGQCGAFVGVYLAGPITNKIGYRWT GAFYAL PVFQKKYGS LNSNTGDYEISV SWQI GLCLCYMAGEIVGLQMT GPSVDYMGNRYT

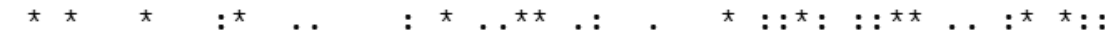
TI GALMFLNAFIFI FYFGNSNGMFFASQILEGI PWGIFIANAPAYCSE IVPMRLRAPATQ TI GGLMFLNA F I F I FYFGN SQGMFLAS $Q I L E G I$ PWG I FVANAPAYCSE IVPMRLRA PATQ TMLGLVLMNA T I I SFEANSLTL LVVGQALEGVPWGFFI ANSPAYASEVVPL PLRAAVTA LIMALF FLAAFIFI LYFCKSLGM IAVGQALCGMPWGCFQCLTVSYASE ICPLALRYYLTT

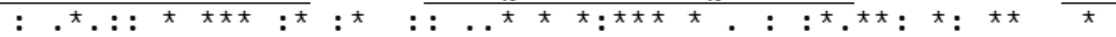
MLQMFWAIGS I IVGGITYHYQSK--QDSSAYRMPIALQWMFPT PLAILLFIAPESPWWLV MLQMFWAIGS I IVGGITYHYQSR--DD PTAYRI PIALQWMFPT PLAILLYLA PESPWWLV TLQMSWS IGS I IVAGATYGYNSL--ETQWEWRA PLALQW IFPT PLMVLLFFA PESPWWLI YSNLCWAFGQLFAAGIMKNS QNKYANSELGY KL PFALQWIWPL PLAVGIFFAPESPWWLV

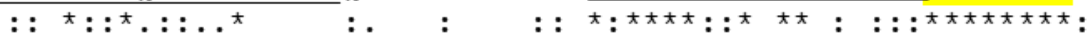
RKGRLAEAEKSVRRLGRASANENP---ADAVAMMRRTIELE-KSEKKPSLI-ELWKGTDR RKGRLADAEKAVRRLGRASANDDP---ADAVAMMRRTIELE-KTEKKP SLV-ELWKGTDL RRGRKEEALKS IKRLGAKTEEQ-A---HQSLAMIERTVK IEEETGGNPTLL-DLWKGTDR KKGRIDQARRSLERTLSGKGPEKELLVSMELDKIKTTIEKEQKMSDEGTYWDCVKDGINR $::^{\star \star} \quad:^{\star}:::^{\star} \quad{ }^{\star} \quad: \quad .^{\star}::^{\star}: \quad: \quad: \quad .^{\star}:$ YRTLIVCGVYASQNLTGNL IANQAVYF FKQAGMASNTAFALGLITSALQWIMVMLSWILT YRTLIVCGVYASQNLTGNL IANQAVYF FKQA GMADNTAFALGLI TSALQWIMVMLSWILT RRTIIT CLIYASQNFAGNL IANQATYFFEQAGISADKSFQLNLITTCLQFVANAVSWVLT RRTRIACLCWIGQCSCGAS LIGYSTYFYEKAGVST DTAFT FSI I QYCLGIAATFISWWAS ${ }^{\star \star}{ }^{\star}{ }^{\star}: .^{\star} \star^{\star}: .:^{\star \star}::^{\star \star}:::^{\star \star}::^{\star} .^{\star} \quad:^{\star \star}:$ TYLGRRTIYVYGQF INCAFLIALGIAASIGD PKTTAASNAQASLGLIVSVLFCLGPAPAS TYLGRR TIYVYGQL INCVFLVALGIAASVGASK--AASNAQASLGLIVSVLFCLGPAPAS SWFRRRTVFLYGTATNITFLFILGIIASVPQNH--KTNYAQACLGVII SVVYAGAQGPIS KYCGRFDLYAFGLAFQAIMFFI I GGL-- GCSDTHGAKMGSGA $\overline{\text { LLMVVAFFYNLGIAPVV }}$

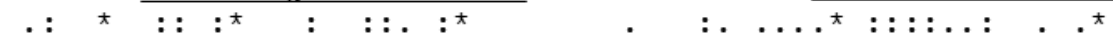
WVIIGETSSVRLRP LTTGIGRGAYYVVNIPC IFLSSYMLNTDKWDLGGKSGYVWAGTAFI WVI IGE TSSVRLRP LTTGIGRGAYYVVNI PC IFLASYMLNADKWNLGGKSGYVWAGTAFI YT I ISETSSVRLRALSTAVGRSAYYITEI PMIYLS SRMLNTTGWNLAGKCGYVWGCTALV FCLVSEIPSSRLRT KTI ILARNAYNVIQVVVTVLIMYQLNSEKWNWGAKSG $\overline{\text { FFWGGFCLA }}$

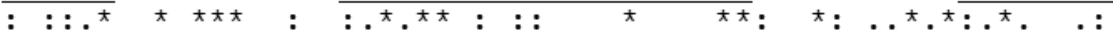

CTAMAWVWVPEMKDRSYRE IDIL FRRRVPARKWKQTVVDIRDDE CT FMSWLWI PEMKDRS FRE IDIL FKRRVPARKWKQTVVD INDDE VWVGAYFGLPELKHRSYREADILFKRKISARKFKTTEIGVDENETLAWAVVDLPETAGRTFIE INEL FRLGVPARKFKS TKVD PFAAAKAAAAEINVKDPKEDI : . : ${ }^{\star \star}{ }^{\star}::^{\star}:{ }^{\star \star}::^{\star \star \star}:{ }^{\star}{ }^{\star}:$.

Figure 41. Multisequence alignment of four putative maltose permease-like protein sequences from MphA (Aspergillus nidulans), Afu4g00150 (Aspergillus fumigatus), Mal11 (Aspergillus niger), Mal31 (Saccharomyces cerevisiae).

The predicted twelve transmembrane regions of the transporters are underlined. The conserved distinctive sugar motif as described by (Horák 1997) is highlighted in yellow. 


\subsubsection{MphA protein supports fungal growth and development}

A gene deletion of $m p h A$ was performed in an $n k u A \Delta$ (AGB552) parental strain. Hülle cells are observable in an $m p h A \Delta ; n k u A \Delta$ (AGB1077) strain. The dry weight of $m p h A \Delta$; $n k u A \Delta$ was determined from submerged liquid cultures and was reduced in comparison to the $n k u A \Delta$ strain and the complementation strain shown in Figure 42.

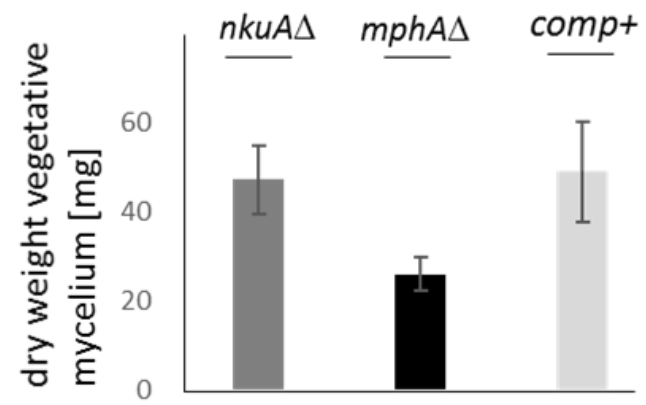

Figure 42.The MphA maltose permease-like protein supports vegetative growth.

Dry weight of vegetative mycelium concerning the parental strain (nkuA $\triangle$, AGB552), the deletion strain

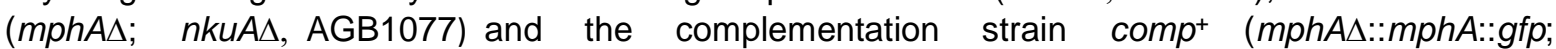
$n k u A \Delta, A G B 1078)$. Vegetative mycelium was harvested 20 hours after inoculation.

The percentage of conidiophores was determined from surface cultures and was reduced in comparison to the $n k u A \Delta$ strain and the complementation strain as shown at the end of this chapter. The development of cleistothecia was studied after three, five and seven days after germination (Figure 43). After three days, no cleistothecia could be observed in the $m p h A \Delta ; n k u A \Delta$ strain, whereas in the $n k u A \Delta$ and in the complementation mphA $\Delta:: m p h A:: g f p ; n k u A \Delta(A G B 1078)$ strain small non-pigmented primordia could be observed. Cleistothecia of $m p h A \Delta$; nkuA $\Delta$ were first visible after five days and at this time point, they were lightly pigmented. In the case of the $n k u A \Delta$ and the complementation strains, the cleistothecia were pigmented and larger in size. After seven days, the cleistothecia of $m p h A \Delta ; n k u A \Delta$ reached almost the size of the $n k u A \Delta$ strain but did not fully recover the pigmentation of cleistothecia. After 14 days, all observable cleistothecia of $m p h A \Delta ; n k u A \Delta$ were fully pigmented. After five days, the cleistothecia of $m p h A \Delta ; n k u A \Delta$ contained no dark reddish ascospores in contrast to the $n k u A \Delta$ and the complementation strain. Dark reddish ascospores could be observed after 14 days in the $m p h A \Delta ; n k u A \Delta$ strain. This finding firmly establishes that MphA supports generally growth, development and also the maturation of the cleistothecia. 


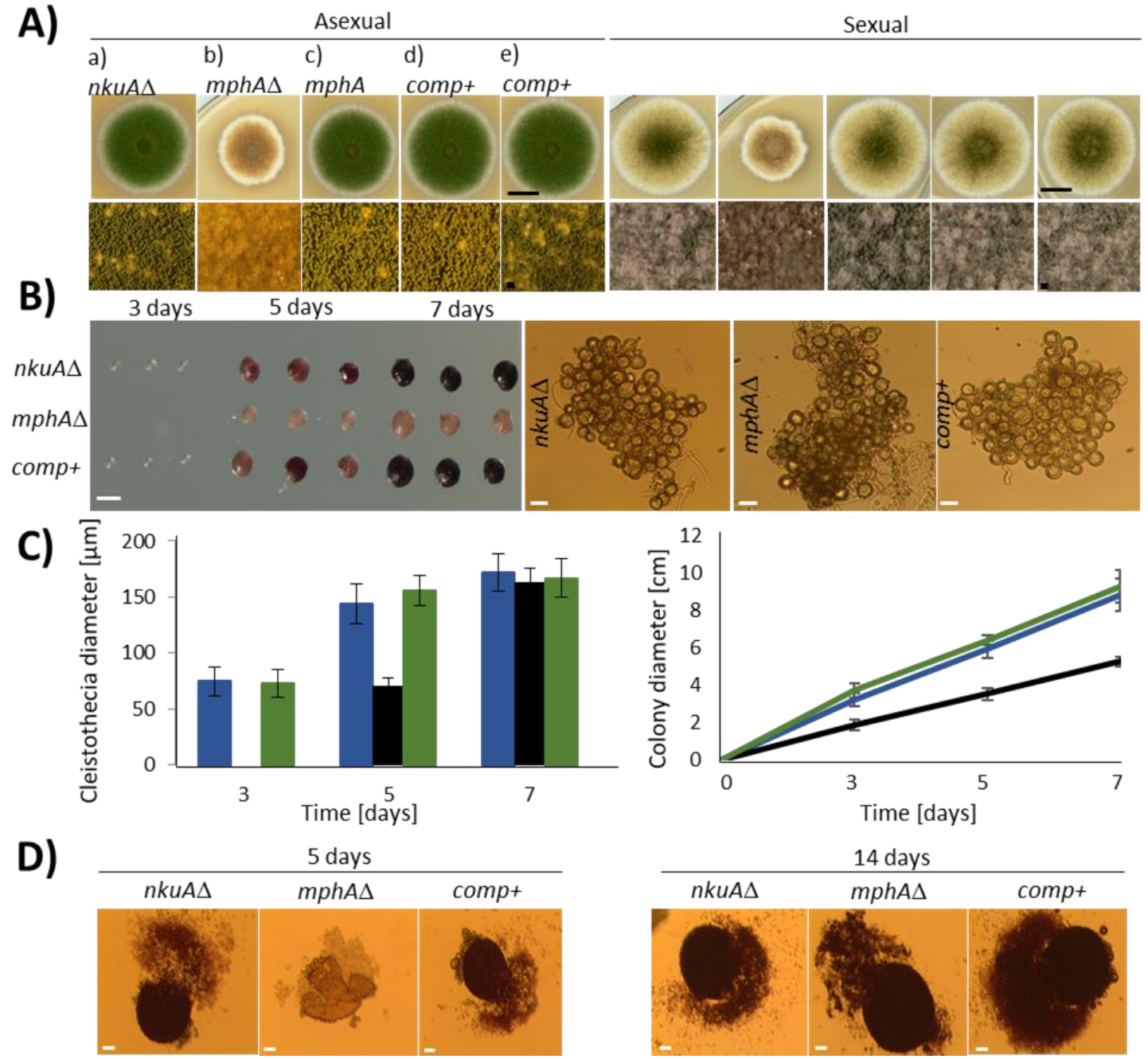

Figure 43. MphA promotes fungal growth and development.

(A) The gene $m p h A$ was knocked out in a a) nkuA (AGB552) strain receiving the b) $m p h A \Delta ; n k u A \Delta$ (AGB1077) strain. The phenotype could be restored in complementation strains with and without a

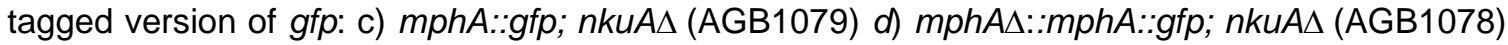
and e) $m p h A \Delta:: m p h A$ nkuA $(A G B 1080$ ). Fungal colonies scale bar is $1 \mathrm{~cm}$. Fungal mycelium scale bar is $100 \mu \mathrm{m}$. B) Cleistothecia were observed on day 3,5 and 7 after germination. 3 days after germination no primordia were observable in sexual mycelium of the deletion strain $(m p h A \Delta$; $n k u A \Delta)$. After 3 days small non-pigmented undeveloped primordia were observable in $n k u A \Delta$ and the complementation strain mphA $:: m p h A:: g f p ; n k u A \Delta\left(c o m p^{+}\right) .5$ and 7 days after germination most of the cleistothecia of the strain $m p h A \Delta$; $n k u A \Delta$ were not fully pigmented. Scale bar is 200 $\mu \mathrm{m}$. Hülle cells are shown and Hülle cells are observable in the deletion strain. Scale bar is $20 \mu \mathrm{m}$. C) The diameters of the cleistothecia were measured after 3, 5 and 7 days after germination. After 3 days the size of the primordia of the strains $n k u A \Delta$ (blue) and mphA $\Delta:: m p h A:: g f p ; n k u A \Delta$ (green); were around $70 \mu \mathrm{m}$ in diameter. After 5 days, the cleistothecia of the knockout strain (black) reached the size of around $70 \mu \mathrm{m}$. Meanwhile the strains $n k u A \Delta$ and $m p h A \Delta:: m p h A:: g f p ; n k u A \Delta$; reached the size of around $150 \mu \mathrm{m}$. On day 7 all three strains could reach the adult cleistothecia

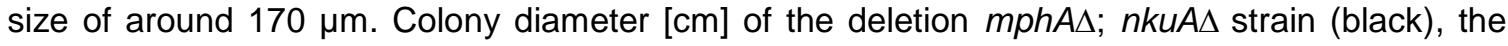
parental strain and the complementation strains were measured after 3, 5 and 7 days. Growth is reduced in the deletion strain in comparison to the $n k u A \Delta$ strain and the complementation strain. The knockout of $m p h A$ shows a defect in the development of ascospores. D) The production of dark reddish ascospores were observed in the $n k u A \Delta$ strain, in the knockout strain $m p h A \Delta ; n k u A \Delta$ and in the complementation strain mphA $:: m p h A:: g f p:: n k u A \Delta$ on day 5 and 14 after germination. Most of the cleistothecia of the knockout strain contained no observable ascospores on day 5 after germination. Instead of dark reddish ascospores only non-pigmented spores were observable. In contrast thereto dark reddish ascospores were observable in the strains $n k u A \Delta$ and the complementation strain mphA $::: m p h A:: g f p:: n k u A \Delta$. On day 14 all three strains were able to produce dark reddish ascospores. Scale bar is $50 \mu \mathrm{m}$. 


\subsubsection{MphA protein is localized to the envelope of Hülle cells}

The localization of MphA::GFP was studied in Hülle cells and in a vegetative mycelium. Therefore, the complementation strain mphA $\Delta:: m p h A:: g f p ; n k u A \Delta$ (AGB1079) was used. Hülle cells were enriched from sexual mycelium using the cleistothecia-rolling technique and the localization of MphA::GFP was mainly observable in the envelope of Hülle cells as shown in Figure 44A. MphA::GFP was also observable in the center of the Hülle cells. The parental strain nkuA $($ AGB552) without GFP and a strain expressing GFP constitutively (AGB596) were used as controls. Only autofluorescence could be detected in the $n k u A \Delta$ strain. The strain expressing GFP constitutively revealed that GFP is mainly visible in the cytoplasm of Hülle cells. Therefore, GFP was mainly observable in the center of Hülle cells and was unrepresentative in the envelope of Hülle cells. In a laeAs; $m p h A:: g f p$; $n k u A \Delta$ (AGB1081) strain almost no Hülle cells were observed. The remaining Hülle cells of a laeA $\Delta$ strain displayed almost no MphA::GFP. In the remaining hyphae MphA::GFP was much stronger detectable.

In order to observe MphA::GFP in vegetative hyphae the strains were grown in submerged liquid conditions for 20 hours and only autofluorescence could be detected in the mphA $\Delta:: m p h A:: g f p ; n k u A \Delta$ and the laeA $\Delta ; m p h A:: g f p ; n k u A \Delta$ strains (Figure $44 \mathrm{~B})$. This result was comparable to the observation of a $n k u A \Delta$ strain where only autofluorescence was detectable. The strain expressing GFP constitutively revealed that GFP is mainly visible in the cytoplasm of vegetative hyphae grown for 20 hours. These results show that MphA is most likely enriched in Hülle cells and is located mainly in the envelope of Hülle cells. Growing the complementation strain $m p h A \Delta:: m p h A:: g f p ; n k u A \Delta$ showed that MphA::GFP is not detectable in a vegetative mycelium grown within submerged cultures for 20 hours.

The sequence of MphA contains 540 amino acids with a predicted molecular mass of $60.3 \mathrm{kDa}$. Western hybridization experiments were performed without success since MphA::GFP, with an expected molecular mass around $87 \mathrm{kDa}$, was not detectable. This finding reveals that MphA is most probably enriched in sexually differentiated cells such as Hülle cells. 
A)
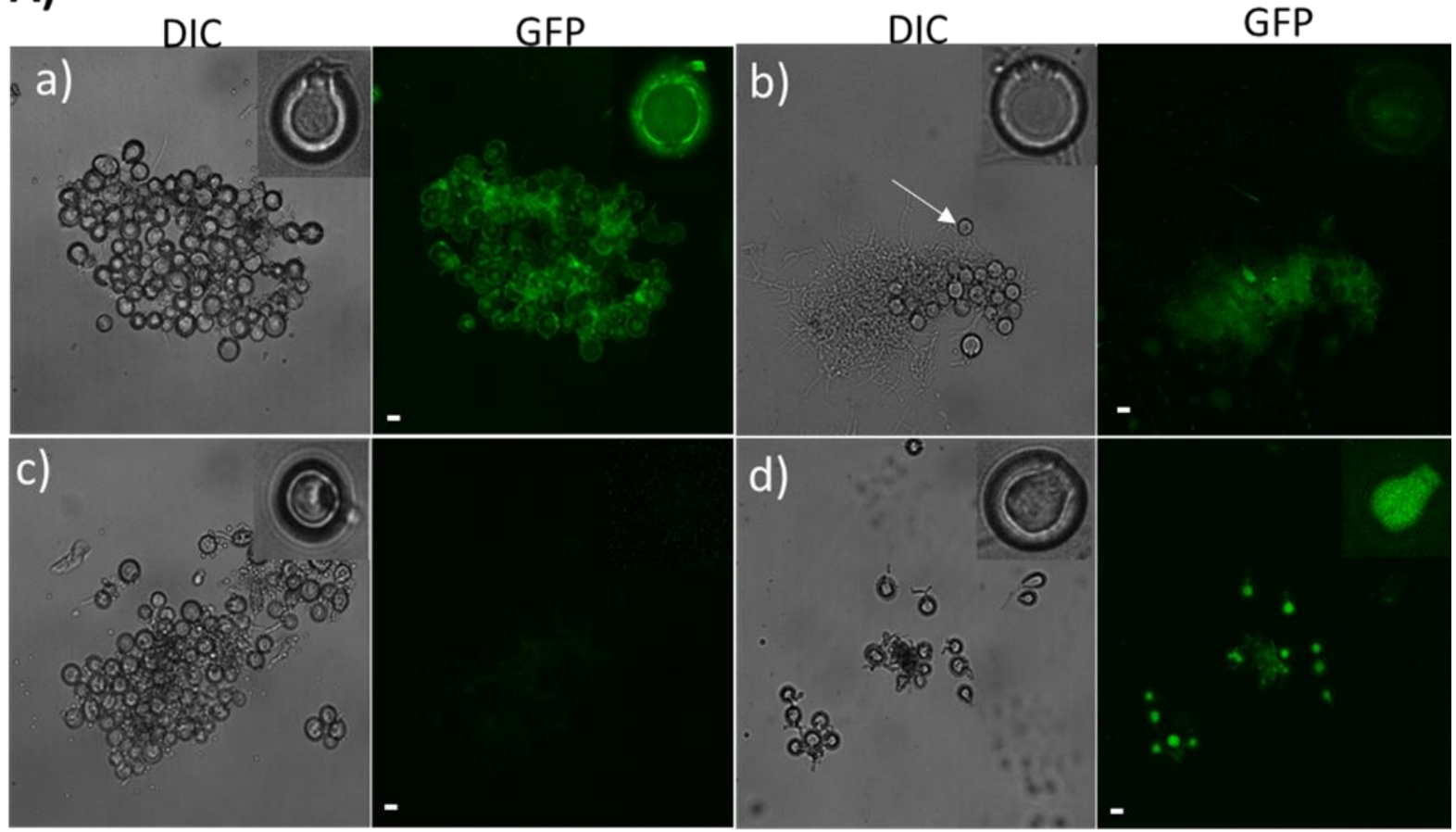

B)
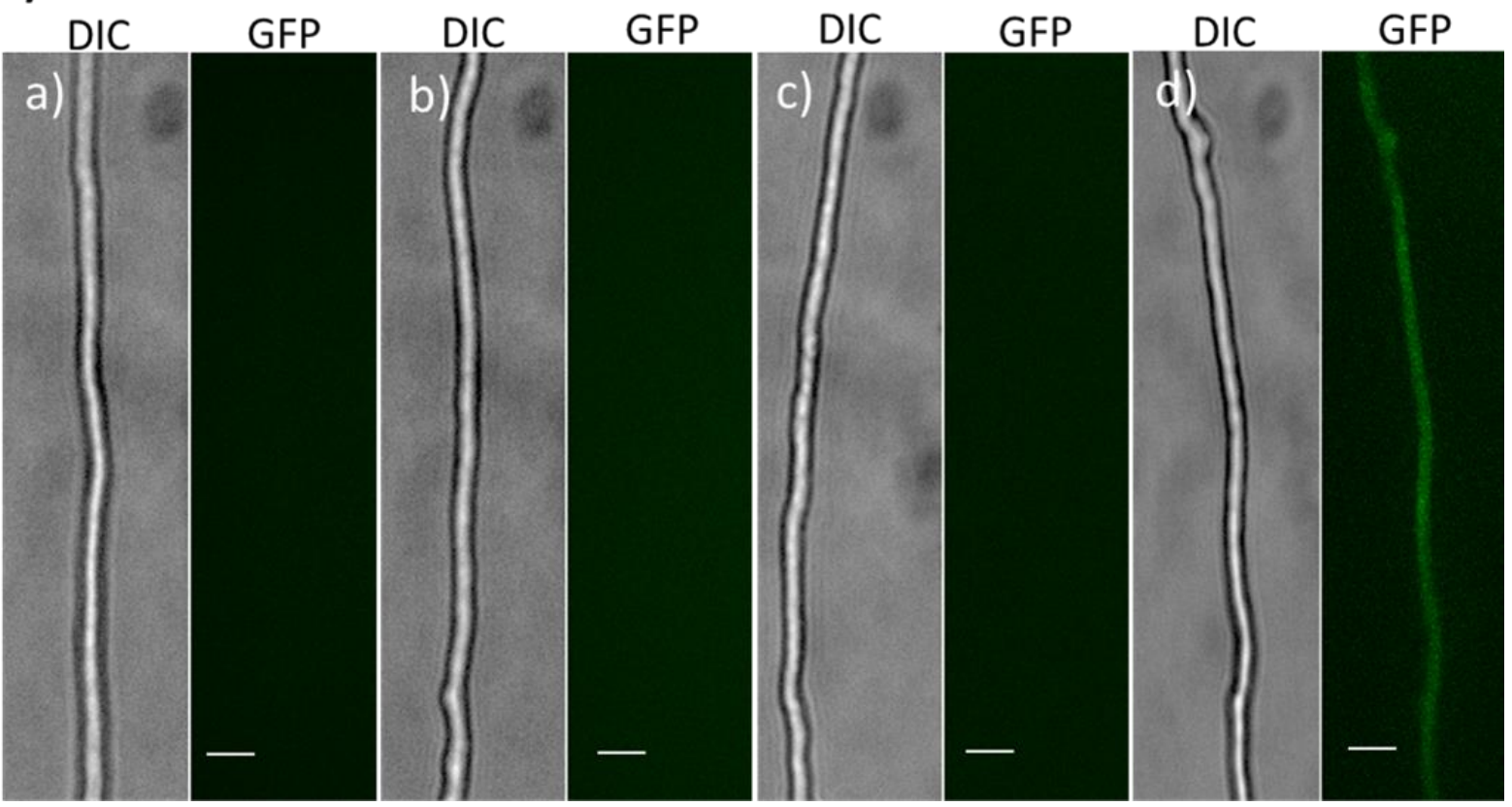

Figure 44. Localization of the maltose permease-like protein MphA.

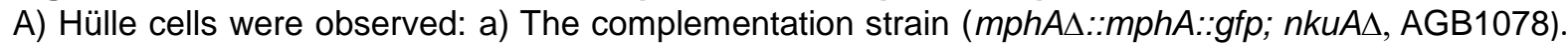
MphA::GFP is localized mainly to the envelope of Hülle cells. MphA::GFP was also detected inside of Hülle cells. b) laeA $\Delta:: m p h A:: g f p ; n k u A \Delta$ (AGB1081), where MphA::GFP was not clearly detectable in hyphae (white arrow points to one Hülle cell). c) nkuA $\Delta$ (AGB552) strain without GFP where mainly autofluorescence was detected. d) A strain expressing GFP constitutively (AGB596) where GFP was mainly detectable in the cytoplasm of Hülle cells. Scale bar is $10 \mu \mathrm{m}$. B) Vegetative mycelium was observed: a) In the complementation strain (mphA $:: m p h A:: g f p ; n k u A \Delta)$, MphA::GFP was not detectable. b) In the strain laeA $\Delta:: m p h A:: g f p ; n k u A \Delta$, no MphA::GFP was detectable. c) $n k u A \Delta$ strain where mainly autofluorescence was detected in the vegetative hypha d) A strain expressing GFP constitutively where GFP was mainly detectable in the cytoplasm of the vegetative hypha. Scale bar is $20 \mu \mathrm{m}$. 


\subsubsection{The deletion of $m p h A$ prevents mycelia differentiation at higher concentration of carbohydrates in an early developmental time point}

In order to investigate the influence of different carbohydrates on the phenotype of the deletion of $m p h A$, different disaccharides and monosaccharide with different concentrations were added to the media. The $n k u A \Delta$ strain and the deletion strain $m p h A \Delta ; n k u A \Delta$ plus the complementation strain were inoculated on solid agar plates containing $1 \%$ or $5 \%$ of different carbohydrates. Three different carbohydrate sources were used and the influence of the different carbohydrates were observed three days after germination. The phenotype of the $m p h A$ deletion strain changed significantly in the case of growing the fungus on a medium containing $5 \%$ of different carbon sources such as disaccharides or monosaccharide. Hülle cells and primordia could not be observed growing the strain $m p h A \Delta$ for three days on $5 \%$ maltose (Figure $45 \mathrm{~A}$ ).

The addition of $5 \%$ maltose to the medium influenced the development of the deletion strain negatively. Therefore, Hülle cells and conidiophores were significantly reduced and instead the fungus formed undifferentiated aerial hyphae after 3 days. The percentage of observable conidiophores in mycelia was determined (Figure 45B). The addition of $5 \%$ glucose or sucrose to the medium had a weaker effect on the phenotype of the mphA deletion strain in contrast to the above mentioned $5 \%$ maltose. This shows that the deletion of $m p h A \Delta$ responds negatively to high concentrations of different carbohydrates since the transportation of carbohydrates is affected in this strain. Adding $1 \%$ maltose resulted in a differentiation of the mycelium, but with reduced development. This was also the case by adding $1 \%$ glucose or sucrose to the media. This supports the observation that with higher concentration of maltose and without the transporter MphA the fungus reacts negatively on developing complex structures such as Hülle cells or conidiophores and instead forms an undifferentiated mycelium.

The key point of this thesis is that the central observations demonstrate that sexual differentiation increases monodictyphenone $(m d p)$ and xanthone $(x p t)$ biosynthetic proteins localized in different sexual cell types. Genetic studies of the deletion strain $m p h A \Delta$ illustrated that MphA protein promotes fungal growth, asexual and sexual development. 

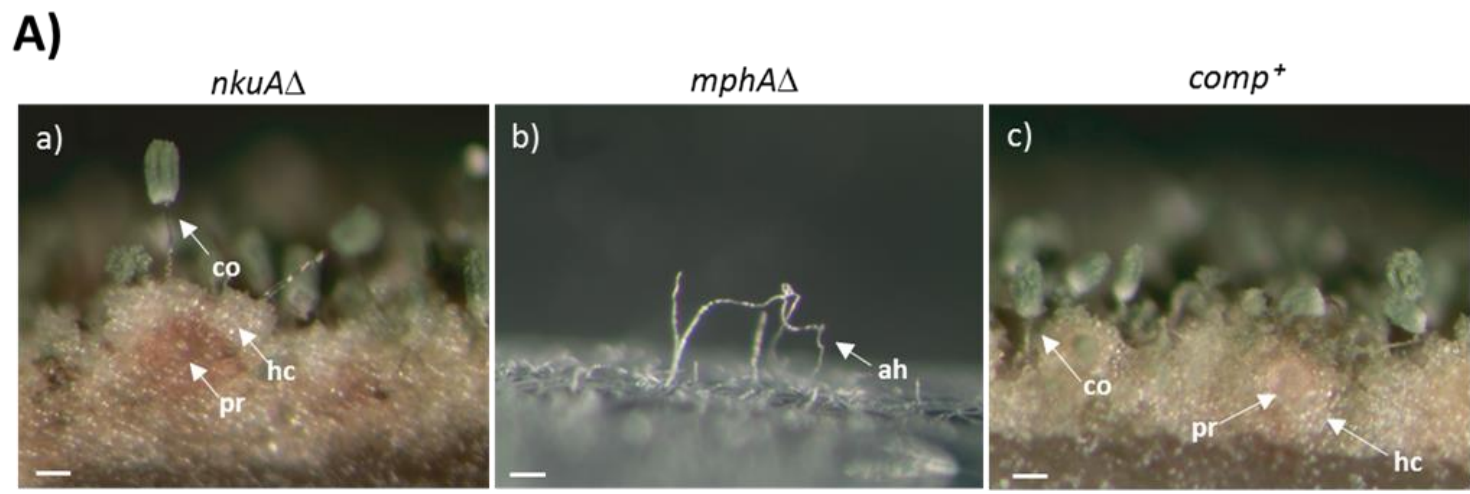

B)
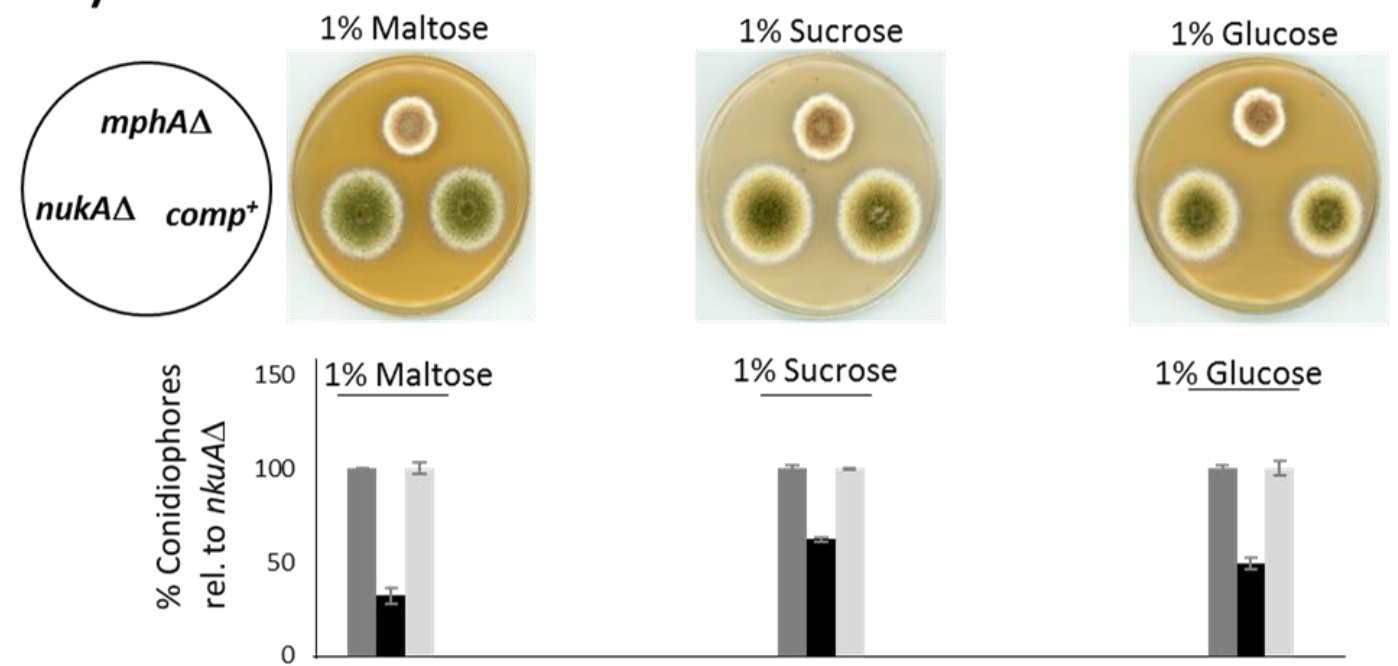

\section{$1 \%$ Glucose}

5\% Maltose

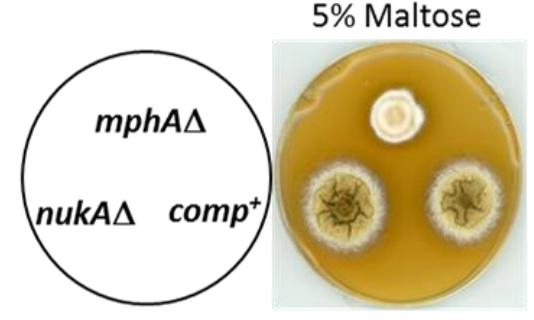

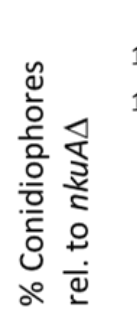

$1 \%$ Sucrose
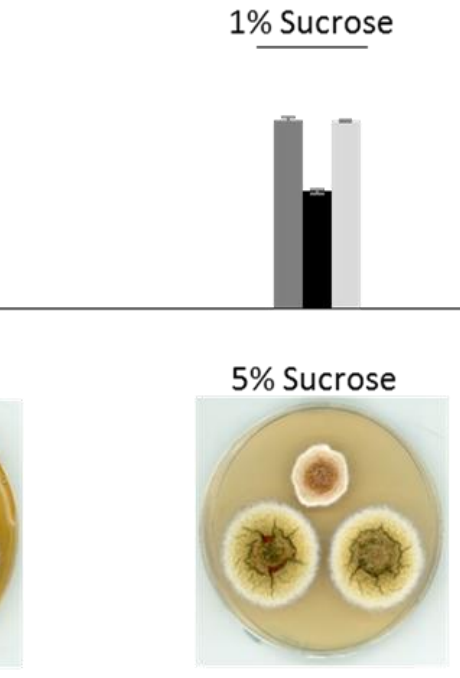

$5 \%$ Sucrose

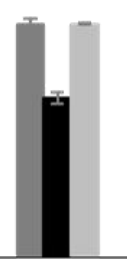

$5 \%$ Glucose

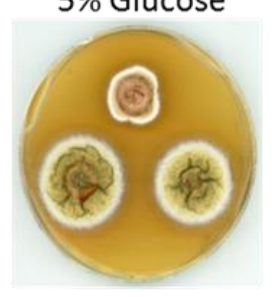

$5 \%$ Glucose

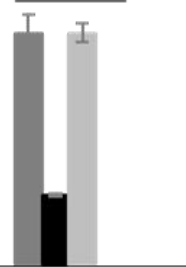

Figure 45. The maltose permease-like protein MphA prevents mycelia differentiation at higher concentration of carbohydrates.

A) Cross section of sexual mycelium three days after inoculation. a) The parental strain ( $n k u A \Delta$, AGB552) b) deletion strain mphA $(m p h A \Delta ; n k u A \Delta, A G B 1077)$ and c) complementation strain $c o m p^{+}(m p h A \Delta:: m p h A ; n k u A \Delta, A G B 1080)$ were inoculated on solid agar plates containing $5 \%$ maltose. In the case of the nkuA $\Delta$ (AGB552) and the complementation strain (AGB1080) sexual (pr: primordium, hc: Hülle cells) and asexual structures (co: conidiophore) were observable. Cleistothecia are surrounded by hundreds of Hülle cells. In the case of $m p h A \Delta ; n k u A \Delta$ (AGB1077) mainly aerial hyphae (ah: aerial hyphae) were observed. Scale bar is $50 \mu \mathrm{m}$. B) The percentage of observable conidiophores relative to the parental strain $n k u A \Delta$ was determined and was significantly reduced in

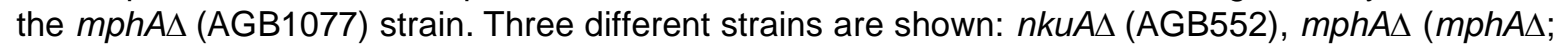
$n k u A \Delta, A G B 1077)$ and $c o m p+(m p h A \Delta:: m p h A ; n k u A \Delta, A G B 1080)$. 


\section{Discussion}

Fungal mutant strains, which are unable to produce Hüll cells, form only small cleistothecia. This suggests that Hülle cells might have a nursing function for the cleistothecia (Sarikaya-Bayram et al., 2010, Braus et al., 2002). This thesis aimed to define specific proteins associated to sexual fungal tissue with a specific emphasis on Hülle cells. Comparative proteomic was used to determine proteins from Hülle cell fractions enriched from surface and submerged liquid cultures. Genetic methods were accomplished to investigate the function of the corresponding genes of the proteins that were identified in the comparative proteomic approach. The major finding of this thesis is that sexual differentiation increases monodictyphenone $(m d p)$ and xanthone (xpt) biosynthetic proteins localized in different sexual cell types. Besides a maltose permease-like protein was identified in Hülle cells that supports fungal growth and development.

\subsection{Hülle cells and sexual tissue grown on solid agar plates revealed the presence of proteins for the synthesis of an antimicrobial substance}

One of the main findings of this thesis is that biosynthetic proteins encoded by the monodictyphenone $(m d p)$ / xanthone $(x p t)$ gene clusters are enriched in Hülle cells and sexual tissue, in comparison to other fungal tissue types (Figure 46). Bayram and co-workers showed that the monodictyphenone $(m d p)$ / xanthone (xpt) gene clusters are specially expressed during sexual development (Bayram et al., 2016). This correlates with the findings of this thesis since expectedly during sexual differentiation biosynthetic proteins encoded by the monodictyphenone ( $m d p)$ / xanthone $(x p t)$ gene clusters are present. These proteins are diminished in other fungal tissues. Furthermore, the present study shows that these proteins are localized in Hülle cells during sexual development. It seems that biosynthetic proteins for the synthesis of monodictyphenone and xanthones are most probably present all over the sexual mycelium, especially within enriched Hülle cells. 


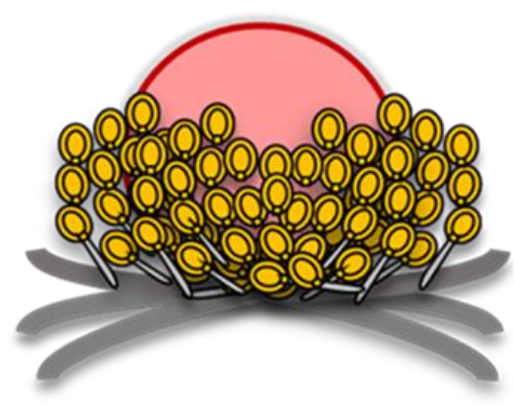

Dark

$m d p / x p t$ gene

clusters active

Antimicrobial

agent

Sexual tissue \&

Hülle cells

Protective

capacity

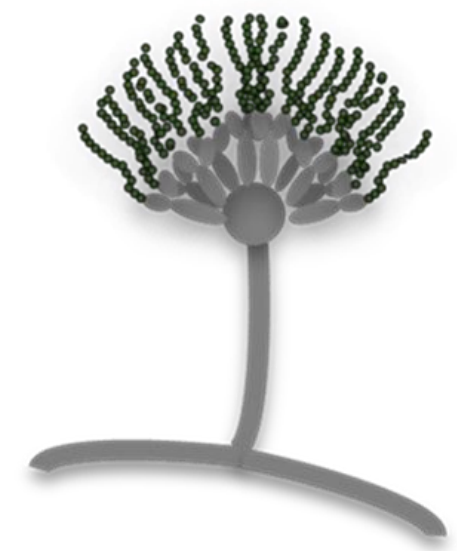

Light

mdp/xpt gene clusters inactive

No antimicrobial agent

No presence in asexual tissue

No protective capacity

Figure 46. The monodictyphenone $(m d p)$ / xanthone (xpt) gene clusters are active in sexual tissue including Hülle cells from surface growth.

Biosynthetic proteins encoded by the monodictyphenone $(m d p)$ / xanthone (xpt) gene clusters are enriched during sexual development. Monodictyphenone and xanthones are antimicrobial agents. The presence of monodictyphenone and xanthones lead to the assumption that the cleistothecium is protected against various harsh environmental situations like fungivory. In asexual tissue the monodictyphene (mdp) / xanthone (xpt) gene clusters are inactive. The compounds of monodictyphenone and xanthones are consequently not present. It seems to be that monodictyphenone and xanthones are not protecting the conidiophores (Bayram et al., 2016).

This suggests that the synthesis of an antimicrobial substance is crucial during maturation of the cleistothecia. This finding aligns to the insight that the cleistothecia of Aspergillus nidulans covered with Hülle cells are more resistant against fungivory when comparing to a vegetative or asexual tissue (Döll et al., 2013). Furthermore, it was shown that monodictyphenone reduces the egg laying activity of Drosophila melanogaster on an A. nidulans mycelium (Regulin and Kempken 2018). Both findings validate the assumption that Hülle cells have a protective capacity. 
Limitations to the findings are that not all biosynthetic proteins encoded by the monodictyphenone $(m d p)$ / xanthone $(x p t)$ gene clusters were present in sexual tissue and Hülle cells. This also correlates to other studies, because not all genes of the monodictyphenone $(m d p)$ / xanthone (xpt) gene clusters were expressed (Bayram et al., 2016). The monodictyphenone ( $m d p)$ gene cluster is located at the silent telomeric region of chromosome VIII. This could lead to the assumption that the expression of the monodictyphenone $(m d p)$ gene cluster is generally reduced under laboratory conditions. Biosynthetic proteins encoded by the monodictyphenone $(m d p)$ gene cluster are required for the production of the precursor monodictyphenone. This compound is converted into prenyl xanthones (Sanchez et al., 2011).

Interestingly genes for the production of xanthones are not embedded in the monodictyphenone ( $m d p)$ gene cluster. Biosynthetic proteins encoded by both gene clusters are present in sexual mycelium and Hülle cells. This suggests that both gene clusters collaborate, further correlating with other insights. Sanchez and co-workers showed that these two gene clusters collaborate for the synthesis of xanthones (Sanchez et al., 2011).

The findings of this thesis indicate that Hülle cells contain biosynthetic proteins for the synthesis of antimicrobial substances such as xanthones. This leads to the assumption that Hülle cells have a protective capacity during the maturation of cleistothecia.

\subsection{Submerged liquid cultures revealed the presence of the prenyltransferase NptA and the serine/threonine kinase RfeA in Hülle cells and in other fungal tissues}

Proteins from liquid cultures were analyzed and quantified. A laeA $\Delta$ strain with abolished Hülle cells was used for this analysis. The result was compared to the parental strain which produces Hülle cells (Figure 47). Biosynthetic proteins encoded by the monodictyphenone $(m d p)$ / xanthone $(x p t)$ gene cluster were present. Besides of that the prenyltransferase NptA and the serine/threonine kinase RfeA which are involved in the process of secondary metabolism are localized to Hülle cells and other fungal tissues. 


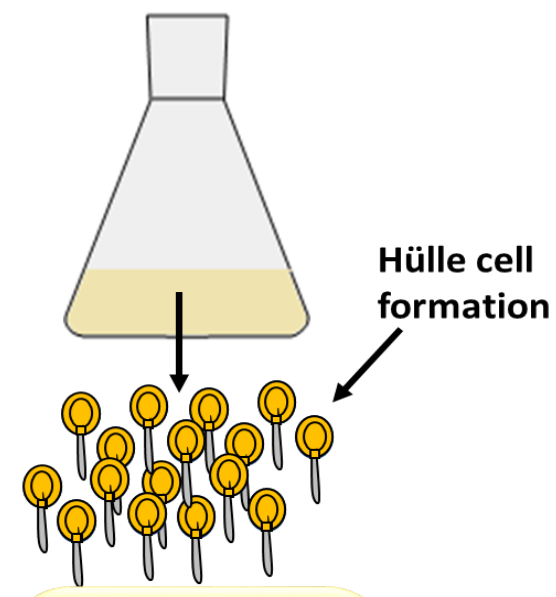

Increased Hülle cell formation in nkuA $\Delta$ strain + mutation (unknown)

Prenyltransferase NptA present

Serine/threonine kinase RfeA present

NptA and RfeA localized in Hülle cells and other fungal tissue

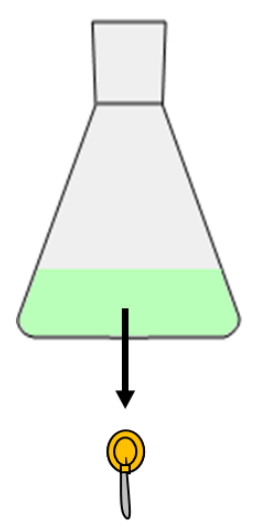

Reduced Hülle cell formation in laeA $\Delta$ strain

Prenyltransferase NptA almost absent Serine/threonine kinase RfeA reduced Localization reduced in fungal structures

Figure 47. Hülle cell formation in submerged liquid cultures and comparison of two strains causing different results.

In a $n k u A \Delta$ parental strain with an unknown mutation increased Hülle cell formation is observable whereas in a laeA $\Delta$ strain reduced Hülle cell formation occurs. Both strains are shown under submerged liquid conditions. The protein amount of the prenyltransferase NptA and the serine/threonine kinase RfeA is significantly reduced in laeA $\Delta$ strain in comparison to the parental strain. The protein quantity of NptA is almost not detectable in a laeA $\Delta$ strain. NptA and RfeA are localized in Hülle cells and other fungal tissues. The localization of these proteins is reduced in a laeA $\Delta$ mycelium in different fungal structures.

Alves and co-workers showed that after the addition of the nutrient choline Hülle cell formation occurred in submerged liquid cultures and the compound monodictyphenone was present (Alves et al., 2016). This suggests that a vegetative mycelium forming Hülle cells in submerged liquid cultures has the potential to produce an antimicrobial agent. This aligns to the insights of this thesis since biosynthetic proteins for the production of monodictyphenone and xanthones are observable in submerged liquid cultures. 
This could lead to the assumption that Hülle cells, present in these submerged liquid cultures, produce also these proteins. These proteins also appear in hyphal structures. Cleistothecia are normally not formed in submerged liquid cultures. This is why the production of monodictyphenone, that has a protective capacity is noteworthy in submerged liquid cultures. The presence of proteins encoded by the monodictyphenone $(m d p)$ / xanthone (xpt) gene clusters is unexpected in submerged liquid cultures since the production of monodictyphenone and xanthones are linked to the sexual development of the fungus (Bayram et al., 2016).

In order to analyze proteins from submerged liquid cultures, a laeA $\Delta$ strain was used. In a laeA $\Delta$ strain, the formation of Hülle cells is abolished in comparison to a $n k u A \Delta$ strain with an additional unknown mutation that produce increased numbers of Hülle cells under submerged conditions. As expected, a laeA $\Delta$ strain correlates with abolished Hülle cells (Sarikaya-Bayram et al., 2010). A. nidulans wild-type (FGSC A4 Glasgow, ve $A^{+}$) usually forms no Hülle cells or cleistothecia in submerged conditions. Prolonging the growth has no effect on the production of Hülle cells (Bayram et al.,

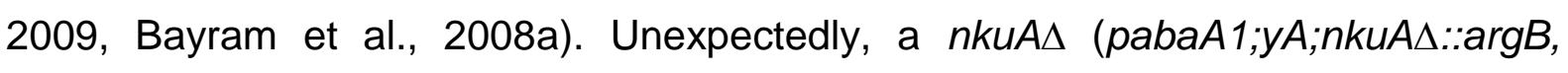
AGB552) parental strain that contains an additional unknown mutation produces enlarged numbers of Hülle cells in submerged liquid cultures. Bayram and co-workers showed that after deleting the cryA gene that encodes a cryptochrome/photolyase Hülle cell formation occurred in submerged liquid cultures. Furthermore, it was shown that CryA has a function in DNA-repair (Bayram et al., 2008a). The gene $n k u A$ encodes an ATP-dependent DNA helicase II that is involved in the repair process of doublestrand breaks in DNA (Nayak et al., 2006). DNA repair activities possibly have an influence on the formation of Hülle cells in submerged liquid conditions. A variety of possible mutations in the nkuA $\triangle$ (AGB552) strain could most probably cause the production of Hülle cell formation in submerged liquid cultures. This mutation could be caused by single-nucleotide polymorphism (SNP) and this leads to a diverse possibility of mutations that could cause Hülle cell formation in submerged cultures.

Bok and co-workers showed that a prenyltransferase $t i d B$ was not expressed in a laeA $\Delta$ mycelium in comparison to the wild-type (Bok et al., 2006). The same applies to the insight of this study regarding the prenyltransferase NptA, since the protein quantity of NptA is significantly reduced in laeAs. 
This is consensual and expected since it is known that LaeA regulates more than $50 \%$ of all secondary metabolite gene clusters in various fungi (Sarikaya-Bayram et al., 2010, Dhingra et al., 2013, Zhao et al., 2017). Andersen, Oakley and co-workers predicted that the prenyltransferase NptA is involved in the prenylation of nidulanin $A$ (Andersen et al., 2013, Oakley et al., 2017). The addition of stable isotope labeled amino acids to $A$. nidulans cultures and the incorporation of these labels into nidulanin $A$, revealed that this compound is a tetracyclopeptide consisting of four different amino acids (Klitgaard et al., 2015).

The finding of this thesis is that the prenyltransferase NptA is localized in the cytoplasm of Hülle cells and other fungal tissues. Therefore, the prenylation of a cyclopeptide such as nidulanin A might also occur in Hülle cells. Besides of NptA which is reduced in a laeA $\Delta$ strain additional proteins such as tRNA ligases are also reduced. It was shown that cyclopeptides influence the production of chlamydospores in Candida albicans (Spraker et al., 2016). This supports the assumption that cyclopeptides may have an influence on Hülle cells.

A serine/threonine kinase $\mathrm{RfeA}$ is not yet characterized in detail and in silico analyses showed that it is a protein kinase with a predicted role in secondary metabolic regulation (Mogensen et al., 2006). Deletion of $r f e A$ in $A$. nidulans had no effects on fungal development (De Souza et al., 2013). Findings of this thesis revealed that the serine/threonine kinase RfeA is localized in different fungal tissues such as Hülle cells and is reduced in a laeA $\Delta$ mycelium. This shows that beside LaeA as a key regulator in secondary metabolism RfeA might also be involved in the process of secondary metabolism. The amino acid sequence identity shared between RfeA and their Homo sapiens homologs is $32 \%$ to Chk1 (Stajich et al., 2012). The serine/threonine-specific protein kinase Chk1 encoded by the chek1 gene coordinates DNA damage response (Kabeche et al., 2018). Again, possible DNA repair activities of RfeA could have an influence on Hülle cells. The finding of this thesis indicates that increased Hülle cell formation in submerged cultures is observable in a $n k u A \Delta$ parental strain together with an additional mutation. This is in contrast to a laeA $\Delta$ strain that causes a significant reduction in Hülle cell formation. Moreover, NptA and RfeA are reduced in a laeA $\Delta$ strain. 


\subsection{Hülle cells from surface and liquid cultures comprise shared proteins encoded by the monodictyphenone ( $m d p)$ / xanthone (xpt) gene clusters}

In order to perform a comparative proteomic approach cultures derived from solid agar plates and submerged liquid media were analyzed. Hülle cells from solid agar plates and submerged liquid cultures were enriched and proteins found in both types of cultures were analyzed. In order to perform the investigation in submerged liquid cultures a nkuA $\Delta$ strain with an additional unknown mutation which forms increased numbers of Hülle cells in submerged liquid cultures was compared to a laeA $\Delta$ strain which under these conditions forms less Hülle cells. The comparison of Hülle cells from surface and liquid cultures shows that both cultures comprise shared proteins encoded by the monodictyphenone $(m d p)$ / xanthone $(x p t)$ gene clusters (Figure 48). The ankyrin repeat domain protein AnkG (AN8434) and a the tyrosinase domain protein (AN8435) are also commonly observable in both cultures. The maltose permease-like protein MphA is observable in enriched Hülle cells from surface cultures. In liquid cultures MphA seems not to be clearly present.

Findings of this thesis showed that different approaches to enrich Hülle cells led to different results. In order to increase the enrichment of Hülle cells from solid agar plate cultures the cleistothecia-rolling technique was applied. Enriched Hülle cell fractions from surface agar plate compared to a submerged liquid culture represent a small amount of starting material. In comparison homogenous material in a submerged liquid culture represents optimal conditions for proteomics. This might be the reason why only 401 solid agar plate culture proteins were identified from enriched Hülle cell fractions. From vegetative mycelia 974 proteins could be identified and differed in more than $50 \%$ compared to the 401 proteins mentioned above.

Limitation in quantification of protein abundances within the SILAC approach need to be considered. The use of only lysine auxotropic parental strains instead of lysine in combination with arginine auxotrophic parental strains limited the quantification of a complete pattern of fungal proteins. Peptides that contain arginine residues were therefore not considered for the quantification. Peptides that only contain isotopically labeled L-lysine reduce the quantification of protein abundances in complex mixtures. 
Sexual mycelium

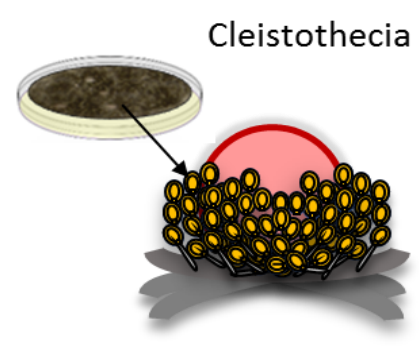

Surface Hülle cells

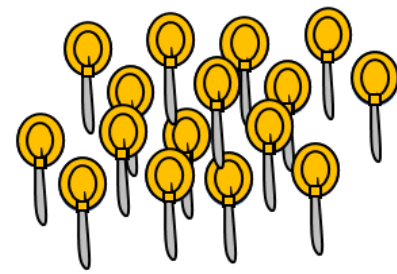

\section{Small amount of starting material, Hülle cells enriched by cleistothecia- rolling technique \\ Mdp/Xpt protein levels present}

AN8434, AN8435

present

MphA mainly present

\section{Vegetative mycelium}

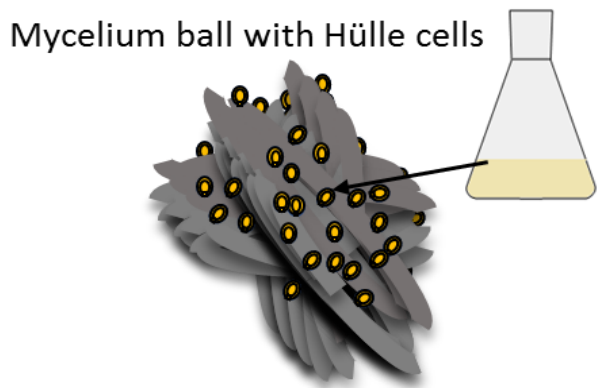

Liquid Hülle cells

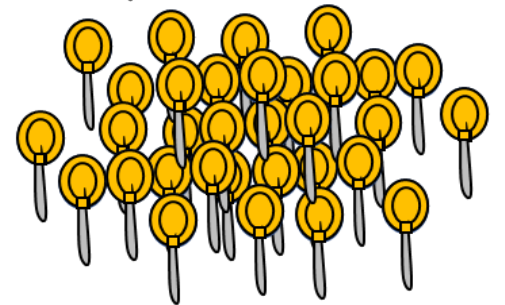

\author{
Higher quantity of \\ starting meterial, \\ Hülle cells enriched \\ by itself
}

\section{Mdp/Xpt protein levels present}

\author{
AN8434, AN8435 \\ present
}

MphA seems to be underrespresented

\section{Figure 48. The comparison of the proteome of both types of Hülle cells.}

The picture shows Hülle cells that are situated in a mycelium grown on surface agar plates or in submerged liquid cultures. On the left-hand side hundreds of Hülle cells surround the cleistothecium grown on solid agar plate and are enriched by the cleistothecia-rolling technique. On the-right hand side Hülle cells are shown in a mycelium ball of a submerged liquid culture. This culture contains thousands of small vegetative mycelium balls with Hülle cells. After 72 hours the undifferentiated vegetative mycelium is capable to produce Hülle cells. These Hülle cells are rather randomly distributed and are not in contact with the cleistothecia since they are not produced in liquid cultures. Hülle cell enrichment is enhanced by itself. Hülle cells contain increased monodictyphenone $(m d p) /$ xanthone (xpt) biosynthetic protein levels. The ankyrin domain protein (AN8434) and the tyrosinase domain protein (AN8435) are found in both types of Hülle cells. The maltose permease-like protein MphA (AN2601) seems to be mainly present in Hülle cells grown on solid agar plates. 
Besides of technical issues, thereare several biological reasons why the different approaches led to different outcomes. Hülle cells in vegetative mycelia in submerged liquid cultures are rather randomly distributed throughout the mycelia ball. In comparison Hülle cells are associated with the cleistothecia on solid agar plate cultures. The development of cleistothecia on surface cultures leads to differences in the composition of the proteome. Formation of cleistothecia on surface cultures most likey requires different carbohydrate transporters (Wei et al., 2004). This could be the reason why MphA is not clearly represented in submerged liquid cultures since cleistothecia are not usually formed under these conditions.

Interestingly biosynthetic proteins encoded by the monodictyphenone (mdp) / xanthone (xpt) gene clusters are present in both cultures. During initial vegetative growth phase, the fungus produces less secondary metabolites (Calvo et al., 2002). The production of secondary metabolites is specifically linked to the distinct developmental programs of the fungus (Bayram et al., 2016). Martins and co-workers showed in a proteomic study that after the addition of the nutrient choline, Hülle cell formation occurred in submerged liquid cultures and proteins encoded by secondary metabolite clusters were found (Martins et al., 2013). It is interesting that in a vegetative growth where Hülle cell formation occurred biosynthetic proteins encoded by the monodictyphenone $(m d p)$ / xanthone $(x p t)$ gene clusters are observable. It seems that the formation of Hülle cells in submerged liquid cultures goes along with the production of proteins which are required for biosynthesis of monodictyphenone and xanthones which are antimicrobial substances.

Different outcome from cultures on solid agar plate and under liquid conditions shows that biosynthetic proteins of the monodictyphenone ( $m d p)$ / xanthone $(x p t)$ clusters are present in both cultures. Only the MphA protein does not seem to be clearly represented in submerged liquid cultures. This could lead to the assumption that MphA has a specific function during surface growth. One of these functions could be the nursing of cleistothecia. 


\subsection{Hülle cells from surface growth and liquid media comprise an ankyrin and a tyrosinase protein}

The AnkG (AN8434) ankyrin repeat domain protein and the tyrosinase domain protein (AN8435) were found in both approaches. The domain architecture of the AnkG (AN8434) ankyrin repeat domain protein and the tyrosinase domain protein (AN8435) is shown in Figure 49.
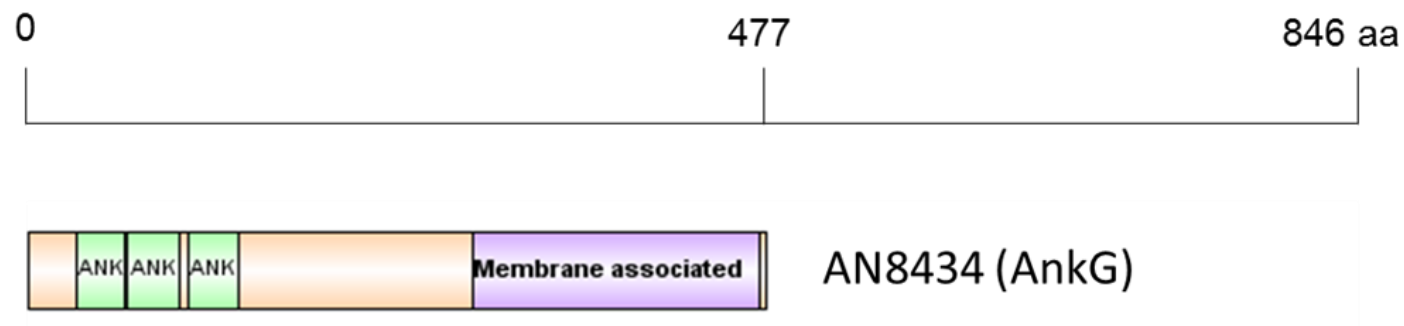

AN8434 (AnkG)

Figure 49. Domain architecture of the AnkG (AN8434) ankyrin repeat domain protein and the tyrosinase domain protein (AN8435).

The sequence of the AnkG ankyrin repeat domain protein of $A$. nidulans comprises 477 amino acids contains three ankyrin repeat domains and seems to have a membrane associated region (with a von Willebrand factor typ A-like domain). The sequence or the tyrosinase domain protein (AN8435) comprises 846 amino acids and a tyrosinase domain (Jones et al., 2014).

The present thesis sheds light on the localization of the ankyrin repeat domain protein AnkG to the membrane of the subtending hyphae of Hülle cells. This aligns to the findings that ankyrin proteins are localized to membranes (Islam et al., 2018). Interestingly AnkG was underrepresented in the membrane of vegetative hyphae and therefore AnkG might play a role in the outer membrane of the subtending hyphae of Hülle cells. During initial growth AnkG is most likely situated also in the endoplasmic reticulum (ER) of vegetative hyphae. AnkG is most probably transported by vesicle mediated transportation to the membrane of the subtending hyphae of Hülle cells (Figure 50). During vegetative growth the fusion protein AnkG::GFP is probably situated in the ER as well as in the cytoplasm shown in Figure $37 \mathrm{E}$ ). The localization of AnkG::GFP in subtending hyphae is shown in Figure $37 \mathrm{~B}$ ). 
A)

Vegetative hyphae

B)

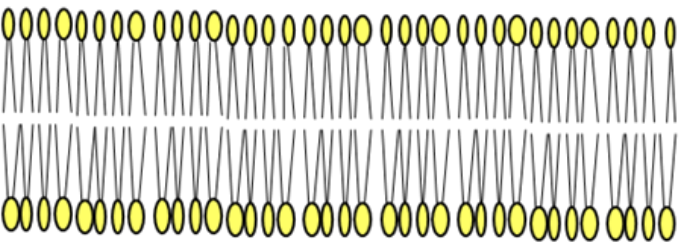

Subtending hyphae of Hülle cells

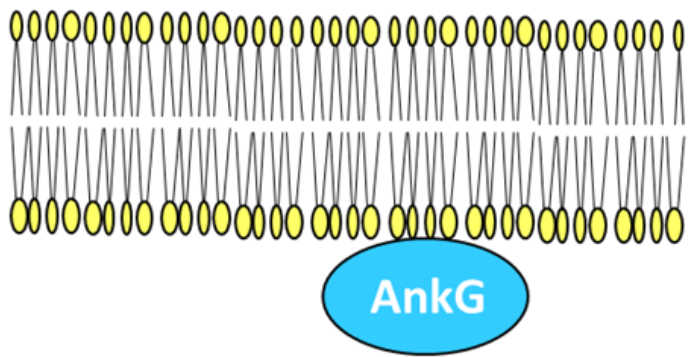

Golgi apparatus
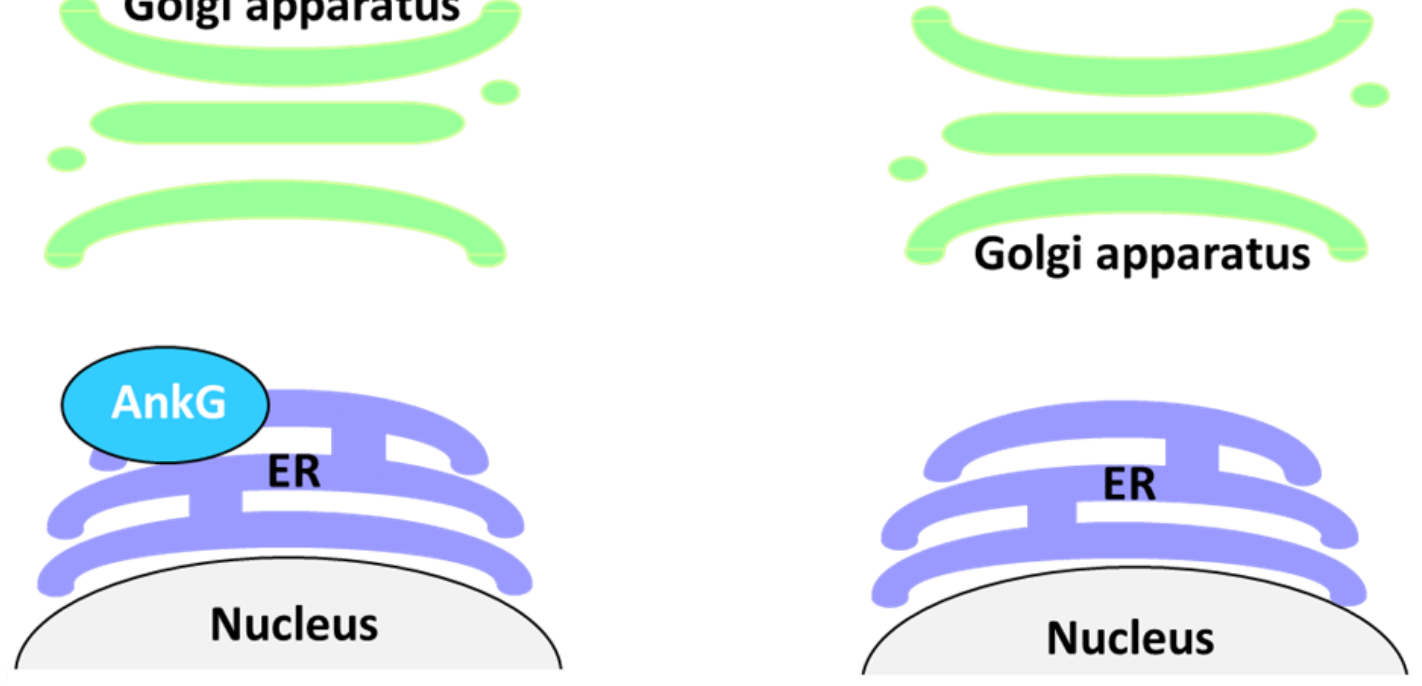

Figure 50. Protein trafficking of the AnkG ankyrin domain protein.

A) During initial vegetative growth AnkG is underrepresented in the membrane. It seems that AnkG is localized in the endoplasmic reticulum (ER) as well as in the cytoplasm during initial vegetative growth.

B) Subsequently AnkG is transported to the subtending hyphae of Hülle cells.

Ankyrin repeat domain proteins are involved in the process of trafficking tyrosinase into melanocytes (Tamura et al., 2011). Melanocytes are cells which produce melanin for pigmentation. Non-pigmented cleistothecia such as those in Aspergillus tonophilus or Aspergillus fisheri are accompanied with the lack of Hülle cell formation (Hermann, et al., 1983). This goes along with the absence of the laccase II CpeA that is localized in Hülle cells (Scherer et al., 2002). Tyrosinase and laccase are known to be involved in the regulation and production of melanin pigmentation (Chai et al., 2017, Hsu et al., 2016). This supports the finding that Hülle cells have an auxiliary function in pigmentation during cleistothecia maturation. The possible localization of the tyrosinase domain protein AN8435 in Hülle cells supports the finding that Hülle cells have an auxiliary function in pigmentation of the cleistothecia. This aligns to the finding that in different Aspergilli without Hülle cells the cleistothecia are not pigmented. 
Tyrosinases are known to undergo a complex post-translational processing before reaching melanocytes. This process includes $\mathrm{N}$-glycosylation in several binding sites, movement from the endoplasmic reticulum (ER) to the golgi apparatus and copper binding (Olivares et al., 2003). As shown in Figure 39 and 40 fluorescence microscope investigation in combination with western hybridization suggest that the tyrosinase domain protein AN8435 found in different cellular compartments within fungal structures like Hülle cells is modified by a post-translational process. This corresponds to the fact that tyrosinase domains are post-translationally modified and are found in different cellular compartments (Olivares et al., 2003). The tyrosinase protein AN8435 seems to be unstable, which limited the observation of a precise localization.

Bayram and co-workers showed that the transcripts of AN8435 and AN8434 (ankG) are expressed in asexual and sexual mycelia (Bayram et al., 2016). This suggests that AN8434 (AnkG) and AN8435 are found in different mycelia types. This aligns to the findings of this thesis since AN8435 and AN8434 (AnkG) is present in different mycelia types including sexual and vegetative mycelia as well as Hülle cells.

The tyrosinase domain protein (AN8435) and the AnkG (AN8434) ankyrin repeat domain protein are encoded by neighbouring genes. This could be interpreted as a co-regulation of these proteins. Bayram and co-workers also suggested that the transcripts $A N 8435$ and $A N 8434$ (ankG) are expressed by a gene cluster which is involved in the production of an unknown pigment (Bayram et al., 2016). This supports the assumption that the proteins are co-regulated. 


\subsection{A maltose permease-like protein enriched in surface Hülle cells supports fungal growth and development}

A so far unknown maltose permease-like protein MphA was identified and investigated. The corresponding $m p h A$ gene was deleted in this study. The presence of the MphA maltose permease-like protein in Hülle cells mainly grown on solid agar plates supports the insight that Hülle cells have a function in nutrient supply during fungal growth (Wei et al., 2001). MphA protein was studied in this thesis and the localization of the protein was observed in Hülle cells. The studies revealed that MphA most probably is a membrane protein with difficulties in respect of solubilization. Western hybridization was performed but without success. MphA contains a distinctive sugar motif and comprises high sequence similarities to other carbohydrate transporters (Horák 1997). This suggests that MphA might be active in the transportation of carbohydrates (Figure 51). Since MphA supports growth in general, vegetative, sexual and asexual growth, it is assumed that MphA could also function in other cell types beside Hülle cells. MphA is not essential for Hülle cell formation when Hülle cells are formed on solid agar plates. Adding a high concentration of carbohydrates reduces the formation of early Hülle cells in a $m p h A \Delta$ strain. This is accompanied by a reduced maturation of the cleistothecia and the development of ascospores. Additionally, the development of conidiophores is stalled.

Several nutrient transporters were identified in Hülle cells. Fungal development especially the maturation of the cleistothecia was not effected by deleting the putative hexose $h x t A$ and the putative purine transporters uapA or azgA (Wei et al., 2004, Dos Reis et al., 2017, Pantazopoulou et al., 2007). This suggests that additional nutrient transporters are needed during maturation of the cleistothecia. Cleistothecia formation requires high amounts of energy in the form of carbohydrate initially stored in vegetative hyphae. This fact indicates an existence of effective transportation systems for nutrient uptake into the cells of developing cleistothecia (Pöggeler et al., 2006). As expected, alternative possible nutrient transporters were observed in Hülle cells in this study. 
A)

)
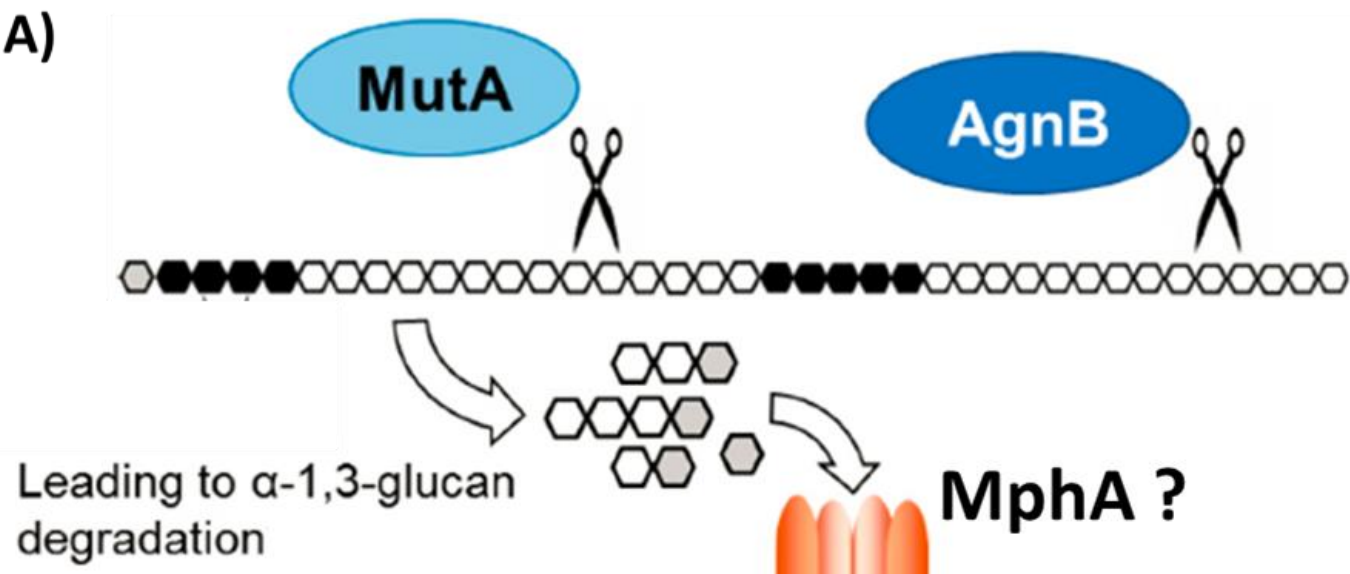
degradation

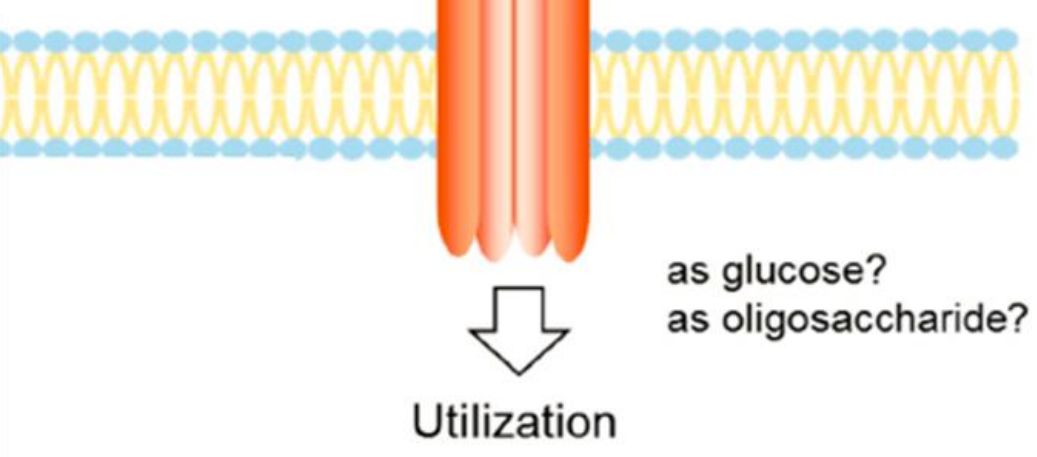

B)

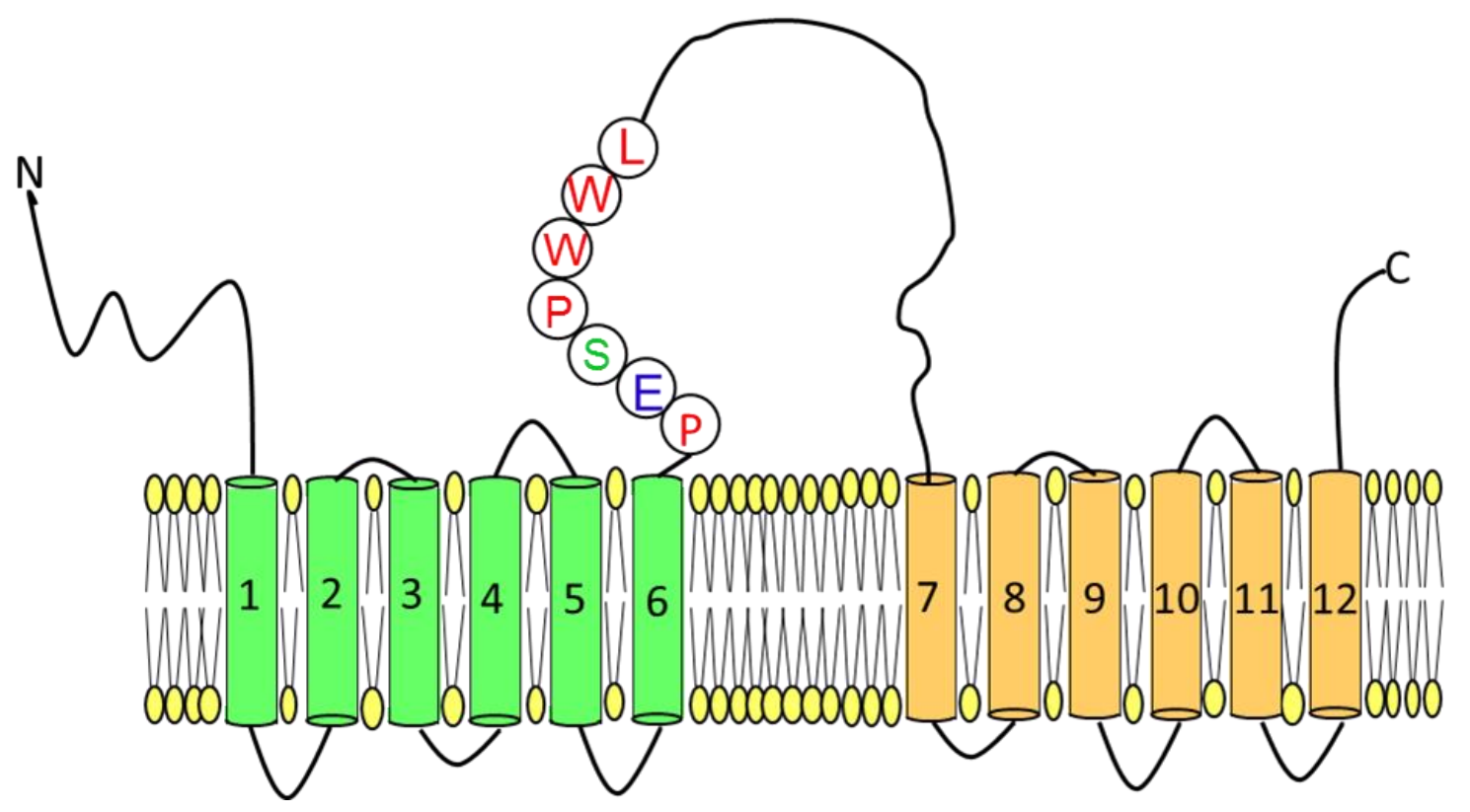

Figure 51. Model for the maltose permease-like protein MphA in the transportation of $\alpha-1,3$ glucans in Aspergillus nidulans.

A) In Hülle cells the $\alpha-1,3$ glucanases MutA and AgnB are required in the processes of degrading of $\alpha$ 1,3 glucans. MphA might be involved in the transportation of carbohydrates. This could lead to a supporting function during nutrient supply for the growth of the fungus, especially the cleistothecium. Image modified (Yoshimi et al., 2017). B) Model for a possible structure of MphA. The sequence of MphA consists of 540 amino acids and contains twelve transmembrane helices which, in turn consist of two 6helix bundles connected by a cytoplasmic loop. This loop contains a sequence motif (PESP(W)L) which is specific for all sugar transporters (Horák 1997). MphA might have a central role regarding transportation of carbohydrates. 
MphA effects the maturation of cleistothecia and ascospores. Interestingly MphA also influences other developmental processes such as the development of asexual structures like conidiophores. This finding differs to previous studies (Wei et al., 2004, Dos reis et al., 2017, Pantazopoulou et al., 2007). The deletion of the gene mphA has an unexpected negative effect on supporting fungal growth, asexual and sexual development. MphA has a central role in supporting fungal structures especially during surface growth. Hülle cells are associated with cleistothecia which need the growth on surfaces. In submerged liquid cultures where cleistothecia are not normally formed, the activity of MphA seems to be reduced.

During vegetative growth $\alpha-1,3$ glucans are stored in the cell wall and $\alpha-1,3$-glucanase like MutA found mainly in Hülle cells during surface growth are required for the degradation of these glucans (Zonneveld 1973, Wei et al., 2001, He et al., 2017, Yoshimi et al., 2017). This finding aligns to the observation of this thesis since $\alpha-1,3$ glucanase MutA is unrepresentative during initial vegetative growth and was found in Hülle cells as well as in sexual mycelium.

Hülle cells are known to nurse the cleistothecia during maturation since abolished Hülle cells correlate with a reduced size of the cleistothecia (Sarikaya-Bayram et al., 2010). The deletion of $m p h A$ appears to correlate with a stalled development of cleistothecia. The addition of higher concentrations of carbohydrates to the $m p h A \Delta$ strain effects the development of the fungus negatively. This suggests that MphA could be crucial for the transportation of carbohydrates since the deletion of gene $m p h A$ causes a significant reduction of the development regarding cleistothecia and other fungal structures. This finding could support the existence of effective transport systems during development (Pöggeler et al., 2006). The development of thick spherical cells called chlamydospores are produced at the very end of the hyphae in Candida albicans and are reduced in higher concentration of carbohydrates (Böttcher et al., 2016). This supports the suggestion and aligns to the observation of this thesis that spore-like structures like chlamydospores and Hülle cells are influenced by carbohydrate metabolism.

Taken together, this study shows that sexual differentiation increases monodictyphenone $(m d p)$ / xanthone $(x p t)$ biosynthetic protein levels localized in differentiated sexual cell types. Hülle cells formed in surface and liquid cultures contain shared proteins encoded by the monodictyphenone $(m d p) /$ xanthone $(x p t)$ gene 
clusters. Proteins encoded by these gene clusters are found in a sexual mycelium with high amounts of Hülle cells grown on surface agar plate cultures. Monodictyphenone and xanthones are antimicrobial substances against fungivory and other environmental threats and thereby protecting the fungus (Regulin and Kempken 2018, Chen et al., 2017, Bok et al., 2009). This suggests that Hülle cells and sexual mycelium are involved in the production of an antimicrobial agent.

Studies of the deletion strain $m p h A \Delta$ demonstrate that MphA protein promotes fungal growth, asexual and sexual development. MphA was identified in enriched Hülle cells from surface growth and was underrepresentend in submerged liquid cultures. This points out that Hülle cells are supporting fungal growth (Figure 52).

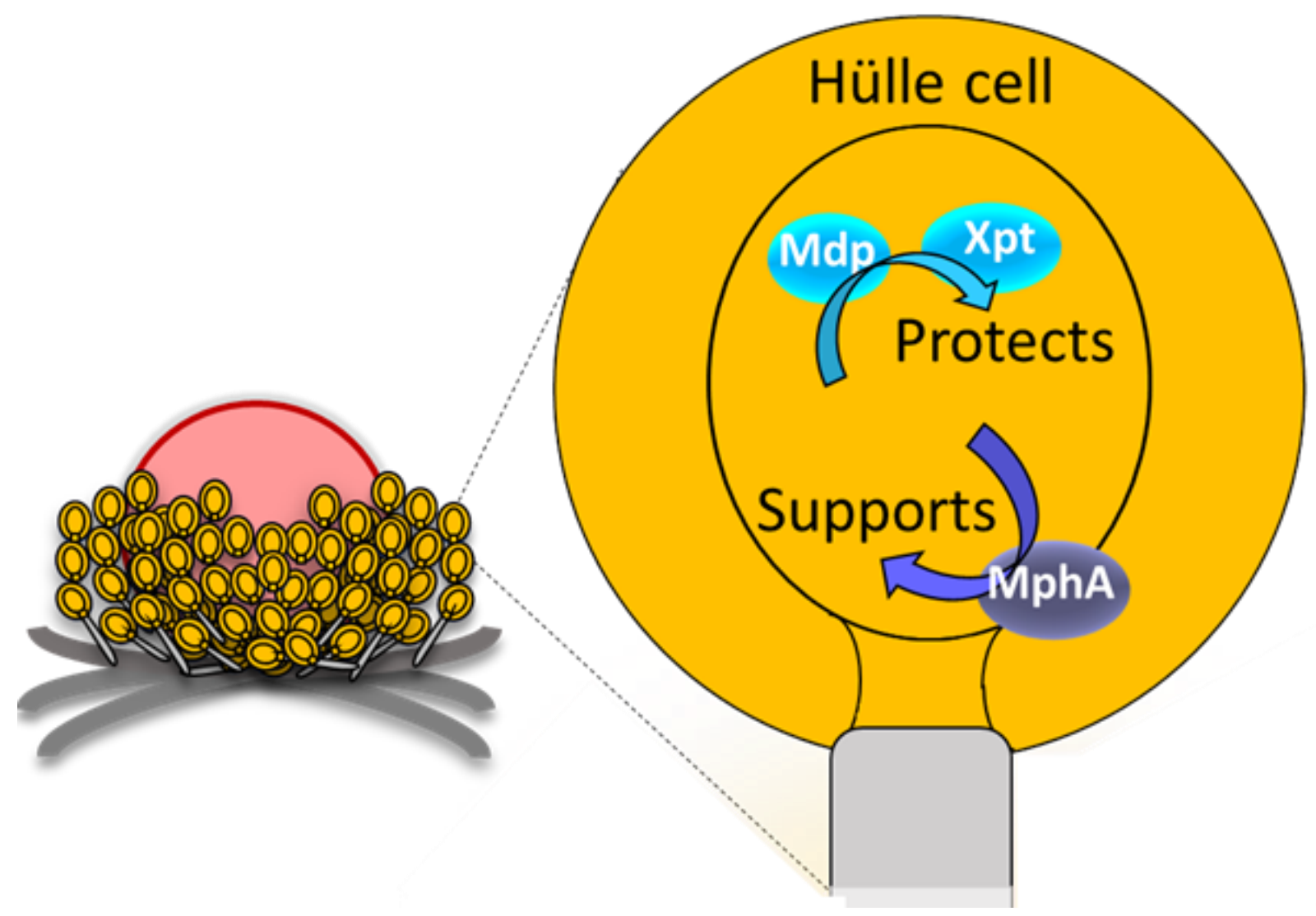

Figure 52. Hülle cells protect and support the cleistothecia.

The picture shows left a cleistothecium surrounded by Hülle cells. On the right a single enlarged Hülle cell is shown. Sexual differentiation of $A$. nidulans increases monodictyphenone ( $m d p)$ / xanthone ( $x p t)$ biosynthetic protein levels. Enzymes encoded by the monodictyphenone $(m d p)$ / xanthone $(x p t)$ gene clusters are found in Hülle cells. Monodictyphenone and xanthones are antimicrobial substances. This suggests that the synthesis of an antimicrobial substance is crucial during maturation of the cleistothecia. The MphA maltose permease-like protein was found in Hülle cells. MphA promotes fungal growth and development. 


\subsection{Conclusion}

The central findings of this thesis lead to the conclusion that sexual differentiation of Aspergillus nidulans increases biosynthetic proteins encoded by the monodictyphenone $(m d p)$ / xanthone $(x p t)$ secondary metabolite gene clusters. These proteins are present in a sexual mycelium with high amounts of Hülle cells from solid agar plate cultures. Proteins encoded by the monodictyphenone $(m d p)$ / xanthone (xpt) secondary metabolite gene clusters are present in Hülle cells and in other fungal cell types. Bayram and co-workers showed that the transcripts of the monodictyphenone $(m d p)$ / xanthone $(x p t)$ clusters are specifically expressed during sexual development (Bayram et al., 2016). The presence of the prenyltransferase $\mathrm{XptB}$ and the oxidoreductase XptC encoded by the xanthone (xpt) secondary metabolite gene cluster was studied in this thesis and their localization in Hülle cells and other fungal tissues could be confirmed. Monodictyphenone and xanthones are antimicrobial agents that protect most probably the fungus especially sexual structures against fungivory and other environmental threats (Regulin and Kempken 2018, Chen et. al., 2017, Bok et al., 2009) The cleistothecia of $A$. nidulans covered with Hülle cells are more resistant against fungivory when comparing to vegetative or asexual tissue (Döll et. al, 2013). In this study it was shown that proteins required for the synthesis of antimicrobial substances such as monodictyphenone and xanthones, are present in Hülle cells. This confirms the assumption that Hülle cells have a capacity to protect the cleistothecia.

Secondly, this thesis shows that protein quantities of prenyltransferase NptA and the serine/threonine kinase RfeA are reduced in a laeA $\Delta$ strain. These proteins are localized in Hülle cells and in other fungal tissues. For this analysis a parental $n k u A \Delta$ strain with an additional unknown mutation that leads to increased numbers of Hülle cells was compared to a lae $A \Delta$ strain that forms reduced numbers of Hülle cells both under submerged liquid conditions. Overall, this thesis provides insights that demonstrate that prenyltransferases NptA and serine/threonine kinase RfeA are localized in different fungal cell types including Hülle cells and the protein quantity is reduced in strains lacking LaeA. This aligns to the findings that other prenyltransferases such as $t i d B$ are not expressed in a laeA $\Delta$ strain (Bok et al., 2006). RefA is mainly uncharacterized in A. nidulans (De Souza et. al., 2013). 
Furthermore, the AnkG (AN8434) ankyrin repeat domain protein and the tyrosine domain protein (AN8435) are found in enriched Hülle cells from solid agar plate as well as in submerged liquid cultures. Ankyrin repeat domain proteins are adaptor proteins associated with membranes (Islam et al., 2017). Additionally, observations in this study aligned to the findings that AnkG (AN8434) ankyrin repeat domain protein is associated to the membrane and furthermore, is localized to the membrane of the subtending hyphae of Hülle cells. Beyond that, in this thesis the localization of tyrosinase domain protein (AN8435) was studied. Probably AN8435 is localized to Hülle cells and other fungal tissues. Tyrosinases are known to be involved in the process of pigmentation (Chai et al., 2017, Hsu et al., 2016). The absence of Hülle cells in Aspergillus tonophilus and Aspergillus fisheri correlates with non-pigmented cleistothecia (Hermann et al., 1983). This indicates that Hülle cells are potentially important for pigmentation and, therefore, tyrosinases are most probably required during the maturation process of the cleistothecia.

Lastly the findings of this thesis reveal that the MphA protein supports fungal growth and development and that MphA protein is specially enriched in Hülle cells. During the thesis research the corresponding gene of MphA was deleted and observation demonstrated that MphA promotes fungal development and growth. MphA protein supports also the maturation of the cleistothecium. Abolished Hülle cell formation correlates with a significantly reduced size of the cleistothecia (Sarikaya-Bayram et al., 2010). This supports the view that Hülle cells have a nursing function to nourish the growing cleistothecia.

Taken together the biological function of Hülle cells is highly likely to have a protective and a nursing function especially during sexual development. Further research is hence needed to determine the biological function of Hülle cells during sexual development in more detail. 


\section{References}

Aaij, C., \& Borst, P. 1972. The gel electrophoresis of DNA. Biochimica et Biophysica Acta (BBA) - Nucleic Acids and Protein Synthesis 269:192-200.

Abraham, W. R. 2018. Fumitremorgins and relatives - from tremorgenic compounds to valuable anti-cancer drugs. Current Medicinal Chemistry 25:123-140.

Ahmed, Y. L., Gerke, J., Park, H. S., Bayram, Ö., Neumann, P., Ni, M., Dickmanns, A., Kim, S. C., Yu, J. H., Braus, G. H., \& Ficner, R. 2013. The velvet family of fungal regulators contains a DNA-binding domain structurally similar to NF-kB. PLoS Biology 11: e1001750.

Alam, S., \& Khan, F. 2018. Virtual screening, docking, ADMET and system pharmacology studies on Garcinia caged xanthone derivatives for anticancer activity. Scientific Report 8: 5524.

Alkahyyat, F., Ni, M., Kim, S. C., \& Yu, J. H. 2015. The WOPR domain protein OsaA orchestrates development in Aspergillus nidulans. PLoS One 10: e0137554.

Alves, P. C., Hartmann, D. O., Núñez, O., Martins, I., Gomes, T. L., Garcia, H., Galceran, M. T., Hampson, R., Becker, J. D., \& Silva-Pereira, C. 2016. Transcriptomic and metabolomic profiling of ionic liquid stimuli unveils enhanced secondary metabolism in Aspergillus nidulans. BMC Genomics 17: 284.

Andersen, M. R., Nielsen, J. B., Klitgaard, A., Petersen, L. M., Zachariasen, M., Hansen, T. J., Blicher, L. H., Gotfredsen, C. H., Larsen, T. O., Nielsen, K. F., \& Mortensen, U. H. 2013. Accurate prediction of secondary metabolite gene clusters in filamentous fungi. Proceedings of the National Academy of Sciences of the United States of America 110: E99-E107.

Bayram, Ö., Feussner, K., Dumkow, M., Herrfurth, C., Feussner, I., \& Braus, G. H. 2016. Changes of global gene expression and secondary metabolite accumulation during light-dependent Aspergillus nidulans development. Fungal Genetics and Biology 87: 30-53.

Bayram, Ö., \& Braus, G. H. 2012. Coordination of secondary metabolism \& development in fungi: the velvet family of regulatory proteins. FEMS Microbiology Reviews 36: 1-24.

Bayram, Ö., Sarikaya-Bayram, Ö., Valerius, O., Jöhnk, B., \& Braus, G. H. 2012. Identification of protein complexes from filamentous fungi with tandem affinity purification. Methods in Molecular Biology 944: 191-205.

Bayram, Ö., Sari, F., Braus, G. H., \& Irniger, S. 2009. The protein kinase ImeB is required for light-mediated inhibition of sexual development and for mycotoxin production in Aspergillus nidulans. Molecular Microbiology 71: 1278-1295.

Bayram, Ö., Biesemann, C., Krappmann, S., Galland, P., \& Braus, G. H. 2008a. More than a repair enzyme: Aspergillus nidulans photolyase-like CryA is a regulator of sexual development. Molecular Biology of the Cell 19: 3254-3262.

Bayram, Ö., Krappmann, S., Ni, M., Bok, J. W., Helmstaedt, K., Valerius, O., BrausStromeyer, S., Kwon, N. J., Keller, N. P., \& Braus, G. H. 2008b. VelB / VeA / LaeA complex coordinates light signal with fungal development and secondary metabolism. Science 320: 1504-1506. 
Beck, J., \& Ebel, F. 2013. Characterization of the major woronin body protein HexA of the human pathogenic mold Aspergillus fumigatus. International Journal of Medical Microbiology 303: 90-97.

Bennett, R. J., \& Turgeon, B. G. 2017. Fungal sex: the Ascomycota. In: The fungal kingdom. Heitman, J., James, T., Gow, N. (eds.), Washington, D.C., United States of America, ASM Press, pp. 117-145.

Böttcher, B., Pöllath, C., Staib, P., Hube, B., \& Brunke, S. 2016. Candida species rewired hyphae developmental programs for chlamydospore formation. Frontiers in Microbiology 7: 1697.

Bok, J. W., \& Keller, N. P. 2016. 2 Insight into fungal secondary metabolism from ten years of LaeA research. In: Biochemistry and molecular biology. The mycota III, a comprehensive treatise on fungi as experimental systems for basic and applied research. Hoffmeister, D. (ed.), Springer International Publishing, pp 21-29.

Bok, J. W., Chiang, Y. M., Szewczyk, E., Reyes-Dominguez, Y., Davidson, A. D., Sanchez, J. F., Lo, H. C., Watanabe, K., Strauss, J., Oakley, B. R., Wang, C. C., \& Keller, N. P. 2009. Chromatin-level regulation of biosynthetic gene clusters. Nature Chemical Biology 5: 462-464.

Bok, J. W., Hoffmeister, D., Maggio-Hall, L. A., Murillo, R., Glasner, J. D., \& Keller, N. P. 2006. Genomic mining for Aspergillus natural products. Chemistry \& Biology. 13: 31-37.

Bok, J. W., \& Keller, N. P. 2004. LaeA, a regulator of secondary metabolism in Aspergillus spp. Eukaryotic Cell 3: 527-535.

Bouhired, S., Weber, M., Kempf-Sontag, A., Keller, N. P., \& Hoffmeister, D. 2007. Accurate prediction of the Aspergillus nidulans terrequinone gene cluster boundaries using the transcriptional regulator LaeA. Fungal Genetics and Biology 44: 1134-1145.

Bradford, M. M. 1976. A rapid and sensitive method for the quantitation of microgram quantities of protein utilizing the principle of protein-dye binding. Analytical biochemistry 72: 248-254.

Brakhage, A. A. 2013. Regulation of fungal secondary metabolism. Nature Reviews Microbiology $11: 21-32$.

Braus, G. H., Krappmann, S., \& Eckert, S. E. 2002. Sexual development in ascomycetes: fruit body formation of Aspergillus nidulans. In: Molecular biology of Fungal Development. Osiewacz, H. D. (ed.), New York, United States of America, Marcel Dekker, Inc., pp. 215-244.

Busch, S., \& Braus, G. H. 2007. How to build a fungal fruit body: from uniform cells to specialized tissue. Molecular Microbiology 64: 873-876.

Caballero-Ortiz, S., Trienens, M., \& Rohlfs, M. 2013. Induced fungal resistance to insect grazing: reciprocal fitness consequences and fungal gene expression in the Drosophila-Aspergillus model system. PLoS One 8: e74951.

Calera, J. A., Sanchez-Weatherby, J., Lopez-Medrano, R., \& Leal, F. 2000. Distinctive properties of the catalase B of Aspergillus nidulans. FEBS letter 475: 117-120.

Calvo, A. M., Wilson, R. A., Bok, J. W., \& Keller, N. P. 2002. Relationship between secondary metabolism and fungal development. Microbiology and Molecular Biology Reviews 66: 447-459. 
Carvalho, M. D. F., Baracho, M. S., \& Baracho, I. R. 2002. An investigation of the nuclei of Hülle cells of Aspergillus nidulans. Genetics and Molecular Biology 25: 485-488.

Cary, J. W., Harris-Coward, P., Scharfenstein, L., Mack, B. M., Chang, P. K., Wei, Q., Lebar, M., Carter-Wientjes, C., Majumdar, R., Mitra, C., Banerjee, S., \& Chanda, A. 2017. The Aspergillus flavus homeobox, $h b x 1$, is required for development and aflatoxin production. Toxins 9: 315.

Cerqueira, G. C., Arnaud, M. B., Inglis, D. O., Skrzypek, M. S., Binkley, G., Simison, M., Miyasato, S. R., Binkley, J., Orvis, J., Shah, P., Wymore, F., Sherlock, G., \& Wortman, J. R. 2014. The Aspergillus Genome Database: multispecies curation and incorporation of RNA-Seq data to improve structural gene annotations. Nucleic Acids Research 42: D705-D710.

Chai, B., Qiao, Y., Wang, H., Zhang, X., Wang, J., Wang, C., Zhou, P., \& Chen, X. 2017. Identification of $\mathrm{YfiH}$ and the catalase CatA as polyphenol oxidases of aeromonas media and CatA as a regulator of pigmentation by its peroxyl radical scavenging capacity. Frontiers in Microbiology 8: 1939.

Champe, S. P., \& Simon, L. D. 1992. Cellular differentiation and tissue formation in the fungus Aspergillus nidulans. In: An analysis of the development of biological structure. Rossomando, E. F., Alexander, S. (eds.), New York, United Staes of America, Marcel Dekker Inc., pp. 63-91.

Chang, P. K., Scharfenstein, L. L., Li, R. W., Arroyo-Manzanares, N., De Saeger, S., \& Diana Di Mavungu, J. 2017. Aspergillus flavus aswA, a gene homolog of Aspergillus nidulans oefC, regulates sclerotial development and biosynthesis of sclerotium-associated secondary metabolites. Fungal Genetics and Biology 104: 29-37.

Chen, A. J., Frisvad, J. C., Sun, B. D., Varga, J., Kocsubé, S., Dijksterhuis, J., Kim, D. H., Hong, S. B., Houbraken, J., \& Samson, R. A. 2016. Aspergillus Section Nidulantes (Formerly Emericella): polyphasic taxonomy, chemistry and biology. Studies in Mycology 84: 1-118.

Chen, X., Leng, J., Rakesh, K. P., Darshini, N., Shubhavathi, T., Vivek, H. K., Mallesha, N., \& Qin, H. L. 2017. Synthesis and molecular docking studies of xanthone attached amino acids as potential antimicrobial and anti-inflammatory agents. MedChemComm 8: 1706-1719.

Chiang, Y. M., Szewczyk, E., Davidson, A. D., Entwistle, R., Keller, N. P., Wang, C. C., \& Oakley, B. R. 2010. Characterization of the Aspergillus nidulans monodictyphenone gene cluster. Applied and Environmental Microbiology 76: 2067-2074.

Chiang, Y. M., Szewczyk, E., Nayak, T., Davidson, A. D., Sanchez, J. F., Lo, H. C., Ho, W. Y., Simityan, H., Kuo, E., Praseuth, A., Watanabe, K., Oakley, B. R., \& Wang, C. C. 2008. Molecular genetic mining of the Aspergillus secondary metabolome: discovery of the emericellamide biosynthetic pathway. Chemistry \& Biology 15: 527-532.

Christmann, M., Schmaler, T., Gordon, C., Huang, X., Bayram, Ö., Schinke, J., Stumpf, S., Dubiel, W., \& Braus, G. H. 2013. Control of multicellular development by the physically interacting deneddylases DEN1/DenA and COP9 signalosome. PLoS Genetics 9: e1003275. 
Clevenger, K. D., Bok, J. W., Ye, R., Miley, G. P., Verdan, M. H., Velk, T., Chen, C., Yang, K., Robey, M. T., Gao, P., Lamprecht, M., Thomas, P. M., Islam, M. N., Palmer, J. M., Wu, C. C., Keller, N., P. \& Kelleher, N. L. 2017. A scalable platform to identify fungal secondary metabolites and their gene clusters. Nature Chemical Biology 13: 895-901.

Conesa, A., Götz, S., García-Gómez, J. M., Terol, J., Talón, M., \& Robles, M. 2005. Blast2GO: a universal tool for annotation, visualization and analysis in functional genomics research. Bioinformatics 21: 3674-3676.

Dambacher, C. M., Worden, E. J., Herzik, M. A., Martin, A., \& Lander, G. C. 2016. Atomic structure of the $26 \mathrm{~S}$ proteasome lid reveals the mechanism of deubiquitinase inhibition. eLife 5: e13027.

Dasgupta, A., Fuller, K. K., Dunlap, J. C., \& Loros, J. J. 2016. Seeing the World differently: variability in the photosensory mechanisms of two model fungi. Environmental Microbiology. 18: 5-20.

De Groot, P. W., Brandt, B. W., Horiuchi, H., Ram, A. F., de Koster, C. G., \& Klis, F. M. 2009. Comprehensive genomic analysis of cell wall genes in Aspergillus nidulans. Fungal Genetics and Biology 46: S72-S81.

Demain, A. L., \& Fang, A. 2000. The natural functions of secondary metabolites. Advances in Biochemical Engineering/Biotechnology 69: 1-39.

De Souza, C. P., Hashmi, S. B., Osmani, A. H., Andrews, P., Ringelberg, C. S., Dunlap, J. C., \& Osmani, S. A. 2013. Functional analysis of the Aspergillus nidulans kinome. PLoS One 8: e58008.

De Vries, R. P., Riley, R., Wiebenga, A., Aguilar-Osorio, G., Amillis, S., Uchima, C. A., Anderluh, G., \& Asadollahi, M. 2017. Comparative genomics reveals high biological diversity and specific adaptations in the industrially and important fungal genus Aspergillus. Genome Biology 18: 28.

Dhingra, S., Lind, A. L., Lin, H. C., Tang Y., Rokas, A., \& Calvo, A. M. 2013. The fumagillin gene cluster, an example of hundreds of genes under veA control in Aspergillus fumigatus. PLoS One 8: e77147.

Döll, K., Chatterjee, S., Scheu, S., Karlovsky, P., \& Rohlfs, M. 2013. Fungal metabolic plasticity and sexual development mediate induced resistance to arthropod fungivory. Proceedings of the Royal Society B: Biological Science 280: 20131219.

Dos Reis, T. F., Nitsche, B. M., de Lima, P. B., de Assis, L. J., Mellado, L., Harris, S. D., Meyer, V., Dos Santos, R. A., Riaño-Pachón, D. M., Ries, L. N., \& Goldman, G. H. 2017. The low affinity glucose transporter HxtB is also involved in glucose signalling and metabolism in Aspergillus nidulans. Scientific Reports 7: 45073.

Drott, M. T., Lazzaro, B. P., Brown, D. L., Carbone, I., \& Milgroom, M. G. 2017. Balancing selection for aflatoxin in Aspergillus flavus is maintained through interference competition with and fungivory by insects. Proceedings of the Royal Society B: Biological Science 284: 20172408.

Durfee, T., \& Schwei, T. 2008. DNASTAR's next-generation software. In: Next generation genome sequencing: towards personalized medicine. Janitz, M. (ed.), Weinheim, Germany, Wiley-VCH Verlag, pp. 89-94. 
Dyer, P. S., \& O' Gorman, C. M. 2012. Sexual development and cryptic sexuality in fungi: insights from Aspergillus species. FEMS Microbiology Reviews 36: 165192.

Dyer, P. S., Ingram, D. S., \& Johnstone, K. 1993. Evidence for the involvement of linoleic acid and other endogenous lipid factors in perithecial development of Nectria haematococca mating population VI. Mycological Research 97: 485-496.

Eckert, S. E., Hoffmann, B., Wanke, C., \& Braus, G. H. 1999. Sexual development of Aspergillus nidulans in tryptophan auxotrophic strains. Archives of Microbiology 172: 157-166.

Eidam, E. 1883. Zur Kenntnis der Entwicklung bei den Ascomyceten. III. Sterigmatocystis nidulans n. sp. In: Beiträge zur Biologie der Pflanzen. Laibach, F. (ed.), Berlin, Germany, Dunker \& Humblot, pp. 377-433.

Elbein, A. D., Pan, Y. T., Pastuszak, I., \& Carroll, D. 2003. New insights on trehalose: a multifunctional molecule. Glycobiology 13: 17-27.

Ellis, T. T., Reynolds, D. R., \& Alexopoulus, C. J. 1973. Hülle cell development in Emericella nidulans. Mycologia 65: 1028-1035.

Eng, J. K., McCormack, A. L., \& Yates, J. R. 1994. An approach to correlate tandem mass spectral data of peptides with amino acid sequences in a protein database. American Society for Mass Spectrometry 5: 976-989.

Engh, I., Nowrousian, M., \& Kück, U. 2007. Regulation of melanin biosynthesis via the dihydroxynaphthalene pathway is dependent on sexual development in the ascomycete Sordaria macrospora. FEMS Microbiology Letters 275: 62-70.

Etxebeste, O., Villarino, M., Markina-Iñarrairaegui, A., Araújo-Bazán, L., \& Espeso, E. 2013. Cytoplasmic dynamics of general nuclear import machinery in apically growing syncytial cells. PLoS One 8: e85076.

Flipphi, M., Sun, J., Robellet, X., Karaffa. L., Fekete, E., Zeng, A. P., \& Kubiecek, C. P. 2009. Biodiversity and evolution of primary carbon metabolism in Aspergillus nidulans and other Aspergillus spp. Fungal Genetics and Biology 1: S19-S44.

Flores-Gallegos, A. C., Veana-Hernandez, F., Michel-Michel, M., Lara-Victoriano, F., \& Rodriguez-Herrera R. 2016. Molecular evolution of Aspergillus. In: New and future developments in microbial biotechnology and bioengineering - Aspergillus system properties and applications. Gupta, V. K. (ed.), Amsterdam, Netherlands, Elsevier, pp. 41-51.

Gacek, A., \& Strauss, J. 2012. The chromatin code of fungal secondary metabolite gene clusters. Applied Microbiology and Biotechnology 95: 1389-1404.

Galagan, J. E., Calvo, S. E., Cuomo, C., Ma, L. J., Wortman, J, R., Batzoglou, S., Lee, S. I. Basturkmen, M., et al. 2005. Sequencing of Aspergillus nidulans and comparative analysis with $A$. fumigatus and A. oryzae. Nature 438: 1105-1115.

Gerke, J., \& Braus, G. H. 2014. Manipulation of fungal development as source of novel secondary metabolites for biotechnology. Applied Microbiology and Biotechnology. 98: 8443-8455.

Goodrich-Tanrikulu, M., Jacobson, D. J., Stafford, A. E., Lin, J. T., \& McKeon, T. A. 1999. Characterization of Neurospora crassa mutants isolated following repeatinduced point mutation of the beta subunit of fatty acid. Current Genetics 36: 147152. 
Goody, R. S., Müller, M. P., \& Wu, Y. W. 2017. Mechanisms of action of Rab proteins, key regulators of intracellular vesicular transport. Biological Chemistry. 398: 565575.

Guerriero, G., Silvestrini, L., Legay, S., Maixner, F., Sulyok, M., Hausman, J. F., \& Strauss, J. 2017. Deletion of the celA gene in Aspergillus nidulans triggers overexpression of secondary metabolite biosynthetic genes. Scientific Reports 7: 5978.

Han, K. H., Lee, D. B., Kim, J. H., Kim, M. S., Han, K. Y., Kim, W. S., Park, Y. S., Kim, H. B., \& Han, D. M. 2003. Environmental factors affecting development of Aspergillus nidulans. The Journal of Microbiology 41: 34-40.

Han, K. H., Han, K. Y., Yu, J. H., Chae, K. S., Jahng, K. Y., \& Han, D. M. 2001. The $n s d D$ gene encodes a putative GATA-Type transcription factor necessary for sexual development of Aspergillus nidulans. Molecular Microbiology 41: 299-309.

Hanahan, D., Jessee, J., \& Bloom, F. R. 1991. Plasmid transformation of Escherichia coli and other bacteria. Methods in Enzymology 204: 63-113.

He, X., Li, S., \& Kaminskyj, S. 2017. An amylase-like protein, AmyD is the major negative regulator for a-glucan synthesis in Aspergillus nidulans during the asexual life cycle. International Journal of Molecular Sciences 18: 695.

Heckman, D. S., Geiser, D. M., Eidell, B. R., Stauffer, R. L., Kardos, N. L., \& Hedges, S. B. 2001. Molecular evidence for the early colonization of land by fungi and plants. Science 293: 1129-1133.

Hermann, T. E., Kurtz, M., \& Champe, S. P. 1983. Laccase localized in Hulle cells and cleistothecial primordia of Aspergillus nidulans. Journal of Bacteriology 154: 955964.

Hernández-Rodríguez, Y., Hastings, S., \& Momany, M. 2012. The septin AspB in Aspergillus nidulans forms bars and filaments and plays roles in growth emergence and conidiation. Eukaryotic Cell 11: 311-323.

Horák, J. 1997. Yeast nutrient transporters. Biochimica et Biophysica Acta (BBA)Reviews on Biomembranes 1: 41-79.

Hou, B., Lin, Y., Wu, H., Guo, M., Petkovic, H., Tao, L., Zhu, X., Ye, J., \& Zhang, H. 2017. The novel transcriptional regulator $\mathrm{LmBU}$ promotes lincomycin biosynthesis through regulating expression of its target genes in Streptomyces lincolnensis. Journal of Bacteriology 200: e00447-17.

Hsu, K. D., Chen, H. J., Wang, C. S., Lum, C. C., Wu, S. P. Lin, S. P., \& Cheng, K. C. 2016. Extract of Ganoderma formosanum mycelium as a highly potent tyrosinase inhibitor. Scientific Reports 6: 32854.

Islam, Z., Nagampalli, R. S. K., Fatima, M. T., \& Ashraf, G. M. 2018. New paradigm in ankyrin repeats: beyond protein-protein interaction module. International Journal of Biological Macromolecules. 109: 1164-1173.

Itoh, E., Shigemoto, R., Oinuma, K. I., Shimizu, M., Masuo, S., \& Takaya, N. 2017. Sirtuin A regulates secondary metabolite production by Aspergillus nidulans. The Journal of General and Applied Microbiology 63: 228-235. 
Jiang, P., Wei, W. F., Zhong, G. W., Zhou, X. G., Qiao, W. R., Fischer, R., \& Lu, L. 2017. The function of the three phosphoribosyl pyrophosphate synthetase (Prs) genes in hyphal growth and conidiation in Aspergillus nidulans. Microbiology 163: 218-232.

Jöhnk, B., Bayram, Ö., Abelmann, A., Heinekamp, T., Mattern, D. J., Brakhage, A. A., Jacobsen, I. D., Valerius, O., \& Braus, G. H. 2016. SCF ubiquitin ligase F-box controls nuclear co-repressor localization, stress response and virulence of the human pathogen Aspergillus fumigatus. PLoS Pathogens 12: e1005899.

Jones, P., Binns, D., Chang, H. Y., Fraser, M., Li, W., McAnulla, C., McWilliam, H. Maslen, J., Mitchell, A., Nuka, G., Pesseat, S., Quinn, A. F., Sangrador-Vegas, A., Scheremetjew, M., Yong, S. Y., Lopez, R., \& Hunter, S. 2014. InterProScan 5: genome-scale protein function classification. Bioinformatics 30: 1236-1240.

Kabeche, L., Nguyen, H. D., Buisson, R., \& Zou, L. 2018. A mitosis-specific and R loop-driven ATR pathway promotes faithful chromosome segregation. Science 359: 108-114.

Kale, S. P., Milde, L., Trapp, M. K., Frisvad, J. C., Keller, N. P., \& Bok, J. W. 2008. Requirement of LaeA for secondary metabolism and sclerotial production in Aspergillus flavus. Fungal Genetics and Biology 45: 1422-1429.

Karimi-Aghcheh, R., Bok, J. W., Phatale, P. A., Smith, K. M., Baker, S. E., Lichius, A., Omann, M., Zeilinger, S., Seiboth, B., Rhee, C., Keller, N. P., Freitag, M., \& Kubicek, C. P. 2013. Functional analyses of Trichoderma reesei LAE1 reveal conserved and contrasting roles of this regulator. G3 (Bethesda) 3: 369-378.

Keller, N. P., Turner, G., \& Bennett, J. W. 2005. Fungal secondary metabolism - from biochemistry to genomics. Nature Reviews Microbiology 3: 937-947.

Kim, H., Han, K., Kim, K., Han, D., Jahng, K., \& Chae, K. 2002. The veA gene activates sexual development in Aspergillus nidulans. Fungal Genetics and Biology 37: 7280 .

Kim, H. Y., Han, K. H., Lee, M., Oh, M., Kim, H. S., Zhixiong, X., Han, D. M., Jahng, K. Y., Kim, J. H., \& Chae, K. S. 2009. The veA gene is necessary for the negative regulation of the veA expression in Aspergillus nidulans. Current Genetics 55: 391-407.

Kim, S., Matsuo, I., Ajisaka, K., Nakajima, H., \& Kitamoto, K. 2002. Cloning and characterization of the nagA gene that encodes beta-n-acetylglucosaminidase from Aspergillus nidulans and its expression in Aspergillus oryzae. Bioscience, Biotechnology, and Biochemistry 66: 2168-2175.

Kim, Y. J., Yu, Y. M., \& Maeng, P. J. 2017. Differential control of asexual development and sterigmatocystin biosynthesis by a novel regulator in Aspergillus nidulans. Scientific reports 7: e46340.

Kirk, K. E., \& Morris, N. R. 1991. The tubB alpha-tubulin gene is essential for sexual development in Aspergillus nidulans. Genes \& Development 5: 2014-2023.

Kirkwood, M., Todd, J. D., Rypien, K. L., \& Johnston, A. W. 2010. The opportunistic coral pathogen Aspergillus sydowii contains $d d d P$ and makes dimethyl sulfide from dimethylsulfoniopropionate. The ISME Journal 4: 147-150. 
Klejnstrup, M. L., Frandsen, R. J. N., Holm, D. K., Nielsen, M. T., Mortensen, U. H., Larsen, T. O., \& Nielsen, J. B. 2012. Genetics of polyketide metabolism in Aspergillus nidulans. Metabolites 2: 100-133.

Klitgaard, A., Nielsen, J. B., Frandsen, R. J., Andersen, M. R., \& Nielsen, K. F. 2015. Combining stable isotope labeling and molecular networking for biosynthetic pathway characterization. Analytical Chemistry 87: 6520-6526.

Knox, B. P., Blachowicz, A., Palmer, J. M., Romsdahl, J., Huttenlocher, A., Wang, C. C., Keller, N. P., Venkateswaran, K. 2016. Characterization of Aspergillus fumigatus isolates from air and surfaces of the international space station. mSphere 1: e00227-16.

Koenig, T., Menze, B. H., Kirchner, M., Monigatti, F., Parker, K. C., Patterson, T., Steen, J. J., Hamprecht, F. A., \& Steen, H. 2008. Robust prediction of the MASCOT score for an improved quality assessment in mass spectrometric proteomics. Journal of Proteome Research 7: 3708-3717.

König, H. G., Schwamborn, R., Andresen, S., Kinsella, S., Watters, O., Fenner, B., \& Prehn, J. H. 2017. NF-kB regulates neuronal ankyrin-G via a negative feedback loop. Scientific Reports 7: e42006.

Krappmann, S., Bayram, Ö., \& Braus, G. H. 2005. Deletion and allelic exchange of the Aspergillus fumigatus veA locus via a novel recyclable marker module. Eukaryotic Cell 4: 1298-1307.

Laemmli, U. K. 1970. Cleavage of structural proteins during the assembly of the head of bacteriophage T4. Nature 227: 680-685.

Lee, S. B. \& Taylor, J. W. 1990. Isolation of DNA from fungal mycelia and single spores. In: PCR protocols: a guide to methods and applications. Innis, N., Gelfand, D., Sninsky, D., \& White, T. (eds.), New York, United States of America, Academic Press, pp 282-287.

Lehman, I. R. 1974. DNA ligase: structure, mechanism, and function. Science 186: 790-797.

Lenobel, R., Sebela, M., \& Frebort, I. 2005. Mapping the primary structure of copper/ topaquinone containing methylamine oxidase from Aspergillus niger. Folia Microbiology 50: 401-408.

Malavazi, I., Savoldi, M., da Silva Ferreira, M. E., Soriani, F. M., Bonato, P. S., de Souza Goldman, M. H., \& Goldman, G. H. 2007. Transcriptome analysis of the Aspergillus nidulans AtmA (ATM, Ataxia-Telangiectasia mutated) null mutant. Molecular Microbiology 66: 74-99.

Malavazi, I., Savoldi, M., Di Mauro, S. M., Menck, C. F., Harris, S. D., Goldman, M. H., \& Goldman, G. H. 2006. Transcriptome analysis of Aspergillus nidulans exposed to camptothecin-induced DNA damage. Eukaryotic Cell 5: 1688-1704.

Margelis, S., D'Souza, C., Small, A. J., Hynes, M. J., Adams, T. H., \& Davis, M. A. 2001. Role of glutamine synthetase in nitrogen metabolite repression in Aspergillus nidulans. Journal of Bacteriology 183: 5826-5833.

Martins, I., Hartmann, D., Alves, P. C., Planchon, S., Renaut, J., Leitão, M. C., Rebelo, L. P. N., \& Pereira, C., S. 2013. Proteomic alterations induced by ionic liquids in Aspergillus nidulans and Neurospora crassa. Journal of Proteomics 94: 262-278. 
Mendoza-Martínez, A. E., Lara-Rojas, F., Sánchez, O., \& Aguirre, J. 2017. NapA mediates a redox regulation of the antioxidant response, carbon utilization and development in Aspergillus nidulans. Frontiers in Microbiology 8: 516.

Mounts, P., Wu, T. C., \& Peden, K. 1989. Method for cloning single-stranded oligonucleotides in a plasmid vector. BioTechniques 7: 356-359.

Muntanjola-Cvetkovic, M., \& Vukic, V. V. 1972. Influence of light on Hülle cell and aleuriospore formation in Aspergillus. Transactions of British Mycological Society 58: $67-72$.

Nakamura, T., Maeda, Y., Tanoue, N., Makita, T., Kato, M., \& Kobayashi, T. 2006. Expression profile of amylolytic genes in Aspergillus nidulans. Bioscience, Biotechnology, and Biochemistry 70: 2363-2370.

Navarathna, D. H., Pathirana, R. U., Lionakis, M. S., Nickerson, K. W., \& Roberts, D. D. 2016. Candida albicans ISW2 regulates chlamydospore suspensor cell formation and virulence in vivo in a mouse model of disseminated candidiasis. PLoS One. 11: e0164449.

Nayak, T., Szewczyk, E., Oakley, C. E., Osmani, A., Ukil, L., Murray, S. L., Hynes, M. J., Osmani, S. A., \& Oakley, B. R. 2006. A versatile and efficient gene-targeting system for Aspergillus nidulans. Genetics 172: 1557-1566.

Nekiunaite, L., Arntzen, M., Svensson, B., Vaaje-Kolstad, G., \& Abou Hachem, M. 2016. Lytic polysaccharide monooxygenases and other oxidative enzymes are abundantly secreted by Aspergillus nidulans grown on different starches. Biotechnology for Biofuels 9: 187.

Neuhoff, V., Arold, N., Taube, D., \& Ehrhardt, W. 1988. Improved staining of proteins in polyacrylamide gels including isoelectric focusing gels with clear background at nanogram sensitivity using coomassie brilliant blue G-250 and R-250. Electrophoresis 9: 255-262.

Nishimura, I., Shinohara, Y., Oguma, T., \& Koyama, Y. 2018. Survival strategy of the salt-tolerant lactic acid bacterium, Tetragenococcus halophilus, to counteract koji mold, Aspergillus oryzae, in soy sauce brewing. Bioscience, Biotechnology and Biochemistry 8: 1-7.

Noble, L. M., \& Andrianopoulos, A. 2013. Reproductive competence: a recurrent logic module in eukaryotic development. Proceedings of the Royal Society B: Biological Science 280: 20130819.

Noordin, M. A. M., Noor, M. M., Kamaruddin, W. M. A. W., Lazim, A. M., \& Fazry, S. 2016. Toxicity test of xanthone from mangosteen on zebrafish embryos. AIP Conference Proceedings 1784: 020014.

Oakley, B. R. 2004. Tubulins in Aspergillus nidulans. Fungal Genetics and Biology 41: 420-427.

Oakley, C. E., Ahuja, M., Sun, W. W., Entwistle, R., Akashi, T., Yaegashi, J., Guo, C. J., Cerqueira, G. C., Russo Wortman, J., Wang, C. C., Chiang, Y. M., \& Oakley, B. R. 2017. Discovery of $m c r A$, a master regulator of Aspergillus secondary metabolism. Molecular Microbiology 103: 347-365. 
Obayashi, E., Luna, R. E., Nagata, T., Martin-Marcos, P., Hiraishi, H., Singh, C. R., Erzberger, J. P., Zhang, F., et al. 2017. Molecular landscape of the ribosome preinitiation complex during mRNA scanning: structural role for elF3c and its control by elF5. Cell Reports 18: 2651-2663.

Olivares, C., Solano, F., \& Garcia-Borron, J. C. 2003. Conformation-dependent posttranslational glycosylation of tyrosinase. Requirement of a specific interaction involving the CuB metal binding site. Journal of Biological Chemistry 278: 1573515743.

Oliveros, J. C. 2007. VENNY an interactive tool for comparing lists with Venn diagrams. http://bioinfogp.cnb.csic.es/tools/venny/index.html.

Pan, L. L., Song, L. F., Miao, Y., Yang, Y., \& Merz, K. M. Jr. 2017. Mechanism of formation of the nonstandard product in the prenyltransferase reaction of the G115T mutant of FtmPT1: a case of reaction dynamics calling the shots? Biochemistry 56: 2995-3007.

Pantazopoulou, A., Lemuh, N. D., Hatzinikolaou, D. G., Drevet, C., Cecchetto, G., Scazzocchio, C., \& Diallinas, G. 2007. Differential physiological and developmental expression of the UapA and AzgA purine transporters in Aspergillus nidulans. Fungal Genetics and Biology 44: 627-640.

Patananan, A. N., Palmer, J. M., Garvey, G. S., Keller, N. P., \& Clarke, S. G. 2013. A novel automethylation reaction in the Aspergillus nidulans LaeA protein generates S- methylmethionine. Journal of Biological Chemistry 288: 14032-14045.

Park, H. S., Lee, M. K., Kim, S. C., \& Yu, J. H. 2017. The role of VosA/VelB-activated developmental gene vadA in Aspergillus nidulans. PLoS One 12: e0177099.

Petersen, L. M., Hoeck, C., Frisvad, J. C., Gotfredsen, C. H., \& Larsen, T. O. 2014. Dereplication guided discovery of secondary metabolites of mixed biosynthetic origin from Aspergillus aculeatus. Molecules 19: 10898-10921.

Pitt, J. I., Samson, R. A., \& Frisvad, J. C. 2000. List of accepted species and their synonyms in the family Trichocomaceae. In: Integration of modern taxonomic methods for Penicillium and Aspergillus classification. Samson R. A., \& Pitt, J. (eds.), Amsterdam, Netherlands, Harwood Academic Publishers, pp. 9-49.

Pockrandt, D., Ludwig, L., Fan, A., König, G. M., \& Li, S. M. 2012. New insights into the biosynthesis of prenylated xanthones: XptB from Aspergillus nidulans catalyses an O-prenylation of xanthones. Chembiochem 13: 2764-2771.

Pöggeler, S., Nowrousian, M., Teichert, I., Beier, A., \& Kück, U. 2018. Fruiting-body development in ascomycetes. In: The mycota $X V$, physiology and genetics 2nd edition. Anke, T., Schüffler, A. (eds.), Springer International Publishing, pp 1-56.

Pöggeler, S., Nowrousian, M., \& Kück, U. 2006. Fruiting-body development in ascomycetes. In: The mycota I, growth, differentiation and sexuality, 2nd edition. Kües, U., \& Fischer, R.(eds.), Berlin, Germany, Springer Verlag, pp 325-355.

Punt, P. J., \& van den Hondel, C. A. 1992. Transformation of filamentous fungi based on hygromycin B and phleomycin resistance markers. Methods in Enzymology 216: 447-457.

Punt, P. J., Dingemanse, M. A., Jacobs-Meijsing, B. J., Pouwels, P.H., \& van den Hondel, C. A. 1988. Isolation and characterization of the glyceraldehyde-3phosphate dehydrogenase gene of Aspergillus nidulans. Gene 69: 49-57. 
Pusztahelyi, T., Molnár, Z., Emri, T., Klement, E., Miskei, M., Kerékgyártó, J., Balla, J., \& Pócsi, I. 2006. Comparative studies of differential expression of chitinolytic enzymes encoded by chiA, chiB, chiC and nagA genes in Aspergillus nidulans. Folia Microbiologica 51: 547-554.

Rajasekaran, K., Sayler, R. J., Sickler, C. M., Majumdar, R., Jaynes, J. M., \& Cary, J. W. 2018. Control of Aspergillus flavus growth and aflatoxin production in transgenic maize kernels expressing a tachyplesin-derived synthetic peptide, AGM182. Plant Science 270: 150-156.

Raper, K. B., \& Fennell, I. 1965. The genus Aspergillus. In: The genus Aspergillus. Austwick, P. K. C. (ed.), Baltimore, Maryland, United States of America, Williams and Wilkins pp. 1-686.

Rappsilber, J., Mann, M., \& Ishihama, Y. 2007. Protocol for micro-purification, enrichment, pre-fractionation and storage of peptides for proteomics using StageTips. Nature Protocols 2: 1896-1906.

Regulin, A., \& Kempken, F. 2018. Fungal genotype determines survival of Drosophila melanogaster when competing with Aspergillus nidulans. PLoS One 13: e0190543.

Reyes-Dominguez, Y., Bok, J. W., Berger, H., Shwab, E. K., Basheer, A., Gallmetzer, A., Scazzocchio, C., Keller, N. P., \& Strauss, J. 2010. Heterochromatic marks are associated with the repression of secondary metabolism clusters in Aspergillus nidulans. Molecular Microbiology 76: 1376-1386.

Röhrig, J., Yu, Z., Chae, K. S., Kim, J. H., Han, K. H., \& Fischer, R. 2017. The Aspergillus nidulans velvet-interacting protein, VipA, is involved in light-stimulated heme biosynthesis. Molecular Microbiology 105: 825-838.

Ruger-Herreros, C., Rodríguez-Romero, J., Fernández-Barranco, R., Olmedo, M., Fischer, R., Corrochano, L. M., \& Canovas, D. 2011. Regulation of conidiation by light in Aspergillus nidulans. Genetics 188: 809-822.

Rypien, K. L., Andras, J. P., \& Harvell, C. D. 2008. Globally panmictic population structure in the opportunistic fungal pathogen Aspergillus sydowii. Molecular Ecology 17: 4068-4078.

Saiki, R. K., Gelfand, D. H., Stoffel, S., Scharf, S. J., Higuchi, R., Horn, G. T., Mullis, K. B., \& Erlich, H. A. 1988. Primer-directed enzymatic amplification of DNA with a thermostable DNA polymerase. Science 239: 487-491.

Salazar, M., Vongsangnak, W., Panagiotou, G., Andersen, R., \& Nielsen, J. 2009. Uncovering transcriptional regulation of glycerol metabolism in Aspergilli through genome-wide gene expression data analysis. Molecular Genetics and Genomics 282: 571-586.

Samson, R. A., Visagie, C. M., Houbraken, J., Hong, S. B., Hubka, V., Klaassen, C. H., Perrone, G., Seifert, K. A., Susca, A., Tanney, J. B., Varga, J., Kocsube, S., Szigeti, G., Yaguchi, T., \& Frisvad, J. C. 2014. Phylogeny, identification and nomenclature of the genus Aspergillus. Studies in Mycology 78: 141-173.

Sanchez, J. F., Chiang, Y. M., Szewczyk, E., Davidson, A. D., Ahuja, M., Elizabeth Oakley, C., Bok, W. J., Keller, N. P., Oakley, B. R., \& Wang, C. C. 2010. Molecular genetic analysis of the orsellinic acid/F9775 gene cluster Aspergillus nidulans. Molecular Biosystems 6: 587-593. 
Sanchez, J. F., Entwistle, R., Hung, J. H., Yaegashi, J., Jain, S., Chiang, Y. M., Wang, C. C., \& Oakley, B. R. 2011. Genome-based deletion analysis reveals the prenyl xanthone biosynthesis pathway in Aspergillus nidulans. Journal of the American Chemical Society 133: 4010-4017.

Sarikaya-Bayram, Ö., Bayram, Ö., Feussner, K., Kim, J. H., Kaever, A., Feussner, I., Chae, K., S., Han, D. M., Han, K. H., \& Braus, G. H. 2014. Membrane-bound methyltransferase complex VapA-VipC-VapB guides epigenetic control of fungal development. Developmental Cell 29: 406-420.

Sarikaya-Bayram, Ö., Bayram, Ö., Valerius, O., Park, H. S., Irniger, S., Gerke, J., Ni, M., Han, K. H., Yu, J. H., \& Braus, G. H. 2010. LaeA control of velvet family regulatory proteins for light-dependent development and fungal cell-type specificity. PLoS Genetics 6: e1001226.

Satterlee, T., Cary, J. W., \& Calvo, A. M. 2016. RmtA, a putative arginine methyltransferase regulates secondary metabolism and development in Aspergillus flavus. PLoS One 11: e0155575.

Scherer, M., Wei, H., Liese, R., \& Fischer, R. 2002. Aspergillus nidulans catalase peroxidase gene $(c p e A)$ is transcriptionally induced during sexual development through the transcription factor stuA. Eukaryotic Cell 1: 725-735.

Schinke, J., Kolog Gulko, M., Christmann, M., Valerius, O., Stumpf, S. K., Stirz, M., \& Braus, G. H. 2016. The DenA/DEN1 interacting phosphatase DipA controls septa positioning and phosphorylation-dependent stability of cytoplasmatic DenA/DEN1 during fungal development. PLoS Genetics 12: e1005949.

Schmitt, K., Smolinski, N., Neumann, P., Schmaul, S., Hofer-Pretz, V., Braus, G. H., \& Valerius, O. 2017. Asc1p/RACK1 connects ribosomes to eukaryotic phosphosignaling. Molecular and Cellular Biology 37: e00279-16.

Serlupi-Crescenzi, O., Kurtz, M. B., \& Champe, S. P. 1983. Developmental defects resulting from arginine auxotrophy in Aspergillus nidulans. Microbiology 129: 3535-3544.

Shevchenko, A., Wilm, M., Vorm, O., \& Mann, M. 1996. Mass spectrometric sequencing of proteins from silver-stained polyacrylamide gels. Analytical chemistry 68: 850-858.

Shin, K. S., Kwon, N. J., Kim, Y. H., Park, H. S., Kwon, G. S., \& Yu, J. H. 2009. Differential roles of the ChiB chitinase in autolysis and cell death of Aspergillus nidulans. Eukaryotic Cell 8: 738-746.

Shlezinger, N., Irmer, H., Dhingra, S., Beattie, S. R., Cramer, R. A., Braus, G. H., Sharon, A., \& Hohl, T. M. 2017. Sterilizing immunity in the lung relies on targeting fungal apoptosis-like programmed cell death. Science 357: 1037-1041.

Simpson, T. J. 2012. Genetic and biosynthetic studies of the fungal prenylated xanthone shamixanthone and related metabolites in Aspergillus spp. revisited. Chembiochem 13: 1680-1688.

Sohn, K. T., \& Yoon, K. S. 2002. Ultrastructural study on the cleistothecium development in Aspergillus nidulans. Mycobiology 30: 117-127. 
Southern, E. M. 1975. Detection of specific sequences among DNA fragments separated by gel electrophoresis. Journal of Molecular Biology 98: 503-517.

Soukup, A. A., Fischer, G. J., Luo, J., \& Keller, N. P. 2017. The Aspergillus nidulans Pbp1 homolog is required for normal sexual development and secondary metabolism. Fungal Genetics and Biology 100: 13-21.

Spraker, J. E., Sanchez, L. M., Lowe, T. M., Dorrestein, P. C., \& Keller, N. P. 2016. Ralstonia solanacearum lipopeptide induces chlamydospore development in fungi and facilitates bacterial entry into fungal tissues. ISME Journal 10: 23172330.

Stajich, J. E., Harris, T., Brunk, B. P., Brestelli, J., Fischer, S., Harb, O. S., Kissinger, J. C., Li, W., Nayak, V., Pinney, D. F., Stoeckert, C. J. Jr., \& Roos, D. S. 2012. FungiDB: an integrated functional genomics database for fungi. Nucleic Acids Research. 40: 675-681.

Tamura, K., Ohbayashi, N., Ishibashi, K., \& Fukuda, M. 2011. Structure function analysis of VPS9-ankyrin-repeat protein (Varp) in the trafficking of tyrosinaserelated protein 1 in melanocytes. Journal of Biological Chemistry 286: 7507- 7521.

Tian, Y. Q., Lin, X. P., Wang, Z., Zhou, X. F., Qin, X. C., Kaliyaperumal, K., Zhang, T. Y., Tu, Z. C., \& Liu, Y. 2015. Asteltoxins with antiviral activities from the marine sponge-derived fungus Aspergillus sp. SCSIO XWS02F40. Molecules 21: e34.

Tsitsigiannis, D. I., \& Keller, N. P. 2004a. Oxylipins as developmental and host-fungal communication signals. Trends in Microbiology 15: 109-118.

Tsitsigiannis, D. I., Zarnowski, R., \& Keller, N. P. 2004b. The lipid body protein, PpoA, coordinates sexual and asexual sporulation in Aspergillus nidulans. Journal of Biological Chemistry 279: 11344-11353.

Tyanova, S., Temu, T., \& Cox, J. 2016. The MaxQuant Computational platform for mass spectrometry-based shotgun proteomics. Nature Protocols. 11: 2301-2319.

Upadhyay, S., \& Shaw, B. D. 2008. The role of actin, fimbrin and endocytosis in growth of hyphae in Aspergillus nidulans. Molecular Microbiology 68: 690-705.

Upadhyay, S., Torres, G., \& Lin, X. 2013. Laccases involved in 1,8dihydroxynaphthalene melanin biosynthesis in Aspergillus fumigatus are regulated by developmental factors and copper homeostasis. Eukaryotic Cell 12: 1641-1652.

Veraldi, S., Chiaratti, A., \& Harak, H. 2010. Onychomycosis caused by Aspergillus versicolor. Mycoses 53: 363-365.

Vienken, K., Scherer, M., \& Fischer, R. 2005. The Zn(II)2Cys6 putative Aspergillus nidulans transcription factor repressor of sexual development inhibits sexual development under low-carbon conditions and in submersed culture. Genetics 169: 619-630.

Wartenberg, D., Vödisch, M., Kniemeyer, O., Albrecht-Eckardt, D., Scherlach, K., Winkler, R., Weide, M., \& Brakhage, A. A. 2012. Proteome analysis of the farnesol-induced stress response in Aspergillus nidulans the role of a putative dehydrin. Journal of Proteomics 75: 4038-4049. 
Wei, H., Vienken, K., Weber, R., Bunting, S., Requena, N., \& Fischer, R. 2004. A putative high affinity hexose transporter, HxtA, of Aspergillus nidulans is induced in vegetative hyphae upon starvation and in ascogenous hyphae during cleistothecium formation. Fungal Genetics and Biology 41: 148-156.

Wei, H., Scherer, M., Singh, A., Liese, R. \& Fischer, R. 2001. Aspergillus nidulans alpha-1,3 glucanase (mutanase), MutA, is expressed during sexual development and mobilizes mutan. Fungal Genetics and Biology 34: 217-227.

Yamazaki, H., Yamazaki, D., Takaya, N., Takagi, M., Ohta, A., \& Horiuchi, H. 2007. A chitinase gene, chiB, involved in the autolytic process of Aspergillus nidulans. Current Genetics 51: 89-98.

Yoshimi, A., Miyazawa, K., \& Abe, K. 2017. Function and biosynthesis of cell wall $\alpha-$ 1,3-glucan in fungi. Journal of Fungi 3: 63.

Yuan, X. L., van der Kaaij R, M., van den Hondel, C. A., Punt, P. J., van der Maarel, M. J., Dijkhuizen, L., \& Ram, A. F. 2008. Aspergillus niger genome-wide analysis reveals a large number of novel alpha-glucan acting enzymes with unexpected expression profiles. Molecular Genetics and Genomics 279: 545-561.

Yu, B., Zhang, X., Sun, W., Xi, X., Zhao, N., Huang, Z., Ying, Z., Liu, L., Liu, D., Niu, H., Wu, J., Zhuang, W., Zhu, C., Chen, Y., \& Ying, H. 2018. Continuous citric acid production in repeated-fed batch fermentation by Aspergillus niger immobilized on a new porous foam. Journal of Biotechnology 24: 276-277.

Zaho, X., Spraker, J. E., Bok, J. W., Velk, T., He, Z. M., \& Keller, N. P. 2017. A cellular fusion cascade regulated by LaeA is required for sclerotial development in Aspergillus flavus. Frontiers in Microbiology 8: 1925.

Zonneveld, B. J. 1973. Inhibitory effect of 2-Deoxyglucose on cell wall alpha-1,3glucan synthesis and cleistothecium development in Aspergillus nidulans. Developmental Biology 34: 1-8. 


\section{Abbreviations}

${ }^{\circ} \mathrm{C}$ celsius

$\Delta$. deletion

$\mu$.

micro

$\Sigma$

sum

aa amino acid

Blast Basic local alignment search tool

bp base pairs

$\mathrm{cm}$. centimeter

comp + complementation

C-terminus carboxy terminus

$\mathrm{Da}$ dalton

DIC differential interference contrast

DNA deoxyribonucleic acid et al. .et alii, and others

e.g exempli gratia, for example

ER endoplasmic reticulum

FGSC Fungal Genetics Stock Center

PSM peptide spectral match

g. gram

gDNA. genomic DNA 
GFP

green fluorescent protein

ID. identification

LC-MS liquid chromatography-mass spectrometry

I....................... liter

$\log _{2}$ logarithm to the base 2

$\mathrm{kDa}$ kilodalton

MS mass spectrometry

ms. millisecond

$\min$ minute(s)

$\mathrm{mg}$ milligram

$\mathrm{ml}$. milliliter

$\mathrm{mm}$ millimeter

$\mathrm{mM}$ millimolar

M. molar

$\mathrm{N}$-terminus amino-terminus

$\mu \mathrm{g}$ microgram

$\mu l$. microliter

$\mu \mathrm{m}$ micrometer

PAGE polyacrylamide gelelectrophoresis

PCR polymerase chain reaction

$\mathrm{pH}$ power of hydrogen

$\mathrm{sp}$ spore

RNA. ribonucleic acid 
rpm revolutions per minute

tRNA. transfer ribonucleic acid

Tris tris(hydroxymethyl)aminomethane

UTR untranslated region

UV. ultraviolet

V................... Volt

v..................... volume

v/v $\ldots \ldots \ldots \ldots \ldots \ldots$ volume per volume

w.................... weight

wt....................wildtype

w/v .................. weight per volume 


\section{List of Figures}

Figure 1. Adult Hülle cells and the subtending hyphae of Hülle cells.

Figure 2. Electron microscope images of the content and septa found in Hülle cells of Aspergillus nidulans.

Figure 3. Asexual and sexual differentation.

Figure 4. Secondary metabolite gene clusters which are involved in the production of monodictyphenone and xanthones.

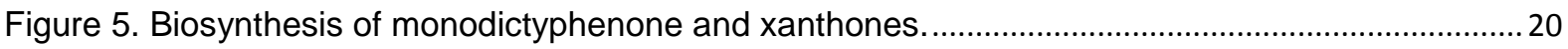

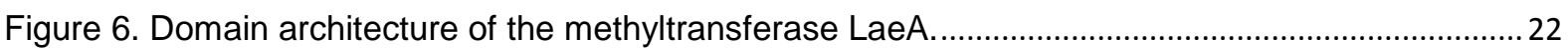

Figure 7. LaeA methyltransferase promotes Hülle cell formation.......................................................... 23

Figure 8. Illustration of enrichment of Hülle cells from solid agar plates: the cleistothecia-rolling technique.

Figure 9. Restriction map and Southern hybridization before and after the marker was recycled for the deletion strain laeAs; nkuA $\Delta$ (AGB1073).

Figure 10. Restriction map and Southern hybridization before and after the marker was recycled for

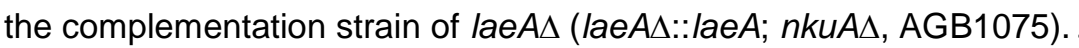

Figure 11. Restriction map and Southern hybridization before and after the marker was recycled for lysine auxotrophic laeA $\Delta$ strain (lysA $\Delta$; laeA $\Delta ; n k u A \Delta$, AGB1074).

Figure 12. Restriction map and Southern hybridization before and after the marker was recycled for the complementation strain lysA $\Delta$; laeA $\Delta$ (lysA $\Delta$;laeA $\Delta::$ laeA;nkuA $\Delta$, AGB1076). ................................ 49

Figure 13. Restricition map and Southern hybridization to confirm nptA::gfp and rfeA::gfp strains .......50

Figure 14. Schematic illustration of the two-step cloning strategy. .....................................................51

Figure 15. Diagnostic PCR to confirm the integration of the $x p t B:: g f p$ cassette. ..................................52

Figure 16. Diagnostic PCR to confirm the integration of $x p t C:: g f p$ cassette.........................................53

Figure 17. Diagnostic PCR to confirm the integration of the AN8434::gfp cassette...............................54

Figure 18. Diagnostic PCR to confirm the integration of the AN8435::gfp cassette...............................55

Figure 19. Restriction map and Southern hybridization before and after the marker was recycled for the $n k u A \Delta ; m p h A \Delta$ (AGB1077) strain.

Figure 20. Restriction map and Southern hybridization before and after the marker was recycled for

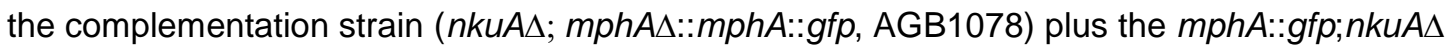
(AGB1079) strain.

Figure 21. Restricition map and Southern hybridization to confirm the complementation strain (mphA $\Delta:: m p h A, n k u A \Delta, A G B 1080)$ and the laeA $\Delta ; m p h A:: g f p ; n k u A \Delta$ (AGB1081) strain.......................58

Figure 22. Enrichment of Hülle cells of cultures from solid agar plates ..................................................66 Figure 23. Proteomics workflow for analyzing enriched surface Hülle cells grown on solid agar plates

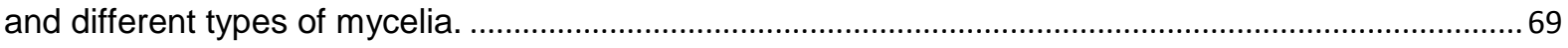

Figure 24. Comparative analysis of identified proteins from surface cultures. ....................................... 70

Figure 25. Enzymes encoded by the xanthone (xpt) gene cluster are localized in Hülle cells. ............. 76 Figure 26. Enzymes encoded by the xanthone $(x p t)$ gene cluster are localized in vegetative mycelium.

Figure 27. The fusion proteins XptB::GFP and XptC::GFP are found in sexual mycelium with high

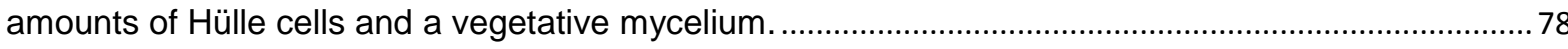

Figure 28. Functional annotation of identified proteins found in surface Hülle cells............................... 80

Figure 29. Proteomics workflow for analyzing enriched Hülle cells from submerged cultures. ..............82

Figure 30. Lysine prototroph and auxotroph laeA $\Delta$ strains for the quantitative analysis of Hülle cells under submerged liquid conditions.

Figure 31. Determination of the number of Hülle cells in vegetative mycelia and determination of the

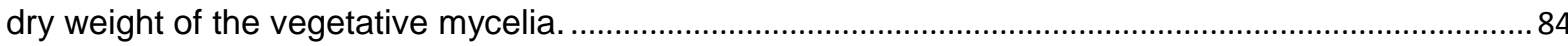

Figure 32. The prenyltransferase NptA is localized in the cytoplasm of Hülle cells. ............................... 89

Figure 33. Reduced protein abundance of the prenyltransferase NptA in a laeA $\Delta$ mycelium. .............90 
Figure 34. The serine/threonine kinase RfeA is localized in Hülle cells and is reduced in a laeA $\Delta$ mycelium.

Figure 35. The serine/threonine kinase RfeA is localized in Hülle cells and the protein quantity is reduced in a laeAs mycelium.

Figure 36. Hülle cells from surface growth compared to Hülle cells from liquid media differ in composition by $28 \%$ beside a shared core proteome.

Figure 37. The AnkG (AN8434) ankyrin repeat domain protein is localized at the membrane of the subtending hyphae of Hülle cells.

Figure 38. The AnkG::GFP fusion protein is found in sexual mycelium with high amounts of Hülle cells

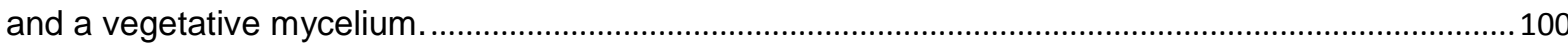

Figure 39. The localization of the tyrosinase domain protein (AN8435).............................................. 101

Figure 40. Western hybridization of AN8435::GFP of a vegetative and a sexual mycelium................ 102

Figure 41. Multisequence alignment of four putative maltose permease-like protein sequences from MphA (Aspergillus nidulans), Afu4g00150 (Aspergillus fumigatus), Mal11 (Aspergillus niger), Mal31

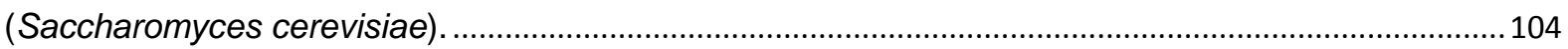

Figure 42. The MphA maltose permease-like protein supports vegetative growth............................... 105

Figure 43. MphA promotes fungal growth and development. ........................................................... 106

Figure 44. Localization of the maltose permease-like protein MphA. ................................................ 108

Figure 45. The maltose permease-like protein MphA prevents mycelia differentiation at higher concentration of carbohydrates. ...................................................................................................... 110

Figure 46. The monodictyphenone $(m d p)$ / xanthone (xpt) gene clusters are active in sexual tissue including Hülle cells from surface growth.

Figure 47. Hülle cell formation in submerged liquid cultures and comparison of two strains causing different results.

Figure 48. The comparison of the proteome of both types of Hülle cells. ........................................... 118

Figure 49. Domain architecture of the AnkG (AN8434) ankyrin repeat domain protein and the

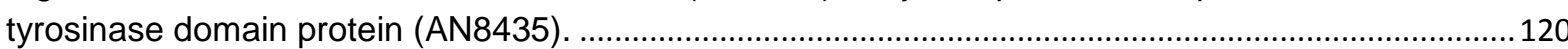

Figure 50. Protein trafficking of the AnkG ankyrin domain protein. ..................................................... 121

Figure 51. Model for the maltose permease-like protein MphA in the transportation of $\alpha-1,3$ glucans in

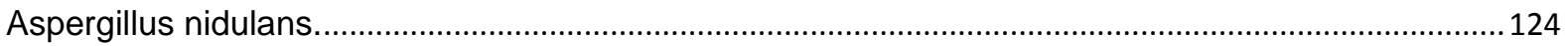

Figure 52. Hülle cells protect and support the cleistothecia........................................................ 126

\section{List of Tables}

Table 1. Strains used in this study.

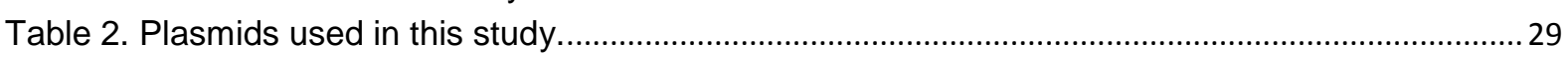

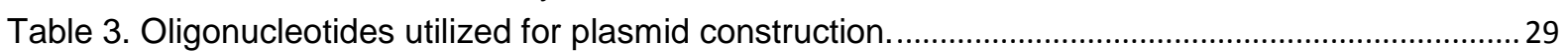

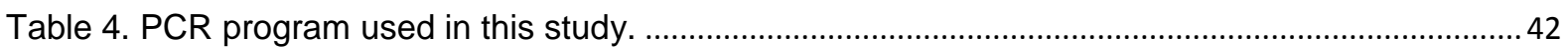

Table 5. Primers used for amplification of Southern probes. ..............................................................4 44

Table 6. Comparative proteomics revealed six proteins that were identified in the enriched Hülle cells.

Table 7. 24 proteins that were common between sexual mycelia and Hülle cells and were identified from solid agar plate cultures.

Table 8. Overlapping proteins of Hülle cells (HC), asexual (Asex.) and vegetative mycelium (Veg.). . 79

Table 9. Proteins that are down-regulated in a laeA $\Delta$ mycelium ................................................................ 86

Table 10. Proteins that are up-regulated in a laeA $\Delta$ mycelium .................................................................8 88

Table 11. List of overlapping proteins identfied in Hülle cells from solid agar plates and submerged liquid cultures (Hülle cells core proteome). 


\section{Acknowledgements}

I would like to thank Professor Dr. Gerhard H. Braus for lots of advice and assistance for my research during my doctoral work. Many thanks also to Professor Dr. Stefanie Pöggeler and Dr. Oliver Valerius to patronize my work as members of the doctoral thesis committee. I appreciated very much the possibility to discuss different results and aspects with Stefanie Pöggeler and Oliver Valerius beyond the thesis committee meetings. I am grateful to my examination board: Professor Dr. Heike Krebber, Professor Dr. Kai Heimel, Privatdozent Dr. Michael Hoppert. I would like to thank Dr. Abishek Kumar who performed with me the functional annotation of the surface Hülle cells proteome during a QuantFung course at the University of Kiel. I would like to thank Dr. Oliver Valerius and Dr. Kerstin Schmitt for helping me to identify proteins by mass spectrometry. I am very grateful to Marie Skłodowska-Curie actions and the Göttingen Graduate School for Neuroscience, Biophysics and Molecular Biosciences for financial support and giving me the opportunity to be part of the QuantFung consortium. I enjoyed very much the networking opportunities within the QuantFung community and also the courses provided during the three years of the project. Many thanks to Dr. Oliver Valerius, Dr. Christoph Sasse, Dr. Jenny Gerke and Dr. Danielle Troppens for helping me in the lab and challenging me in many discussions. Cindy Meister for the construction of the lysine auxotrophic strain. Enikö Fekete-Szücs, for in gel digestion. For proof - reading I am grateful to Oliver, Christoph, Jenny. Moreover, I am grateful to Cindy Meister, Dr. Mirit Gluko, Dr. Razieh Aghcheh Karimi and Liu Li for proof-reading of my doctoral thesis. Special thanks goes to my lab 102, Dr. Razieh Aghcheh Karimi, Dr. Karl Thieme, Sabine Thieme, Anja Abelmann, Verena Große. I am grateful for the moral support of my mum, Franz, my Sister Maria and Toby Boyce, her kids Henry and Elsa. For english proofreading I am grateful to Toby Boyce. I enjoyed the time in Hannover, Celle, Stuttgart and Goettingen very much. The research leading to these results has received funding from the European Union's Seventh Framework Programme FP7/2007-2013, under grant agreement no 607332. This work was partly supported by the Göttingen Graduate School for Neuroscience, Biophysics and Molecular Biosciences (DFG GSC 226/2). 


\section{Curriculum vitae}

\section{Private data}

Name: Benedict Dirnberger

Data of birth: 22. April 1984

Birthplace: Vienna

Civil status: unmarried

\section{Academic achievements}

02/2014 - ongoing PhD student / Doctor rerum naturalium in Biochemistry and Microbiology

Place of education: Georg August University of Goettingen, Institute: Department for Molecular Microbiology and Genetics Title of the thesis: Proteomics of Aspergillus nidulans sexually differentiated cells

Supervisor: Prof. Dr. Gerhard H. Braus

11/2010 - 01/2013 Diploma (corresponding to M.Sc.) in Biology, Major in Genetics and Microbiology

Place of education: University of Vienna Institute: Department for Molecular Systems Biology Title of the thesis: A subcellular fractionation that allows the measurement of the proteome and the metabolome Supervisor: Prof. Dr. Wolfram Weckwerth \& Ass. Prof. Dr. Stefanie Wienkoop

10/2004 - 11/2010 Prediploma in Biology

Place of education: University of Vienna

\section{International experience}
2/2013- ongoing
University of Goettingen (Ger)
$07 / 2009-08 / 2009$
University of Cambridge (UK)
$07 / 2007$
University of Bristol (UK)

\section{Publications in peer reviewed international journals}

Büttel, Z., Díaz, R., Dirnberger, B., Flak, M., Grijseels, S., Kwon, M. J., Nielsen, J. C. F., Nygård, Y., Phule, P., Pohl, C., Prigent, S., Randelovic, M., Schütze, T., Troppens, D., \& Viggiano. A. 2015. Unlocking the potential of fungi: the QuantFung project. Fungal Biology and Biotechnology 2: 6. 


\section{Presentations in scientific meetings (talks and posters)}

[1] Benedict Dirnberger, Oliver Valerius, Enikő Fekete-Szücs, Cindy Meister, Ines Teichert, Jennifer Gerke, Danielle Troppens, Gerhard H. Braus (2017). A quantitative comparative proteomic approach to investigate Hülle cells from the filamentous fungus Aspergillus nidulans. $16^{\text {th }}$ Human Proteome Organization World Congress (HUPO2017), Dublin, Ireland (poster A-016).

[2] Benedict Dirnberger, Oliver Valerius, Enikő Fekete-Szücs, Cindy Meister, Ines Teichert, Jennifer Gerke, Danielle Troppens, Gerhard H. Braus (2016). A comparative proteomic approach to investigate secondary metabolite gene cluster expression in various Aspergillus nidulans cell types. $13^{\text {th }}$ European Conference on Fungal Genetics, Paris, France, p 567 (poster CS7W41).

[3] Danielle Troppens, Benedict Dirnberger, Gerhard Braus (2016). Investigating the potential of Hülle cells in Aspergillus nidulans. 13 ${ }^{\text {th }}$ European Conference on Fungal Genetics, Paris, France, p 134 (poster CS1M28).

[4] Benedict Dirnberger, Oliver Valerius, Enikő Fekete-Szücs, Cindy Meister, Ines Teichert, Jennifer Gerke, Danielle Troppens, Gerhard H. Braus (2016). A comparative proteomic approach to investigate secondary metabolite gene cluster expression in various Aspergillus nidulans cell types. The Thirteenth International Aspergillus Meeting, Paris, France, p 17 (poster 23).

[5] Benedict Dirnberger et al., (2015). Investigation of Hülle cells from the filamentous fungus Aspergillus nidulans. Proteomics Forum 2015, Berlin, Germany, p48 (poster 091).

[6] Danielle Troppens, Özgür Bayram, Benedict Dirnberger, Gerhard Braus (2015). Investigating the potential of Hülle cells in Aspergillus nidulans. Annual Conference of the Association for General and Applied Microbiology, Marburg, Germany $p$ 218 (poster SMaP07).

[7] Benedict Dirnberger et al., (2015). Investigation of Hülle cells from the filamentous fungus Aspergillus nidulans. Annual Conference 2015 of the Association for General and Applied Microbiology, Marburg, Germany p 228 (poster SCP01).

[8] Benedict Dirnberger (2015). Investigation and quantification of secondary metabolite gene cluster expression in Aspergillus nidulans. Annual Conference 2015 of the Association for General and Applied Microbiology, Marburg, Germany (oral presentation).

[9] Benedict Dirnberger, Oliver Valerius, Ines Teichert, Holm Frauendorf, Danielle Troppens, Bastian Jöhnk, Gerhard H. Braus (2014). Investigation of Hülle cells from the filamentous fungus Aspergillus nidulans. ESF-EMBO Symposium Synthetic biology of antibiotic production II, Sant Feliu de Guixols, Spain, p14 (poster013). 
[10] Benedict Dirnberger \& Gerhard H. Braus (2014). Exploration of molecular switches from filamentous growth to single Hülle cells as tool for synthetic biology. Proceeding of the $1^{\text {th }}$ European Conference of Fungal Genetics (ECFG), Seville, Spain, p78 (poster 018).

\section{Fellowships, scholarships and awards}

$03 / 2018$

TOP scholarship foreign countries, Lower Austria, awarded for Doctoral thesis

11/2017 Travel award, 16 $6^{\text {th }}$ Human Proteome Organization World Congress (HUPO2017) 17.09-21.09.2017, awarded by European proteomics association (EUPA)

$08 / 2017$

Travel award, $16^{\text {th }}$ Human Proteome Organization World Congress (HUPO2017), 17.09-21.09.2017, awarded by German society for proteomics

$11 / 2016$

GGNB scholarship (DFG Grant GSC 226/2), awarded for Doctoral thesis

$04 / 2016$

Award for best poster presentation, The Thirteenth International Aspergillus Meeting, Paris, France, p 17 (poster 23), awarded by Novozymes

07/2015

Travel award (offered), $9^{\text {th }}$ European Summer School Advanced Proteomics, 02.08-08.08. 2015 Kloster Neustift Brixen, awarded by German society for proteomics

$02 / 2015$

Travel award, Proteomics Forum 2015, 22.03-25.03.2015 Berlin Germany, awarded by Austrian society for proteomics

$02 / 2014$

Marie Skłodowska-Curie Fellowship (ITN), awarded for Doctoral thesis (University of Goettingen)

$08 / 2013$

Leonardo da Vinci scholarship, awarded for research in the Mass Spectrometry - Yeast Group (University of Goettingen)

$01 / 2013$

University of Goettingen scholarship, awarded for research in the Department of Plant Biochemistry 


\section{Supplements}

\section{Supplementary Table 1:}

Overwiew of the proteome data evalution using Proteome Discoverer 1.4.

\begin{tabular}{|c|c|}
\hline \multicolumn{2}{|r|}{ Proteome experiment 1} \\
\hline No. & Description \\
\hline 1 & $\begin{array}{l}\text { Vegetative mycelium: } 20 \text { hours after germination in liquid shake flasks } \\
\text { Three biological replicates }\end{array}$ \\
\hline 2 & Filter: proteins identified in two or more biological replicates and with more than two peptides per proteins \\
\hline 3 & $\begin{array}{l}\text { Asexual mycelium: } 3 \text { days after germination on solid agar plate cultures } \\
\text { Three biological replicates }\end{array}$ \\
\hline 4 & Filter: proteins identified in two or more biological replicates and with more than two peptides per proteins \\
\hline 5 & $\begin{array}{l}\text { Asexual mycelium: } \mathbf{5} \text { days after germination on solid agar plate cultures } \\
\text { Three biological replicates }\end{array}$ \\
\hline 6 & Filter: proteins identified in two or more biological replicates and with more than two peptides per proteins \\
\hline 7 & $\begin{array}{l}\text { Asexual mycelium } 7 \text { days after germination on solid agar plate cultures } \\
\text { Three biological replicates }\end{array}$ \\
\hline 8 & Filter: proteins identified in two or more biological replicates and with more than two peptides per proteins \\
\hline 9 & $\begin{array}{l}\text { Sexual mycelium: } 3 \text { days after germination on solid agar plate cultures } \\
\text { Three biological replicates }\end{array}$ \\
\hline 10 & Filter: proteins identified in two or more biological replicates and with more than two peptides per proteins \\
\hline 11 & $\begin{array}{l}\text { Sexual mycelium: } \mathbf{5} \text { days after germination on solid agar plate cultures } \\
\text { Three biological replicates }\end{array}$ \\
\hline 12 & Filter: proteins identified in two or more biological replicates and with more than two peptides per proteins \\
\hline 13 & $\begin{array}{l}\text { Sexual mycelium: } 7 \text { days after germination on solid agar plate cultures } \\
\text { Three biological replicates }\end{array}$ \\
\hline 14 & Filter: proteins identified in two or more biological replicates and with more than two peptides per proteins \\
\hline 15 & $\begin{array}{l}\text { Hülle cells: } \mathbf{3} \text { days after germination on solid agar plate cultures } \\
\text { Three biological replicates }\end{array}$ \\
\hline 16 & Filter: proteins identified in two or more biological replicates and with more than two peptides per proteins \\
\hline 17 & $\begin{array}{l}\text { Hülle cells: } \mathbf{5} \text { days after germination on solid agar plate cultures } \\
\text { Three biological replicates }\end{array}$ \\
\hline 18 & Filter: proteins identified in two or more biological replicates and with more than two peptides per proteins \\
\hline 19 & $\begin{array}{l}\text { Hülle cells: } 7 \text { days after germination on solid agar plate cultures } \\
\text { Three biological replicates }\end{array}$ \\
\hline 20 & Filter: proteins identified in two or more biological replicates and with more than two peptides per proteins \\
\hline 21 & Insert lists into a Venn diagram \\
\hline 22 & Additional steps were performed \\
\hline
\end{tabular}

\section{Supplementary Table 2:}

Overwiew of the proteome data evalution using Perseus 1.5.0.15.

\begin{tabular}{|r|l|l|}
\hline \multicolumn{2}{|c|}{ Proteome experiment 2} \\
\hline No. & Command & Description \\
\hline 1 & Generic matrix upload & ProteinGroup.txt normailzed ratio \\
\hline 2.1 & Filter rows based on categorical columns & Remove rows with + in reverse column \\
\hline 2.2 & Filter rows based on categorical columns & Remove rows with + in only identified by site \\
\hline 3 & Select rows manually & Remove rows with contaminants \\
\hline 4 & Transform & $\begin{array}{l}\text { Inverse ratio }(1 / x) \text { when lys } A \Delta ; n k u A \Delta \text { is not in the } \\
\text { denominator }\end{array}$ \\
\hline 5 & Transform & Log $(\mathrm{X})$ \\
\hline 6 & Categorical annotation rows & Group biological replicates \\
\hline 8 & Normalization & Substract column median of ratio \\
\hline 9 & Sample t-test & Calculate median of each group \\
\hline 10 & Select rows manually & One - sample t-test, side both, $p$ value 0.05 \\
\hline 11 & Select rows manually & Selected proteins with t-test significants $(+)$ \\
\hline 12 & Additional steps and analyses were performed beside using Perseus 1.5.0.15. \\
\hline
\end{tabular}




\section{Supplementary Table 3.}

The list of the 401 proteins found in enriched Hülle cells. Hülle cells enriched from solid agar plate cultures were analyzed within three different time points. Proteins were sorted according to the criteria of the Venn diagram shown in Figure 24. For each time point three biological replicates were considered. Only proteins identified in two or more biological replicates and with two or more peptides per protein were considered for the analysis. Numbers represent the average of spectral counts from three biological replicates. Spectral counts were obtained from enriched Hülle cells and are listed. Proteins that were common between Hülle cells and different type of mycelia are also listed. Putative function or role proteins are listed under Description. Different sources were used, mainly AspGD (Cerqueira et al., 2014).

\begin{tabular}{|c|c|c|c|c|}
\hline \multicolumn{5}{|c|}{ Found only in Hülle cells ( 6 proteins) } \\
\hline \multirow[b]{2}{*}{ Gene ID } & \multirow[b]{2}{*}{ Description } & \multicolumn{3}{|c|}{$\begin{array}{l}\text { Spectral counts, } \\
\text { found in Hülle cells }\end{array}$} \\
\hline & & 3 day & 5 day & 7 day \\
\hline AN2601 (MphA) & Major facilitator superfamily & & 8 & 8 \\
\hline AN9392 & Major facilitator superfamily & 7 & 4 & \\
\hline AN3407 & Protein with a predicted serine-type peptidase domain & & 25 & 29 \\
\hline AN4695 (HexA) & Woronin body protein & & 8 & 7 \\
\hline AN8434 (AnkG) & Ankyrin repeat domain protein & & 4 & 4 \\
\hline AN8435 & Tyrosinase domain protein & & 2 & 3 \\
\hline \multicolumn{5}{|c|}{ Shared in Hülle cells \& sexual mycelium ( 24 proteins) } \\
\hline & & \multicolumn{3}{|c|}{$\begin{array}{l}\text { Spectral counts, } \\
\text { found in Hülle cells }\end{array}$} \\
\hline Gene ID & Description & 3 day & 5 day & 7 day \\
\hline AN7349 (MutA) & Alpha-1,3-glucanase, specifically expressed in Hülle cells & 3 & 43 & 28 \\
\hline AN0941 (AgdE) & Alpha-glucosidase activity, predicted role in maltose metabolism & 6 & 32 & 24 \\
\hline AN3790 (AgnB) & Putative alpha-1,3-glucanase & & 18 & \\
\hline AN9443 & Predicted cataytic activity and role in carbohydrate metabolic process & & & 11 \\
\hline AN7345 (AgdC) & Glucosidase activity, involved in degradation of glucans & 6 & 32 & 24 \\
\hline AN11143 (GlaA) & Putative Glucoamylase & & 4 & \\
\hline AN11049 & NmrA-like, predicted secondary metabolite member & & 35 & 49 \\
\hline AN10023 (MdpL) & Member of the monodictyphenone $(m d p)$ / xanthone $(x p t)$ gene clusters & 25 & & 42 \\
\hline AN7999 & $\begin{array}{l}\text { Oxoreductase, member of the monodictyphenone }(m d p) / \text { xanthone (xpt) } \\
\text { gene clusters }\end{array}$ & & 8 & 47 \\
\hline AN7998 (XptC) & $\begin{array}{l}\text { GMC oxoreductase, member of the monodictyphenone }(m d p) \text { / xanthone } \\
(x p t) \text { gene clusters }\end{array}$ & 7 & 6 & \\
\hline AN12402 (XptB) & $\begin{array}{l}\text { Prenytransferase, member of the monodictyphenone }(m d p) / \text { xanthone } \\
(x p t) \text { gene clusters }\end{array}$ & 5 & & 8 \\
\hline AN10022 & Member of the monodictyphenone $(m d p)$ / xanthone $(x p t)$ gene clusters & & 5 & 6 \\
\hline AN0150 (MdpG) & $\begin{array}{l}\text { Polyketide synthase, member of the monodictphenone }(m d p) / \text { xanthone } \\
(x p t) \text { gene clusters }\end{array}$ & 4 & 3 & \\
\hline AN7812 (StcN) & Putative versicolorin B synthase & 3 & 4 & \\
\hline AN7641 & Putative copper amine oxidase & 22 & 31 & \\
\hline AN6314 & Oxidoreductase & 5 & 27 & 48 \\
\hline AN8203 & Hydrolase & & 5 & \\
\hline AN1142 & Oxidoreductase & & 4 & \\
\hline AN11897 & Ribonuclease & & 6 & \\
\hline AN5669 & Putative succinyl-CoA:3-ketoacid-coenzyme A transferase & 8 & & 2 \\
\hline AN10977 & Ortholog(s) have extracellular region localization & & 6 & \\
\hline AN6930 & Predicted transaminase activity & & 9 & \\
\hline AN5488 & Protein of unknown function & 2 & 20 & \\
\hline AN1863 & Protein of unknown function & 2 & & 4 \\
\hline
\end{tabular}




\section{Supplementary Table 3.}

Continued.

\begin{tabular}{|c|c|c|c|c|}
\hline \multicolumn{5}{|c|}{ Shared in Hülle cells $\&$ asexual mycelium (10 proteins) } \\
\hline \multirow[b]{2}{*}{ Gene ID } & \multirow[b]{2}{*}{ Description } & \multicolumn{3}{|c|}{$\begin{array}{l}\text { Spectral counts, } \\
\text { found in Hülle cells }\end{array}$} \\
\hline & & 3 day & 5 day & 7 day \\
\hline AN5324 (DlpA) & Dehydrin-like protein & 9 & 9 & 6 \\
\hline AN5004 & Induced in light & 2 & 30 & 7 \\
\hline AN6856 & Upregulated in atm $\Delta$ & 5 & 6 & \\
\hline AN5015 (ConJ) & Induced in light & 2 & 8 & 2 \\
\hline AN5971 & Induced in light & 7 & 4 & \\
\hline AN1362 & Cue5 ortholog & & 4 & \\
\hline AN0635 & Intracellular localization & 8 & 4 & 8 \\
\hline AN0691 & Protein of unknown function & 6 & 16 & \\
\hline AN4646 & Protein of unknown function & & 13 & \\
\hline AN5764 & Induced by light & 2 & & \\
\hline \multicolumn{5}{|c|}{ Shared in Hülle cells \& vegetative mycelium (8 proteins) } \\
\hline & & \multicolumn{3}{|c|}{$\begin{array}{c}\text { Spectral counts, } \\
\text { found in Hülle cells }\end{array}$} \\
\hline Gene ID & Description & 3 day & 5 day & 7 day \\
\hline AN1182 (BenA) & Beta-tubulin & 5 & 4 & 23 \\
\hline AN4236 & Proteasome regulatory particle & 3 & & 5 \\
\hline AN6688 (AspB) & Putative Septin B & 7 & & 2 \\
\hline AN2918 (Cct4) & Chaperonin complex component & 3 & & 3 \\
\hline AN4159 (GInA) & Glutamate-ammonia ligase & 4 & & \\
\hline AN2149 (Cct1) & Chaperonin & 2 & & 2 \\
\hline AN10476 & Dehydrogenase & 7 & 9 & 10 \\
\hline AN4281 (SrgB) & GTPase & & 2 & 3 \\
\hline \multicolumn{5}{|c|}{ Shared in Hülle cells, sexual mycelium \& asexual mycelium (73 proteins) } \\
\hline & & \multicolumn{3}{|c|}{$\begin{array}{l}\text { Spectral counts, } \\
\text { found in Hülle cells }\end{array}$} \\
\hline Gene ID & Description & 3 day & 5 day & 7 day \\
\hline AN0045 & Induced by light & 15 & 55 & \\
\hline AN0158 & 2-alkenal reductase $[N A D(P)]$ activity, & 21 & & 4 \\
\hline AN0472 (EngA) & 1,3-beta-glucosidase & 33 & 9 & 5 \\
\hline AN0567 & Alcohol oxidase & 10 & & 6 \\
\hline AN0693 & Induced by light & & 23 & 7 \\
\hline AN0694 & Intracellular localization & & 66 & \\
\hline AN0779 & Glucan 1,3-beta-glucosidase & 6 & 22 & \\
\hline AN0787 & Mannosyl-oligosaccharide 1,2-alpha-mannosidase & 6 & & 8 \\
\hline AN0950 & Protein of unknown proteins & 4 & 36 & 9 \\
\hline AN10040 & Oxidoreductase & 59 & & 10 \\
\hline AN10281 & Serine/threonine phosphatase & 2 & 20 & 12 \\
\hline AN10499 & Intracellular localization & 6 & 9 & \\
\hline AN10563 (Pho8) & Vacuolar alkaline phosphatase & 4 & & 8 \\
\hline AN10631 & Protein of unknown function & 5 & 10 & \\
\hline AN10930 & UDP-N-acetylmuramate dehydrogenase activity & 16 & 66 & \\
\hline AN11080 (NptA) & Prenyltransferase & 11 & & 26 \\
\hline
\end{tabular}


Supplementary Table 3.

Continued.

\begin{tabular}{|c|c|c|c|c|}
\hline \multicolumn{5}{|c|}{ Shared in Hülle cells, sexual mycelium \& asexual mycelium (73 proteins) } \\
\hline \multirow[b]{2}{*}{ Gene ID } & \multirow[b]{2}{*}{ Description } & \multicolumn{3}{|c|}{$\begin{array}{c}\text { Spectral counts, } \\
\text { found in Hülle cells }\end{array}$} \\
\hline & & 3 day & 5 day & 7 day \\
\hline AN12027 & Protein of unknown function & 6 & & \\
\hline AN1502 (NagA) & Chitin hydrolysis & 6 & & 7 \\
\hline AN1616 & Oxidoreductase & 7 & 15 & \\
\hline AN1675 & Lysophospholipase & 2 & 17 & \\
\hline AN1733 (PrnC) & Delta-1-pyrroline-5-carboxylate dehydrogenase & 13 & & \\
\hline AN1918 (AcuF) & Phosphoenolpyruvate carboxykinase & 25 & 44 & \\
\hline AN2000 (Ubi4) & Polyubiquitin & 15 & 9 & \\
\hline AN2017 (AgdA) & Alpha-glucosidase & 2 & 2 & \\
\hline AN2092 & Prolyl aminopeptidase & 3 & 4 & \\
\hline AN2314 & 1,4-alpha-glucane-branching enzyme & 6 & & \\
\hline AN2383 & Protein of unknown function & & 8 & 25 \\
\hline AN2395 & Beta-glucuronidase & & 4 & 2 \\
\hline AN2572 & Dipeptidyl-peptidase & 6 & & \\
\hline AN2828 (BglL) & Beta-glucosidase & 28 & & 10 \\
\hline AN2860 & Protein of unknown function & 4 & & 5 \\
\hline AN2866 & Oxidoreductase & 2 & & 8 \\
\hline AN2936 & Alpha-mannosidase & 17 & 2 & \\
\hline AN3121 & Protein of unknown function & & 8 & 4 \\
\hline AN3402 (AmyB) & Alpha-amylase & 6 & 5 & \\
\hline AN3416 (SsoA) & Syntaxin protein & 2 & 15 & \\
\hline AN3512 & Protein of unkown function & 5 & 4 & \\
\hline AN3983 & Protein of unknown function & & 9 & 21 \\
\hline AN4058 & Dihydroxy acid dehydratase & 2 & & 10 \\
\hline AN4102 (BglA) & Beta-glucosidase & 16 & 2 & \\
\hline AN4577 (fmdS) & Kynurenine formamidase & & 2 & \\
\hline AN4825 & Glucan 1,3-beta-glucosidase & 2 & & 8 \\
\hline AN4871 (ChiB) & Chitinase & 78 & 111 & 16 \\
\hline AN4940 & Meiotic recombination & 13 & 64 & 12 \\
\hline AN4988 & Intracellular localization & 16 & 55 & 2 \\
\hline AN5217 (PilA) & Protein similarity to sphingolipid & 8 & 65 & \\
\hline AN5281 & Pyranose oxidase & 8 & 44 & \\
\hline AN5422 & Beta-lactamase family protein & 11 & 8 & 7 \\
\hline AN5442 & Carboxypeptidase $Y$ & 7 & & \\
\hline AN5446 & Protein of unknown function & 14 & 62 & \\
\hline AN5634 (AcuB) & Isocitrate lyase & 39 & & \\
\hline AN6024 (GstB) & Glutathione S-transferase & 6 & 10 & 4 \\
\hline AN6273 & Intracellular localization & & 4 & 8 \\
\hline AN6279 (AcuJ) & Carnitine acetyltransferase & 16 & & 8 \\
\hline AN6398 & Intracellular localization & 4 & 8 & \\
\hline AN6796 & Intracellular localization & 2 & 22 & \\
\hline
\end{tabular}


Supplementary Table 3.

Continued.

\begin{tabular}{|l|l|r|r|r|}
\hline \multicolumn{2}{|c|}{ Shared in Hülle cells, sexual mycelium \& asexual mycelium (73 proteins) } \\
\hline \multicolumn{2}{|l|}{ Spectral counts, } \\
found in Hülle cells
\end{tabular}

Shared in Hülle cells, sexual mycelium \& vegtative mycelium (21 proteins)

\begin{tabular}{|c|c|c|c|c|}
\hline & & $\begin{array}{l}\text { Spe } \\
\text { founc }\end{array}$ & $\begin{array}{l}\text { ctral col } \\
\text { in Hüll }\end{array}$ & $\begin{array}{l}\text { Ints, } \\
\text { cells }\end{array}$ \\
\hline Gene ID & Description & 3 day & 5 day & 7 day \\
\hline AN10276 & Nucleic acid binding & 2 & & 4 \\
\hline AN10614 & G-quadruplex DNA binding & 4 & 3 & \\
\hline AN10946 & Protein of unknown function & 7 & 9 & \\
\hline AN1222 & S-adenosylmethionine synthetase & 18 & 6 & 4 \\
\hline AN1358 & Serine/threonine phosphatase activity & 2 & 4 & 4 \\
\hline AN1990 & Homocitrate synthase & 5 & & 5 \\
\hline AN2142 (kapA) & Karyopherin (importin) alpha & 4 & & 2 \\
\hline AN2455 & Zinc ion binding activity & 6 & & 2 \\
\hline AN2980 & Ribosome activity & 6 & 15 & 2 \\
\hline AN4575 & Protein of unknown function & 6 & 9 & 8 \\
\hline AN4667 (AspA) & Septin & 11 & & \\
\hline AN4727 & Involved in galactose metabolism & 2 & 30 & \\
\hline AN4775 & Cullin deneddylation & 10 & & 9 \\
\hline AN5134 (GltA) & Glutamate synthase & 12 & 2 & \\
\hline AN5601 & Saccharopine dehydrogenase & 16 & & \\
\hline AN5602 & Chaperone & 6 & 66 & \\
\hline AN5740 & Rho family GTPase & 6 & & 2 \\
\hline AN5895 & Rab GDP-dissociation inhibitor & 16 & 19 & 19 \\
\hline AN7570 (tubB) & Alpha-tubulin & 2 & & 8 \\
\hline AN8182 (AspC) & Septin & 12 & & \\
\hline AN8863 & Nap/SET family protein & 4 & & 9 \\
\hline
\end{tabular}


Supplementary Table 3.

Continued.

\begin{tabular}{|c|c|c|c|c|}
\hline \multicolumn{5}{|c|}{ Shared in Hülle cells, asexual mycelium \& vegetative mycelium (6 proteins) } \\
\hline \multirow[b]{2}{*}{ Gene ID } & \multirow[b]{2}{*}{ Description } & \multicolumn{3}{|c|}{$\begin{array}{c}\text { Spectral counts, } \\
\text { found in Hülle cells }\end{array}$} \\
\hline & & 3 day & 5 day & 7 day \\
\hline AN0316 (tubA) & Alpha-tubulin & 19 & & 16 \\
\hline AN1126 & ADP ribosylation factor & 6 & 2 & 2 \\
\hline AN1971 & ATP-dependent 3'-5' DNA helicase & 2 & 3 & 6 \\
\hline AN2012 & Protein of unknown function & 2 & 4 & 3 \\
\hline AN6631 & F1F0-ATPase complex subunit & 8 & 8 & \\
\hline AN7350 & Nucleic acid binding & 8 & 9 & 3 \\
\hline
\end{tabular}

\section{Shared in Hülle cells, sexual mycelium, asexual mycelium \& vegetative mycelium} (253 proteins)

\begin{tabular}{|c|c|c|c|c|}
\hline \multirow[b]{2}{*}{ Gene ID } & \multirow[b]{2}{*}{ Description } & \multicolumn{3}{|c|}{$\begin{array}{l}\text { Spectral counts, } \\
\text { found in Hülle cells }\end{array}$} \\
\hline & & 3 day & 5 day & 7 day \\
\hline AN0046 & Protein of unknown function & 13 & & 19 \\
\hline AN0084 & Ran GTPase binding activity & 8 & 11 & \\
\hline AN0170 (TrXA) & Thioredoxin & & 6 & 6 \\
\hline AN0240 (PppA) & Transaldolase & 64 & 25 & 30 \\
\hline AN0241 (SodA) & Cu/Zn-superoxide dismutase & 5 & 50 & 11 \\
\hline AN0252 & F1F0-ATPase complex gamma & 9 & 12 & 2 \\
\hline AN0262 & Ribosomal large subunit assembly & 4 & 16 & 6 \\
\hline AN0285 & 6-phosphogluconolactonase & 8 & 16 & 3 \\
\hline AN0297 & Protoplast secreted protein 2 & 8 & 6 & 9 \\
\hline AN0359 (SgdA) & Translation initiation factor 3 (elF3) & 8 & 3 & \\
\hline AN0432 & Cytochrome-b5 reductase activity & 4 & 3 & \\
\hline AN0433 & Ribosome activity & & 4 & 10 \\
\hline AN0443 & Alcohol dehydrogenase & 6 & 7 & 21 \\
\hline AN0465 & Protein of unknown function & 9 & 10 & 4 \\
\hline AN0554 (AldA) & Aldehyde dehydrogenase & 57 & 43 & 89 \\
\hline AN0579 & Isopentenyl-diphosphate delta-isomerase & 6 & & 9 \\
\hline AN0641 & Osmoadaptation & 11 & 8 & 8 \\
\hline AN0687 (SpdA) & Spermidine synthase & & 4 & 4 \\
\hline AN0688 & Transketolase & 52 & 57 & 63 \\
\hline AN0734 & Histone $\mathrm{H} 4$ & 5 & & 6 \\
\hline AN0747 & Ubiquinol-cytochrome-c reductase & 10 & 10 & 3 \\
\hline AN0776 & Ribosome activity & 4 & 8 & 10 \\
\hline AN0843 & Ribosome activity & & 8 & 3 \\
\hline AN0870 & Transporter & 6 & 6 & 14 \\
\hline AN0893 & Adenylosuccinate synthase & 16 & 5 & 3 \\
\hline AN0932 (GlrA) & Glutathione oxidoreductase & 3 & 4 & 7 \\
\hline AN1003 & Isocitrate dehydrogenase (NAD+) & 12 & 2 & \\
\hline AN10030 & Serine protease & 4 & 18 & 5 \\
\hline AN1013 & 60 S ribosomal protein L5 & 29 & 7 & 25 \\
\hline AN1015 & Phosphorylase & 7 & 10 & 8 \\
\hline AN10170 & ATPase activity and cytoplasm localization & 28 & & \\
\hline AN10202 & ATP binding activity & 20 & 5 & 7 \\
\hline AN10223 & Peroxiredoxin & 6 & 7 & 2 \\
\hline
\end{tabular}


Supplementary Table 3.

Continued.

\begin{tabular}{|c|c|c|c|c|}
\hline \multicolumn{5}{|c|}{$\begin{array}{l}\text { Shared in Hülle cells, sexual mycelium, asexual mycelium \& vegetative mycelium } \\
\text { (253 proteins) }\end{array}$} \\
\hline \multirow[b]{2}{*}{ Gene ID } & \multirow[b]{2}{*}{ Description } & \multicolumn{3}{|c|}{$\begin{array}{l}\text { Spectral counts, } \\
\text { found in Hülle cells }\end{array}$} \\
\hline & & 3 day & 5 day & 7 day \\
\hline AN10266 & Ubiquitin-activating enzyme & 7 & 3 & \\
\hline AN10273 (Gst3) & Glutathione S-transferase & 16 & & \\
\hline AN10279 & Nucleic acid binding & 5 & 2 & 11 \\
\hline AN10311 (MnpA) & Mannoprotein & 4 & 6 & 2 \\
\hline AN10351 & Aminopeptidase activity & 19 & 3 & 23 \\
\hline AN10416 & 60 s ribosomal protein similar to subunits $L 15$ and L27 & 10 & & 6 \\
\hline AN1047 & Heat shock protein & 33 & 32 & 5 \\
\hline AN10474 & Protein of unknown function & 6 & & \\
\hline AN10540 & Dipeptidyl-peptidase activity & 14 & 12 & 4 \\
\hline AN10675 & Mitochondrion localization & 5 & 3 & \\
\hline AN10709 (GfaA) & Glutamine-fructose-6-phosphate transaminase & 13 & & 6 \\
\hline AN10745 & Glycine hydroxymethyltransferase activity & 10 & 10 & 9 \\
\hline AN1084 & Elongation factor EF-Tu & 8 & 9 & \\
\hline AN11005 & Metalloexopeptidase activity & 5 & 5 & \\
\hline AN11045 & D-lactate dehydrogenase (cytochrome) activity & 2 & & 5 \\
\hline AN11125 & Protein of unknown function & 8 & 6 & \\
\hline AN1122 & Ribosome activity & 3 & 7 & \\
\hline AN11227 & 70 kilodalton heat shock protein & 26 & 15 & 20 \\
\hline AN1152 & Protein of unknown function & & 7 & \\
\hline AN1162 & Guanyl-nucleotide exchange factor & 26 & 20 & 3 \\
\hline AN1166 & Ribosome activity & 10 & 9 & 9 \\
\hline AN11898 & Protein of unknown function & 2 & & 10 \\
\hline AN1228 & Maturation of rRNA & 2 & 8 & 10 \\
\hline AN1246 (PgkA) & Phosphoglycerate kinase & 53 & 10 & 16 \\
\hline AN12465 & Intracellular localization & 35 & 18 & 33 \\
\hline AN1263 & Adenosylhomocysteinase & 31 & 3 & 7 \\
\hline AN1342 & Alanine-glyoxylate transaminase & 9 & 6 & 4 \\
\hline AN1378 & Protein of unknown function & & 10 & \\
\hline AN1380 & tRNA ligase & 4 & & \\
\hline AN1409 & Acetyl-CoA C-acetyltransferase & 30 & 7 & 14 \\
\hline AN1430 & Oxidoreductase & 2 & & 4 \\
\hline AN1523 & F1F0-ATPase complex & 62 & 35 & 77 \\
\hline AN1543 & Succinate dehydrogenase & 13 & 7 & 7 \\
\hline AN1547 & Carboxylate CoA-transferase & 27 & 13 & 4 \\
\hline AN1638 & Metalloaminopeptidase & 21 & 24 & 3 \\
\hline AN1689 & Oxidoreductase & 4 & 10 & 2 \\
\hline AN1757 (ssfA) & 20s core proteosome & & 8 & \\
\hline AN1810 & Ornithine transaminase & 19 & 2 & \\
\hline
\end{tabular}


Supplementary Table 3.

Continued.

\begin{tabular}{|c|c|c|c|c|}
\hline \multicolumn{5}{|c|}{$\begin{array}{l}\text { Shared in Hülle cells, sexual mycelium, asexual mycelium \& vegetative mycelium } \\
\text { ( } 253 \text { proteins) }\end{array}$} \\
\hline \multirow[b]{2}{*}{ Gene ID } & \multirow[b]{2}{*}{ Description } & \multicolumn{3}{|c|}{$\begin{array}{c}\text { Spectral counts } \\
\text { found in Hülle cells }\end{array}$} \\
\hline & & 3 day & 5 day & 7 day \\
\hline AN1883 & Argininosuccinate synthase & 19 & 10 & \\
\hline AN1923 & Alanine transaminase & 12 & 35 & 26 \\
\hline AN1964 & Protein of unknown function & 8 & 4 & \\
\hline AN1993 & Aspartate transaminase & 24 & 10 & 12 \\
\hline AN2062 (BipA) & Chaperone & 14 & 15 & 14 \\
\hline AN2150 & Protein of unknown function & 5 & 2 & \\
\hline AN2208 & Galactose 1-dehydrogenase & 9 & 2 & 6 \\
\hline AN2225 & Role in cytoplasmic translation & 7 & 4 & \\
\hline AN2248 (GatA) & 4-aminobutyrate transaminase & 23 & 16 & \\
\hline AN2272 & Protein of unknown function & 10 & & 4 \\
\hline AN2275 & Ribosome activity & 8 & & \\
\hline AN2286 (AlcC) & Alcohol dehydrogenase III & 11 & 2 & 8 \\
\hline AN2295 & Succinate-CoA ligase & 4 & 6 & 6 \\
\hline AN2304 & Protein of unknown function & 8 & 9 & \\
\hline AN2315 & DNA-directed RNA polymerase activity & 120 & 33 & \\
\hline AN2435 (AlcA) & Citrate synthase & 49 & & 40 \\
\hline AN2436 (AclB) & ATP citrate synthase & 64 & 3 & 13 \\
\hline AN2526 & Ketol-acid reductoisomerase & 44 & 5 & 2 \\
\hline AN2734 & rRNA binding activity & 3 & 8 & 10 \\
\hline AN2867 (PgmB) & Phosphoglucomutase & 24 & 29 & 39 \\
\hline AN2875 (FbaA) & Fructose-bisphosphate aldolase & 80 & 36 & 26 \\
\hline AN2903 (PepE) & Aspartic protease & 22 & 9 & 22 \\
\hline AN2914 & Argininosuccinate lyase & 14 & & 3 \\
\hline AN2916 & Succinate dehydrogenase & 19 & 14 & 3 \\
\hline AN2932 & Eukaryotic initiation factor $4 \mathrm{~A}$ & 17 & & 4 \\
\hline AN2954 & Protein of unknown function & 4 & & 4 \\
\hline AN2968 (IppA) & Inorganic diphosphatase & 20 & 24 & 25 \\
\hline AN2981 (GsdA) & Glucose 6-phosphate 1-dehydrogenase & 18 & & 12 \\
\hline AN2999 (IdpA) & Isocitrate dehydrogenase & 22 & 7 & 7 \\
\hline AN3031 & Threonine synthase & 7 & & 2 \\
\hline AN3058 & Glycine hydroxymethyltransferase & 23 & & 23 \\
\hline AN3059 (PgmA) & Phosphoglycerate mutase & 24 & 2 & 7 \\
\hline AN3112 (UgmA) & UDP-galactopyranose mutase & 19 & & 14 \\
\hline AN3172 & Protein of unknown function & 11 & 11 & 7 \\
\hline AN3413 & Ribosomal protein S2 and S5 & 3 & 2 & \\
\hline AN3459 & Metallodipeptidase activity & 7 & 2 & \\
\hline AN3466 (KgdB) & Dihydrolipoamide S-succinyl transferase & 21 & & 10 \\
\hline AN3592 (ClxA) & Calnexin & & 5 & 15 \\
\hline AN3674 & Protein of unknown function & 40 & 22 & 43 \\
\hline
\end{tabular}


Supplementary Table 3.

Continued.

\begin{tabular}{|c|c|c|c|c|}
\hline \multicolumn{5}{|c|}{$\begin{array}{l}\text { Shared in Hülle cells, sexual mycelium, asexual mycelium \& vegetative mycelium } \\
\text { ( } 253 \text { proteins) }\end{array}$} \\
\hline \multirow[b]{2}{*}{ Gene ID } & \multirow[b]{2}{*}{ Description } & \multicolumn{3}{|c|}{$\begin{array}{c}\text { Spectral counts, } \\
\text { found in Hülle cells }\end{array}$} \\
\hline & & 3 day & 5 day & 7 day \\
\hline AN3814 (СурА) & Peptidyl-prolyl cis-trans isomerase & 6 & 6 & 2 \\
\hline AN3829 & Succinate-semialdehyde dehydrogenase & 7 & & 15 \\
\hline AN3873 & Oxidoreductase & 15 & 8 & \\
\hline AN3918 & Aminopeptidase activity & 3 & 9 & \\
\hline AN3928 (ThiF) & Thiazole synthase & 26 & 10 & 6 \\
\hline AN3954 & Phosphogluconate dehydrogenase & 102 & 20 & 46 \\
\hline AN4000 (FabM) & Poly(A)-binding proteins & 9 & 10 & 5 \\
\hline AN4064 & ADP/ATP carrier protein & 5 & 8 & 17 \\
\hline AN4087 & 40 S ribosomal protein subunit & 30 & 29 & 17 \\
\hline AN4163 (СpcB) & Response to amino acid starvation & 18 & 15 & 17 \\
\hline AN4218 & Translation elongation factor activity & 58 & 41 & 33 \\
\hline AN4259 & Protein of unknown function & 10 & & 12 \\
\hline AN4282 & Intracellular localization & 16 & 19 & 4 \\
\hline AN4288 & Protein of unknown function & 27 & 3 & \\
\hline AN4323 & Aminotransferase & 4 & 4 & 4 \\
\hline AN4376 & NADP-linked glutamate dehydrogenase & 42 & 9 & 37 \\
\hline AN4390 (EcmA) & GPI-anchored protein,role in cell wall biosynthesis & 3 & 5 & \\
\hline AN4409 (ArgB) & Ornithine carbamoyltransferase & 11 & & 3 \\
\hline AN4414 & Diphosphomevalonate decarboxylase & 17 & & \\
\hline AN4443 (MetH) & Methionine synthase & 95 & 64 & 115 \\
\hline AN4462 (PycA) & Pyruvate carboxylase & 46 & 16 & 16 \\
\hline AN4464 (PurH) & Bifunctional enzyme & 19 & & 9 \\
\hline AN4470 & Role in positive regulation of translaion & 6 & & 10 \\
\hline AN4475 & Ribosomal large subunit assembly & 2 & 9 & 4 \\
\hline AN4501 (ArtA) & 14-3-3 protein & 24 & 24 & 56 \\
\hline AN4594 & Maturation of rRNA & & 5 & 5 \\
\hline AN4616 & Protein of unknown function & 5 & & 4 \\
\hline AN4769 & ATP sulfurylase & 18 & 5 & 9 \\
\hline AN4793 & Aspartate semialdehyde dehydrogenase & 6 & 4 & 8 \\
\hline AN4794 & Ribosomal protein & & 11 & 9 \\
\hline AN4802 & $60 \mathrm{~S}$ ribosomal protein L21 & 3 & 7 & 2 \\
\hline AN4862 & Ran GTPase activating & 4 & & \\
\hline AN4888 (PdcA) & Decarboxylase & 16 & & 9 \\
\hline AN4905 (GstA) & Glutathione S-transferase & & 6 & 6 \\
\hline AN4916 & Ribosome biogenesis & 10 & 6 & 9 \\
\hline AN5014 & Ribosome activity & & 4 & 2 \\
\hline AN5129 & Heat shock protein & 104 & & 75 \\
\hline AN5162 (PdhB) & Pyruvate dehydrogenase & 17 & & 2 \\
\hline AN5210 (PkiA) & Pyruvate kinase & 15 & 5 & 6 \\
\hline AN5441 & Endonucleolytic cleavage & & 21 & 3 \\
\hline
\end{tabular}


Supplementary Table 3.

Continued.

\begin{tabular}{|c|c|c|c|c|}
\hline \multicolumn{5}{|c|}{$\begin{array}{l}\text { Shared in Hülle cells, sexual mycelium, asexual mycelium \& vegetative mycelium } \\
\text { (253 proteins) }\end{array}$} \\
\hline \multirow[b]{2}{*}{ Gene ID } & \multirow[b]{2}{*}{ Description } & \multicolumn{3}{|c|}{$\begin{array}{l}\text { Spectral counts, } \\
\text { found in Hülle cells }\end{array}$} \\
\hline & & 3 day & 5 day & 7 day \\
\hline AN5520 & Ribosome biogenesis & 8 & 15 & 5 \\
\hline AN5523 & Alpha-trehalose-phosphate synthase & 6 & & 5 \\
\hline AN5525 (AcoA) & Aconitate hydratase & 52 & 49 & 9 \\
\hline AN5563 & Dehydrogenase & 22 & & 19 \\
\hline AN5564 & Phosphatidyl synthase & 10 & 2 & \\
\hline AN5566 & Protein of unknown function & 10 & & 11 \\
\hline AN5571 (KgdA) & Oxoglutarate dehydrogenase & 18 & & 2 \\
\hline AN5626 & Acetyl-CoA synthase & 22 & 31 & 4 \\
\hline AN5686 (TpmA) & Tropomysin & & 10 & 3 \\
\hline AN5701 (AroF) & 3-deoxy-D-arabino-heptulosonate 7-phosphate synthase & 7 & & 3 \\
\hline AN5715 & 40 s ribosomal protein S26 & & 5 & 2 \\
\hline AN5719 & Ribosome activity & 2 & 3 & 14 \\
\hline AN5744 & 14-3-3-like protein & 19 & 17 & 19 \\
\hline AN5746 (AcuN) & Phosphopyruvate hydratase & 91 & 29 & 59 \\
\hline AN5800 & Ribosome activity & 6 & 20 & 7 \\
\hline AN5810 (PepP) & Prolidase & 7 & & 10 \\
\hline AN5872 & Proteasom & & 6 & 8 \\
\hline AN5907 & Ribose-5-phosphate isomerase & & & 7 \\
\hline AN5960 & Ribosomal small subunit assembly & & 9 & 4 \\
\hline AN5975 & Mannitol-1-phosphate 5-dehydrogenase & 45 & 24 & 64 \\
\hline AN5996 & Ribosome activity & & 9 & 6 \\
\hline AN5997 & Role in rRNA export from nucleus & 5 & & 5 \\
\hline AN5999 & Arginine or pyrimidine metabolism & 16 & 5 & \\
\hline AN6004 & Protein of unknown function & 6 & 6 & 2 \\
\hline AN6010 (SgdE) & Hsp70-family protein & 73 & 21 & 22 \\
\hline AN6037 (SwoB) & Glucose-6-phosphate isomerase & 37 & 10 & 71 \\
\hline AN6048 & Aspartate transaminase & 17 & 9 & 4 \\
\hline AN6089 & Heat shock protein & 48 & 10 & 5 \\
\hline AN6202 & Ribosomal protein L3 & 20 & 7 & 8 \\
\hline AN6209 & 5'-phosphoribosyl-4-(N-succinocarboxamide)-5-aminoimidazole lyase & 5 & 7 & 10 \\
\hline AN6232 (VmaB) & F1F0-ATPase complex subunit & 15 & & 9 \\
\hline AN6330 & Elongation factor 2 & 98 & 28 & 9 \\
\hline AN6341 & Similarity to Saccharomyces cerevisiae Crn1p & 15 & & 6 \\
\hline AN6346 & Dihydroxy-acid dehydratase & 10 & 8 & 5 \\
\hline AN6499 (MdhC) & Malate dehydrogenase & 35 & 27 & 86 \\
\hline AN6500 & Ribosome activity & 35 & 8 & 2 \\
\hline AN6525 (AciA) & Formate dehydrogenase & 41 & 23 & 29 \\
\hline AN6542 (ActA) & Actin A & 41 & 25 & 29 \\
\hline AN6547 & Proteasom & & 25 & 5 \\
\hline AN6563 & Translation elongation factor EF-1 gamma & 50 & 6 & 73 \\
\hline
\end{tabular}


Supplementary Table 3.

Continued.

Shared in Hülle cells, sexual mycelium, asexual mycelium \& vegetative mycelium (253 proteins)

\begin{tabular}{|c|c|c|c|c|}
\hline \multirow{2}{*}{ Gene ID } & \multirow[b]{2}{*}{ Description } & \multicolumn{3}{|c|}{$\begin{array}{c}\text { Spectral counts, } \\
\text { found in Hülle cells }\end{array}$} \\
\hline & & 3 day & 5 day & 7 day \\
\hline AN6629 & Ribosomal protein L14 & 12 & 23 & 10 \\
\hline AN6630 & Polypeptide-associated complex & 6 & 12 & 7 \\
\hline AN6639 (McdB) & 2-methylcitrate dehydratase & 28 & 9 & 27 \\
\hline AN6653 (AcuE) & Malate synthase & 28 & 7 & 10 \\
\hline AN6679 & DNA binding activity and nucleus localization & & 10 & \\
\hline AN6699 & Electron carrier activity & & 4 & 19 \\
\hline AN6700 & ATPase activity & 23 & 2 & \\
\hline AN6708 (PdhA) & Dihydrolipoamide S-acetyltransferase & 8 & 2 & 2 \\
\hline AN6717 (MdhA) & Mitochondrial malate dehydrogenase & 76 & 87 & 72 \\
\hline AN6840 & Hydroxyacylglutathione hydrolase & & 11 & 10 \\
\hline AN6900 (TpiA) & Triose-phosphate isomerase & 13 & 24 & 7 \\
\hline AN6921 & Chaperone & 3 & 2 & 5 \\
\hline AN7003 & Ribosome activity & & 5 & 2 \\
\hline AN7105 & Translation initiation factor 3 (elF3) & 8 & 9 & \\
\hline AN7107 & Ribosome activity & & 9 & 10 \\
\hline AN7141 & NAD-dependent aldehyde dehydrogenase & 4 & 4 & 11 \\
\hline AN7193 & NADPH-dependent glycerol dehydrogenase & 8 & & 4 \\
\hline AN7254 & Cell division protein & 44 & & \\
\hline AN7262 & Protein of unknown function & 2 & 11 & 2 \\
\hline AN7299 & Role in cellular process & & 7 & 4 \\
\hline AN7354 & Ribosome activity & 2 & 6 & 10 \\
\hline AN7388 (CpeA) & Laccase & 24 & 40 & 89 \\
\hline AN7436 (PdiA) & Protein disulfide isomerase & 19 & 16 & \\
\hline AN7451 & NAD-glutamate dehydrogenase & 9 & 23 & \\
\hline AN7459 (hxkA) & Hexokinase & 15 & 10 & 27 \\
\hline AN7590 & Reductase & 4 & 6 & 2 \\
\hline AN7600 & Iron-sulfur cluster binding & 4 & 8 & \\
\hline AN7625 & Myo-inositol-1-phosphate synthase & 32 & 22 & \\
\hline AN7632 & Dehydrogenase & 15 & 12 & \\
\hline AN7657 & 1,3-beta-transglycosidase & 6 & 10 & 2 \\
\hline AN7708 & NADP+1-oxidoreductase activity & 2 & 3 & 3 \\
\hline AN7710 & Intracellular localization & 3 & 19 & 13 \\
\hline AN7725 (PyroA) & Protein required for biosynthesis of pyridoxine & 3 & 5 & \\
\hline AN7950 (EgIC) & Glucan endo-1,3-beta-D-glucosidase & 3 & 17 & \\
\hline AN8009 (Nmt1) & Protein of unknown function & 21 & 20 & 29 \\
\hline AN8041 (GpdA) & Glyceraldehyde-3-phosphate dehydrogenase & 106 & 58 & 47 \\
\hline AN8054 & 20S core proteasome & & 5 & 10 \\
\hline AN8170 (NapB) & Nap/SET family member & 7 & & 4 \\
\hline AN8176 & Ribosome activity & 63 & 22 & 30 \\
\hline AN8187 & Protein of unknown function & 4 & & 3 \\
\hline
\end{tabular}


Supplementary Table 3.

Continued.

Shared in Hülle cells, sexual mycelium, asexual mycelium \& vegetative mycelium (253 proteins)

\begin{tabular}{|c|c|c|c|c|}
\hline \multirow{2}{*}{ Gene ID } & \multirow[b]{2}{*}{ Description } & \multicolumn{3}{|c|}{$\begin{array}{l}\text { Spectral counts, } \\
\text { found in Hülle cells }\end{array}$} \\
\hline & & 3 day & 5 day & 7 day \\
\hline AN8216 (SwoH) & Nucleoside diphosphate kinase & 10 & 19 & 19 \\
\hline AN8218 (TrxB) & Thioredoxin reductase & 10 & 16 & 3 \\
\hline AN8269 (Hsp90) & Heat shock protein & 47 & 22 & 55 \\
\hline AN8273 & Ubiquinol-cytochrome-c reductase & 19 & 10 & 10 \\
\hline AN8275 & Mitochondrial citrate synthase & 69 & 24 & 17 \\
\hline AN8277 (CysD) & Bifunctional enzyme & & 13 & 4 \\
\hline AN8605 (Cyp1) & Peptidyl-prolyl cis-trans isomerase & 5 & & 11 \\
\hline AN8637 (CatA) & Catalase & 8 & & 6 \\
\hline AN8689 (GlkA) & Glucokinase & 15 & 10 & 16 \\
\hline AN8692 & Thioredoxin-dependent peroxidase & 11 & 8 & 7 \\
\hline AN8704 & Ribosomal protein & 4 & 6 & 6 \\
\hline AN8707 & Fumarate dehydratase & 20 & 8 & 9 \\
\hline AN8770 & Bifunctional enzyme & 3 & & 4 \\
\hline AN8856 & RNA binding activity & 9 & 5 & 6 \\
\hline AN8866 & Phosphoglycerate dehydrogenase & 7 & 6 & 9 \\
\hline AN8867 & Serine-tRNA ligase activity & 17 & 3 & 9 \\
\hline AN8953 (AgdB) & Alpha-glucosidase & 21 & 17 & 2 \\
\hline AN9042 (AgnC) & Alpha-1,3-glucanase & & 21 & 6 \\
\hline AN9103 (AifA) & Oxidoreductase & 14 & 5 & 6 \\
\hline AN9148 & UTP-glucose-1-phosphate uridylyltransferase & 32 & 16 & 31 \\
\hline AN9339 (CatB) & Catalase & 18 & 34 & 10 \\
\hline AN9403 (PdhC) & Pyruvate dehydrogenase (lipoamide) & 7 & 5 & 7 \\
\hline AN9465 & Ribosome activity & 2 & 14 & 4 \\
\hline
\end{tabular}




\section{Supplementary Table 4.}

The list of protein found in sexual, asexual and vegetative mycelium from solid agar plates (Figure 24). Sexual and asexual mycelium from solid agar plate cultures were analyzed within three different time points. Vegetative mycelium was analyzed 20 hours after inoculation (submerged liquid cultures). For each time points three biological replicates were considered for the different mycelia types. Only proteins identified in two or more biological replicates and with two or more peptides per protein were considered for the analysis. Proteins that were common between the different mycelia types are also listed. Numbers represent the average of spectral counts from three biological replicates. Putative function or role proteins are listed under Description. Different sources were used, mainly AspGD (Cerqueira et al., 2014).

\begin{tabular}{|c|c|c|c|c|}
\hline \multicolumn{5}{|c|}{ Found in sexual mycelium (203 proteins) } \\
\hline \multirow[b]{2}{*}{ Gene ID } & \multirow{2}{*}{ 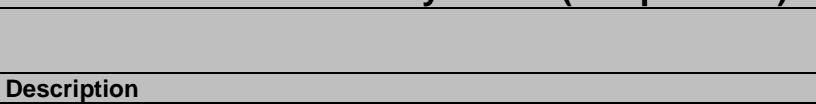 } & \multicolumn{3}{|c|}{$\begin{array}{c}\text { Spectral counts } \\
\text { found in sex. mycelium }\end{array}$} \\
\hline & & 3 day & 5 day & 7 day \\
\hline AN6000 (AptA) & Polyketide synthase & 153 & 60 & 127 \\
\hline AN7806 (StcU) & Versicolorin reductase & 13 & 43 & 22 \\
\hline AN8162 & Oxidoreductase activity & 20 & 63 & 58 \\
\hline AN8466 & Cell wall macromolecule catabolic process & 20 & 21 & 2 \\
\hline AN5348 & Nucleotide binding activity & 17 & 5 & 40 \\
\hline AN5558 & Protease & 63 & 10 & 3 \\
\hline AN10965 & Protein of unknown function & 18 & 25 & 15 \\
\hline AN6002 (AptC) & Monooxygenase & 3 & 22 & 21 \\
\hline AN4105 & Erythromycin esterase & 16 & 22 & 5 \\
\hline AN8514 (TdiB) & Prenyltransferase & 14 & 16 & 7 \\
\hline AN12267 & UDP-N-acetylmuramate dehydrogenase & 15 & 10 & 33 \\
\hline AN6784 (XptA) & Prenyltransferase & 5 & & 3 \\
\hline AN0146 (MdpC) & Monodictyphenone secondary metabolite cluster & 4 & 10 & \\
\hline AN2704 & Aryl-alcohol oxidase-related & 9 & 8 & 4 \\
\hline AN3206 & Aryl-alcohol oxidase-related & 10 & 35 & \\
\hline AN10952 & Monooxygenase activity & 6 & 31 & 6 \\
\hline AN0052 & Oxidoreductase acitivity & 16 & 26 & \\
\hline AN3573 & Oxidoreductase activity & 2 & 12 & 34 \\
\hline AN4016 & 60S ribosomal protein $\mathrm{L} 40$ & 30 & 42 & \\
\hline AN6082 & Ribosome activity & 15 & 31 & 22 \\
\hline AN3432 & Aldose 1-epimerase & 21 & 24 & \\
\hline AN3601 & Catalytic activity & 15 & 21 & 5 \\
\hline AN5698 & Fatty acid metabolism & & 37 & 33 \\
\hline AN8004 & Cytochrome P450 & 2 & 4 & 30 \\
\hline AN8086 & Protein of unknown function & 18 & 12 & 2 \\
\hline AN8106 & Protein of unknown function & 9 & 19 & 3 \\
\hline AN9322 & Nucleotide binding activity & 7 & 17 & 10 \\
\hline AN0034 & Glycerone kinase & 5 & 2 & 2 \\
\hline AN0212 & Oxidoreductase & 8 & 8 & \\
\hline AN0221 & Chitinase & 12 & 8 & 8 \\
\hline AN0270 & Kinase & 4 & & 6 \\
\hline AN0380 (Cyp10) & Peptidyl-prolyl cis-trans isomerase & 4 & & 8 \\
\hline AN0385 & Aminotransferase & 4 & 7 & \\
\hline AN0558 (GelB) & 1,3-beta-transglycosidase & 7 & & 8 \\
\hline AN0593 & Dehydrogenase & 2 & 17 & \\
\hline AN0596 (DdbA) & DNA damage binding protein & 11 & & 5 \\
\hline AN0602 & Protein of unknown function & 5 & & 5 \\
\hline AN0628 & D-lactate dehydrogenase & 2 & 3 & \\
\hline AN0788 & Protein of unknown function & 8 & 5 & \\
\hline AN0806 & Protein of unknown function & 14 & 2 & \\
\hline AN0839 & oxidoreductase & 4 & 2 & \\
\hline AN0875 & Protein of unknown function & & 9 & 8 \\
\hline AN0887 (LamA) & Urea amidolyase & 5 & & 5 \\
\hline AN10130 & Ribosome activity & 2 & 4 & \\
\hline AN10214 & Protein of unknown function & 6 & 19 & \\
\hline AN10290 & Pyridoxamine-phosphate oxidase & 7 & & 2 \\
\hline AN10326 & Protein of unknown function & 4 & & 4 \\
\hline AN10358 & Oxidoreductase activity & 2 & 3 & 9 \\
\hline AN10370 & Oxidoreductase & 4 & & 6 \\
\hline AN10379 & Glutatthione transferase & 17 & 8 & 4 \\
\hline AN10429 & Phosphatase & 8 & 6 & \\
\hline AN10444 & Involved in sexual development, gamma glutamyl transpeptidase & 9 & 3 & \\
\hline
\end{tabular}


Supplementary Table 4.

Continued.

\begin{tabular}{|c|c|c|c|c|}
\hline \multicolumn{5}{|c|}{ Found in sexual mycelium (203 proteins) } \\
\hline \multirow[b]{2}{*}{ Gene ID } & \multirow[b]{2}{*}{ Description } & \multicolumn{3}{|c|}{$\begin{array}{l}\text { Spectral counts, found } \\
\text { in sex. mycelium }\end{array}$} \\
\hline & & 3 day & 5 day & 7 day \\
\hline AN10863 & Oxidoreductase & 4 & 9 & \\
\hline AN10973 & Citrate synthase & & 4 & 8 \\
\hline AN11035 & Monooxygenase activity & 10 & 5 & \\
\hline AN11097 & Dioxygenase activity & 10 & 33 & \\
\hline AN1115 & Purine nucleosidase & 3 & & 9 \\
\hline AN11246 & Protein of unknown function & 16 & 15 & 4 \\
\hline AN11419 & Ribosome activity & 2 & 8 & 4 \\
\hline AN11917 & Methyltransferase activity & 4 & 4 & \\
\hline AN1204 & Protein of unknown function & 8 & 2 & \\
\hline AN12050 & Nucleotide binding activity & 3 & 3 & \\
\hline AN12090 & Methyltransferase activity & 5 & 14 & \\
\hline AN12335 (AcdA) & Acyl-CoA dehydrogenase domain & 3 & 6 & \\
\hline AN12369 & Protein of unknown function & & 6 & 6 \\
\hline AN12446 & Protein of unknown function & 14 & 5 & \\
\hline AN1271 & Arylformamidase activity & 6 & 5 & \\
\hline AN1277 (AdfC) & Alpha-arabinofuranosidase activity & 2 & 4 & \\
\hline AN1291 & Carbon-sulfur lyase activity & 2 & 4 & \\
\hline AN1446 (MecB) & Cystathionine gamma-lyase & 9 & 6 & \\
\hline AN1477 & Beta-1,4-xylosidase & 4 & 2 & \\
\hline AN1611 & Flavin adenine dinucleotide binding & 2 & 8 & \\
\hline AN1639 & Oxidoreductase & 14 & 2 & \\
\hline AN1688 & Protein of unknown function & & 5 & 5 \\
\hline AN1699 & Acyl-coA dehydrogenase & 2 & 7 & 9 \\
\hline AN1763 & Oxidoreductase & 6 & 12 & 5 \\
\hline AN1837 & Hydrophobin & 12 & & 2 \\
\hline AN1849 & Protein of unknown function & 12 & 2 & \\
\hline AN1979 & Protein of unknown function & 3 & 4 & \\
\hline AN2161 (Ngn1) & GNAT-type acetyltransferase & 13 & 2 & \\
\hline AN2166 & Protein of unknown function & 4 & 7 & 8 \\
\hline AN2180 (XprF) & Hexokinase-like protein & 13 & 13 & \\
\hline AN2311 & Phosphomevalonate kinase & & 5 & 6 \\
\hline AN2351 & Alcohol dehydrogenase & & 9 & 7 \\
\hline AN2359 (XInD) & Beta-xylosidase & 6 & 8 & \\
\hline AN2366 & Trypsin-like protease & 14 & 8 & 5 \\
\hline AN2405 & Protein of unknown function & 5 & 7 & \\
\hline AN2416 & Ubiquitin-activating enzyme & 7 & & 4 \\
\hline AN2426 & Protein of unknown function & 13 & 11 & \\
\hline AN2439 (SldB) & Spindle assembly checkpoint protein & 4 & 19 & \\
\hline AN2441 & Nucleotide binding activity & 6 & 5 & \\
\hline AN2463 (LacF) & Beta-galactosidase & 5 & 5 & \\
\hline AN2469 & Oxidoreductase & 2 & 13 & 4 \\
\hline AN2493 & Alkaline phosphatase & 17 & 5 & 3 \\
\hline AN2577 & Oxidoreductase & & 5 & 5 \\
\hline AN2622 (IpnA) & Isopenicillin- $\mathrm{N}$ synthase & 6 & 5 & \\
\hline AN2762 & Acyl-coA dehydrogenase & 8 & 2 & \\
\hline AN2801 & Oxidoreductase activity & 2 & 8 & \\
\hline AN2853 & Protein of unknown function & 8 & 3 & \\
\hline AN2859 & Lyase activity & 5 & 21 & 4 \\
\hline AN2878 & Protein of unknown function & 17 & 2 & \\
\hline AN2921 & Protein of unknown function & & 13 & 2 \\
\hline AN3135 & Protein of unknown function & & 2 & 3 \\
\hline AN3184 & Aldose 1-epimerase & 6 & & 2 \\
\hline AN3191 & Hydrolase activity & 3 & 2 & 3 \\
\hline AN3201 (LacD) & Beta-galactosidase & 17 & 14 & \\
\hline AN3312 & L-xylulose reductase & 2 & 2 & \\
\hline AN3375 & Heat shock protein binding & 8 & 8 & \\
\hline AN3419 & Acetyltransferase activity & 6 & 4 & \\
\hline AN3488 & Flavin adenine dinucleotide binding & 4 & & 8 \\
\hline AN3499 & Phosphotransferase activity & 4 & 4 & \\
\hline AN3565 & Hydrolase activity & 2 & 2 & 6 \\
\hline AN10723 & Acetyltransferase activity & 2 & 2 & \\
\hline AN10581 & Protein of unknown function & 2 & 10 & 4 \\
\hline AN1059 (FacC) & Carnitine acetyltransferase & 6 & 3 & \\
\hline AN10673 & Serine-type peptidase activity & 10 & 5 & \\
\hline
\end{tabular}


Supplementary Table 4.

Continued.

\begin{tabular}{|c|c|c|c|c|}
\hline \multicolumn{5}{|c|}{ Found in sexual mycelium (203 proteins) } \\
\hline \multirow[b]{2}{*}{ Gene ID } & \multirow[t]{2}{*}{ ( } & \multicolumn{3}{|c|}{$\begin{array}{l}\text { Spectral counts } \\
\text { in sex. mycelium }\end{array}$} \\
\hline & & 3 day & 5 day & 7 day \\
\hline AN3577 & Citrate lyase & 2 & 10 & \\
\hline AN3590 & Protein of unknown function & 12 & 6 & \\
\hline AN3598 (FprA) & Peptidyl-prolyl cis-trans isomerase & 2 & 6 & \\
\hline AN3706 & Role in rRNA export from nucleus & 4 & 6 & 2 \\
\hline AN3708 & Hydrolase activity & 25 & & 4 \\
\hline AN3741 (AlcB) & Alcohol dehydrogenase & 2 & 18 & 8 \\
\hline AN3779 & Exopolyphosphatase activity & 7 & 2 & \\
\hline AN3789 & Protein of unknown function & 19 & 12 & \\
\hline AN3805 & Oxaloacetase & & 22 & 23 \\
\hline AN3867 & Pheromone precursor processing & 6 & 2 & \\
\hline AN3916 & Glycerol kinase & 3 & 5 & \\
\hline AN3972 & Cytosol localization & 15 & 20 & \\
\hline AN4011 & 5'-phosphoribosyl-4-(N-succinocarboxamide)-5-aminoimidazole lyase & 2 & 2 & \\
\hline AN4041 & Protein of unknown function & 2 & 3 & \\
\hline AN4177 & Catalytic activity & 14 & 6 & \\
\hline AN4231 & Protein required for riboflavin biosynthesis & 4 & 5 & 6 \\
\hline AN4290 & S-methyl-5-thioribose-1-phosphate isomerase & 4 & 31 & \\
\hline AN4299 & Protein of unknown function & 4 & 5 & 7 \\
\hline AN4317 & Nuclear pore complex protein & 8 & 6 & \\
\hline AN4353 & 3-oxoacyl-[acyl-carrier-protein] synthase & 4 & 26 & \\
\hline AN4396 & Ras guanine nucleotide exchange factor & 2 & 2 & \\
\hline AN4458 & Ubiquitin thiolesterase activity & 5 & 4 & \\
\hline AN4494 & Ribosome activity & 2 & 22 & 4 \\
\hline AN4504 (DfgG) & Endo-mannanase & 10 & 23 & \\
\hline AN4522 & Ribosome activity & 6 & 7 & 3 \\
\hline AN4532 & Catechol oxygenase & 12 & 12 & 20 \\
\hline AN4687 (MccB) & 3-methylcrotonyl-CoA carboxylase & 13 & 4 & \\
\hline AN4691 & Oxidoreductase & 24 & & 10 \\
\hline AN4777 & Ribosome activity & 11 & 5 & 4 \\
\hline AN4822 & Tartrate dehydrogenase & 11 & 5 & \\
\hline AN4830 & Coenzyme $\mathrm{A}$ biosynthetic process & 4 & 4 & \\
\hline AN4901 & Glutaminase A & 11 & 21 & \\
\hline AN4967 & Protein of unknown function & 2 & 8 & \\
\hline AN5019 & 5-methyltetrahydropteroyltriglutamate-homocysteine S-methyltransferase & 2 & 16 & 5 \\
\hline AN5109 & Oxidoreductase activity & & 10 & 13 \\
\hline AN5144 (PfkZ) & 6-phosphofructo-2-kinase & 2 & 4 & \\
\hline AN5178 & Glycerol dehydrogenase & 2 & 2 & \\
\hline AN5193 & 1-aminocyclopropane-1-carboxylate synthase & 7 & & 9 \\
\hline AN5373 & Oxidoreductase activity & 8 & 21 & \\
\hline AN5421 & Protein of unknown function & & & \\
\hline AN5480 & RNA binding protein & 9 & 15 & 2 \\
\hline AN5556 & Oxidoreductase activity & 3 & 13 & \\
\hline AN5718 & Fumarate hydratase & 22 & & 13 \\
\hline AN5737 & Oxidoreductase & 21 & 3 & \\
\hline AN5777 & Triglyceride lipase activity & 26 & 4 & \\
\hline AN5830 & Hydrolase activity & 2 & 11 & 5 \\
\hline AN5937 & Manganese ion binding & 2 & 2 & 6 \\
\hline AN5977 & Carbonyl reductase (NADPH) activity & 5 & 2 & 2 \\
\hline AN5986 & Reductase & 6 & 6 & 4 \\
\hline AN6031 & Monooxygenase activity & 4 & 6 & 7 \\
\hline AN6035 & Catalytic activity & 4 & 5 & \\
\hline AN6197 & Nuclear migration protein & & 8 & 23 \\
\hline AN6329 & Protein of unknown function & 4 & 9 & \\
\hline AN6362 & Arsenate reductase activity & 4 & 4 & \\
\hline AN6394 & Acyl-coA dehydrogenase & 9 & 8 & \\
\hline AN6423 & Protein of unknown function & 11 & & 13 \\
\hline AN6470 & Carbohydrate catabolism & 12 & & 6 \\
\hline AN6535 & Protein of unknown function & 21 & 4 & 8 \\
\hline AN6632 & 40 S ribosomal protein S28 & 2 & & 8 \\
\hline AN6687 & DNA binding activity & 11 & & 6 \\
\hline AN6933 (MaeB) & Malate dehydrogenase & 7 & 9 & \\
\hline AN7044 & Histidinol-phosphatase & 6 & 4 & \\
\hline AN7128 & Oxidoreductase activity & 2 & 4 & \\
\hline
\end{tabular}


Supplementary Table 4.

Continued.

\begin{tabular}{|c|c|c|c|c|}
\hline \multicolumn{5}{|c|}{ Found in sexual mycelium (203 proteins) } \\
\hline \multirow[b]{2}{*}{ Gene ID } & \multirow[b]{2}{*}{ Description } & \multicolumn{3}{|c|}{$\begin{array}{l}\text { Spectral counts found } \\
\text { in sex. mycelium }\end{array}$} \\
\hline & & 3 day & 5 day & 7 day \\
\hline AN7259 (DcnA) & NEDD8 ligase activity, ubiquitin bindin & 4 & 3 & \\
\hline AN7274 & Fumiquinazoline $\mathrm{C}$ biosynthetic protein & 5 & 15 & \\
\hline AN7367 & Hydrolase activity & 2 & 18 & 17 \\
\hline AN7564 & Threonine aldolase & 7 & & 8 \\
\hline AN7704 & Catabolic process & 16 & & 6 \\
\hline AN7705 & Protein of unknown function & 3 & 3 & \\
\hline AN7711 & ADP-ribose diphosphatase & & 8 & 5 \\
\hline AN8016 & ATP-dependent RNA helicase & & 4 & 22 \\
\hline AN8045 & Protein of unknown function & 8 & 5 & \\
\hline AN8163 & Short-chain dehydrogenase/reductase & 12 & 18 & \\
\hline AN8415 (ApdG) & Acyl-coA dehydrogenase & 7 & 2 & \\
\hline AN8592 & Monooxygenase activity & 6 & 3 & 4 \\
\hline AN8606 (GudA) & Glucose 1-dehydrogenase & 2 & 2 & 3 \\
\hline AN8654 & Aminomethyltransferase & 4 & 3 & 4 \\
\hline AN8657 & Oxidoreductase & 12 & & 8 \\
\hline AN8797 & Protein of unknown function & 20 & & 14 \\
\hline AN8808 & Phosphoric diester hydrolase & 9 & 18 & \\
\hline AN8899 & 1-aminocyclopropane-1-carboxylate deaminase & 2 & 2 & \\
\hline AN8988 & oxidoreductase & & 9 & 10 \\
\hline AN9116 & Phosphoribosyltransferase & 3 & 6 & 22 \\
\hline AN9227 & Dioxygenase & 12 & 12 & \\
\hline AN9285 & Glucose repressible & & 4 & 22 \\
\hline AN9323 & Protein of unknown function & 4 & 3 & 13 \\
\hline AN10762 & Protein of unknown function & 8 & 4 & \\
\hline
\end{tabular}

\begin{tabular}{|c|c|c|c|c|}
\hline \multicolumn{5}{|c|}{ Found in asexual mycelium (118 proteins) } \\
\hline \multirow[b]{2}{*}{ Gene ID } & \multirow[b]{2}{*}{ Description } & \multicolumn{3}{|c|}{$\begin{array}{l}\text { Spectral counts found } \\
\text { in asex. mycelium }\end{array}$} \\
\hline & & 3 day & 5 day & 7 day \\
\hline AN7558 & Transcript induced by light in developmentally competent mycelia & & 3 & 37 \\
\hline AN8339 & Transcript induced by light in developmentally competent mycelia & & 29 & 29 \\
\hline AN1553 & Role in fruiting body development & 29 & 29 & \\
\hline AN10378 & bZIP transcription factor & 4 & 8 & \\
\hline AN2946 & Pheromone precursor processing & 41 & 41 & \\
\hline AN7734 & Transcription factor & 4 & & 5 \\
\hline AN9171 & Protein of unknown function & & 10 & 15 \\
\hline AN4852 & Glucan 1,3-beta-glucosidase & 68 & 20 & \\
\hline AN1754 & Protein of unknown function & 3 & 8 & 3 \\
\hline AN1035 (AfoF) & Asperfuranone biosynthesis & & 9 & 10 \\
\hline AN4742 & Translation initiation factor & 4 & 6 & \\
\hline AN3239 & Oxidoreductase & 26 & & 26 \\
\hline AN0357 & Ubiquinol-cytochrome-c reductase subunit & 5 & & 5 \\
\hline AN0483 & Protein of unknown function & & 6 & 8 \\
\hline AN0941 (AgdE) & Alpha-glucosidase activity & 13 & 13 & \\
\hline AN10113 & Protein of unknown function & 8 & 8 & \\
\hline AN10174 & Protein of unknown function & 3 & & 3 \\
\hline AN10219 & Transcript induced in response to calcium dichloride in a CrzA-dependent & 4 & 4 & \\
\hline AN10308 & Protein of unknown function & 5 & 15 & \\
\hline AN10510 & Protein of unknown function & 3 & & 3 \\
\hline AN10522 & Peptidase & 4 & 4 & 4 \\
\hline AN1063 & NADH dehydrogenase & 8 & 2 & 8 \\
\hline AN11149 & Arylsulfatase activity & 2 & 10 & 2 \\
\hline AN11533 & Protein of unknown function & 3 & 5 & 3 \\
\hline AN11698 & Exopeptidase activity & & 33 & 22 \\
\hline AN11718 & Mitochondrial intermembrane spce localization & & 11 & 11 \\
\hline AN11764 & Binding activity & 2 & 4 & 2 \\
\hline AN11946 & Protein of unknown function & 2 & 4 & 2 \\
\hline AN12376 & Nucleotide binding & 4 & 6 & 2 \\
\hline AN1396 & Role in glycerol metabolism & 9 & & 9 \\
\hline AN1403 & Protein of unknown function & 14 & 15 & 10 \\
\hline AN1426 & Serine-type carboxypeptidase activity & 5 & 5 & \\
\hline
\end{tabular}


Supplementary Table 4.

Continued.

\begin{tabular}{|c|c|c|c|c|}
\hline \multicolumn{5}{|c|}{ Found in asexual mycelium (118 proteins) } \\
\hline \multirow[b]{2}{*}{ Gene ID } & \multirow[b]{2}{*}{ Description } & \multicolumn{3}{|c|}{$\begin{array}{l}\text { Spectral counts found } \\
\text { in asex. mycelium }\end{array}$} \\
\hline & & 3 day & 5 day & 7 day \\
\hline AN1433 & Protein of unknown function & & 9 & 8 \\
\hline AN1532 & Protein of unknown function & 3 & 4 & \\
\hline AN1683 & Oligosaccharyltransferase delta & 2 & & 10 \\
\hline AN1778 (PantoB) & Ketopentoate hydroxymethyl transferase & & 2 & 10 \\
\hline AN1857 & Kynureninase & 4 & 4 & \\
\hline AN1986 & Ferroxidase activity & 6 & 2 & 6 \\
\hline AN2005 (YpdA) & Histidine-containing phosphotransfer & 2 & 6 & 2 \\
\hline AN2047 & Calmodulin & 3 & 5 & 3 \\
\hline AN2050 & Cell wall organization and Golgi apparatus & & 10 & 10 \\
\hline AN2069 & Cytochrome b5 & 2 & 2 & 8 \\
\hline AN2070 & Protein of unknown function & 4 & 10 & \\
\hline AN2110 & Oxidoreductase activity & 3 & 3 & 3 \\
\hline AN2119 & Sphingolipid transporter activity & 5 & 2 & 5 \\
\hline AN2140 & Endoplasmic reticulum localization & 2 & 5 & 2 \\
\hline AN2185 & Protein of unknown function & & 3 & 10 \\
\hline AN2237 & Carboxypeptidase & & 4 & 8 \\
\hline AN2325 & Carbohydrate binding & 4 & 23 & \\
\hline AN2431 (Nup49) & Nuclear pore complex & & 2 & \\
\hline AN2472 & Serine/threonine phosphatase activity & 2 & & 2 \\
\hline AN2576 & Monooxygenase activity & 14 & 2 & 14 \\
\hline AN2662 & Carbon-nitrogen ligase activity & & 13 & 15 \\
\hline AN2776 & Protein of unknown function & & 4 & 6 \\
\hline AN3022 & Protein of unknown function & & 6 & 8 \\
\hline AN3163 (StoA) & Stomatin ortholog & 2 & & 2 \\
\hline AN3367 & Sequence-specific DNA binding activity & 2 & 5 & 2 \\
\hline AN3388 (AmyF) & Alpha-amylase & 5 & 16 & \\
\hline AN3687 & Protein of unknown function & & 18 & 10 \\
\hline AN3783 & Protein of unknown function & 2 & 10 & \\
\hline AN3931 (PilB) & \begin{tabular}{|l|} 
Conserved eisosome protein \\
\end{tabular} & & 2 & 10 \\
\hline AN4034 (HapC) & Component of AnCP/AnCF CCAAT-binding complex & 4 & 6 & \\
\hline AN4081 & Cysteine dioxygenase activity & 2 & 4 & 2 \\
\hline AN4277 & Glucose transmembrane transporter activity & 12 & & 10 \\
\hline AN4292 & Possible pseudogene & 3 & 3 & 6 \\
\hline AN4305 & Catalytic activity & 3 & & 3 \\
\hline AN4499 & Nuclear transport protein & 5 & & 8 \\
\hline AN4515 (CrhB) & Transglycosidase & 4 & 4 & 5 \\
\hline AN4525 & Transglycosidase & & 10 & 5 \\
\hline AN4553 & Mitochondrial outer membrane & 5 & 6 & 8 \\
\hline AN4615 & Transmembrane domain-containing protein & 5 & 6 & 11 \\
\hline AN4636 & Lipid particle localization & 5 & 10 & 5 \\
\hline AN4911 & Protein of unknown function & 4 & 4 & \\
\hline AN4927 & F1F0-ATPase complex & 5 & & 5 \\
\hline AN4946 & Protein of unknown function & 6 & 5 & \\
\hline AN5485 & Nuclear pore complex & 6 & 4 & 3 \\
\hline AN5624 & DNA binding activity & 9 & & 10 \\
\hline AN5670 & Protein transporter activity & 8 & & 8 \\
\hline AN5671 & Protein of unknown function & 2 & 5 & 2 \\
\hline AN6078 (NadA) & Adenine deaminase & 3 & & 3 \\
\hline AN6203 & Protein of unknown function & 2 & 5 & \\
\hline AN6228 & Cytosol localization & & 13 & 6 \\
\hline AN6256 & Nucleotide binding activity & & 6 & 8 \\
\hline AN6337 & Protein of unknown function & 2 & 2 & 3 \\
\hline AN6382 & Phospholipase $\mathrm{C}$ activity & & 4 & 8 \\
\hline AN6445 & Paryl-alcohol oxidase-related protein & 22 & 36 & \\
\hline AN6450 & Oxidoreductase & 5 & & 5 \\
\hline AN6473 & Protein of unknown function & 2 & 6 & 2 \\
\hline AN6518 & Hydrolase activity & 2 & & 2 \\
\hline AN6847 & Sulfuric ester hydrolase & & 9 & 10 \\
\hline AN7102 & Protein of unknown function & 5 & 2 & 11 \\
\hline AN7153 & UDP-N-acetylmuramate dehydrogenase & 12 & 12 & \\
\hline AN7201 & Role in proteolysis & 8 & 7 & \\
\hline AN7214 & Oxidoreductase activity & 9 & 29 & \\
\hline AN7488 & Endoplasmic reticulum, fungal-type vacuole localization & 2 & 2 & 5 \\
\hline
\end{tabular}


Supplementary Table 4.

Continued.

\begin{tabular}{|c|c|c|c|c|}
\hline \multicolumn{5}{|c|}{ Found in asexual mycelium (118 proteins) } \\
\hline \multirow[b]{2}{*}{ Gene ID } & \multirow[b]{2}{*}{ Description } & \multicolumn{3}{|c|}{$\begin{array}{l}\text { Spectral counts found in } \\
\text { asex. mycelium }\end{array}$} \\
\hline & & 3 day & 5 day & 7 day \\
\hline AN7567 & Role in actin cytoskeleton organization & 4 & & 4 \\
\hline AN7579 & K48-linked polyubiquitin binding & & 4 & 5 \\
\hline AN7595 & Protein of unknown function & & 4 & 8 \\
\hline AN7669 & Hydrolase activity & 6 & 4 & \\
\hline AN7680 & Protein of unknown function & & 11 & 8 \\
\hline AN7864 (BxID) & Beta-1,4-xylosidase & 7 & 7 & 9 \\
\hline AN7960 & Protein of unknown function & 8 & 2 & \\
\hline AN7990 & Protein of unknown function & 4 & 4 & 5 \\
\hline AN7992 & Protein of unknown function & 5 & 5 & \\
\hline AN8043 & Protein of unknown function & 8 & 10 & \\
\hline AN8234 & Protein phosphatase inhibitor activity & & 8 & 6 \\
\hline AN8242 & Lipase & & 8 & 5 \\
\hline AN8546 & Phospholipase C & 8 & 10 & \\
\hline AN8607 & Protein of unknown function & 2 & 10 & 10 \\
\hline AN8690 & Protein expressed at increased levels during osmoadaptation & 5 & & 3 \\
\hline AN8805 & Unfolded protein binding activity & & 5 & 8 \\
\hline AN8974 & Protein of unknown function & & 4 & 8 \\
\hline AN9004 & Oxidoreductase activity & 13 & 4 & 13 \\
\hline AN9027 & Hydrolase activity & 3 & & 3 \\
\hline AN9037 & Oxidoreductase & & 2 & 10 \\
\hline AN9163 & Protein of unknown function & 2 & 2 & 2 \\
\hline AN9235 & Catalytic activity & & 2 & 12 \\
\hline AN0328 & Nucleus localisation & 3 & 4 & \\
\hline
\end{tabular}

\begin{tabular}{|c|c|c|c|c|c|c|c|}
\hline \multicolumn{8}{|c|}{ Found in vegetative mycelium (299 proteins) } \\
\hline \multirow[t]{2}{*}{ Gene ID } & \multirow[t]{2}{*}{ Description } & \multicolumn{2}{|c|}{$\begin{array}{l}\text { Spectral counts } \\
\text { found in veg. mycelium }\end{array}$} & \multirow[t]{2}{*}{ Gene ID } & \multirow[t]{2}{*}{ Description } & \multicolumn{2}{|c|}{$\begin{array}{l}\text { Spectral counts } \\
\text { found in veg. mycelium }\end{array}$} \\
\hline & & & $20 \mathrm{~h}$ & & & & $20 \mathrm{~h}$ \\
\hline AN0117 & Cellular response & to oxidative stress & 32 & AN10480 & Protein of unknowr & & 19 \\
\hline AN0133 & RNA helicase & & 30 & AN10489 & Peptidyl-prolyl cis- & ase & 25 \\
\hline AN0183 & Molybdopterin bin & ding domain protein & 13 & AN10519 & Binding activity & & 50 \\
\hline AN0242 & Hydrolase activity & & 68 & AN10535 & Translation initiatic & & 4 \\
\hline AN0327 & Role in ribosomal & small subunit & 41 & AN1055 & Formation of trans & iation complex & 12 \\
\hline AN0381 & Unfolded protein & inding activity & 71 & AN10557 & ATP-dependent R & & 91 \\
\hline AN0411 & Role in ER to Gol & ji transport & 36 & AN10595 (AspE) & Septin & & 23 \\
\hline AN0490 & CTP synthase & & 10 & AN10734 & Role in regulation & al elongation & 87 \\
\hline AN0565 & Multifunctional en & zyme & 422 & AN10743 & Establishment or $n$ & of actin cytoskeleton & 19 \\
\hline AN0692 & Cytoplasm localiz & ation & 13 & AN10765 & Nucleic acid bindir & & 11 \\
\hline AN0707 & 5'-3' exoribonucle & ase activity & 5 & AN10837 & Amidophosphoribc & se activity & 25 \\
\hline AN0708 & Polypeptide & & 86 & AN10848 & Nucleic acid bindir & & 26 \\
\hline AN0717 & Histidinol-phosph & te aminotransferase & 47 & AN11008 & Squalene monoox & vity & 18 \\
\hline AN0753 & Intracellular locali & zation & 106 & AN11052 & 5'-3' exonuclease & & 35 \\
\hline AN0757 & tRNA (cytosine-5- & -methyltransferase & 54 & AN11128 & Binding activity & & 19 \\
\hline AN0809 & DNA binding & & 25 & AN11168 & Nucleus localizatic & & 13 \\
\hline AN0840 & Alpha-isopropylm & alate synthase & 131 & AN11238 & IMP dehydrogena & uctase & 23 \\
\hline AN0879 & Protein of unknow & n function & 29 & AN1158 & mRNA 5'-UTR bin & & 128 \\
\hline AN0917 & Nucleotide bindin & activity & 7 & AN1163 & Chaperone & & 22 \\
\hline
\end{tabular}


Supplementary Table 4.

Continued.

\begin{tabular}{|c|c|c|c|c|c|c|c|}
\hline \multicolumn{8}{|c|}{ Found in vegetative mycelium (299 proteins) } \\
\hline \multirow[t]{2}{*}{ Gene ID } & \multirow[t]{2}{*}{ Description } & \multicolumn{2}{|c|}{$\begin{array}{l}\text { Spectral counts found } \\
\text { in veg. mycelium }\end{array}$} & \multirow[t]{2}{*}{ Gene ID } & \multirow[t]{2}{*}{ Description } & \multicolumn{2}{|c|}{$\begin{array}{l}\text { Spectral counts found } \\
\text { in veg. mycelium }\end{array}$} \\
\hline & & & $20 \mathrm{~h}$ & & & & $20 \mathrm{~h}$ \\
\hline $\begin{array}{l}\text { AN1558 } \\
\text { (MyoA) }\end{array}$ & $\begin{array}{l}\text { Myosin I, required } \\
\text { growth }\end{array}$ & secretion and polarized & 17 & AN2523 (ChsB) & Class III chitin sy & & 6 \\
\hline AN1606 & Calcium ion bindin & & 31 & AN2682 & Oxidoreductase & & 35 \\
\hline AN1636 & Protein of unknow & function & 7 & AN2731 & ATPase activator & & 46 \\
\hline AN1667 & Protein of unknow & function & 19 & AN2751 & topoisomerase II & rotein & 15 \\
\hline AN1700 & $26 \mathrm{~S}$ proteasome $\mathrm{r}$ & julatory & 53 & AN2756 (SalB) & Actin binding pro & & 126 \\
\hline AN1709 & Mitochondrial tyro & l-tRNA synthetase & 5 & AN2765 & Localized to chro & & 14 \\
\hline AN1752 & Sulfite reductase & & 210 & AN2862 & CAP-Gly domain & & 41 \\
\hline AN1851 & Unfolded protein $\mathrm{b}$ & ding activity & 90 & AN2871 (McnC) & CUE-domain con & hoprotein & 22 \\
\hline AN1873 & Protein of unknow & function & 9 & AN2904 & $26 \mathrm{~S}$ proteasome & bunit & 64 \\
\hline $\begin{array}{l}\text { AN1901 } \\
\text { (PdmA) }\end{array}$ & Sterol 14 alpha-de & ethylase & 3 & AN2907 & Protein of unknov & & 135 \\
\hline AN1904 & Chaperonin-conta & ing T-complex & 55 & AN2909 & ATP binding & & 16 \\
\hline AN1911 & Mannose-1-phosp & ate guanyltransferase & 60 & AN2917 & Role in positive $r$ & NA polymerase II & 37 \\
\hline AN1922 & \begin{tabular}{|l} 
Proteasome regul \\
\end{tabular} & ory particle & 31 & AN2954 & Protein of unknov & & 8 \\
\hline AN1929 & DNA-dependent A & Pase activity & 9 & AN2967 & tRNA dihydrouric & & 4 \\
\hline AN1949 & RNA helicase acti & & 12 & AN2976 & Intracellular local & & 6 \\
\hline AN1954 & \begin{tabular}{|l} 
Protein of unknow \\
\end{tabular} & function & 13 & AN2992 & Eukaryotic transl & factor 2 complex & 15 \\
\hline AN1965 & Ribose-phosphate & yrophosphokinase & 11 & AN3019 & Ubiquitin-depend & & 56 \\
\hline AN1966 (HulE) & HECT ubiquitin lig & & 37 & AN3029 & Protein transport & & 23 \\
\hline AN2014 & 7S RNA binding a & & 12 & AN3055 & Ribosome bindin & & 23 \\
\hline AN2042 & Oxidoreductase & & 23 & AN3070 & ATP binding, unf & & 45 \\
\hline AN2068 & RNA binding activ & & 124 & AN3080 & Role in ER to Go & diated transport & 38 \\
\hline AN2080 & \begin{tabular}{|l} 
Intracellular localiz \\
\end{tabular} & & 58 & AN3122 & $\begin{array}{l}\text { Transcript levels } \\
\text { protein }\end{array}$ & ig the unfolded- & 42 \\
\hline $\begin{array}{l}\text { AN2120 } \\
\text { (KapJ) }\end{array}$ & Karyopherin (impo & in) beta 3 & 181 & AN3134 & ATP binding, unf & & 65 \\
\hline AN2126 & Actin capping prot & & 32 & AN3147 & Intracellular local & & 28 \\
\hline AN2147 & Ribosomal RNA p & cessing protein & 37 & AN3156 & Eukaryotic transl & factor 2 complex & 47 \\
\hline AN2164 & \begin{tabular}{|l|} 
Protein transporte \\
\end{tabular} & activity & 90 & AN3169 & Ribose-phosphat & lokinase & 22 \\
\hline AN2210 & ABC-transporter & & 80 & AN3188 & Phosphatidylseri & & 21 \\
\hline AN2213 & ATPase activity & & 25 & AN3344 (Ngn27) & PGNAT-type ace & & 10 \\
\hline AN2226 & Protein of unknow & function & 6 & AN3628 & \begin{tabular}{|l} 
Peptide alpha-N- \\
\end{tabular} & & 34 \\
\hline AN2278 & Helicase activity & & 30 & AN3709 & Protein of unknov & & 20 \\
\hline $\begin{array}{l}\text { AN2284 } \\
\text { (HemA) }\end{array}$ & 5-aminolevulinic a & d synthase & 46 & AN3716 & Protein of unknor & & 34 \\
\hline AN2412 & NADH dehydroger & & 11 & AN3719 & Protein of unknov & & 6 \\
\hline AN2458 & \begin{tabular}{|l} 
Protein of unknow \\
\end{tabular} & function & 56 & AN3720 & $\begin{array}{l}\text { Putative dehydro } \\
\end{array}$ & & 61 \\
\hline $\begin{array}{l}\text { AN2516 } \\
\text { (AmpA) }\end{array}$ & $\begin{array}{l}\text { Localized to peripl } \\
\text { tips }\end{array}$ & ral patches and to hyphal & 11 & AN3739 & Intracellular local & & 45 \\
\hline AN2518 & Involved in exocyt & & 16 & AN3744 & Ribosome activit & & 35 \\
\hline
\end{tabular}


Supplementary Table 4.

Continued.

\begin{tabular}{|c|c|c|c|c|c|c|c|}
\hline \multicolumn{8}{|c|}{ Found in vegetative mycelium (299 proteins) } \\
\hline \multirow[t]{2}{*}{ Gene ID } & \multirow[t]{2}{*}{ Description } & \multicolumn{2}{|c|}{$\begin{array}{l}\text { Spectral counts found in } \\
\text { veg. mycelium }\end{array}$} & \multirow[t]{2}{*}{ Gene ID } & \multirow[t]{2}{*}{ Description } & \multicolumn{2}{|c|}{$\begin{array}{l}\text { Spectral counts found in } \\
\text { veg. mycelium }\end{array}$} \\
\hline & & & $20 \mathrm{~h}$ & & & & $20 \mathrm{~h}$ \\
\hline AN3804 & IgE binding activit & & 25 & AN4865 & Nucleic acid bindi & & 35 \\
\hline AN3807 & Lipid binding activ & & 7 & AN4890 & Role in Golgi to $\mathrm{pl}$ & nembrane transport & 13 \\
\hline AN3824 & Phenylalanine-tRI & ligase activity & 65 & AN4891 & Histone binding ac & & 10 \\
\hline AN3827 & Role in cell prolife & & 17 & AN4892 & Role in mRNA pro & & 13 \\
\hline AN3830 (lleA) & L-threonine dehyo & & 38 & AN4908 & Eukaryotic transla & tiation factor subunit & 184 \\
\hline AN3832 & Mitochondrial tran & ation & 11 & AN4923 & 3-hydroxy-3-meth & yl coenzyme A synthase & 147 \\
\hline $\begin{array}{l}\text { AN3839 } \\
\text { (SwoF) }\end{array}$ & Control of polar gr & & 25 & AN4947 & Protein of unknow & & 5 \\
\hline AN3933 & DNA-directed RN/ & olymerase activity & 42 & AN5068 & Aryl formamidase & & 16 \\
\hline AN4025 & Tubulin-tyrosine li & & 10 & AN5141 & Protein of unknow & & 28 \\
\hline AN4038 & Translation initiati & factor & 133 & AN5186 & Ubiquitin thioleste & ctivity & 20 \\
\hline AN4051 & Heme binding & & 36 & AN5318 & Non-ribosomal pe & ynthetase & 68 \\
\hline AN4094 & Role in sterol mets & olism & 5 & AN5521 (AlpA) & Microtubule stabill & & 15 \\
\hline AN4187 & Helicase activity & & 21 & AN5529 (CotA) & Protein involved ir & olarity & 24 \\
\hline AN4192 & Heat shock protei & inding & 16 & AN5629 & NADH dehydroge & & 7 \\
\hline AN4207 & Protein transporte & Ictivity & 34 & AN5635 (TreB) & Trehalase & & 23 \\
\hline AN4258 & Role in phospholif & metabolism & 24 & AN5652 & Hydantoinase/oxo & & 29 \\
\hline AN4300 & Protein of unknow & function & 5 & AN5666 (MpkA) & Mitogen-activated & $n$ kinase (MAP kinase) & 25 \\
\hline AN4346 & Nucleotide bindinc & ctivity & 10 & AN5688 & Role in lipid biosy & process & 11 \\
\hline AN4380 & Ribonucleotide rec & ctase & 77 & AN5702 & Role in ribosomal & ubunit biogenesis & 11 \\
\hline AN4412 & $\begin{array}{l}\text { Nuclear exosomal } \\
\text { helicase }\end{array}$ & EAD-box family RNA & 10 & AN5705 & Protein of unknow & & 12 \\
\hline AN4430 & Acetolactate synth & & 34 & AN5713 & chaperonin compl & pponent & 65 \\
\hline AN4431 & RNA binding activ & & 5 & AN5716 & Inosine-5'-monopl & te dehydrogenase & 17 \\
\hline AN4453 & Protein of unknow & function & 22 & AN5717 (Kapl) & Required for norm & hal growth & 117 \\
\hline AN4460 & 18S rRNA proces: & g complex subunit & 4 & AN5743 & Potassium-transp & ATPase & 8 \\
\hline AN4483 & Serine/threonine $\mathrm{k}$ & ase activity & 6 & AN5747 & Protein domain sp & oinding & 20 \\
\hline AN4492 & Ubiquitin-specific & tease activity & 25 & AN5775 & DNA binding trans & in factor & 4 \\
\hline AN4523 & Spliceosome invol & d in pre-mRNA splicing & 37 & AN5823 & Protein of unknow & & 38 \\
\hline AN4546 & RNA binding activ & & 33 & AN5865 & GTP-binding prote & & 20 \\
\hline AN4547 & $\begin{array}{l}\text { Role in establishm } \\
\text { polarity }\end{array}$ & t or maintenance of cell & 90 & AN5883 (MetF) & Methylenetetrahyc & te reductase & 59 \\
\hline AN4563 & Protein serine/thre & ine kinase activity & 30 & AN5894 & RNA polymerase & binding & 11 \\
\hline $\begin{array}{l}\text { AN4564 } \\
\text { (TeaA) }\end{array}$ & Cell-end marker $\mathrm{p}$ & & 11 & AN5918 (CatC) & Catalase with a ro & luconic acid & 6 \\
\hline AN4602 & Tubulin binding ac & & 9 & AN5931 & ATP-dependent R & licase & 13 \\
\hline $\begin{array}{l}\text { AN4717 } \\
\text { (PkaB) }\end{array}$ & Cyclic AMP-deper & ent protein kinase $\mathrm{A}$ (PKA) & 9 & AN5957 & Amino acid amino & erase & 78 \\
\hline AN4762 & Protein of unknow & function & 11 & AN5970 & Disulfide isomeras & Iocalization & 13 \\
\hline AN4774 & Uroporphyrin-III C & ethyltransferase & 48 & AN5972 & Ubiquitin binding & & 24 \\
\hline
\end{tabular}


Supplementary Table 4.

Continued.

\begin{tabular}{|c|c|c|c|c|c|c|c|}
\hline \multicolumn{8}{|c|}{ Found in vegetative mycelium (229 proteins) } \\
\hline \multirow[t]{2}{*}{ Gene ID } & \multirow[t]{2}{*}{ Description } & \multicolumn{2}{|c|}{$\begin{array}{l}\text { Spectral counts found in } \\
\text { veg. mycelium }\end{array}$} & \multirow[t]{2}{*}{ Gene ID } & \multirow[t]{2}{*}{ Description } & \multicolumn{2}{|c|}{$\begin{array}{l}\text { Spectral counts found in } \\
\text { veg. mycelium }\end{array}$} \\
\hline & & & $20 \mathrm{~h}$ & & & & $20 \mathrm{~h}$ \\
\hline $\begin{array}{l}\text { AN5973 } \\
\text { (PkcB) }\end{array}$ & \multicolumn{2}{|c|}{ Similarity to protein kinase $\mathrm{C}$} & 26 & AN6980 & \multicolumn{2}{|c|}{ Component of the nuclear pore complex } & 10 \\
\hline AN5992 & \multicolumn{2}{|l|}{ ATP binding } & 9 & AN6993 & \multicolumn{2}{|c|}{ Phosphoribosyltransferase } & 27 \\
\hline $\begin{array}{l}\text { AN6006 } \\
\text { (KapD) }\end{array}$ & \multicolumn{2}{|c|}{ Karyopherin and nuclear receptor } & 75 & AN7005 & \multicolumn{2}{|c|}{ Protein of unknown function } & 7 \\
\hline $\begin{array}{l}\text { AN6014 } \\
(\mathrm{FaaA})\end{array}$ & \multicolumn{2}{|c|}{ Long-chain-fatty-acid-CoA ligase } & 12 & AN7028 & \multicolumn{2}{|c|}{ Thymidylate synthase } & 6 \\
\hline AN6033 & \multicolumn{2}{|c|}{ Role in ER to Golgi vesicle-mediated transport } & 28 & AN7146 & \multicolumn{2}{|c|}{ Role in sterol metabolism } & 24 \\
\hline AN6058 & \multicolumn{2}{|c|}{ Menadione stress-induced protein } & 20 & AN7169 (FhbA) & \multicolumn{2}{|c|}{ NirA-dependent flavohemoprotein } & 167 \\
\hline AN6067 & \multicolumn{2}{|c|}{ GTPase activator activity } & 43 & AN7199 & \multicolumn{2}{|c|}{ Cytoplasm localization } & 29 \\
\hline $\begin{array}{l}\text { AN6126 } \\
\text { (AccA) }\end{array}$ & \multicolumn{2}{|c|}{ Acetyl-CoA carboxylase } & 377 & AN7208 & \multicolumn{2}{|c|}{ Protein of unknown function } & 19 \\
\hline $\begin{array}{l}\text { AN6168 } \\
\text { (MaeA) }\end{array}$ & \multicolumn{2}{|c|}{ Malate dehydrogenase } & 40 & AN7297 & \multicolumn{2}{|c|}{ Role in chromatin remodeling } & 4 \\
\hline AN6193 & \multicolumn{2}{|c|}{ ATP-dependent peptidase activity } & 37 & AN7422 & ubiquitin carboxyl- & inal hydrolase & 12 \\
\hline AN6207 & ATP binding & & 14 & AN7441 & ATP-dependent 3 & NA helicase activity & 25 \\
\hline AN6231 (TrpB) & Tryptophan synth & & 149 & AN7474 & RNA binding & & 8 \\
\hline AN6266 & Ribosome biogen & $\mathrm{s}$ and nucleus localization & 6 & AN7498 & Deoxyhypusine $\mathrm{m}$ & oxygenase activity & 26 \\
\hline AN6267 & Nucleotide bindin & ctivity & 11 & AN7540 & Translation initiati & actor & 93 \\
\hline AN6366 & Oxidoreductase a & & 8 & AN7544 & Zinc ion binding & & 7 \\
\hline AN6489 & Ribosome activity & le in translation & 19 & AN7659 & RNA helicase acti & & 60 \\
\hline AN6508 & Protein kinase & & 52 & AN7687 & Membrane translo & e complex & 31 \\
\hline AN6510 & $\begin{array}{l}\text { Translocase of ou } \\
\text { complex }\end{array}$ & mitochondrial membrane & 12 & AN7699 & Protein of unknow & nction & 4 \\
\hline AN6515 & $\begin{array}{l}\text { Protein targeting t } \\
\text { membrane }\end{array}$ & ndoplasmic reticulum & 35 & AN7706 & Nucleic acid bindi & & 8 \\
\hline AN6521 (LysF) & Homoaconitate hy & atase & 65 & AN7752 & Ferrochelatase ac & & 5 \\
\hline AN6643 (BioB) & Biotin synthase & & 48 & AN7928 & Possible pseudog & & 4 \\
\hline AN6651 & Ribosomal small s & unit biogenesis & 33 & AN7995 & Role in ribose met & lism & 9 \\
\hline AN6676 & Nucleic acid bindi & & 9 & AN8023 (VpsA) & Required for vacu & iogenesis & 85 \\
\hline AN6705 & DNA-dependent $A$ & ase activity & 35 & AN8038 & Nucleic acid bindi & & 10 \\
\hline AN6712 (PIdA) & Phospholipase D & & 7 & AN8072 & Protein of unknow & nction & 9 \\
\hline $\begin{array}{l}\text { AN6731 } \\
\text { (SdeA) }\end{array}$ & Delta-9-stearic ac & desaturase & 22 & AN8073 & RNA binding, $\mathrm{S}-\mathrm{a}$ & sylmethionine-dependent & 7 \\
\hline $\begin{array}{l}\text { AN6734 } \\
\text { (KapF) }\end{array}$ & Karyopherin & & 73 & AN8102 (PepAc) & Pepsin-like aspart & otease & 4 \\
\hline AN6753 & NADH-dependent & ivin oxidoreductase & 35 & AN8118 & cytochrome c oxid & & 4 \\
\hline $\begin{array}{l}\text { AN6838 } \\
\text { (TubC) }\end{array}$ & Beta-tubulin & & 149 & AN8225 & Ribosomal protein & & 6 \\
\hline AN6853 & Phosphatidylinosi & transporter activity & 25 & AN8233 & Role in phospholip & ansport & 51 \\
\hline AN6865 & Protein of unknow & unction & 7 & AN8268 & RasGAP SH3 binc & protein & 47 \\
\hline $\begin{array}{l}\text { AN6866 } \\
\text { (AroC) }\end{array}$ & Role in aromatic a & no acid biosynthesis & 12 & AN8346 & Oxidoreductase a & & 49 \\
\hline AN6903 & Nucleic acid bindi & & 13 & AN8488 & Palmitoyltransfera & Ictivity & 13 \\
\hline AN6922 & Role in cytoplasm & ranslation & 11 & AN8706 (GnaA) & Glucosamine-pho & ate $\mathrm{N}$-acetyltransferase & 13 \\
\hline AN6978 & Nucleotide exchar & factor & 17 & AN8709 & Aspartate transam & & 34 \\
\hline
\end{tabular}


Supplementary Table 4.

Continued.

\begin{tabular}{|c|c|c|c|c|c|c|c|}
\hline \multicolumn{8}{|c|}{ Found in vegetative mycelium (229 proteins) } \\
\hline \multirow[t]{2}{*}{ Gene ID } & \multirow[t]{2}{*}{ Description } & \multicolumn{2}{|c|}{$\begin{array}{l}\text { Spectral counts found } \\
\text { in veg. mycelium }\end{array}$} & \multirow[t]{2}{*}{ Gene ID } & \multirow[t]{2}{*}{ Description } & \multicolumn{2}{|c|}{$\begin{array}{l}\text { Spectral counts found } \\
\text { in veg. mycelium }\end{array}$} \\
\hline & & & 20h & & & & $20 \mathrm{~h}$ \\
\hline AN8722 & \multicolumn{2}{|c|}{ ATP-dependent RNA helicase } & 39 & AN1177 & \multicolumn{2}{|c|}{ Structural molecule activity } & 75 \\
\hline AN8748 & \multicolumn{2}{|c|}{ Palmitoyl-(protein) hydrolase activity } & 12 & AN1194 & \multicolumn{2}{|c|}{ Adenylyl phosphosulfate kinase } & 18 \\
\hline AN8794 & \multicolumn{2}{|l|}{ RNA binding } & 6 & AN12101 & \multicolumn{2}{|c|}{ NADPH dehydrogenase } & 21 \\
\hline AN8815 & \multicolumn{2}{|c|}{ Isoflavone reductase family protein } & 40 & AN12272 & \multicolumn{2}{|c|}{ Protein of unknown function } & 5 \\
\hline AN8819 & \multicolumn{2}{|l|}{ Dehydrogenase } & 7 & AN12419 & \multicolumn{2}{|c|}{ DNA-directed RNA polymerase activity } & 9 \\
\hline AN8836 & \multicolumn{2}{|c|}{ PAK (p21-activated kinase) family protein } & 14 & AN1270 & \multicolumn{2}{|c|}{ Translation initiation factor 3} & 40 \\
\hline AN8843 & \multicolumn{2}{|l|}{ Homoserine kinase } & 54 & AN1281 & \multicolumn{2}{|c|}{ Chaperone binding, protein binding } & 27 \\
\hline $\begin{array}{l}\text { AN8853 } \\
\text { (SnpA) }\end{array}$ & \multicolumn{2}{|c|}{ Eukaryotic polypeptide releasing } & 33 & AN1287 (StoB) & \multicolumn{2}{|c|}{ Stomatin-like protein } & 4 \\
\hline AN8859 & \multicolumn{2}{|l|}{ Aspartate kinase } & 32 & AN1288 & \multicolumn{2}{|c|}{ Protein of unknown function } & 77 \\
\hline $\begin{array}{l}\text { AN8862 } \\
\text { (MyoA) }\end{array}$ & \multicolumn{2}{|c|}{$\begin{array}{l}\text { Involved in the movement of vesicles to the } \\
\text { hyphal tip }\end{array}$} & 30 & AN0922 & \multicolumn{2}{|c|}{ Golgi to ER and COPI vesicle coat localization } & 37 \\
\hline AN8869 & \multicolumn{2}{|c|}{ Uracil phosphoribosyltransferase } & 10 & AN0999 (CapA) & \multicolumn{2}{|c|}{ Adenylate cyclase-associated protein } & 31 \\
\hline AN8874 & \multicolumn{2}{|c|}{ GTPase activity } & 38 & AN1006 (NiaD) & \multicolumn{2}{|l|}{ Nitrate reductase } & 38 \\
\hline AN9067 (TinC) & NIMA-interacting $\mathrm{F}$ & tein & 37 & AN10088 & Protein of unknow & $\mathrm{n}$ function & 9 \\
\hline $\begin{array}{l}\text { AN9090 } \\
\text { (RrmA) }\end{array}$ & RNA binding prote & & 50 & AN10103 & DNA binding activ & & 19 \\
\hline AN9149 & Protein of unknow & unction & 14 & AN10156 & Phosphotransfera & se activity & 27 \\
\hline AN9304 (ElfA) & Glutathione S-tran & erase & 31 & AN10173 & RNA binding activ & & 24 \\
\hline AN9357 & Cytoplasm localize & & 9 & AN1023 (SagA) & Sensitivity to DNA & -damaging agents & 12 \\
\hline AN9467 & Serine/threonine $p$ & sphatase activity & 13 & AN10257 & mRNA binding act & ivity & 42 \\
\hline AN9497 & Hydrolase activity & & 5 & AN1306 & Role in actin filam & ent severing & 18 \\
\hline AN10301 & Nucleotide binding & ctivity & 10 & AN1328 (NnaA) & GNAT-type acetyl & transferase & 6 \\
\hline AN10337 & Enzyme regulator & tivity & 28 & AN1401 (KapK) & Essential exportin & & 62 \\
\hline AN10350 & Phosphatidylinosit & binding activity & 55 & AN1405 & Protein of unknow & n function & 4 \\
\hline AN10352 & rRNA processing & & 26 & AN1408 & U5 snRNP-specifi & c protein & 42 \\
\hline AN10396 & Farnesyl-diphosph & e farnesyltransferase & 5 & AN1466 & Nucleus localizatic & & 25 \\
\hline AN1045 & RNA binding & & 30 & AN1524 & Methylenetetrahyc & Irofolate dehydrogenase & 21 \\
\hline AN10475 & Tryptophan-tRNA & ase & 41 & & & & \\
\hline
\end{tabular}


Supplementary Table 4.

Continued.

\begin{tabular}{|c|c|c|c|c|}
\hline \multicolumn{5}{|c|}{ Shared in sexual and asexual mycelium (221 proteins) } \\
\hline \multirow[t]{2}{*}{ Gene ID } & \multirow[t]{2}{*}{ Description } & \multicolumn{3}{|c|}{$\begin{array}{l}\text { Spectral counts found in } \\
\text { sex. mycelium }\end{array}$} \\
\hline & & 3 day & 5 day & 7 day \\
\hline AN0050 & Picolinic acid decarboxylase & 29 & 28 & \\
\hline AN0076 & Role in interspecies interaction & 11 & 2 & 4 \\
\hline AN0089 (AvaA) & Small GTPase & 4 & & 10 \\
\hline AN0131 & Cytoplasm localization & 2 & 6 & \\
\hline AN0184 & Role in actin filament & 6 & 2 & \\
\hline AN0193 & Hydrolase activity & 11 & 12 & 10 \\
\hline AN0224 & Dipeptidase activity & 15 & 18 & 18 \\
\hline AN0231 (IvoB) & Conidiophore-specific phenol oxidase & 15 & 9 & 15 \\
\hline AN0248 (PdiB) & Disulfide isomerase & 13 & 2 & \\
\hline AN0391 & Protein of unknown function & 58 & 69 & \\
\hline AN0400 & Protein of unknown function & & 10 & 10 \\
\hline AN0447 & Iron ion binding & 11 & & 12 \\
\hline AN0733 (HhtA) & Histone H3; core histone protein & 2 & & 2 \\
\hline AN0768 & Protein of unknown function & 31 & 60 & 26 \\
\hline AN0774 & Nucleotide binding & 7 & 10 & \\
\hline AN0775 & Oxidoreductase activity & 5 & 20 & \\
\hline AN0783 & Carbon-nitrogen ligase & & 32 & 4 \\
\hline AN0824 (ScdA) & Short-chain fatty acid beta-oxidation & 15 & 54 & 8 \\
\hline AN0880 & Peroxisomal targeting signal 2 & 21 & 21 & \\
\hline AN0886 & Role in nitrogen metabolism & & 16 & 14 \\
\hline AN0895 & Oxidoreductase & 41 & 87 & 19 \\
\hline AN0933 (CrhC) & Transglycosidase & 10 & 10 & 4 \\
\hline AN0942 (LadA) & L-arabinitol 4-dehydrogenase & 15 & 43 & 14 \\
\hline AN10054 & Phosphotransferase activity & 8 & 9 & \\
\hline AN10060 & Alpha-amylase & 41 & 116 & 11 \\
\hline AN10109 & Protein of unknown function & 19 & 32 & \\
\hline AN10131 (PyrD) & Dihydroorotase & 4 & 16 & \\
\hline AN10146 & Protein of unknown function & 8 & 20 & \\
\hline AN10197 & Role in coenzyme $\mathrm{M}$ biosynthetic & 12 & 4 & \\
\hline AN10217 & Oxidoreductase activity & 3 & 4 & \\
\hline AN10233 & Phosphogluconate dehydrogenase & 8 & 119 & \\
\hline AN10260 & Menadione stress-induced protein & 14 & 61 & \\
\hline AN10335 & Nucleotide binding & 6 & 9 & \\
\hline AN10421 & Protein of unknown function & 3 & 13 & \\
\hline AN10437 & Mitochondrion localization & 22 & 21 & \\
\hline AN10482 & Beta-glucosidase & & 5 & 4 \\
\hline AN10494 & Nucleotide binding & 12 & 13 & 5 \\
\hline AN1050 & 3-ketoacyl-CoA thiolase & 23 & 91 & \\
\hline AN10507 & Unfolded protein binding activity & & 6 & 10 \\
\hline AN10520 & Alpha/beta hydrolase & 3 & 32 & \\
\hline AN10626 (RmtA) & Arginine methyltransferase & 3 & 146 & 18 \\
\hline AN10695 (AspE) & Septin & 4 & 3 & 4 \\
\hline AN10700 & Protein of unknown function & 7 & 10 & \\
\hline AN10708 & Role in proteasomal ubiquitin & 15 & 42 & 6 \\
\hline AN1074 & Glycine dehydrogenase & 9 & 6 & \\
\hline AN10797 & Catalytic activity & 8 & 10 & 4 \\
\hline AN10839 & Role in retrograde transport & 8 & 16 & \\
\hline AN11039 & Carbon-sulfur lyase activity & 4 & 20 & 4 \\
\hline AN11062 & Protein of unknown function & 11 & 9 & 8 \\
\hline AN11161 & Phosphatidylserine decarboxylase & 14 & 14 & 4 \\
\hline AN11187 & Monooxygenase activity & 17 & 10 & \\
\hline AN11233 & Chitinase activity & 23 & 3 & \\
\hline AN11778 & Exoinulinase & 13 & 29 & \\
\hline AN1184 & Ribosome localization & 13 & & 8 \\
\hline AN11862 & TRC complex localization & 11 & 9 & \\
\hline AN11908 & Hydrolase activity & 4 & 7 & \\
\hline AN1191 (SumO) & Small ubiquitin-like modifier (SUMO) protein & & 2 & 5 \\
\hline AN11945 & Protein of unknown function & 2 & 18 & 4 \\
\hline AN1197 & Catalytic activity & 16 & 5 & 4 \\
\hline AN11985 & Protein of unknown function & & 4 & 13 \\
\hline AN12004 & Protein of unknown function & 7 & 7 & \\
\hline AN12070 & Carbon-nitrogen ligase activity & 3 & 5 & \\
\hline AN12198 & Protein of unknown function & & 4 & 8 \\
\hline AN12221 & Deoxyribose-phosphate aldolase activity & 9 & 19 & 4 \\
\hline
\end{tabular}


Supplementary Table 4.

Continued.

\begin{tabular}{|c|c|c|c|c|}
\hline \multicolumn{5}{|c|}{ Shared in sexual and asexual mycelium (221 proteins) } \\
\hline \multirow[t]{2}{*}{ Gene ID } & \multirow[t]{2}{*}{ Description } & \multicolumn{3}{|c|}{$\begin{array}{l}\text { Spectral counts found in } \\
\text { sex. mycelium }\end{array}$} \\
\hline & & 3 day & 5 day & 7 day \\
\hline AN12229 & Zinc ion binding activity & 13 & & 14 \\
\hline AN12466 & Glutathione synthase activity & 7 & 11 & \\
\hline AN1418 & Glucosamine-6-phosphate deaminase activity & 22 & 4 & \\
\hline AN1427 & Role in transmembrane transport & 8 & 10 & 2 \\
\hline AN1428 & $\mathrm{N}$-acetylglucosamine-6-phosphate deacetylase & 42 & 47 & 2 \\
\hline AN1503 & Dihydrodipicolinate synthase & 10 & 19 & \\
\hline AN1659 & Amino acid transporter & & 10 & 5 \\
\hline AN1715 & Mannose-6-phosphate isomerase & 31 & 87 & 30 \\
\hline AN1734 & Protein of unknown function & 5 & 45 & \\
\hline AN1742 & Fumarylacetoacetase activity & 38 & 4 & \\
\hline AN1809 & Fumarylacetoacetase & & 34 & 66 \\
\hline AN1868 & Glycerol dehydrogenase & 15 & 12 & \\
\hline AN1882 & Role in cell redox homeostasis & & 58 & 7 \\
\hline AN1896 (FahA) & Fumarylacetoacetate hydrolase & 41 & 79 & 27 \\
\hline AN1897 (HmgA) & Homogentisate 1,2-dioxygenase & 41 & & 16 \\
\hline AN1899 (HpdA) & Role in aromatic amino acid biosynthes & 24 & 7 & 4 \\
\hline AN1947 & Hydrolase activity & 5 & 12 & \\
\hline AN2085 & Endopeptidase activity & 3 & & 5 \\
\hline AN2091 & Carboxy-lyase activity & 9 & 4 & \\
\hline AN2133 & Uracil phosphoribosyltransferase & 7 & 45 & 8 \\
\hline AN2332 & Succinate dehydrogenase & 5 & 49 & \\
\hline AN2393 & Nucleotide binding & 10 & 25 & \\
\hline AN2404 & Protein of unknown function & 5 & 6 & \\
\hline AN2470 & Nucleotide binding & 32 & 45 & 4 \\
\hline AN2471 & Protein of unknown function & 15 & 8 & \\
\hline AN2479 (Ngn16) & GNAT-type acetyltransferase & 4 & 4 & \\
\hline AN2532 & Copper ion binding & 11 & 12 & \\
\hline AN2548 (EasC) & Required for emericellamide biosynthesis & 4 & 2 & 4 \\
\hline AN2720 & Catalytic activity & 8 & 30 & 4 \\
\hline AN2815 & Mannitol 2-dehydrogenase & 11 & 81 & 3 \\
\hline AN2847 & DNA binding activity & 15 & 13 & \\
\hline AN2879 & Carbon-nitrogen ligase activity & 10 & & 15 \\
\hline AN2896 & Catalytic activity & 10 & 20 & 10 \\
\hline AN2977 & Role in small molecule transport & 2 & 4 & \\
\hline AN3017 & Epoxide hydrolase & 25 & 11 & \\
\hline AN3091 & Metalloendopeptidase & 44 & 12 & 9 \\
\hline AN3104 & Allantoicase & 10 & 12 & \\
\hline AN3200 & Beta-glucuronidase & 4 & 16 & \\
\hline AN3222 & IMP 5'-nucleotidase activity & 22 & 2 & \\
\hline AN3299 & Protein of unknown function & 11 & 7 & \\
\hline AN3305 & Nucleotide binding activity & 18 & 47 & \\
\hline AN3334 & Nucleotide binding activity & 37 & 145 & 19 \\
\hline AN3351 & UDP-N-acetylmuramate dehydrogenase activity & 28 & 18 & 9 \\
\hline AN3361 (NopA) & Rhodopsin family G-protein coupled receptor-like & 8 & 19 & 9 \\
\hline AN3431 & Nicotinate-nucleotide diphosphorylase & 9 & 21 & \\
\hline AN3605 & Oxidoreductase activity & 7 & 7 & 9 \\
\hline AN3627 & Intracellular localization & 47 & 2 & 2 \\
\hline AN3634 & Phosphoribosyltransferase & 11 & 25 & 7 \\
\hline AN3679 & Nucleotide binding & 6 & 44 & \\
\hline AN3756 & Endopeptidase activity & 9 & 2 & 2 \\
\hline AN3869 & Role in sterol metabolism & 44 & 10 & 6 \\
\hline AN3987 & Tetratricopeptide & 7 & 4 & \\
\hline AN4018 & Role in protein targeting to vacuole & 28 & 13 & 19 \\
\hline AN4048 & Endodeoxyribonuclease activity & 4 & & 19 \\
\hline AN4052 (ExgC) & Glucan 1,3-beta-glucosidase & 9 & & 29 \\
\hline AN4245 & Ceramidase & 18 & 10 & \\
\hline AN4268 & Monooxygenase activity & 2 & 28 & \\
\hline AN4397 & Protein of unknown functionp & 9 & 15 & \\
\hline AN4421 & Oxidoreductase activity & 46 & 123 & 11 \\
\hline AN4452 & Ribosome activity & 2 & 3 & 2 \\
\hline AN4467 (СурB) & Cyclophilin B & 4 & 5 & \\
\hline AN4531 & Protein of unknown function & 10 & 7 & \\
\hline AN4688 (IvdA) & Acyl-coA dehydrogenase & 17 & 23 & 4 \\
\hline AN4690 (MccA) & Alpha subunit of 3-methylcrotonyl-CoA carboxylase & 19 & 10 & \\
\hline
\end{tabular}


Supplementary Table 4.

Continued.

\begin{tabular}{|c|c|c|c|c|}
\hline \multicolumn{5}{|c|}{ Shared in sexual and asexual mycelium (221 proteins) } \\
\hline \multirow[t]{2}{*}{ Gene ID } & \multirow[t]{2}{*}{ (2) } & \multicolumn{3}{|c|}{$\begin{array}{c}\text { Spectral counts found in sex. } \\
\text { mycelium }\end{array}$} \\
\hline & & 3 day & 5 day & 7 day \\
\hline AN4807 & Protein of unknown function & 6 & 3 & 4 \\
\hline AN4809 (GtaA) & Glutaminase A & 61 & 33 & 27 \\
\hline AN4843 & Alpha-glucosidase & & 6 & \\
\hline AN4913 (PhK) & Phosphoketolase & 5 & 25 & 2 \\
\hline AN4914 & Acetate kinase & 22 & 34 & \\
\hline AN4957 (GalE) & Galactokinase & 11 & 22 & 4 \\
\hline AN4979 & Dihydroneopterin aldolase activity & 8 & 10 & \\
\hline AN4987 (PkaR) & Protein kinase $\mathrm{A}$ & 30 & 47 & \\
\hline AN5021 & Role in biosynthetic process & 19 & 21 & 2 \\
\hline AN5110 & Protein of unknown function & 4 & 32 & 2 \\
\hline AN5194 & ATPase activity & 7 & 2 & 3 \\
\hline AN5354 & Oxidoreductase activity & 7 & 12 & \\
\hline AN5387 & Protein of unknown function & 7 & 27 & \\
\hline AN5411 & Metal ion binding, phosphoric diester hydrolase & 9 & 28 & 2 \\
\hline AN5452 & Splicing factor $3 b$ & 25 & 28 & \\
\hline AN5524 & Hydrolase activity & 8 & 5 & \\
\hline AN5607 & Role in proteasome assembly & 26 & 2 & \\
\hline AN5613 (HxA) & Xanthine dehydrogenase & 29 & 2 & \\
\hline AN5658 & Gamma-glutamyltransferase activity & 35 & 16 & \\
\hline AN5704 & Type II fatty acid synthase & 10 & 9 & \\
\hline AN5831 & Chorismate synthase & 8 & 16 & \\
\hline AN5879 & Ribosomal small subunit assembly & 5 & 32 & 5 \\
\hline AN5916 & Mitochondrial enoyl-CoA hydratase & & 55 & 6 \\
\hline AN5942 & Protein of unknown function & & 7 & 2 \\
\hline AN5989 & Epimerase/dehydratase & & 36 & 15 \\
\hline AN5994 & ATP-dependent NAD $(\mathrm{P}) \mathrm{H}$-hydrate dehydratase & 56 & 36 & 2 \\
\hline AN6066 & Catalytic activity & 19 & 20 & \\
\hline AN6111 & Exosome & & 6 & 11 \\
\hline AN6169 & Rho guanyl-nucleotide exchange factor & 7 & 9 & 10 \\
\hline AN6274 & Oxidoreductase activity & 50 & 41 & 5 \\
\hline AN6438 & Aromatic-amino-acid transaminase & 20 & 18 & 24 \\
\hline AN6512 & ATPase activity & 6 & 6 & \\
\hline AN6536 (HisB) & Imidazole glycerol-phosphate dehydratase & 7 & 2 & \\
\hline AN6606 & Role in post-translational protein modification & 8 & 10 & \\
\hline AN6635 (YA) & Conidial laccase (p-diphenol oxidase) & 30 & 62 & 22 \\
\hline AN6654 & Glutamate-ammonia ligase activity & 10 & & \\
\hline AN6655 (GudC) & Glucose 1-dehydrogenase & 11 & 44 & 8 \\
\hline AN6723 (DhbD) & 2,3-dihydroxybenzoate carboxylyase & 6 & 13 & 5 \\
\hline AN6792 (GfdB) & Dehydrogenase & 5 & 91 & \\
\hline AN6804 & Transporter of the major facilitator superfamily (MFS) & 7 & 9 & 12 \\
\hline AN6862 & Protein of unknown function & 10 & & \\
\hline AN6918 & Oxidoreductase & 2 & & 26 \\
\hline AN6923 (HxtA) & High-affinity hexose transporter & 5 & 9 & 2 \\
\hline AN6985 & Ribulokinase & 48 & 60 & 37 \\
\hline AN7008 (HadA) & Mitochondrial hydroxyacyl-CoA dehydrogenase & 10 & 10 & \\
\hline AN7011 & Protein of unknown function & 13 & 6 & \\
\hline AN7035 & Peptidase activity & & 8 & 4 \\
\hline AN7140 & Protein of unknown function & 34 & & \\
\hline AN7181 & Protein of unknown function & 38 & 46 & 20 \\
\hline AN7231 & Serine-type peptidase & 15 & 27 & 4 \\
\hline AN7278 & Glutamate decarboxylase & 12 & 15 & \\
\hline AN7298 & Starvation-induced autophagy & 17 & 15 & 16 \\
\hline AN7331 & Cyanate hydratase activity & 12 & 31 & 5 \\
\hline AN7471 & Hydrolase activity & 4 & 3 & \\
\hline AN7517 & Protein of unknown function & 22 & 4 & 6 \\
\hline AN7691 (PlcB) & Phospholipase & 14 & 7 & \\
\hline AN7742 & Single-stranded DNA binding activity & 14 & 8 & 2 \\
\hline AN7805 (StcV) & Role in sterigmatocystin/aflatoxin biosynthesis & 13 & 21 & 24 \\
\hline AN7907 & Glyoxylate-bleomycin resistance protein & 15 & 6 & \\
\hline AN7911 (OrsB) & Member of the F9775 SM gene cluster & 35 & 71 & 9 \\
\hline AN7959 & Protein of unknown function & 4 & & 15 \\
\hline AN8010 & Glycogen (starch) synthase & 14 & 16 & \\
\hline AN8046 & Triacylglycerol lipase & 6 & 25 & 2 \\
\hline AN8050 & Protein of unknown function & 7 & 8 & \\
\hline
\end{tabular}


Supplementary Table 4.

Continued.

\begin{tabular}{|l|l|r|r|r|}
\hline \multicolumn{7}{|l}{ Shared in sexual and asexual mycelium (221 proteins) } \\
\hline \multirow{2}{*}{ Gene ID } & Description & \multicolumn{2}{c|}{ Spectral counts found in sex. } \\
\hline & & $\mathbf{3}$ day & $\mathbf{5}$ day & $\mathbf{7}$ day \\
\hline AN8219 & Plasma membrane ATPase & 25 & 9 & \\
\hline AN8335 & Protein of unknown function & 12 & 51 & \\
\hline AN8396 (PdcB) & Pyruvate decarboxylase & 36 & 34 & 4 \\
\hline AN8445 & Aminopeptidase Y & 26 & 35 & 31 \\
\hline AN8496 & Metal ion binding activity & 23 & 16 & 16 \\
\hline AN8561 & Nucleotide binding & 2 & & 15 \\
\hline AN8566 & Catechol 1,2-dioxygenase activity & & 33 & 4 \\
\hline AN8628 & Cofactor binding & 5 & 64 & 4 \\
\hline AN8638 (cetJ) & Transcript enriched in dormant conidia induced by light & 37 & 24 & \\
\hline AN8639 & Alpha-trehalose-phosphate synthase & 19 & 82 & 2 \\
\hline AN8737 (MstA) & Sugar transporter & 3 & 2 & 9 \\
\hline AN8744 & Oxidoreductase activity & 2 & 5 & \\
\hline AN8755 (MclA) & Methylisocitrate lyase & 24 & 43 & 6 \\
\hline AN8777 (amdS) & Acetamidase & 13 & 3 & 6 \\
\hline AN8782 & S-formylglutathione hydrolase & 13 & 44 & 10 \\
\hline AN8803 (RodA) & Hydrophobin & 26 & 9 & 11 \\
\hline AN8908 & Phosphoric diester hydrolase & 9 & 53 & 14 \\
\hline AN8932 & TIM-barrel enzyme family protein & 10 & 9 & \\
\hline AN8968 & Isoflavone reductase & 5 & 38 & \\
\hline AN8977 (AlcP) & Gluconolactonase & 18 & 6 & 4 \\
\hline AN9011 & Aryl-alcohol oxidase-related & 15 & 23 & 4 \\
\hline AN9054 & Protein of unknown function & 5 & 53 & 26 \\
\hline AN9064 & Xylitol dehydrogenase & 25 & 30 & 2 \\
\hline AN9130 (AifA) & Apoptosis-inducing factor (AIF)-like & 53 & 17 & 10 \\
\hline AN9183 (BgIR) & Beta-glucosidase & 3 & 4 & 4 \\
\hline AN9348 & Aryl-alcohol oxidase-related protein & 13 & 16 & \\
\hline AN9380 & Chitin deacetylase & 6 & 17 & 4 \\
\hline AN9425 & Carbon-carbon lyase & 6 & 22 \\
\hline AN9434 & Nucleus localization & 10 & 10 \\
\hline & & & & \\
\hline
\end{tabular}

\begin{tabular}{|l|l|r|r|r|}
\hline \multicolumn{2}{|c|}{ Shared in sexual, asexual and vegetative mycelium (164 proteins) } \\
\hline & Description & \multicolumn{2}{c|}{ Spectral counts found in sex. } \\
Gene ID & & $\mathbf{3}$ day & $\mathbf{5}$ day & $\mathbf{7}$ day \\
\hline & & 7 & & 9 \\
\hline AN0121 (HemC) & Porphobilinogen deaminase & 24 & 15 & 5 \\
\hline AN0140 & Role in actin assembly & & 12 & \\
\hline AN0163 & Rho GDP-dissociation inhibitor activity & 5 & & \\
\hline AN0182 (RasA) & Small monomeric GTPase & 13 & 5 & \\
\hline AN0261 (Sec23) & COPII coat component & 15 & 3 & 10 \\
\hline AN0271 & dUTP pyrophosphatase & 29 & 23 & 4 \\
\hline AN0306 & Role in regulation of actin filament polymerization & 20 & 8 & 12 \\
\hline AN0317 & Ubiquitin binding activity & 22 & 8 & \\
\hline AN0410 (BimG) & Required for the completion of anaphase & 16 & 79 & 10 \\
\hline AN0445 & Ribosome activity & 6 & 11 & 22 \\
\hline AN0570 & RNA binding & 41 & 41 & 21 \\
\hline AN0648 (TrpC) & Involved in tryptophan biosynthesis & 22 & 28 & 8 \\
\hline AN0667 (ManA) & Mannose-6-phosphate isomerase & 10 & 26 & 3 \\
\hline AN0705 & Isoleucine-tRNA ligase activity & 65 & 29 & 57 \\
\hline AN0797 & Multifunctional enzyme & 3 & 8 & 19 \\
\hline AN0847 & Chaperone & 4 & 2 & \\
\hline AN0858 (Hsp104) & Chaperone & 12 & & 7 \\
\hline AN0906 (KapB) & Essential nuclear transport protein & 11 & 23 & 17 \\
\hline AN0912 & Beta-isopropylmalate dehydrogenase & 7 & & 13 \\
\hline AN0952 & Acid phosphatase activity & 25 & 13 & 6 \\
\hline AN10020 & Regulator activity & 7 & 7 & 13 \\
\hline AN10079 (UreB) & Urease & 24 & 46 & 8 \\
\hline AN10087 & Similar to proliferating cell nuclear antigen (PCNA) & 2 & & \\
\hline AN10188 & Protein of unknown function & 9 & & 2 \\
\hline AN10194 & Helicase activity & 13 & 15 & 9 \\
\hline AN10195 & Valine-tRNA ligase activity & 14 & & 8 \\
\hline AN10220 (Ccp1) & Cytochrome c peroxidase & & & \\
\hline & & & & \\
\hline
\end{tabular}


Supplementary Table 4.

Continued.

\begin{tabular}{|c|c|c|c|c|}
\hline \multicolumn{5}{|c|}{ Shared in sexual, asexual and vegetative mycelium (164 proteins) } \\
\hline \multirow[t]{2}{*}{ Gene ID } & \multirow[t]{2}{*}{ 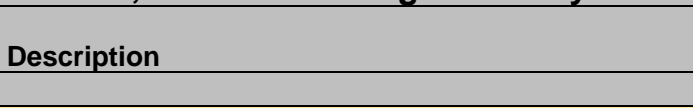 } & \multicolumn{3}{|c|}{$\begin{array}{l}\text { Spectral counts found } \\
\text { in sex. mycelium }\end{array}$} \\
\hline & & 3 day & 5 day & 7 day \\
\hline AN10222 & Glucose-6-phosphate 1-epimerase activity & 31 & 31 & \\
\hline AN10230 & S-methyl-5-thioadenosine phosphorylase activity & 20 & 14 & 9 \\
\hline AN10284 & Glutathione synthase & 12 & 8 & 7 \\
\hline AN10296 & Fumarate reductase (NADH) activity & 32 & 10 & 14 \\
\hline AN10298 & 3-phosphoserine aminotransferase & 37 & 160 & 5 \\
\hline AN10512 (MthA) & Mitochondrial ketoacyl-CoA thiolase & 26 & 92 & 5 \\
\hline AN10533 & Trehalose-6-phosphate synthase & & 2 & 2 \\
\hline AN10681 & Ribosome activity & 5 & 10 & 2 \\
\hline AN10710 & Rhosphomannomutase activity & 13 & 19 & \\
\hline AN10718 (RiboG) & 6,7-mimethyl-8-ribityl-lumazine synthase & 23 & 46 & 5 \\
\hline AN10740 & Ribosome activity, role in translati & 14 & 75 & 25 \\
\hline AN10783 & Coenzyme binding & 15 & 44 & \\
\hline AN10901 & Glycine dehydrogenase & 11 & 51 & 37 \\
\hline AN10942 & Actin depolymerizing & 15 & 35 & 13 \\
\hline AN10981 & Bifunctional GTP cyclohydrolase II & 16 & 10 & 2 \\
\hline AN11054 & Alpha-1,4-glucosidase & 12 & 6 & 10 \\
\hline AN11070 & Metalloaminopeptidase activity & 45 & 163 & 7 \\
\hline AN11094 & Zinc-binding oxidoreductase & 4 & 67 & \\
\hline AN1198 & Aminomethyltransferase & 12 & 38 & 11 \\
\hline AN12237 (AbpA) & Actin-binding protein & 8 & 13 & 5 \\
\hline AN1274 & NADP+1-oxidoreductase activity & 33 & 79 & \\
\hline AN1345 & Structural constituent of ribosome activity & 6 & 17 & 10 \\
\hline AN1429 (CodA) & Choline oxidase & 26 & 46 & \\
\hline AN1485 & Serine/threonine kinase activity & 27 & 6 & 3 \\
\hline AN1534 & Succinate dehydrogenase & 46 & 90 & 10 \\
\hline AN1677 & Short-chain dehydrogenase & 10 & 90 & 10 \\
\hline AN1805 (CanB) & Carbonic anhydrase & 19 & & 21 \\
\hline AN1913 & Lysyl-tRNA synthetase & & 78 & 8 \\
\hline AN2306 & Ubiquinol-cytochrome-c reductase & 4 & 2 & \\
\hline AN2317 & Actin depolymerizing protein & 5 & 3 & \\
\hline AN2414 & NADH dehydrogenase (ubiquinone) & 11 & 24 & 2 \\
\hline AN2440 & Ribose-5-phosphate isomerase & 18 & 16 & \\
\hline AN2873 (LysA) & Saccharopine dehydrogenase & 22 & 81 & 3 \\
\hline AN2882 & Homoserine dehydrogenase & 59 & 129 & 9 \\
\hline AN2930 & Mitochondrion localization & 9 & 14 & 2 \\
\hline AN2964 (PdhX) & Dehydrogenase complex component & 19 & 7 & \\
\hline AN2970 & Phosphatase activity & 10 & 9 & \\
\hline AN2998 & Multifunctional enzyme & 18 & 133 & 5 \\
\hline AN3034 (SuAprgA1) & Regulation of penicillin biosynthesis & 7 & 31 & 2 \\
\hline AN3223 (PfkA) & 6-phosphofructokinase & 36 & 171 & 19 \\
\hline AN3469 (H2B) & Histone $\mathrm{H} 2 \mathrm{~B}$ & 3 & 5 & 2 \\
\hline AN3581 (TrxR) & Thioredoxin reductase & 34 & 58 & 4 \\
\hline AN3591 & Propionyl-CoA-yielding methylmalonate semialdehyde & 74 & 77 & \\
\hline AN3593 & Aldolase/adducin domain protein & 9 & 27 & \\
\hline AN3626 & Phosphoribosylamino-imidazole-carboxylase & 18 & 30 & 10 \\
\hline AN3695 & Anthranilate synthase & 8 & 9 & 11 \\
\hline AN3702 & Leucine-tRNA ligase activity & 2 & 14 & 5 \\
\hline AN3712 & Dienelactone hydrolase & 25 & 79 & \\
\hline AN3748 & Phosphoribosyltransferase & 44 & 39 & 14 \\
\hline AN3853 & Metalloendopeptidase activity & 22 & 13 & 19 \\
\hline AN3932 & Proteasome beta- 5 subunit & 19 & 46 & 13 \\
\hline AN3973 & Peroxiredoxin & 15 & 27 & \\
\hline AN4015 & Translation elongation factor activity & & 41 & 15 \\
\hline AN4060 (Rps16) & Ribosomal protein S16 & 16 & 40 & \\
\hline AN4073 & Cytosolic small ribosomal subunit protein S12 & 7 & 18 & 2 \\
\hline AN4085 & Intracellular localization & 14 & & 4 \\
\hline AN4127 & Intracellular localization & 4 & 6 & \\
\hline AN4174 & Lactoylglutathione lyase & 39 & 68 & 18 \\
\hline AN4178 (Myg1) & UPF0160 domain-containing protein & 15 & 26 & 12 \\
\hline AN4202 (Rpl16A) & Ribosomal protein of the large (60S) ribosomal subunit & 8 & 46 & 38 \\
\hline
\end{tabular}


Supplementary Table 4.

Continued.

\begin{tabular}{|c|c|c|c|c|}
\hline \multicolumn{5}{|c|}{ Shared in sexual, asexual and vegetative mycelium (164 proteins) } \\
\hline \multirow[t]{2}{*}{ Gene ID } & \multirow[t]{2}{*}{ Description } & \multicolumn{3}{|c|}{$\begin{array}{l}\text { Spectral counts found } \\
\text { in sex. mycelium }\end{array}$} \\
\hline & & 3 day & 5 day & 7 day \\
\hline AN4222 & Ribosome activity & 29 & 54 & 16 \\
\hline AN4234 (PcmA) & Phosphoacetylglucosamine mutase & 22 & 54 & 48 \\
\hline AN4402 & Voltage-gated anion channel activity & 9 & 7 & 9 \\
\hline AN4449 & Endopeptidase activator activity & 21 & 8 & 3 \\
\hline AN4457 & Endopeptidase activator activity & 4 & 13 & 7 \\
\hline AN4550 (Cyp7) & Peptidyl-prolyl cis-trans isomerase D & 29 & & 4 \\
\hline AN4583 & Peptidyl-prolyl cis-trans isomerase D & & 53 & 7 \\
\hline AN4591 & Phosphopentomutase activity & & 50 & 16 \\
\hline AN4803 & rRNA binding & 12 & 101 & 49 \\
\hline AN4859 (PmaA) & Plasma membrane ATPase & 10 & & \\
\hline AN4869 & 20S proteasome component & 19 & 59 & 13 \\
\hline AN5028 (PpoC) & Fatty acid oxygenase & 69 & & 10 \\
\hline AN5121 & Protein similar to proteasome regulatory & 5 & 11 & 13 \\
\hline AN5122 & Kinase & 5 & & 10 \\
\hline AN5222 & Ribosome activity & 12 & 52 & \\
\hline AN5226 (AcpA) & Acetate permease & 5 & 7 & 8 \\
\hline AN5376 & Protein of unknown function & 7 & 10 & 10 \\
\hline AN5482 & Ran GTPase & 27 & 4 & 2 \\
\hline AN5547 & Oxidoreductase & & 8 & 2 \\
\hline AN5577 & Manganese-superoxide dismutase & & 36 & 10 \\
\hline AN5586 & Mannose-1-phosphate guanylyltransferase & & 5 & \\
\hline AN5604 (AcuG) & Fructose-bisphosphatase & 45 & & 28 \\
\hline AN5610 & L-aminoadipate-semialdehyde dehydrogenase & 12 & 62 & 11 \\
\hline AN5616 & Pyridoxal phosphate binding & 9 & 23 & 5 \\
\hline AN5646 & Role in fatty acid degradation & 15 & 42 & 13 \\
\hline AN5662 & Threonine-tRNA ligase activity & 24 & 59 & 23 \\
\hline AN5749 & Metallopeptidase activity & 27 & 32 & 11 \\
\hline AN5784 & Role in proteasomal ubiquitin-dependent protein & 17 & 51 & 14 \\
\hline AN5790 & Isocitrate dehydrogenase (NAD+) & 3 & 18 & \\
\hline AN5793 & $20 S$ proteasome beta-type subunit & 22 & 51 & 22 \\
\hline AN5799 & Gamma-glutamyl phosphate reductase & 18 & 9 & 22 \\
\hline AN5803 (FimA) & Fimbrin protein & 22 & 8 & 10 \\
\hline AN5812 & Epoxide hydrolase activity & 39 & 48 & 24 \\
\hline AN5884 (PyrF) & Orotate phosphoribosyltransferase & 16 & & \\
\hline AN5886 (LuA) & Alpha-isopropylmalate isomerase & 10 & & 10 \\
\hline AN5979 & Role in ribosomal small subunit & 5 & 34 & 2 \\
\hline AN6083 & Role in ribosomal large subunit assembly & 15 & 70 & 11 \\
\hline AN6157 (PyrG) & Orotidine-5'-phosphate decarboxylase & 15 & 36 & 14 \\
\hline AN6182 (GalD) & Hexose-1-phosphate uridylyltransferase & 8 & 9 & 2 \\
\hline AN6214 (Nha1) & Hat1 acetyltransferase & 4 & & 7 \\
\hline AN6227 & Catalytic activity & 29 & 10 & 19 \\
\hline AN6248 & Adenyl-nucleotide exchange factor activity & & 22 & 5 \\
\hline AN6257 & Protein of unknown function & 12 & 15 & 4 \\
\hline AN6368 & Arginyl-tRNA synthetase & 19 & 6 & \\
\hline AN6490 & Phosphorylase & 14 & 27 & 4 \\
\hline AN6650 (McsA) & Methylcitrate synthase & 85 & 141 & 69 \\
\hline AN6726 & Role in proteasomal ubiquitin-dependent protein & 42 & 91 & 13 \\
\hline AN7000 & Succinate-CoA ligase & 11 & 3 & 2 \\
\hline AN7111 (FoxA) & Peroxisomal multifunctional enzyme & 23 & 4 & \\
\hline AN7194 & Nucleotide binding & 25 & 25 & 3 \\
\hline AN7484 & Increased levels during osmoadaptation & 13 & 7 & 4 \\
\hline AN7511 (GelE) & 1,3-beta-transglycosidase & 8 & & 66 \\
\hline AN7554 & Poly(A) RNA binding activity & 2 & 10 & 10 \\
\hline AN7594 & Protein of unknown function & & 6 & \\
\hline AN7721 & Translocon & 4 & & 5 \\
\hline AN8012 (StcN) & Versicolorin B synthase & 32 & 11 & 6 \\
\hline AN8021 (VmaA) & Vacuolar ATPase (V-ATPase) & 32 & 30 & 20 \\
\hline AN8022 & Protein of unknown function & 4 & & 9 \\
\hline AN8032 & C-3 sterol dehydrogenase & 9 & 22 & \\
\hline AN8044 & Metalloendopeptidase activity & 34 & 3 & 35 \\
\hline
\end{tabular}


Supplementary Table 4.

Continued.

\begin{tabular}{|c|c|c|c|c|}
\hline \multicolumn{5}{|c|}{ Shared in sexual, asexual and vegetative mycelium (164 proteins) } \\
\hline \multirow[t]{2}{*}{ Gene ID } & \multirow[t]{2}{*}{ Description } & \multicolumn{3}{|c|}{$\begin{array}{l}\text { Spectral counts found } \\
\text { in sex. mycelium }\end{array}$} \\
\hline & & 3 day & 5 day & 7 day \\
\hline AN8057 (CysB) & Cysteine synthase & 16 & 32 & \\
\hline AN8065 & Role in actin filament organization & 5 & & 6 \\
\hline AN8080 & Thioredoxin peroxidase activity & 17 & 80 & 2 \\
\hline AN8204 (NdxC) & Undix hydrolase & 9 & 2 & 6 \\
\hline AN8664 & Hydrolase activity & 19 & 79 & 5 \\
\hline AN8674 & Vacuolar proton-transporting V-type ATPase & 12 & 2 & \\
\hline AN8698 & Role in actin cortical patch assembly & 8 & 41 & \\
\hline AN8870 & Expression increased in salt-adapted strains & 30 & 140 & 27 \\
\hline AN8979 (AlcA) & Alcohol dehydrogenase & 52 & & 24 \\
\hline AN9085 & Protein of unknown function & 10 & 6 & 2 \\
\hline AN9097 & Ribosomal protein & 14 & 20 & 3 \\
\hline AN9124 & Hsp90 protein binding & 18 & 9 & 10 \\
\hline AN9308 & UDP-N-acetylmuramate dehydrogenase activity & 3 & 2 & 2 \\
\hline AN9401 & Mitochondrian localization & 50 & 69 & \\
\hline AN9407 (FasA) & Fatty acid synthase & 16 & 14 & 2 \\
\hline AN9468 & Maturation of SSU-rRNA & 9 & 45 & 3 \\
\hline AN9470 (UaZ) & 5-hydroxy-isourate & 15 & 10 & 2 \\
\hline
\end{tabular}

\begin{tabular}{|c|c|c|c|c|}
\hline \multicolumn{5}{|c|}{ Shared in asexual and vegetative mycelium (32 proteins) } \\
\hline \multirow[t]{2}{*}{ Gene ID } & \multirow[t]{2}{*}{ Description } & \multicolumn{3}{|c|}{$\begin{array}{l}\text { Spectral counts found } \\
\text { in asex. mycelium }\end{array}$} \\
\hline & & 3 day & 5 day & 7 day \\
\hline AN0075 (TigA) & Disulfide isomerase & & 11 & \\
\hline AN0162 & Sequence-specific DNA binding & 2 & 5 & 2 \\
\hline AN0745 & Nucleolar protein & & 2 & 4 \\
\hline AN0943 & Mitochondrial F1F0-ATP synthase & 2 & 5 & 2 \\
\hline AN10229 & NADH dehydrogenase & & 13 & 12 \\
\hline AN11055 & Phosphatase & 4 & & 2 \\
\hline AN1195 & Hydrolase & & 2 & 2 \\
\hline AN1282 & Role in posttranslational protein targeting to membrane & & 14 & \\
\hline AN2086 & Nuclear pore complex protein & 2 & & \\
\hline AN2279 & Endoplasmic reticulum organization & 3 & & 2 \\
\hline AN2316 & Cytochrome c oxidase & & 10 & 6 \\
\hline AN2420 & U2 snRNP localization & 2 & & 10 \\
\hline AN2743 & Regulation of translation in response & & 6 & \\
\hline AN2885 & Role in sequence-specific DNA binding & & 6 & 2 \\
\hline AN3843 & Role in cristae formation & 2 & & 2 \\
\hline AN3906 & Protein of unknown function & 27 & & \\
\hline AN4080 & Role in cytoplasmic translation, polysomal ribosome & & 2 & 2 \\
\hline AN4270 & Role in actin cortical patch assembly & & 2 & \\
\hline AN4919 & Role in actin cortical patch assembly & & 3 & 3 \\
\hline AN4929 & Protein of unknown function & & 43 & \\
\hline AN5181 (NudC) & Protein involved in nuclear migration & & 11 & 2 \\
\hline AN5499 & Nuclear pore complex; Spindle-assembly checkpoint & & 12 & \\
\hline AN5606 & Proton-transporting ATPase activity & 9 & 24 & 7 \\
\hline AN5745 & Eukaryotic translation initiation factor 3 & 4 & 12 & \\
\hline AN6060 & Binding activity and role in RNA metabolic process & 5 & 4 & \\
\hline AN6077 & NADH dehydrogenase & 10 & 4 & 3 \\
\hline AN6287 & F1F0-ATPase complex subunit & 3 & 11 & 6 \\
\hline AN6591 & Essential nuclear export receptor & 3 & 2 & 2 \\
\hline AN7051 (MetG) & Cystathionine beta-lyase & 4 & & \\
\hline AN7159 & Tripeptidyl-peptidase activity & 20 & & \\
\hline AN7177 & Protein of unknown function & & 8 & \\
\hline AN8274 & DNA binding activity & & 4 & 2 \\
\hline
\end{tabular}


Supplementary Table 4.

Continued.

\begin{tabular}{|c|c|c|c|c|}
\hline \multicolumn{5}{|c|}{ Shared in sexual and vegetative mycelium (87 proteins) } \\
\hline \multirow[t]{2}{*}{ Gene ID } & \multirow[t]{2}{*}{ Description } & \multicolumn{3}{|c|}{$\begin{array}{l}\text { Spectral counts found } \\
\text { in sex. mycelium }\end{array}$} \\
\hline & & 3 day & 5 day & 7 day \\
\hline AN0057 & Tyrosine-tRNA ligase activity & & 4 & 5 \\
\hline AN0179 & Oxidoreductase & 2 & & 2 \\
\hline AN0351 (GfdA) & Glycerol-3-phosphate dehydrogenase & & 16 & \\
\hline AN0354 (GroG) & 3-deoxy-D-arabino-heptulosonate 7-phosphate synthase & 10 & & \\
\hline AN0495 & Formyltetrahydrofolate deformylase & & 11 & 3 \\
\hline AN0651 (FadA) & Heterotrimeric G protein & & 4 & 5 \\
\hline AN0665 & Involved in vesicle transport & 10 & 7 & 7 \\
\hline AN0673 & Role in actin assembly & 5 & 6 & \\
\hline AN0907 & Ribosome activity & 2 & 11 & 23 \\
\hline AN0997 & Ribosome activity & & 2 & 5 \\
\hline AN10148 (ChpA) & Cysteine- and histidine-rich-domain [CHORD]-containing protein & & 6 & 3 \\
\hline AN10182 & Translation initiation factor 3 & 8 & 7 & \\
\hline AN10278 & Cytosol, mitochondrion, nucleus localization & 5 & 6 & \\
\hline AN10282 & Nucleus localization & & 11 & 5 \\
\hline AN10418 & Protein of unknown function & 2 & 9 & \\
\hline AN10472 & Hydroxyethylthiazole kinase activity & 2 & 5 & \\
\hline AN10526 (RmtA) & Arginine methyltransferase & 2 & 3 & \\
\hline AN11058 & Intracellular localization & 7 & 7 & \\
\hline AN1150 & Role in arginine metabolism & 10 & 7 & \\
\hline AN12246 & Ribosome activity & & 2 & 9 \\
\hline AN1256 & ATPase activity & 10 & 24 & 4 \\
\hline AN1379 & Role in cysteine metabolism & 3 & 18 & \\
\hline AN1394 (AspD) & Septin & 6 & 8 & \\
\hline AN1769 & Role in cysteine metabolism & 3 & 19 & 7 \\
\hline AN2051 & Hsp90p co-chaperone & & 3 & 8 \\
\hline AN2243 & Carbamoyl-phosphate synthase & 10 & 2 & \\
\hline AN2343 & Protein of unknown function & 2 & 10 & 5 \\
\hline AN2733 & Uroporphyrinogen decarboxylase activity & 4 & 2 & \\
\hline AN2775 & Protein of unknown function & & 11 & 5 \\
\hline AN2997 & Protein of unknown function & 2 & 7 & \\
\hline AN3026 (CopA) & Alpha-COP coatamer-related protein & 7 & 6 & \\
\hline AN3456 & Cystathionine gamma-synthase & 2 & 4 & 4 \\
\hline AN3823 & Ribosome activity & 9 & 4 & \\
\hline AN3894 & Aconitate hydratase & & 10 & 7 \\
\hline AN3901 & Lactic acid dehydrogenase & & 3 & 5 \\
\hline AN4086 & Phenylalanine-tRNA ligase & 9 & 6 & \\
\hline AN4401 & Asparagine synthase & & 10 & 2 \\
\hline AN4404 & Aminopeptidase activity & & 2 & 10 \\
\hline AN4463 & Vesicle-mediated transport and clathrin coat of coated pit & 2 & 2 & \\
\hline AN4647 & Protein of unknown function & 2 & 4 & 4 \\
\hline AN4739 & Phosphoribosyl amino imidazolesuccinocarbozamide synthetase & & 5 & 8 \\
\hline AN4820 & Succinate-semialdehyde dehydrogenase & 5 & 16 & \\
\hline AN4872 & Protein of unknown function & & 94 & 5 \\
\hline AN4956 & Acetolactate synthase & & 2 & 4 \\
\hline AN4997 & Phosphatidylinositol transporter & 8 & 12 & \\
\hline AN5123 & Oxidoreductase & & 7 & 12 \\
\hline AN5130 & Coproporphyrinogen oxidase & 2 & 8 & \\
\hline AN5206 (LysB) & Homoisocitrate dehydrogenase & 9 & 10 & \\
\hline AN5534 & Glyoxylate reductase activity & & 2 & 4 \\
\hline AN5589 & Glycerol kinase & 10 & 5 & 5 \\
\hline AN5591 & Aminotransferase & 10 & 8 & 10 \\
\hline AN5731 & Chorismate synthase & 3 & 8 & \\
\hline AN5741 & Ribosome activity & & 5 & 10 \\
\hline AN5778 & Actin binding activity & & 9 & 18 \\
\hline AN5782 & Catalytic activity & & 12 & 19 \\
\hline AN5820 (MecA) & Cystathionine beta-synthase & & 13 & 11 \\
\hline AN5904 & Beta-ketoacyl-[acyl-carrier-protein] synthase & & 12 & 6 \\
\hline AN5954 & Eukaryotic translation initiation factor 3 & & 11 & 8 \\
\hline AN6338 & Aromatic-amino-acid transaminase & & 20 & 5 \\
\hline AN6354 & Ubiquitin C-terminal hydrolase & 3 & & 4 \\
\hline AN6391 (PphA) & Phosphatase & 2 & 3 & 4 \\
\hline AN6505 (RcoA) & WD40 repeat protein & 10 & 19 & 3 \\
\hline AN6541 & Ligase with a role in purine metabolism & 2 & 8 & 4 \\
\hline AN6644 (BiA) & Dethiobiotin synthetase & 7 & 6 & \\
\hline
\end{tabular}


Supplementary Table 4.

Continued.

\begin{tabular}{|l|l|r|r|r|}
\hline \multicolumn{3}{|c|}{ Shared in sexual and vegetative mycelium (87 proteins) } \\
\hline & Description & \multicolumn{2}{c|}{$\begin{array}{c}\text { Spectral counts found } \\
\text { in sex. mycelium }\end{array}$} \\
\hline & & $\mathbf{3}$ day & $\mathbf{5}$ day & $\mathbf{7}$ day \\
\hline Gene ID & Role in biosynthetic process & & 10 & 10 \\
\hline AN7010 & Cytosol localization & 14 & 10 & 11 \\
\hline AN7283 & Actin monomer binding activity & 2 & \\
\hline AN7387 (PcrA) & Pyrroline-5-carboxylate reductase & 3 & 8 & 4 \\
\hline AN7430 (HisHF) & Glutamine amidotransferase & 8 & 3 & \\
\hline AN7479 & Asparaginyl-tRNA synthetase & & 9 & 12 \\
\hline AN7587 & Protein of unknown function & 5 & 9 & \\
\hline AN7636 & Oxidoreductase & 9 & 2 & \\
\hline AN7722 & Role in arginine metabolism & & 37 & \\
\hline AN7895 (CipB) & Oxidoreductase & & 9 & \\
\hline AN8121 & 5'-phosphoribosylformyl glycinamidine synthetase & & 15 & 7 \\
\hline AN8224 & Glutamate-tRNA ligase & & 10 & 11 \\
\hline AN8406 & Menadione stress-induced & 5 & 6 \\
\hline AN8547 & Glucose-methanol-choline (GMC) oxidoreductase & 3 & 6 \\
\hline AN8790 & D-xylulokinase & & 4 & 8 \\
\hline AN8800 (SgdC) & Cysteinyl tRNA synthase & 2 & 13 & 9 \\
\hline AN8820 (CnaA) & Calmodulin-dependent protein phosphatase & 18 & 16 \\
\hline AN8824 & Ribosomal large subunit binding activity & & 8 & 5 \\
\hline AN9080 & Nucleus localization & & 5 & 6 \\
\hline AN9157 & Glutamine-tRNA ligase & & 32 & 8 \\
\hline AN9408 (FasB) & Fatty acid synthase & 23 & 11 \\
\hline AN9419 & Alanine-tRNA ligase & 10 & 5 & \\
\hline AN6906 & Ubiquitin ligase E3 & & & \\
\hline
\end{tabular}




\section{Supplementary Table 5. Proteins that were unchanged in laeA $\Delta$ vegetative mycelium}

The protein quantity of the following proteins is unchanged in a laeA $\Delta$ vegetative mycelium. The $\log _{2}$ SILAC ratio was determined for the strains laeA $\triangle$ (AGB1074) in comparison to laeA (AGB1092). The following threshholds were set. In the range of a $\log _{2}$ SILAC ratio between -0.5 and +0.5 the protein quantity is unchanged. The $\log _{2}$ SILAC ratio for the complementation strain (laeAcomp ${ }^{+}$, AGB1076) in comparison to the parental laeA strain (AGB1092) is also listed. $\varnothing=$ median of $\log _{2}$ SILAC ratios, SD = standard deviation, $\mathrm{NaN}=$ not a number. Biological replicates are numbered 1-3. Spectral counts (PSM) for three biological replicates are shown (Spectral counts were obtained by Proteome Discoverer 1.4.). The color scales represent $\log _{2}$ SILAC ratios

\section{$\begin{array}{lllllllllllllllllll}-5 & -3.25 & -1.5 & -1.3 & -1 & -0.75 & -0.5 & -0.25 & 0 & 0.25 & 0.5 & 0.75 & 1 & 1.25 & 1.5 & 3.25 & 5\end{array}$}

\begin{tabular}{|c|c|c|c|c|c|c|c|c|c|c|c|c|c|c|}
\hline \multirow[t]{2}{*}{ Gene ID } & \multirow[t]{2}{*}{ Description } & \multicolumn{3}{|c|}{ Spectral counts } & \multicolumn{3}{|c|}{ laeAs/laeA } & \multirow[t]{2}{*}{$\varnothing$} & \multirow[t]{2}{*}{ SD } & \multicolumn{3}{|c|}{ laeAcomp+/laeA } & \multirow[t]{2}{*}{$\varnothing$} & \multirow[t]{2}{*}{ SD } \\
\hline & & 1 & 2 & 3 & 1 & 2 & 3 & & & 1 & 2 & 3 & & \\
\hline \multicolumn{15}{|c|}{ Actin } \\
\hline AN0306 & Actin filament & 80 & 79 & 105 & -0.5 & 0 & -0.5 & -0.5 & 0.3 & 0.2 & -0.1 & 0.5 & 0.2 & 0.3 \\
\hline AN6542 (ActA) & Actin A & 335 & 425 & 563 & -0.4 & 0 & 0.0 & 0.0 & 0.2 & 0.2 & -0.1 & 0.5 & 0.2 & 0.3 \\
\hline AN0140 & Actin assembly & 53 & 68 & 91 & -0.3 & 0.1 & -0.1 & -0.1 & 0.2 & 0.2 & -0.1 & 0.5 & 0.2 & 0.3 \\
\hline AN2756 (SlaB) & Actin binding protein & 117 & 100 & 191 & -0.5 & 0 & -0.5 & -0.5 & 0.3 & 0 & -0.4 & 0.3 & 0.0 & 0.4 \\
\hline AN2862 & Cytoskeleton protein & 69 & 55 & 84 & -0.5 & -0.1 & -0.5 & -0.5 & 0.2 & 0.5 & 0 & 0.4 & 0.4 & 0.3 \\
\hline \multicolumn{15}{|c|}{ Cellular processes } \\
\hline AN3720 & Coat protein complex II & 21 & 43 & 56 & -0.5 & 0.3 & 0.5 & 0.3 & 0.5 & -0.1 & 0.2 & 0.4 & 0.2 & 0.2 \\
\hline AN0117 & Response to oxidative stress & & 6 & 26 & $\mathrm{NaN}$ & -0.5 & -0.5 & -0.5 & 0.3 & $\mathrm{NaN}$ & 0 & -0.5 & -0.3 & 0.3 \\
\hline AN1757 (SsfA) & Proteasome subunit & 13 & 20 & 29 & -0.5 & 0.4 & -0.2 & -0.2 & 0.5 & 0.4 & 0.1 & 0.5 & 0.4 & 0.2 \\
\hline AN0084 & GTPase-activating protein & 118 & 135 & 164 & -0.2 & 0.2 & -0.5 & -0.2 & 0.4 & 0.4 & 0.1 & 0.3 & 0.3 & 0.2 \\
\hline AN0999 (capA) & Adenylate cyclase & 13 & 32 & 54 & -0.4 & 0.1 & -0.5 & -0.4 & 0.3 & 0.5 & 0.1 & 0.3 & 0.3 & 0.2 \\
\hline \multicolumn{15}{|c|}{ Metabolic process } \\
\hline AN8041 (GpdA) & $\begin{array}{l}\begin{array}{l}\text { Glyceraldehyde-3-phosphate } \\
\text { dehydrogenase }\end{array} \\
\end{array}$ & 1104 & 971 & 1794 & 0 & 0 & -0.3 & 0.0 & 0.2 & -0.3 & -0.1 & 0.3 & -0.1 & 0.3 \\
\hline AN0932 (GIrA) & Oxidoreductase & 15 & 42 & 52 & -0.4 & -0.1 & -0.4 & -0.4 & 0.2 & 0.3 & 0.1 & 0.4 & 0.3 & 0.1 \\
\hline AN10526 (RmtA) & Arginine methyltransferase & 4 & 15 & $\mathrm{NaN}$ & $\mathrm{NaN}$ & 0 & 0.2 & 0.1 & 0.1 & 0 & 0 & 0.2 & 0.0 & 0.1 \\
\hline AN1430 & Oxidoreductase & & 3 & 14 & $\mathrm{NaN}$ & 0.2 & -0.5 & -0.2 & 0.4 & $\mathrm{NaN}$ & 0 & 0.4 & 0.2 & 0.2 \\
\hline AN7451 & NAD-glutamate dehydrogenase & 244 & 229 & & -0.4 & 0 & $\mathrm{NaN}$ & -0.2 & 0.2 & 0.2 & -0.4 & $\mathrm{NaN}$ & -0.1 & 0.3 \\
\hline AN2999 (IdpA) & Isocitrate dehydrogenase & 99 & 69 & 205 & -0.2 & 0.5 & -0.2 & -0.2 & 0.4 & -0.1 & -0.4 & 0.2 & -0.1 & 0.3 \\
\hline AN8012 & Farnesyl-pyrophosphate synthase & 28 & 41 & 80 & -0.4 & -0.2 & -0.3 & -0.3 & 0.1 & 0.4 & -0.2 & 0.4 & 0.4 & 0.3 \\
\hline AN7632 & Dehydrogenase & 93 & 83 & 99 & -0.4 & 0.4 & 0.2 & 0.2 & 0.4 & 0.5 & -0.3 & 0.2 & 0.2 & 0.4 \\
\hline AN1342 & Alanine-glyoxylate transaminase & 42 & 47 & 27 & -0.3 & 0.5 & -0.5 & -0.3 & 0.5 & 0.1 & -0.3 & 0.3 & 0.1 & 0.3 \\
\hline AN0254 & Catalytic activity & & 29 & 4 & $\mathrm{NaN}$ & -0.5 & -0.4 & -0.5 & 0.3 & $\mathrm{NaN}$ & -0.5 & -0.5 & -0.5 & 0.3 \\
\hline \multicolumn{15}{|c|}{ Catabolic process } \\
\hline AN2903 (PepE) & Aspartic protease & 167 & 184 & 164 & -0.5 & 0.1 & 0.0 & 0.0 & 0.3 & 0.1 & -0.5 & 0.6 & 0.1 & 0.5 \\
\hline AN5442 (CpyA) & Carboxypeptidase $\mathrm{Y}$ & 16 & 39 & 94 & -0.5 & 0 & 0.1 & 0.0 & 0.3 & 0.2 & -0.3 & -0.5 & -0.3 & 0.4 \\
\hline AN5810 (PepP) & Prolidase & 11 & 67 & 67 & -0.3 & 0.4 & 0.5 & 0.4 & 0.4 & 0.3 & 0.4 & 0.3 & 0.3 & 0.1 \\
\hline \multicolumn{15}{|c|}{ Vacuole function } \\
\hline AN1195 & V-ATP synthase subunit C & 28 & 22 & 28 & -0.3 & 0.3 & -0.2 & -0.2 & 0.3 & 0.5 & -0.1 & 0.4 & 0.4 & 0.3 \\
\hline AN10563 (Pho8) & Vacuolar alkaline phosphatase & 38 & 10 & 12 & -0.5 & 0.5 & 0.5 & 0.5 & 0.6 & 0.5 & -0.1 & 0.2 & 0.2 & 0.3 \\
\hline
\end{tabular}


Supplementary Table 5, continued. Protein quantity of the following proteins was unchanged or unquantifiable in lae $A \Delta$ vegetative mycelium.

The $\log _{2}$ SILAC ratio was determined for the strains laeA $(A G B 1074$ ) in comparison to laeA (AGB1092). Additionally, the $\log _{2}$ ratio for the complementation strain (laeAcomp ${ }^{+}$, AGB1076) in comparison to the parental laeA strain (AGB1092) is listed. The range between these two ratios are unchanged or unquantifiable. Proteins without a $\log _{2}$ SILAC ratio are listed (marked with NaN). These proteins are unquantifiable. It cannot be ruled out that protein quantities of some of the following identified proteins are quantifiable.

$\varnothing=$ median of $\log _{2}$ SILAC ratios, SD = standard deviation, $\mathrm{NaN}=$ not a number. Biological replicates are numbered 1-3. Spectral counts (PSM) for three biological replicates are shown(Spectral counts were obtained by Proteome Discoverer 1.4.). The color scales represent $\log _{2}$ SILAC ratios.

\section{$\begin{array}{lllllllllllllllll}-5 & -3.25 & -1.5 & -1.25 & -1 & -0.75 & -0.5 & -0.25 & 0 & 0.25 & 0.5 & 0.75 & 1 & 1.25 & 1.5 & 3.25 & 5\end{array}$}

\begin{tabular}{|c|c|c|c|c|c|c|c|c|c|c|c|c|c|c|}
\hline \multirow[t]{2}{*}{ Gene ID } & \multirow[t]{2}{*}{ Description } & \multicolumn{3}{|c|}{$\begin{array}{l}\text { Spectral } \\
\text { counts }\end{array}$} & \multicolumn{3}{|c|}{ IaeAL/laeA } & \multirow[t]{2}{*}{$\varnothing$} & \multirow[t]{2}{*}{ SD } & \multicolumn{3}{|c|}{ laeAcomp+/laeA } & \multirow[t]{2}{*}{$\varnothing$} & \multirow[t]{2}{*}{ SD } \\
\hline & & 1 & 2 & 3 & 1 & 2 & 3 & & & 1 & 2 & 3 & & \\
\hline AN6700 & ATPase binding activity & 77 & 237 & 638 & -4.2 & -4.4 & -1.5 & -2.9 & 1.7 & -2.4 & 0.5 & -1.6 & -1.6 & 1.5 \\
\hline AN5028 (PpoC) & Fatty acid oxygenase & 124 & 99 & 86 & 1.4 & -3.3 & -1.8 & -2.6 & 2.4 & 1.2 & -0.2 & 3.9 & 1.2 & 2.1 \\
\hline AN8777 (AmdS) & Acetamidase & 17 & 44 & 51 & -2.3 & -2.7 & -1.7 & -2.2 & 0.5 & -0.2 & -1.0 & 1.8 & -0.2 & 1.5 \\
\hline AN3017 & Epoxide hydrolase & 83 & 73 & 88 & -3.1 & -2.2 & -1.5 & -2.2 & 0.8 & -1.8 & -1.1 & 1.5 & -1.1 & 1.8 \\
\hline AN0870 & Small molecule transport & 74 & 33 & 129 & -2.1 & -0.3 & -2.8 & -2.1 & 1.3 & -0.8 & -0.2 & -1.3 & -0.8 & 0.6 \\
\hline AN0354 (AroG) & DAHP synthase & 78 & 91 & 124 & -2.6 & -1.6 & -1.7 & -2.1 & 0.5 & -1.7 & -0.8 & -0.4 & -0.8 & 0.7 \\
\hline AN1913 & Lysyl-tRNA synthetase & 62 & 95 & 139 & -2.6 & -1.4 & -2.0 & -2.0 & 0.6 & -1.1 & -0.4 & -0.7 & -0.7 & 0.3 \\
\hline AN10745 & Glycine hydroxymethyltransferase & 36 & 90 & 90 & -2.0 & -0.7 & -2.5 & -2.0 & 0.9 & -0.8 & -0.9 & -1.7 & -0.9 & 0.5 \\
\hline AN8770 & Acetylglutamate kinase & 66 & 89 & 198 & -1.6 & -0.4 & -3.6 & -2.0 & 1.6 & -1.1 & -0.3 & -2.3 & -1.1 & 1.0 \\
\hline AN1990 (LysD) & Homocitrate synthase & 48 & 123 & 191 & -4.1 & -2.0 & -1.3 & -2.0 & 1.5 & -2.4 & -0.2 & -1.5 & -1.5 & 1.1 \\
\hline AN1306 & Gelsolin & 17 & 19 & 19 & -3.4 & -2.0 & -1.1 & -2.0 & 1.2 & -1.3 & -1.1 & -0.9 & -1.1 & 0.2 \\
\hline AN6227 & Hercynylcysteine sulfoxide lyase & 77 & 110 & 69 & -3.0 & -1.8 & -2.1 & -1.9 & 0.7 & -1.7 & -0.8 & 3.2 & -0.8 & 2.6 \\
\hline AN10298 & 3-phosphoserine aminotransferase & 96 & 108 & 181 & -2.3 & -1.1 & -1.9 & -1.9 & 0.6 & -1.5 & -0.6 & -1.1 & -1.1 & 0.5 \\
\hline AN11227 (HscA) & Heat shock protein & 165 & 233 & 510 & -1.9 & -0.7 & -1.9 & -1.9 & 0.7 & -0.5 & -0.1 & -1.7 & -0.5 & 0.8 \\
\hline AN2295 & Succinate-CoA ligase & 36 & 50 & 93 & -1.8 & -0.4 & -2.0 & -1.8 & 0.9 & -0.3 & -0.2 & -1.7 & -0.3 & 0.9 \\
\hline AN0860 & Protein of unknown function & 30 & 21 & 29 & -2.3 & -1.3 & -1.8 & -1.8 & 0.5 & 1.3 & 0.0 & 1.7 & 1.3 & 0.9 \\
\hline AN2272 & Kinase & 57 & 110 & 170 & -1.7 & -0.8 & -3.0 & -1.7 & 1.1 & -0.5 & -0.3 & -1.6 & -0.5 & 0.7 \\
\hline AN5601 & Saccharopine dehydrogenase & 13 & 57 & 132 & -2.7 & -1.4 & -2.1 & -1.7 & 0.6 & -1.2 & -0.4 & -1.2 & -1.2 & 0.5 \\
\hline AN4409 (ArgB) & Ornithine carbamoyltransferase & 52 & 206 & 282 & -2.3 & -1.0 & -2.5 & -1.7 & 0.8 & -1.9 & -0.7 & -0.9 & -0.9 & 0.6 \\
\hline AN7625 & Myo-inositol-1-phosphate synthase & 104 & 248 & 668 & -1.8 & -0.4 & -3.1 & -1.7 & 1.3 & -1.5 & -0.3 & -2.8 & -1.5 & 1.3 \\
\hline AN0443 & Alcohol dehydrogenase & 59 & 111 & 178 & -2.5 & -1.1 & -1.7 & -1.7 & 0.7 & -0.6 & -5.6 & -1.9 & -1.9 & 2.6 \\
\hline AN1523 & F1F0-ATPase complex subunit & 250 & 419 & 577 & -1.6 & -0.4 & -1.6 & -1.6 & 0.7 & -0.4 & -0.5 & -1.6 & -0.5 & 0.7 \\
\hline AN3695 & Anthranilate synthase & 16 & 39 & 63 & -2.3 & -1.4 & -1.8 & -1.6 & 0.4 & -1.0 & -0.5 & -0.8 & -0.8 & 0.3 \\
\hline AN2436 (AcIB) & ATP citrate synthase & 407 & 500 & 1057 & -2.0 & -0.7 & -1.6 & -1.6 & 0.7 & 0.8 & 0.6 & -0.8 & 0.6 & 0.9 \\
\hline AN3059 (PgmA) & Phosphoglycerate mutase & 153 & 235 & 503 & -1.6 & -0.3 & -1.5 & -1.5 & 0.7 & -0.5 & -0.1 & -1.6 & -0.5 & 0.8 \\
\hline AN5793 & $20 S$ proteasome beta-type subunit & 9 & 38 & 36 & -1.9 & -0.9 & -2.1 & -1.5 & 0.7 & -0.2 & 0.0 & -1.0 & -0.2 & 0.5 \\
\hline AN0240 (PppA) & Pentose-phosphate & 450 & 621 & 820 & -1.5 & -0.4 & -2.2 & -1.5 & 0.9 & -0.2 & -2.4 & -1.5 & -1.5 & 1.1 \\
\hline AN2164 & Chromatid cohesion & 17 & 29 & 33 & -1.9 & -0.5 & -1.5 & -1.5 & 0.7 & 0.5 & 0.2 & -0.7 & 0.2 & 0.6 \\
\hline
\end{tabular}

Supplementary Table 5, is continued from page 185-198. 


\begin{tabular}{|c|c|c|c|c|c|c|c|c|c|c|c|c|c|c|}
\hline \multirow[t]{2}{*}{ Gene ID } & \multirow[t]{2}{*}{ Description } & \multicolumn{3}{|c|}{ PSM } & \multicolumn{3}{|c|}{ laeAd/laeA } & \multirow[t]{2}{*}{$\varnothing$} & \multirow[t]{2}{*}{ SD } & \multicolumn{3}{|c|}{ laeAcomp+/laeA } & \multirow[t]{2}{*}{$\varnothing$} & \multirow[t]{2}{*}{ SD } \\
\hline & & 1 & 2 & 3 & 1 & 2 & 3 & & & 1 & 2 & 3 & & \\
\hline AN6048 & Aspartate transaminase & 169 & 350 & 399 & -2.2 & -0.9 & -2.0 & -1.5 & 0.7 & -0.9 & -1.2 & -1.5 & -1.2 & 0.3 \\
\hline AN1177 & Coatomer subunit beta & 34 & 43 & 102 & -1.5 & -0.5 & -2.1 & -1.5 & 0.8 & -0.1 & -0.5 & -1.4 & -0.5 & 0.7 \\
\hline AN10675 & Protein of unknown function & 39 & 40 & 75 & -1.5 & -0.6 & -1.6 & -1.5 & 0.6 & 0.0 & -0.4 & -0.7 & -0.4 & 0.4 \\
\hline AN10278 & Electron transfer flavoprotein & 8 & 38 & 59 & -1.5 & -0.2 & -1.5 & -1.5 & 0.7 & -0.1 & -0.3 & -1.5 & -0.3 & 0.8 \\
\hline AN2126 (KapJ) & Importin & 35 & 19 & 42 & -1.4 & 0.6 & -2.0 & -1.4 & 1.4 & 0.2 & 0.1 & -1.1 & 0.1 & 0.8 \\
\hline AN2286 (AlcC) & Alcohol dehydrogenase III & 259 & 384 & 437 & -1.4 & 0.0 & -2.1 & -1.4 & 1.1 & -0.3 & 0.0 & -2.1 & -0.3 & 1.1 \\
\hline AN8277 (CysD) & Methionin-Synthase & 157 & 262 & 210 & -1.6 & -0.5 & -2.3 & -1.4 & 0.9 & 0.1 & -0.5 & -1.3 & -0.5 & 0.7 \\
\hline AN6708 (PhdA) & Acetyltransferase & 87 & 108 & 470 & -1.8 & -0.4 & -2.5 & -1.4 & 1.1 & -0.5 & -0.3 & -2.1 & -0.5 & 1.0 \\
\hline AN1263 & Adenosylhomocysteinase & 195 & 433 & 447 & -1.4 & -0.2 & -1.4 & -1.4 & 0.7 & -0.4 & -0.3 & -1.7 & -0.4 & 0.8 \\
\hline AN9408 (FasB) & Fatty acid synthase & 81 & 183 & 578 & -2.1 & -0.3 & -2.5 & -1.4 & 1.2 & 0.0 & 0.8 & -1.5 & 0.0 & 1.2 \\
\hline AN1964 & $40 \mathrm{~S}$ ribosomal protein $\mathrm{S} 6$ & 24 & 21 & 143 & -1.4 & -0.1 & -1.4 & -1.4 & 0.8 & -0.3 & -0.2 & -2.1 & -0.3 & 1.1 \\
\hline AN0688 & Transketolase & 558 & 633 & 859 & -1.6 & -0.6 & -1.3 & -1.3 & 0.5 & 0.6 & 2.4 & -1.0 & 0.6 & 1.7 \\
\hline AN5141 & Protein of unknown function & 6 & 12 & 80 & -1.1 & -0.3 & -2.3 & -1.3 & 1.0 & -0.4 & -0.3 & -1.5 & -0.4 & 0.7 \\
\hline AN6168 (MaeA) & Malate dehydrogenase & 12 & 35 & 40 & -3.3 & -1.6 & -1.1 & -1.3 & 1.2 & -2.4 & -0.6 & -0.6 & -0.6 & 1.0 \\
\hline AN6010 (SgdE) & Heat shock protein & 305 & 438 & 861 & -2.4 & -1.0 & -1.7 & -1.3 & 0.7 & -1.1 & -0.6 & -2.3 & -1.1 & 0.8 \\
\hline AN2896 & Catalytic activity & 10 & 8 & 16 & -1.4 & 0.2 & -1.3 & -1.3 & 0.9 & -0.5 & -0.4 & -1.4 & -0.5 & 0.6 \\
\hline AN10148 (CphA) & CHORD-containing protein & 7 & 5 & 17 & -1.7 & -1.3 & -1.1 & -1.3 & 0.3 & 0.1 & -0.8 & 1.1 & 0.1 & 0.9 \\
\hline AN1013 & 60 S ribosomal protein L5 & 72 & 56 & 313 & -1.3 & 0.2 & -1.8 & -1.3 & 1.0 & -0.4 & -0.2 & -1.3 & -0.4 & 0.6 \\
\hline AN8722 (Sub2) & RNA helicase & 33 & 42 & 66 & -1.2 & -0.6 & -2.0 & -1.3 & 0.7 & -0.4 & -0.1 & -1.4 & -0.4 & 0.7 \\
\hline AN10030 & Alkaline serine protease & 27 & 114 & 150 & -1.3 & -0.4 & -1.9 & -1.3 & 0.8 & -0.2 & -0.6 & 0.1 & -0.2 & 0.3 \\
\hline AN3466 (KgdB) & Succinyl transferase & 47 & 117 & 353 & -1.3 & 0.1 & -1.4 & -1.3 & 0.8 & -0.3 & -0.4 & -2.1 & -0.4 & 1.0 \\
\hline AN2213 & Proteasome & 39 & 47 & 80 & -1.3 & -0.4 & -1.7 & -1.3 & 0.7 & 0.3 & -0.5 & -1.2 & -0.5 & 0.7 \\
\hline AN5210 (PkiA) & Pyruvate kinase & 207 & 258 & 440 & -1.7 & -0.5 & -2.1 & -1.3 & 0.8 & -0.4 & -0.4 & -2.3 & -0.4 & 1.1 \\
\hline AN5975 & Dehydrogenase & 459 & 443 & 359 & -1.3 & -0.5 & -2.1 & -1.3 & 0.8 & 1.0 & 0.4 & 1.7 & 1.0 & 0.7 \\
\hline AN1256 & Protein of unknown function & 52 & 76 & 130 & -1.3 & -0.6 & -1.3 & -1.3 & 0.4 & -0.2 & -0.2 & -1.4 & -0.2 & 0.7 \\
\hline AN3112 (UgmA) & UDP-galactopyranose mutase & 91 & 98 & 182 & -1.8 & -0.4 & -1.3 & -1.3 & 0.7 & 0.4 & 0.2 & -1.9 & 0.2 & 1.3 \\
\hline AN8866 & Phosphoglycerate dehydrogenase & 110 & 141 & 150 & -1.7 & -0.8 & -1.7 & -1.3 & 0.5 & -0.8 & -0.1 & -1.4 & -0.8 & 0.6 \\
\hline AN3829 & Dehydrogenase & 33 & 60 & 219 & -1.0 & 0.4 & -2.9 & -1.3 & 1.6 & -0.8 & -1.1 & -3.8 & -1.1 & 1.6 \\
\hline AN5884 & Orotate phosphorik & 28 & 33 & 49 & -1.5 & -0.7 & -1.8 & -1.2 & 0.6 & -0.3 & -0.3 & -1.9 & -0.3 & 0.9 \\
\hline AN4163 (CpcB) & Protein with seven WD repeats & 84 & 90 & 287 & -1.0 & -0.2 & -2.3 & -1.2 & 1.1 & 0.0 & -0.3 & -2.0 & -0.3 & 1.1 \\
\hline AN3906 & Protein of unknown function & 51 & 89 & 182 & -1.4 & 0.2 & -2.7 & -1.2 & 1.4 & 0.8 & 0.2 & -1.3 & 0.2 & 1.0 \\
\hline AN4380 & Ribonucleotide reductase & 16 & 35 & 45 & -2.0 & -0.8 & -1.6 & -1.2 & 0.6 & 0.7 & 0.5 & -1.5 & 0.5 & 1.2 \\
\hline AN6058 & Protein of unknown function & 51 & 69 & 102 & -2.6 & -1.4 & -1.0 & -1.2 & 0.8 & -1.6 & -1.2 & -2.5 & -1.6 & 0.7 \\
\hline AN0912 & Dehydrogenase & 32 & 58 & 115 & -1.9 & -0.4 & -1.2 & -1.2 & 0.7 & -0.5 & 0.3 & -1.4 & -0.5 & 0.8 \\
\hline AN1638 & Serine-type peptidase & 280 & 378 & 473 & -1.2 & 0.0 & -1.3 & -1.2 & 0.7 & 0.3 & -0.1 & -0.9 & -0.1 & 0.6 \\
\hline AN0242 & Hydrolase & 56 & 70 & 222 & -1.3 & -0.3 & -1.2 & -1.2 & 0.5 & 0.0 & -3.5 & -1.6 & -1.6 & 1.8 \\
\hline AN0840 & Alpha-isopropylmalate synthase & 58 & 107 & 180 & -2.5 & -1.2 & -0.3 & -1.2 & 1.1 & -1.2 & -0.4 & -1.5 & -1.2 & 0.6 \\
\hline AN4462 (PycA) & Pyruvate carboxylase & 297 & 369 & 1671 & -1.6 & -0.5 & -1.8 & -1.2 & 0.7 & -0.2 & -0.2 & -1.0 & -0.2 & 0.5 \\
\hline AN2909 & Arsenite-transporting ATPase & 6 & 13 & 37 & -1.2 & -0.3 & -1.6 & -1.2 & 0.7 & 0.5 & 0.3 & -1.2 & 0.3 & 0.9 \\
\hline AN4401 & Asparagine synthase & 14 & 53 & 138 & -2.3 & -1.1 & -1.3 & -1.2 & 0.6 & -1.6 & -0.3 & -1.7 & -1.6 & 0.8 \\
\hline AN7010 & Catalytic activity & 54 & 65 & 48 & -3.3 & -1.9 & -0.5 & -1.2 & 1.4 & -2.6 & -0.4 & 2.3 & -0.4 & 2.5 \\
\hline AN1282 & Protein of unknown function & 41 & 45 & 114 & -1.8 & -0.5 & -1.2 & -1.2 & 0.7 & -0.1 & -0.2 & -1.1 & -0.2 & 0.6 \\
\hline AN4259 & 43S preinitiation complex & 18 & 29 & 107 & -1.8 & -0.6 & -1.7 & -1.2 & 0.7 & -0.6 & -0.6 & -1.9 & -0.6 & 0.7 \\
\hline AN1401 (KapK) & Exportin 1 & 32 & 50 & 117 & -1.2 & -0.2 & -1.4 & -1.2 & 0.6 & 0.3 & 0.0 & -1.0 & 0.0 & 0.7 \\
\hline AN5744 & 14-3-3-like protein & 340 & 443 & 689 & -1.2 & -0.1 & -2.2 & -1.2 & 1.0 & 0.2 & -0.3 & -1.3 & -0.3 & 0.8 \\
\hline AN10710 & Phosphomannomutase & 39 & 62 & 79 & -1.2 & -0.3 & -1.5 & -1.2 & 0.6 & 0.2 & 0.2 & -1.6 & 0.2 & 1.0 \\
\hline AN5206 (LysB) & Homoisocitrate dehydrogenase & 37 & 74 & 117 & -2.2 & -0.6 & -1.7 & -1.2 & 0.8 & -1.0 & -0.5 & -2.7 & -1.0 & 1.2 \\
\hline AN12465 & Dihydrolipoamide dehydrogenase & 113 & 241 & 358 & -1.2 & 0.0 & -1.8 & -1.2 & 0.9 & -0.8 & -0.8 & -2.1 & -0.8 & 0.7 \\
\hline AN6391 (PphA) & Protein phosphatase & 23 & 27 & 56 & -1.7 & -0.3 & -2.0 & -1.1 & 1.0 & 0.3 & 0.0 & -1.2 & 0.0 & 0.8 \\
\hline AN8269 (Hsp90) & Heat shock protein & 625 & 758 & 1431 & -1.6 & -0.4 & -1.9 & -1.1 & 0.8 & 0.1 & -0.1 & -1.5 & -0.1 & 0.8 \\
\hline AN2914 & Argininosuccinate lyase & 35 & 103 & 151 & -2.1 & -1.1 & -1.1 & -1.1 & 0.5 & -1.3 & -0.4 & -1.3 & -1.3 & 0.5 \\
\hline AN10266 & Ubiquitin-activating enzyme E1 & 111 & 245 & 299 & -1.6 & -0.5 & -1.1 & -1.1 & 0.6 & 0.3 & -0.2 & -0.8 & -0.2 & 0.6 \\
\hline AN1923 & Alanine transaminase & 157 & 157 & 223 & -1.4 & -0.4 & -1.1 & -1.1 & 0.5 & -1.6 & -1.2 & -2.1 & -1.6 & 0.5 \\
\hline AN0359 (SgdA) & Translation initiation factor 3 (elF3) & 4 & 13 & 217 & -2.5 & 0.2 & 0.5 & -1.1 & 1.6 & -0.6 & 2.5 & -1.8 & -0.6 & 2.2 \\
\hline AN4085 & Serine threonine phosphatase & 42 & 62 & 90 & -1.3 & -0.3 & -2.0 & -1.1 & 0.8 & 0.5 & 0.0 & -1.1 & 0.0 & 0.8 \\
\hline AN6639 (McdB) & 2-methylcitrate dehydratase & 121 & 163 & 220 & -2.0 & -0.6 & -1.6 & -1.1 & 0.7 & -0.3 & -0.9 & -1.0 & -0.9 & 0.4 \\
\hline AN0753 & Protein of unknown function & 16 & 58 & 231 & -1.1 & 0.2 & -1.6 & -1.1 & 1.0 & 2.4 & 1.3 & -4.0 & 1.3 & 3.4 \\
\hline AN3236 & Methyltransferase & 13 & 20 & 14 & -2.6 & -1.1 & 5.0 & -1.1 & 4.0 & -2.4 & -0.8 & 1.9 & -0.8 & 2.2 \\
\hline AN1274 & Oxidoreductase & 11 & 41 & 20 & -1.1 & -0.2 & -1.4 & -1.1 & 0.6 & 0.4 & 0.1 & -1.1 & 0.1 & 0.8 \\
\hline AN1911 & Guanyltransferase & 44 & 42 & 81 & -1.1 & 0.2 & -1.6 & -1.1 & 0.9 & 0.6 & 0.2 & -1.3 & 0.2 & 1.0 \\
\hline AN4862 (RanGAP) & Ran GTPase activating protein & 10 & 29 & 104 & -1.2 & 0.2 & -2.3 & -1.1 & 1.2 & 0.3 & 0.2 & -1.9 & 0.2 & 1.3 \\
\hline AN11045 & D-lactate dehydrogenase & 6 & 8 & 48 & -1.0 & -0.5 & -1.8 & -1.0 & 0.7 & -0.7 & -0.4 & -2.3 & -0.7 & 1.0 \\
\hline AN3413 & Ribosomal protein S2 & 76 & 55 & 252 & -1.0 & -0.1 & -1.8 & -1.0 & 0.9 & -0.3 & -0.3 & -2.0 & -0.3 & 1.0 \\
\hline AN6346 & Dihydroxy-acid dehydratase & 23 & 61 & 6 & -1.6 & -0.2 & -1.9 & -1.0 & 0.9 & -0.8 & -0.2 & -2.2 & -0.8 & 1.0 \\
\hline
\end{tabular}




\begin{tabular}{|c|c|c|c|c|c|c|c|c|c|c|c|c|c|c|}
\hline \multirow[t]{2}{*}{ Gene ID } & \multirow[t]{2}{*}{ Description } & \multicolumn{3}{|c|}{ PSM } & \multicolumn{3}{|c|}{ IaeA $A$ /aeA } & \multirow[t]{2}{*}{$\varnothing$} & \multirow[t]{2}{*}{ SD } & \multicolumn{3}{|c|}{ laeAcomp+/laeA } & $\varnothing$ & SD \\
\hline & & 1 & 2 & 3 & 1 & 2 & 3 & & & 1 & 2 & 3 & & \\
\hline AN2875 (FbaA) & Fructose-bisphosphate aldolase & 323 & 507 & 596 & -1.0 & -0.1 & -1.4 & -1.0 & 0.7 & 0.2 & 0.0 & -1.5 & 0.0 & 0.9 \\
\hline AN7169 (FhbA) & NirA-dependent flavohemoprotein & 170 & 252 & 315 & -1.1 & -0.1 & -1.9 & -1.0 & 0.9 & 0.4 & -0.2 & -2.0 & -0.2 & 1.2 \\
\hline AN5989 & Epimerase/dehydratase & 459 & 45 & 41 & -1.3 & -1.9 & -0.2 & -1.0 & 0.8 & 1.0 & -0.9 & 0.4 & 0.4 & 1.0 \\
\hline AN2210 & ABC-transporter & 58 & 82 & 20 & -2.2 & -1.0 & -0.4 & -1.0 & 0.9 & -0.7 & 0.1 & -1.6 & -0.7 & 0.8 \\
\hline AN6202 (Rpl3) & Ribosomal protein L3 & 18 & 32 & 325 & -1.2 & -0.1 & -1.9 & -1.0 & 0.9 & -0.6 & -0.2 & -2.1 & -0.6 & 1.0 \\
\hline AN2133 & Actin capping protein & 45 & 18 & 23 & -1.0 & -0.4 & -1.3 & -1.0 & 0.5 & 0.6 & -0.3 & 0.7 & 0.6 & 0.5 \\
\hline AN2743 & Translation initiation factor 3 & 9 & 19 & 158 & -1.0 & 0.1 & -1.9 & -1.0 & 1.0 & -0.5 & -0.3 & -2.0 & -0.5 & 0.9 \\
\hline AN5747 & $26 \mathrm{~S}$ protease subunit & 12 & 31 & 63 & -0.9 & -0.7 & -1.3 & -1.0 & 0.3 & 0.3 & -0.5 & -1.2 & -0.5 & 0.7 \\
\hline AN2932 & Eukaryotic initiation factor $4 \mathrm{~A}$ & 101 & 245 & 438 & -1.5 & -0.7 & -1.0 & -1.0 & 0.4 & -0.3 & -0.2 & -1.5 & -0.3 & 0.7 \\
\hline AN7430 & Glutamine amidotransferase & 17 & 47 & 78 & -2.3 & -1.9 & -0.1 & -1.0 & 1.2 & -1.2 & -0.7 & -1.4 & -1.2 & 0.4 \\
\hline AN4464 & Bifunctional purine biosynthesis & 146 & 148 & 338 & -1.5 & -0.6 & -1.4 & -1.0 & 0.5 & 0.2 & -0.1 & -1.5 & -0.1 & 0.9 \\
\hline AN1810 (OtaA) & Ornithine transaminase & 293 & 427 & 781 & -1.8 & -1.0 & 0.7 & -1.0 & 1.3 & -0.9 & 0.1 & -2.3 & -0.9 & 1.2 \\
\hline AN6547 & Proteasome subunit & 50 & 47 & 51 & -0.9 & 0.0 & -1.9 & -1.0 & 1.0 & 0.2 & -0.1 & -1.0 & -0.1 & 0.6 \\
\hline AN5746 & Phosphopyruvate hydratase & 20 & 832 & 963 & -1.0 & -0.2 & -1.7 & -1.0 & 0.7 & 0.1 & -0.3 & -1.6 & -0.3 & 0.9 \\
\hline AN10079 (UreB) & Urease & 81 & 57 & 51 & -1.4 & -0.1 & -1.0 & -1.0 & 0.7 & 1.5 & 0.4 & -0.8 & 0.4 & 1.2 \\
\hline AN12237 (AbpA) & Actin-binding protein & 62 & 52 & 62 & -0.9 & 0.3 & -1.8 & -0.9 & 1.1 & 0.8 & 0.0 & -1.1 & 0.0 & 0.9 \\
\hline AN4470 & Regulation of translational fidelity & 24 & 35 & 73 & -1.4 & -0.4 & -1.5 & -0.9 & 0.6 & -0.3 & -0.3 & -1.7 & -0.3 & 0.8 \\
\hline AN4769 & Sulfurylase & 108 & 263 & 376 & -1.2 & 0.0 & -1.9 & -0.9 & 1.0 & 0.4 & -0.2 & -2.4 & -0.2 & 1.5 \\
\hline AN0075 (TigA) & Disulfide isomerase & 19 & 24 & 33 & -0.9 & 0.1 & -1.6 & -0.9 & 0.9 & 1.0 & 0.6 & -0.9 & 0.6 & 1.0 \\
\hline AN10279 & elF4G binding & 28 & 27 & 59 & -0.9 & 0.0 & -1.4 & -0.9 & 0.7 & -0.2 & -0.3 & -1.8 & -0.3 & 0.9 \\
\hline AN8824 & Translation initiation factor (elF-6) & 43 & 40 & 29 & -2.0 & -0.8 & -1.1 & -0.9 & 0.6 & -0.3 & -0.8 & -0.8 & -0.8 & 0.3 \\
\hline AN2930 & Protein of unknown function & 4 & 23 & 20 & -1.3 & 0.3 & -0.9 & -0.9 & 0.8 & 0.2 & 0.1 & -1.2 & 0.1 & 0.8 \\
\hline AN2068 & RNA binding effector protein & 52 & 77 & 184 & -1.1 & -0.6 & -0.9 & -0.9 & 0.3 & 0.0 & -0.4 & -1.6 & -0.4 & 0.8 \\
\hline AN0554 (AldA) & Aldehyde dehydrogenase & 877 & 828 & 506 & -2.0 & -0.9 & 0.8 & -0.9 & 1.4 & -1.5 & -0.9 & 2.1 & -0.9 & 1.9 \\
\hline AN4869 & 20S proteasome component & 30 & 36 & 48 & -1.2 & 0.1 & -1.9 & -0.9 & 1.0 & 0.0 & 0.2 & -1.1 & 0.0 & 0.7 \\
\hline AN8182 (AspC) & Septin & 139 & 160 & 252 & -0.8 & 0.1 & -1.8 & -0.9 & 0.9 & 1.1 & 0.4 & -1.1 & 0.4 & 1.1 \\
\hline AN5162 (PdhB) & Pyruvate dehydrogenase & 36 & 70 & 214 & -2.0 & -0.2 & -1.5 & -0.9 & 0.9 & -0.5 & -0.4 & -2.1 & -0.5 & 1.0 \\
\hline AN10527 & Trimethyllysine dioxygenase & 9 & 8 & 27 & -1.6 & -0.2 & -0.8 & -0.8 & 0.7 & -0.7 & -1.2 & -2.1 & -1.2 & 0.7 \\
\hline AN6267 & Regulation of G0 to G1 transition & 20 & 5 & 14 & -1.3 & -0.2 & -1.5 & -0.8 & 0.7 & 0.7 & 0.1 & -0.7 & 0.1 & 0.7 \\
\hline AN10222 & Glucose-6-phosphate 1-epimerase & 57 & 52 & 59 & -1.8 & -0.7 & -0.8 & -0.8 & 0.6 & -0.3 & 0.0 & -0.6 & -0.3 & 0.3 \\
\hline AN9403 & Pyruvate dehydrogenase & 75 & 57 & 225 & -2.0 & -0.4 & -1.3 & -0.8 & 0.8 & -0.5 & -0.1 & -2.0 & -0.5 & 1.0 \\
\hline AN6699 & Electron-transfer flavoprotein & 29 & 94 & 141 & -1.3 & -0.3 & -1.4 & -0.8 & 0.6 & 0.1 & -0.2 & -1.8 & -0.2 & 1.0 \\
\hline AN8748 & Palmitoyl-(protein) hydrolase & 10 & 3 & 11 & -1.6 & -0.6 & -1.1 & -0.8 & 0.5 & 0.1 & -0.3 & -1.2 & -0.3 & 0.6 \\
\hline AN1017 (HogA) & Mitogen-activated protein kinase & 17 & 14 & 17 & -1.3 & -0.3 & -0.8 & -0.8 & 0.5 & 0.3 & 0.2 & -1.3 & 0.2 & 0.9 \\
\hline AN2440 & Ribose-5-phosphate isomerase & 7 & 27 & 29 & -0.8 & 0.2 & -1.1 & -0.8 & 0.7 & 0.3 & 0.3 & -1.1 & 0.3 & 0.8 \\
\hline AN2968 (IppA) & Inorganic diphosphatase & 239 & 358 & 473 & -0.8 & 0.0 & -1.8 & -0.8 & 0.9 & 0.6 & 0.1 & -1.1 & 0.1 & 0.9 \\
\hline AN3928 (ThiF) & Thiazole synthase & 35 & 132 & 370 & -3.2 & -0.6 & -1.0 & -0.8 & 1.4 & -1.8 & 0.5 & -1.9 & -1.8 & 1.4 \\
\hline AN7000 & Succinate-CoA ligase & 60 & 65 & 138 & -1.9 & -0.5 & -1.1 & -0.8 & 0.7 & -0.2 & 0.1 & -1.4 & -0.2 & 0.8 \\
\hline AN4888 (PdcA) & Pyruvate decarboxylase & 140 & 499 & 580 & -2.6 & -0.9 & -0.7 & -0.8 & 1.0 & -0.9 & -0.5 & -2.0 & -0.9 & 0.8 \\
\hline AN4174 & Lactoylglutathione lyase & 75 & 79 & 116 & -1.0 & 0.0 & -1.6 & -0.8 & 0.8 & 0.6 & -0.2 & -1.4 & -0.2 & 1.0 \\
\hline AN1182 (BenA) & Beta-tubulin & 352 & 327 & 648 & -0.8 & 0.0 & -1.4 & -0.8 & 0.7 & 0.7 & 0.3 & -1.0 & 0.3 & 0.9 \\
\hline AN7107 & Role in translation & 18 & 30 & 210 & -1.0 & 0.0 & -1.6 & -0.8 & 0.8 & -0.3 & -0.2 & -2.1 & -0.3 & 1.0 \\
\hline AN6630 & Nascent polypeptide-associated & 118 & 138 & 264 & -1.1 & -0.1 & -1.5 & -0.8 & 0.7 & -0.1 & -0.2 & -1.7 & -0.2 & 0.9 \\
\hline AN8435 & Tryrosinase domain protein & 110 & 58 & 73 & 1.5 & -0.2 & -1.4 & -0.8 & 1.5 & 4.2 & 2.8 & 5.1 & 4.2 & 1.1 \\
\hline AN6591 (Cse1) & Essential nuclear export receptor & 38 & 48 & 113 & -1.0 & -0.5 & -1.1 & -0.8 & 0.3 & 0.2 & 0.0 & -1.2 & 0.0 & 0.8 \\
\hline AN2212 & Ubiquitin-conjugating enzyme E2 & 7 & 2 & 7 & -0.8 & 0.6 & -1.6 & -0.8 & 1.1 & 0.8 & 0.0 & -1.2 & 0.0 & 1.0 \\
\hline AN9401 & Oxidoreductase & 7 & 14 & 4 & -2.1 & -0.5 & -1.0 & -0.8 & 0.8 & -0.4 & -0.7 & -1.7 & -0.7 & 0.7 \\
\hline AN4739 & SAICAR synthetase & 6 & 6 & 47 & -3.0 & -0.7 & -0.9 & -0.8 & 1.3 & -0.8 & 0.1 & -1.7 & -0.8 & 0.9 \\
\hline AN0906 (KapB) & Nuclear transport protein & 22 & 57 & 110 & -1.5 & -0.1 & -0.8 & -0.8 & 0.7 & 0.0 & 0.1 & -1.5 & 0.0 & 0.9 \\
\hline AN8273 & Ubiquinol-cytochrome-c reductase & 45 & 63 & 126 & -1.6 & -0.2 & -1.3 & -0.7 & 0.7 & -0.5 & -0.4 & -2.4 & -0.5 & 1.1 \\
\hline AN2012 & Protein of unknown function & 117 & 148 & 175 & -0.9 & 0.1 & -0.7 & -0.7 & 0.5 & 0.6 & -0.1 & -0.2 & -0.1 & 0.5 \\
\hline AN5999 & Carbamoyl-phosphate synthase & 93 & 218 & 481 & -2.6 & -1.2 & -0.3 & -0.7 & 1.2 & -1.8 & -0.5 & -1.7 & -1.7 & 0.7 \\
\hline AN10223 & 1-Cys peroxiredoxin & 363 & 335 & 459 & -1.6 & -0.7 & 0.0 & -0.7 & 0.8 & 0.2 & -0.3 & -1.4 & -0.3 & 0.8 \\
\hline AN0687 & Arginine metabolism & 60 & 42 & 63 & -1.3 & -0.3 & -0.7 & -0.7 & 0.5 & 0.3 & 1.6 & -1.1 & 0.3 & 1.4 \\
\hline AN6563 & Translation elongation factor & 330 & 445 & 722 & -1.7 & -0.7 & -0.8 & -0.7 & 0.6 & -0.1 & 0.0 & -1.2 & -0.1 & 0.7 \\
\hline AN6726 & Proteasome subunit & 37 & 55 & 51 & -0.9 & 0.0 & -1.5 & -0.7 & 0.8 & 0.2 & -0.3 & -1.1 & -0.3 & 0.6 \\
\hline AN0179 & Oxidoreductase & 18 & 63 & 69 & -1.7 & -0.7 & -0.5 & -0.7 & 0.7 & 0.1 & -2.5 & -1.3 & -1.3 & 1.3 \\
\hline AN8204 & NAD+ diphosphatase & 6 & 12 & 14 & -1.9 & -0.9 & -0.6 & -0.7 & 0.7 & 0.1 & -0.6 & -1.3 & -0.6 & 0.7 \\
\hline AN5745 & Translation initiation factor & 425 & 2 & 35 & -1.2 & -0.3 & -1.1 & -0.7 & 0.4 & -0.3 & -0.5 & -1.8 & -0.5 & 0.8 \\
\hline AN7335 & Protein of unknown function & 8 & 3 & & -0.7 & -0.3 & -1.1 & -0.7 & 0.4 & 0.8 & 0.0 & -1.8 & 0.0 & 1.3 \\
\hline AN5571 (KgdA) & Oxoglutarate dehydrogenase & 71 & 106 & 224 & -1.7 & -0.1 & -1.3 & -0.7 & 0.9 & -0.5 & -0.4 & -2.0 & -0.5 & 0.9 \\
\hline AN5713 (Cct7) & Chaperonin & 23 & 24 & 93 & -1.8 & -0.5 & -0.8 & -0.7 & 0.7 & -0.1 & -0.3 & -1.8 & -0.3 & 0.9 \\
\hline AN4591 & Phosphoglucomutase & 81 & 60 & 68 & -1.3 & -0.5 & -0.9 & -0.7 & 0.4 & 0.3 & -0.5 & -0.8 & -0.5 & 0.6 \\
\hline AN6921 & Co-chaperone & 62 & 61 & 77 & -0.9 & 0.0 & -1.3 & -0.7 & 0.7 & 0.2 & -0.1 & -0.8 & -0.1 & 0.5 \\
\hline AN7436 (PdiA) & Disulfide isomerase & 118 & 152 & 204 & -1.7 & -0.7 & -0.6 & -0.6 & 0.6 & 0.6 & -0.2 & -0.5 & -0.2 & 0.5 \\
\hline AN2904 & $26 \mathrm{~S}$ proteasome regulatory subunit & 25 & 69 & 99 & -1.6 & -0.4 & -0.6 & -0.6 & 0.6 & -0.1 & -0.2 & -1.1 & -0.2 & 0.5 \\
\hline AN6341 & Coronin & 137 & 110 & 194 & -0.4 & 0.6 & -1.8 & -0.6 & 1.2 & 1.1 & 0.5 & -1.2 & 0.5 & 1.2 \\
\hline
\end{tabular}




\begin{tabular}{|c|c|c|c|c|c|c|c|c|c|c|c|c|c|c|}
\hline \multirow[t]{2}{*}{ Gene ID } & \multirow[t]{2}{*}{ Description } & \multicolumn{3}{|c|}{ PSM } & \multicolumn{3}{|c|}{ laeAs/laeA } & \multirow[t]{2}{*}{$\varnothing$} & \multirow[t]{2}{*}{ SD } & \multicolumn{3}{|c|}{ laeAcomp+/laeA } & $\varnothing$ & SD \\
\hline & & 1 & 2 & 3 & 1 & 2 & 3 & & & 1 & 2 & 3 & & \\
\hline AN6508 (GskA) & Kinase & 69 & 53 & 47 & -1.4 & -0.1 & -1.2 & -0.6 & 0.7 & 0.7 & 0.2 & -0.5 & 0.2 & 0.6 \\
\hline AN3748 & Phosphoribosyltransferase & 43 & 95 & 109 & -2.1 & -0.9 & -0.3 & -0.6 & 0.9 & -0.6 & -0.3 & -1.1 & -0.6 & 0.4 \\
\hline AN4667 (AspA) & Septin & 92 & 185 & 226 & -0.9 & 0.2 & -1.4 & -0.6 & 0.8 & 0.9 & 0.3 & -1.0 & 0.3 & 1.0 \\
\hline AN4102 (BglA & Beta-glucosidase & 138 & 100 & 40 & -0.3 & 0.4 & -1.7 & -0.6 & 1.1 & 1.4 & -0.8 & 1.1 & 1.1 & 1.2 \\
\hline AN5547 & Oxidoreductase & 28 & 21 & 29 & -1.5 & -0.4 & -0.8 & -0.6 & 0.6 & -1.2 & -1.2 & -1.6 & -1.2 & 0.2 \\
\hline AN4402 & Voltage-gated anion channel & 35 & 26 & 82 & -1.6 & -0.3 & -0.9 & -0.6 & 0.6 & -0.3 & -0.5 & -2.9 & -0.5 & 1.5 \\
\hline AN7003 & $60 S$ ribosomal protein $\mathrm{L} 13$ & 18 & 28 & 159 & -1.2 & 0.0 & -1.3 & -0.6 & 0.7 & -0.3 & -0.3 & -2.1 & -0.3 & 1.0 \\
\hline AN5973 (PkcB) & Protein kinase $\mathrm{C}$ & 16 & 15 & 36 & -1.6 & 0.1 & -1.3 & -0.6 & 0.9 & 0.5 & 0.3 & -1.4 & 0.3 & 1.1 \\
\hline AN5122 & Kinase & 69 & 63 & 104 & -1.8 & -0.5 & -0.7 & -0.6 & 0.7 & -0.8 & -0.5 & -2.0 & -0.8 & 0.8 \\
\hline AN5529 (CotA) & Serine/threonine protein kinase & 7 & 18 & 55 & -1.4 & 0.0 & -1.1 & -0.6 & 0.7 & 0.3 & -0.1 & -1.4 & -0.1 & 0.9 \\
\hline AN5895 (GdiA) & Rab GDP-dissociation inhibitor & 112 & 142 & 251 & -0.9 & 0.2 & -1.4 & -0.6 & 0.8 & 0.8 & 0.3 & -1.4 & 0.3 & 1.2 \\
\hline AN6900 (TpiA) & Triose-phosphate isomerase & 113 & 189 & 231 & -0.9 & 0.0 & -1.2 & -0.6 & 0.6 & -0.2 & -0.3 & -1.5 & -0.3 & 0.7 \\
\hline AN6257 & Protein of unknown function & 87 & 107 & 162 & -1.7 & -0.3 & -0.8 & -0.6 & 0.7 & 0.1 & 0.0 & -1.4 & 0.0 & 0.8 \\
\hline AN4087 & $40 \mathrm{~S}$ ribosomal protein subunit & 89 & 78 & 237 & -1.2 & -0.1 & -1.0 & -0.5 & 0.6 & -0.3 & 0.0 & -2.1 & -0.3 & 1.1 \\
\hline AN1015 & Phosphorylase & 108 & 80 & 82 & -1.0 & -0.5 & 1.2 & -0.5 & 1.2 & 1.5 & -0.3 & -0.6 & -0.3 & 1.1 \\
\hline AN3954 & Phosphogluconate dehydrogenase & 483 & 863 & 944 & -1.5 & -0.3 & -0.7 & -0.5 & 0.6 & -0.2 & -0.2 & -1.6 & -0.2 & 0.8 \\
\hline AN3592 (ClxA) & Calnexin & 38 & 33 & 106 & -1.8 & -0.2 & -0.5 & -0.5 & 0.8 & 0.6 & 0.2 & -1.3 & 0.2 & 1.0 \\
\hline AN1993 & Aspartate transaminase & 151 & 342 & 498 & -1.5 & -0.3 & -0.5 & -0.5 & 0.6 & -1.4 & -0.9 & -2.3 & -1.4 & 0.7 \\
\hline AN10718 (RiboG) & Lumazine synthase & 2 & 22 & 27 & -0.5 & 1.1 & -1.6 & -0.5 & 1.4 & 1.4 & 0.8 & -0.8 & 0.8 & 1.1 \\
\hline AN6004 & Protein of unknown function & 119 & 110 & 119 & -1.3 & -0.2 & -0.8 & -0.5 & 0.5 & 0.7 & -0.2 & -1.3 & -0.2 & 1.0 \\
\hline AN7570 (TubB) & Alpha-tubulin & 192 & 263 & 363 & -0.8 & 0.0 & -1.0 & -0.5 & 0.5 & 0.9 & 0.1 & 0.4 & 0.4 & 0.4 \\
\hline AN2916 & Succinate dehydrogenase & 17 & 40 & 97 & -1.0 & 0.3 & -0.5 & -0.5 & 0.7 & 0.1 & -0.5 & -2.3 & -0.5 & 1.3 \\
\hline AN2458 & Cullin binding protein & 39 & 51 & 81 & -1.3 & -0.4 & -0.5 & -0.5 & 0.5 & 0.1 & -0.4 & -1.2 & -0.4 & 0.7 \\
\hline AN1733 (PrnC) & Oxidoreductase & 68 & 39 & 37 & -0.5 & 0.2 & -1.0 & -0.5 & 0.6 & 1.5 & -0.8 & -0.4 & -0.4 & 1.2 \\
\hline AN6650 (McsA) & Methylcitrate synthase & 57 & 79 & 46 & -1.6 & -0.9 & 0.0 & -0.5 & 0.8 & 0.2 & -0.9 & 0.9 & 0.2 & 0.9 \\
\hline AN8870 & $40 \mathrm{~S}$ ribosomal protein $\mathrm{S} 3 \mathrm{Ae}$ & 8 & 25 & 123 & -1.3 & 0.0 & -0.9 & -0.5 & 0.7 & -0.2 & -0.2 & -2.0 & -0.2 & 1.1 \\
\hline AN10273 (Gst3) & Glutathione S-transferase & 38 & 32 & 37 & -2.4 & 0.5 & -0.5 & -0.5 & 1.5 & 0.1 & 0.5 & -0.7 & 0.1 & 0.6 \\
\hline AN5602 & Chaperone & 38 & 34 & 47 & -2.1 & -0.3 & -0.6 & -0.5 & 1.0 & -0.5 & 0.0 & -1.5 & -0.5 & 0.8 \\
\hline AN6499 (MdhC) & Malate dehydrogenase & 437 & 548 & 429 & -0.9 & 0.0 & -0.9 & -0.5 & 0.5 & 0.9 & 0.1 & -0.1 & 0.1 & 0.5 \\
\hline AN6840 & Hydroxyacylglutathione hydrolase & 38 & 29 & 19 & -1.1 & -0.3 & -0.6 & -0.5 & 0.4 & 0.5 & -0.6 & -0.9 & -0.6 & 0.8 \\
\hline AN4501 (ArtA) & 14-3-3 protein & 427 & 599 & 892 & -1.0 & -0.1 & -0.8 & -0.4 & 0.5 & 0.7 & 0.0 & -1.0 & 0.0 & 0.9 \\
\hline AN5129 (Hsp70) & Heat shock protein & 604 & 842 & 1322 & -1.6 & -0.5 & -0.4 & -0.4 & 0.7 & 0.0 & 0.0 & -1.4 & 0.0 & 0.8 \\
\hline AN8022 & Protein of unknown function & 23 & 30 & 28 & -0.9 & 0.0 & -0.8 & -0.4 & 0.5 & 0.3 & -0.2 & -1.0 & -0.2 & 0.7 \\
\hline AN9497 & Hydrolase & 141 & 9 & 19 & -1.7 & -0.3 & -0.5 & -0.4 & 0.7 & -0.8 & -0.2 & -1.1 & -0.8 & 0.5 \\
\hline AN9308 & Dehydrogenase & 31 & 32 & 12 & -2.0 & -0.6 & -0.2 & -0.4 & 0.9 & 0.7 & 0.1 & -0.5 & 0.1 & 0.6 \\
\hline AN4820 & Dehydrogenase & 52 & 51 & 22 & 0.5 & 1.1 & -1.9 & -0.4 & 1.6 & 2.0 & 0.2 & 1.7 & 1.7 & 0.9 \\
\hline AN11070 & Metalloaminopeptidase & 75 & 32 & 20 & -1.2 & -0.4 & 0.1 & -0.4 & 0.7 & 0.0 & -1.0 & -0.9 & -0.9 & 0.6 \\
\hline AN5986 & Reductase & 16 & 35 & 13 & -1.6 & 1.2 & -1.9 & -0.4 & 1.7 & 0.5 & 0.3 & 0.3 & 0.3 & 0.1 \\
\hline AN5790 & Isocitrate dehydrogenase & 9 & 21 & 126 & -0.9 & 0.1 & -0.9 & -0.4 & 0.6 & 0.2 & -0.3 & -2.2 & -0.3 & 1.3 \\
\hline AN1426 & Serine-type carboxypeptidase & 34 & 16 & 14 & -0.4 & 0.6 & -0.9 & -0.4 & 0.8 & 2.7 & 0.0 & -0.1 & 0.0 & 1.6 \\
\hline AN4463 & Clathrin & 102 & 298 & 436 & -1.2 & 0.0 & -0.6 & -0.3 & 0.6 & 0.4 & 0.1 & -1.2 & 0.1 & 0.8 \\
\hline AN3932 & Proteasome beta- 5 subunit & 12 & 28 & 60 & -0.5 & 1.7 & -2.3 & -0.3 & 2.0 & 0.2 & 0.0 & -1.0 & 0.0 & 0.6 \\
\hline AN5812 & Aminopeptidase & 16 & 19 & 15 & -1.9 & 0.2 & -0.8 & -0.3 & 1.1 & 0.2 & -0.3 & -1.0 & -0.3 & 0.6 \\
\hline AN10709 (GfaA) & Transaminase activity & 224 & 451 & 672 & -1.3 & -0.3 & 2.5 & -0.3 & 2.0 & 0.7 & 0.2 & -1.0 & 0.2 & 0.8 \\
\hline AN4871 (ChiB) & Chitinase & 44 & 62 & 43 & -0.1 & 0.2 & -0.8 & -0.3 & 0.5 & 0.0 & -1.7 & -0.9 & -0.9 & 0.9 \\
\hline AN5525 (AcoA) & Aconitate hydratase & 339 & 380 & 55 & -1.4 & -0.1 & -0.4 & -0.3 & 0.7 & -0.4 & -0.4 & -1.8 & -0.4 & 0.8 \\
\hline AN3739 & Protein of unknown function & 18 & 10 & 63 & -1.5 & -0.3 & -0.2 & -0.3 & 0.7 & 0.0 & -0.6 & -0.4 & -0.4 & 0.3 \\
\hline AN10020 & Proteasome complex localization & 44 & 105 & 105 & -1.5 & -0.3 & 3.0 & -0.3 & 2.3 & -0.3 & -0.2 & -1.3 & -0.3 & 0.6 \\
\hline AN2142 & Uracil phosphoribosyltransferase & 43 & 66 & 111 & -1.5 & -0.2 & 1.0 & -0.2 & 1.3 & 0.1 & -0.2 & -1.6 & -0.2 & 0.9 \\
\hline AN4794 & Ribosomal protein & 3 & 19 & 129 & -1.8 & 0.2 & -0.6 & -0.2 & 1.0 & -0.6 & 0.0 & -2.0 & -0.6 & 1.1 \\
\hline AN4414 & Decarboxylase & 96 & 121 & 209 & -2.0 & -1.0 & 0.5 & -0.2 & 1.3 & 0.5 & -0.1 & -0.7 & -0.1 & 0.6 \\
\hline AN6525 (AciA) & Formate dehydrogenase & 384 & 358 & 231 & 0.7 & 1.5 & -1.9 & -0.2 & 1.7 & 1.9 & 0.5 & 2.4 & 1.9 & 1.0 \\
\hline AN2998 & Tetrahydrofolate synthase & 110 & 143 & 260 & -0.9 & -0.2 & 0.3 & -0.2 & 0.6 & 0.7 & 0.0 & -1.4 & 0.0 & 1.1 \\
\hline AN7262 & Protein of unknown function & 116 & 84 & 189 & -1.0 & 0.1 & -0.4 & -0.1 & 0.6 & 1.3 & 0.6 & -1.3 & 0.6 & 1.3 \\
\hline AN2051 (Cdc37) & Cell division cycle 37 & 6 & 10 & 42 & -1.5 & -0.1 & 0.3 & -0.1 & 1.0 & 0.4 & -0.1 & -0.7 & -0.1 & 0.6 \\
\hline AN8689 (GlkA) & Glucokinase & 56 & 72 & 102 & -0.1 & 0.9 & -1.1 & -0.1 & 1.0 & -0.3 & 0.0 & -2.3 & -0.3 & 1.2 \\
\hline AN3973 & Peroxiredoxin & 45 & 54 & 85 & -2.5 & -0.9 & 0.7 & -0.1 & 1.6 & -1.5 & -0.7 & -2.8 & -1.5 & 1.0 \\
\hline AN8674 & V-type ATPase & 36 & 60 & 40 & -2.6 & 0.1 & -0.2 & 0.0 & 1.5 & 0.6 & -0.1 & -1.0 & -0.1 & 0.8 \\
\hline AN6232 (VamB) & F1F0-ATPase complex subunit & 112 & 173 & 234 & -1.0 & 0.0 & 0.0 & 0.0 & 0.6 & 0.3 & -0.3 & -1.2 & -0.3 & 0.7 \\
\hline AN2412 (CmkA) & Kinase & 26 & 28 & 50 & -0.4 & 0.6 & 0.0 & 0.0 & 0.5 & 1.2 & 0.5 & -0.8 & 0.5 & 1.0 \\
\hline AN2936 & Alpha-mannosidase & 32 & 31 & 29 & 0.0 & 1.0 & -1.3 & 0.0 & 1.1 & 1.3 & -0.4 & 0.1 & 0.1 & 0.9 \\
\hline AN5604 (AcuG) & Fructose-bisphosphatase & 33 & 43 & 3 & 0.7 & 1.4 & -1.3 & 0.0 & 1.4 & -0.2 & -1.0 & -1.0 & -1.0 & 0.4 \\
\hline AN6988 & Proteasome regulatory particle & 20 & 46 & 66 & -1.6 & -0.5 & 0.6 & 0.1 & 1.1 & 0.0 & -0.2 & -1.1 & -0.2 & 0.6 \\
\hline AN1358 & Serine/threonine phosphatase & 41 & 28 & 71 & 0.8 & 0.1 & -1.8 & 0.1 & 1.3 & 1.5 & 0.2 & -0.8 & 0.2 & 1.1 \\
\hline AN5916 (EchA) & Mitochondrial enoyl-CoA hydratase & 2 & 8 & 8 & -0.7 & 0.7 & -0.5 & 0.1 & 0.7 & 0.9 & -0.8 & -1.2 & -0.8 & 1.1 \\
\hline AN2526 & Ketol-acid reductoisomerase & 149 & 308 & 499 & -1.2 & 0.2 & 0.1 & 0.1 & 0.8 & -0.7 & 0.0 & -2.3 & -0.7 & 1.2 \\
\hline AN7708 & Oxidoreductase & 63 & 82 & 129 & 0.8 & 0.7 & -0.4 & 0.1 & 0.6 & 5.2 & 0.5 & -1.2 & 0.5 & 3.3 \\
\hline
\end{tabular}




\begin{tabular}{|c|c|c|c|c|c|c|c|c|c|c|c|c|c|c|}
\hline \multirow[t]{2}{*}{ Gene ID } & \multirow[t]{2}{*}{ Description } & \multicolumn{3}{|c|}{ PSM } & \multicolumn{3}{|c|}{ IaeAd/aeA } & \multirow[t]{2}{*}{$\varnothing$} & \multirow[t]{2}{*}{ SD } & \multicolumn{3}{|c|}{ laeAcomp+/laeA } & $\varnothing$ & SD \\
\hline & & 1 & 2 & 3 & 1 & 2 & 3 & & & 1 & 2 & 3 & & \\
\hline AN3716 & $26 \mathrm{~S}$ proteasome & 13 & 48 & 55 & -1.0 & -0.1 & 0.4 & 0.2 & 0.7 & 0.0 & -0.1 & -1.1 & -0.1 & 0.6 \\
\hline AN7111 (FoxA) & Role in fatty acid beta-oxidation & 131 & 172 & 40 & 1.4 & 2.3 & -1.9 & 0.2 & 2.2 & 1.7 & -0.5 & -1.3 & -0.5 & 1.5 \\
\hline AN5994 & Dehydratase & 27 & 7 & 19 & -2.0 & -0.4 & 1.0 & 0.3 & 1.5 & 0.5 & -0.5 & -0.9 & -0.5 & 0.7 \\
\hline AN2532 & Amine oxidase & 73 & 102 & 85 & 0.3 & 1.7 & -2.3 & 0.3 & 2.0 & 0.8 & 0.1 & -1.8 & 0.1 & 1.3 \\
\hline AN4127 & Protein of unknown function & 29 & 39 & 138 & -2.5 & -1.4 & 2.0 & 0.3 & 2.4 & -1.7 & -0.8 & -3.2 & -1.7 & 1.2 \\
\hline AN5977 & Carbonyl reductase & 27 & 18 & 34 & -2.0 & -0.6 & 1.4 & 0.4 & 1.7 & 0.5 & -0.2 & 0.4 & 0.4 & 0.4 \\
\hline AN0824 (ScdA) & Dehydrogenase & 6 & 10 & & -1.0 & 0.6 & 1.1 & 0.6 & 1.0 & 0.1 & -0.7 & -1.6 & -0.7 & 0.8 \\
\hline AN7950 (EgIC) & Glucosidase & 13 & 65 & 71 & -2.0 & -0.4 & 1.5 & 0.6 & 1.8 & -0.7 & -0.9 & -1.0 & -0.9 & 0.1 \\
\hline AN8707 & Fumarate dehydratase & 88 & 172 & 258 & -0.8 & 0.5 & 0.8 & 0.6 & 0.8 & 0.1 & -0.3 & -2.3 & -0.3 & 1.3 \\
\hline AN6330 & Elongation factor 2 & 896 & 1127 & 1483 & -1.2 & -0.3 & 1.6 & 0.6 & 1.4 & 0.0 & -0.1 & -1.4 & -0.1 & 0.8 \\
\hline AN9124 & Heat shock protein & 44 & 113 & 219 & -1.4 & -0.3 & 1.7 & 0.7 & 1.6 & 0.6 & 0.1 & -1.2 & 0.1 & 0.9 \\
\hline AN6653 (AcuE) & Malate synthase & 11 & 15 & 24 & 0.4 & 0.4 & 1.8 & 1.1 & 0.8 & 0.1 & -2.3 & -2.9 & -2.3 & 1.6 \\
\hline AN5872 & Proteasome subunit & 17 & 79 & 64 & -0.9 & 0.0 & 2.7 & 1.4 & 1.8 & 0.1 & -0.2 & -1.0 & -0.2 & 0.6 \\
\hline AN8953 (AgdB) & Alpha-glucosidase & 68 & 164 & 78 & 3.4 & 3.8 & -1.1 & 1.4 & 2.7 & 2.4 & 2.2 & 4.7 & 2.4 & 1.4 \\
\hline AN5626 (FacA) & Acetyl-CoA synthase & 375 & 351 & 227 & 1.8 & 2.5 & 0.3 & 1.4 & 1.1 & 2.3 & -0.3 & -0.3 & -0.3 & 1.5 \\
\hline AN8782 & S-formylglutathione hydrolase & 10 & 28 & 12 & -0.1 & 0.7 & 2.4 & 1.6 & 1.3 & 0.7 & -0.3 & 0.6 & 0.6 & 0.5 \\
\hline AN8664 & Hydrolase & 78 & 66 & 89 & -0.8 & 0.3 & 2.9 & 1.6 & 1.9 & -0.5 & -1.0 & -1.3 & -1.0 & 0.4 \\
\hline AN6231 (TepB) & Tryptophan synthase & 121 & 157 & 277 & -3.1 & -1.5 & 5.0 & 1.7 & 4.2 & -1.8 & -0.5 & -0.7 & -0.7 & 0.7 \\
\hline AN8233 & Phosphatidylinositol transporter & 94 & 122 & 176 & -0.3 & 0.8 & 3.3 & 2.0 & 1.8 & 1.0 & 0.7 & -1.4 & 0.7 & 1.3 \\
\hline AN3499 & Phosphotransferase & 12 & 26 & 10 & $\mathrm{NaN}$ & -1.7 & -1.6 & -1.7 & 1.0 & -2.1 & -1.6 & -2.1 & -2.1 & 0.3 \\
\hline AN2977 & Small molecule transport & 17 & 11 & 10 & $\mathrm{NaN}$ & -0.4 & -1.4 & -0.9 & 0.7 & -0.8 & -0.9 & -1.9 & -0.9 & 0.6 \\
\hline AN3626 & Carboxylase & 3 & 25 & 59 & -2.1 & $\mathrm{NaN}$ & -2.6 & -2.6 & 1.4 & -0.4 & -2.7 & -1.7 & -1.7 & 1.1 \\
\hline AN10096 & Hydrolase & 29 & 27 & 26 & -3.5 & -2.0 & $\mathrm{NaN}$ & -2.8 & 1.7 & -2.0 & -0.9 & -2.4 & -2.0 & 0.7 \\
\hline AN0158 & 2-alkenal reductase & 15 & 35 & 38 & -2.9 & -1.9 & $\mathrm{NaN}$ & -2.4 & 1.5 & -1.0 & -0.8 & -1.9 & -1.0 & 0.5 \\
\hline AN3222 & 5'-nucleotidase & 25 & 25 & 20 & -2.8 & -1.9 & $\mathrm{NaN}$ & -2.3 & 1.4 & -0.6 & -1.1 & -0.5 & -0.6 & 0.3 \\
\hline AN7074 & Oxidoreductase & 134 & 63 & 60 & -2.5 & -2.2 & $\mathrm{NaN}$ & -2.2 & 1.4 & -2.0 & -1.7 & 1.2 & -1.7 & 1.8 \\
\hline AN1883 & Argininosuccinate synthase & 92 & 175 & 212 & -2.6 & -1.5 & $\mathrm{NaN}$ & -2.0 & 1.3 & -1.5 & -0.7 & -1.4 & -1.4 & 0.4 \\
\hline AN2867 (PgmB) & Phosphoglucomutase & 243 & 240 & 417 & -2.0 & -1.0 & $\mathrm{NaN}$ & -1.5 & 1.0 & -0.3 & -0.4 & -0.5 & -0.4 & 0.1 \\
\hline AN3031 & Threonine synthase & 24 & 101 & 177 & -2.0 & -0.9 & $\mathrm{NaN}$ & -1.4 & 1.0 & -0.9 & -0.5 & -2.0 & -0.9 & 0.8 \\
\hline AN7141 & Aldehyde dehydrogenase & 71 & 76 & 72 & -2.4 & -1.4 & $\mathrm{NaN}$ & -1.4 & 1.2 & -0.7 & -0.7 & -0.6 & -0.7 & 0.0 \\
\hline AN1045 & Protein of unknown function & 12 & 17 & 50 & -2.1 & -0.6 & $\mathrm{NaN}$ & -1.4 & 1.1 & -1.1 & -0.3 & -1.7 & -1.1 & 0.7 \\
\hline AN5610 & Dehydrogenase & 55 & 128 & 200 & -3.1 & -1.3 & $\mathrm{NaN}$ & -1.3 & 1.6 & -1.4 & -0.4 & -1.4 & -1.4 & 0.5 \\
\hline AN7479 & Asparaginyl-tRNA synthetase & 40 & 122 & 243 & -1.7 & -1.3 & $\mathrm{NaN}$ & -1.3 & 0.9 & -1.6 & -0.4 & -0.6 & -0.6 & 0.7 \\
\hline AN2435 (AclA) & ATP citrate synthase & 282 & 352 & 540 & -1.8 & -0.7 & $\mathrm{NaN}$ & -1.3 & 0.9 & 0.7 & 0.5 & -0.8 & 0.5 & 0.9 \\
\hline AN9339 (CatB) & Catalase & 637 & 669 & 575 & -1.8 & -1.2 & $\mathrm{NaN}$ & -1.2 & 0.9 & 1.2 & 0.3 & 1.6 & 1.2 & 0.7 \\
\hline AN2964 (PdhX) & Pyruvate dehydrogenase & 17 & 28 & 48 & -2.0 & -0.3 & $\mathrm{NaN}$ & -1.1 & 1.1 & -0.6 & -0.3 & -2.1 & -0.6 & 1.0 \\
\hline AN5701 (Arof) & DAHP synthase & 76 & 66 & 94 & -2.3 & -1.1 & $\mathrm{NaN}$ & -1.1 & 1.1 & -1.0 & -0.3 & -1.4 & -1.0 & 0.6 \\
\hline AN1904 & Chaperonin & 4 & 10 & 52 & -1.7 & -0.5 & $\mathrm{NaN}$ & -1.1 & 0.9 & -0.1 & -0.3 & -1.8 & -0.3 & 0.9 \\
\hline AN10981 & GTP cyclohydrolase II & 69 & 72 & 42 & -1.3 & -0.9 & $\mathrm{NaN}$ & -1.1 & 0.7 & 1.3 & 0.1 & 2.4 & 1.3 & 1.1 \\
\hline AN1922 & Proteosome & 27 & 22 & 68 & -1.8 & -0.4 & $\mathrm{NaN}$ & -1.1 & 0.9 & 0.0 & -0.3 & -1.1 & -0.3 & 0.6 \\
\hline AN4376 (GdhA) & Glutamate dehydrogenase & 535 & 710 & 1032 & -2.2 & -1.1 & $\mathrm{NaN}$ & -1.1 & 1.1 & -0.7 & -0.2 & -2.0 & -0.7 & 0.9 \\
\hline AN10946 & Protein of unknown function & 57 & 65 & 216 & -1.7 & -0.4 & $\mathrm{NaN}$ & -1.1 & 0.9 & -0.6 & -0.5 & -1.4 & -0.6 & 0.5 \\
\hline AN1003 & Isocitrate dehydrogenase & 34 & 151 & 178 & -1.8 & -0.3 & $\mathrm{NaN}$ & -1.0 & 0.9 & -0.3 & -0.3 & -2.3 & -0.3 & 1.1 \\
\hline AN3058 & Glycine hydroxymethyltransferase & 94 & 159 & 233 & -1.5 & -0.5 & $\mathrm{NaN}$ & -1.0 & 0.8 & -0.6 & -0.4 & -2.0 & -0.6 & 0.9 \\
\hline AN10540 & Dipeptidyl-peptidase & 166 & 126 & 187 & -1.5 & -0.5 & $\mathrm{NaN}$ & -1.0 & 0.8 & 0.7 & 0.1 & 0.3 & 0.3 & 0.3 \\
\hline AN3172 & 40S ribosomal protein SO & 52 & 55 & 106 & -1.7 & -0.3 & $\mathrm{NaN}$ & -1.0 & 0.9 & -0.5 & -0.2 & -2.1 & -0.5 & 1.0 \\
\hline AN10257 & Initiation factor $4 \mathrm{G}$ binding & 32 & 45 & 80 & -1.6 & -0.4 & $\mathrm{NaN}$ & -1.0 & 0.8 & -0.4 & -0.3 & -1.5 & -0.4 & 0.7 \\
\hline AN1700 & $26 \mathrm{~S}$ proteasome regulatory subunit & 17 & 42 & 139 & -1.3 & -0.6 & $\mathrm{NaN}$ & -1.0 & 0.6 & -0.1 & -0.6 & -1.1 & -0.6 & 0.5 \\
\hline AN1635 & Protein of unknown function & 14 & 23 & 59 & -1.6 & -0.3 & $\mathrm{NaN}$ & -0.9 & 0.8 & -0.1 & -0.3 & -1.5 & -0.3 & 0.7 \\
\hline AN0747 & Ubiquinol-cytochrome-c reductase & 28 & 52 & 72 & -1.6 & -0.3 & $\mathrm{NaN}$ & -0.9 & 0.8 & -0.5 & -1.3 & -2.2 & -1.3 & 0.8 \\
\hline AN2225 & Oxidoreductase & 33 & 48 & 22 & -1.2 & -0.6 & $\mathrm{NaN}$ & -0.9 & 0.6 & 1.1 & -0.3 & -0.1 & -0.1 & 0.7 \\
\hline AN0858 (Hsp104) & Chaperone & 38 & 100 & 158 & -1.6 & -0.2 & $\mathrm{NaN}$ & -0.9 & 0.9 & -0.3 & -0.5 & -2.0 & -0.5 & 0.9 \\
\hline AN5563 (GldB) & Dehydrogenase & 150 & 169 & 219 & -1.7 & -0.9 & $\mathrm{NaN}$ & -0.9 & 0.9 & 0.8 & 0.2 & -0.4 & 0.2 & 0.6 \\
\hline AN4793 & Dehydrogenase & 60 & 67 & 96 & -1.9 & -0.9 & $\mathrm{NaN}$ & -0.9 & 1.0 & -1.1 & -0.6 & -0.9 & -0.9 & 0.3 \\
\hline AN1246 (PgkA) & Phosphoglycerate kinase & 424 & 815 & 1074 & -1.3 & -0.3 & $\mathrm{NaN}$ & -0.8 & 0.7 & -0.7 & -0.6 & -2.1 & -0.7 & 0.8 \\
\hline AN10797 & Hydroxymethylglutaryl-CoA lyase & 5 & 17 & 13 & -1.4 & -0.3 & $\mathrm{NaN}$ & -0.8 & 0.7 & 0.0 & -0.6 & -1.6 & -0.6 & 0.8 \\
\hline AN5731 & Chorismate synthase & 20 & 38 & 48 & -2.5 & -0.8 & $\mathrm{NaN}$ & -0.8 & 1.3 & -1.2 & -0.5 & -1.6 & -1.2 & 0.6 \\
\hline AN0648 (TrpC) & Tryptophan biosynthesis & 31 & 89 & 113 & 0.3 & -1.9 & $\mathrm{NaN}$ & -0.8 & 1.2 & $\mathrm{NaN}$ & -0.7 & -1.2 & -0.9 & 0.4 \\
\hline AN4727 (UrgeA) & UDP-glucose 4-epimerase & 144 & 218 & 272 & -2.0 & -0.8 & $\mathrm{NaN}$ & -0.8 & 1.0 & -0.8 & -0.8 & -1.4 & -0.8 & 0.3 \\
\hline AN8800 (SgdC) & Cysteinyl tRNA synthase & 41 & 38 & 49 & -2.2 & -0.8 & $\mathrm{NaN}$ & -0.8 & 1.1 & 0.0 & 0.1 & -1.1 & 0.0 & 0.6 \\
\hline AN3712 & Carboxymethylenebutenolidase & 48 & 81 & 52 & -1.5 & -0.7 & $\mathrm{NaN}$ & -0.7 & 0.8 & 1.1 & 0.1 & 0.6 & 0.6 & 0.5 \\
\hline AN0351 (GfdA) & Dehydrogenase & 8 & 6 & 30 & -1.1 & -0.4 & $\mathrm{NaN}$ & -0.7 & 0.5 & -0.1 & -1.5 & -2.0 & -1.5 & 1.0 \\
\hline AN10351 & Aminopeptidase & 180 & 141 & 158 & -1.0 & -0.2 & $\mathrm{NaN}$ & -0.6 & 0.6 & 0.0 & -0.4 & -1.1 & -0.4 & 0.6 \\
\hline AN7254 & Cell division control protein 48 & 213 & 207 & 433 & -1.7 & -0.6 & $\mathrm{NaN}$ & -0.6 & 0.9 & 0.1 & -0.2 & -0.7 & -0.2 & 0.4 \\
\hline AN8434 (AnkG) & Ankyrin repeat doamin protein & 102 & 36 & 62 & -1.6 & -0.6 & $\mathrm{NaN}$ & -0.6 & 0.8 & 4.0 & 2.9 & 1.1 & 2.9 & 1.5 \\
\hline AN2248 (GatA) & 4-aminobutyrate transaminase & 96 & 200 & 513 & -1.1 & 0.0 & $\mathrm{NaN}$ & -0.5 & 0.6 & 0.3 & -0.4 & -2.9 & -0.4 & 1.7 \\
\hline AN2237 & Carboxypeptidase C & 23 & 14 & 14 & -0.9 & -0.2 & $\mathrm{NaN}$ & -0.5 & 0.4 & 2.4 & 1.2 & 1.5 & 1.5 & 0.6 \\
\hline
\end{tabular}




\begin{tabular}{|c|c|c|c|c|c|c|c|c|c|c|c|c|c|c|}
\hline \multirow[t]{2}{*}{ Gene ID } & \multirow[t]{2}{*}{ Description } & \multicolumn{3}{|c|}{ PSM } & \multicolumn{3}{|c|}{ laeAL/laeA } & \multirow[t]{2}{*}{$\varnothing$} & \multirow[t]{2}{*}{ SD } & \multicolumn{3}{|c|}{ laeAcomp+/laeA } & $\varnothing$ & SD \\
\hline & & 1 & 2 & 3 & 1 & 2 & 3 & & & 1 & 2 & 3 & & \\
\hline AN7517 & Protein of unknown function & 30 & 4 & 7 & -2.3 & -0.5 & $\mathrm{NaN}$ & -0.5 & 1.2 & 0.8 & -0.1 & 0.1 & 0.1 & 0.5 \\
\hline AN6037 (SwoB) & Glucose-6-phosphate isomerase & 216 & 411 & 615 & -1.7 & -0.5 & $\mathrm{NaN}$ & -0.5 & 0.9 & -0.2 & -0.3 & -1.1 & -0.3 & 0.5 \\
\hline AN9148 (GalF) & Uridylyltransferase & 173 & 299 & 716 & -1.5 & -0.4 & $\mathrm{NaN}$ & -0.4 & 0.8 & -0.3 & -0.6 & -2.3 & -0.6 & 1.1 \\
\hline AN7725 (PyroA) & Pyridoxal 5'-phosphate synthase & 231 & 227 & 399 & -1.8 & -0.4 & $\mathrm{NaN}$ & -0.4 & 0.9 & -1.5 & -0.3 & -1.8 & -1.5 & 0.8 \\
\hline AN1394 (AspD) & Septin & 195 & 170 & 255 & -0.9 & 0.1 & $\mathrm{NaN}$ & -0.4 & 0.6 & 1.0 & 0.4 & -1.0 & 0.4 & 1.0 \\
\hline AN5784 & Proteasome core complex & 32 & 70 & 41 & -1.8 & -0.4 & $\mathrm{NaN}$ & -0.4 & 1.0 & -0.3 & -0.2 & -1.1 & -0.3 & 0.5 \\
\hline AN10337 & roteasome regulatory particle & 30 & 40 & 101 & -2.1 & 1.4 & $\mathrm{NaN}$ & -0.4 & 1.7 & -0.3 & -0.2 & -1.2 & -0.3 & 0.6 \\
\hline AN4583 (Cyp7) & Eptidyl-prolyl cis-trans isomerase D & 53 & 87 & 92 & -1.0 & -0.3 & $\mathrm{NaN}$ & -0.3 & 0.5 & 0.5 & 0.1 & -0.8 & 0.1 & 0.7 \\
\hline AN7299 & DNA-binding protein & 79 & 98 & 229 & -1.2 & -0.3 & $\mathrm{NaN}$ & -0.3 & 0.6 & -0.1 & -0.2 & -1.4 & -0.2 & 0.7 \\
\hline AN4492 & Protease activity & 18 & 6 & 55 & -1.5 & -0.2 & $\mathrm{NaN}$ & -0.2 & 0.8 & 0.1 & -0.3 & -1.2 & -0.3 & 0.7 \\
\hline AN2304 & RAD23 homolog & 44 & 52 & 31 & -0.7 & 0.2 & $\mathrm{NaN}$ & -0.2 & 0.5 & 0.9 & 0.1 & -0.8 & 0.1 & 0.9 \\
\hline AN10399 & Oxidoreductase & 89 & 54 & 54 & -1.0 & 0.6 & $\mathrm{NaN}$ & -0.2 & 0.8 & 1.4 & 0.8 & -0.2 & 0.8 & 0.8 \\
\hline AN4443 (MetH) & Methionine synthase & 863 & 1264 & 16 & -1.0 & -0.2 & $\mathrm{NaN}$ & -0.2 & 0.6 & 0.1 & 0.1 & -1.7 & 0.1 & 1.0 \\
\hline AN6717 (MdhA) & Malate dehydrogenase & 488 & 564 & 766 & -1.6 & -0.2 & $\mathrm{NaN}$ & -0.2 & 0.9 & -0.6 & -0.3 & -1.8 & -0.6 & 0.8 \\
\hline AN4546 & RNA binding activity & 29 & 52 & 96 & -1.2 & -0.2 & $\mathrm{NaN}$ & -0.2 & 0.7 & 0.1 & -0.1 & -0.9 & -0.1 & 0.6 \\
\hline AN1534 & F1F0-ATPase & 17 & 143 & 7 & -1.9 & 1.7 & $\mathrm{NaN}$ & -0.1 & 1.8 & -0.7 & -0.4 & -2.7 & -0.7 & 1.3 \\
\hline AN1769 & 3'-5' bisphosphate nucleotidase & 31 & 46 & 25 & -0.6 & 0.4 & $\mathrm{NaN}$ & -0.1 & 0.5 & 1.0 & -0.1 & -1.3 & -0.1 & 1.2 \\
\hline AN4997 & Phosphatidylinositol transporter & 44 & 85 & 110 & -1.0 & -0.1 & $\mathrm{NaN}$ & -0.1 & 0.6 & 0.3 & 0.2 & -1.6 & 0.2 & 1.1 \\
\hline AN7944 (Ngn3) & GNAT-type acetyltransferase & 62 & 102 & 70 & -1.0 & 0.0 & $\mathrm{NaN}$ & 0.0 & 0.6 & -0.7 & 0.1 & 0.8 & 0.1 & 0.8 \\
\hline AN8176 & $60 \mathrm{~S}$ ribosomal protein $\mathrm{L} 4$ & 135 & 126 & 444 & -1.1 & 0.0 & $\mathrm{NaN}$ & 0.0 & 0.6 & -0.4 & -0.2 & -2.1 & -0.4 & 1.0 \\
\hline AN8275 (CitA) & Citrate synthase & 90 & 199 & 401 & -1.6 & 0.0 & $\mathrm{NaN}$ & 0.0 & 0.9 & -1.1 & -0.4 & -2.7 & -1.1 & 1.2 \\
\hline AN6279 (AcuJ) & Carnitine acetyltransferase & 21 & 53 & 64 & -1.3 & 0.1 & $\mathrm{NaN}$ & 0.1 & 0.8 & -0.7 & -1.8 & -1.8 & -1.8 & 0.7 \\
\hline AN3344 (Ngn27) & GNAT-type acetyltransferase & 39 & 62 & 112 & -0.6 & 0.8 & $\mathrm{NaN}$ & 0.1 & 0.7 & 1.0 & 0.7 & -2.2 & 0.7 & 1.7 \\
\hline AN4282 & Metalloaminopeptidase & 85 & 137 & 146 & -0.8 & 0.1 & $\mathrm{NaN}$ & 0.1 & 0.5 & 0.7 & 0.0 & -1.3 & 0.0 & 1.0 \\
\hline AN8054 & 20S core proteasome & 61 & 75 & 83 & -0.7 & 0.1 & $\mathrm{NaN}$ & 0.1 & 0.4 & 0.2 & -0.3 & -1.0 & -0.3 & 0.6 \\
\hline AN10512 (MthA) & Ketoacyl-CoA thiolase & 18 & 7 & 21 & -0.7 & 1.0 & $\mathrm{NaN}$ & 0.1 & 0.9 & 0.9 & -0.6 & -1.6 & -0.6 & 1.2 \\
\hline AN6089 & Heat shock protein & 107 & 355 & 650 & -1.1 & 0.2 & $\mathrm{NaN}$ & 0.2 & 0.7 & -0.9 & -0.5 & -2.9 & -0.9 & 1.3 \\
\hline AN3299 & ne S-transferase & 15 & 10 & 7 & -0.2 & 0.9 & $\mathrm{NaN}$ & 0.3 & 0.6 & 1.4 & -0.4 & 1.3 & 1.3 & 1.0 \\
\hline AN3459 & Metall & 46 & 61 & 99 & 0.0 & 0.7 & $\mathrm{NaN}$ & 0.3 & 0.4 & 1.4 & 0.2 & -1.0 & 0.2 & 1.2 \\
\hline AN1689 & Oxidc & 76 & 74 & 37 & 0.1 & 0.6 & $\mathrm{NaN}$ & 0.4 & 0.3 & 0.8 & -0.3 & -0.2 & -0.2 & 0.6 \\
\hline AN3674 & inding activity & 628 & 357 & 615 & -0.5 & 0.4 & $\mathrm{NaN}$ & 0.4 & 0.5 & 2.3 & 1.2 & -0.6 & 1.2 & 1.5 \\
\hline AN5803 (F & Fimb & 76 & 155 & 165 & -0.5 & 0.7 & $\mathrm{NaN}$ & 0.7 & 0.6 & 1.2 & 0.1 & -0.8 & 0.1 & 1.0 \\
\hline AN7193 & Glyce & 50 & 127 & 113 & -0.2 & 0.8 & $\mathrm{NaN}$ & 0.8 & 0.5 & 1.3 & 0.3 & -0.4 & 0.3 & 0.8 \\
\hline AN1543 & Succi & 192 & 143 & 132 & 0.3 & 1.7 & $\mathrm{NaN}$ & 1.0 & 0.9 & 1.5 & -0.4 & -1.4 & -0.4 & 1.5 \\
\hline AN8756 & Monooxygenase & 3 & 34 & 78 & -0.5 & 1.3 & $\mathrm{NaN}$ & 1.3 & 0.9 & -0.7 & -0.6 & -3.7 & -0.7 & 1.7 \\
\hline AN2383 & Protei & 118 & 150 & 189 & 1.0 & 2.1 & $\mathrm{NaN}$ & 1.5 & 1.1 & 3.9 & 4.3 & 2.2 & 3.9 & 1.1 \\
\hline AN6490 & Phosphorylase & 17 & 31 & 27 & -0.8 & 1.7 & $\mathrm{NaN}$ & 1.7 & 1.3 & 0.8 & 0.4 & -0.6 & 0.4 & 0.7 \\
\hline AN6031 & Nitronate monooxyg & 36 & 90 & 32 & 0.8 & 1.9 & $\mathrm{NaN}$ & 1.9 & 0.9 & 1.4 & -0.8 & -0.4 & -0.4 & 1.1 \\
\hline AN8406 & Alcohol dehydrogenase & 67 & 84 & 28 & 0.7 & 1.9 & $\mathrm{NaN}$ & 1.9 & 1.0 & -0.6 & -1.5 & -0.9 & -0.9 & 0.5 \\
\hline AN5646 & Fatty acid degradation & 26 & 46 & 2 & 1.6 & 2.0 & $\mathrm{NaN}$ & 2.0 & 1.1 & 1.5 & -0.8 & -0.9 & -0.8 & 1.4 \\
\hline AN7902 & Monooxygenase & 19 & 31 & 6 & 1.9 & 2.1 & $\mathrm{NaN}$ & 2.1 & 1.2 & 0.6 & 1.0 & 1.2 & 1.0 & 0.3 \\
\hline AN2859 & Dihydrodipicolinate synthase & 69 & 47 & 13 & 1.7 & 3.0 & $\mathrm{NaN}$ & 2.4 & 1.5 & 1.8 & -0.9 & -1.0 & -0.9 & 1.6 \\
\hline AN7388 (CpeA) & Laccase & 450 & 319 & 63 & 1.9 & 3.1 & $\mathrm{NaN}$ & 3.1 & 1.6 & 3.2 & -0.6 & 4.7 & 3.2 & 2.7 \\
\hline AN7895 (ChiB) & Oxidoredu & 155 & 340 & 241 & 2.7 & 3.9 & $\mathrm{NaN}$ & 3.9 & 2.0 & 1.5 & 1.6 & -0.1 & 1.5 & 1.0 \\
\hline AN10087 & Proliferating cell nuc & 5 & & 17 & -1.1 & -0.2 & -1.2 & -1.1 & 0.6 & 0.6 & 0.4 & $\mathrm{NaN}$ & 0.5 & 0.3 \\
\hline AN7387 (PcrA) & Pyrroline-5-carboxylate reductase & 23 & 23 & 40 & -2.2 & -0.8 & -1.3 & -1.1 & 0.7 & -1.0 & -1.0 & $\mathrm{NaN}$ & -1.0 & 0.6 \\
\hline AN1799 & Triglyceride lipase & 32 & 22 & & -1.1 & -0.2 & -1.7 & -1.1 & 0.8 & 0.1 & 0.0 & $\mathrm{NaN}$ & 0.1 & 0.1 \\
\hline AN2493 & Alkaline phosphatase & 21 & 42 & 14 & -2.1 & -0.8 & -0.7 & -0.8 & 0.8 & 1.5 & 1.3 & $\mathrm{NaN}$ & 1.4 & 0.8 \\
\hline AN4231 & Riboflavin biosynthesis & 21 & 9 & 5 & -1.4 & -0.1 & -1.2 & -0.6 & 0.7 & 0.6 & 0.3 & $\mathrm{NaN}$ & 0.4 & 0.3 \\
\hline AN6014 (FaaA) & Long-chain-fatty-acid-CoA ligase & 29 & 9 & & -0.5 & 0.5 & -1.8 & -0.6 & 1.2 & 1.9 & 0.7 & $\mathrm{NaN}$ & 1.3 & 0.9 \\
\hline AN4905 (GstA) & Glutathione S-transferase & 36 & 38 & & 0.2 & 1.0 & -2.1 & -0.5 & 1.6 & 2.3 & 0.6 & $\mathrm{NaN}$ & 1.4 & 1.2 \\
\hline AN5558 (PrtA) & Alkaline protease & 17 & 102 & 73 & 0.1 & 0.4 & -0.7 & -0.2 & 0.6 & 2.9 & 3.3 & $\mathrm{NaN}$ & 3.1 & 1.8 \\
\hline AN1763 & Oxidoreductase & 11 & 10 & & -0.6 & 0.4 & 0.1 & 0.1 & 0.5 & 0.5 & 0.1 & $\mathrm{NaN}$ & 0.3 & 0.2 \\
\hline AN2572 & Dipeptidyl-peptidase & 65 & 136 & 29 & 0.2 & 1.4 & -2.7 & 0.2 & 2.1 & 1.1 & -0.1 & $\mathrm{NaN}$ & 0.5 & 0.7 \\
\hline AN1378 & Protein of unknown function & 169 & 6 & & 0.2 & 2.5 & -1.0 & 0.2 & 1.8 & 1.9 & 0.9 & $\mathrm{NaN}$ & 1.4 & 0.9 \\
\hline AN8415 (ApdG) & Acyl-coA dehydrogenase & 15 & 9 & & 0.4 & 1.4 & -0.1 & 0.6 & 0.8 & 0.9 & -2.6 & $\mathrm{NaN}$ & -0.8 & 1.8 \\
\hline AN5421 & Monooxygenase & 146 & 40 & 9 & 0.7 & 1.8 & -0.4 & 0.7 & 1.1 & 3.5 & 0.6 & $\mathrm{NaN}$ & 2.0 & 1.9 \\
\hline AN8942 & Protein of unknown function & 21 & 17 & 10 & -1.4 & -0.9 & 2.4 & 0.8 & 2.1 & 0.2 & -0.6 & $\mathrm{NaN}$ & -0.2 & 0.4 \\
\hline AN9340 (TreA) & Alpha-trehalase & 27 & 17 & 3 & 0.3 & 1.2 & 1.2 & 1.2 & 0.5 & 1.7 & -0.6 & $\mathrm{NaN}$ & 0.6 & 1.2 \\
\hline AN8445 & Aminopeptidase $Y$ & 55 & 58 & 52 & -1.0 & -0.3 & 2.9 & 1.3 & 2.1 & 2.9 & 1.5 & $\mathrm{NaN}$ & 2.2 & 1.4 \\
\hline AN6035 & D-fuconate dehydratase & 28 & 11 & 7 & 2.9 & 5.0 & -1.8 & 1.6 & 3.5 & 4.1 & 1.0 & $\mathrm{NaN}$ & 2.6 & 2.2 \\
\hline AN2166 & Phytanoyl-CoA dioxygenase & 39 & 30 & 3 & 2.0 & 2.8 & -1.3 & 2.0 & 2.2 & 2.1 & 1.1 & $\mathrm{NaN}$ & 1.6 & 1.1 \\
\hline AN1050 & 3-ketoacyl-CoA thiolase & 46 & 33 & & 2.3 & 2.6 & -2.1 & 2.3 & 2.6 & 2.4 & -1.4 & $\mathrm{NaN}$ & 0.5 & 1.9 \\
\hline AN6853 & Phosphatidylinositol transporter & & 10 & 33 & $\mathrm{NaN}$ & -1.3 & -1.2 & -1.3 & 0.7 & $\mathrm{NaN}$ & -0.1 & -1.4 & -0.8 & 0.8 \\
\hline AN3593 & Dehydratase & 6 & 17 & 27 & $\mathrm{NaN}$ & -0.5 & -1.8 & -1.2 & 0.9 & $\mathrm{NaN}$ & 0.6 & -0.9 & -0.2 & 0.7 \\
\hline AN3719 (MpkB) & Mitogen-activated protein kinase & & 7 & 43 & $\mathrm{NaN}$ & -0.9 & -0.9 & -0.9 & 0.5 & $\mathrm{NaN}$ & 0.2 & -0.2 & 0.0 & 0.2 \\
\hline AN5954 & Translation initiation factor & 8 & 21 & 116 & $\mathrm{NaN}$ & -1.6 & -0.3 & -0.9 & 0.9 & $\mathrm{NaN}$ & -0.4 & -1.8 & -1.1 & 1.0 \\
\hline
\end{tabular}




\begin{tabular}{|c|c|c|c|c|c|c|c|c|c|c|c|c|c|c|}
\hline \multirow[t]{2}{*}{ Gene ID } & \multirow[t]{2}{*}{ Description } & \multicolumn{3}{|c|}{ PSM } & \multicolumn{3}{|c|}{ IaeAd/aeA } & \multirow[t]{2}{*}{$\varnothing$} & \multirow[t]{2}{*}{ SD } & \multicolumn{3}{|c|}{ laeAcomp+/laeA } & $\varnothing$ & SD \\
\hline & & 1 & 2 & 3 & 1 & 2 & 3 & & & 1 & 2 & 3 & & \\
\hline AN1673 & DAHP synthase & 4 & 9 & 18 & $\mathrm{NaN}$ & -1.2 & -1.1 & -1.1 & 0.7 & -1.6 & $\mathrm{NaN}$ & -1.0 & $\mathrm{NaN}$ & $\mathrm{NaN}$ \\
\hline AN7914 & Alcohol dehydrogenase & 203 & 159 & 75 & \begin{tabular}{|l|}
-6.2 \\
\end{tabular} & -4.9 & $\mathrm{NaN}$ & -4.9 & 3.3 & -1.8 & -3.9 & $\mathrm{NaN}$ & -2.8 & 1.9 \\
\hline AN2343 & Nitroreductase & 97 & 8 & & -4.9 & -2.8 & $\mathrm{NaN}$ & -3.9 & 2.5 & -3.1 & -1.8 & $\mathrm{NaN}$ & -2.4 & 1.5 \\
\hline AN7836 & Protein of unknown function & 19 & 36 & 23 & -3.5 & -3.0 & $\mathrm{NaN}$ & -3.0 & 1.9 & 1.2 & -1.5 & $\mathrm{NaN}$ & -0.2 & 1.4 \\
\hline AN2622 (IpnA) & Isopenicillin- $\mathrm{N}$ synthase & 8 & 2 & & -2.1 & -4.0 & $\mathrm{NaN}$ & -3.0 & 2.0 & 2.0 & 0.4 & $\mathrm{NaN}$ & 1.2 & 1.1 \\
\hline AN7268 & Oxidoreductase & 35 & 17 & 2 & -1.1 & -2.9 & $\mathrm{NaN}$ & -2.9 & 1.5 & 2.9 & 0.8 & $\mathrm{NaN}$ & 1.8 & 1.5 \\
\hline AN1539 (CsnD) & COP9 signalosome & 3 & & 4 & -1.5 & 1.0 & -2.1 & -1.5 & 1.6 & 0.9 & $\mathrm{NaN}$ & $\mathrm{NaN}$ & $\mathrm{NaN}$ & $\mathrm{NaN}$ \\
\hline AN3628 & Peptide alpha-N-acetyltransferase & 5 & 7 & 41 & -1.9 & $\mathrm{NaN}$ & -1.2 & -1.2 & 1.0 & -0.6 & $\mathrm{NaN}$ & -1.6 & -1.1 & 0.8 \\
\hline AN2315 & F1F0-ATPase complex subunit & 417 & 515 & 842 & -1.7 & -0.3 & $\mathrm{NaN}$ & -1.0 & 0.9 & -0.4 & -0.5 & $\mathrm{NaN}$ & -0.4 & 0.3 \\
\hline AN1194 & Adenylyl phosphosulfate kinas & 14 & 28 & 50 & -1.5 & -0.4 & $\mathrm{NaN}$ & -0.9 & 0.8 & 0.6 & 0.2 & $\mathrm{NaN}$ & 0.4 & 0.3 \\
\hline AN2668 & Oxidoreductase & 2 & 3 & & -1.2 & -0.6 & $\mathrm{NaN}$ & -0.9 & 0.6 & -0.3 & -1.0 & $\mathrm{NaN}$ & -0.6 & 0.5 \\
\hline AN5981 & Myosin I binding activity & 12 & 6 & 28 & -1.2 & $\mathrm{NaN}$ & 0.9 & -0.1 & 1.1 & 0.1 & $\mathrm{NaN}$ & \begin{tabular}{|r|}
-1.1 \\
\end{tabular} & -0.5 & 0.7 \\
\hline AN3524 & Galactose 1-dehydrogenase & & 29 & 43 & $\mathrm{NaN}$ & 2.1 & -1.3 & 0.4 & 1.7 & $\mathrm{NaN}$ & $\mathrm{NaN}$ & -4.6 & -4.6 & 2.7 \\
\hline AN5878 & Thiolases & 2 & 5 & 4 & 1.0 & 1.8 & -0.7 & 0.6 & 1.3 & -0.9 & $\mathrm{NaN}$ & $\mathrm{NaN}$ & $\mathrm{NaN}$ & $\mathrm{NaN}$ \\
\hline AN0034 & Kinase & 84 & 51 & & 0.6 & 1.5 & $\mathrm{NaN}$ & 1.0 & 0.8 & 2.6 & -0.4 & $\mathrm{NaN}$ & 1.1 & 1.6 \\
\hline AN2828 (BglL) & Beta-glucosidase & 58 & 6 & & 1.1 & 1.3 & -0.3 & 1.1 & 0.9 & 3.4 & $\mathrm{NaN}$ & $\mathrm{NaN}$ & $\mathrm{NaN}$ & $\mathrm{NaN}$ \\
\hline AN10335 & Oxidoreductase & 5 & 8 & & 1.0 & 2.0 & $\mathrm{NaN}$ & 1.5 & 1.0 & 3.0 & -0.2 & $\mathrm{NaN}$ & 1.4 & 1.8 \\
\hline AN0783 & Carbon-nitrogen ligase & 3 & 17 & 10 & 1.7 & 1.8 & -1.8 & 1.7 & 2.1 & 2.6 & $\mathrm{NaN}$ & $\mathrm{NaN}$ & $\mathrm{NaN}$ & $\mathrm{NaN}$ \\
\hline AN2577 & Oxidoreductase & 36 & 25 & & 1.3 & 2.3 & $\mathrm{NaN}$ & 1.8 & 1.2 & 0.7 & $\mathrm{NaN}$ & $\mathrm{NaN}$ & $\mathrm{NaN}$ & $\mathrm{NaN}$ \\
\hline AN1677 & Short-chain dehydrogenase & 45 & 48 & 18 & 2.0 & 3.0 & $\mathrm{NaN}$ & 2.5 & 1.5 & 1.1 & $\mathrm{NaN}$ & $\mathrm{NaN}$ & $\mathrm{NaN}$ & $\mathrm{NaN}$ \\
\hline AN5695 & Carbon-sulfur lyase & 7 & 2 & & 1.2 & 2.7 & $\mathrm{NaN}$ & 2.7 & 1.3 & 1.0 & -0.1 & $\mathrm{NaN}$ & 0.5 & 0.6 \\
\hline AN5373 & Oxidoreductase & 49 & 25 & 5 & 1.9 & 2.9 & $\mathrm{NaN}$ & 2.9 & 1.5 & 3.5 & 1.5 & $\mathrm{NaN}$ & 2.5 & 1.7 \\
\hline AN5883 (MetF) & Reductase & 14 & 5 & 42 & $\mathrm{NaN}$ & -1.3 & $\mathrm{NaN}$ & $\mathrm{NaN}$ & $\mathrm{NaN}$ & -1.4 & 0.3 & \begin{tabular}{|l|}
-1.8 \\
\end{tabular} & -1.4 & 1.1 \\
\hline AN3591 & Dehydrogenase & 56 & 78 & 62 & $\mathrm{NaN}$ & 0.7 & $\mathrm{NaN}$ & $\mathrm{NaN}$ & $\mathrm{NaN}$ & 1.0 & -0.8 & -1.2 & -0.8 & 1.2 \\
\hline AN0651 (FadA) & Heterotrimeric G protein & 5 & 6 & 3 & $\mathrm{NaN}$ & $\mathrm{NaN}$ & -0.5 & $\mathrm{NaN}$ & 0.3 & $\mathrm{NaN}$ & $\mathrm{NaN}$ & -1.2 & $\mathrm{NaN}$ & $\mathrm{NaN}$ \\
\hline AN3594 (SogA) & Vacuolar protein-sorting protein & 7 & 24 & 22 & $\mathrm{NaN}$ & $\mathrm{NaN}$ & -1.5 & $\mathrm{NaN}$ & $\mathrm{NaN}$ & $\mathrm{NaN}$ & 0.0 & -1.8 & $\mathrm{NaN}$ & $\mathrm{NaN}$ \\
\hline AN7579 & $26 \mathrm{~S}$ proteasome regulatory subunit & 5 & & 23 & \begin{tabular}{|r|}
-1.0 \\
\end{tabular} & $\mathrm{NaN}$ & -1.7 & $\mathrm{NaN}$ & 0.9 & $\mathrm{NaN}$ & $\mathrm{NaN}$ & -0.8 & $\mathrm{NaN}$ & $\mathrm{NaN}$ \\
\hline AN1805 (CanB) & Carbonic anhydrase & & 35 & 36 & $\mathrm{NaN}$ & -2.0 & $\mathrm{NaN}$ & $\mathrm{NaN}$ & $\mathrm{NaN}$ & $\mathrm{NaN}$ & 0.1 & $\mathrm{NaN}$ & $\mathrm{NaN}$ & $\mathrm{NaN}$ \\
\hline AN3349 & Cytochrome P450 & 16 & 8 & 7 & $\mathrm{NaN}$ & $\mathrm{NaN}$ & -3.8 & $\mathrm{NaN}$ & $\mathrm{NaN}$ & 0.3 & $\mathrm{NaN}$ & $\mathrm{NaN}$ & $\mathrm{NaN}$ & $\mathrm{NaN}$ \\
\hline AN6078 (NadA) & Adenine deaminase & 4 & & 10 & $\mathrm{NaN}$ & $\mathrm{NaN}$ & -2.3 & $\mathrm{NaN}$ & $\mathrm{NaN}$ & $\mathrm{NaN}$ & $\mathrm{NaN}$ & $\mathrm{NaN}$ & $\mathrm{NaN}$ & $\mathrm{NaN}$ \\
\hline AN6712 (PldA) & Phospholipase D & 14 & 5 & & $\mathrm{NaN}$ & $\mathrm{NaN}$ & -2.0 & $\mathrm{NaN}$ & $\mathrm{NaN}$ & $\mathrm{NaN}$ & $\mathrm{NaN}$ & $\mathrm{NaN}$ & $\mathrm{NaN}$ & $\mathrm{NaN}$ \\
\hline AN3573 & Oxidoreductase & 54 & 6 & 5 & 1.8 & $\mathrm{NaN}$ & $\mathrm{NaN}$ & $\mathrm{NaN}$ & $\mathrm{NaN}$ & 5.4 & $\mathrm{NaN}$ & $\mathrm{NaN}$ & $\mathrm{NaN}$ & $\mathrm{NaN}$ \\
\hline AN9103 (AifA) & Apoptosis-inducing factor (AIF)-like & 48 & 59 & 17 & $\mathrm{NaN}$ & $\mathrm{NaN}$ & -1.1 & $\mathrm{NaN}$ & $\mathrm{NaN}$ & $\mathrm{NaN}$ & $\mathrm{NaN}$ & 1.8 & $\mathrm{NaN}$ & $\mathrm{NaN}$ \\
\hline AN7143 & Heat shock protein & 3 & & 103 & $\mathrm{NaN}$ & $\mathrm{NaN}$ & -5.6 & $\mathrm{NaN}$ & $\mathrm{NaN}$ & $\mathrm{NaN}$ & $\mathrm{NaN}$ & -1.8 & $\mathrm{NaN}$ & $\mathrm{NaN}$ \\
\hline AN8797 (MvlA) & Orsellinic acid gene cluster & & 22 & 14 & $\mathrm{NaN}$ & $\mathrm{NaN}$ & -1.5 & $\mathrm{NaN}$ & $\mathrm{NaN}$ & $\mathrm{NaN}$ & $\mathrm{NaN}$ & -1.7 & $\mathrm{NaN}$ & $\mathrm{NaN}$ \\
\hline AN6838 (TubC) & Beta-tubulin & 157 & & 365 & $\mathrm{NaN}$ & $\mathrm{NaN}$ & -3.7 & $\mathrm{NaN}$ & $\mathrm{NaN}$ & $\mathrm{NaN}$ & $\mathrm{NaN}$ & -0.9 & $\mathrm{NaN}$ & $\mathrm{NaN}$ \\
\hline AN8692 & Thioredoxin-dependent peroxidase & 123 & & 6 & $\mathrm{NaN}$ & $\mathrm{NaN}$ & -2.4 & $\mathrm{NaN}$ & $\mathrm{NaN}$ & $\mathrm{NaN}$ & $\mathrm{NaN}$ & 0.6 & $\mathrm{NaN}$ & $\mathrm{NaN}$ \\
\hline AN6126 (AccA) & Acetyl-CoA carboxylase & 36 & 156 & 351 & $\mathrm{NaN}$ & $\mathrm{NaN}$ & -2.4 & $\mathrm{NaN}$ & $\mathrm{NaN}$ & $\mathrm{NaN}$ & $\mathrm{NaN}$ & -0.8 & $\mathrm{NaN}$ & $\mathrm{NaN}$ \\
\hline AN6157 (PyrG) & Decarboxylase & & 6 & 16 & $\mathrm{NaN}$ & $\mathrm{NaN}$ & -2.2 & $\mathrm{NaN}$ & $\mathrm{NaN}$ & $\mathrm{NaN}$ & $\mathrm{NaN}$ & -1.4 & $\mathrm{NaN}$ & $\mathrm{NaN}$ \\
\hline AN8932 & TIM-barrel enzyme family protein & & 6 & 2 & $\mathrm{NaN}$ & $\mathrm{NaN}$ & -2.1 & $\mathrm{NaN}$ & $\mathrm{NaN}$ & $\mathrm{NaN}$ & $\mathrm{NaN}$ & 1.5 & $\mathrm{NaN}$ & $\mathrm{NaN}$ \\
\hline AN8072 & Protein of unknown function & 7 & 6 & 21 & $\mathrm{NaN}$ & $\mathrm{NaN}$ & -2.1 & $\mathrm{NaN}$ & $\mathrm{NaN}$ & $\mathrm{NaN}$ & $\mathrm{NaN}$ & -1.1 & $\mathrm{NaN}$ & $\mathrm{NaN}$ \\
\hline AN6060 & Role in RNA metabolic process & 7 & 22 & 107 & $\mathrm{NaN}$ & $\mathrm{NaN}$ & -2.0 & $\mathrm{NaN}$ & $\mathrm{NaN}$ & $\mathrm{NaN}$ & $\mathrm{NaN}$ & -2.0 & $\mathrm{NaN}$ & $\mathrm{NaN}$ \\
\hline AN7008 & Hydroxyacyl-CoA dehydrogenase & & 8 & 6 & $\mathrm{NaN}$ & $\mathrm{NaN}$ & -2.0 & $\mathrm{NaN}$ & $\mathrm{NaN}$ & $\mathrm{NaN}$ & $\mathrm{NaN}$ & -1.3 & $\mathrm{NaN}$ & $\mathrm{NaN}$ \\
\hline AN6753 & Oxidoreductase & & 15 & 34 & $\mathrm{NaN}$ & $\mathrm{NaN}$ & -1.9 & $\mathrm{NaN}$ & $\mathrm{NaN}$ & $\mathrm{NaN}$ & $\mathrm{NaN}$ & -1.8 & $\mathrm{NaN}$ & $\mathrm{NaN}$ \\
\hline AN8268 & Ras GTPase-activating protein & 12 & & 45 & $\mathrm{NaN}$ & $\mathrm{NaN}$ & -1.8 & $\mathrm{NaN}$ & $\mathrm{NaN}$ & $\mathrm{NaN}$ & $\mathrm{NaN}$ & -1.8 & $\mathrm{NaN}$ & $\mathrm{NaN}$ \\
\hline AN6077 & NADH dehydrogenase (ubiquinone) & & 5 & 77 & $\mathrm{NaN}$ & $\mathrm{NaN}$ & -1.8 & $\mathrm{NaN}$ & $\mathrm{NaN}$ & $\mathrm{NaN}$ & $\mathrm{NaN}$ & -2.6 & $\mathrm{NaN}$ & $\mathrm{NaN}$ \\
\hline AN8874 & Dynamin-related protein & 14 & 8 & 41 & $\mathrm{NaN}$ & $\mathrm{NaN}$ & -1.8 & $\mathrm{NaN}$ & $\mathrm{NaN}$ & $\mathrm{NaN}$ & $\mathrm{NaN}$ & -1.9 & $\mathrm{NaN}$ & $\mathrm{NaN}$ \\
\hline AN5908 (TpiB) & Triose-phosphate isomerase & 12 & 10 & 11 & $\mathrm{NaN}$ & $\mathrm{NaN}$ & -1.8 & $\mathrm{NaN}$ & $\mathrm{NaN}$ & $\mathrm{NaN}$ & $\mathrm{NaN}$ & -0.7 & $\mathrm{NaN}$ & $\mathrm{NaN}$ \\
\hline AN8036 & Oxidoreductase & & 15 & 14 & $\mathrm{NaN}$ & $\mathrm{NaN}$ & -1.7 & $\mathrm{NaN}$ & $\mathrm{NaN}$ & $\mathrm{NaN}$ & $\mathrm{NaN}$ & 0.7 & $\mathrm{NaN}$ & $\mathrm{NaN}$ \\
\hline AN9407 (FasA) & Fatty acid synthase & 41 & 144 & 524 & $\mathrm{NaN}$ & $\mathrm{NaN}$ & -1.7 & $\mathrm{NaN}$ & $\mathrm{NaN}$ & $\mathrm{NaN}$ & $\mathrm{NaN}$ & -1.6 & $\mathrm{NaN}$ & $\mathrm{NaN}$ \\
\hline AN7159 & Tripeptidyl-peptidase & & 24 & 22 & $\mathrm{NaN}$ & $\mathrm{NaN}$ & -1.6 & $\mathrm{NaN}$ & $\mathrm{NaN}$ & $\mathrm{NaN}$ & $\mathrm{NaN}$ & -1.4 & $\mathrm{NaN}$ & $\mathrm{NaN}$ \\
\hline AN3629 & DNA glycosylase & & 4 & 13 & $\mathrm{NaN}$ & $\mathrm{NaN}$ & -1.5 & $\mathrm{NaN}$ & $\mathrm{NaN}$ & $\mathrm{NaN}$ & $\mathrm{NaN}$ & -0.6 & $\mathrm{NaN}$ & $\mathrm{NaN}$ \\
\hline AN6688 (AspB) & Putative Septin B & 8 & 180 & 314 & $\mathrm{NaN}$ & $\mathrm{NaN}$ & -1.5 & $\mathrm{NaN}$ & $\mathrm{NaN}$ & $\mathrm{NaN}$ & $\mathrm{NaN}$ & -0.8 & $\mathrm{NaN}$ & $\mathrm{NaN}$ \\
\hline AN7035 & Peptidase & & 10 & 34 & $\mathrm{NaN}$ & $\mathrm{NaN}$ & -1.5 & $\mathrm{NaN}$ & $\mathrm{NaN}$ & $\mathrm{NaN}$ & $\mathrm{NaN}$ & -0.1 & $\mathrm{NaN}$ & $\mathrm{NaN}$ \\
\hline AN9090 (RrmA) & RNA binding protein & 22 & 21 & 86 & $\mathrm{NaN}$ & $\mathrm{NaN}$ & -1.4 & $\mathrm{NaN}$ & $\mathrm{NaN}$ & $\mathrm{NaN}$ & $\mathrm{NaN}$ & -1.5 & $\mathrm{NaN}$ & $\mathrm{NaN}$ \\
\hline AN6006 (KapD) & Karyopherin & 9 & 24 & 79 & $\mathrm{NaN}$ & $\mathrm{NaN}$ & -1.4 & $\mathrm{NaN}$ & $\mathrm{NaN}$ & $\mathrm{NaN}$ & $\mathrm{NaN}$ & -1.7 & $\mathrm{NaN}$ & $\mathrm{NaN}$ \\
\hline AN9083 & Adenine phosphoribosyltransferase & 11 & 12 & 11 & $\mathrm{NaN}$ & $\mathrm{NaN}$ & 0.1 & $\mathrm{NaN}$ & $\mathrm{NaN}$ & $\mathrm{NaN}$ & $\mathrm{NaN}$ & -0.8 & $\mathrm{NaN}$ & $\mathrm{NaN}$ \\
\hline AN6705 & Protein of unknown function & & 12 & 44 & $\mathrm{NaN}$ & $\mathrm{NaN}$ & -1.4 & $\mathrm{NaN}$ & $\mathrm{NaN}$ & $\mathrm{NaN}$ & $\mathrm{NaN}$ & -1.5 & $\mathrm{NaN}$ & $\mathrm{NaN}$ \\
\hline AN8203 & Hydrolase & 16 & 10 & 35 & $\mathrm{NaN}$ & $\mathrm{NaN}$ & -1.3 & $\mathrm{NaN}$ & $\mathrm{NaN}$ & $\mathrm{NaN}$ & $\mathrm{NaN}$ & -0.9 & $\mathrm{NaN}$ & $\mathrm{NaN}$ \\
\hline AN7590 & Mannitol 2-dehydrogenase & 18 & 23 & 17 & $\mathrm{NaN}$ & $\mathrm{NaN}$ & -1.3 & $\mathrm{NaN}$ & $\mathrm{NaN}$ & $\mathrm{NaN}$ & $\mathrm{NaN}$ & -1.3 & $\mathrm{NaN}$ & $\mathrm{NaN}$ \\
\hline AN6741 & Aspartic-type endopeptidase & 2 & & 3 & $\mathrm{NaN}$ & $\mathrm{NaN}$ & -1.3 & $\mathrm{NaN}$ & $\mathrm{NaN}$ & $\mathrm{NaN}$ & $\mathrm{NaN}$ & -1.3 & $\mathrm{NaN}$ & $\mathrm{NaN}$ \\
\hline AN6338 & Aromatic-amino-acid transaminase & & 14 & 29 & $\mathrm{NaN}$ & $\mathrm{NaN}$ & -1.2 & $\mathrm{NaN}$ & $\mathrm{NaN}$ & $\mathrm{NaN}$ & $\mathrm{NaN}$ & -2.3 & $\mathrm{NaN}$ & $\mathrm{NaN}$ \\
\hline AN7909 (OrsA) & Polyketide synthase & 13 & 15 & 45 & $\mathrm{NaN}$ & $\mathrm{NaN}$ & -1.2 & $\mathrm{NaN}$ & $\mathrm{NaN}$ & $\mathrm{NaN}$ & $\mathrm{NaN}$ & 0.4 & $\mathrm{NaN}$ & $\mathrm{NaN}$ \\
\hline AN8755 (MclA) & Methylisocitrate lyase & & 3 & 15 & $\mathrm{NaN}$ & $\mathrm{NaN}$ & -1.1 & $\mathrm{NaN}$ & $\mathrm{NaN}$ & $\mathrm{NaN}$ & $\mathrm{NaN}$ & -1.0 & $\mathrm{NaN}$ & $\mathrm{NaN}$ \\
\hline AN6193 & Peptidase & & 15 & 59 & $\mathrm{NaN}$ & $\mathrm{NaN}$ & -1.1 & $\mathrm{NaN}$ & $\mathrm{NaN}$ & $\mathrm{NaN}$ & $\mathrm{NaN}$ & -2.3 & $\mathrm{NaN}$ & $\mathrm{NaN}$ \\
\hline AN6734 (KapF) & Karyopherin & 23 & 31 & 47 & $\mathrm{NaN}$ & $\mathrm{NaN}$ & -1.0 & $\mathrm{NaN}$ & $\mathrm{NaN}$ & $\mathrm{NaN}$ & $\mathrm{NaN}$ & -1.2 & $\mathrm{NaN}$ & $\mathrm{NaN}$ \\
\hline AN7199 & Protein of unknown function & & 2 & 48 & $\mathrm{NaN}$ & $\mathrm{NaN}$ & -1.0 & $\mathrm{NaN}$ & $\mathrm{NaN}$ & $\mathrm{NaN}$ & $\mathrm{NaN}$ & -2.8 & $\mathrm{NaN}$ & $\mathrm{NaN}$ \\
\hline
\end{tabular}




\begin{tabular}{|c|c|c|c|c|c|c|c|c|c|c|c|c|c|c|}
\hline \multirow[t]{2}{*}{ Gene ID } & \multirow[t]{2}{*}{ Description } & \multicolumn{3}{|c|}{ PSM } & \multicolumn{3}{|c|}{ IaeAd/laeA } & \multirow[t]{2}{*}{$\varnothing$} & \multirow[t]{2}{*}{ SD } & \multicolumn{3}{|c|}{ laeAcomp+/laeA } & $\varnothing$ & SD \\
\hline & & 1 & 2 & 3 & 1 & 2 & 3 & & & 1 & 2 & 3 & & \\
\hline AN7194 & Oxidoreductase & 6 & 4 & 14 & $\mathrm{NaN}$ & $\mathrm{NaN}$ & -0.9 & $\mathrm{NaN}$ & $\mathrm{NaN}$ & $\mathrm{NaN}$ & $\mathrm{NaN}$ & -1.3 & $\mathrm{NaN}$ & $\mathrm{NaN}$ \\
\hline AN8869 & Uracil phosphoribosyltransferase & 12 & 11 & 15 & $\mathrm{NaN}$ & $\mathrm{NaN}$ & -0.9 & $\mathrm{NaN}$ & $\mathrm{NaN}$ & $\mathrm{NaN}$ & $\mathrm{NaN}$ & -1.0 & $\mathrm{NaN}$ & $\mathrm{NaN}$ \\
\hline AN9094 (UngA) & Pyrophosphorylase & 147 & 233 & 287 & $\mathrm{NaN}$ & $\mathrm{NaN}$ & -0.9 & $\mathrm{NaN}$ & $\mathrm{NaN}$ & $\mathrm{NaN}$ & $\mathrm{NaN}$ & -0.8 & $\mathrm{NaN}$ & $\mathrm{NaN}$ \\
\hline AN6507 & Cap binding protein & & 4 & 32 & $\mathrm{NaN}$ & $\mathrm{NaN}$ & -0.9 & $\mathrm{NaN}$ & $\mathrm{NaN}$ & $\mathrm{NaN}$ & $\mathrm{NaN}$ & -1.5 & $\mathrm{NaN}$ & $\mathrm{NaN}$ \\
\hline AN8023 (VpsA) & Required for vacuole biogenesis & 17 & 51 & 111 & $\mathrm{NaN}$ & $\mathrm{NaN}$ & -0.8 & $\mathrm{NaN}$ & $\mathrm{NaN}$ & $\mathrm{NaN}$ & $\mathrm{NaN}$ & -1.6 & $\mathrm{NaN}$ & $\mathrm{NaN}$ \\
\hline AN8057 (CysB) & Cysteine synthase & & 15 & 63 & $\mathrm{NaN}$ & $\mathrm{NaN}$ & -0.8 & $\mathrm{NaN}$ & $\mathrm{NaN}$ & $\mathrm{NaN}$ & $\mathrm{NaN}$ & -2.4 & $\mathrm{NaN}$ & $\mathrm{NaN}$ \\
\hline AN6978 (Rcc1) & Nucleotide exchange factor & & 6 & 49 & $\mathrm{NaN}$ & $\mathrm{NaN}$ & -0.8 & $\mathrm{NaN}$ & $\mathrm{NaN}$ & $\mathrm{NaN}$ & $\mathrm{NaN}$ & -1.4 & $\mathrm{NaN}$ & $\mathrm{NaN}$ \\
\hline AN7441 & Histone acetyltransferase & 3 & 4 & 20 & $\mathrm{NaN}$ & $\mathrm{NaN}$ & -0.7 & $\mathrm{NaN}$ & $\mathrm{NaN}$ & $\mathrm{NaN}$ & $\mathrm{NaN}$ & -1.0 & $\mathrm{NaN}$ & $\mathrm{NaN}$ \\
\hline AN6512 & ATPase & & 8 & 14 & $\mathrm{NaN}$ & $\mathrm{NaN}$ & -0.7 & $\mathrm{NaN}$ & $\mathrm{NaN}$ & $\mathrm{NaN}$ & $\mathrm{NaN}$ & -0.9 & $\mathrm{NaN}$ & $\mathrm{NaN}$ \\
\hline AN7498 & Deoxyhypusine monooxygenase & 12 & 14 & 14 & $\mathrm{NaN}$ & $\mathrm{NaN}$ & -0.7 & $\mathrm{NaN}$ & $\mathrm{NaN}$ & $\mathrm{NaN}$ & $\mathrm{NaN}$ & -1.2 & $\mathrm{NaN}$ & $\mathrm{NaN}$ \\
\hline AN6045 & Chaperone & 3 & & 7 & $\mathrm{NaN}$ & $\mathrm{NaN}$ & -0.6 & $\mathrm{NaN}$ & $\mathrm{NaN}$ & $\mathrm{NaN}$ & $\mathrm{NaN}$ & -1.2 & $\mathrm{NaN}$ & $\mathrm{NaN}$ \\
\hline AN6844 & 3-hydroxyisobutyryl-CoA hydrolase & 8 & 12 & 10 & $\mathrm{NaN}$ & $\mathrm{NaN}$ & -0.6 & $\mathrm{NaN}$ & $\mathrm{NaN}$ & $\mathrm{NaN}$ & $\mathrm{NaN}$ & -2.3 & $\mathrm{NaN}$ & $\mathrm{NaN}$ \\
\hline AN6054 & Genome maintenance protein & & 2 & 3 & $\mathrm{NaN}$ & $\mathrm{NaN}$ & -0.5 & $\mathrm{NaN}$ & $\mathrm{NaN}$ & $\mathrm{NaN}$ & $\mathrm{NaN}$ & -2.0 & $\mathrm{NaN}$ & $\mathrm{NaN}$ \\
\hline AN6505 (RcoA) & WD40 repeat protein & 25 & 39 & 57 & $\mathrm{NaN}$ & $\mathrm{NaN}$ & -0.3 & $\mathrm{NaN}$ & $\mathrm{NaN}$ & $\mathrm{NaN}$ & $\mathrm{NaN}$ & -0.4 & $\mathrm{NaN}$ & $\mathrm{NaN}$ \\
\hline AN8795 & AP-1 adaptor complex subunit & 2 & 7 & 16 & $\mathrm{NaN}$ & $\mathrm{NaN}$ & -0.3 & $\mathrm{NaN}$ & $\mathrm{NaN}$ & $\mathrm{NaN}$ & $\mathrm{NaN}$ & -1.7 & $\mathrm{NaN}$ & $\mathrm{NaN}$ \\
\hline AN7142 (PacA) & Phosphatase & & 7 & 216 & $\mathrm{NaN}$ & $\mathrm{NaN}$ & 0.0 & $\mathrm{NaN}$ & $\mathrm{NaN}$ & $\mathrm{NaN}$ & $\mathrm{NaN}$ & -4.2 & $\mathrm{NaN}$ & $\mathrm{NaN}$ \\
\hline AN6033 & Coat protein complex I & 17 & & 14 & $\mathrm{NaN}$ & $\mathrm{NaN}$ & 0.0 & $\mathrm{NaN}$ & $\mathrm{NaN}$ & $\mathrm{NaN}$ & $\mathrm{NaN}$ & -1.8 & $\mathrm{NaN}$ & $\mathrm{NaN}$ \\
\hline AN6182 (GalD) & Uridylyltransferase & 5 & & 4 & $\mathrm{NaN}$ & $\mathrm{NaN}$ & 0.1 & $\mathrm{NaN}$ & $\mathrm{NaN}$ & $\mathrm{NaN}$ & $\mathrm{NaN}$ & -0.4 & $\mathrm{NaN}$ & $\mathrm{NaN}$ \\
\hline AN7491 & Deubiquitinating enzymes & & 6 & 14 & $\mathrm{NaN}$ & $\mathrm{NaN}$ & 0.2 & $\mathrm{NaN}$ & $\mathrm{NaN}$ & $\mathrm{NaN}$ & $\mathrm{NaN}$ & -0.6 & $\mathrm{NaN}$ & $\mathrm{NaN}$ \\
\hline AN8945 & Methyltransferase & & 7 & 20 & $\mathrm{NaN}$ & $\mathrm{NaN}$ & 0.6 & $\mathrm{NaN}$ & $\mathrm{NaN}$ & $\mathrm{NaN}$ & $\mathrm{NaN}$ & -0.7 & $\mathrm{NaN}$ & $\mathrm{NaN}$ \\
\hline AN7540 & Role in translational initiation & & 263 & 141 & $\mathrm{NaN}$ & $\mathrm{NaN}$ & 0.6 & $\mathrm{NaN}$ & $\mathrm{NaN}$ & $\mathrm{NaN}$ & $\mathrm{NaN}$ & -1.7 & $\mathrm{NaN}$ & $\mathrm{NaN}$ \\
\hline AN8790 & D-xylulokinase & 10 & 4 & 9 & $\mathrm{NaN}$ & $\mathrm{NaN}$ & 0.8 & $\mathrm{NaN}$ & $\mathrm{NaN}$ & $\mathrm{NaN}$ & $\mathrm{NaN}$ & -1.0 & $\mathrm{NaN}$ & $\mathrm{NaN}$ \\
\hline AN8045 & Role in mRNA polyadenylation & 3 & & 31 & $\mathrm{NaN}$ & $\mathrm{NaN}$ & 0.8 & $\mathrm{NaN}$ & $\mathrm{NaN}$ & $\mathrm{NaN}$ & $\mathrm{NaN}$ & -1.0 & $\mathrm{NaN}$ & $\mathrm{NaN}$ \\
\hline AN6325 & 5'-nucleotidase & & 6 & 9 & $\mathrm{NaN}$ & $\mathrm{NaN}$ & 2.4 & $\mathrm{NaN}$ & $\mathrm{NaN}$ & $\mathrm{NaN}$ & $\mathrm{NaN}$ & 0.5 & $\mathrm{NaN}$ & $\mathrm{NaN}$ \\
\hline AN7105 & Translation initiation factor 3 (elF3) & 7 & 22 & 237 & $\mathrm{NaN}$ & $\mathrm{NaN}$ & 2.5 & $\mathrm{NaN}$ & $\mathrm{NaN}$ & $\mathrm{NaN}$ & $\mathrm{NaN}$ & -1.9 & $\mathrm{NaN}$ & $\mathrm{NaN}$ \\
\hline AN9011 & Aryl-alcohol oxidase & 35 & 12 & 12 & $\mathrm{NaN}$ & $\mathrm{NaN}$ & 2.8 & $\mathrm{NaN}$ & $\mathrm{NaN}$ & $\mathrm{NaN}$ & $\mathrm{NaN}$ & 3.9 & $\mathrm{NaN}$ & $\mathrm{NaN}$ \\
\hline AN7017 & Protein of unknown function & & 6 & 14 & $\mathrm{NaN}$ & $\mathrm{NaN}$ & 3.5 & $\mathrm{NaN}$ & $\mathrm{NaN}$ & $\mathrm{NaN}$ & $\mathrm{NaN}$ & -2.7 & $\mathrm{NaN}$ & $\mathrm{NaN}$ \\
\hline AN7422 & Deubiquitinating enzymes & 20 & 14 & 38 & $\mathrm{NaN}$ & $\mathrm{NaN}$ & 4.3 & $\mathrm{NaN}$ & $\mathrm{NaN}$ & $\mathrm{NaN}$ & $\mathrm{NaN}$ & -0.5 & $\mathrm{NaN}$ & $\mathrm{NaN}$ \\
\hline AN3070 & Chaperone & & 21 & 59 & $\mathrm{NaN}$ & $\mathrm{NaN}$ & -1.5 & $\mathrm{NaN}$ & $\mathrm{NaN}$ & $\mathrm{NaN}$ & $\mathrm{NaN}$ & -1.6 & $\mathrm{NaN}$ & $\mathrm{NaN}$ \\
\hline AN5737 & Oxidoreductase & & 2 & 10 & $\mathrm{NaN}$ & $\mathrm{NaN}$ & -1.5 & $\mathrm{NaN}$ & $\mathrm{NaN}$ & $\mathrm{NaN}$ & $\mathrm{NaN}$ & 0.9 & $\mathrm{NaN}$ & $\mathrm{NaN}$ \\
\hline AN0252 & F1F0-ATPase complex gamma & 43 & & 27 & $\mathrm{NaN}$ & $\mathrm{NaN}$ & -1.5 & $\mathrm{NaN}$ & $\mathrm{NaN}$ & $\mathrm{NaN}$ & $\mathrm{NaN}$ & -2.1 & $\mathrm{NaN}$ & $\mathrm{NaN}$ \\
\hline AN3080 & Coat protein complex II protein & 20 & 11 & 31 & $\mathrm{NaN}$ & $\mathrm{NaN}$ & -1.5 & $\mathrm{NaN}$ & $\mathrm{NaN}$ & $\mathrm{NaN}$ & $\mathrm{NaN}$ & -1.2 & $\mathrm{NaN}$ & $\mathrm{NaN}$ \\
\hline AN1163 & Chaperone & & 13 & 20 & $\mathrm{NaN}$ & $\mathrm{NaN}$ & -1.5 & $\mathrm{NaN}$ & $\mathrm{NaN}$ & $\mathrm{NaN}$ & $\mathrm{NaN}$ & -2.8 & $\mathrm{NaN}$ & $\mathrm{NaN}$ \\
\hline AN5144 (PfkZ) & 6-phosphofructo-2-kinase & 5 & 12 & 71 & $\mathrm{NaN}$ & $\mathrm{NaN}$ & -1.5 & $\mathrm{NaN}$ & $\mathrm{NaN}$ & $\mathrm{NaN}$ & $\mathrm{NaN}$ & -1.4 & $\mathrm{NaN}$ & $\mathrm{NaN}$ \\
\hline AN1158 & Cell wall biogenesis protein & 27 & 69 & 130 & $\mathrm{NaN}$ & $\mathrm{NaN}$ & -1.5 & $\mathrm{NaN}$ & $\mathrm{NaN}$ & $\mathrm{NaN}$ & $\mathrm{NaN}$ & -1.2 & $\mathrm{NaN}$ & $\mathrm{NaN}$ \\
\hline AN2441 & E1 NeddH/Nedd8-activating & 20 & 12 & 21 & $\mathrm{NaN}$ & $\mathrm{NaN}$ & -1.5 & $\mathrm{NaN}$ & $\mathrm{NaN}$ & $\mathrm{NaN}$ & $\mathrm{NaN}$ & -0.6 & $\mathrm{NaN}$ & $\mathrm{NaN}$ \\
\hline AN4550 (Dps1) & Asparaginyl-tRNA synthetase & 90 & 108 & 207 & $\mathrm{NaN}$ & $\mathrm{NaN}$ & -1.5 & $\mathrm{NaN}$ & $\mathrm{NaN}$ & $\mathrm{NaN}$ & $\mathrm{NaN}$ & -1.2 & $\mathrm{NaN}$ & $\mathrm{NaN}$ \\
\hline AN2970 & Phosphatase & 2 & 10 & 11 & $\mathrm{NaN}$ & $\mathrm{NaN}$ & -1.5 & $\mathrm{NaN}$ & $\mathrm{NaN}$ & $\mathrm{NaN}$ & $\mathrm{NaN}$ & -1.6 & $\mathrm{NaN}$ & $\mathrm{NaN}$ \\
\hline AN5123 & Oxidoreductase & & 10 & 7 & $\mathrm{NaN}$ & $\mathrm{NaN}$ & -1.4 & $\mathrm{NaN}$ & $\mathrm{NaN}$ & $\mathrm{NaN}$ & $\mathrm{NaN}$ & -0.5 & $\mathrm{NaN}$ & $\mathrm{NaN}$ \\
\hline AN5520 & Role in ribosome biogenesis & 30 & 32 & 287 & $\mathrm{NaN}$ & $\mathrm{NaN}$ & -1.4 & $\mathrm{NaN}$ & $\mathrm{NaN}$ & $\mathrm{NaN}$ & $\mathrm{NaN}$ & -2.2 & $\mathrm{NaN}$ & $\mathrm{NaN}$ \\
\hline AN10229 & Dehydrogenase & 7 & & 9 & $\mathrm{NaN}$ & $\mathrm{NaN}$ & -1.4 & $\mathrm{NaN}$ & $\mathrm{NaN}$ & $\mathrm{NaN}$ & $\mathrm{NaN}$ & -2.6 & $\mathrm{NaN}$ & $\mathrm{NaN}$ \\
\hline AN4745 & Rho GTPase activating & 4 & 23 & 40 & $\mathrm{NaN}$ & $\mathrm{NaN}$ & -1.4 & $\mathrm{NaN}$ & $\mathrm{NaN}$ & $\mathrm{NaN}$ & $\mathrm{NaN}$ & -1.7 & $\mathrm{NaN}$ & $\mathrm{NaN}$ \\
\hline AN3804 & Protein of unknown function & & 3 & 41 & $\mathrm{NaN}$ & $\mathrm{NaN}$ & -1.4 & $\mathrm{NaN}$ & $\mathrm{NaN}$ & $\mathrm{NaN}$ & $\mathrm{NaN}$ & -3.5 & $\mathrm{NaN}$ & $\mathrm{NaN}$ \\
\hline AN10164 & Polyadenylated RNA-binding & 12 & 15 & 46 & $\mathrm{NaN}$ & $\mathrm{NaN}$ & -1.4 & $\mathrm{NaN}$ & $\mathrm{NaN}$ & $\mathrm{NaN}$ & $\mathrm{NaN}$ & -0.4 & $\mathrm{NaN}$ & $\mathrm{NaN}$ \\
\hline AN11902 & Formyltetrahydrofolate cyclo-ligase & & 2 & 4 & $\mathrm{NaN}$ & $\mathrm{NaN}$ & -1.4 & $\mathrm{NaN}$ & $\mathrm{NaN}$ & $\mathrm{NaN}$ & $\mathrm{NaN}$ & -0.7 & $\mathrm{NaN}$ & $\mathrm{NaN}$ \\
\hline AN5957 & Aminotransferase & 18 & 40 & 85 & $\mathrm{NaN}$ & $\mathrm{NaN}$ & -1.4 & $\mathrm{NaN}$ & $\mathrm{NaN}$ & $\mathrm{NaN}$ & $\mathrm{NaN}$ & -1.5 & $\mathrm{NaN}$ & $\mathrm{NaN}$ \\
\hline AN5717 (Kapl) & Importin subunit & 21 & 35 & 88 & $\mathrm{NaN}$ & $\mathrm{NaN}$ & -1.4 & $\mathrm{NaN}$ & $\mathrm{NaN}$ & $\mathrm{NaN}$ & $\mathrm{NaN}$ & -1.3 & $\mathrm{NaN}$ & $\mathrm{NaN}$ \\
\hline AN4178 (Myg1) & Melanocyte proliferating protein & & 8 & 19 & $\mathrm{NaN}$ & $\mathrm{NaN}$ & -1.3 & $\mathrm{NaN}$ & $\mathrm{NaN}$ & $\mathrm{NaN}$ & $\mathrm{NaN}$ & -2.1 & $\mathrm{NaN}$ & $\mathrm{NaN}$ \\
\hline AN4288 & Oxidoreductase & 9 & & 101 & $\mathrm{NaN}$ & $\mathrm{NaN}$ & -1.3 & $\mathrm{NaN}$ & $\mathrm{NaN}$ & $\mathrm{NaN}$ & $\mathrm{NaN}$ & -2.8 & $\mathrm{NaN}$ & $\mathrm{NaN}$ \\
\hline AN10182 & Translation initiation factor 3 & 5 & 24 & 95 & $\mathrm{NaN}$ & $\mathrm{NaN}$ & -1.3 & $\mathrm{NaN}$ & $\mathrm{NaN}$ & $\mathrm{NaN}$ & $\mathrm{NaN}$ & -1.4 & $\mathrm{NaN}$ & $\mathrm{NaN}$ \\
\hline AN3034 & Regulation of penicillin biosynthesis & & 12 & 50 & $\mathrm{NaN}$ & $\mathrm{NaN}$ & -1.3 & $\mathrm{NaN}$ & $\mathrm{NaN}$ & $\mathrm{NaN}$ & $\mathrm{NaN}$ & -2.6 & $\mathrm{NaN}$ & $\mathrm{NaN}$ \\
\hline AN2983 (Msb1) & Rho GTPase-activating protein & 3 & & 8 & $\mathrm{NaN}$ & $\mathrm{NaN}$ & -1.3 & $\mathrm{NaN}$ & $\mathrm{NaN}$ & $\mathrm{NaN}$ & $\mathrm{NaN}$ & -1.9 & $\mathrm{NaN}$ & $\mathrm{NaN}$ \\
\hline AN5130 & Coproporphyrinogen oxidase & 50 & 125 & 202 & $\mathrm{NaN}$ & $\mathrm{NaN}$ & -1.3 & $\mathrm{NaN}$ & $\mathrm{NaN}$ & $\mathrm{NaN}$ & $\mathrm{NaN}$ & -4.0 & $\mathrm{NaN}$ & $\mathrm{NaN}$ \\
\hline AN9509 & Role in transcription termination & 15 & 4 & 28 & $\mathrm{NaN}$ & $\mathrm{NaN}$ & -1.3 & $\mathrm{NaN}$ & $\mathrm{NaN}$ & $\mathrm{NaN}$ & $\mathrm{NaN}$ & -0.8 & $\mathrm{NaN}$ & $\mathrm{NaN}$ \\
\hline AN10783 & Phosphogluconate dehydrogenase & 32 & 24 & 28 & $\mathrm{NaN}$ & $\mathrm{NaN}$ & -1.3 & $\mathrm{NaN}$ & $\mathrm{NaN}$ & $\mathrm{NaN}$ & $\mathrm{NaN}$ & 1.1 & $\mathrm{NaN}$ & $\mathrm{NaN}$ \\
\hline AN11058 & Protein of unknown function & 14 & 7 & 10 & $\mathrm{NaN}$ & $\mathrm{NaN}$ & -1.2 & $\mathrm{NaN}$ & $\mathrm{NaN}$ & $\mathrm{NaN}$ & $\mathrm{NaN}$ & 0.6 & $\mathrm{NaN}$ & $\mathrm{NaN}$ \\
\hline AN4207 & Clathrin adaptor protein & 4 & 6 & 31 & $\mathrm{NaN}$ & $\mathrm{NaN}$ & -1.2 & $\mathrm{NaN}$ & $\mathrm{NaN}$ & $\mathrm{NaN}$ & $\mathrm{NaN}$ & -1.3 & $\mathrm{NaN}$ & $\mathrm{NaN}$ \\
\hline AN0317 & Role in endocytosis & 24 & 36 & 49 & $\mathrm{NaN}$ & $\mathrm{NaN}$ & -1.2 & $\mathrm{NaN}$ & $\mathrm{NaN}$ & $\mathrm{NaN}$ & $\mathrm{NaN}$ & -1.4 & $\mathrm{NaN}$ & $\mathrm{NaN}$ \\
\hline AN2000 (Ubi4) & Polyubiquitin & 3 & 59 & 90 & $\mathrm{NaN}$ & $\mathrm{NaN}$ & -1.2 & $\mathrm{NaN}$ & $\mathrm{NaN}$ & $\mathrm{NaN}$ & $\mathrm{NaN}$ & -1.0 & $\mathrm{NaN}$ & $\mathrm{NaN}$ \\
\hline AN1084 & Elongation factor EF-Tu & 96 & 151 & 8 & $\mathrm{NaN}$ & $\mathrm{NaN}$ & -1.2 & $\mathrm{NaN}$ & $\mathrm{NaN}$ & $\mathrm{NaN}$ & $\mathrm{NaN}$ & -2.0 & $\mathrm{NaN}$ & $\mathrm{NaN}$ \\
\hline AN10765 & Translation initiation factor & & 14 & 40 & $\mathrm{NaN}$ & $\mathrm{NaN}$ & -1.2 & $\mathrm{NaN}$ & $\mathrm{NaN}$ & $\mathrm{NaN}$ & $\mathrm{NaN}$ & -1.2 & $\mathrm{NaN}$ & $\mathrm{NaN}$ \\
\hline AN0193 & Hydrolase & 14 & & 18 & $\mathrm{NaN}$ & $\mathrm{NaN}$ & -1.2 & $\mathrm{NaN}$ & $\mathrm{NaN}$ & $\mathrm{NaN}$ & $\mathrm{NaN}$ & -1.5 & $\mathrm{NaN}$ & $\mathrm{NaN}$ \\
\hline AN0295 & Polyubiquitin binding activity & & 8 & 4 & $\mathrm{NaN}$ & $\mathrm{NaN}$ & -1.2 & $\mathrm{NaN}$ & $\mathrm{NaN}$ & $\mathrm{NaN}$ & $\mathrm{NaN}$ & -1.2 & $\mathrm{NaN}$ & $\mathrm{NaN}$ \\
\hline AN4323 & Aminotransferase & & 48 & 108 & $\mathrm{NaN}$ & $\mathrm{NaN}$ & -1.2 & $\mathrm{NaN}$ & $\mathrm{NaN}$ & $\mathrm{NaN}$ & $\mathrm{NaN}$ & -2.6 & $\mathrm{NaN}$ & $\mathrm{NaN}$ \\
\hline AN1466 & PWWP domain protein & & 4 & 27 & $\mathrm{NaN}$ & $\mathrm{NaN}$ & -1.2 & $\mathrm{NaN}$ & $\mathrm{NaN}$ & $\mathrm{NaN}$ & $\mathrm{NaN}$ & -1.3 & $\mathrm{NaN}$ & $\mathrm{NaN}$ \\
\hline AN2066 & Prospore assembly & 23 & 27 & 35 & $\mathrm{NaN}$ & $\mathrm{NaN}$ & -1.1 & $\mathrm{NaN}$ & $\mathrm{NaN}$ & $\mathrm{NaN}$ & $\mathrm{NaN}$ & -0.9 & $\mathrm{NaN}$ & $\mathrm{NaN}$ \\
\hline AN10519 & Protein of unknown function & 36 & 43 & 61 & $\mathrm{NaN}$ & $\mathrm{NaN}$ & -1.1 & $\mathrm{NaN}$ & $\mathrm{NaN}$ & $\mathrm{NaN}$ & $\mathrm{NaN}$ & -1.3 & $\mathrm{NaN}$ & $\mathrm{NaN}$ \\
\hline
\end{tabular}




\begin{tabular}{|c|c|c|c|c|c|c|c|c|c|c|c|c|c|c|}
\hline \multirow[t]{2}{*}{ Gene ID } & \multirow[t]{2}{*}{ Description } & \multicolumn{3}{|c|}{ PSM } & \multicolumn{3}{|c|}{ laeA $\Delta / / a e A$} & \multirow[t]{2}{*}{$\varnothing$} & \multirow[t]{2}{*}{ SD } & \multicolumn{3}{|c|}{ laeAcomp+/laeA } & $\varnothing$ & SD \\
\hline & & 1 & 2 & 3 & 1 & 2 & 3 & & & 1 & 2 & 3 & & \\
\hline AN2981 (GsdA) & Dehydrogenase & 136 & 219 & 266 & $\mathrm{NaN}$ & $\mathrm{NaN}$ & -1.1 & $\mathrm{NaN}$ & $\mathrm{NaN}$ & $\mathrm{NaN}$ & $\mathrm{NaN}$ & -1.5 & $\mathrm{NaN}$ & $\mathrm{NaN}$ \\
\hline AN4563 & Serine/threonine kinase & 14 & 15 & 27 & $\mathrm{NaN}$ & $\mathrm{NaN}$ & -1.1 & $\mathrm{NaN}$ & $\mathrm{NaN}$ & $\mathrm{NaN}$ & $\mathrm{NaN}$ & -1.2 & $\mathrm{NaN}$ & $\mathrm{NaN}$ \\
\hline AN1409 & Acetyl-CoA C-acetyltransferase & & 206 & 293 & $\mathrm{NaN}$ & $\mathrm{NaN}$ & -1.1 & $\mathrm{NaN}$ & $\mathrm{NaN}$ & $\mathrm{NaN}$ & $\mathrm{NaN}$ & -1.1 & $\mathrm{NaN}$ & $\mathrm{NaN}$ \\
\hline AN2275 & Large ribosomal subunit & & 22 & 119 & $\mathrm{NaN}$ & $\mathrm{NaN}$ & -1.1 & $\mathrm{NaN}$ & $\mathrm{NaN}$ & $\mathrm{NaN}$ & $\mathrm{NaN}$ & -2.0 & $\mathrm{NaN}$ & $\mathrm{NaN}$ \\
\hline AN10281 & Serine/threonine phosphatase & 16 & 11 & 28 & $\mathrm{NaN}$ & $\mathrm{NaN}$ & -1.1 & $\mathrm{NaN}$ & $\mathrm{NaN}$ & $\mathrm{NaN}$ & $\mathrm{NaN}$ & -1.3 & $\mathrm{NaN}$ & $\mathrm{NaN}$ \\
\hline AN4397 (FatD) & Coenzyme A synthetase & 11 & 5 & 6 & $\mathrm{NaN}$ & $\mathrm{NaN}$ & -1.1 & $\mathrm{NaN}$ & $\mathrm{NaN}$ & $\mathrm{NaN}$ & $\mathrm{NaN}$ & -1.5 & $\mathrm{NaN}$ & $\mathrm{NaN}$ \\
\hline AN10080 & Siderophore biosynthetic & 10 & & 18 & $\mathrm{NaN}$ & $\mathrm{NaN}$ & -1.1 & $\mathrm{NaN}$ & $\mathrm{NaN}$ & $\mathrm{NaN}$ & $\mathrm{NaN}$ & -1.0 & $\mathrm{NaN}$ & $\mathrm{NaN}$ \\
\hline AN1404 & Diacylglycerol kinase & 3 & 4 & 5 & $\mathrm{NaN}$ & $\mathrm{NaN}$ & -1.1 & $\mathrm{NaN}$ & $\mathrm{NaN}$ & $\mathrm{NaN}$ & $\mathrm{NaN}$ & -0.4 & $\mathrm{NaN}$ & $\mathrm{NaN}$ \\
\hline AN5566 & GMP synthase & 16 & 38 & 106 & $\mathrm{NaN}$ & $\mathrm{NaN}$ & -1.1 & $\mathrm{NaN}$ & $\mathrm{NaN}$ & $\mathrm{NaN}$ & $\mathrm{NaN}$ & -1.6 & $\mathrm{NaN}$ & $\mathrm{NaN}$ \\
\hline AN4258 & Kinase & 28 & 50 & 67 & $\mathrm{NaN}$ & $\mathrm{NaN}$ & -1.0 & $\mathrm{NaN}$ & $\mathrm{NaN}$ & $\mathrm{NaN}$ & $\mathrm{NaN}$ & -1.7 & $\mathrm{NaN}$ & $\mathrm{NaN}$ \\
\hline AN4000 (FabM) & Poly (A)-binding protein & 15 & 67 & 256 & $\mathrm{NaN}$ & $\mathrm{NaN}$ & -1.0 & $\mathrm{NaN}$ & $\mathrm{NaN}$ & $\mathrm{NaN}$ & $\mathrm{NaN}$ & -2.0 & $\mathrm{NaN}$ & $\mathrm{NaN}$ \\
\hline AN3026 (CopA) & Coatomer protein complex & 25 & 44 & 53 & $\mathrm{NaN}$ & $\mathrm{NaN}$ & -1.0 & $\mathrm{NaN}$ & $\mathrm{NaN}$ & $\mathrm{NaN}$ & $\mathrm{NaN}$ & -1.4 & $\mathrm{NaN}$ & $\mathrm{NaN}$ \\
\hline AN9470 & Urate oxidase & & 260 & 159 & $\mathrm{NaN}$ & $\mathrm{NaN}$ & -0.9 & $\mathrm{NaN}$ & $\mathrm{NaN}$ & $\mathrm{NaN}$ & $\mathrm{NaN}$ & -1.2 & $\mathrm{NaN}$ & $\mathrm{NaN}$ \\
\hline AN10743 & Role in endocytosis & 9 & 10 & 28 & $\mathrm{NaN}$ & $\mathrm{NaN}$ & -0.9 & $\mathrm{NaN}$ & $\mathrm{NaN}$ & $\mathrm{NaN}$ & $\mathrm{NaN}$ & -1.1 & $\mathrm{NaN}$ & $\mathrm{NaN}$ \\
\hline AN0717 & Aminotransferase & 28 & 29 & 53 & $\mathrm{NaN}$ & $\mathrm{NaN}$ & -0.9 & $\mathrm{NaN}$ & $\mathrm{NaN}$ & $\mathrm{NaN}$ & $\mathrm{NaN}$ & -0.6 & $\mathrm{NaN}$ & $\mathrm{NaN}$ \\
\hline AN1162 & Guanyl-nucleotide exchange factor & 212 & 237 & 513 & $\mathrm{NaN}$ & $\mathrm{NaN}$ & -0.9 & $\mathrm{NaN}$ & $\mathrm{NaN}$ & $\mathrm{NaN}$ & $\mathrm{NaN}$ & -1.9 & $\mathrm{NaN}$ & $\mathrm{NaN}$ \\
\hline AN0106 (PkcA) & Protein kinase C & 11 & 11 & 27 & $\mathrm{NaN}$ & $\mathrm{NaN}$ & -0.9 & $\mathrm{NaN}$ & $\mathrm{NaN}$ & $\mathrm{NaN}$ & $\mathrm{NaN}$ & -0.7 & $\mathrm{NaN}$ & $\mathrm{NaN}$ \\
\hline AN2907 & Translation initiation factor 3 & & 16 & 98 & $\mathrm{NaN}$ & $\mathrm{NaN}$ & -0.9 & $\mathrm{NaN}$ & $\mathrm{NaN}$ & $\mathrm{NaN}$ & $\mathrm{NaN}$ & -2.0 & $\mathrm{NaN}$ & $\mathrm{NaN}$ \\
\hline AN2734 & $60 \mathrm{~S}$ acidic ribosomal protein $\mathrm{P} 0$ & 27 & 29 & 299 & $\mathrm{NaN}$ & $\mathrm{NaN}$ & -0.9 & $\mathrm{NaN}$ & $\mathrm{NaN}$ & $\mathrm{NaN}$ & $\mathrm{NaN}$ & -2.2 & $\mathrm{NaN}$ & $\mathrm{NaN}$ \\
\hline AN5749 & Metallopeptidase & 8 & 39 & 23 & $\mathrm{NaN}$ & $\mathrm{NaN}$ & -0.9 & $\mathrm{NaN}$ & $\mathrm{NaN}$ & $\mathrm{NaN}$ & $\mathrm{NaN}$ & -0.7 & $\mathrm{NaN}$ & $\mathrm{NaN}$ \\
\hline AN0673 & Actin assembly & & 32 & 39 & $\mathrm{NaN}$ & $\mathrm{NaN}$ & -0.9 & $\mathrm{NaN}$ & $\mathrm{NaN}$ & $\mathrm{NaN}$ & $\mathrm{NaN}$ & -1.2 & $\mathrm{NaN}$ & $\mathrm{NaN}$ \\
\hline AN5972 & Coat protein complex I & 12 & 6 & 48 & $\mathrm{NaN}$ & $\mathrm{NaN}$ & -0.8 & $\mathrm{NaN}$ & $\mathrm{NaN}$ & $\mathrm{NaN}$ & $\mathrm{NaN}$ & -1.4 & $\mathrm{NaN}$ & $\mathrm{NaN}$ \\
\hline AN5820 (MecA) & Cystathionine beta-synthase & 63 & 66 & 97 & $\mathrm{NaN}$ & $\mathrm{NaN}$ & -0.8 & $\mathrm{NaN}$ & $\mathrm{NaN}$ & $\mathrm{NaN}$ & $\mathrm{NaN}$ & -1.7 & $\mathrm{NaN}$ & $\mathrm{NaN}$ \\
\hline AN5499 (Mlp1) & Nuclear pore complex protein & 2 & & 31 & $\mathrm{NaN}$ & $\mathrm{NaN}$ & -0.8 & $\mathrm{NaN}$ & $\mathrm{NaN}$ & $\mathrm{NaN}$ & $\mathrm{NaN}$ & -1.2 & $\mathrm{NaN}$ & $\mathrm{NaN}$ \\
\hline AN7704 & Protein of unknown function & 47 & 15 & 25 & $\mathrm{NaN}$ & $\mathrm{NaN}$ & -0.8 & $\mathrm{NaN}$ & $\mathrm{NaN}$ & $\mathrm{NaN}$ & $\mathrm{NaN}$ & -0.6 & $\mathrm{NaN}$ & $\mathrm{NaN}$ \\
\hline AN10469 & Oxidoreductase & & 8 & 5 & $\mathrm{NaN}$ & $\mathrm{NaN}$ & -0.8 & $\mathrm{NaN}$ & $\mathrm{NaN}$ & $\mathrm{NaN}$ & $\mathrm{NaN}$ & -1.5 & $\mathrm{NaN}$ & $\mathrm{NaN}$ \\
\hline AN5799 & Reductase & 30 & & 49 & $\mathrm{NaN}$ & $\mathrm{NaN}$ & -0.8 & $\mathrm{NaN}$ & $\mathrm{NaN}$ & $\mathrm{NaN}$ & $\mathrm{NaN}$ & -1.3 & $\mathrm{NaN}$ & $\mathrm{NaN}$ \\
\hline AN7721 & Translocon subunit & 12 & & 27 & $\mathrm{NaN}$ & $\mathrm{NaN}$ & -0.7 & $\mathrm{NaN}$ & $\mathrm{NaN}$ & $\mathrm{NaN}$ & $\mathrm{NaN}$ & -1.8 & $\mathrm{NaN}$ & $\mathrm{NaN}$ \\
\hline AN5677 & ¿nknown function & 14 & 12 & 29 & $\mathrm{NaN}$ & $\mathrm{NaN}$ & -0.7 & $\mathrm{NaN}$ & $\mathrm{NaN}$ & $\mathrm{NaN}$ & $\mathrm{NaN}$ & -1.2 & $\mathrm{NaN}$ & $\mathrm{NaN}$ \\
\hline AN5666 (MpkA) & Mitogen-activated protein kinase & 44 & 50 & 98 & $\mathrm{NaN}$ & $\mathrm{NaN}$ & -0.7 & $\mathrm{NaN}$ & $\mathrm{NaN}$ & $\mathrm{NaN}$ & $\mathrm{NaN}$ & -0.4 & $\mathrm{NaN}$ & $\mathrm{NaN}$ \\
\hline AN1639 & Disulf & 11 & 7 & 32 & NaN & $\mathrm{NaN}$ & -0.7 & $\mathrm{NaN}$ & $\mathrm{NaN}$ & $\mathrm{NaN}$ & $\mathrm{NaN}$ & -0.1 & $\mathrm{NaN}$ & $\mathrm{NaN}$ \\
\hline AN11702 & function & & 2 & 102 & $\mathrm{NaN}$ & $\mathrm{NaN}$ & -0.6 & $\mathrm{NaN}$ & $\mathrm{NaN}$ & $\mathrm{NaN}$ & $\mathrm{NaN}$ & 0.2 & $\mathrm{NaN}$ & $\mathrm{NaN}$ \\
\hline AN4547 & Coat & 21 & 34 & 119 & $\mathrm{NaN}$ & $\mathrm{NaN}$ & -0.6 & $\mathrm{NaN}$ & $\mathrm{NaN}$ & $\mathrm{NaN}$ & $\mathrm{NaN}$ & -1.6 & $\mathrm{NaN}$ & $\mathrm{NaN}$ \\
\hline AN4430 & Aceto & 8 & & 46 & $\mathrm{NaN}$ & $\mathrm{NaN}$ & -0.5 & $\mathrm{NaN}$ & $\mathrm{NaN}$ & $\mathrm{NaN}$ & $\mathrm{NaN}$ & -2.0 & $\mathrm{NaN}$ & $\mathrm{NaN}$ \\
\hline AN5613 ( & Xanth & 4 & 37 & 27 & $\mathrm{NaN}$ & $\mathrm{NaN}$ & -0.5 & $\mathrm{NaN}$ & $\mathrm{NaN}$ & $\mathrm{NaN}$ & $\mathrm{NaN}$ & 0.5 & $\mathrm{NaN}$ & $\mathrm{NaN}$ \\
\hline AN5311 & Oxido & & 15 & 56 & $\mathrm{NaN}$ & $\mathrm{NaN}$ & -0.5 & $\mathrm{NaN}$ & $\mathrm{NaN}$ & $\mathrm{NaN}$ & $\mathrm{NaN}$ & -4.8 & $\mathrm{NaN}$ & $\mathrm{NaN}$ \\
\hline AN12229 & Protein of unknow & 9 & 8 & 26 & $\mathrm{NaN}$ & $\mathrm{NaN}$ & -0.5 & $\mathrm{NaN}$ & $\mathrm{NaN}$ & $\mathrm{NaN}$ & $\mathrm{NaN}$ & -1.3 & $\mathrm{NaN}$ & $\mathrm{NaN}$ \\
\hline AN1150 & Transe & 17 & 15 & 62 & $\mathrm{NaN}$ & $\mathrm{NaN}$ & -0.5 & $\mathrm{NaN}$ & $\mathrm{NaN}$ & $\mathrm{NaN}$ & $\mathrm{NaN}$ & -1.3 & $\mathrm{NaN}$ & $\mathrm{NaN}$ \\
\hline AN0316 (TubA) & Alpha-tubulin & 99 & 199 & 338 & $\mathrm{NaN}$ & $\mathrm{NaN}$ & -0.4 & $\mathrm{NaN}$ & $\mathrm{NaN}$ & $\mathrm{NaN}$ & $\mathrm{NaN}$ & -1.2 & $\mathrm{NaN}$ & $\mathrm{NaN}$ \\
\hline AN2243 & Carbamoyl-phosphate synthase & & 9 & 44 & $\mathrm{NaN}$ & $\mathrm{NaN}$ & -0.4 & $\mathrm{NaN}$ & $\mathrm{NaN}$ & $\mathrm{NaN}$ & $\mathrm{NaN}$ & -2.0 & $\mathrm{NaN}$ & $\mathrm{NaN}$ \\
\hline AN0076 & Regulation in translation & 8 & 7 & 37 & $\mathrm{NaN}$ & $\mathrm{NaN}$ & -0.4 & $\mathrm{NaN}$ & $\mathrm{NaN}$ & $\mathrm{NaN}$ & $\mathrm{NaN}$ & -0.7 & $\mathrm{NaN}$ & $\mathrm{NaN}$ \\
\hline AN11102 & Thiolesterase & 3 & 7 & 34 & $\mathrm{NaN}$ & $\mathrm{NaN}$ & -0.3 & $\mathrm{NaN}$ & $\mathrm{NaN}$ & $\mathrm{NaN}$ & $\mathrm{NaN}$ & -1.6 & $\mathrm{NaN}$ & $\mathrm{NaN}$ \\
\hline AN10695 & Protein of unknown & 13 & & 4 & $\mathrm{NaN}$ & $\mathrm{NaN}$ & -0.3 & $\mathrm{NaN}$ & $\mathrm{NaN}$ & $\mathrm{NaN}$ & $\mathrm{NaN}$ & 2.0 & $\mathrm{NaN}$ & $\mathrm{NaN}$ \\
\hline AN1328 (NnaA) & GNAT-type acetyltransferase & 5 & 5 & 19 & $\mathrm{NaN}$ & $\mathrm{NaN}$ & -0.2 & $\mathrm{NaN}$ & $\mathrm{NaN}$ & $\mathrm{NaN}$ & $\mathrm{NaN}$ & -1.9 & $\mathrm{NaN}$ & $\mathrm{NaN}$ \\
\hline AN10301 & Protein of unknown function & 5 & 5 & 11 & $\mathrm{NaN}$ & $\mathrm{NaN}$ & -0.1 & $\mathrm{NaN}$ & $\mathrm{NaN}$ & $\mathrm{NaN}$ & $\mathrm{NaN}$ & 0.9 & $\mathrm{NaN}$ & $\mathrm{NaN}$ \\
\hline AN8831 (AmpB) & Role in actin filament organization & 5 & 9 & 17 & $\mathrm{NaN}$ & $\mathrm{NaN}$ & 0.0 & $\mathrm{NaN}$ & $\mathrm{NaN}$ & $\mathrm{NaN}$ & $\mathrm{NaN}$ & -1.5 & $\mathrm{NaN}$ & $\mathrm{NaN}$ \\
\hline AN11055 & Phosphatase & & 4 & 24 & NaN & $\mathrm{NaN}$ & 0.0 & $\mathrm{NaN}$ & $\mathrm{NaN}$ & $\mathrm{NaN}$ & $\mathrm{NaN}$ & -1.3 & $\mathrm{NaN}$ & $\mathrm{NaN}$ \\
\hline AN2871 (McnC) & Phosphoprotein & 4 & 3 & 33 & $\mathrm{NaN}$ & $\mathrm{NaN}$ & 0.0 & $\mathrm{NaN}$ & $\mathrm{NaN}$ & $\mathrm{NaN}$ & $\mathrm{NaN}$ & -1.8 & $\mathrm{NaN}$ & $\mathrm{NaN}$ \\
\hline AN5743 & Potassium-transporting ATPase & 2 & & 11 & $\mathrm{NaN}$ & $\mathrm{NaN}$ & 0.0 & $\mathrm{NaN}$ & $\mathrm{NaN}$ & $\mathrm{NaN}$ & $\mathrm{NaN}$ & -3.1 & $\mathrm{NaN}$ & $\mathrm{NaN}$ \\
\hline AN1809 & Fumarylacetoacetase & 17 & 19 & 13 & $\mathrm{NaN}$ & $\mathrm{NaN}$ & 0.1 & $\mathrm{NaN}$ & $\mathrm{NaN}$ & $\mathrm{NaN}$ & $\mathrm{NaN}$ & 1.1 & $\mathrm{NaN}$ & $\mathrm{NaN}$ \\
\hline AN10614 & G-quadruplex DNA binding activity & & 30 & 175 & $\mathrm{NaN}$ & $\mathrm{NaN}$ & 0.3 & $\mathrm{NaN}$ & $\mathrm{NaN}$ & $\mathrm{NaN}$ & $\mathrm{NaN}$ & -2.0 & $\mathrm{NaN}$ & $\mathrm{NaN}$ \\
\hline AN3226 & Oxidoreductase & 21 & 68 & 80 & $\mathrm{NaN}$ & $\mathrm{NaN}$ & 0.5 & $\mathrm{NaN}$ & $\mathrm{NaN}$ & $\mathrm{NaN}$ & $\mathrm{NaN}$ & 2.4 & $\mathrm{NaN}$ & $\mathrm{NaN}$ \\
\hline AN5435 & Oxidoreductase & & 15 & 25 & $\mathrm{NaN}$ & $\mathrm{NaN}$ & 0.5 & $\mathrm{NaN}$ & $\mathrm{NaN}$ & $\mathrm{NaN}$ & $\mathrm{NaN}$ & -0.7 & $\mathrm{NaN}$ & $\mathrm{NaN}$ \\
\hline AN9467 & Serine/threonine phosphatase & & 6 & 21 & $\mathrm{NaN}$ & $\mathrm{NaN}$ & 0.7 & $\mathrm{NaN}$ & $\mathrm{NaN}$ & $\mathrm{NaN}$ & $\mathrm{NaN}$ & -0.8 & $\mathrm{NaN}$ & $\mathrm{NaN}$ \\
\hline AN7659 & RNA helicase & 58 & 63 & 66 & $\mathrm{NaN}$ & $\mathrm{NaN}$ & 0.7 & $\mathrm{NaN}$ & $\mathrm{NaN}$ & $\mathrm{NaN}$ & $\mathrm{NaN}$ & -1.0 & $\mathrm{NaN}$ & $\mathrm{NaN}$ \\
\hline AN5616 & Aminotransferase & 14 & 28 & 34 & $\mathrm{NaN}$ & $\mathrm{NaN}$ & 0.9 & $\mathrm{NaN}$ & $\mathrm{NaN}$ & $\mathrm{NaN}$ & $\mathrm{NaN}$ & -0.9 & $\mathrm{NaN}$ & $\mathrm{NaN}$ \\
\hline AN3312 & L-xylulose reductase & & 7 & 7 & $\mathrm{NaN}$ & $\mathrm{NaN}$ & 1.2 & $\mathrm{NaN}$ & $\mathrm{NaN}$ & $\mathrm{NaN}$ & $\mathrm{NaN}$ & 3.2 & $\mathrm{NaN}$ & $\mathrm{NaN}$ \\
\hline AN10060 & Protein of unknown function & 33 & 3 & & $\mathrm{NaN}$ & $\mathrm{NaN}$ & 1.2 & $\mathrm{NaN}$ & $\mathrm{NaN}$ & $\mathrm{NaN}$ & $\mathrm{NaN}$ & -2.4 & $\mathrm{NaN}$ & $\mathrm{NaN}$ \\
\hline AN0052 & Oxidoreductase & 6 & 12 & 6 & $\mathrm{NaN}$ & $\mathrm{NaN}$ & 1.4 & $\mathrm{NaN}$ & $\mathrm{NaN}$ & $\mathrm{NaN}$ & $\mathrm{NaN}$ & 2.5 & $\mathrm{NaN}$ & $\mathrm{NaN}$ \\
\hline AN7600 & Oxidoreductase & 6 & 29 & 283 & $\mathrm{NaN}$ & $\mathrm{NaN}$ & 1.5 & $\mathrm{NaN}$ & $\mathrm{NaN}$ & $\mathrm{NaN}$ & $\mathrm{NaN}$ & -2.3 & $\mathrm{NaN}$ & $\mathrm{NaN}$ \\
\hline AN10306 & $\mathrm{N}$-terminal subunit of Cand1 & & 7 & 3 & $\mathrm{NaN}$ & $\mathrm{NaN}$ & 1.7 & $\mathrm{NaN}$ & $\mathrm{NaN}$ & $\mathrm{NaN}$ & $\mathrm{NaN}$ & -1.5 & $\mathrm{NaN}$ & $\mathrm{NaN}$ \\
\hline AN0788 & Protein of unknown function & & 3 & 4 & $\mathrm{NaN}$ & $\mathrm{NaN}$ & 1.8 & $\mathrm{NaN}$ & $\mathrm{NaN}$ & $\mathrm{NaN}$ & $\mathrm{NaN}$ & -0.2 & $\mathrm{NaN}$ & $\mathrm{NaN}$ \\
\hline AN6541 & Ligase & 24 & 37 & 60 & $\mathrm{NaN}$ & $\mathrm{NaN}$ & 1.9 & $\mathrm{NaN}$ & $\mathrm{NaN}$ & $\mathrm{NaN}$ & $\mathrm{NaN}$ & -1.8 & $\mathrm{NaN}$ & $\mathrm{NaN}$ \\
\hline AN11005 & Metalloexopeptidase & & 18 & 27 & $\mathrm{NaN}$ & $\mathrm{NaN}$ & 2.3 & $\mathrm{NaN}$ & $\mathrm{NaN}$ & $\mathrm{NaN}$ & $\mathrm{NaN}$ & -1.5 & $\mathrm{NaN}$ & $\mathrm{NaN}$ \\
\hline AN3019 & Proteasome regulatory particle & 28 & 48 & 64 & $\mathrm{NaN}$ & $\mathrm{NaN}$ & 3.4 & $\mathrm{NaN}$ & $\mathrm{NaN}$ & $\mathrm{NaN}$ & $\mathrm{NaN}$ & -0.8 & $\mathrm{NaN}$ & $\mathrm{NaN}$ \\
\hline AN3987 & Protein of unknown function & 21 & 16 & 60 & $\mathrm{NaN}$ & $\mathrm{NaN}$ & 4.5 & $\mathrm{NaN}$ & $\mathrm{NaN}$ & $\mathrm{NaN}$ & $\mathrm{NaN}$ & -1.7 & $\mathrm{NaN}$ & $\mathrm{NaN}$ \\
\hline AN8009 (Nmt1) & Thiamine biosynthesis protein & 64 & 491 & 953 & $\mathrm{NaN}$ & $\mathrm{NaN}$ & 4.8 & $\mathrm{NaN}$ & $\mathrm{NaN}$ & $\mathrm{NaN}$ & $\mathrm{NaN}$ & -1.7 & $\mathrm{NaN}$ & $\mathrm{NaN}$ \\
\hline
\end{tabular}




\begin{tabular}{|c|c|c|c|c|c|c|c|c|c|c|c|c|c|c|}
\hline \multirow[t]{2}{*}{ Gene ID } & \multirow[t]{2}{*}{ Description } & \multicolumn{3}{|c|}{ PSM } & \multicolumn{3}{|c|}{ IaeAL/laeA } & \multirow[t]{2}{*}{$\varnothing$} & \multirow[t]{2}{*}{ SD } & \multicolumn{3}{|c|}{ laeAcomp+/laeA } & $\varnothing$ & SD \\
\hline & & 1 & 2 & 3 & 1 & 2 & 3 & & & 1 & 2 & 3 & & \\
\hline AN0224 & Dipeptidase & 27 & 40 & 33 & $\mathrm{NaN}$ & $\mathrm{NaN}$ & -1.2 & $\mathrm{NaN}$ & $\mathrm{NaN}$ & $\mathrm{NaN}$ & $\mathrm{NaN}$ & $\mathrm{NaN}$ & $\mathrm{NaN}$ & $\mathrm{NaN}$ \\
\hline AN0271 & dUTP pyrophosphatase & 19 & 6 & 2 & $\mathrm{NaN}$ & $\mathrm{NaN}$ & -1.1 & $\mathrm{NaN}$ & $\mathrm{NaN}$ & $\mathrm{NaN}$ & $\mathrm{NaN}$ & $\mathrm{NaN}$ & $\mathrm{NaN}$ & $\mathrm{NaN}$ \\
\hline AN0182 (RasA) & Small monomeric GTPase & & 10 & 5 & $\mathrm{NaN}$ & $\mathrm{NaN}$ & -0.9 & $\mathrm{NaN}$ & $\mathrm{NaN}$ & $\mathrm{NaN}$ & $\mathrm{NaN}$ & $\mathrm{NaN}$ & $\mathrm{NaN}$ & $\mathrm{NaN}$ \\
\hline AN7222 & NACHT domain-containing protein & 40 & 16 & 45 & $\mathrm{NaN}$ & $\mathrm{NaN}$ & -2.8 & $\mathrm{NaN}$ & $\mathrm{NaN}$ & $\mathrm{NaN}$ & $\mathrm{NaN}$ & $\mathrm{NaN}$ & $\mathrm{NaN}$ & $\mathrm{NaN}$ \\
\hline AN7264 & Methyltransferase & 5 & 9 & & $\mathrm{NaN}$ & $\mathrm{NaN}$ & -2.7 & $\mathrm{NaN}$ & $\mathrm{NaN}$ & $\mathrm{NaN}$ & $\mathrm{NaN}$ & $\mathrm{NaN}$ & $\mathrm{NaN}$ & $\mathrm{NaN}$ \\
\hline AN7177 & Protein of unknown function & 52 & 30 & 63 & $\mathrm{NaN}$ & $\mathrm{NaN}$ & -2.6 & $\mathrm{NaN}$ & $\mathrm{NaN}$ & $\mathrm{NaN}$ & $\mathrm{NaN}$ & $\mathrm{NaN}$ & $\mathrm{NaN}$ & $\mathrm{NaN}$ \\
\hline AN6207 (PkpC) & Kinase & 8 & 16 & 22 & $\mathrm{NaN}$ & $\mathrm{NaN}$ & -1.8 & $\mathrm{NaN}$ & $\mathrm{NaN}$ & $\mathrm{NaN}$ & $\mathrm{NaN}$ & $\mathrm{NaN}$ & $\mathrm{NaN}$ & $\mathrm{NaN}$ \\
\hline AN2879 & Carbon-nitrogen ligase & 95 & 4 & 7 & $\mathrm{NaN}$ & $\mathrm{NaN}$ & -1.7 & $\mathrm{NaN}$ & $\mathrm{NaN}$ & $\mathrm{NaN}$ & $\mathrm{NaN}$ & $\mathrm{NaN}$ & $\mathrm{NaN}$ & $\mathrm{NaN}$ \\
\hline AN7350 & Translation initiation factor 4B & 45 & 29 & 95 & $\mathrm{NaN}$ & $\mathrm{NaN}$ & -1.7 & $\mathrm{NaN}$ & $\mathrm{NaN}$ & $\mathrm{NaN}$ & $\mathrm{NaN}$ & $\mathrm{NaN}$ & $\mathrm{NaN}$ & $\mathrm{NaN}$ \\
\hline AN8074 & Thiolesterase & 6 & 17 & 25 & $\mathrm{NaN}$ & $\mathrm{NaN}$ & -1.5 & $\mathrm{NaN}$ & $\mathrm{NaN}$ & $\mathrm{NaN}$ & $\mathrm{NaN}$ & $\mathrm{NaN}$ & $\mathrm{NaN}$ & $\mathrm{NaN}$ \\
\hline AN8168 (NmrA) & Nitrogen metabolite repression & & 4 & 5 & $\mathrm{NaN}$ & $\mathrm{NaN}$ & -1.5 & $\mathrm{NaN}$ & $\mathrm{NaN}$ & $\mathrm{NaN}$ & $\mathrm{NaN}$ & $\mathrm{NaN}$ & $\mathrm{NaN}$ & $\mathrm{NaN}$ \\
\hline AN9138 & Amidase/acetamidase & 13 & 6 & 7 & $\mathrm{NaN}$ & $\mathrm{NaN}$ & -1.4 & $\mathrm{NaN}$ & $\mathrm{NaN}$ & $\mathrm{NaN}$ & $\mathrm{NaN}$ & $\mathrm{NaN}$ & $\mathrm{NaN}$ & $\mathrm{NaN}$ \\
\hline AN7469 & Riboflavin kinase & & 8 & 5 & $\mathrm{NaN}$ & $\mathrm{NaN}$ & -1.3 & $\mathrm{NaN}$ & $\mathrm{NaN}$ & $\mathrm{NaN}$ & $\mathrm{NaN}$ & $\mathrm{NaN}$ & $\mathrm{NaN}$ & $\mathrm{NaN}$ \\
\hline AN6515 & Protein of unknown function & 11 & 17 & 37 & $\mathrm{NaN}$ & $\mathrm{NaN}$ & -1.2 & $\mathrm{NaN}$ & $\mathrm{NaN}$ & $\mathrm{NaN}$ & $\mathrm{NaN}$ & $\mathrm{NaN}$ & $\mathrm{NaN}$ & $\mathrm{NaN}$ \\
\hline AN7298 & Protein of unknown function & 6 & & 2 & $\mathrm{NaN}$ & $\mathrm{NaN}$ & -1.2 & $\mathrm{NaN}$ & $\mathrm{NaN}$ & $\mathrm{NaN}$ & $\mathrm{NaN}$ & $\mathrm{NaN}$ & $\mathrm{NaN}$ & $\mathrm{NaN}$ \\
\hline AN7307 & Protein of unknown function & 13 & 3 & & $\mathrm{NaN}$ & $\mathrm{NaN}$ & -1.1 & $\mathrm{NaN}$ & $\mathrm{NaN}$ & $\mathrm{NaN}$ & $\mathrm{NaN}$ & $\mathrm{NaN}$ & $\mathrm{NaN}$ & $\mathrm{NaN}$ \\
\hline AN6980 (Nic96) & Nuclear pore complex & 6 & & 9 & $\mathrm{NaN}$ & $\mathrm{NaN}$ & -1.0 & $\mathrm{NaN}$ & $\mathrm{NaN}$ & $\mathrm{NaN}$ & $\mathrm{NaN}$ & $\mathrm{NaN}$ & $\mathrm{NaN}$ & $\mathrm{NaN}$ \\
\hline AN8218 (TrxB) & Thioredoxin reductase & 17 & 15 & 22 & $\mathrm{NaN}$ & $\mathrm{NaN}$ & -0.9 & $\mathrm{NaN}$ & $\mathrm{NaN}$ & $\mathrm{NaN}$ & $\mathrm{NaN}$ & $\mathrm{NaN}$ & $\mathrm{NaN}$ & $\mathrm{NaN}$ \\
\hline AN7128 & Oxidoreductase & 21 & 13 & & $\mathrm{NaN}$ & $\mathrm{NaN}$ & -0.9 & $\mathrm{NaN}$ & $\mathrm{NaN}$ & $\mathrm{NaN}$ & $\mathrm{NaN}$ & $\mathrm{NaN}$ & $\mathrm{NaN}$ & $\mathrm{NaN}$ \\
\hline AN7511 (GelE) & 1,3-beta-transglycosidase & 14 & 17 & 30 & $\mathrm{NaN}$ & $\mathrm{NaN}$ & -0.8 & $\mathrm{NaN}$ & $\mathrm{NaN}$ & $\mathrm{NaN}$ & $\mathrm{NaN}$ & $\mathrm{NaN}$ & $\mathrm{NaN}$ & $\mathrm{NaN}$ \\
\hline AN6438 & Exopeptidase & 20 & & 6 & $\mathrm{NaN}$ & $\mathrm{NaN}$ & -0.8 & $\mathrm{NaN}$ & $\mathrm{NaN}$ & $\mathrm{NaN}$ & $\mathrm{NaN}$ & $\mathrm{NaN}$ & $\mathrm{NaN}$ & $\mathrm{NaN}$ \\
\hline AN6272 & Oxidoreductase & & 4 & 10 & $\mathrm{NaN}$ & $\mathrm{NaN}$ & -0.6 & $\mathrm{NaN}$ & $\mathrm{NaN}$ & $\mathrm{NaN}$ & $\mathrm{NaN}$ & $\mathrm{NaN}$ & $\mathrm{NaN}$ & $\mathrm{NaN}$ \\
\hline AN6286 & Protein of unknown function & 4 & 3 & & $\mathrm{NaN}$ & $\mathrm{NaN}$ & -0.5 & $\mathrm{NaN}$ & $\mathrm{NaN}$ & $\mathrm{NaN}$ & $\mathrm{NaN}$ & $\mathrm{NaN}$ & $\mathrm{NaN}$ & $\mathrm{NaN}$ \\
\hline AN7998 (XptC) & GMC Oxidoreductase $m d p / x p t$ & 7 & 3 & & $\mathrm{NaN}$ & $\mathrm{NaN}$ & 0.1 & $\mathrm{NaN}$ & $\mathrm{NaN}$ & $\mathrm{NaN}$ & $\mathrm{NaN}$ & $\mathrm{NaN}$ & $\mathrm{NaN}$ & $\mathrm{NaN}$ \\
\hline AN7051 (MetG) & Cystathionine beta-lyase & & 11 & 23 & $\mathrm{NaN}$ & $\mathrm{NaN}$ & 0.1 & $\mathrm{NaN}$ & $\mathrm{NaN}$ & $\mathrm{NaN}$ & $\mathrm{NaN}$ & $\mathrm{NaN}$ & $\mathrm{NaN}$ & $\mathrm{NaN}$ \\
\hline AN8433 & Protein of unknown function & 27 & 24 & 15 & $\mathrm{NaN}$ & $\mathrm{NaN}$ & 0.2 & $\mathrm{NaN}$ & $\mathrm{NaN}$ & $\mathrm{NaN}$ & $\mathrm{NaN}$ & $\mathrm{NaN}$ & $\mathrm{NaN}$ & $\mathrm{NaN}$ \\
\hline AN7911 (OrsB) & Amidohydrolase & 6 & & 3 & $\mathrm{NaN}$ & $\mathrm{NaN}$ & 2.4 & $\mathrm{NaN}$ & $\mathrm{NaN}$ & $\mathrm{NaN}$ & $\mathrm{NaN}$ & $\mathrm{NaN}$ & $\mathrm{NaN}$ & $\mathrm{NaN}$ \\
\hline AN9012 & Lyase & 11 & & 6 & $\mathrm{NaN}$ & $\mathrm{NaN}$ & 3.9 & $\mathrm{NaN}$ & $\mathrm{NaN}$ & $\mathrm{NaN}$ & $\mathrm{NaN}$ & $\mathrm{NaN}$ & $\mathrm{NaN}$ & $\mathrm{NaN}$ \\
\hline AN7897 & Monooxygenase & & 6 & 12 & $\mathrm{NaN}$ & $\mathrm{NaN}$ & -4.2 & $\mathrm{NaN}$ & $\mathrm{NaN}$ & $\mathrm{NaN}$ & $\mathrm{NaN}$ & $\mathrm{NaN}$ & $\mathrm{NaN}$ & $\mathrm{NaN}$ \\
\hline AN10437 & Protein of unknown function & 13 & 14 & 21 & $\mathrm{NaN}$ & $\mathrm{NaN}$ & -4.1 & $\mathrm{NaN}$ & $\mathrm{NaN}$ & $\mathrm{NaN}$ & $\mathrm{NaN}$ & $\mathrm{NaN}$ & $\mathrm{NaN}$ & $\mathrm{NaN}$ \\
\hline AN5353 & Protein of unknown function & & 11 & 8 & $\mathrm{NaN}$ & $\mathrm{NaN}$ & -3.9 & $\mathrm{NaN}$ & $\mathrm{NaN}$ & $\mathrm{NaN}$ & $\mathrm{NaN}$ & $\mathrm{NaN}$ & $\mathrm{NaN}$ & $\mathrm{NaN}$ \\
\hline AN3565 & Hydrolase activity & 7 & 2 & & $\mathrm{NaN}$ & $\mathrm{NaN}$ & -3.3 & $\mathrm{NaN}$ & $\mathrm{NaN}$ & $\mathrm{NaN}$ & $\mathrm{NaN}$ & $\mathrm{NaN}$ & $\mathrm{NaN}$ & $\mathrm{NaN}$ \\
\hline AN4058 & Dihydroxy acid dehydratase & & 18 & 6 & $\mathrm{NaN}$ & $\mathrm{NaN}$ & -2.9 & $\mathrm{NaN}$ & $\mathrm{NaN}$ & $\mathrm{NaN}$ & $\mathrm{NaN}$ & $\mathrm{NaN}$ & $\mathrm{NaN}$ & $\mathrm{NaN}$ \\
\hline AN1849 & Protein of unknown function & & 2 & 5 & $\mathrm{NaN}$ & $\mathrm{NaN}$ & -2.6 & $\mathrm{NaN}$ & $\mathrm{NaN}$ & $\mathrm{NaN}$ & $\mathrm{NaN}$ & $\mathrm{NaN}$ & $\mathrm{NaN}$ & $\mathrm{NaN}$ \\
\hline AN10942 & Actin depolymerizing protein & 38 & 39 & 45 & $\mathrm{NaN}$ & $\mathrm{NaN}$ & -2.5 & $\mathrm{NaN}$ & $\mathrm{NaN}$ & $\mathrm{NaN}$ & $\mathrm{NaN}$ & $\mathrm{NaN}$ & $\mathrm{NaN}$ & $\mathrm{NaN}$ \\
\hline AN2244 & Cytoplasmic translation & & 6 & 8 & $\mathrm{NaN}$ & $\mathrm{NaN}$ & -2.5 & $\mathrm{NaN}$ & $\mathrm{NaN}$ & $\mathrm{NaN}$ & $\mathrm{NaN}$ & $\mathrm{NaN}$ & $\mathrm{NaN}$ & $\mathrm{NaN}$ \\
\hline AN1007 (NiiA) & Nitrite reductase & 7 & 69 & 286 & $\mathrm{NaN}$ & $\mathrm{NaN}$ & -2.4 & $\mathrm{NaN}$ & $\mathrm{NaN}$ & $\mathrm{NaN}$ & $\mathrm{NaN}$ & $\mathrm{NaN}$ & $\mathrm{NaN}$ & $\mathrm{NaN}$ \\
\hline AN5688 & Lipid biosynthetic process & & 8 & 10 & $\mathrm{NaN}$ & $\mathrm{NaN}$ & -2.2 & $\mathrm{NaN}$ & $\mathrm{NaN}$ & $\mathrm{NaN}$ & $\mathrm{NaN}$ & $\mathrm{NaN}$ & $\mathrm{NaN}$ & $\mathrm{NaN}$ \\
\hline AN11191 & Polyketide synthase (PKS) & & 188 & 197 & $\mathrm{NaN}$ & $\mathrm{NaN}$ & -2.2 & $\mathrm{NaN}$ & $\mathrm{NaN}$ & $\mathrm{NaN}$ & $\mathrm{NaN}$ & $\mathrm{NaN}$ & $\mathrm{NaN}$ & $\mathrm{NaN}$ \\
\hline AN3197 & Oxidoreductase & 9 & 3 & & $\mathrm{NaN}$ & $\mathrm{NaN}$ & -2.1 & $\mathrm{NaN}$ & $\mathrm{NaN}$ & $\mathrm{NaN}$ & $\mathrm{NaN}$ & $\mathrm{NaN}$ & $\mathrm{NaN}$ & $\mathrm{NaN}$ \\
\hline AN3057 & Oxidoreductase & 5 & 4 & 9 & $\mathrm{NaN}$ & $\mathrm{NaN}$ & -2.1 & $\mathrm{NaN}$ & $\mathrm{NaN}$ & $\mathrm{NaN}$ & $\mathrm{NaN}$ & $\mathrm{NaN}$ & $\mathrm{NaN}$ & $\mathrm{NaN}$ \\
\hline AN11168 & Protein of unknown function & 3 & 17 & 21 & $\mathrm{NaN}$ & $\mathrm{NaN}$ & -2.1 & $\mathrm{NaN}$ & $\mathrm{NaN}$ & $\mathrm{NaN}$ & $\mathrm{NaN}$ & $\mathrm{NaN}$ & $\mathrm{NaN}$ & $\mathrm{NaN}$ \\
\hline AN7722 & Arginine metabolism & 32 & 25 & 63 & $\mathrm{NaN}$ & $\mathrm{NaN}$ & -2.1 & $\mathrm{NaN}$ & $\mathrm{NaN}$ & $\mathrm{NaN}$ & $\mathrm{NaN}$ & $\mathrm{NaN}$ & $\mathrm{NaN}$ & $\mathrm{NaN}$ \\
\hline AN8274 & Alpha-ketoglutarate transport & 10 & & 17 & $\mathrm{NaN}$ & $\mathrm{NaN}$ & -2.0 & $\mathrm{NaN}$ & $\mathrm{NaN}$ & $\mathrm{NaN}$ & $\mathrm{NaN}$ & $\mathrm{NaN}$ & $\mathrm{NaN}$ & $\mathrm{NaN}$ \\
\hline AN2335 & Dehydrogenase & & 30 & & $\mathrm{NaN}$ & $\mathrm{NaN}$ & -1.9 & $\mathrm{NaN}$ & $\mathrm{NaN}$ & $\mathrm{NaN}$ & $\mathrm{NaN}$ & NAN & $\mathrm{NaN}$ & $\mathrm{NaN}$ \\
\hline AN12022 & Monooxygenase & & 8 & 2 & $\mathrm{NaN}$ & $\mathrm{NaN}$ & -1.9 & $\mathrm{NaN}$ & $\mathrm{NaN}$ & $\mathrm{NaN}$ & $\mathrm{NaN}$ & $\mathrm{NaN}$ & $\mathrm{NaN}$ & $\mathrm{NaN}$ \\
\hline AN3416 & Syntaxin & 39 & 27 & 50 & $\mathrm{NaN}$ & $\mathrm{NaN}$ & -1.8 & $\mathrm{NaN}$ & $\mathrm{NaN}$ & $\mathrm{NaN}$ & $\mathrm{NaN}$ & $\mathrm{NaN}$ & $\mathrm{NaN}$ & $\mathrm{NaN}$ \\
\hline AN1211 & Vacuolar ATP synthase subunit $\mathrm{H}$ & 22 & 7 & 8 & $\mathrm{NaN}$ & $\mathrm{NaN}$ & -1.8 & $\mathrm{NaN}$ & $\mathrm{NaN}$ & $\mathrm{NaN}$ & $\mathrm{NaN}$ & $\mathrm{NaN}$ & $\mathrm{NaN}$ & $\mathrm{NaN}$ \\
\hline AN0628 & D-lactate dehydrogenase & 3 & 4 & 4 & $\mathrm{NaN}$ & $\mathrm{NaN}$ & -1.8 & $\mathrm{NaN}$ & $\mathrm{NaN}$ & $\mathrm{NaN}$ & $\mathrm{NaN}$ & $\mathrm{NaN}$ & $\mathrm{NaN}$ & $\mathrm{NaN}$ \\
\hline AN9193 (LImJ) & LaeA-like methyltransferase & & 4 & 4 & $\mathrm{NaN}$ & $\mathrm{NaN}$ & -1.7 & $\mathrm{NaN}$ & $\mathrm{NaN}$ & $\mathrm{NaN}$ & $\mathrm{NaN}$ & $\mathrm{NaN}$ & $\mathrm{NaN}$ & $\mathrm{NaN}$ \\
\hline AN3456 & Cystathionine gamma-synthase & & 13 & 32 & $\mathrm{NaN}$ & $\mathrm{NaN}$ & -1.7 & $\mathrm{NaN}$ & $\mathrm{NaN}$ & $\mathrm{NaN}$ & $\mathrm{NaN}$ & $\mathrm{NaN}$ & $\mathrm{NaN}$ & $\mathrm{NaN}$ \\
\hline AN9149 & Protein of unknown function & 22 & & 23 & $\mathrm{NaN}$ & $\mathrm{NaN}$ & -1.7 & $\mathrm{NaN}$ & $\mathrm{NaN}$ & $\mathrm{NaN}$ & $\mathrm{NaN}$ & $\mathrm{NaN}$ & $\mathrm{NaN}$ & $\mathrm{NaN}$ \\
\hline AN3916 & Glycerol kinase & 50 & 9 & & $\mathrm{NaN}$ & $\mathrm{NaN}$ & -1.7 & $\mathrm{NaN}$ & $\mathrm{NaN}$ & $\mathrm{NaN}$ & $\mathrm{NaN}$ & $\mathrm{NaN}$ & $\mathrm{NaN}$ & $\mathrm{NaN}$ \\
\hline AN0948 & ATPase activity & 10 & 6 & 6 & $\mathrm{NaN}$ & $\mathrm{NaN}$ & -1.7 & $\mathrm{NaN}$ & $\mathrm{NaN}$ & $\mathrm{NaN}$ & $\mathrm{NaN}$ & $\mathrm{NaN}$ & $\mathrm{NaN}$ & $\mathrm{NaN}$ \\
\hline AN10230 & Phosphorylase & 34 & 28 & 37 & $\mathrm{NaN}$ & $\mathrm{NaN}$ & -1.6 & $\mathrm{NaN}$ & $\mathrm{NaN}$ & $\mathrm{NaN}$ & $\mathrm{NaN}$ & $\mathrm{NaN}$ & $\mathrm{NaN}$ & $\mathrm{NaN}$ \\
\hline AN0327 & DNA helicase & & 5 & 22 & $\mathrm{NaN}$ & $\mathrm{NaN}$ & -1.6 & $\mathrm{NaN}$ & $\mathrm{NaN}$ & $\mathrm{NaN}$ & $\mathrm{NaN}$ & $\mathrm{NaN}$ & $\mathrm{NaN}$ & $\mathrm{NaN}$ \\
\hline AN5831 & Protein of unknown function & & 44 & 75 & $\mathrm{NaN}$ & $\mathrm{NaN}$ & -1.6 & $\mathrm{NaN}$ & $\mathrm{NaN}$ & $\mathrm{NaN}$ & $\mathrm{NaN}$ & $\mathrm{NaN}$ & $\mathrm{NaN}$ & $\mathrm{NaN}$ \\
\hline AN10856 & Protein of unknown function & 6 & 3 & 18 & $\mathrm{NaN}$ & $\mathrm{NaN}$ & -1.6 & $\mathrm{NaN}$ & $\mathrm{NaN}$ & $\mathrm{NaN}$ & $\mathrm{NaN}$ & $\mathrm{NaN}$ & $\mathrm{NaN}$ & $\mathrm{NaN}$ \\
\hline AN2091 & Carboxy-lyase & 12 & 30 & 22 & $\mathrm{NaN}$ & $\mathrm{NaN}$ & -1.6 & $\mathrm{NaN}$ & $\mathrm{NaN}$ & $\mathrm{NaN}$ & $\mathrm{NaN}$ & $\mathrm{NaN}$ & $\mathrm{NaN}$ & $\mathrm{NaN}$ \\
\hline AN2853 & Transcription regulator protein & & 8 & 2 & $\mathrm{NaN}$ & $\mathrm{NaN}$ & -1.6 & $\mathrm{NaN}$ & $\mathrm{NaN}$ & $\mathrm{NaN}$ & $\mathrm{NaN}$ & $\mathrm{NaN}$ & $\mathrm{NaN}$ & $\mathrm{NaN}$ \\
\hline AN4008 & Methyltransferase & 20 & 41 & 33 & $\mathrm{NaN}$ & $\mathrm{NaN}$ & -1.5 & $\mathrm{NaN}$ & $\mathrm{NaN}$ & $\mathrm{NaN}$ & $\mathrm{NaN}$ & $\mathrm{NaN}$ & $\mathrm{NaN}$ & $\mathrm{NaN}$ \\
\hline AN3029 & AP-1 adaptor complex & 17 & 23 & & $\mathrm{NaN}$ & $\mathrm{NaN}$ & -1.5 & $\mathrm{NaN}$ & $\mathrm{NaN}$ & $\mathrm{NaN}$ & $\mathrm{NaN}$ & $\mathrm{NaN}$ & $\mathrm{NaN}$ & $\mathrm{NaN}$ \\
\hline AN10533 & Trehalose-6-phosphate synthase & & 28 & 23 & $\mathrm{NaN}$ & $\mathrm{NaN}$ & -1.5 & $\mathrm{NaN}$ & $\mathrm{NaN}$ & $\mathrm{NaN}$ & $\mathrm{NaN}$ & $\mathrm{NaN}$ & $\mathrm{NaN}$ & $\mathrm{NaN}$ \\
\hline AN8010 & Glycogen (starch) synthase & 321 & 9 & & $\mathrm{NaN}$ & $\mathrm{NaN}$ & -1.5 & $\mathrm{NaN}$ & $\mathrm{NaN}$ & $\mathrm{NaN}$ & $\mathrm{NaN}$ & $\mathrm{NaN}$ & $\mathrm{NaN}$ & $\mathrm{NaN}$ \\
\hline AN2298 & SUMO activating enzyme & 3 & 14 & 6 & $\mathrm{NaN}$ & $\mathrm{NaN}$ & -1.5 & $\mathrm{NaN}$ & $\mathrm{NaN}$ & $\mathrm{NaN}$ & $\mathrm{NaN}$ & $\mathrm{NaN}$ & $\mathrm{NaN}$ & $\mathrm{NaN}$ \\
\hline AN3161 & Oxidoreductase & & 2 & 5 & $\mathrm{NaN}$ & $\mathrm{NaN}$ & -1.5 & $\mathrm{NaN}$ & $\mathrm{NaN}$ & $\mathrm{NaN}$ & $\mathrm{NaN}$ & $\mathrm{NaN}$ & $\mathrm{NaN}$ & $\mathrm{NaN}$ \\
\hline AN0447 & Iron-sulfur cluster binding activity & & 6 & 11 & $\mathrm{NaN}$ & $\mathrm{NaN}$ & -1.4 & $\mathrm{NaN}$ & $\mathrm{NaN}$ & $\mathrm{NaN}$ & $\mathrm{NaN}$ & $\mathrm{NaN}$ & $\mathrm{NaN}$ & $\mathrm{NaN}$ \\
\hline
\end{tabular}




\begin{tabular}{|c|c|c|c|c|c|c|c|c|c|c|c|c|c|c|}
\hline \multirow[t]{2}{*}{ Gene ID } & \multirow[t]{2}{*}{ Description } & \multicolumn{3}{|c|}{ PSM } & \multicolumn{3}{|c|}{ laeA $A / I a e A$} & \multirow[t]{2}{*}{$\varnothing$} & \multirow[t]{2}{*}{ SD } & \multicolumn{3}{|c|}{ laeAcomp+/laeA } & $\varnothing$ & SD \\
\hline & & 1 & 2 & 3 & 1 & 2 & 3 & & & 1 & 2 & 3 & & \\
\hline AN4483 & Serine/threonine kinase & & 3 & 11 & $\mathrm{NaN}$ & $\mathrm{NaN}$ & -1.4 & $\mathrm{NaN}$ & $\mathrm{NaN}$ & $\mathrm{NaN}$ & $\mathrm{NaN}$ & $\mathrm{NaN}$ & $\mathrm{NaN}$ & $\mathrm{NaN}$ \\
\hline AN1873 & Protein of unknown function & & 10 & 10 & $\mathrm{NaN}$ & $\mathrm{NaN}$ & -1.4 & $\mathrm{NaN}$ & $\mathrm{NaN}$ & $\mathrm{NaN}$ & $\mathrm{NaN}$ & $\mathrm{NaN}$ & $\mathrm{NaN}$ & $\mathrm{NaN}$ \\
\hline AN0665 (AneA) & Coatomer subunit epsilon & & 10 & 12 & $\mathrm{NaN}$ & $\mathrm{NaN}$ & -1.4 & $\mathrm{NaN}$ & $\mathrm{NaN}$ & $\mathrm{NaN}$ & $\mathrm{NaN}$ & $\mathrm{NaN}$ & $\mathrm{NaN}$ & $\mathrm{NaN}$ \\
\hline AN0697 & Septin cytoskeleton & 7 & & 16 & $\mathrm{NaN}$ & $\mathrm{NaN}$ & -1.4 & $\mathrm{NaN}$ & $\mathrm{NaN}$ & $\mathrm{NaN}$ & $\mathrm{NaN}$ & $\mathrm{NaN}$ & $\mathrm{NaN}$ & $\mathrm{NaN}$ \\
\hline AN2414 & NADH dehydrogenase (ubiquinone) & 8 & 3 & 32 & $\mathrm{NaN}$ & $\mathrm{NaN}$ & -1.4 & $\mathrm{NaN}$ & $\mathrm{NaN}$ & $\mathrm{NaN}$ & $\mathrm{NaN}$ & $\mathrm{NaN}$ & $\mathrm{NaN}$ & $\mathrm{NaN}$ \\
\hline AN4353 & Protein of unknown function & 33 & 22 & & $\mathrm{NaN}$ & $\mathrm{NaN}$ & -1.4 & $\mathrm{NaN}$ & $\mathrm{NaN}$ & $\mathrm{NaN}$ & $\mathrm{NaN}$ & $\mathrm{NaN}$ & $\mathrm{NaN}$ & $\mathrm{NaN}$ \\
\hline AN4575 & Protein of unknown function & 6 & 25 & 14 & $\mathrm{NaN}$ & $\mathrm{NaN}$ & -1.4 & $\mathrm{NaN}$ & $\mathrm{NaN}$ & $\mathrm{NaN}$ & $\mathrm{NaN}$ & $\mathrm{NaN}$ & $\mathrm{NaN}$ & $\mathrm{NaN}$ \\
\hline AN4688 (IvdA) & Acyl-coA dehydrogenase & 10 & 3 & & $\mathrm{NaN}$ & $\mathrm{NaN}$ & -1.4 & $\mathrm{NaN}$ & $\mathrm{NaN}$ & $\mathrm{NaN}$ & $\mathrm{NaN}$ & $\mathrm{NaN}$ & $\mathrm{NaN}$ & $\mathrm{NaN}$ \\
\hline AN12209 & Protein of unknown function & 2 & & 3 & $\mathrm{NaN}$ & $\mathrm{NaN}$ & -1.4 & $\mathrm{NaN}$ & $\mathrm{NaN}$ & $\mathrm{NaN}$ & $\mathrm{NaN}$ & $\mathrm{NaN}$ & $\mathrm{NaN}$ & $\mathrm{NaN}$ \\
\hline AN4916 & Role in ribosome biogenesis & 13 & & 4 & $\mathrm{NaN}$ & $\mathrm{NaN}$ & -1.4 & $\mathrm{NaN}$ & $\mathrm{NaN}$ & $\mathrm{NaN}$ & $\mathrm{NaN}$ & $\mathrm{NaN}$ & $\mathrm{NaN}$ & $\mathrm{NaN}$ \\
\hline AN4268 & Nitronate monooxygenase & 5 & 6 & 3 & $\mathrm{NaN}$ & $\mathrm{NaN}$ & -1.3 & $\mathrm{NaN}$ & $\mathrm{NaN}$ & $\mathrm{NaN}$ & $\mathrm{NaN}$ & $\mathrm{NaN}$ & $\mathrm{NaN}$ & $\mathrm{NaN}$ \\
\hline AN4965 & Protein of unknown function & & 6 & 24 & $\mathrm{NaN}$ & $\mathrm{NaN}$ & -1.3 & $\mathrm{NaN}$ & $\mathrm{NaN}$ & $\mathrm{NaN}$ & $\mathrm{NaN}$ & $\mathrm{NaN}$ & $\mathrm{NaN}$ & $\mathrm{NaN}$ \\
\hline AN3961 & Protein of unknown function & & 38 & 10 & $\mathrm{NaN}$ & $\mathrm{NaN}$ & -1.3 & $\mathrm{NaN}$ & $\mathrm{NaN}$ & $\mathrm{NaN}$ & $\mathrm{NaN}$ & $\mathrm{NaN}$ & $\mathrm{NaN}$ & $\mathrm{NaN}$ \\
\hline AN4439 & Adenylyltransferase & 11 & & 8 & $\mathrm{NaN}$ & $\mathrm{NaN}$ & -1.3 & $\mathrm{NaN}$ & $\mathrm{NaN}$ & $\mathrm{NaN}$ & $\mathrm{NaN}$ & $\mathrm{NaN}$ & $\mathrm{NaN}$ & $\mathrm{NaN}$ \\
\hline AN1502 (NagA) & Chitin hydrolysis & 8 & 8 & & $\mathrm{NaN}$ & $\mathrm{NaN}$ & -1.2 & $\mathrm{NaN}$ & $\mathrm{NaN}$ & $\mathrm{NaN}$ & $\mathrm{NaN}$ & $\mathrm{NaN}$ & $\mathrm{NaN}$ & $\mathrm{NaN}$ \\
\hline AN4024 & Protein of unknown function & 8 & 6 & 11 & $\mathrm{NaN}$ & $\mathrm{NaN}$ & -1.2 & $\mathrm{NaN}$ & $\mathrm{NaN}$ & $\mathrm{NaN}$ & $\mathrm{NaN}$ & $\mathrm{NaN}$ & $\mathrm{NaN}$ & $\mathrm{NaN}$ \\
\hline AN10417 & RNA helicase & & 11 & 21 & $\mathrm{NaN}$ & $\mathrm{NaN}$ & -1.2 & $\mathrm{NaN}$ & $\mathrm{NaN}$ & $\mathrm{NaN}$ & $\mathrm{NaN}$ & $\mathrm{NaN}$ & $\mathrm{NaN}$ & $\mathrm{NaN}$ \\
\hline AN2860 & Alcohol dehydrogenase & 6 & 2 & & $\mathrm{NaN}$ & $\mathrm{NaN}$ & -1.1 & $\mathrm{NaN}$ & $\mathrm{NaN}$ & $\mathrm{NaN}$ & $\mathrm{NaN}$ & $\mathrm{NaN}$ & $\mathrm{NaN}$ & $\mathrm{NaN}$ \\
\hline AN10282 & Protein of unknown function & 3 & 9 & 95 & $\mathrm{NaN}$ & $\mathrm{NaN}$ & -1.1 & $\mathrm{NaN}$ & $\mathrm{NaN}$ & $\mathrm{NaN}$ & $\mathrm{NaN}$ & $\mathrm{NaN}$ & $\mathrm{NaN}$ & $\mathrm{NaN}$ \\
\hline AN8396 (PdcB) & Decarboxylase & 22 & 17 & & $\mathrm{NaN}$ & $\mathrm{NaN}$ & -1.1 & $\mathrm{NaN}$ & $\mathrm{NaN}$ & $\mathrm{NaN}$ & $\mathrm{NaN}$ & $\mathrm{NaN}$ & $\mathrm{NaN}$ & $\mathrm{NaN}$ \\
\hline AN8859 & Aspartate kinase & 4 & & 16 & $\mathrm{NaN}$ & $\mathrm{NaN}$ & -1.1 & $\mathrm{NaN}$ & $\mathrm{NaN}$ & $\mathrm{NaN}$ & $\mathrm{NaN}$ & $\mathrm{NaN}$ & $\mathrm{NaN}$ & $\mathrm{NaN}$ \\
\hline AN4532 (Prp8) & Catalytic core of the spliceosome & 16 & 8 & 6 & $\mathrm{NaN}$ & $\mathrm{NaN}$ & -1.1 & $\mathrm{NaN}$ & $\mathrm{NaN}$ & $\mathrm{NaN}$ & $\mathrm{NaN}$ & $\mathrm{NaN}$ & $\mathrm{NaN}$ & $\mathrm{NaN}$ \\
\hline AN2311 & Phosphomevalonate kinase & 44 & 31 & 44 & $\mathrm{NaN}$ & $\mathrm{NaN}$ & -1.1 & $\mathrm{NaN}$ & $\mathrm{NaN}$ & $\mathrm{NaN}$ & $\mathrm{NaN}$ & $\mathrm{NaN}$ & $\mathrm{NaN}$ & $\mathrm{NaN}$ \\
\hline AN10379 & Protein of unknown function & 16 & 17 & 20 & $\mathrm{NaN}$ & $\mathrm{NaN}$ & -1.1 & $\mathrm{NaN}$ & $\mathrm{NaN}$ & $\mathrm{NaN}$ & $\mathrm{NaN}$ & $\mathrm{NaN}$ & $\mathrm{NaN}$ & $\mathrm{NaN}$ \\
\hline AN1545 & Phosphatase & 18 & & 19 & $\mathrm{NaN}$ & $\mathrm{NaN}$ & -1.1 & $\mathrm{NaN}$ & $\mathrm{NaN}$ & $\mathrm{NaN}$ & $\mathrm{NaN}$ & $\mathrm{NaN}$ & $\mathrm{NaN}$ & $\mathrm{NaN}$ \\
\hline AN5718 & Fumarate hydratase & 8 & 7 & 16 & $\mathrm{NaN}$ & $\mathrm{NaN}$ & -1.0 & $\mathrm{NaN}$ & $\mathrm{NaN}$ & $\mathrm{NaN}$ & $\mathrm{NaN}$ & $\mathrm{NaN}$ & $\mathrm{NaN}$ & $\mathrm{NaN}$ \\
\hline AN12335 (AcdA) & Acyl-CoA dehydrogenase & 20 & 22 & & $\mathrm{NaN}$ & $\mathrm{NaN}$ & -1.0 & $\mathrm{NaN}$ & $\mathrm{NaN}$ & $\mathrm{NaN}$ & $\mathrm{NaN}$ & $\mathrm{NaN}$ & $\mathrm{NaN}$ & $\mathrm{NaN}$ \\
\hline AN10311 (MnpA) & Cell wall mannoprotein & 20 & 4 & & $\mathrm{NaN}$ & $\mathrm{NaN}$ & -1.0 & $\mathrm{NaN}$ & $\mathrm{NaN}$ & $\mathrm{NaN}$ & $\mathrm{NaN}$ & $\mathrm{NaN}$ & $\mathrm{NaN}$ & $\mathrm{NaN}$ \\
\hline AN7805 (StcV) & Norsolorinic acid reductase & 154 & 4 & & $\mathrm{NaN}$ & $\mathrm{NaN}$ & -1.0 & $\mathrm{NaN}$ & $\mathrm{NaN}$ & $\mathrm{NaN}$ & $\mathrm{NaN}$ & $\mathrm{NaN}$ & $\mathrm{NaN}$ & $\mathrm{NaN}$ \\
\hline AN4779 & Protein of unknown function & 4 & 4 & 4 & $\mathrm{NaN}$ & $\mathrm{NaN}$ & -1.0 & $\mathrm{NaN}$ & $\mathrm{NaN}$ & $\mathrm{NaN}$ & $\mathrm{NaN}$ & $\mathrm{NaN}$ & $\mathrm{NaN}$ & $\mathrm{NaN}$ \\
\hline AN8836 & Serine/threonine-protein kinase & & 4 & 13 & $\mathrm{NaN}$ & $\mathrm{NaN}$ & -1.0 & $\mathrm{NaN}$ & $\mathrm{NaN}$ & $\mathrm{NaN}$ & $\mathrm{NaN}$ & $\mathrm{NaN}$ & $\mathrm{NaN}$ & $\mathrm{NaN}$ \\
\hline AN3867 & Pheromone precursor & 14 & 11 & 19 & $\mathrm{NaN}$ & $\mathrm{NaN}$ & -0.9 & $\mathrm{NaN}$ & $\mathrm{NaN}$ & $\mathrm{NaN}$ & $\mathrm{NaN}$ & $\mathrm{NaN}$ & $\mathrm{NaN}$ & $\mathrm{NaN}$ \\
\hline AN0423 & D-xylose reductase & 4 & 6 & 35 & $\mathrm{NaN}$ & $\mathrm{NaN}$ & -0.9 & $\mathrm{NaN}$ & $\mathrm{NaN}$ & $\mathrm{NaN}$ & $\mathrm{NaN}$ & $\mathrm{NaN}$ & $\mathrm{NaN}$ & $\mathrm{NaN}$ \\
\hline AN10350 & Phosphatidylinositol binding activity & 8 & 9 & 13 & $\mathrm{NaN}$ & $\mathrm{NaN}$ & -0.9 & $\mathrm{NaN}$ & $\mathrm{NaN}$ & $\mathrm{NaN}$ & $\mathrm{NaN}$ & $\mathrm{NaN}$ & $\mathrm{NaN}$ & $\mathrm{NaN}$ \\
\hline AN4315 & Translational elongation & 7 & 4 & 15 & $\mathrm{NaN}$ & $\mathrm{NaN}$ & -0.9 & $\mathrm{NaN}$ & $\mathrm{NaN}$ & $\mathrm{NaN}$ & $\mathrm{NaN}$ & $\mathrm{NaN}$ & $\mathrm{NaN}$ & $\mathrm{NaN}$ \\
\hline AN10960 & Protein of unknown function & 10 & 9 & 2 & $\mathrm{NaN}$ & $\mathrm{NaN}$ & -0.9 & $\mathrm{NaN}$ & $\mathrm{NaN}$ & $\mathrm{NaN}$ & $\mathrm{NaN}$ & $\mathrm{NaN}$ & $\mathrm{NaN}$ & $\mathrm{NaN}$ \\
\hline AN2224 (Sog) & Vacuolar protein-sorting protein & 9 & 18 & 26 & $\mathrm{NaN}$ & $\mathrm{NaN}$ & -0.9 & $\mathrm{NaN}$ & $\mathrm{NaN}$ & $\mathrm{NaN}$ & $\mathrm{NaN}$ & $\mathrm{NaN}$ & $\mathrm{NaN}$ & $\mathrm{NaN}$ \\
\hline AN5800 & Role in translation & 160 & & 4 & $\mathrm{NaN}$ & $\mathrm{NaN}$ & -0.8 & $\mathrm{NaN}$ & $\mathrm{NaN}$ & $\mathrm{NaN}$ & $\mathrm{NaN}$ & $\mathrm{NaN}$ & $\mathrm{NaN}$ & $\mathrm{NaN}$ \\
\hline AN8801 & Nitronate monooxygenase & 3 & 4 & & $\mathrm{NaN}$ & $\mathrm{NaN}$ & -0.8 & $\mathrm{NaN}$ & $\mathrm{NaN}$ & $\mathrm{NaN}$ & $\mathrm{NaN}$ & $\mathrm{NaN}$ & $\mathrm{NaN}$ & $\mathrm{NaN}$ \\
\hline AN10023 (MdpL) & Member of the $m d p / x p t$ gene cl. & 19 & 14 & 18 & $\mathrm{NaN}$ & $\mathrm{NaN}$ & -0.8 & $\mathrm{NaN}$ & $\mathrm{NaN}$ & $\mathrm{NaN}$ & $\mathrm{NaN}$ & $\mathrm{NaN}$ & $\mathrm{NaN}$ & $\mathrm{NaN}$ \\
\hline AN0847 & Chaperone & & 4 & 14 & $\mathrm{NaN}$ & $\mathrm{NaN}$ & -0.8 & $\mathrm{NaN}$ & $\mathrm{NaN}$ & $\mathrm{NaN}$ & $\mathrm{NaN}$ & $\mathrm{NaN}$ & $\mathrm{NaN}$ & $\mathrm{NaN}$ \\
\hline AN5634 (AcuD) & Isocitrate lyase & 6 & 29 & 16 & $\mathrm{NaN}$ & $\mathrm{NaN}$ & -0.7 & $\mathrm{NaN}$ & $\mathrm{NaN}$ & $\mathrm{NaN}$ & $\mathrm{NaN}$ & $\mathrm{NaN}$ & $\mathrm{NaN}$ & $\mathrm{NaN}$ \\
\hline AN1524 & Dehydrogenase & 3 & 8 & 28 & $\mathrm{NaN}$ & $\mathrm{NaN}$ & -0.7 & $\mathrm{NaN}$ & $\mathrm{NaN}$ & $\mathrm{NaN}$ & $\mathrm{NaN}$ & $\mathrm{NaN}$ & $\mathrm{NaN}$ & $\mathrm{NaN}$ \\
\hline AN9320 & Protein of unknown function & & 6 & 46 & $\mathrm{NaN}$ & $\mathrm{NaN}$ & -0.6 & $\mathrm{NaN}$ & $\mathrm{NaN}$ & $\mathrm{NaN}$ & $\mathrm{NaN}$ & $\mathrm{NaN}$ & $\mathrm{NaN}$ & $\mathrm{NaN}$ \\
\hline AN1611 & U1 snRNP localization & & 17 & 15 & $\mathrm{NaN}$ & $\mathrm{NaN}$ & -0.6 & $\mathrm{NaN}$ & $\mathrm{NaN}$ & $\mathrm{NaN}$ & $\mathrm{NaN}$ & $\mathrm{NaN}$ & $\mathrm{NaN}$ & $\mathrm{NaN}$ \\
\hline AN3778 & Gephyrin-related protein & 3 & 9 & 12 & $\mathrm{NaN}$ & $\mathrm{NaN}$ & -0.5 & $\mathrm{NaN}$ & $\mathrm{NaN}$ & $\mathrm{NaN}$ & $\mathrm{NaN}$ & $\mathrm{NaN}$ & $\mathrm{NaN}$ & $\mathrm{NaN}$ \\
\hline AN4602 & Role in tubulin complex assembly & 7 & 6 & & $\mathrm{NaN}$ & $\mathrm{NaN}$ & -0.5 & $\mathrm{NaN}$ & $\mathrm{NaN}$ & $\mathrm{NaN}$ & $\mathrm{NaN}$ & $\mathrm{NaN}$ & $\mathrm{NaN}$ & $\mathrm{NaN}$ \\
\hline AN3642 & Vacuolar protein sorting protein & 2 & & 8 & $\mathrm{NaN}$ & $\mathrm{NaN}$ & -0.4 & $\mathrm{NaN}$ & $\mathrm{NaN}$ & $\mathrm{NaN}$ & $\mathrm{NaN}$ & $\mathrm{NaN}$ & $\mathrm{NaN}$ & $\mathrm{NaN}$ \\
\hline AN0656 & Menaquinone biosynthesis & & 16 & 11 & $\mathrm{NaN}$ & $\mathrm{NaN}$ & -0.4 & $\mathrm{NaN}$ & $\mathrm{NaN}$ & $\mathrm{NaN}$ & $\mathrm{NaN}$ & $\mathrm{NaN}$ & $\mathrm{NaN}$ & $\mathrm{NaN}$ \\
\hline AN2017 (AgdA) & Alpha-glucosidase & 6 & & 8 & $\mathrm{NaN}$ & $\mathrm{NaN}$ & -0.4 & $\mathrm{NaN}$ & $\mathrm{NaN}$ & $\mathrm{NaN}$ & $\mathrm{NaN}$ & $\mathrm{NaN}$ & $\mathrm{NaN}$ & $\mathrm{NaN}$ \\
\hline AN11915 & Formyltetrahydrofolate cyclo ligase & & 4 & 12 & $\mathrm{NaN}$ & $\mathrm{NaN}$ & -0.3 & $\mathrm{NaN}$ & $\mathrm{NaN}$ & $\mathrm{NaN}$ & $\mathrm{NaN}$ & $\mathrm{NaN}$ & $\mathrm{NaN}$ & $\mathrm{NaN}$ \\
\hline AN5778 & Cytoskeleton localization & 3 & 11 & 33 & $\mathrm{NaN}$ & $\mathrm{NaN}$ & -0.2 & $\mathrm{NaN}$ & $\mathrm{NaN}$ & $\mathrm{NaN}$ & $\mathrm{NaN}$ & $\mathrm{NaN}$ & $\mathrm{NaN}$ & $\mathrm{NaN}$ \\
\hline AN1694 & Protein of unknown function & & 12 & 5 & $\mathrm{NaN}$ & $\mathrm{NaN}$ & -0.1 & $\mathrm{NaN}$ & $\mathrm{NaN}$ & $\mathrm{NaN}$ & $\mathrm{NaN}$ & $\mathrm{NaN}$ & $\mathrm{NaN}$ & $\mathrm{NaN}$ \\
\hline AN5606 & ATPase subunit & 14 & & 13 & $\mathrm{NaN}$ & $\mathrm{NaN}$ & -0.1 & $\mathrm{NaN}$ & $\mathrm{NaN}$ & $\mathrm{NaN}$ & $\mathrm{NaN}$ & $\mathrm{NaN}$ & $\mathrm{NaN}$ & $\mathrm{NaN}$ \\
\hline AN3709 & Protein of unknown function & & 4 & 6 & $\mathrm{NaN}$ & $\mathrm{NaN}$ & 0.0 & $\mathrm{NaN}$ & $\mathrm{NaN}$ & $\mathrm{NaN}$ & $\mathrm{NaN}$ & $\mathrm{NaN}$ & $\mathrm{NaN}$ & $\mathrm{NaN}$ \\
\hline AN2229 (MetE) & Acetyltransferase & & 3 & 3 & $\mathrm{NaN}$ & $\mathrm{NaN}$ & 0.0 & $\mathrm{NaN}$ & $\mathrm{NaN}$ & $\mathrm{NaN}$ & $\mathrm{NaN}$ & $\mathrm{NaN}$ & $\mathrm{NaN}$ & $\mathrm{NaN}$ \\
\hline AN1917 (DicB) & Dicarboxylate-tricarboxylate & 17 & 4 & & $\mathrm{NaN}$ & $\mathrm{NaN}$ & 0.1 & $\mathrm{NaN}$ & $\mathrm{NaN}$ & $\mathrm{NaN}$ & $\mathrm{NaN}$ & $\mathrm{NaN}$ & $\mathrm{NaN}$ & $\mathrm{NaN}$ \\
\hline AN2947 & Phosphodiesterase & 15 & 11 & 8 & $\mathrm{NaN}$ & $\mathrm{NaN}$ & 0.4 & $\mathrm{NaN}$ & $\mathrm{NaN}$ & $\mathrm{NaN}$ & $\mathrm{NaN}$ & $\mathrm{NaN}$ & $\mathrm{NaN}$ & $\mathrm{NaN}$ \\
\hline AN4843 (AgdG) & Alpha-glucosidase & 12 & & 2 & $\mathrm{NaN}$ & $\mathrm{NaN}$ & 0.4 & $\mathrm{NaN}$ & $\mathrm{NaN}$ & $\mathrm{NaN}$ & $\mathrm{NaN}$ & $\mathrm{NaN}$ & $\mathrm{NaN}$ & $\mathrm{NaN}$ \\
\hline AN5658 & Gamma-glutamyltransferase & 5 & 5 & & $\mathrm{NaN}$ & $\mathrm{NaN}$ & 0.4 & $\mathrm{NaN}$ & $\mathrm{NaN}$ & $\mathrm{NaN}$ & $\mathrm{NaN}$ & $\mathrm{NaN}$ & $\mathrm{NaN}$ & $\mathrm{NaN}$ \\
\hline AN0740 & Oxidoreductase & 9 & 10 & & $\mathrm{NaN}$ & $\mathrm{NaN}$ & 0.5 & $\mathrm{NaN}$ & $\mathrm{NaN}$ & $\mathrm{NaN}$ & $\mathrm{NaN}$ & $\mathrm{NaN}$ & $\mathrm{NaN}$ & $\mathrm{NaN}$ \\
\hline AN1675 & Lysophospholipase & 26 & 15 & 15 & $\mathrm{NaN}$ & $\mathrm{NaN}$ & 0.7 & $\mathrm{NaN}$ & $\mathrm{NaN}$ & $\mathrm{NaN}$ & $\mathrm{NaN}$ & $\mathrm{NaN}$ & $\mathrm{NaN}$ & $\mathrm{NaN}$ \\
\hline AN2389 & 2-dehydropantoate 2-reductase & & 15 & 4 & $\mathrm{NaN}$ & $\mathrm{NaN}$ & 1.0 & $\mathrm{NaN}$ & $\mathrm{NaN}$ & $\mathrm{NaN}$ & $\mathrm{NaN}$ & $\mathrm{NaN}$ & $\mathrm{NaN}$ & $\mathrm{NaN}$ \\
\hline AN5635 (TreB) & Alpha-trehalase & 4 & & 27 & $\mathrm{NaN}$ & $\mathrm{NaN}$ & 1.2 & $\mathrm{NaN}$ & $\mathrm{NaN}$ & $\mathrm{NaN}$ & $\mathrm{NaN}$ & $\mathrm{NaN}$ & $\mathrm{NaN}$ & $\mathrm{NaN}$ \\
\hline AN0866 & Heat shock protein-like & 9 & 13 & 28 & $\mathrm{NaN}$ & $\mathrm{NaN}$ & 1.3 & $\mathrm{NaN}$ & $\mathrm{NaN}$ & $\mathrm{NaN}$ & $\mathrm{NaN}$ & $\mathrm{NaN}$ & $\mathrm{NaN}$ & $\mathrm{NaN}$ \\
\hline AN0562 & Catalytic activity & & 6 & 3 & $\mathrm{NaN}$ & $\mathrm{NaN}$ & 2.7 & $\mathrm{NaN}$ & $\mathrm{NaN}$ & $\mathrm{NaN}$ & $\mathrm{NaN}$ & $\mathrm{NaN}$ & $\mathrm{NaN}$ & $\mathrm{NaN}$ \\
\hline AN3255 & Glutathione peroxidase & 24 & 24 & 18 & $\mathrm{NaN}$ & $\mathrm{NaN}$ & 2.8 & $\mathrm{NaN}$ & $\mathrm{NaN}$ & $\mathrm{NaN}$ & $\mathrm{NaN}$ & $\mathrm{NaN}$ & $\mathrm{NaN}$ & $\mathrm{NaN}$ \\
\hline
\end{tabular}




\begin{tabular}{|c|c|c|c|c|c|c|c|c|c|c|c|c|c|c|}
\hline \multirow[t]{2}{*}{ Gene ID } & \multirow[t]{2}{*}{ Description } & \multicolumn{3}{|c|}{ PSM } & \multicolumn{3}{|c|}{ laeAL/laeA } & \multirow[t]{2}{*}{$\varnothing$} & \multirow[t]{2}{*}{ SD } & \multicolumn{3}{|c|}{ laeAcomp+/laeA } & $\varnothing$ & SD \\
\hline & & 1 & 2 & 3 & 1 & 2 & 3 & & & 1 & 2 & 3 & & \\
\hline AN1897 (HmgA) & Homogentisate 1,2-dioxygenase & 24 & 15 & & $\mathrm{NaN}$ & $\mathrm{NaN}$ & 2.9 & $\mathrm{NaN}$ & $\mathrm{NaN}$ & $\mathrm{NaN}$ & $\mathrm{NaN}$ & $\mathrm{NaN}$ & $\mathrm{NaN}$ & $\mathrm{NaN}$ \\
\hline AN10788 & Protease & & 9 & 11 & $\mathrm{NaN}$ & $\mathrm{NaN}$ & 3.2 & $\mathrm{NaN}$ & $\mathrm{NaN}$ & $\mathrm{NaN}$ & $\mathrm{NaN}$ & $\mathrm{NaN}$ & $\mathrm{NaN}$ & $\mathrm{NaN}$ \\
\hline AN5068 & Arylformamidase & 18 & 6 & 13 & $\mathrm{NaN}$ & $\mathrm{NaN}$ & 3.5 & $\mathrm{NaN}$ & $\mathrm{NaN}$ & $\mathrm{NaN}$ & $\mathrm{NaN}$ & $\mathrm{NaN}$ & $\mathrm{NaN}$ & $\mathrm{NaN}$ \\
\hline AN3330 & Protein of unknown function & 53 & 61 & 54 & $\mathrm{NaN}$ & $\mathrm{NaN}$ & 3.6 & $\mathrm{NaN}$ & $\mathrm{NaN}$ & $\mathrm{NaN}$ & $\mathrm{NaN}$ & $\mathrm{NaN}$ & $\mathrm{NaN}$ & $\mathrm{NaN}$ \\
\hline AN0234 & Hydrolase & & 21 & 79 & $\mathrm{NaN}$ & $\mathrm{NaN}$ & $\mathrm{NaN}$ & $\mathrm{NaN}$ & $\mathrm{NaN}$ & $\mathrm{NaN}$ & $\mathrm{NaN}$ & -4.6 & $\mathrm{NaN}$ & $\mathrm{NaN}$ \\
\hline AN2555 & Serine-type carboxypeptidase & 5 & 11 & 67 & $\mathrm{NaN}$ & $\mathrm{NaN}$ & $\mathrm{NaN}$ & $\mathrm{NaN}$ & $\mathrm{NaN}$ & $\mathrm{NaN}$ & $\mathrm{NaN}$ & -3.7 & $\mathrm{NaN}$ & $\mathrm{NaN}$ \\
\hline AN10901 & Dehydrogenase & 17 & 76 & 221 & $\mathrm{NaN}$ & $\mathrm{NaN}$ & $\mathrm{NaN}$ & $\mathrm{NaN}$ & $\mathrm{NaN}$ & $\mathrm{NaN}$ & $\mathrm{NaN}$ & -3.4 & $\mathrm{NaN}$ & $\mathrm{NaN}$ \\
\hline AN4908 & Translation initiation factor subunit & 5 & 29 & 185 & $\mathrm{NaN}$ & $\mathrm{NaN}$ & $\mathrm{NaN}$ & $\mathrm{NaN}$ & $\mathrm{NaN}$ & $\mathrm{NaN}$ & $\mathrm{NaN}$ & -3.3 & $\mathrm{NaN}$ & $\mathrm{NaN}$ \\
\hline AN0893 (AdB) & Adenylosuccinate synthase & 56 & 65 & 97 & $\mathrm{NaN}$ & $\mathrm{NaN}$ & $\mathrm{NaN}$ & $\mathrm{NaN}$ & $\mathrm{NaN}$ & $\mathrm{NaN}$ & $\mathrm{NaN}$ & -3.1 & $\mathrm{NaN}$ & $\mathrm{NaN}$ \\
\hline AN6209 & Adenylosuccinate lyase & 4 & 26 & 38 & $\mathrm{NaN}$ & $\mathrm{NaN}$ & $\mathrm{NaN}$ & $\mathrm{NaN}$ & $\mathrm{NaN}$ & $\mathrm{NaN}$ & $\mathrm{NaN}$ & -2.4 & $\mathrm{NaN}$ & $\mathrm{NaN}$ \\
\hline AN6521 (LysF) & Homoaconitate hydratase & & 13 & 31 & $\mathrm{NaN}$ & $\mathrm{NaN}$ & $\mathrm{NaN}$ & $\mathrm{NaN}$ & $\mathrm{NaN}$ & $\mathrm{NaN}$ & $\mathrm{NaN}$ & -2.3 & $\mathrm{NaN}$ & $\mathrm{NaN}$ \\
\hline AN1558 (MyoA) & Myosir & 12 & & 11 & $\mathrm{NaN}$ & $\mathrm{NaN}$ & $\mathrm{NaN}$ & $\mathrm{NaN}$ & $\mathrm{NaN}$ & $\mathrm{NaN}$ & $\mathrm{NaN}$ & -2.3 & $\mathrm{NaN}$ & $\mathrm{NaN}$ \\
\hline AN11192 & P450 & & 28 & 18 & $\mathrm{NaN}$ & $\mathrm{NaN}$ & $\mathrm{NaN}$ & $\mathrm{NaN}$ & $\mathrm{NaN}$ & $\mathrm{NaN}$ & $\mathrm{NaN}$ & -2.2 & $\mathrm{NaN}$ & $\mathrm{NaN}$ \\
\hline AN4064 & carrier protein & 137 & 136 & 263 & $\mathrm{NaN}$ & $\mathrm{NaN}$ & $\mathrm{NaN}$ & $\mathrm{NaN}$ & $\mathrm{NaN}$ & $\mathrm{NaN}$ & $\mathrm{NaN}$ & -2.1 & $\mathrm{NaN}$ & $\mathrm{NaN}$ \\
\hline AN1503 & icolinate synthase & 3 & 2 & & $\mathrm{NaN}$ & $\mathrm{NaN}$ & $\mathrm{NaN}$ & $\mathrm{NaN}$ & $\mathrm{NaN}$ & $\mathrm{NaN}$ & $\mathrm{NaN}$ & -2.1 & $\mathrm{NaN}$ & $\mathrm{NaN}$ \\
\hline AN0952 & ase & 9 & 2 & 32 & $\mathrm{NaN}$ & $\mathrm{NaN}$ & $\mathrm{NaN}$ & $\mathrm{NaN}$ & $\mathrm{NaN}$ & $\mathrm{NaN}$ & $\mathrm{NaN}$ & -2.1 & $\mathrm{NaN}$ & $\mathrm{NaN}$ \\
\hline AN12070 & ogen ligase & 7 & 7 & 24 & $\mathrm{NaN}$ & $\mathrm{NaN}$ & $\mathrm{NaN}$ & $\mathrm{NaN}$ & $\mathrm{NaN}$ & $\mathrm{NaN}$ & $\mathrm{NaN}$ & -2.1 & $\mathrm{NaN}$ & $\mathrm{NaN}$ \\
\hline AN10426 & & 5 & 19 & 56 & $\mathrm{NaN}$ & $\mathrm{NaN}$ & $\mathrm{NaN}$ & $\mathrm{NaN}$ & $\mathrm{NaN}$ & $\mathrm{NaN}$ & $\mathrm{NaN}$ & -2.1 & $\mathrm{NaN}$ & $\mathrm{NaN}$ \\
\hline AN0595 & & 5 & 3 & 21 & $\mathrm{NaN}$ & $\mathrm{NaN}$ & $\mathrm{NaN}$ & $\mathrm{NaN}$ & $\mathrm{NaN}$ & $\mathrm{NaN}$ & $\mathrm{NaN}$ & -2.1 & $\mathrm{NaN}$ & $\mathrm{NaN}$ \\
\hline AN23 & dehydrogenase & & 2 & 8 & $\mathrm{NaN}$ & $\mathrm{NaN}$ & $\mathrm{NaN}$ & $\mathrm{NaN}$ & $\mathrm{NaN}$ & $\mathrm{NaN}$ & $\mathrm{NaN}$ & -2.1 & $\mathrm{NaN}$ & $\mathrm{NaN}$ \\
\hline AN10296 & ductase & 256 & 297 & 390 & $\mathrm{NaN}$ & $\mathrm{NaN}$ & $\mathrm{NaN}$ & $\mathrm{NaN}$ & $\mathrm{NaN}$ & $\mathrm{NaN}$ & $\mathrm{NaN}$ & -2.0 & $\mathrm{NaN}$ & $\mathrm{NaN}$ \\
\hline AN4C & initiation factor elF5B & & 8 & 84 & $\mathrm{NaN}$ & $\mathrm{NaN}$ & $\mathrm{NaN}$ & $\mathrm{NaN}$ & $\mathrm{NaN}$ & $\mathrm{NaN}$ & $\mathrm{NaN}$ & -2.0 & $\mathrm{NaN}$ & $\mathrm{NaN}$ \\
\hline AN4956 & synthase & & 16 & 48 & $\mathrm{NaN}$ & $\mathrm{NaN}$ & $\mathrm{NaN}$ & $\mathrm{NaN}$ & $\mathrm{NaN}$ & $\mathrm{NaN}$ & $\mathrm{NaN}$ & -2.0 & $\mathrm{NaN}$ & $\mathrm{NaN}$ \\
\hline AN8121 & hase & 7 & 22 & 36 & $\mathrm{NaN}$ & $\mathrm{NaN}$ & $\mathrm{NaN}$ & $\mathrm{NaN}$ & $\mathrm{NaN}$ & $\mathrm{NaN}$ & $\mathrm{NaN}$ & -2.0 & $\mathrm{NaN}$ & $\mathrm{NaN}$ \\
\hline AN3894 & ydratase & 4 & 16 & 57 & $\mathrm{NaN}$ & $\mathrm{NaN}$ & $\mathrm{NaN}$ & $\mathrm{NaN}$ & $\mathrm{NaN}$ & $\mathrm{NaN}$ & $\mathrm{NaN}$ & -2.0 & $\mathrm{NaN}$ & $\mathrm{NaN}$ \\
\hline AN7386 & known function & & 7 & 5 & $\mathrm{NaN}$ & $\mathrm{NaN}$ & $\mathrm{NaN}$ & $\mathrm{NaN}$ & $\mathrm{NaN}$ & $\mathrm{NaN}$ & $\mathrm{NaN}$ & -1.9 & $\mathrm{NaN}$ & $\mathrm{NaN}$ \\
\hline AN4859 (PmaA) & mbrane ATPase & 11 & 4 & 61 & $\mathrm{NaN}$ & $\mathrm{NaN}$ & $\mathrm{NaN}$ & $\mathrm{NaN}$ & $\mathrm{NaN}$ & $\mathrm{NaN}$ & $\mathrm{NaN}$ & -1.9 & $\mathrm{NaN}$ & $\mathrm{NaN}$ \\
\hline AN2516 (A & ociated protein & & 2 & 32 & $\mathrm{NaN}$ & $\mathrm{NaN}$ & $\mathrm{NaN}$ & $\mathrm{NaN}$ & $\mathrm{NaN}$ & $\mathrm{NaN}$ & $\mathrm{NaN}$ & -1.9 & $\mathrm{NaN}$ & $\mathrm{NaN}$ \\
\hline AN0432 & e-b5 reductase & 22 & 30 & 35 & $\mathrm{NaN}$ & $\mathrm{NaN}$ & $\mathrm{NaN}$ & $\mathrm{NaN}$ & $\mathrm{NaN}$ & $\mathrm{NaN}$ & $\mathrm{NaN}$ & -1.9 & $\mathrm{NaN}$ & $\mathrm{NaN}$ \\
\hline AN2120 & uctase & 5 & 27 & 201 & $\mathrm{NaN}$ & $\mathrm{NaN}$ & $\mathrm{NaN}$ & $\mathrm{NaN}$ & $\mathrm{NaN}$ & $\mathrm{NaN}$ & $\mathrm{NaN}$ & -1.8 & $\mathrm{NaN}$ & $\mathrm{NaN}$ \\
\hline AN3375 & protein & 3 & 6 & 21 & $\mathrm{NaN}$ & $\mathrm{NaN}$ & $\mathrm{NaN}$ & $\mathrm{NaN}$ & $\mathrm{NaN}$ & $\mathrm{NaN}$ & $\mathrm{NaN}$ & -1.8 & $\mathrm{NaN}$ & $\mathrm{NaN}$ \\
\hline AN2731 & otein binding activity & 7 & 8 & 53 & $\mathrm{NaN}$ & $\mathrm{NaN}$ & $\mathrm{NaN}$ & $\mathrm{NaN}$ & $\mathrm{NaN}$ & $\mathrm{NaN}$ & $\mathrm{NaN}$ & -1.8 & $\mathrm{NaN}$ & $\mathrm{NaN}$ \\
\hline AN2185 (NucA) & Endo & 16 & 12 & 16 & $\mathrm{NaN}$ & $\mathrm{NaN}$ & $\mathrm{NaN}$ & $\mathrm{NaN}$ & $\mathrm{NaN}$ & $\mathrm{NaN}$ & $\mathrm{NaN}$ & -1.8 & $\mathrm{NaN}$ & $\mathrm{NaN}$ \\
\hline AN12221 & ose-phosphate aldolase & 27 & 28 & 20 & $\mathrm{NaN}$ & $\mathrm{NaN}$ & $\mathrm{NaN}$ & $\mathrm{NaN}$ & $\mathrm{NaN}$ & $\mathrm{NaN}$ & $\mathrm{NaN}$ & -1.7 & $\mathrm{NaN}$ & $\mathrm{NaN}$ \\
\hline AN0708 (AromA) & amino acid biosynthesis & 29 & 34 & 93 & $\mathrm{NaN}$ & $\mathrm{NaN}$ & $\mathrm{NaN}$ & $\mathrm{NaN}$ & $\mathrm{NaN}$ & $\mathrm{NaN}$ & $\mathrm{NaN}$ & -1.7 & $\mathrm{NaN}$ & $\mathrm{NaN}$ \\
\hline AN1216 (GppA) & 3-phosphate phosphatase & & 7 & 11 & $\mathrm{NaN}$ & $\mathrm{NaN}$ & $\mathrm{NaN}$ & $\mathrm{NaN}$ & $\mathrm{NaN}$ & $\mathrm{NaN}$ & $\mathrm{NaN}$ & -1.7 & $\mathrm{NaN}$ & $\mathrm{NaN}$ \\
\hline AN8805 & Ankyrin repeat protein & & 2 & 8 & $\mathrm{NaN}$ & $\mathrm{NaN}$ & $\mathrm{NaN}$ & $\mathrm{NaN}$ & $\mathrm{NaN}$ & $\mathrm{NaN}$ & $\mathrm{NaN}$ & -1.7 & $\mathrm{NaN}$ & $\mathrm{NaN}$ \\
\hline AN5447 & Glutamate decarboxylase & 56 & 75 & 183 & $\mathrm{NaN}$ & $\mathrm{NaN}$ & $\mathrm{NaN}$ & $\mathrm{NaN}$ & $\mathrm{NaN}$ & $\mathrm{NaN}$ & $\mathrm{NaN}$ & -1.7 & $\mathrm{NaN}$ & $\mathrm{NaN}$ \\
\hline AN9159 & Protein of unknown function & 6 & 11 & 23 & $\mathrm{NaN}$ & $\mathrm{NaN}$ & $\mathrm{NaN}$ & $\mathrm{NaN}$ & $\mathrm{NaN}$ & $\mathrm{NaN}$ & $\mathrm{NaN}$ & -1.6 & $\mathrm{NaN}$ & $\mathrm{NaN}$ \\
\hline AN2882 & ne dehydrogenase & & 80 & 219 & $\mathrm{NaN}$ & $\mathrm{NaN}$ & $\mathrm{NaN}$ & $\mathrm{NaN}$ & $\mathrm{NaN}$ & $\mathrm{NaN}$ & $\mathrm{NaN}$ & -1.6 & $\mathrm{NaN}$ & $\mathrm{NaN}$ \\
\hline AN0290 & Actin $\mathrm{f}$ & & 18 & 43 & $\mathrm{NaN}$ & $\mathrm{NaN}$ & $\mathrm{NaN}$ & $\mathrm{NaN}$ & $\mathrm{NaN}$ & $\mathrm{NaN}$ & $\mathrm{NaN}$ & -1.6 & $\mathrm{NaN}$ & $\mathrm{NaN}$ \\
\hline AN2847 & Protein of unknown function & & 5 & 2 & $\mathrm{NaN}$ & $\mathrm{NaN}$ & $\mathrm{NaN}$ & $\mathrm{NaN}$ & $\mathrm{NaN}$ & $\mathrm{NaN}$ & $\mathrm{NaN}$ & -1.6 & $\mathrm{NaN}$ & $\mathrm{NaN}$ \\
\hline AN8016 (F & case & 7 & 20 & 44 & $\mathrm{NaN}$ & $\mathrm{NaN}$ & $\mathrm{NaN}$ & $\mathrm{NaN}$ & $\mathrm{NaN}$ & $\mathrm{NaN}$ & $\mathrm{NaN}$ & -1.6 & $\mathrm{NaN}$ & $\mathrm{NaN}$ \\
\hline AN0183 & Molybdopterin binding protein & & 23 & 23 & $\mathrm{NaN}$ & $\mathrm{NaN}$ & $\mathrm{NaN}$ & $\mathrm{NaN}$ & $\mathrm{NaN}$ & $\mathrm{NaN}$ & $\mathrm{NaN}$ & -1.5 & $\mathrm{NaN}$ & $\mathrm{NaN}$ \\
\hline AN3163 (StoA) & protein & 19 & & 13 & $\mathrm{NaN}$ & $\mathrm{NaN}$ & $\mathrm{NaN}$ & $\mathrm{NaN}$ & $\mathrm{NaN}$ & $\mathrm{NaN}$ & $\mathrm{NaN}$ & -1.5 & $\mathrm{NaN}$ & $\mathrm{NaN}$ \\
\hline AN4234 (PcmA) & oacetylglucosamine mutase & 21 & 37 & 106 & $\mathrm{NaN}$ & $\mathrm{NaN}$ & $\mathrm{NaN}$ & $\mathrm{NaN}$ & $\mathrm{NaN}$ & $\mathrm{NaN}$ & $\mathrm{NaN}$ & -1.5 & $\mathrm{NaN}$ & $\mathrm{NaN}$ \\
\hline AN1198 & $\mathrm{H}$ & 9 & 13 & 41 & $\mathrm{NaN}$ & $\mathrm{NaN}$ & $\mathrm{NaN}$ & $\mathrm{NaN}$ & $\mathrm{NaN}$ & $\mathrm{NaN}$ & $\mathrm{NaN}$ & -1.4 & $\mathrm{NaN}$ & $\mathrm{NaN}$ \\
\hline AN0661 & ted DNA polymerase & 5 & 6 & & $\mathrm{NaN}$ & $\mathrm{NaN}$ & $\mathrm{NaN}$ & $\mathrm{NaN}$ & $\mathrm{NaN}$ & $\mathrm{NaN}$ & $\mathrm{NaN}$ & -1.4 & $\mathrm{NaN}$ & $\mathrm{NaN}$ \\
\hline AN4015 & ongation factor & 63 & & 19 & $\mathrm{NaN}$ & $\mathrm{NaN}$ & $\mathrm{NaN}$ & $\mathrm{NaN}$ & $\mathrm{NaN}$ & $\mathrm{NaN}$ & $\mathrm{NaN}$ & -1.3 & $\mathrm{NaN}$ & $\mathrm{NaN}$ \\
\hline AN4317 (Sec13) & ar pore complex protein & 24 & & 7 & $\mathrm{NaN}$ & $\mathrm{NaN}$ & $\mathrm{NaN}$ & $\mathrm{NaN}$ & $\mathrm{NaN}$ & $\mathrm{NaN}$ & $\mathrm{NaN}$ & -1.3 & $\mathrm{NaN}$ & $\mathrm{NaN}$ \\
\hline AN8862 (MyoV) & & 8 & 18 & 36 & $\mathrm{NaN}$ & $\mathrm{NaN}$ & $\mathrm{NaN}$ & $\mathrm{NaN}$ & $\mathrm{NaN}$ & $\mathrm{NaN}$ & $\mathrm{NaN}$ & -1.3 & $\mathrm{NaN}$ & $\mathrm{NaN}$ \\
\hline AN8 & e (V-ATPase) & 49 & 57 & 90 & $\mathrm{NaN}$ & $\mathrm{NaN}$ & $\mathrm{NaN}$ & $\mathrm{NaN}$ & $\mathrm{NaN}$ & $\mathrm{NaN}$ & $\mathrm{NaN}$ & -1.3 & $\mathrm{NaN}$ & $\mathrm{NaN}$ \\
\hline AN5662 & RNA ligase & 51 & 107 & 193 & $\mathrm{NaN}$ & $\mathrm{NaN}$ & $\mathrm{NaN}$ & $\mathrm{NaN}$ & $\mathrm{NaN}$ & $\mathrm{NaN}$ & $\mathrm{NaN}$ & -1.2 & $\mathrm{NaN}$ & $\mathrm{NaN}$ \\
\hline AN3445 & & 12 & 6 & 36 & $\mathrm{NaN}$ & $\mathrm{NaN}$ & $\mathrm{NaN}$ & $\mathrm{NaN}$ & $\mathrm{NaN}$ & $\mathrm{NaN}$ & $\mathrm{NaN}$ & -1.2 & $\mathrm{NaN}$ & $\mathrm{NaN}$ \\
\hline AN7289 & mer binding protein & 42 & 50 & 59 & $\mathrm{NaN}$ & $\mathrm{NaN}$ & $\mathrm{NaN}$ & $\mathrm{NaN}$ & $\mathrm{NaN}$ & $\mathrm{NaN}$ & $\mathrm{NaN}$ & -1.1 & $\mathrm{NaN}$ & $\mathrm{NaN}$ \\
\hline AN8853 (S & e releasing factor & 17 & 6 & 46 & $\mathrm{NaN}$ & $\mathrm{NaN}$ & $\mathrm{NaN}$ & $\mathrm{NaN}$ & $\mathrm{NaN}$ & $\mathrm{NaN}$ & $\mathrm{NaN}$ & -1.1 & $\mathrm{NaN}$ & $\mathrm{NaN}$ \\
\hline AN4616 & at shock protein & 33 & 49 & 138 & $\mathrm{NaN}$ & $\mathrm{NaN}$ & $\mathrm{NaN}$ & $\mathrm{NaN}$ & $\mathrm{NaN}$ & $\mathrm{NaN}$ & $\mathrm{NaN}$ & -1.0 & $\mathrm{NaN}$ & $\mathrm{NaN}$ \\
\hline AN5121 & roteasome regulatory subunit 8 & 48 & 71 & 78 & $\mathrm{NaN}$ & $\mathrm{NaN}$ & $\mathrm{NaN}$ & $\mathrm{NaN}$ & $\mathrm{NaN}$ & $\mathrm{NaN}$ & $\mathrm{NaN}$ & -1.0 & $\mathrm{NaN}$ & $\mathrm{NaN}$ \\
\hline AN3918 & minopeptidase & 8 & 24 & 28 & $\mathrm{NaN}$ & $\mathrm{NaN}$ & $\mathrm{NaN}$ & $\mathrm{NaN}$ & $\mathrm{NaN}$ & $\mathrm{NaN}$ & $\mathrm{NaN}$ & -0.9 & $\mathrm{NaN}$ & $\mathrm{NaN}$ \\
\hline AN9357 & Short-chain dehydrogenase & 8 & 14 & & $\mathrm{NaN}$ & $\mathrm{NaN}$ & $\mathrm{NaN}$ & $\mathrm{NaN}$ & $\mathrm{NaN}$ & $\mathrm{NaN}$ & $\mathrm{NaN}$ & -0.9 & $\mathrm{NaN}$ & $\mathrm{NaN}$ \\
\hline AN7334 & & 19 & 25 & 74 & $\mathrm{NaN}$ & $\mathrm{NaN}$ & $\mathrm{NaN}$ & $\mathrm{NaN}$ & $\mathrm{NaN}$ & $\mathrm{NaN}$ & $\mathrm{NaN}$ & -0.8 & $\mathrm{NaN}$ & $\mathrm{NaN}$ \\
\hline AN3789 & Protein of unknown function & 26 & 12 & 13 & $\mathrm{NaN}$ & $\mathrm{NaN}$ & $\mathrm{NaN}$ & $\mathrm{NaN}$ & $\mathrm{NaN}$ & $\mathrm{NaN}$ & $\mathrm{NaN}$ & -0.8 & $\mathrm{NaN}$ & $\mathrm{NaN}$ \\
\hline AN0667 (ManA) & e-6-phosphate isomerase & & 26 & 27 & $\mathrm{NaN}$ & $\mathrm{NaN}$ & $\mathrm{NaN}$ & $\mathrm{NaN}$ & $\mathrm{NaN}$ & $\mathrm{NaN}$ & $\mathrm{NaN}$ & -0.8 & $\mathrm{NaN}$ & $\mathrm{NaN}$ \\
\hline AN2026 & anscription factor & 4 & 5 & 7 & $\mathrm{NaN}$ & $\mathrm{NaN}$ & $\mathrm{NaN}$ & $\mathrm{NaN}$ & $\mathrm{NaN}$ & $\mathrm{NaN}$ & $\mathrm{NaN}$ & -0.8 & $\mathrm{NaN}$ & $\mathrm{NaN}$ \\
\hline AN9067 & otein of unknown function & & 18 & 30 & $\mathrm{NaN}$ & $\mathrm{NaN}$ & $\mathrm{NaN}$ & $\mathrm{NaN}$ & $\mathrm{NaN}$ & $\mathrm{NaN}$ & $\mathrm{NaN}$ & -0.5 & $\mathrm{NaN}$ & $\mathrm{NaN}$ \\
\hline AN9297 & otein of unknown function & & 53 & 67 & $\mathrm{NaN}$ & $\mathrm{NaN}$ & $\mathrm{NaN}$ & $\mathrm{NaN}$ & $\mathrm{NaN}$ & $\mathrm{NaN}$ & $\mathrm{NaN}$ & -0.5 & $\mathrm{NaN}$ & $\mathrm{NaN}$ \\
\hline AN5404 & Protein of unknown function & & 4 & 15 & $\mathrm{NaN}$ & $\mathrm{NaN}$ & $\mathrm{NaN}$ & $\mathrm{NaN}$ & $\mathrm{NaN}$ & $\mathrm{NaN}$ & $\mathrm{NaN}$ & -0.5 & $\mathrm{NaN}$ & $\mathrm{NaN}$ \\
\hline
\end{tabular}




\begin{tabular}{|c|c|c|c|c|c|c|c|c|c|c|c|c|c|c|}
\hline \multirow[t]{2}{*}{ Gene ID } & \multirow[t]{2}{*}{ Description } & \multicolumn{3}{|c|}{ PSM } & \multicolumn{3}{|c|}{ IaeAd/aeA } & \multirow[t]{2}{*}{$\varnothing$} & \multirow[t]{2}{*}{ SD } & \multicolumn{3}{|c|}{ laeAcomp+/laeA } & $\varnothing$ & SD \\
\hline & & 1 & 2 & 3 & 1 & 2 & 3 & & & 1 & 2 & 3 & & \\
\hline AN10170 & ATPase activity & 89 & 133 & 180 & $\mathrm{NaN}$ & $\mathrm{NaN}$ & $\mathrm{NaN}$ & $\mathrm{NaN}$ & $\mathrm{NaN}$ & $\mathrm{NaN}$ & $\mathrm{NaN}$ & -0.4 & $\mathrm{NaN}$ & $\mathrm{NaN}$ \\
\hline AN0495 & Formyltetrahydrofolate deformylase & & 22 & 34 & $\mathrm{NaN}$ & $\mathrm{NaN}$ & $\mathrm{NaN}$ & $\mathrm{NaN}$ & $\mathrm{NaN}$ & $\mathrm{NaN}$ & $\mathrm{NaN}$ & -0.2 & $\mathrm{NaN}$ & $\mathrm{NaN}$ \\
\hline AN2405 & Methyltransferases & 16 & 6 & 2 & $\mathrm{NaN}$ & $\mathrm{NaN}$ & $\mathrm{NaN}$ & $\mathrm{NaN}$ & $\mathrm{NaN}$ & $\mathrm{NaN}$ & $\mathrm{NaN}$ & 0.1 & $\mathrm{NaN}$ & $\mathrm{NaN}$ \\
\hline AN8430 & Protein of unknown function & 11 & 14 & 25 & $\mathrm{NaN}$ & $\mathrm{NaN}$ & $\mathrm{NaN}$ & $\mathrm{NaN}$ & $\mathrm{NaN}$ & $\mathrm{NaN}$ & $\mathrm{NaN}$ & 0.1 & $\mathrm{NaN}$ & $\mathrm{NaN}$ \\
\hline AN6985 & Ribulokinase & 20 & & 2 & $\mathrm{NaN}$ & $\mathrm{NaN}$ & $\mathrm{NaN}$ & $\mathrm{NaN}$ & $\mathrm{NaN}$ & $\mathrm{NaN}$ & $\mathrm{NaN}$ & 0.6 & $\mathrm{NaN}$ & $\mathrm{NaN}$ \\
\hline AN7999 & Oxidoreductase $m d p / x p t$ & 63 & 63 & 84 & $\mathrm{NaN}$ & $\mathrm{NaN}$ & $\mathrm{NaN}$ & $\mathrm{NaN}$ & $\mathrm{NaN}$ & $\mathrm{NaN}$ & $\mathrm{NaN}$ & 0.9 & $\mathrm{NaN}$ & $\mathrm{NaN}$ \\
\hline AN8604 (Ngn23) & GNAT-type acetyltransferase & 7 & 8 & 9 & $\mathrm{NaN}$ & $\mathrm{NaN}$ & $\mathrm{NaN}$ & $\mathrm{NaN}$ & $\mathrm{NaN}$ & $\mathrm{NaN}$ & $\mathrm{NaN}$ & 1.6 & $\mathrm{NaN}$ & $\mathrm{NaN}$ \\
\hline AN0787 (Mns1B) & Mannosidase $1 \mathrm{~A}$ & 15 & 3 & 10 & $\mathrm{NaN}$ & $\mathrm{NaN}$ & $\mathrm{NaN}$ & $\mathrm{NaN}$ & $\mathrm{NaN}$ & $\mathrm{NaN}$ & $\mathrm{NaN}$ & 1.7 & $\mathrm{NaN}$ & $\mathrm{NaN}$ \\
\hline AN1117 & COPII adaptor activity & 21 & 20 & 22 & $\mathrm{NaN}$ & $\mathrm{NaN}$ & $\mathrm{NaN}$ & $\mathrm{NaN}$ & $\mathrm{NaN}$ & $\mathrm{NaN}$ & $\mathrm{NaN}$ & 1.9 & $\mathrm{NaN}$ & $\mathrm{NaN}$ \\
\hline AN5423 & Protein of unknown function & 16 & 6 & 19 & $\mathrm{NaN}$ & $\mathrm{NaN}$ & $\mathrm{NaN}$ & $\mathrm{NaN}$ & $\mathrm{NaN}$ & $\mathrm{NaN}$ & $\mathrm{NaN}$ & 2.1 & $\mathrm{NaN}$ & $\mathrm{NaN}$ \\
\hline AN0050 & Picolinic acid decarboxylase & 8 & 22 & 4 & $\mathrm{NaN}$ & $\mathrm{NaN}$ & $\mathrm{NaN}$ & $\mathrm{NaN}$ & $\mathrm{NaN}$ & $\mathrm{NaN}$ & $\mathrm{NaN}$ & $\mathrm{NaN}$ & $\mathrm{NaN}$ & $\mathrm{NaN}$ \\
\hline AN0051 & Dioxygenase & 14 & 17 & & $\mathrm{NaN}$ & $\mathrm{NaN}$ & $\mathrm{NaN}$ & $\mathrm{NaN}$ & $\mathrm{NaN}$ & $\mathrm{NaN}$ & $\mathrm{NaN}$ & $\mathrm{NaN}$ & $\mathrm{NaN}$ & $\mathrm{NaN}$ \\
\hline AN0121 (HemC) & Porphobilinogen deaminase & 6 & 17 & 22 & $\mathrm{NaN}$ & $\mathrm{NaN}$ & $\mathrm{NaN}$ & $\mathrm{NaN}$ & $\mathrm{NaN}$ & $\mathrm{NaN}$ & $\mathrm{NaN}$ & $\mathrm{NaN}$ & $\mathrm{NaN}$ & $\mathrm{NaN}$ \\
\hline AN0133 & RNA helicase & 5 & 2 & 11 & $\mathrm{NaN}$ & $\mathrm{NaN}$ & $\mathrm{NaN}$ & $\mathrm{NaN}$ & $\mathrm{NaN}$ & $\mathrm{NaN}$ & $\mathrm{NaN}$ & $\mathrm{NaN}$ & $\mathrm{NaN}$ & $\mathrm{NaN}$ \\
\hline AN0146 (MdpC) & Versicolorin ketoreductase & 33 & 13 & 23 & $\mathrm{NaN}$ & $\mathrm{NaN}$ & $\mathrm{NaN}$ & $\mathrm{NaN}$ & $\mathrm{NaN}$ & $\mathrm{NaN}$ & $\mathrm{NaN}$ & $\mathrm{NaN}$ & $\mathrm{NaN}$ & $\mathrm{NaN}$ \\
\hline AN0150 (MdpG) & Polketide synthase $m d p / x p t$ & 17 & 4 & 5 & $\mathrm{NaN}$ & $\mathrm{NaN}$ & $\mathrm{NaN}$ & $\mathrm{NaN}$ & $\mathrm{NaN}$ & $\mathrm{NaN}$ & $\mathrm{NaN}$ & $\mathrm{NaN}$ & $\mathrm{NaN}$ & $\mathrm{NaN}$ \\
\hline AN0228 & DNA helicase & 6 & 9 & 9 & $\mathrm{NaN}$ & $\mathrm{NaN}$ & $\mathrm{NaN}$ & $\mathrm{NaN}$ & $\mathrm{NaN}$ & $\mathrm{NaN}$ & $\mathrm{NaN}$ & $\mathrm{NaN}$ & $\mathrm{NaN}$ & $\mathrm{NaN}$ \\
\hline AN0261 (Sec23) & Coat protein complex II & 36 & 8 & 133 & $\mathrm{NaN}$ & $\mathrm{NaN}$ & $\mathrm{NaN}$ & $\mathrm{NaN}$ & $\mathrm{NaN}$ & $\mathrm{NaN}$ & $\mathrm{NaN}$ & $\mathrm{NaN}$ & $\mathrm{NaN}$ & $\mathrm{NaN}$ \\
\hline AN0381 & Chaperonin & 15 & 26 & 77 & $\mathrm{NaN}$ & $\mathrm{NaN}$ & $\mathrm{NaN}$ & $\mathrm{NaN}$ & $\mathrm{NaN}$ & $\mathrm{NaN}$ & $\mathrm{NaN}$ & $\mathrm{NaN}$ & $\mathrm{NaN}$ & $\mathrm{NaN}$ \\
\hline AN0410 & Phosphatase & 7 & 9 & 34 & $\mathrm{NaN}$ & $\mathrm{NaN}$ & $\mathrm{NaN}$ & $\mathrm{NaN}$ & $\mathrm{NaN}$ & $\mathrm{NaN}$ & $\mathrm{NaN}$ & $\mathrm{NaN}$ & $\mathrm{NaN}$ & $\mathrm{NaN}$ \\
\hline AN0465 & Protein of unknown function & 42 & & 6 & $\mathrm{NaN}$ & $\mathrm{NaN}$ & $\mathrm{NaN}$ & $\mathrm{NaN}$ & $\mathrm{NaN}$ & $\mathrm{NaN}$ & $\mathrm{NaN}$ & $\mathrm{NaN}$ & $\mathrm{NaN}$ & $\mathrm{NaN}$ \\
\hline AN0574 & Nucleotide binding & 17 & 26 & & $\mathrm{NaN}$ & $\mathrm{NaN}$ & $\mathrm{NaN}$ & $\mathrm{NaN}$ & $\mathrm{NaN}$ & $\mathrm{NaN}$ & $\mathrm{NaN}$ & $\mathrm{NaN}$ & $\mathrm{NaN}$ & $\mathrm{NaN}$ \\
\hline AN0579 & IPP isomerase & 40 & 43 & 38 & $\mathrm{NaN}$ & $\mathrm{NaN}$ & $\mathrm{NaN}$ & $\mathrm{NaN}$ & $\mathrm{NaN}$ & $\mathrm{NaN}$ & $\mathrm{NaN}$ & $\mathrm{NaN}$ & $\mathrm{NaN}$ & $\mathrm{NaN}$ \\
\hline AN0593 & Dehydrogenase & 21 & 11 & 3 & $\mathrm{NaN}$ & $\mathrm{NaN}$ & $\mathrm{NaN}$ & $\mathrm{NaN}$ & $\mathrm{NaN}$ & $\mathrm{NaN}$ & $\mathrm{NaN}$ & $\mathrm{NaN}$ & $\mathrm{NaN}$ & $\mathrm{NaN}$ \\
\hline AN0757 & tRNA methylation & 4 & 6 & 46 & $\mathrm{NaN}$ & $\mathrm{NaN}$ & $\mathrm{NaN}$ & $\mathrm{NaN}$ & $\mathrm{NaN}$ & $\mathrm{NaN}$ & $\mathrm{NaN}$ & $\mathrm{NaN}$ & $\mathrm{NaN}$ & $\mathrm{NaN}$ \\
\hline AN0922 & Golgi vesicle-mediated transport & 11 & 21 & 62 & $\mathrm{NaN}$ & $\mathrm{NaN}$ & $\mathrm{NaN}$ & $\mathrm{NaN}$ & $\mathrm{NaN}$ & $\mathrm{NaN}$ & $\mathrm{NaN}$ & $\mathrm{NaN}$ & $\mathrm{NaN}$ & $\mathrm{NaN}$ \\
\hline AN0987 & Protein of unknown function & 25 & & 48 & $\mathrm{NaN}$ & $\mathrm{NaN}$ & $\mathrm{NaN}$ & $\mathrm{NaN}$ & $\mathrm{NaN}$ & $\mathrm{NaN}$ & $\mathrm{NaN}$ & $\mathrm{NaN}$ & $\mathrm{NaN}$ & $\mathrm{NaN}$ \\
\hline AN10108 & Oxidoreductase & & 4 & 24 & $\mathrm{NaN}$ & $\mathrm{NaN}$ & $\mathrm{NaN}$ & $\mathrm{NaN}$ & $\mathrm{NaN}$ & $\mathrm{NaN}$ & $\mathrm{NaN}$ & $\mathrm{NaN}$ & $\mathrm{NaN}$ & $\mathrm{NaN}$ \\
\hline AN1019 & SCF complex protein & & 4 & 13 & $\mathrm{NaN}$ & $\mathrm{NaN}$ & $\mathrm{NaN}$ & $\mathrm{NaN}$ & $\mathrm{NaN}$ & $\mathrm{NaN}$ & $\mathrm{NaN}$ & $\mathrm{NaN}$ & $\mathrm{NaN}$ & $\mathrm{NaN}$ \\
\hline AN1023 (SagA) & Cytoskeletal adaptor protein & 7 & & 7 & $\mathrm{NaN}$ & $\mathrm{NaN}$ & $\mathrm{NaN}$ & $\mathrm{NaN}$ & $\mathrm{NaN}$ & $\mathrm{NaN}$ & $\mathrm{NaN}$ & $\mathrm{NaN}$ & $\mathrm{NaN}$ & $\mathrm{NaN}$ \\
\hline AN10276 & Initiation factor $4 \mathrm{G}$ binding & & 11 & 32 & $\mathrm{NaN}$ & $\mathrm{NaN}$ & $\mathrm{NaN}$ & $\mathrm{NaN}$ & $\mathrm{NaN}$ & $\mathrm{NaN}$ & $\mathrm{NaN}$ & $\mathrm{NaN}$ & $\mathrm{NaN}$ & $\mathrm{NaN}$ \\
\hline AN10284 & Glutathione synthase & 12 & 9 & & $\mathrm{NaN}$ & $\mathrm{NaN}$ & $\mathrm{NaN}$ & $\mathrm{NaN}$ & $\mathrm{NaN}$ & $\mathrm{NaN}$ & $\mathrm{NaN}$ & $\mathrm{NaN}$ & $\mathrm{NaN}$ & $\mathrm{NaN}$ \\
\hline AN10476 & Dehydrogenase/GMP reductase & 57 & 39 & 98 & $\mathrm{NaN}$ & $\mathrm{NaN}$ & $\mathrm{NaN}$ & $\mathrm{NaN}$ & $\mathrm{NaN}$ & $\mathrm{NaN}$ & $\mathrm{NaN}$ & $\mathrm{NaN}$ & $\mathrm{NaN}$ & $\mathrm{NaN}$ \\
\hline AN10734 & Regulation translational elongation & 3 & 6 & 35 & $\mathrm{NaN}$ & $\mathrm{NaN}$ & $\mathrm{NaN}$ & $\mathrm{NaN}$ & $\mathrm{NaN}$ & $\mathrm{NaN}$ & $\mathrm{NaN}$ & $\mathrm{NaN}$ & $\mathrm{NaN}$ & $\mathrm{NaN}$ \\
\hline AN10864 & Phosphatase & 3 & & 3 & $\mathrm{NaN}$ & $\mathrm{NaN}$ & $\mathrm{NaN}$ & $\mathrm{NaN}$ & $\mathrm{NaN}$ & $\mathrm{NaN}$ & $\mathrm{NaN}$ & $\mathrm{NaN}$ & $\mathrm{NaN}$ & $\mathrm{NaN}$ \\
\hline AN11052 & 5'-3' exonuclease & & 12 & 83 & $\mathrm{NaN}$ & $\mathrm{NaN}$ & $\mathrm{NaN}$ & $\mathrm{NaN}$ & $\mathrm{NaN}$ & $\mathrm{NaN}$ & $\mathrm{NaN}$ & $\mathrm{NaN}$ & $\mathrm{NaN}$ & $\mathrm{NaN}$ \\
\hline AN1122 & $60 S$ ribosomal protein $\mathrm{L} 1$ & 12 & 22 & 234 & $\mathrm{NaN}$ & $\mathrm{NaN}$ & $\mathrm{NaN}$ & $\mathrm{NaN}$ & $\mathrm{NaN}$ & $\mathrm{NaN}$ & $\mathrm{NaN}$ & $\mathrm{NaN}$ & $\mathrm{NaN}$ & $\mathrm{NaN}$ \\
\hline AN11246 & Protein of unknown function & & 11 & 31 & $\mathrm{NaN}$ & $\mathrm{NaN}$ & $\mathrm{NaN}$ & $\mathrm{NaN}$ & $\mathrm{NaN}$ & $\mathrm{NaN}$ & $\mathrm{NaN}$ & $\mathrm{NaN}$ & $\mathrm{NaN}$ & $\mathrm{NaN}$ \\
\hline AN1167 & Protein of unknown function & 21 & 14 & 40 & $\mathrm{NaN}$ & $\mathrm{NaN}$ & $\mathrm{NaN}$ & $\mathrm{NaN}$ & $\mathrm{NaN}$ & $\mathrm{NaN}$ & $\mathrm{NaN}$ & $\mathrm{NaN}$ & $\mathrm{NaN}$ & $\mathrm{NaN}$ \\
\hline AN11981 & Aminomethyltransferase & 2 & 11 & & $\mathrm{NaN}$ & $\mathrm{NaN}$ & $\mathrm{NaN}$ & $\mathrm{NaN}$ & $\mathrm{NaN}$ & $\mathrm{NaN}$ & $\mathrm{NaN}$ & $\mathrm{NaN}$ & $\mathrm{NaN}$ & $\mathrm{NaN}$ \\
\hline AN12027 & Protein of unknown function & 26 & 35 & 16 & $\mathrm{NaN}$ & $\mathrm{NaN}$ & $\mathrm{NaN}$ & $\mathrm{NaN}$ & $\mathrm{NaN}$ & $\mathrm{NaN}$ & $\mathrm{NaN}$ & $\mathrm{NaN}$ & $\mathrm{NaN}$ & $\mathrm{NaN}$ \\
\hline AN12054 (SsnF) & Transcriptional co-repressor & 10 & 10 & 24 & $\mathrm{NaN}$ & $\mathrm{NaN}$ & $\mathrm{NaN}$ & $\mathrm{NaN}$ & $\mathrm{NaN}$ & $\mathrm{NaN}$ & $\mathrm{NaN}$ & $\mathrm{NaN}$ & $\mathrm{NaN}$ & $\mathrm{NaN}$ \\
\hline AN1222 & S-adenosylmethionine synthetase & 144 & 157 & 357 & $\mathrm{NaN}$ & $\mathrm{NaN}$ & $\mathrm{NaN}$ & $\mathrm{NaN}$ & $\mathrm{NaN}$ & $\mathrm{NaN}$ & $\mathrm{NaN}$ & $\mathrm{NaN}$ & $\mathrm{NaN}$ & $\mathrm{NaN}$ \\
\hline AN12402 (XptB) & Prenyltransferase $(m p d / x p t)$ & 10 & 9 & 17 & $\mathrm{NaN}$ & $\mathrm{NaN}$ & $\mathrm{NaN}$ & $\mathrm{NaN}$ & $\mathrm{NaN}$ & $\mathrm{NaN}$ & $\mathrm{NaN}$ & $\mathrm{NaN}$ & $\mathrm{NaN}$ & $\mathrm{NaN}$ \\
\hline AN1546 & Histone deacetylase & & 2 & 4 & $\mathrm{NaN}$ & $\mathrm{NaN}$ & $\mathrm{NaN}$ & $\mathrm{NaN}$ & $\mathrm{NaN}$ & $\mathrm{NaN}$ & $\mathrm{NaN}$ & $\mathrm{NaN}$ & $\mathrm{NaN}$ & $\mathrm{NaN}$ \\
\hline AN1547 (CoaT) & Carboxylate CoA-transferase & & 17 & 13 & $\mathrm{NaN}$ & $\mathrm{NaN}$ & $\mathrm{NaN}$ & $\mathrm{NaN}$ & $\mathrm{NaN}$ & $\mathrm{NaN}$ & $\mathrm{NaN}$ & $\mathrm{NaN}$ & $\mathrm{NaN}$ & $\mathrm{NaN}$ \\
\hline AN1606 & Annexin & & 16 & 40 & $\mathrm{NaN}$ & $\mathrm{NaN}$ & $\mathrm{NaN}$ & $\mathrm{NaN}$ & $\mathrm{NaN}$ & $\mathrm{NaN}$ & $\mathrm{NaN}$ & $\mathrm{NaN}$ & $\mathrm{NaN}$ & $\mathrm{NaN}$ \\
\hline AN1851 & Chaperonin & 21 & 34 & 85 & $\mathrm{NaN}$ & $\mathrm{NaN}$ & $\mathrm{NaN}$ & $\mathrm{NaN}$ & $\mathrm{NaN}$ & $\mathrm{NaN}$ & $\mathrm{NaN}$ & $\mathrm{NaN}$ & $\mathrm{NaN}$ & $\mathrm{NaN}$ \\
\hline AN1867 (PhoB) & Cyclin-dependent protein kinase & 2 & & 5 & $\mathrm{NaN}$ & $\mathrm{NaN}$ & $\mathrm{NaN}$ & $\mathrm{NaN}$ & $\mathrm{NaN}$ & $\mathrm{NaN}$ & $\mathrm{NaN}$ & $\mathrm{NaN}$ & $\mathrm{NaN}$ & $\mathrm{NaN}$ \\
\hline AN1868 & Glycerol dehydrogenase & 11 & 19 & & $\mathrm{NaN}$ & $\mathrm{NaN}$ & $\mathrm{NaN}$ & $\mathrm{NaN}$ & $\mathrm{NaN}$ & $\mathrm{NaN}$ & $\mathrm{NaN}$ & $\mathrm{NaN}$ & $\mathrm{NaN}$ & $\mathrm{NaN}$ \\
\hline AN1882 & Oxidoreductase & & 8 & 4 & $\mathrm{NaN}$ & $\mathrm{NaN}$ & $\mathrm{NaN}$ & $\mathrm{NaN}$ & $\mathrm{NaN}$ & $\mathrm{NaN}$ & $\mathrm{NaN}$ & $\mathrm{NaN}$ & $\mathrm{NaN}$ & $\mathrm{NaN}$ \\
\hline AN1896 (FahA) & Fumarylacetoacetate hydrolase & 42 & 49 & 5 & $\mathrm{NaN}$ & $\mathrm{NaN}$ & $\mathrm{NaN}$ & $\mathrm{NaN}$ & $\mathrm{NaN}$ & $\mathrm{NaN}$ & $\mathrm{NaN}$ & $\mathrm{NaN}$ & $\mathrm{NaN}$ & $\mathrm{NaN}$ \\
\hline AN1918 (AcuF) & Carboxykinase & 16 & 29 & 39 & $\mathrm{NaN}$ & $\mathrm{NaN}$ & $\mathrm{NaN}$ & $\mathrm{NaN}$ & $\mathrm{NaN}$ & $\mathrm{NaN}$ & $\mathrm{NaN}$ & $\mathrm{NaN}$ & $\mathrm{NaN}$ & $\mathrm{NaN}$ \\
\hline AN1967 & Fatty acid dioxygenase & 22 & 41 & 87 & $\mathrm{NaN}$ & $\mathrm{NaN}$ & $\mathrm{NaN}$ & $\mathrm{NaN}$ & $\mathrm{NaN}$ & $\mathrm{NaN}$ & $\mathrm{NaN}$ & $\mathrm{NaN}$ & $\mathrm{NaN}$ & $\mathrm{NaN}$ \\
\hline AN1971 & 3'-5' DNA helicase & 16 & 10 & 35 & $\mathrm{NaN}$ & $\mathrm{NaN}$ & $\mathrm{NaN}$ & $\mathrm{NaN}$ & $\mathrm{NaN}$ & $\mathrm{NaN}$ & $\mathrm{NaN}$ & $\mathrm{NaN}$ & $\mathrm{NaN}$ & $\mathrm{NaN}$ \\
\hline AN2080 & Translation release factor eRF3 & & 21 & 39 & $\mathrm{NaN}$ & $\mathrm{NaN}$ & $\mathrm{NaN}$ & $\mathrm{NaN}$ & $\mathrm{NaN}$ & $\mathrm{NaN}$ & $\mathrm{NaN}$ & $\mathrm{NaN}$ & $\mathrm{NaN}$ & $\mathrm{NaN}$ \\
\hline AN2092 (PapA) & Prolyl aminopeptidase & & 8 & 8 & $\mathrm{NaN}$ & $\mathrm{NaN}$ & $\mathrm{NaN}$ & $\mathrm{NaN}$ & $\mathrm{NaN}$ & $\mathrm{NaN}$ & $\mathrm{NaN}$ & $\mathrm{NaN}$ & $\mathrm{NaN}$ & $\mathrm{NaN}$ \\
\hline AN2149 (Cct1) & Chaperonin complex component & 12 & 27 & 86 & $\mathrm{NaN}$ & $\mathrm{NaN}$ & $\mathrm{NaN}$ & $\mathrm{NaN}$ & $\mathrm{NaN}$ & $\mathrm{NaN}$ & $\mathrm{NaN}$ & $\mathrm{NaN}$ & $\mathrm{NaN}$ & $\mathrm{NaN}$ \\
\hline AN2208 & Galactose 1-dehydrogenase & 55 & 41 & 91 & $\mathrm{NaN}$ & $\mathrm{NaN}$ & $\mathrm{NaN}$ & $\mathrm{NaN}$ & $\mathrm{NaN}$ & $\mathrm{NaN}$ & $\mathrm{NaN}$ & $\mathrm{NaN}$ & $\mathrm{NaN}$ & $\mathrm{NaN}$ \\
\hline AN2293 & Isomerase activity & & 2 & 7 & $\mathrm{NaN}$ & $\mathrm{NaN}$ & $\mathrm{NaN}$ & $\mathrm{NaN}$ & $\mathrm{NaN}$ & $\mathrm{NaN}$ & $\mathrm{NaN}$ & $\mathrm{NaN}$ & $\mathrm{NaN}$ & $\mathrm{NaN}$ \\
\hline AN2314 & Glucan branching enzyme & 43 & 25 & 22 & $\mathrm{NaN}$ & $\mathrm{NaN}$ & $\mathrm{NaN}$ & $\mathrm{NaN}$ & $\mathrm{NaN}$ & $\mathrm{NaN}$ & $\mathrm{NaN}$ & $\mathrm{NaN}$ & $\mathrm{NaN}$ & $\mathrm{NaN}$ \\
\hline AN2336 & Phospholipase C & & 80 & 211 & $\mathrm{NaN}$ & $\mathrm{NaN}$ & $\mathrm{NaN}$ & $\mathrm{NaN}$ & $\mathrm{NaN}$ & $\mathrm{NaN}$ & $\mathrm{NaN}$ & $\mathrm{NaN}$ & $\mathrm{NaN}$ & $\mathrm{NaN}$ \\
\hline AN2439 (SldB) & Spindle assembly checkpoint & & 14 & 14 & $\mathrm{NaN}$ & $\mathrm{NaN}$ & $\mathrm{NaN}$ & $\mathrm{NaN}$ & $\mathrm{NaN}$ & $\mathrm{NaN}$ & $\mathrm{NaN}$ & $\mathrm{NaN}$ & $\mathrm{NaN}$ & $\mathrm{NaN}$ \\
\hline AN2514 & Protein of unknown function & & 9 & 19 & $\mathrm{NaN}$ & $\mathrm{NaN}$ & $\mathrm{NaN}$ & $\mathrm{NaN}$ & $\mathrm{NaN}$ & $\mathrm{NaN}$ & $\mathrm{NaN}$ & $\mathrm{NaN}$ & $\mathrm{NaN}$ & $\mathrm{NaN}$ \\
\hline AN2523 (ChsB) & Chitin synthase & 3 & & 25 & $\mathrm{NaN}$ & $\mathrm{NaN}$ & $\mathrm{NaN}$ & $\mathrm{NaN}$ & $\mathrm{NaN}$ & $\mathrm{NaN}$ & $\mathrm{NaN}$ & $\mathrm{NaN}$ & $\mathrm{NaN}$ & $\mathrm{NaN}$ \\
\hline AN2525 & L-serine dehydratase & & 3 & 14 & $\mathrm{NaN}$ & $\mathrm{NaN}$ & $\mathrm{NaN}$ & $\mathrm{NaN}$ & $\mathrm{NaN}$ & $\mathrm{NaN}$ & $\mathrm{NaN}$ & $\mathrm{NaN}$ & $\mathrm{NaN}$ & $\mathrm{NaN}$ \\
\hline AN2549 (EasD) & Acyl-CoA ligase & 3 & 10 & & $\mathrm{NaN}$ & $\mathrm{NaN}$ & $\mathrm{NaN}$ & $\mathrm{NaN}$ & $\mathrm{NaN}$ & $\mathrm{NaN}$ & $\mathrm{NaN}$ & $\mathrm{NaN}$ & $\mathrm{NaN}$ & $\mathrm{NaN}$ \\
\hline
\end{tabular}




\begin{tabular}{|c|c|c|c|c|c|c|c|c|c|c|c|c|c|c|}
\hline \multirow[t]{2}{*}{ Gene ID } & \multirow[t]{2}{*}{ Description } & \multicolumn{3}{|c|}{ PSM } & \multicolumn{3}{|c|}{ laeA $A /$ laeA } & \multirow[t]{2}{*}{$\varnothing$} & \multirow[t]{2}{*}{ SD } & \multicolumn{3}{|c|}{ laeAcomp+/laeA } & $\varnothing$ & SD \\
\hline & & 1 & 2 & 3 & 1 & 2 & 3 & & & 1 & 2 & 3 & & \\
\hline AN2588 & Protein of unknown function & 46 & 21 & 18 & $\mathrm{NaN}$ & $\mathrm{NaN}$ & $\mathrm{NaN}$ & $\mathrm{NaN}$ & $\mathrm{NaN}$ & $\mathrm{NaN}$ & $\mathrm{NaN}$ & $\mathrm{NaN}$ & $\mathrm{NaN}$ & $\mathrm{NaN}$ \\
\hline AN2682 & Oxidoreductase & 2 & 4 & 93 & $\mathrm{NaN}$ & $\mathrm{NaN}$ & $\mathrm{NaN}$ & $\mathrm{NaN}$ & $\mathrm{NaN}$ & $\mathrm{NaN}$ & $\mathrm{NaN}$ & $\mathrm{NaN}$ & $\mathrm{NaN}$ & $\mathrm{NaN}$ \\
\hline AN2733 & Uroporphyrinogen decarboxylase & & 4 & 5 & $\mathrm{NaN}$ & $\mathrm{NaN}$ & $\mathrm{NaN}$ & $\mathrm{NaN}$ & $\mathrm{NaN}$ & $\mathrm{NaN}$ & $\mathrm{NaN}$ & $\mathrm{NaN}$ & $\mathrm{NaN}$ & $\mathrm{NaN}$ \\
\hline AN2775 & elF2A subunit & 2 & 9 & 43 & $\mathrm{NaN}$ & $\mathrm{NaN}$ & $\mathrm{NaN}$ & $\mathrm{NaN}$ & $\mathrm{NaN}$ & $\mathrm{NaN}$ & $\mathrm{NaN}$ & $\mathrm{NaN}$ & $\mathrm{NaN}$ & $\mathrm{NaN}$ \\
\hline AN2815 & Mannitol 2-dehydrogenase & & 12 & 36 & $\mathrm{NaN}$ & $\mathrm{NaN}$ & $\mathrm{NaN}$ & $\mathrm{NaN}$ & $\mathrm{NaN}$ & $\mathrm{NaN}$ & $\mathrm{NaN}$ & $\mathrm{NaN}$ & $\mathrm{NaN}$ & $\mathrm{NaN}$ \\
\hline AN2917 & Proteasome regulatory particle & 29 & 20 & 49 & $\mathrm{NaN}$ & $\mathrm{NaN}$ & $\mathrm{NaN}$ & $\mathrm{NaN}$ & $\mathrm{NaN}$ & $\mathrm{NaN}$ & $\mathrm{NaN}$ & $\mathrm{NaN}$ & $\mathrm{NaN}$ & $\mathrm{NaN}$ \\
\hline AN2954 & Protein of unknown function & 71 & 131 & 96 & $\mathrm{NaN}$ & $\mathrm{NaN}$ & $\mathrm{NaN}$ & $\mathrm{NaN}$ & $\mathrm{NaN}$ & $\mathrm{NaN}$ & $\mathrm{NaN}$ & $\mathrm{NaN}$ & $\mathrm{NaN}$ & $\mathrm{NaN}$ \\
\hline AN2993 & Protein of unknown function & 34 & 14 & 11 & $\mathrm{NaN}$ & $\mathrm{NaN}$ & $\mathrm{NaN}$ & $\mathrm{NaN}$ & $\mathrm{NaN}$ & $\mathrm{NaN}$ & $\mathrm{NaN}$ & $\mathrm{NaN}$ & $\mathrm{NaN}$ & $\mathrm{NaN}$ \\
\hline AN3122 & Clathrin-coated vesiclec protein & 19 & 13 & 35 & $\mathrm{NaN}$ & $\mathrm{NaN}$ & $\mathrm{NaN}$ & $\mathrm{NaN}$ & $\mathrm{NaN}$ & $\mathrm{NaN}$ & $\mathrm{NaN}$ & $\mathrm{NaN}$ & $\mathrm{NaN}$ & $\mathrm{NaN}$ \\
\hline AN3134 & T-complex protein 1 & 18 & 24 & 71 & $\mathrm{NaN}$ & $\mathrm{NaN}$ & $\mathrm{NaN}$ & $\mathrm{NaN}$ & $\mathrm{NaN}$ & $\mathrm{NaN}$ & $\mathrm{NaN}$ & $\mathrm{NaN}$ & $\mathrm{NaN}$ & $\mathrm{NaN}$ \\
\hline AN3156 & Translation initiation factor 2 & & 9 & 31 & $\mathrm{NaN}$ & $\mathrm{NaN}$ & $\mathrm{NaN}$ & $\mathrm{NaN}$ & $\mathrm{NaN}$ & $\mathrm{NaN}$ & $\mathrm{NaN}$ & $\mathrm{NaN}$ & $\mathrm{NaN}$ & $\mathrm{NaN}$ \\
\hline AN3331 & Esterase & 22 & 21 & 24 & $\mathrm{NaN}$ & $\mathrm{NaN}$ & $\mathrm{NaN}$ & $\mathrm{NaN}$ & $\mathrm{NaN}$ & $\mathrm{NaN}$ & $\mathrm{NaN}$ & $\mathrm{NaN}$ & $\mathrm{NaN}$ & $\mathrm{NaN}$ \\
\hline AN3339 & Oxidoreductase & & 2 & 7 & $\mathrm{NaN}$ & $\mathrm{NaN}$ & $\mathrm{NaN}$ & $\mathrm{NaN}$ & $\mathrm{NaN}$ & $\mathrm{NaN}$ & $\mathrm{NaN}$ & $\mathrm{NaN}$ & $\mathrm{NaN}$ & $\mathrm{NaN}$ \\
\hline AN3351 & Dehydrogenase & 6 & 16 & 19 & $\mathrm{NaN}$ & $\mathrm{NaN}$ & $\mathrm{NaN}$ & $\mathrm{NaN}$ & $\mathrm{NaN}$ & $\mathrm{NaN}$ & $\mathrm{NaN}$ & $\mathrm{NaN}$ & $\mathrm{NaN}$ & $\mathrm{NaN}$ \\
\hline AN3431 & Pyrophosphorylase & 6 & 7 & 13 & $\mathrm{NaN}$ & $\mathrm{NaN}$ & $\mathrm{NaN}$ & $\mathrm{NaN}$ & $\mathrm{NaN}$ & $\mathrm{NaN}$ & $\mathrm{NaN}$ & $\mathrm{NaN}$ & $\mathrm{NaN}$ & $\mathrm{NaN}$ \\
\hline AN3432 & Aldose 1-epimerase & & 7 & 14 & $\mathrm{NaN}$ & $\mathrm{NaN}$ & $\mathrm{NaN}$ & $\mathrm{NaN}$ & $\mathrm{NaN}$ & $\mathrm{NaN}$ & $\mathrm{NaN}$ & $\mathrm{NaN}$ & $\mathrm{NaN}$ & $\mathrm{NaN}$ \\
\hline AN3590 & Protein of unknown function & 25 & 16 & 18 & $\mathrm{NaN}$ & $\mathrm{NaN}$ & $\mathrm{NaN}$ & $\mathrm{NaN}$ & $\mathrm{NaN}$ & $\mathrm{NaN}$ & $\mathrm{NaN}$ & $\mathrm{NaN}$ & $\mathrm{NaN}$ & $\mathrm{NaN}$ \\
\hline AN3830 (lleA) & L-threonine dehydratase & 2 & & 45 & $\mathrm{NaN}$ & $\mathrm{NaN}$ & $\mathrm{NaN}$ & $\mathrm{NaN}$ & $\mathrm{NaN}$ & $\mathrm{NaN}$ & $\mathrm{NaN}$ & $\mathrm{NaN}$ & $\mathrm{NaN}$ & $\mathrm{NaN}$ \\
\hline AN3839 (SwoF) & Peptide tetradecanoyltransferase & 5 & 13 & 22 & $\mathrm{NaN}$ & $\mathrm{NaN}$ & $\mathrm{NaN}$ & $\mathrm{NaN}$ & $\mathrm{NaN}$ & $\mathrm{NaN}$ & $\mathrm{NaN}$ & $\mathrm{NaN}$ & $\mathrm{NaN}$ & $\mathrm{NaN}$ \\
\hline AN3853 & Metalloendopeptidase & 6 & 16 & 77 & $\mathrm{NaN}$ & $\mathrm{NaN}$ & $\mathrm{NaN}$ & $\mathrm{NaN}$ & $\mathrm{NaN}$ & $\mathrm{NaN}$ & $\mathrm{NaN}$ & $\mathrm{NaN}$ & $\mathrm{NaN}$ & $\mathrm{NaN}$ \\
\hline AN3901 & Lactic acid dehydrogenase & 27 & 31 & 96 & $\mathrm{NaN}$ & $\mathrm{NaN}$ & $\mathrm{NaN}$ & $\mathrm{NaN}$ & $\mathrm{NaN}$ & $\mathrm{NaN}$ & $\mathrm{NaN}$ & $\mathrm{NaN}$ & $\mathrm{NaN}$ & $\mathrm{NaN}$ \\
\hline AN3973 & Peroxiredoxin & 45 & 54 & 85 & $\mathrm{NaN}$ & $\mathrm{NaN}$ & $\mathrm{NaN}$ & $\mathrm{NaN}$ & $\mathrm{NaN}$ & $\mathrm{NaN}$ & $\mathrm{NaN}$ & $\mathrm{NaN}$ & $\mathrm{NaN}$ & $\mathrm{NaN}$ \\
\hline AN4051 & Protein of unknown function & & 16 & 173 & $\mathrm{NaN}$ & $\mathrm{NaN}$ & $\mathrm{NaN}$ & $\mathrm{NaN}$ & $\mathrm{NaN}$ & $\mathrm{NaN}$ & $\mathrm{NaN}$ & $\mathrm{NaN}$ & $\mathrm{NaN}$ & $\mathrm{NaN}$ \\
\hline AN4080 & Role in cytoplasmic translation & & 9 & & $\mathrm{NaN}$ & $\mathrm{NaN}$ & $\mathrm{NaN}$ & $\mathrm{NaN}$ & $\mathrm{NaN}$ & $\mathrm{NaN}$ & $\mathrm{NaN}$ & $\mathrm{NaN}$ & $\mathrm{NaN}$ & $\mathrm{NaN}$ \\
\hline AN4081 & Cysteine dioxygenase & 14 & 6 & 24 & $\mathrm{NaN}$ & $\mathrm{NaN}$ & $\mathrm{NaN}$ & $\mathrm{NaN}$ & $\mathrm{NaN}$ & $\mathrm{NaN}$ & $\mathrm{NaN}$ & $\mathrm{NaN}$ & $\mathrm{NaN}$ & $\mathrm{NaN}$ \\
\hline AN4236 & Proteasome regulatory particle & 25 & 32 & 55 & $\mathrm{NaN}$ & $\mathrm{NaN}$ & $\mathrm{NaN}$ & $\mathrm{NaN}$ & $\mathrm{NaN}$ & $\mathrm{NaN}$ & $\mathrm{NaN}$ & $\mathrm{NaN}$ & $\mathrm{NaN}$ & $\mathrm{NaN}$ \\
\hline AN4270 & Actin cortical patch assembly & 22 & 6 & 28 & $\mathrm{NaN}$ & $\mathrm{NaN}$ & $\mathrm{NaN}$ & $\mathrm{NaN}$ & $\mathrm{NaN}$ & $\mathrm{NaN}$ & $\mathrm{NaN}$ & $\mathrm{NaN}$ & $\mathrm{NaN}$ & $\mathrm{NaN}$ \\
\hline AN4290 & Isome & 11 & 5 & 16 & $\mathrm{NaN}$ & $\mathrm{NaN}$ & $\mathrm{NaN}$ & $\mathrm{NaN}$ & $\mathrm{NaN}$ & $\mathrm{NaN}$ & $\mathrm{NaN}$ & $\mathrm{NaN}$ & $\mathrm{NaN}$ & $\mathrm{NaN}$ \\
\hline AN4303 & Cytid & 11 & 6 & 40 & $\mathrm{NaN}$ & $\mathrm{NaN}$ & $\mathrm{NaN}$ & $\mathrm{NaN}$ & $\mathrm{NaN}$ & $\mathrm{NaN}$ & $\mathrm{NaN}$ & $\mathrm{NaN}$ & $\mathrm{NaN}$ & $\mathrm{NaN}$ \\
\hline AN4390 & nknown function & & 67 & 76 & $\mathrm{NaN}$ & $\mathrm{NaN}$ & $\mathrm{NaN}$ & $\mathrm{NaN}$ & $\mathrm{NaN}$ & $\mathrm{NaN}$ & $\mathrm{NaN}$ & $\mathrm{NaN}$ & $\mathrm{NaN}$ & $\mathrm{NaN}$ \\
\hline AN4647 & dioxygenase & & 16 & 6 & $\mathrm{NaN}$ & $\mathrm{NaN}$ & $\mathrm{NaN}$ & $\mathrm{NaN}$ & $\mathrm{NaN}$ & $\mathrm{NaN}$ & $\mathrm{NaN}$ & $\mathrm{NaN}$ & $\mathrm{NaN}$ & $\mathrm{NaN}$ \\
\hline AN4774 & Meth & & 4 & 27 & $\mathrm{NaN}$ & $\mathrm{NaN}$ & $\mathrm{NaN}$ & $\mathrm{NaN}$ & $\mathrm{NaN}$ & $\mathrm{NaN}$ & $\mathrm{NaN}$ & $\mathrm{NaN}$ & $\mathrm{NaN}$ & $\mathrm{NaN}$ \\
\hline AN4775 & Cull & 45 & 47 & 101 & $\mathrm{NaN}$ & $\mathrm{NaN}$ & $\mathrm{NaN}$ & $\mathrm{NaN}$ & $\mathrm{NaN}$ & $\mathrm{NaN}$ & $\mathrm{NaN}$ & $\mathrm{NaN}$ & $\mathrm{NaN}$ & $\mathrm{NaN}$ \\
\hline AN4915 (S & RAB & 16 & 6 & 25 & $\mathrm{NaN}$ & $\mathrm{NaN}$ & $\mathrm{NaN}$ & $\mathrm{NaN}$ & $\mathrm{NaN}$ & $\mathrm{NaN}$ & $\mathrm{NaN}$ & $\mathrm{NaN}$ & $\mathrm{NaN}$ & $\mathrm{NaN}$ \\
\hline AN4929 & Protein $\mathrm{c}$ & 18 & 11 & 20 & $\mathrm{NaN}$ & $\mathrm{NaN}$ & $\mathrm{NaN}$ & $\mathrm{NaN}$ & $\mathrm{NaN}$ & $\mathrm{NaN}$ & $\mathrm{NaN}$ & $\mathrm{NaN}$ & $\mathrm{NaN}$ & $\mathrm{NaN}$ \\
\hline AN4934 & Dehyd & 4 & 24 & & $\mathrm{NaN}$ & $\mathrm{NaN}$ & $\mathrm{NaN}$ & $\mathrm{NaN}$ & $\mathrm{NaN}$ & $\mathrm{NaN}$ & NaN & $\mathrm{NaN}$ & $\mathrm{NaN}$ & $\mathrm{NaN}$ \\
\hline AN4951 & Protein $\mathrm{t}$ & 4 & 8 & 17 & $\mathrm{NaN}$ & $\mathrm{NaN}$ & $\mathrm{NaN}$ & $\mathrm{NaN}$ & $\mathrm{NaN}$ & $\mathrm{NaN}$ & $\mathrm{NaN}$ & $\mathrm{NaN}$ & $\mathrm{NaN}$ & $\mathrm{NaN}$ \\
\hline AN4987 (Pr & Protein kinase A & 2 & 7 & 8 & $\mathrm{NaN}$ & $\mathrm{NaN}$ & $\mathrm{NaN}$ & $\mathrm{NaN}$ & $\mathrm{NaN}$ & $\mathrm{NaN}$ & $\mathrm{NaN}$ & $\mathrm{NaN}$ & $\mathrm{NaN}$ & $\mathrm{NaN}$ \\
\hline AN5021 & Role in conidium form & & 6 & 35 & $\mathrm{NaN}$ & $\mathrm{NaN}$ & $\mathrm{NaN}$ & $\mathrm{NaN}$ & $\mathrm{NaN}$ & $\mathrm{NaN}$ & $\mathrm{NaN}$ & $\mathrm{NaN}$ & $\mathrm{NaN}$ & $\mathrm{NaN}$ \\
\hline AN5132 & Uncoupling protein (UCP) & 6 & & 24 & $\mathrm{NaN}$ & $\mathrm{NaN}$ & $\mathrm{NaN}$ & $\mathrm{NaN}$ & $\mathrm{NaN}$ & $\mathrm{NaN}$ & $\mathrm{NaN}$ & $\mathrm{NaN}$ & $\mathrm{NaN}$ & $\mathrm{NaN}$ \\
\hline AN5134 (GItA) & Glutamate synthase & 75 & 294 & 789 & $\mathrm{NaN}$ & $\mathrm{NaN}$ & $\mathrm{NaN}$ & $\mathrm{NaN}$ & $\mathrm{NaN}$ & $\mathrm{NaN}$ & $\mathrm{NaN}$ & $\mathrm{NaN}$ & $\mathrm{NaN}$ & $\mathrm{NaN}$ \\
\hline AN5226 (AcpA) & Acetate permease & 67 & & 24 & $\mathrm{NaN}$ & $\mathrm{NaN}$ & $\mathrm{NaN}$ & $\mathrm{NaN}$ & $\mathrm{NaN}$ & $\mathrm{NaN}$ & $\mathrm{NaN}$ & $\mathrm{NaN}$ & $\mathrm{NaN}$ & $\mathrm{NaN}$ \\
\hline AN5257 & Oxidoreductase & & 13 & 14 & $\mathrm{NaN}$ & $\mathrm{NaN}$ & $\mathrm{NaN}$ & $\mathrm{NaN}$ & $\mathrm{NaN}$ & $\mathrm{NaN}$ & $\mathrm{NaN}$ & $\mathrm{NaN}$ & $\mathrm{NaN}$ & $\mathrm{NaN}$ \\
\hline AN5376 & Protein of unknown function & 9 & 5 & 17 & $\mathrm{NaN}$ & $\mathrm{NaN}$ & $\mathrm{NaN}$ & $\mathrm{NaN}$ & $\mathrm{NaN}$ & $\mathrm{NaN}$ & $\mathrm{NaN}$ & $\mathrm{NaN}$ & $\mathrm{NaN}$ & $\mathrm{NaN}$ \\
\hline AN5422 & Beta-lactamase & 43 & 43 & 4 & $\mathrm{NaN}$ & $\mathrm{NaN}$ & $\mathrm{NaN}$ & $\mathrm{NaN}$ & $\mathrm{NaN}$ & $\mathrm{NaN}$ & $\mathrm{NaN}$ & $\mathrm{NaN}$ & $\mathrm{NaN}$ & $\mathrm{NaN}$ \\
\hline AN5452 & Splicing factor $3 b$ & 7 & & 29 & $\mathrm{NaN}$ & $\mathrm{NaN}$ & $\mathrm{NaN}$ & $\mathrm{NaN}$ & $\mathrm{NaN}$ & $\mathrm{NaN}$ & $\mathrm{NaN}$ & $\mathrm{NaN}$ & $\mathrm{NaN}$ & $\mathrm{NaN}$ \\
\hline AN5523 (TpsA) & Trehalose-phosphate synthase & 28 & 31 & 31 & $\mathrm{NaN}$ & $\mathrm{NaN}$ & $\mathrm{NaN}$ & $\mathrm{NaN}$ & $\mathrm{NaN}$ & $\mathrm{NaN}$ & $\mathrm{NaN}$ & $\mathrm{NaN}$ & $\mathrm{NaN}$ & $\mathrm{NaN}$ \\
\hline AN5534 & Glyoxylate reductase & 8 & 6 & 29 & $\mathrm{NaN}$ & $\mathrm{NaN}$ & $\mathrm{NaN}$ & $\mathrm{NaN}$ & $\mathrm{NaN}$ & $\mathrm{NaN}$ & $\mathrm{NaN}$ & $\mathrm{NaN}$ & $\mathrm{NaN}$ & $\mathrm{NaN}$ \\
\hline AN5586 & Guanylyltransferase & 36 & 79 & 82 & $\mathrm{NaN}$ & $\mathrm{NaN}$ & $\mathrm{NaN}$ & $\mathrm{NaN}$ & $\mathrm{NaN}$ & $\mathrm{NaN}$ & $\mathrm{NaN}$ & $\mathrm{NaN}$ & $\mathrm{NaN}$ & $\mathrm{NaN}$ \\
\hline AN5607 & Role in proteasome assembly & & 4 & 7 & $\mathrm{NaN}$ & $\mathrm{NaN}$ & $\mathrm{NaN}$ & $\mathrm{NaN}$ & $\mathrm{NaN}$ & $\mathrm{NaN}$ & $\mathrm{NaN}$ & $\mathrm{NaN}$ & $\mathrm{NaN}$ & $\mathrm{NaN}$ \\
\hline AN5690 & Amine oxidase & & 3 & 4 & $\mathrm{NaN}$ & $\mathrm{NaN}$ & $\mathrm{NaN}$ & $\mathrm{NaN}$ & $\mathrm{NaN}$ & $\mathrm{NaN}$ & $\mathrm{NaN}$ & $\mathrm{NaN}$ & $\mathrm{NaN}$ & $\mathrm{NaN}$ \\
\hline AN5782 & Fumarylacetoacetate hydrolase & 24 & 31 & 17 & $\mathrm{NaN}$ & $\mathrm{NaN}$ & $\mathrm{NaN}$ & $\mathrm{NaN}$ & $\mathrm{NaN}$ & $\mathrm{NaN}$ & $\mathrm{NaN}$ & $\mathrm{NaN}$ & $\mathrm{NaN}$ & $\mathrm{NaN}$ \\
\hline AN6314 & Oxidoreductase & & 15 & 10 & $\mathrm{NaN}$ & $\mathrm{NaN}$ & $\mathrm{NaN}$ & $\mathrm{NaN}$ & $\mathrm{NaN}$ & $\mathrm{NaN}$ & $\mathrm{NaN}$ & $\mathrm{NaN}$ & $\mathrm{NaN}$ & $\mathrm{NaN}$ \\
\hline AN6488 & Tryptophanyl-tRNA synthetase & 9 & 11 & 13 & $\mathrm{NaN}$ & $\mathrm{NaN}$ & $\mathrm{NaN}$ & $\mathrm{NaN}$ & $\mathrm{NaN}$ & $\mathrm{NaN}$ & $\mathrm{NaN}$ & $\mathrm{NaN}$ & $\mathrm{NaN}$ & $\mathrm{NaN}$ \\
\hline AN7181 & Protein of unknown function & 49 & 29 & 32 & $\mathrm{NaN}$ & $\mathrm{NaN}$ & $\mathrm{NaN}$ & $\mathrm{NaN}$ & $\mathrm{NaN}$ & $\mathrm{NaN}$ & $\mathrm{NaN}$ & $\mathrm{NaN}$ & $\mathrm{NaN}$ & $\mathrm{NaN}$ \\
\hline AN7231 & Serine-type peptidase & 21 & 17 & 5 & $\mathrm{NaN}$ & $\mathrm{NaN}$ & $\mathrm{NaN}$ & $\mathrm{NaN}$ & $\mathrm{NaN}$ & $\mathrm{NaN}$ & $\mathrm{NaN}$ & $\mathrm{NaN}$ & $\mathrm{NaN}$ & $\mathrm{NaN}$ \\
\hline AN7267 & Oxidoreductase & 179 & 73 & 27 & $\mathrm{NaN}$ & $\mathrm{NaN}$ & $\mathrm{NaN}$ & $\mathrm{NaN}$ & $\mathrm{NaN}$ & $\mathrm{NaN}$ & $\mathrm{NaN}$ & $\mathrm{NaN}$ & $\mathrm{NaN}$ & $\mathrm{NaN}$ \\
\hline AN7269 & Dehydrogenase & 26 & 28 & 25 & $\mathrm{NaN}$ & $\mathrm{NaN}$ & $\mathrm{NaN}$ & $\mathrm{NaN}$ & $\mathrm{NaN}$ & $\mathrm{NaN}$ & $\mathrm{NaN}$ & $\mathrm{NaN}$ & $\mathrm{NaN}$ & $\mathrm{NaN}$ \\
\hline AN7657 (GelA) & 1,3-beta-transglycosidase & 81 & 105 & 101 & $\mathrm{NaN}$ & $\mathrm{NaN}$ & $\mathrm{NaN}$ & $\mathrm{NaN}$ & $\mathrm{NaN}$ & $\mathrm{NaN}$ & $\mathrm{NaN}$ & $\mathrm{NaN}$ & $\mathrm{NaN}$ & $\mathrm{NaN}$ \\
\hline AN7900 & Oxidoreductase & 11 & 22 & 4 & $\mathrm{NaN}$ & $\mathrm{NaN}$ & $\mathrm{NaN}$ & $\mathrm{NaN}$ & $\mathrm{NaN}$ & $\mathrm{NaN}$ & $\mathrm{NaN}$ & $\mathrm{NaN}$ & $\mathrm{NaN}$ & $\mathrm{NaN}$ \\
\hline AN7912 (OrsC) & Tyrosinase & 14 & 24 & & $\mathrm{NaN}$ & $\mathrm{NaN}$ & $\mathrm{NaN}$ & $\mathrm{NaN}$ & $\mathrm{NaN}$ & $\mathrm{NaN}$ & $\mathrm{NaN}$ & $\mathrm{NaN}$ & $\mathrm{NaN}$ & $\mathrm{NaN}$ \\
\hline AN8102 & Pepsin-like aspartic protease & & 5 & 5 & $\mathrm{NaN}$ & $\mathrm{NaN}$ & $\mathrm{NaN}$ & $\mathrm{NaN}$ & $\mathrm{NaN}$ & $\mathrm{NaN}$ & $\mathrm{NaN}$ & $\mathrm{NaN}$ & $\mathrm{NaN}$ & $\mathrm{NaN}$ \\
\hline AN8478 & Protein of unknown function & 10 & 4 & & $\mathrm{NaN}$ & $\mathrm{NaN}$ & $\mathrm{NaN}$ & $\mathrm{NaN}$ & $\mathrm{NaN}$ & $\mathrm{NaN}$ & $\mathrm{NaN}$ & $\mathrm{NaN}$ & $\mathrm{NaN}$ & $\mathrm{NaN}$ \\
\hline AN8496 & Metal ion binding activity & 7 & 11 & & $\mathrm{NaN}$ & $\mathrm{NaN}$ & $\mathrm{NaN}$ & $\mathrm{NaN}$ & $\mathrm{NaN}$ & $\mathrm{NaN}$ & $\mathrm{NaN}$ & $\mathrm{NaN}$ & $\mathrm{NaN}$ & $\mathrm{NaN}$ \\
\hline AN8528 & Protein of unknown function & 22 & 20 & 8 & $\mathrm{NaN}$ & $\mathrm{NaN}$ & $\mathrm{NaN}$ & $\mathrm{NaN}$ & $\mathrm{NaN}$ & $\mathrm{NaN}$ & $\mathrm{NaN}$ & $\mathrm{NaN}$ & $\mathrm{NaN}$ & $\mathrm{NaN}$ \\
\hline AN8815 & Isoflavone reductase & 11 & 3 & 45 & $\mathrm{NaN}$ & $\mathrm{NaN}$ & $\mathrm{NaN}$ & $\mathrm{NaN}$ & $\mathrm{NaN}$ & $\mathrm{NaN}$ & $\mathrm{NaN}$ & $\mathrm{NaN}$ & $\mathrm{NaN}$ & $\mathrm{NaN}$ \\
\hline AN8820 (CnaA) & Calcineurin A & 39 & 28 & 72 & $\mathrm{NaN}$ & $\mathrm{NaN}$ & $\mathrm{NaN}$ & $\mathrm{NaN}$ & $\mathrm{NaN}$ & $\mathrm{NaN}$ & $\mathrm{NaN}$ & $\mathrm{NaN}$ & $\mathrm{NaN}$ & $\mathrm{NaN}$ \\
\hline
\end{tabular}


Supplements

\begin{tabular}{|c|c|c|c|c|c|c|c|c|c|c|c|c|c|c|}
\hline \multirow[t]{2}{*}{ Gene ID } & \multirow[t]{2}{*}{ Description } & \multicolumn{3}{|c|}{ PSM } & \multicolumn{3}{|c|}{ laeA $A / I a e A$} & \multirow[t]{2}{*}{$\varnothing$} & \multirow[t]{2}{*}{ SD } & \multicolumn{3}{|c|}{ IaeAcomp+/laeA } & \multirow[t]{2}{*}{$\varnothing$} & \multirow[t]{2}{*}{ SD } \\
\hline & & 1 & 2 & 3 & 1 & 2 & 3 & & & 1 & 2 & 3 & & \\
\hline AN8843 & Homoserine kinase & 8 & 17 & 15 & $\mathrm{NaN}$ & $\mathrm{NaN}$ & $\mathrm{NaN}$ & $\mathrm{NaN}$ & $\mathrm{NaN}$ & $\mathrm{NaN}$ & $\mathrm{NaN}$ & $\mathrm{NaN}$ & $\mathrm{NaN}$ & $\mathrm{NaN}$ \\
\hline AN8863 & Nap/SET family protein & 12 & 15 & 137 & $\mathrm{NaN}$ & $\mathrm{NaN}$ & $\mathrm{NaN}$ & $\mathrm{NaN}$ & $\mathrm{NaN}$ & $\mathrm{NaN}$ & $\mathrm{NaN}$ & $\mathrm{NaN}$ & $\mathrm{NaN}$ & $\mathrm{NaN}$ \\
\hline AN9063 & Oxysterol-binding protein & & 4 & 3 & $\mathrm{NaN}$ & $\mathrm{NaN}$ & $\mathrm{NaN}$ & $\mathrm{NaN}$ & $\mathrm{NaN}$ & $\mathrm{NaN}$ & $\mathrm{NaN}$ & $\mathrm{NaN}$ & $\mathrm{NaN}$ & $\mathrm{NaN}$ \\
\hline AN9065 & Translation regulator activity & & 3 & 7 & $\mathrm{NaN}$ & $\mathrm{NaN}$ & $\mathrm{NaN}$ & $\mathrm{NaN}$ & $\mathrm{NaN}$ & $\mathrm{NaN}$ & $\mathrm{NaN}$ & $\mathrm{NaN}$ & $\mathrm{NaN}$ & $\mathrm{NaN}$ \\
\hline AN9220 & Protein of unknown function & & 9 & 24 & $\mathrm{NaN}$ & $\mathrm{NaN}$ & $\mathrm{NaN}$ & $\mathrm{NaN}$ & $\mathrm{NaN}$ & $\mathrm{NaN}$ & $\mathrm{NaN}$ & $\mathrm{NaN}$ & $\mathrm{NaN}$ & $\mathrm{NaN}$ \\
\hline AN9322 & Triphenylmethane Reductase & 5 & & 3 & $\mathrm{NaN}$ & $\mathrm{NaN}$ & $\mathrm{NaN}$ & $\mathrm{NaN}$ & $\mathrm{NaN}$ & $\mathrm{NaN}$ & $\mathrm{NaN}$ & $\mathrm{NaN}$ & $\mathrm{NaN}$ & $\mathrm{NaN}$ \\
\hline AN9425 & Aldolase & & 10 & 9 & $\mathrm{NaN}$ & $\mathrm{NaN}$ & $\mathrm{NaN}$ & $\mathrm{NaN}$ & $\mathrm{NaN}$ & $\mathrm{NaN}$ & $\mathrm{NaN}$ & $\mathrm{NaN}$ & $\mathrm{NaN}$ & $\mathrm{NaN}$ \\
\hline
\end{tabular}

